\title{
Novel Secondary Metabolites from New Zealand Marine Sponges
}

by

John Martin Ryan

\section{Victoria UNIVERSITY OF WELLINGTON \\ Te Whare Wānanga o te Ūpoko o te Ika a Māui}

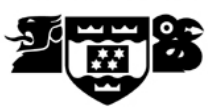

\author{
A thesis \\ submitted to Victoria University of Wellington \\ in fulfilment of the \\ requirements for the degree of \\ Doctor of Philosophy \\ in Chemistry.
}

Victoria University of Wellington 2007 


\begin{abstract}
The isolation and structure elucidation of 12 new compounds from four different genera of marine sponge is described. Continued work with the marine sponge Raspailia topsenti resulted in the isolation of two clerodane diterpenes, raspailodanes $F(40)$ and $\mathrm{G}$ (41). Raspailodane F contains a novel tricyclo[5.4.0.0 $\left.0^{1,3}\right]$ undecane scaffold including a cyclopropyl ring. A nonadecanoic acid derivative, petrosianoic acid (122), was isolated from an unknown species of the genus Petrosia. It is believed that $\mathbf{1 2 2}$ is only the third nonadecanoic acid derivative reported from the marine environment. The marine sponge Dendrilla rosea was examined for the presence of new spongian diterpenes. While no new diterpenes were discovered, the acetylenic nitrile dendronitrile (158) was isolated along with two known diterpenes and a known steroid. Dendronitrile is the first acetylenic nitrile discovered from the marine environment and only the third ever reported. Seven new lamellarins and one new dictyodendrin were isolated from Dictyodendrilla dendyi alongside one known lamellarin and two known dictyodendrins. Lamellarins $\theta$ (187) and $\kappa(\mathbf{1 8 8})$ are related to known lamellarins. The remaining five lamellarins are sulfated derivatives, lamellarin $\theta 4^{\prime \prime}, 4^{\prime \prime \prime}$-disulfate (190), lamellarin O $4^{\prime \prime \prime}$-sulfate (191), lamellarin O $4^{\prime \prime}, 4^{\prime \prime \prime}$-disulfate (192), lamellarin $\kappa 4^{\prime \prime \prime}$-sulfate (193), and lamellarin $\kappa 4^{\prime \prime}, 4^{\prime \prime \prime}$ disulfate (194). Dictyodendrin F (195) is a new natural product previously only reported as a semi-synthetic derivative of known dictyodendrins. Lamellarin $\theta$ shows moderate cytotoxic activity. The biological activity of the remaining compounds, particularly the sulfated derivatives, is under investigation.
\end{abstract}

The screening protocol used to analyse crude sponge extracts was refined and a number of advances were made towards the automated analysis of the spectra generated. A method was devised to extract peak data from screen HSQC spectra and by combining these data, to produce a software-based mask of known correlations. The application of this mask was demonstrated in three different ways to three different screen HSQC spectra. To aid in the identification of interesting correlations identified by the mask, a database of HSQC correlations was compiled from literature and in-house sources. A new method of describing the chemical environment of a given position was developed to suit the needs 
of the database. At present, the database contains 91 compounds and represents over 2500 individual HSQC correlations. Development of both the software screening technique and the HSQC correlation database is ongoing.

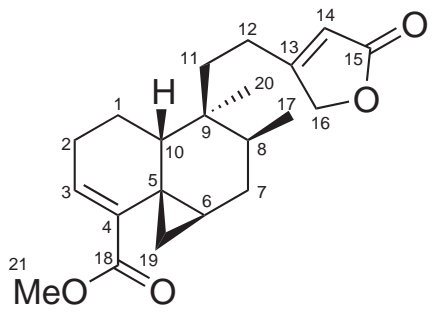

40<smiles>CCC(=O)CCCCCCCCC=CC=CC(=O)CCC(=O)O</smiles>

122

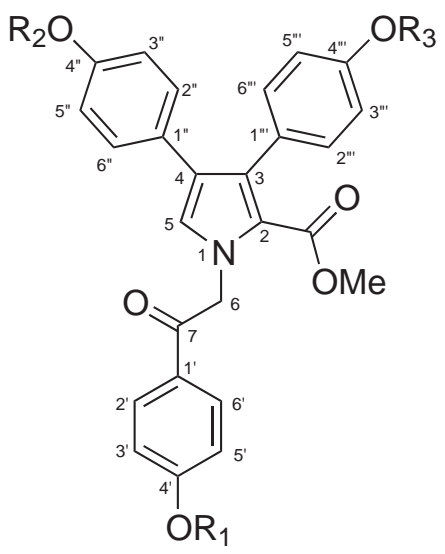

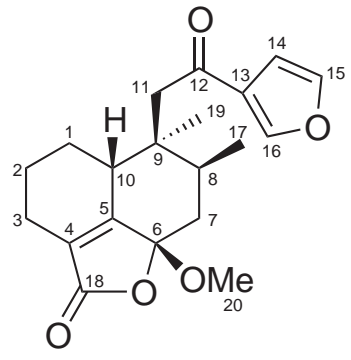

41

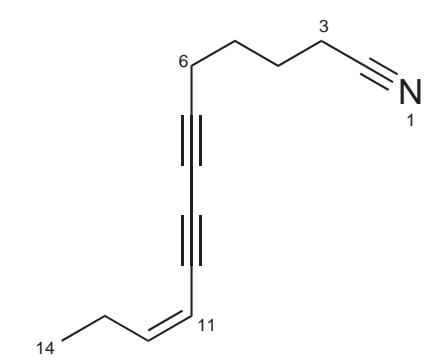

158
$187 \quad \mathrm{R}_{1}=\mathrm{H} \quad \mathrm{R}_{2}=\mathrm{H}$
$\mathrm{R}_{3}=\mathrm{H}$
$188 \mathrm{R}_{1}=\mathrm{H}$
$\mathrm{R}_{2}=\mathrm{H}$
$190 \mathrm{R}_{1}=\mathrm{H}$
$\mathrm{R}_{2}=\mathrm{SO}_{3} \mathrm{Na}$
$\mathrm{R}_{3}=\mathrm{SO}_{3} \mathrm{Na}$
$193 \mathrm{R}_{1}=\mathrm{H}$
$\mathrm{R}_{2}=\mathrm{SO}_{3} \mathrm{Na}$
$191 \mathrm{R}_{1}=\mathrm{Me}$
$\mathrm{R}_{2}=\mathrm{H}$
$\mathrm{R}_{3}=\mathrm{SO}_{3} \mathrm{Na}$
194
$192 \mathrm{R}_{1}=\mathrm{Me}$
$\mathrm{R}_{2}=\mathrm{SO}_{3} \mathrm{Na}$
$\mathrm{R}_{3}=\mathrm{SO}_{3} \mathrm{Na}$

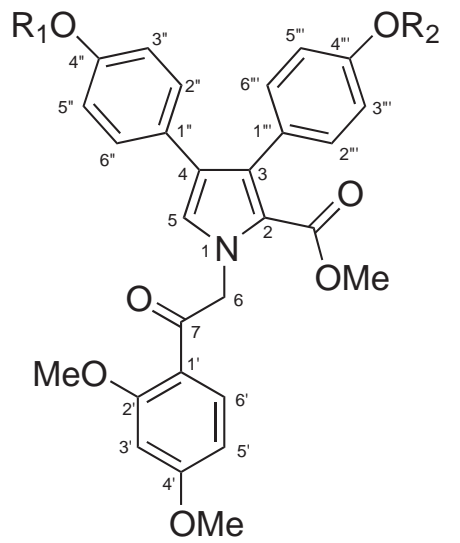




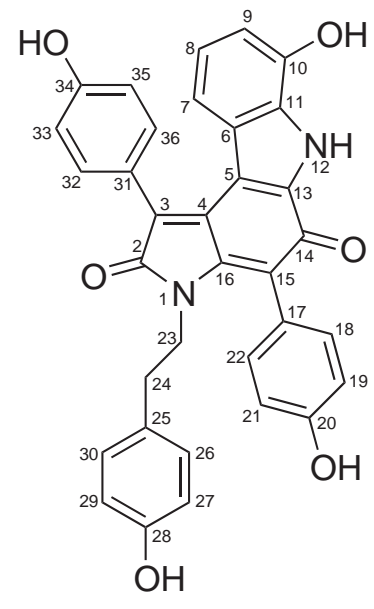

195 


\section{Acknowledgments}

As anyone who has ever undertaken a project like this knows, it simply wouldn't be possible without the support of innumerable people along the way. I have been compiling this list for quite some time and while I know it is extensive, I fear it may still not be complete.

First and foremost, I have to thank my supervisor, Peter Northcote, for his enthusiasm and encouragement throughout. Working for Peter has been particularly rewarding in terms of access to the NMR instruments and my inclusion on sample collection field trips. I simply cannot imagine having done a $\mathrm{PhD}$ under anyone else.

Secondly, and in many ways almost as importantly, I'd like to thank Rob Keyzers for guiding me through that formative time at the beginning of postgraduate research. Our discussions, sometimes heated, ranged from chemistry, to punctuation, to target shooting, to exactly how we were supposed to get Guybrush Threepwood out of his latest jam. Now, at the tail end of the thesis, Rob's prompt editing of this document has been invaluable.

I owe much to rest of the marine chemistry group, too - Lyndon West, Stephen Mackey, Stephen Haylett-Petty, Joanna Wojnar, Wendy Popplewell, Greta Moraes, Jonathan Singh, Mina Razzak, Izabela Pomer and Mike Page. Each and every one of you has contributed to this project more than you know.

Thanks too to the synthesis group next door for putting up with me on the odd occasions I pretended to be a synthetic chemist. In particular, thanks to Laine Cousins, my flatmate for a period (although I saw more of her at work) and Rhys Batchelor. Carissa Jones, Shivali Gulab, Emma Turner, Anna Win, Bridget Stocker, John Hoberg, Joanne Harvey, Brendan Burkett, Paul Teesdale-Spittle and Mattie Timmer have all been of significant help.

As a postgraduate, you stop being one of the faces in the crowd and start to interact more with the academics. I'd like to thank Brian Halton, Jim Johnston, Jim Pearce, John Spencer, David Weatherburn, John Lekner, Kate McGrath, Ken MacKenzie and Pablo Etchegoin in particular for the help and tutelage they have provided.

Studying in the chemistry department was particularly fun on account of the collegial atmosphere between all the students and research staff so I also need to thank Kirsten Edgar, Andy MacFarlane, Thomas Borrmann, Michael Richardson, Mathew Cairns, Almas Zayya, John Moraes, Melissa Marshall, Ray Vagana and Ray McLoughlin for all the fun times.

As many will be aware, my interests have shifted a little from chemistry to NMR spectroscopy. During my research I had the opportunity to interact with a number of people in the NMR community to whom I am grateful for one reason or another - Alan Ross, Bill Keane, Ron Crouch, Simon Evans, Hamish Grant and Paul Callaghan.

Assistance in performing various biological assays is acknowledged from Michael Berridge of the Malaghan Institute for Medical Research, and John Miller, Kylie Hood and Thomas Gaitanos from the School of Biological Sciences.

Teaching is of course a significant part of being a postgraduate student and I had the 
privilege of demonstrating for a number of courses. In particular I would like to single out CHEM204 and thank all the students I have interacted with in that course.

The SCPS technical support staff are in many ways the backbone of much of the research that occurs in the school. Much of my work would have been significantly more difficult without the repeated assistance of Alan Rennie, Manu Pouagen-Blakiston, David Gilmour, Rob Lenihan, Nick Lott, Johnny McClymont, Gordon Heeley, Teresa Gen, Jackie King, Peter Coord, David Stead and Oleg Zubkov.

The administration staff are equally as important so thank too to Margaret Brown, Jamie Jones, Kathy Goddard, Diana Beswetherick, Darren Alexander, Jenny Hall, Rhyl Singleton, Emily Mossman and Celia Falchi.

Somewhere in-between technical and administration staff lie the chemical stores staff. Thanks to Ying Shang, Bill Leck and Sally Wisheart for often managing to supply a required chemical yesterday.

As I mentioned, one of the great things about studying marine natural products is the chance to go on collecting trips. I was fortunate enough to be included on three of these trips which were only as much fun as they were thanks to Noel Erickson, Rhys, Moera and Gareth Jones, Des, Mary, Kauri, Tom, Jamie, David Mason and Kel Nairn.

Almost every Friday night saw a significant number of the chemistry department at the staff club enjoying a drink (or two). Thanks to the many bar staff, in particular Tom Cranney. Thanks too to Les Allan for the weekly round of jokes.

One of the things which kept me sane while I was studying was small-bore target shooting so I'd also like to thank the VUW club members, David Rew, Steve Caskey, Dean Grey and Matt Watson.

There are always a few people who don't quite fit in to any category but who need thanking nonetheless. I am indebted to Peter's wife Lisa Northcote, Rob's partner Lucy McCabe and Rhys' wife Janeen Batchelor for all their input. I'd also like to thank Duncan Henry, Daniel Diggins, Adrian Hills, Maria Gyles, Fiona Murray and Graeme Bell - all people who have contributed to me making it this far.

Finally I would like to thank my family. Thanks first to my brother, Philip, who was instrumental in me being who I am. To my parents I am forever grateful for their unfailing and unquestioning support in me and what I wanted to do and their assistance in helping me do it. And lastly, many, many thanks to my partner Cat, who has been far more patient than I gave her credit for while I worked long hours and paid her less attention than I should. 


\section{Table of Contents}

Abstract ii

$\begin{array}{lll}\text { Acknowledgments } & \text { v }\end{array}$

Table of Contents vii

List of Figures $\quad$ xi

List of Schemes $\quad$ xiv

$\begin{array}{ll}\text { List of Tables } & \text { Xv }\end{array}$

$\begin{array}{ll}\text { Glossary } & \text { xviii }\end{array}$

1 Introduction 1

1.1 Marine Natural Products . . . . . . . . . . . . . . . . . . . . . . 1

1.2 Nitrogen-15 NMR Spectroscopy . . . . . . . . . . . . . . 3

2 Raspailodanes F and G: Two New Clerodanes from the New Zealand Marine Sponge Raspailia topsenti 6

2.1 Clerodane Diterpenes . . . . . . . . . . . . . . . . . 6

2.2 Raspailia topsenti . . . . . . . . . . . . . . . . . . . 10

2.3 Raspailodane $\mathrm{F} \ldots \ldots \ldots \ldots$. . . . . . . . . . . . . . 14

2.4 Raspailodane $\mathrm{G} \ldots \ldots \ldots$. . . . . . . . . . . . . 20

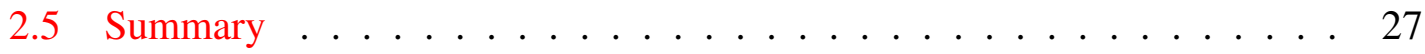

3 Screening Methods $\quad 28$

3.1 Cyclic Loading . . . . . . . . . . . . . . . . . . . . . 28

3.2 Screening History . . . . . . . . . . . . . . . . . . . 30

3.3 Sponge Screening . . . . . . . . . . . . . . . . 32 


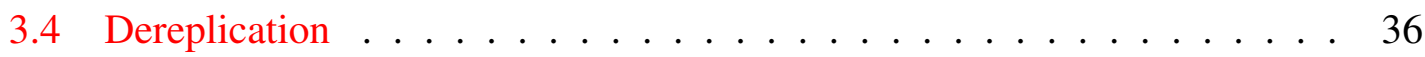

3.5 Computer-based Screen . . . . . . . . . . . . . . . . . 38

3.6 HSQC Correlation Database . . . . . . . . . . . . . . . . . . 48

3.7 Summary . . . . . . . . . . . . . . . . . . . 59

4 Petrosianoic Acid: A New $\mathrm{C}_{19}$ Fatty Acid from the New Zealand Marine Sponge Petrosia sp. $\quad \mathbf{6 0}$

4.1 Background ............................ 60

4.2 Petrosianoic Acid . . . . . . . . . . . . . . . . 65

4.3 Methylpetrosianoate . . . . . . . . . . . . . . . . 70

4.4 Summary . . . . . . . . . . . . . . . . . . 70

5 A Novel Polyacetylenic Nitrile and Other Constituents of the New Zealand Marine Sponge Dendrilla rosea

5.1 Dendrilla rosea . . . . . . . . . . . . . . . . . 72

5.2 Dendrillol $1 \ldots \ldots \ldots \ldots \ldots$. . . . . . . . . . . . . 81

5.3 Aplyroseol $6 \ldots \ldots \ldots \ldots$. . . . . . . . . . . . . . 83

5.4 Dendronitrile . . . . . . . . . . . . . . . 85

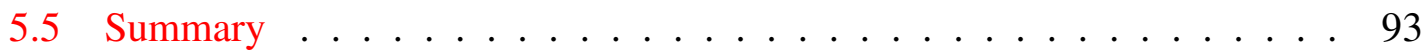

6 New Lamellarins from the New Zealand Marine Sponge Dictyodendrilla dendyi 95

6.1 Dictyodendrilla dendyi . . . . . . . . . . . . . . . . 95

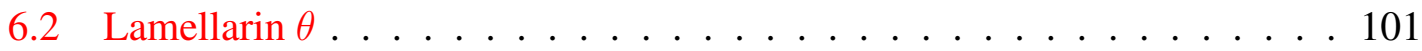

6.3 Synthetic Derivatives of Lamellarin $\theta$. . . . . . . . . . . . . 109

6.4 Lamellarin $\mathrm{O} \ldots \ldots$. . . . . . . . . . . . . . . . . . 120

6.5 Lamellarin $\theta 4^{\prime \prime}, 4^{\prime \prime \prime}$-disulfate . . . . . . . . . . . . . . . . . . . 122

6.6 Synthetic Derivatives of Lamellarin $\theta 4^{\prime \prime}, 4^{\prime \prime \prime}$-disulfate . . . . . . . . . . 126

6.7 Lamellarin $\mathrm{O} 4^{\prime \prime \prime}$-sulfate . . . . . . . . . . . . . . . . . . 127

6.8 Lamellarin O 4",4"'-disulfate . . . . . . . . . . . . . . . . . . . . . 129 


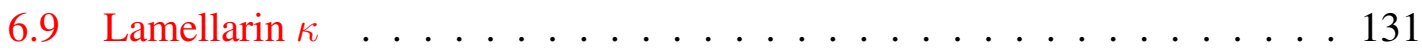

6.10 Lamellarin $\kappa 4^{\prime \prime \prime}$-sulfate . . . . . . . . . . . . . . . . . . . . 134

6.11 Lamellarin $\kappa 4^{\prime \prime}, 4^{\prime \prime \prime}$-disulfate . . . . . . . . . . . . . . . . . 137

6.12 Summary . . . . . . . . . . . . . . . . . . 140

6.13 Dictyodendrins $\mathrm{C}, \mathrm{D}$ and $\mathrm{F} \ldots \ldots . \ldots . \ldots . . \ldots 145$

6.14 Polyaromatic Pyrrole Alkaloids . . . . . . . . . . . . . . . . . . 152

6.15 Biogenesis of Polyaromatic Pyrrole Alkaloids . . . . . . . . . . . . 155

7 Conclusion $\quad 160$

8 Experimental $\quad 162$

8.1 General Methods . . . . . . . . . . . . . . . . . . . . 162

8.2 Isolation of Raspailodane F and G from Raspailia topsenti . . . . . . . 165

8.3 Isolation of Petrosianoic Acid from Petrosia sp. . . . . . . . . . . . . . . 167

8.4 Isolation of Metabolites from Dendrilla rosea . . . . . . . . . . . . . 169

8.5 Isolation of Metabolites from Dictyodendrilla dendyi . . . . . . . . . . 173

$\begin{array}{lr}\text { A Existing Sponge Screening Protocol } & 184\end{array}$

$\begin{array}{ll}\text { B Selected Functions of Peaks Source Code } & 191\end{array}$

C Matlab Macros Used to Generate a Screen Mask 198

$\begin{array}{lr}\text { D Raspailodane F Spectra } & \mathbf{2 0 2}\end{array}$

$\begin{array}{lrr}\text { E Raspailodane G Spectra } & \mathbf{2 0 8}\end{array}$

$\begin{array}{lrr}\text { F Petrosianoic Acid Spectra } & 212\end{array}$

$\begin{array}{lr}\text { G Dendronitrile Spectra } & \mathbf{2 1 8}\end{array}$

$\begin{array}{ll}\text { H Lamellarin } \theta \text { Spectra } & \mathbf{2 2 3}\end{array}$ 
I Lamellarin $\theta \mathbf{4}^{\prime \prime}, \mathbf{4}^{\prime \prime \prime}$-disulfate Spectra

J Lamellarin O 4'"'-sulfate Spectra

K Lamellarin O 4", $4^{\prime \prime \prime}$-disulfate Spectra

L Lamellarin $\kappa$ Spectra

M Lamellarin $\kappa \mathbf{4}^{\prime \prime \prime}$-sulfate Spectra

238

N Lamellarin $\kappa 4^{\prime \prime}, 4^{\prime \prime \prime}$-disulfate Spectra

O Dictyodendrin F Spectra 


\section{List of Figures}

1.1 The ${ }^{15} \mathrm{~N}$ chemical shift referencing convention used in this study. . . . . . 4

2.1 Raspailia topsenti. . . . . . . . . . . . . . . . . . 10

2.2 Selected COSY and HMBC correlations establishing substructures of raspailodane F. . . . . . . . . . . . . . . . . . 15

2.3 HMBC correlations connecting the substructures of raspailodane F. . . . . 15

2.4 HMBC correlations establishing the structure of raspailodane F. $\quad \ldots \ldots 16$

2.5 COSY W-coupling and selected NOE enhancements used to determine the relative configuration of raspailodane F. . . . . . . . . . . 17

2.6 Selected COSY and HMBC correlations establishing substructures of

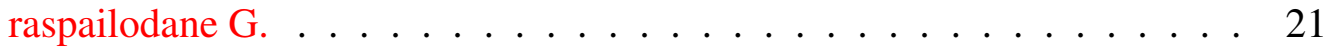

2.7 HMBC correlations connecting the substructures of raspailodane G. . . . 22

2.8 Selected HMBC correlations completing the structure of raspailodane G. . 23

2.9 COSY W-coupling and selected NOE enhancements establishing the relative configuration of raspailodane G. . . . . . . . . . . 23

3.1 Cyclic loading. . . . . . . . . . . . . . . . . . 29

3.2 Idealised mass vs. polarity for the adsorbed components of a biological extract. ........................ 30

3.3 A representation of an HSQC spectrum indicating regions of significance to the selection of correlations. . . . . . . . . . . . . . 40

3.4 The amplitude mask. . . . . . . . . . . . . . . . . . 41

3.5 The frequency mask. . . . . . . . . . . . . . . . . 42

3.6 The HSQC spectrum of the screen of MNP993. . . . . . . . . . . . . 44

3.7 The amplitude-masked HSQC spectrum of the screen of MNP993. . . . . 44

3.8 The frequency-masked HSQC spectrum of the screen of MNP993. . . . . 44

3.9 The combination amplitude-frequency-masked HSQC spectrum of the screen of MNP993. . . . . . . . . . . . . . . . . . . . 45

3.10 The HSQC spectrum of the screen of MNP988. . . . . . . . . . . . . . . 45 
3.11 The HSQC spectrum of the screen of PTN2 50E.

3.12 The amplitude-masked HSQC spectrum of the screen of PTN2_50E. . . . 46

3.13 The frequency-masked HSQC spectrum of the screen of PTN2 50E. . . . 46

3.14 The combination amplitude-frequency-masked HSQC spectrum of the screen of PTN2 50E. . . . . . . . . . . . . . . . 46

3.15 Schematic representation of the initial layout of the dual database. . . . . 48

3.16 The 13 substructures used in the HSQC correlation database to date. . . . 54

3.17 Differently drawn structures of 3-bromotoluene. . . . . . . . . . 55

3.18 Schematic representation of the current layout of the dual database. . . . . 55

4.1 Selected COSY and HMBC correlations establishing substructures of

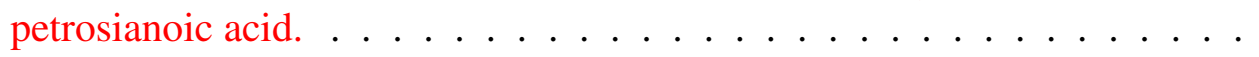

4.2 1D trace at $\delta_{\mathrm{C}} 128.9$ of a 2D HSQC experiment showing dd $(15.8,11.1 \mathrm{~Hz})$

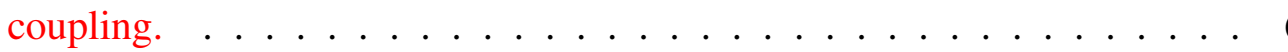

4.3 1D trace at $\delta_{\mathrm{C}} 146.7$ of a $2 \mathrm{D}$ HSQC experiment showing $\mathrm{dt}(15.0,7.4 \mathrm{~Hz})$ coupling. . . . . . . . . . . . . . . . 69

5.1 Dendrilla rosea. . . . . . . . . . . . . . . . . . 72

5.2 An HMBC spectrum of a complex mixture of spongian-type diterpenes. . 79

5.3 HMBC correlations used to correctly assign the chemical shifts of dendrillol-1. . . . . . . . . . . . . . . . . 81

5.4 HMBC correlations used to correctly assign the chemical shifts of

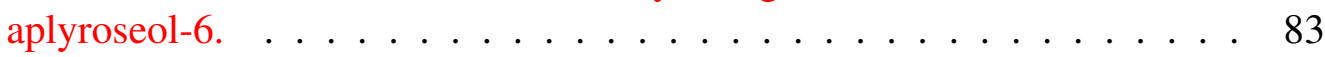

5.5 The UV spectrum of dendronitrile. . . . . . . . . . . . . . 86

5.6 COSY correlations establishing the substructures of dendronitrile. . . . . 86

5.7 COSY and HMBC correlations extending the substructure of dendronitrile. 87

5.8 The proposed possible structures for dendronitrile. . . . . . . . . . . . 88

5.9 The IR spectrum of dendronitrile. . . . . . . . . . . . . . . . . . 90

5.10 The Raman spectrum of dendronitrile. . . . . . . . . . . . . . . . 90

5.11 The combination amplitude-frequency-masked HSQC spectrum of the screen of Dendrilla rosea. 
6.1 Dictyodendrilla dendyi. . . . . . . . . . . . . . . . . . . 95

$6.2{ }^{1} \mathrm{H}$ NMR spectra of $D$. dendyi and MNP993 extracts. . . . . . . . . . . . 96

6.3 Selected COSY and HMBC correlations establishing substructures of lamellarin $\theta \ldots \ldots \ldots \ldots$. . . . . . . . . . . . . . 103

6.4 Correlations connecting the substructures of lamellarin $\theta$. . . . . . . . . 104

6.5 The initially proposed pyridine $N$-oxide structure for lamellarin $\theta$. . . . 108

6.6 Selected COSY and HMBC correlations establishing substructures A-C of lamellarin $\theta 4^{\prime \prime}, 4^{\prime \prime \prime}$-disulfate. . . . . . . . . . . . . . . . . . 123

6.7 Selected correlations connecting the substructures of lamellarin $\theta 4^{\prime \prime}, 4^{\prime \prime \prime}$ disulfate. . . . . . . . . . . . . . . . . . . 124

6.8 Selected COSY and HMBC correlations establishing the ring A substructure of lamellarin $\kappa \ldots \ldots 132$ 


\section{List of Schemes}

2.1 Formation of a clerodane carbon skeleton from geranylgeranylpyrophosphate. ....................... 7

2.2 The isolation procedure for raspailodanes $\mathrm{F}$ and $\mathrm{G}$ from $R$. topsenti. . . . 13

2.3 A proposed biogenesis of the C-4, C-5, C-19 cyclopropyl moiety in clerodanes. . . . . . . . . . . . . . . . . . . . . . . 19

4.1 The isolation procedure for petrosianoic acid from Petrosia sp. . . . . . . 64

5.1 The isolation procedure for metabolites from D. rosea. . . . . . . . . . . 78

6.1 The isolation procedure for metabolites from D. dendyi. . . . . . . . . . . 100

6.2 Proposed mechanism of deuterium exchange at C-5 . . . . . . . . 110

6.3 Increased acidity of the $4^{\prime}-\mathrm{OH}$ position in lamellarin $\theta \ldots . . . . . .114$

6.4 The proposed mechanism for the formation of 3,4-dihydro- $4^{\prime}, 4^{\prime \prime}, 4^{\prime \prime \prime}-$ trimethoxylukianol A. . . . . . . . . . . . . . . . . 115

6.5 The proposed mechanism for the cyclisation of the pyridine $N$-oxide structure. . . . . . . . . . . . . . . 117

6.6 Formation of tyramine and 3-(4-hydroxyphenyl)pyruvate. . . . . . . . . 156

6.7 A proposed biogenesis of lamellarin $\theta \ldots \ldots \ldots$. . . . . . . . 156

6.8 A biomimetic synthesis of the pyrrole core . . . . . . . . . . . . 157

6.9 Formation of indole-3-pyruvic acid. . . . . . . . . . . . . . 158

6.10 A proposed biogenesis of a dictyodendrin precursor. . . . . . . . . . . . . 159

6.11 Formation of dictyodendrin $\mathrm{F}$ as proposed by Warabi et al. . . . . . . . . 159 


\section{List of Tables}

1.1 Taxonomic classification of phylum Porifera to the order level. . . . . . . 2

1.2 Chemical shift conventions for ${ }^{15} \mathrm{~N}$ NMR . . . . . . . . . . . . . 4

2.1 Taxonomic classification of genus Raspailia from order Poecilosclerida. . 11

$2.2{ }^{13} \mathrm{C}(150 \mathrm{MHz})$ and ${ }^{1} \mathrm{H}(600 \mathrm{MHz}) \mathrm{NMR}$ data $\left(\mathrm{CDCl}_{3}\right)$ for raspailodane $\mathrm{F} . \quad 18$

2.3 ${ }^{13} \mathrm{C}(150 \mathrm{MHz})$ and ${ }^{1} \mathrm{H}(600 \mathrm{MHz}) \mathrm{NMR}$ data $\left(\mathrm{CDCl}_{3}\right)$ for raspailodane $\mathrm{G} . \quad 25$

3.1 Screening statistics. . . . . . . . . . . . . . 33

3.2 Some examples of the use of the class, subclass and adjacent fields. . . . 49

3.3 Further examples of describing chemical environments. . . . . . . . . . 50

3.4 Peloruside A as described in the HSQC correlation database. . . . . . . . 53

3.5 Obyanamide as described in the HSQC correlation database. . . . . . . . 56

3.6 Compounds included in the HSQC database to date. . . . . . . . . . . . 58

4.1 Taxonomic classification of genus Petrosia from order Haplosclerida. . . 60

4.2 Fatty acid composition of Petrosia ficiformis as reported by Djerassi et al. 63

$4.3{ }^{13} \mathrm{C}(150 \mathrm{MHz})$ and ${ }^{1} \mathrm{H}(600 \mathrm{MHz}) \mathrm{NMR}$ data $\left(\mathrm{CDCl}_{3}\right)$ for petrosianoic

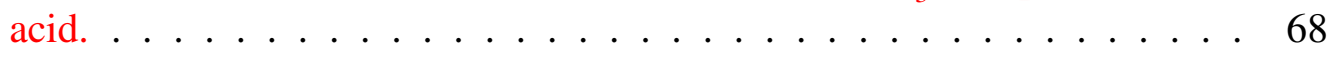

$4.4{ }^{13} \mathrm{C}(150 \mathrm{MHz})$ and ${ }^{1} \mathrm{H}(600 \mathrm{MHz}) \mathrm{NMR}$ data $\left(\mathrm{CDCl}_{3}\right)$ for methylpetrosianoate. . . . . . . . . . . . . . 70

5.1 Taxonomic classification of genus Dendrilla from order Dendroceratida. . 73

$5.2{ }^{13} \mathrm{C}(150 \mathrm{MHz})$ and ${ }^{1} \mathrm{H}(600 \mathrm{MHz}) \mathrm{NMR}$ data $\left(\mathrm{CDCl}_{3}\right)$ for dendrillol-1. . $\quad 82$

$5.3{ }^{13} \mathrm{C}(150 \mathrm{MHz})$ and ${ }^{1} \mathrm{H}(600 \mathrm{MHz}) \mathrm{NMR}$ data $\left(\mathrm{CDCl}_{3}\right)$ for aplyroseol-6. . $\quad 84$

$5.4{ }^{13} \mathrm{C}$ NMR data for the enediyne systems of selected compounds. . . . . . 88

$5.5{ }^{15} \mathrm{~N}(60 \mathrm{MHz}),{ }^{13} \mathrm{C}(150 \mathrm{MHz})$ and ${ }^{1} \mathrm{H}(600 \mathrm{MHz}) \mathrm{NMR}$ data $\left(\mathrm{CDCl}_{3}\right)$ for dendronitrile. . . . . . . . . . . . . . . . . . . . 91

6.1 Taxonomic classification of genus Dictyodendrilla from order Dendroceratida. . . . . . . . . . . . . . . . . 96 
$6.2{ }^{15} \mathrm{~N}(60 \mathrm{MHz}),{ }^{13} \mathrm{C}(75 \mathrm{MHz})$ and ${ }^{1} \mathrm{H}(600 \mathrm{MHz}) \mathrm{NMR}$ data $\left(\mathrm{CD}_{3} \mathrm{OD}\right)$ for lamellarin $\theta \ldots \ldots \ldots \ldots$. . . . . . . . . . . . . . . . . . . . . . . .

$6.3{ }^{15} \mathrm{~N}(60 \mathrm{MHz}),{ }^{13} \mathrm{C}(75 \mathrm{MHz})$ and ${ }^{1} \mathrm{H}(300 \mathrm{MHz}) \mathrm{NMR}$ data $\left(\mathrm{d}_{6}\right.$-DMSO) for lamellarin $\theta \ldots$. . . . . . . . . . . . . . . . . 107

$6.4{ }^{15} \mathrm{~N}(60 \mathrm{MHz}),{ }^{13} \mathrm{C}(75 \mathrm{MHz})$ and ${ }^{1} \mathrm{H}(300 \mathrm{MHz}) \mathrm{NMR}$ data $\left(\mathrm{CDCl}_{3}\right)$ for $4^{\prime}, 4^{\prime \prime}, 4^{\prime \prime \prime}$-triacetyllamellarin $\theta \ldots \ldots \ldots 111$

$6.5{ }^{15} \mathrm{~N}(60 \mathrm{MHz}),{ }^{13} \mathrm{C}(75 \mathrm{MHz})$ and ${ }^{1} \mathrm{H}(300 \mathrm{MHz}) \mathrm{NMR}$ data $\left(\mathrm{CD}_{3} \mathrm{OD}\right)$ for $4^{\prime}, 4^{\prime \prime}, 4^{\prime \prime \prime}$-trimethoxylamellarin $\theta \ldots \ldots \ldots 113$

$6.6{ }^{15} \mathrm{~N}(60 \mathrm{MHz}),{ }^{13} \mathrm{C}(150 \mathrm{MHz})$ and ${ }^{1} \mathrm{H}(600 \mathrm{MHz}) \mathrm{NMR}$ data $\left(\mathrm{CDCl}_{3}\right)$ for 3,4-dihydro-4',4",4"'-trimethoxylukianol A. . . . . . . . . . . . . 116

$6.7{ }^{13} \mathrm{C}(75 \mathrm{MHz})$ and ${ }^{1} \mathrm{H}(300 \mathrm{MHz}) \mathrm{NMR}$ data $\left(\mathrm{CD}_{3} \mathrm{OD}\right)$ for 7-hydroxy$4^{\prime}, 4^{\prime \prime}, 4^{\prime \prime \prime}$-trimethoxylamellarin $\theta \ldots$. . . . . . . . . . . . 119

$6.8{ }^{15} \mathrm{~N}(60 \mathrm{MHz}),{ }^{13} \mathrm{C}(125 \mathrm{MHz})$ and ${ }^{1} \mathrm{H}(600 \mathrm{MHz}) \mathrm{NMR}$ data $\left(\mathrm{CD}_{3} \mathrm{OD}\right)$ for lamellarin O . . . . . . . . . . . . . . . . . . . . 121

6.9 Chemical shift differences between selected NMR data $\left(\mathrm{CD}_{3} \mathrm{OD}\right)$ for lamellarins $\theta$ and $\theta 4^{\prime \prime}, 4^{\prime \prime \prime}$-disulfate. . . . . . . . . . . . . . 124

$6.10{ }^{15} \mathrm{~N}(60 \mathrm{MHz}),{ }^{13} \mathrm{C}(125 \mathrm{MHz})$ and ${ }^{1} \mathrm{H}(500 \mathrm{MHz}) \mathrm{NMR}$ data $\left(\mathrm{CD}_{3} \mathrm{OD}\right)$ for lamellarin $\theta 4^{\prime \prime}, 4^{\prime \prime \prime}$-disulfate.

6.11 Chemical shift differences between selected NMR data $\left(\mathrm{CD}_{3} \mathrm{OD}\right)$ for lamellarins $\mathrm{O}$ and $\mathrm{O} 4^{\prime \prime \prime}$-sulfate. . . . . . . . . . . . . . . . .

$6.12{ }^{15} \mathrm{~N}(60 \mathrm{MHz}),{ }^{13} \mathrm{C}(125 \mathrm{MHz})$ and ${ }^{1} \mathrm{H}(600 \mathrm{MHz}) \mathrm{NMR}$ data $\left(\mathrm{CD}_{3} \mathrm{OD}\right)$ for lamellarin $\mathrm{O} 4^{\prime \prime \prime}$-sulfate.

6.13 Chemical shift differences between selected NMR data $\left(\mathrm{CD}_{3} \mathrm{OD}\right)$ for lamellarins $\mathrm{O}$ and $\mathrm{O} 4^{\prime \prime}, 4^{\prime \prime \prime}$-disulfate. . . . . . . . . . . . . . . .

$6.14{ }^{15} \mathrm{~N}(60 \mathrm{MHz}),{ }^{13} \mathrm{C}(125 \mathrm{MHz})$ and ${ }^{1} \mathrm{H}(500 \mathrm{MHz}) \mathrm{NMR}$ data $\left(\mathrm{CD}_{3} \mathrm{OD}\right)$ for lamellarin $\mathrm{O} 4^{\prime \prime}, 4^{\prime \prime \prime}$-disulfate.

$6.15{ }^{15} \mathrm{~N}(60 \mathrm{MHz}),{ }^{13} \mathrm{C}(125 \mathrm{MHz})$ and ${ }^{1} \mathrm{H}(600 \mathrm{MHz}) \mathrm{NMR}$ data $\left(\mathrm{d}_{6}\right.$-DMSO $)$ for lamellarin $\kappa \ldots \ldots \ldots 133$

6.16 Chemical shift differences between selected NMR data ( $\mathrm{d}_{6}$-DMSO) for lamellarins $\kappa$ and $\kappa 4^{\prime \prime \prime}$-sulfate.

$6.17{ }^{15} \mathrm{~N}(60 \mathrm{MHz}),{ }^{13} \mathrm{C}(150 \mathrm{MHz})$ and ${ }^{1} \mathrm{H}(600 \mathrm{MHz}) \mathrm{NMR}$ data $\left(\mathrm{CD}_{3} \mathrm{OD}\right)$ for lamellarin $\kappa 4^{\prime \prime \prime}$-sulfate.

$6.18{ }^{15} \mathrm{~N}(60 \mathrm{MHz}),{ }^{13} \mathrm{C}(150 \mathrm{MHz})$ and ${ }^{1} \mathrm{H}(600 \mathrm{MHz}) \mathrm{NMR}$ data $\left(\mathrm{d}_{6}-\mathrm{DMSO}\right)$ for lamellarin $\kappa 4^{\prime \prime \prime}$-sulfate.

6.19 Chemical shift differences between selected NMR data ( $\mathrm{d}_{6}$-DMSO) for lamellarins $\kappa$ and $\kappa 4^{\prime \prime}, 4^{\prime \prime \prime}$-disulfate. 
$6.20{ }^{15} \mathrm{~N}(60 \mathrm{MHz}),{ }^{13} \mathrm{C}(125 \mathrm{MHz})$ and ${ }^{1} \mathrm{H}(600 \mathrm{MHz}) \mathrm{NMR}$ data $\left(\mathrm{CD}_{3} \mathrm{OD}\right)$ for lamellarin $\kappa 4^{\prime \prime}, 4^{\prime \prime \prime}$-disulfate. . . . . . . . . . . . . . . . 138

$6.21{ }^{15} \mathrm{~N}(60 \mathrm{MHz}),{ }^{13} \mathrm{C}(125 \mathrm{MHz})$ and ${ }^{1} \mathrm{H}(600 \mathrm{MHz}) \mathrm{NMR}$ data $\left(\mathrm{d}_{6}\right.$-DMSO $)$ for lamellarin $\kappa 4^{\prime \prime}, 4^{\prime \prime \prime}$-disulfate. . . . . . . . . . . . . . . . . 139

$6.22{ }^{15} \mathrm{~N}(60 \mathrm{MHz}),{ }^{13} \mathrm{C}(150 \mathrm{MHz})$ and ${ }^{1} \mathrm{H}(600 \mathrm{MHz}) \mathrm{NMR}$ data $\left(\mathrm{CD}_{3} \mathrm{OH}\right)$ for dictyodendrin C . . . . . . . . . . . . . . . . . 146

$6.23{ }^{15} \mathrm{~N}(60 \mathrm{MHz}),{ }^{13} \mathrm{C}(150 \mathrm{MHz})$ and ${ }^{1} \mathrm{H}(600 \mathrm{MHz}) \mathrm{NMR}$ data $\left(\mathrm{CD}_{3} \mathrm{OD}\right)$ for dictyodendrin C . . . . . . . . . . . . . . . . . . . 147

$6.24{ }^{15} \mathrm{~N}(60 \mathrm{MHz}),{ }^{13} \mathrm{C}(125 \mathrm{MHz})$ and ${ }^{1} \mathrm{H}(600 \mathrm{MHz}) \mathrm{NMR}$ data $\left(\mathrm{CD}_{3} \mathrm{OH}\right)$ for dictyodendrin D. . . . . . . . . . . . . . . . . . . . . 148

$6.25{ }^{15} \mathrm{~N}(60 \mathrm{MHz}),{ }^{13} \mathrm{C}(150 \mathrm{MHz})$ and ${ }^{1} \mathrm{H}(600 \mathrm{MHz}) \mathrm{NMR}$ data $\left(\mathrm{CD}_{3} \mathrm{OD}\right)$ for dictyodendrin D . . . . . . . . . . . . . . . . . . . . 149

$6.26{ }^{15} \mathrm{~N}(60 \mathrm{MHz}),{ }^{13} \mathrm{C}(150 \mathrm{MHz})$ and ${ }^{1} \mathrm{H}(600 \mathrm{MHz}) \mathrm{NMR}$ data $\left(\mathrm{CD}_{3} \mathrm{OH}\right)$ for dictyodendrin F. . . . . . . . . . . . . . . . . . . . 150

$6.27{ }^{15} \mathrm{~N}(60 \mathrm{MHz}),{ }^{13} \mathrm{C}(125 \mathrm{MHz})$ and ${ }^{1} \mathrm{H}(600 \mathrm{MHz}) \mathrm{NMR}$ data $\left(\mathrm{d}_{6}\right.$-DMSO $)$ for dictyodendrin F. . . . . . . . . . . . . . . . 151 


\section{Glossary}

DIOL 2,3-dihydroxy-1-propoxypropyl-derivatised silica gel

HRESIMS high-resolution electrospray ionisation mass spectrometry

IPA isopropyl alcohol

PSDVB poly(styrene-divinylbenzene)

SCUBA self-contained underwater breathing apparatus

SMILES simplified molecular input line entry specification

TANGO testing for adjacent nuclei with a gyration operator

TMS tetramethylsilane 


\section{Chapter 1}

\section{Introduction}

\subsection{Marine Natural Products}

It has been over 60 years since the advent of the SCUBA and the discovery of new compounds from marine organisms continues unabated with the number of reported structures continually trending upwards. ${ }^{1}$ While a large variety of organisms are responsible for these compounds, marine sponges are one of the most significant producers with around $35 \%$ of the compounds isolated annually attributable to them. ${ }^{2-4}$ Furthermore, up to $50 \%$ of the compounds reported from sponges have been shown to possess some form of biological activity. ${ }^{3}$

Sponges make up the entire phylum Porifera, the most primitive phylogenetic branch of the kingdom of Animalia (Metazoa). ${ }^{5}$ Despite their sessile nature, sponges continue to thrive in modern oceans indicating that these otherwise primitive animals must have evolved some form of defence against predation and encroachment. ${ }^{6,7}$ The high incidence of biological activity in compounds isolated from sponges is consistent with this hypothesis.

The taxonomy of sponges is not always firmly established and classifications are often revisited (even at the order level). The most recent examination of the phylogenic classification of sponges, compiled by Hooper and van Soest, makes some significant changes to a number of previously accepted classifications. ${ }^{5}$ Most notably, the order Lithistida ("rock sponges") is no longer recognised as valid; its members are now informally grouped as "lithistids" and await reclassification. The taxonomy of Porifera to the order level is shown in Table 1.1 with blue entries representing orders examined in this study.

Unfortunately, the last decade has seen the pharmaceutical industry turn somewhat of a blind eye towards the large number of natural products being reported, focusing instead 
Table 1.1 Taxonomic classification of phylum Porifera to the order level as presented by Hooper and van Soest. ${ }^{5}$

\begin{tabular}{|c|c|c|c|}
\hline Phylum & Class & Sub-class & Order \\
\hline \multirow{25}{*}{ Porifera } & \multirow{5}{*}{ Calcarea } & \multirow{3}{*}{ Calcaronea } & 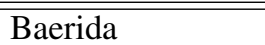 \\
\hline & & & Leucosolenida \\
\hline & & & Lithonida \\
\hline & & \multirow{2}{*}{ Calcinea } & Clathrinida \\
\hline & & & Murrayonida \\
\hline & \multirow{15}{*}{ Demospongiae } & \multirow{9}{*}{ Ceractinomorpha } & Agelasida \\
\hline & & & Dendroceratida \\
\hline & & & Dictyoceratida \\
\hline & & & Halichondrida \\
\hline & & & Halisarcida \\
\hline & & & Haplosclerida \\
\hline & & & Poecilosclerida \\
\hline & & & Verongida \\
\hline & & & Verticillitida \\
\hline & & Homoscleromorpha & Homosclerophida \\
\hline & & \multirow{5}{*}{ Tetractinomorpha } & Astrophorida \\
\hline & & & Chondrasida \\
\hline & & & Hadromerida \\
\hline & & & "Lithistids" \\
\hline & & & Spirophorida \\
\hline & \multirow{5}{*}{ Hexactinellida } & Amphodiscophora & Amphodiscosida \\
\hline & & \multirow{4}{*}{ Hexasterophora } & Aulocalycoida \\
\hline & & & Hexactinosida \\
\hline & & & Lychnicosida \\
\hline & & & Lyssacinosida \\
\hline
\end{tabular}

on libraries provided through combinatorial synthesis. ${ }^{8}$ However, combinatorial synthesis has seemingly failed to deliver the structural and chemical diversity that it promised and the focus for drug candidates is now turning back towards natural products. ${ }^{8,9}$

Much attention has now been directed toward "diversity-oriented synthesis" of biologically active natural products. ${ }^{9}$ This approach is a combination of traditional natural product synthesis and combinatorial synthesis. The goal is to produce libraries of analogues of a given structure in the hope, ideally, of producing an analogue which is simpler to make and more active than the parent natural product. ${ }^{9,10}$ This approach has been used successfully to generate an analogue of halichondrin B (a cytotoxic metabolite isolated from the marine sponge Halichondria okadai in 1985) ${ }^{11}$ which is both simpler to synthesise and exhibits increased activity. ${ }^{9}$

The last few years have also seen a dramatic increase in the capability to assay large numbers of compounds quickly. So called high-throughput screening (HTS) technology, 
which was developed in part due to the need to screen large combinatorial libraries, ${ }^{9}$ now allows these targeted libraries to be analysed in a timely manner.

There has also been an expansion in the number of available biological assays and as a result, the number of compounds from the marine (and presumably the terrestrial) environment reported with biological activity is increasing. ${ }^{4}$ One very new form of analysis is chemical genetics ${ }^{10}$ which uses gene deletion sets to probe for biological activity which might not be detectable in a wild-type organism. The very nature of chemical genetic screening - analysing large numbers of genes and drug-candidates simultaneously - is dependent upon the ability to perform high-throughput screening.

In light of the advances in biological testing, the challenge for the modern natural products chemist is not just to continue identifying new compounds to add to the vast array of chemical diversity already available, but to revisit older classes of compounds.

In this study, an NMR spectroscopy-based procedure for the identification of interesting compounds in a crude sponge extract is employed. One of the challenges of this approach is the dereplication of known compounds within a crude extract. Being able to quickly and efficiently identify these compounds is fundamental. Depending on the nature of these known compounds, the decision can be made either to avoid spending time purifying them, or instead to re-isolate them for re-submission to a plethora of new biological tests.

\subsection{Nitrogen-15 NMR Spectroscopy}

The analysis of ${ }^{15} \mathrm{~N}$ NMR spectra is used extensively in this study so it is appropriate to first touch upon some of the issues which complicate such analyses. Several different reference standards have been used in ${ }^{15} \mathrm{~N}$ NMR over the years but two have become significantly more prominent; liquid $\mathrm{NH}_{3}$, and $\mathrm{CH}_{3} \mathrm{NO}_{2} \cdot{ }^{12}$ Liquid $\mathrm{NH}_{3}$ was one of the earliest standards used, but the difficulty of sample handling led to the use of simpler alternatives. The $\mathrm{NH}_{3}$ standard defines zero ppm on the chemical shift scale and

represents a chemical shift near the upfield extreme of the ${ }^{15} \mathrm{~N}$ chemical shift range. The chemical shift scale follows the same convention as the TMS scale, that is, resonances 
which are deshielded relative to $\mathrm{NH}_{3}$ resonate at positive ppm while relatively shielded resonances have a negative chemical shift. The $\mathrm{CH}_{3} \mathrm{NO}_{2}$ standard also defines a zero on the chemical shift scale but one which is 380.4 ppm downfield with respect to $\mathrm{NH}_{3}$ and downfield of the chemical shift range of the majority of ${ }^{15} \mathrm{~N}$ functional groups. ${ }^{\dagger}$ Older reports published under this standard use an inverted scale relative to the TMS scale - resonances which are deshielded relative to $\mathrm{CH}_{3} \mathrm{NO}_{2}$ resonate at negative ppm while positive chemical shifts are assigned for more shielded resonances. As this convention is contrary to IUPAC recommendations, ${ }^{14}$ more recent publications have reversed this scale and assigned chemical shifts analogous to the TMS scale. ${ }^{12}$ Table 1.2 illustrates these different conventions. In this study, the latter convention is applied; $\mathrm{CH}_{3} \mathrm{NO}_{2}$ is used as the ${ }^{15} \mathrm{~N}$ standard with the chemical shift scale assigned using IUPAC recommendations; downfield assigned as positive, upfield assigned as negative (see Figure 1.1).

Table 1.2 Chemical shift conventions for ${ }^{15} \mathrm{~N}$ NMR.

\begin{tabular}{ccc}
\hline Standard & $\delta_{\mathrm{N}} \mathrm{CH}_{3} \mathrm{NO}_{2}$ & $\delta_{\mathrm{N}}$ liquid $\mathrm{NH}_{3}$ \\
\hline Liquid $\mathrm{NH}_{3}$ & +380.4 & 0 \\
$\mathrm{CH}_{3} \mathrm{NO}_{2}$ (old) & 0 & +380.4 \\
$\mathrm{CH}_{3} \mathrm{NO}_{2}$ (IUPAC) & 0 & -380.4 \\
\hline
\end{tabular}

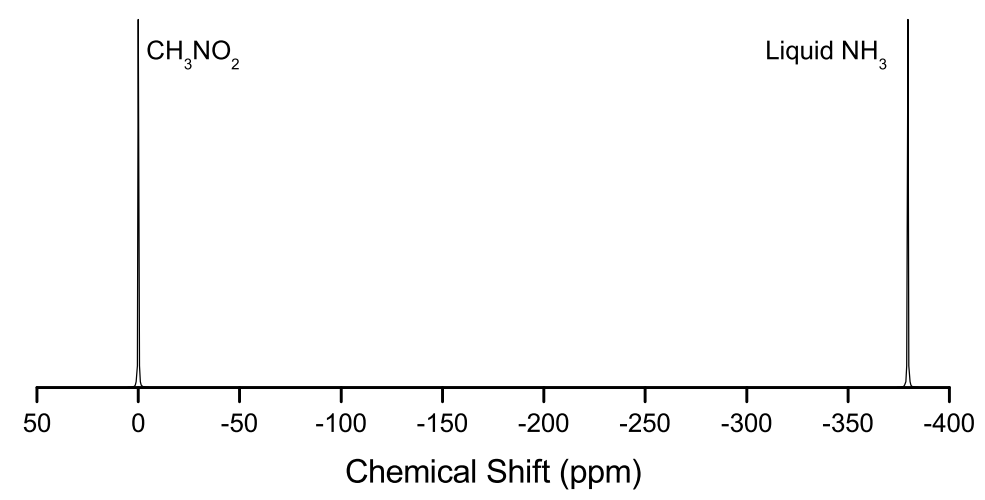

Figure 1.1 The ${ }^{15} \mathrm{~N}$ chemical shift referencing convention used in this study.

Initially, this study will continue the analysis of the chemical composition of the marine sponge Raspailia topsenti from which our laboratory has reported a number of compounds. ${ }^{15-17}$ The primary goal of the study will be to examine a number of marine sponges with an in-house screening protocol to identify metabolites with interesting

\footnotetext{
${ }^{\dagger}$ The use of $\mathrm{CH}_{3} \mathrm{NO}_{2}$ as a secondary standard relative to liquid $\mathrm{NH}_{3}$ has also been mooted. ${ }^{13}$
} 
structural features. Attempts will be made to purify and characterise these metabolites via an NMR-spectroscopy directed isolation. The dereplication of known compounds in these extracts will be examined and improved with particular emphasis on the automation of existing procedures. 


\section{Chapter 2}

\section{Raspailodanes F and G: Two New Clerodanes from the New Zealand Marine Sponge Raspailia topsenti}

\subsection{Clerodane Diterpenes}

Clerodane diterpenes are an extensive class of natural products based upon the rearranged diterpene carbon skeleton 1 which are represented in the literature by approximately 850 reported structures. ${ }^{18,19}$ The clerodane family is structurally diverse and consists of many nor-clerodanes where one carbon is lost. The stereochemistry is also quite variable, in particular the configurations of methyls $\mathrm{C}-17$ and $\mathrm{C}-20$, and of the decalin ring junction. The first reported clerodane diterpene was clerodin (2) which was isolated from the Indian Bhat tree in $1936^{20}$ and structurally elucidated by X-ray crystallography in $1961 .{ }^{21}$ In 1979 the absolute configuration of clerodin was revised. ${ }^{22}$

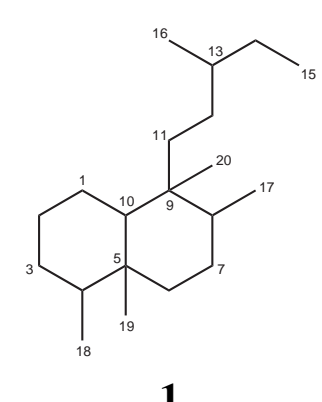

1

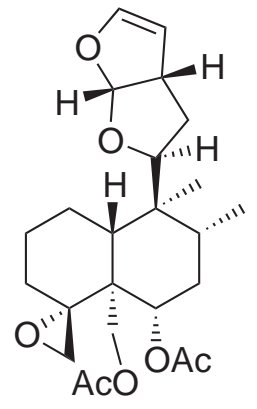

2

The stereochemical diversity of the clerodane skeleton can be accounted for by an examination of its biogenesis. Initial cyclisation of geranylgeranylpyrophosphate in either of two ways forms enantiomers of a labdane skeleton. These can then undergo a series of 1,2 methyl and hydride shifts to produce the clerodane skeleton. ${ }^{18,23}$ Scheme 2.1 illustrates the process for one enantiomer of the labdane skeleton. If the migration process takes place in a series of discrete steps, the final 1,2 methyl shift can involve either methyl of the geminal methyl pair which can give rise to either cis or trans ring-fused clerodanes. In the instance that these shifts occur in a concerted fashion, electronic factors ensure that 

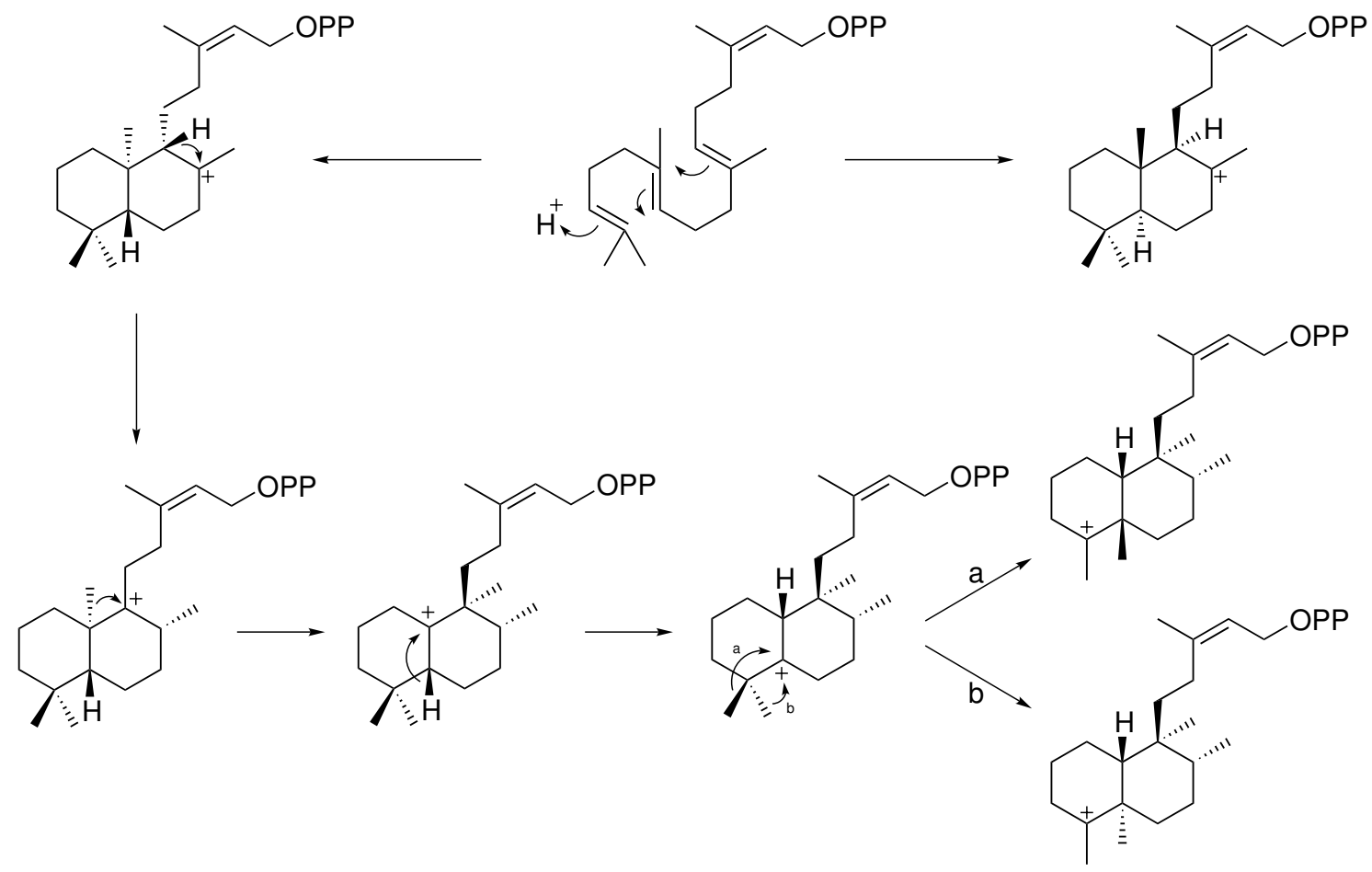

Scheme 2.1 Formation of a clerodane carbon skeleton from geranylgeranylpyrophosphate.

only trans ring-fused clerodanes are formed. A predominance of trans ring-fused over cis ring-fused clerodanes exists, ${ }^{18}$ although several partially rearranged labdane diterpenes have been isolated, for example chettaphanin $(\mathbf{3}),{ }^{24}$ salmantic acid (4) ${ }^{25}$ and pleurodiol (5). ${ }^{26}$ This biosynthetic scheme clearly indicates the diversity of stereochemistry available to the clerodanes at positions C-4, C-5, C-8, C-9 and C-10.<smiles>COC(=O)[C@]1(O)CC(=O)C=C2[C@@H]3CCc4ccoc4[C@H]3CC[C@]21C</smiles>

3

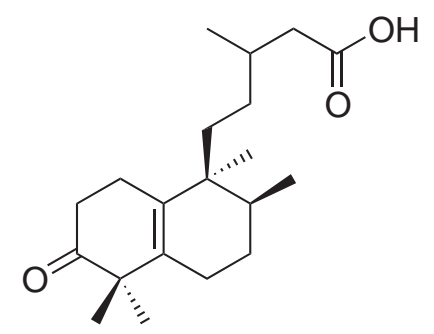

4<smiles>C=CC(C)(O)CCC[C@@H]1[C@@H]2CCC[C@@](C)(O)C2CC[C@H]1C</smiles>

5

The majority of isolated clerodanes have been found in angiosperms (flowering plants) while gymnosperms (conifers), liverworts, fungi, bacteria, tunicates and marine sponges are all minor sources. ${ }^{18}$ To date, there are only 25 reported clerodanes isolated from the marine sponges. Ageline B (6), ${ }^{27}$ agelasines A, B (7-8), ${ }^{28} \mathrm{G}(\mathbf{9}),{ }^{29} \mathrm{H}$ and I (1011) $)^{30}$ and nakamurols B-D (12-14) $)^{31}$ were all isolated from sponges of the genus Agelas. Chelonaplysilla erecta afforded chelodane $(\mathbf{1 5})^{32}$ while the uncommon 15-norclerodane sigmosceptrins B and C (16-17) were isolated from Sigmosceptrella sp. ${ }^{33}$ A total of 11 
asmarines (A-K) (18-28) have been reported from unidentified species of Raspailia. ${ }^{34-36}$ Finally, the clerodanes raspailol (29) and raspailenone A (30) were isolated from a collection of Raspailia topsenti. ${ }^{15}$

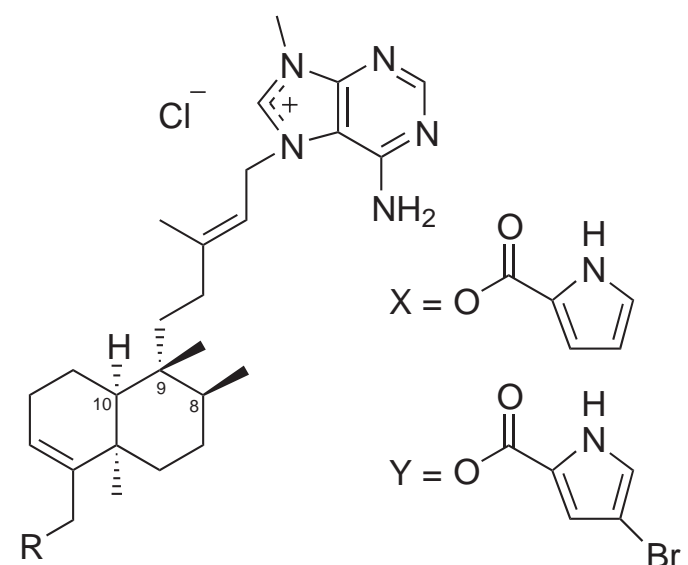

$$
\begin{array}{rl}
\mathbf{6} & \mathrm{R}=\mathrm{X} \\
\mathbf{7} & \mathrm{R}=\mathrm{H} \\
\mathbf{8} & \mathrm{R}=\mathrm{H}, 8 \text { epi, } 9 \text { epi, } 10 \text { epi } \\
\mathbf{9} & \mathrm{R}=\mathrm{Y} \\
\mathbf{1 0} & \mathrm{R}=\mathrm{OH}
\end{array}
$$<smiles>[R]CC1=CC(=O)C[C@@H]2[C@@H]1CC[C@@H](C)[C@@H]2CCC(C)(O)C=C</smiles>

$12 \mathrm{R}=\mathrm{H}$

$13 \mathrm{R}=\mathrm{H}, 5$ epi

$14 \mathrm{R}=\mathrm{X}$<smiles>C=C1CCC[C@H]2[C@H]1CC[C@@H](C)[C@@]2(C)/C=C/[C@@H](C)C(=O)O</smiles>

16<smiles></smiles>

11<smiles>C=CC(C)(O)CC[C@@H]1[C@@H]2CCCC(=C)[C@@H]2CC[C@H]1C</smiles>

15<smiles>C=C1CCC[C@H]2C1CC[C@@H](C)[C@]2(C)CC[C@@H](C)C(=O)O</smiles>

17

The gamut of biological activity displayed by the marine-derived clerodanes reported to date is quite varied. Agelasines A and B (7-8) are reported to inhibit the activity of Na,KATPase ${ }^{28}$ agelasine G (9) is cytotoxic to murine lymphoma L1210 cells, agelasine I (11) inhibits Saccharomyces cerevisiae at a concentration of $200 \mu \mathrm{g} / \mathrm{mL}$ and asmarines A-K (18-28) all show varying degrees of cytotoxicity to various human cancer cell lines. ${ }^{34-36}$ 
Raspailol (29) has recently been shown to moderately inhibit superoxide production by human neutrophils stimulated with $N$-formylmethionyl-leucyl-phenylalanine (fMLP) in the low $\mu \mathrm{g} / \mathrm{mL}$ range. Raspailenone A (30) also displayed activity around 100 times weaker in the same assay. ${ }^{37,38}$ The high incidence of reported bioactive marine clerodanes is a reflection of the bioactivity of clerodanes in general as biological activity is wellestablished in a number of terrestrial clerodanes. ${ }^{18}$ One noteworthy bioactive terrestrial clerodane is salvinorin A (31), isolated from the Mexican sage Salvia divinorum, ${ }^{39}$ which is an exceptionally potent $\kappa$ opioid receptor agonist causing severe psychotropic hallucinations in microgram dosages. ${ }^{40}$ Salvinorin A is particularly interesting because it is not an alkaloid and does not act on the 5-HT2a serotonin receptor traditionally associated with hallucinatory effects. ${ }^{41}$

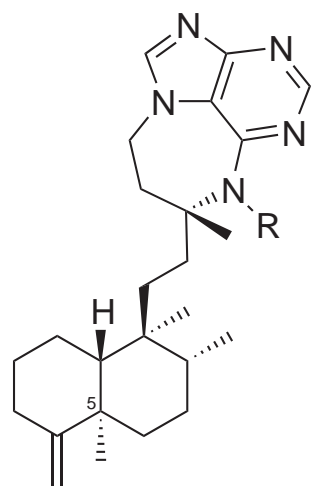

$18 \mathrm{R}=\mathrm{OH}$

$19 \mathrm{R}=\mathrm{OH}, 5$ epi

$24 \mathrm{R}=\mathrm{OMe}$

$25 \mathrm{R}=\mathrm{H}$

$28 \mathrm{R}=\mathrm{H}, 5$ epi

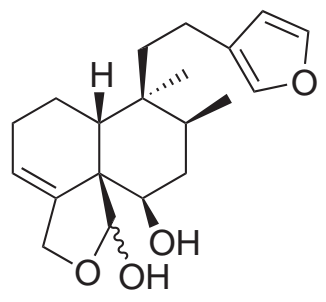

29

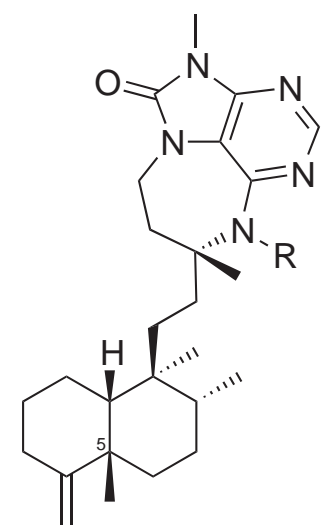

$20 \mathrm{R}=\mathrm{H}$

$21 \mathrm{R}=\mathrm{H}, 5$ epi

$22 \mathrm{R}=\mathrm{OMe}, 5$ epi

$23 \mathrm{R}=\mathrm{OMe}$<smiles>CC1=CC(=O)C[C@H]2[C@@H]3CCc4ccoc4C[C@H]3CC[C@]12C</smiles>

30

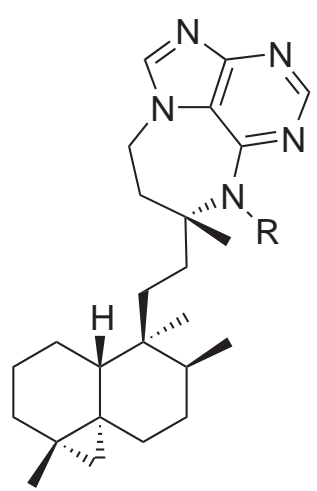

$26 \mathrm{R}=\mathrm{OH}$

$27 \mathrm{R}=\mathrm{H}$

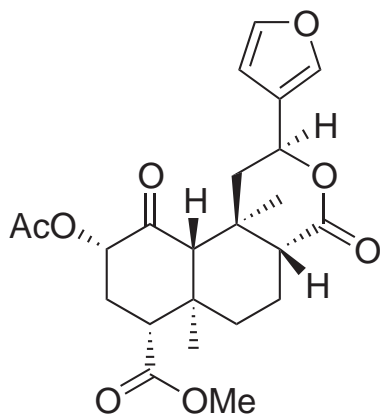

31 


\subsection{Raspailia topsenti}

The New Zealand marine sponge Raspailia topsenti (Dendy) (Figure 2.1, taxonomy see Table 2.1) has proved to be a rich source of secondary metabolites. From our original collection of $R$. topsenti from Doubtful Sound, Fiordland were isolated the clerodane diterpenoids raspailol (29), raspailenone A (30) ${ }^{15}$ and raspailodanes $\mathrm{C}(\mathbf{3 4})$ and $\mathrm{D}(\mathbf{3 5}) .{ }^{16}$

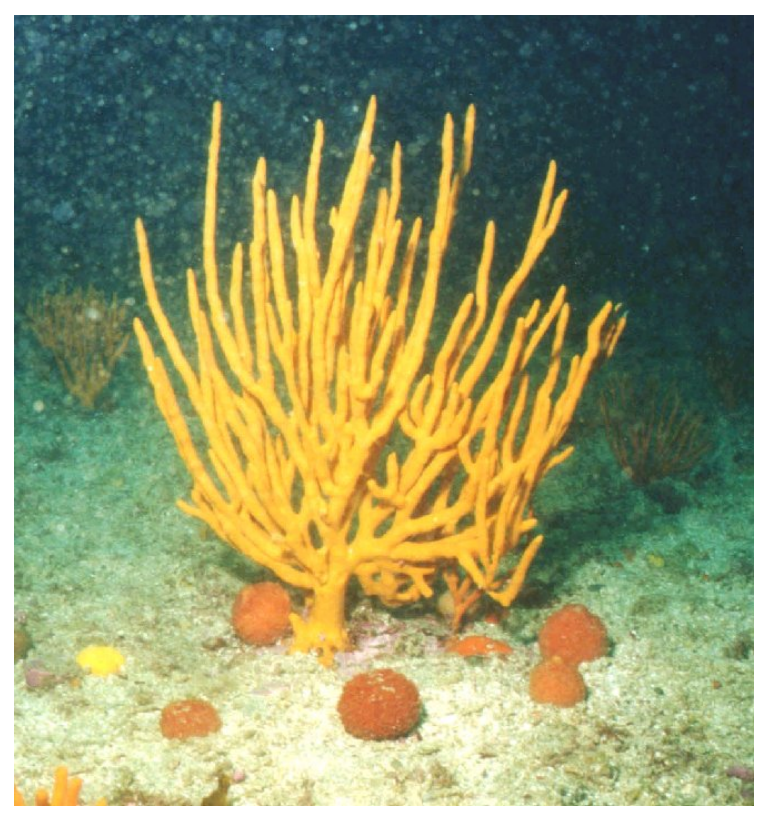

Figure 2.1 Raspailia topsenti.

Further work with $R$. topsenti collected from two further locations around New Zealand d'Urville Island, Marlborough Sounds and off the coast of New Plymouth - resulted in the isolation of three further clerodanes, raspailodanes A (32), B (33) and E (36). ${ }^{16}$ Notably, different clerodanes were isolated from different collections of $R$. topsenti indicating that a geographical distribution of compounds may exist. Raspailodanes C-E (34-36) also represent the first 19-norclerodanes isolated from the marine environment although the loss of carbon C-19 is a common motif in terrestrial clerodanes. ${ }^{18}$

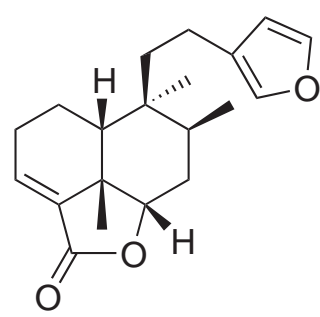

32<smiles>COC(=O)C1=CCC[C@H]2[C@@H]3CCC4=CC(=O)O[C@H]4[C@H]3CC[C@]12C</smiles>

33

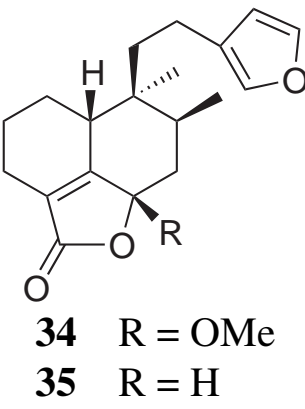

$35 \mathrm{R}=\mathrm{H}$<smiles></smiles>

36

More recently, a large scale collection of $R$. topsenti was made at the Three Kings Islands, 
Table 2.1 Taxonomic classification of genus Raspailia from order Poecilosclerida as presented by Hooper and van Soest. ${ }^{5}$

\begin{tabular}{|c|c|c|c|c|}
\hline Order & Sub-order & Family & Sub-family & Genus \\
\hline \multirow{42}{*}{ Poecilosclerida } & Latrunculina & Latrunculiidae & $\bar{~} \ldots$ & \\
\hline & \multirow{21}{*}{ Microcionina } & Acarnidae & $\ldots$ & \\
\hline & & Microcionidae & $\ldots$ & \\
\hline & & \multirow{18}{*}{ Raspailiidae } & \multirow{3}{*}{ Cyamoninae } & Cyamon \\
\hline & & & & Trikentrion \\
\hline & & & & Waltherarndtia \\
\hline & & & \multirow{2}{*}{ Echinodictyinae } & Amphinomia \\
\hline & & & & Echinodictyum \\
\hline & & & \multirow{2}{*}{ Plocamioninae } & Lithoplocamia \\
\hline & & & & Plocamione \\
\hline & & & \multirow{8}{*}{ Raspailiinae } & Aulospongis \\
\hline & & & & Ectyoplasia \\
\hline & & & & Endectyon \\
\hline & & & & Eurypon \\
\hline & & & & Hymeraphia \\
\hline & & & & Raspaciona \\
\hline & & & & Raspailia \\
\hline & & & & Rhabdeurypon \\
\hline & & & \multirow{3}{*}{ Thrinacophorinae } & Axechina \\
\hline & & & & Ceratopsion \\
\hline & & & & Thrinacophora \\
\hline & & Rhabderemiidae & $\ldots$ & \\
\hline & \multirow{9}{*}{ Mycalina } & Chladorhizidae & $\ldots$ & \\
\hline & & Desmacellidae & $\ldots$ & \\
\hline & & Esperiopsidae & $\ldots$ & \\
\hline & & Guitarridae & $\ldots$ & \\
\hline & & Hamacanthidae & $\ldots$ & \\
\hline & & Isodictyidae & $\ldots$ & \\
\hline & & Merliidae & $\ldots$ & \\
\hline & & Mycalidae & $\ldots$ & \\
\hline & & Podospongiidae & $\ldots$ & \\
\hline & \multirow{11}{*}{ Myxillina } & Chondropsidae & $\ldots$ & \\
\hline & & Coelosphaeridae & $\ldots$ & \\
\hline & & Crambeidae & $\ldots$ & \\
\hline & & Crellidae & $\ldots$ & \\
\hline & & Dendoricellidae & $\ldots$ & \\
\hline & & Desmacididae & $\ldots$ & \\
\hline & & Hymedesmiidae & $\ldots$ & \\
\hline & & Iotrochotidae & $\ldots$ & \\
\hline & & Myxillidae & $\ldots$ & \\
\hline & & Phellodermidae & $\ldots$ & \\
\hline & & Tedaniidae & $\ldots$ & \\
\hline
\end{tabular}


north of Cape Reinga, New Zealand. Investigation of the extracts of the new collection indicated the presence of several further clerodane diterpenes. Very recently, the new clerodanes topsentanes A and B (37-38) and raspailenone B (39) were isolated from this collection in our laboratory. ${ }^{17}$ Notably, the clerodanes isolated to date from $R$. topsenti show a greater degree of chemical modification in the decalin ring portion of the skeleton than most of the other marine derived structures.

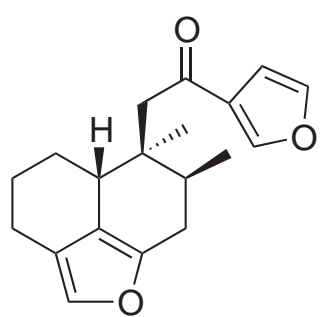

37

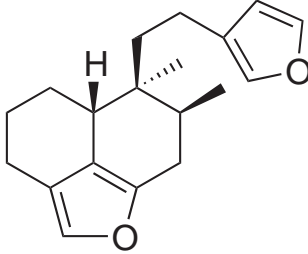

38

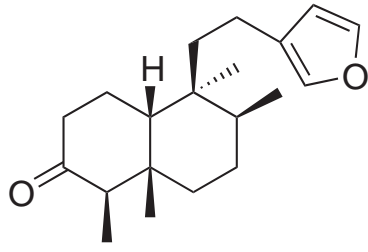

39

In this study, an extraction of $500 \mathrm{~g}$ of Raspailia topsenti collected from the Three Kings Islands, was performed. Repeated reversed-phase chromatography on HP20, HP20S and Amberchrom resins resulted in mixtures of clerodane compounds. Final purification by HPLC on a $\mathrm{C}_{18}$ reversed-phase column resulted in the isolation of the known structures raspailol (29) and raspailodane B (33) and two further new clerodane diterpenes, raspailodane $F(\mathbf{4 0})$ and raspailodane $G(\mathbf{4 1})$ (Scheme 2.2) whose structure elucidations are herein presented. 


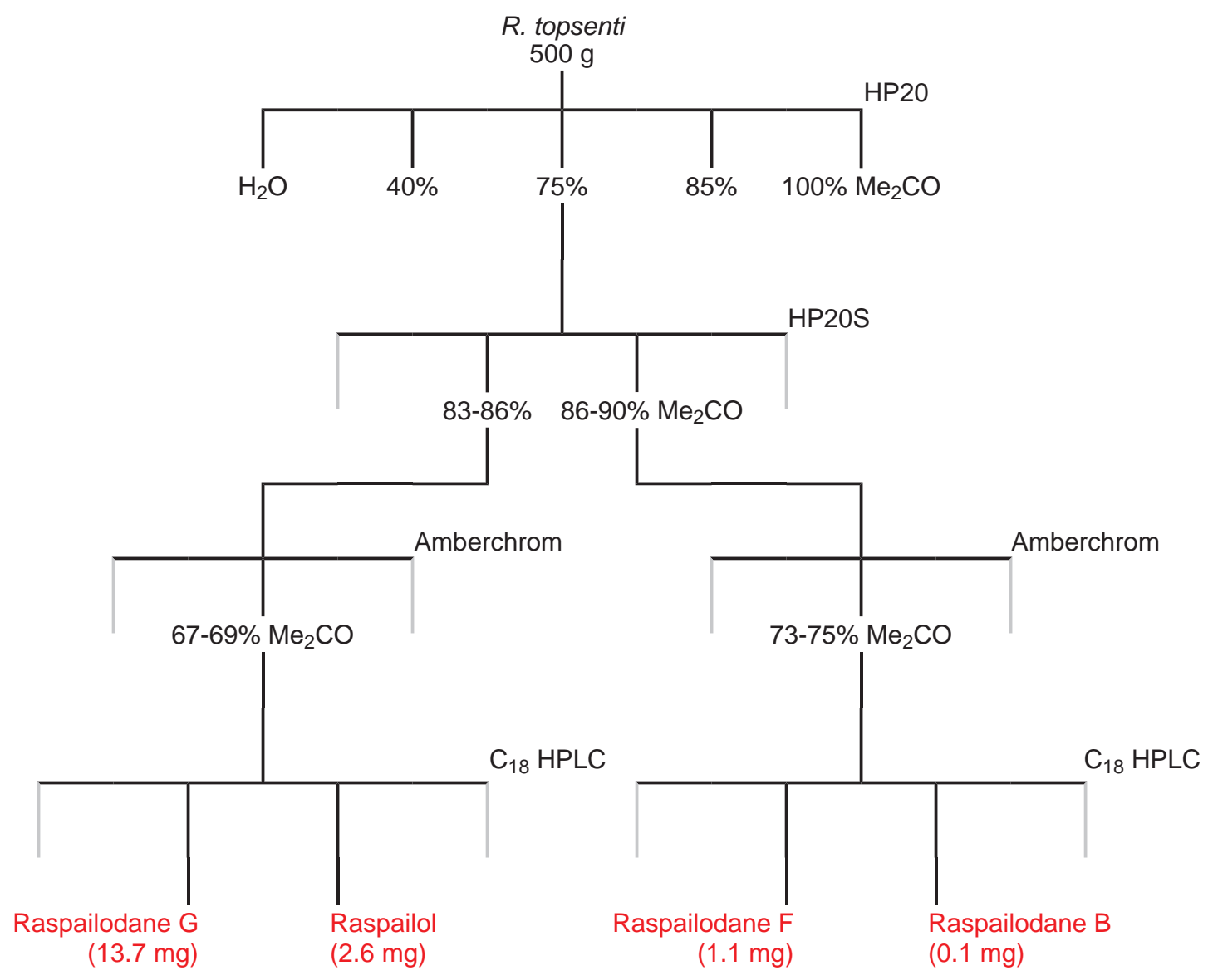

Scheme 2.2 The isolation procedure for raspailodanes F and G (40-41) from $R$. topsenti. 


\subsection{Raspailodane F}

Raspailodane F (40) was isolated as a colourless oil. The molecular formula $\mathrm{C}_{21} \mathrm{H}_{28} \mathrm{O}_{4}$ was established from the HRESIMS observation of an $[\mathrm{M}+\mathrm{H}]^{+}$pseudomolecular ion at $m / z 345.2074(\Delta 4.0 \mathrm{ppm})$ requiring eight double bond equivalents. The ${ }^{13} \mathrm{C} \mathrm{NMR}$ spectrum contained 21 signals and a multiplicity edited HSQC experiment confirmed that all 28 hydrogens were attached to carbon, consistent with this molecular formula. Three carbon resonances at $\delta_{\mathrm{C}} 174.2,171.3$ and 167.7 were identified as two ester/lactones and a polarised olefin. Three further olefinic carbons were identified - one non-protonated $\left(\delta_{\mathrm{C}}\right.$ 136.7) and two protonated $\left(\delta_{\mathrm{C}} 138.6\right.$ and 115.2). An oxymethyl group $\left(\delta_{\mathrm{C}}\right.$ 51.6, $\left.\delta_{\mathrm{H}} 3.65\right)$, a tertiary methyl $\left(\delta_{\mathrm{C}} 21.7, \delta_{\mathrm{H}} 0.96\right)$ and a secondary methyl $\left(\delta_{\mathrm{C}} 17.1, \delta_{\mathrm{H}} 0.85\right)$ were also evident. Two further carbons $\left(\delta_{\mathrm{C}} 37.5\right.$ and 20.6) were identified as quaternary centres as no corresponding HSQC correlations were observed.

Three substructures were established on the basis of observed COSY and HMBC correlations. The first substructure consisted of a chain of an olefinic methine (C-3: $\left.\delta_{\mathrm{C}} 138.6, \delta_{\mathrm{H}} 6.83\right)$, a methylene $\left(\mathrm{C}-2: \delta_{\mathrm{C}} 24.2, \delta_{\mathrm{H}} 2.25,2.16\right)$, a second methylene $(\mathrm{C}-1$ : $\left.\delta_{\mathrm{C}} 23.3, \delta_{\mathrm{H}} 1.83,1.59\right)$ and a methine $\left(\mathrm{C}-10: \delta_{\mathrm{C}} 41.3, \delta_{\mathrm{H}} 1.67\right)$ which was constructed through the observation of a series of COSY correlations between their respective proton resonances (Figure 2.2, substructure A).

A second substructure (Figure 2.2, substructure B) was constructed from another series of COSY correlations which indicated the connection of a methyl doublet (C-17: $\delta_{\mathrm{C}} 17.1$, $\left.\delta_{\mathrm{H}} 0.85\right)$ to a methine $\left(\mathrm{C}-8: \delta_{\mathrm{C}} 35.0, \delta_{\mathrm{H}} 1.58\right)$, to a methylene $\left(\mathrm{C}-7: \delta_{\mathrm{C}} 27.0, \delta_{\mathrm{H}} 2.15\right.$, $1.51)$ to a methine $\left(\mathrm{C}-6: \delta_{\mathrm{C}} 18.0, \delta_{\mathrm{H}} 1.76\right)$ to a final methylene $\left(\mathrm{C}-19: \delta_{\mathrm{C}} 24.2, \delta_{\mathrm{H}} 1.26\right.$, 0.54). The assignment of this substructure was supported by the observation of an HMBC correlation between methyl protons $\mathrm{H}_{3}-17$ and C-7.

A final substructure was constructed through the observation of COSY correlations between a methylene $\left(\mathrm{C}-11: \delta_{\mathrm{C}} 35.4, \delta_{\mathrm{H}} 1.56,1.43\right)$ and another methylene $(\mathrm{C}-12$ : $\left.\delta_{\mathrm{C}} 23.1, \delta_{\mathrm{H}} 2.29\right)$ which further displayed an allylic COSY correlation to an olefinic methine $\left(\mathrm{C}-14: \delta_{\mathrm{C}} 115.2, \delta_{\mathrm{H}} 5.84\right)$ and a second COSY correlation to an oxygenated 
methylene $\left(\mathrm{C}-16: \delta_{\mathrm{C}} 73.2, \delta_{\mathrm{H}} 4.74\right)$. HMBC correlations from $\mathrm{H}_{2}-12$ to $\mathrm{C}-14, \mathrm{C}-16$ and a non-protonated olefinic carbon C-13 $\left(\delta_{\mathrm{C}} 171.3\right)$, and from methylene protons $\mathrm{H}_{2}$ 16 to $\mathrm{C}-13$ and $\mathrm{C}-14$, indicated the placement of $\mathrm{C}-13$ between $\mathrm{C}-12, \mathrm{C}-14$ and $\mathrm{C}-16$. The resonances of $\mathrm{H}-14$ and $\mathrm{H}_{2}-16$ showed HMBC correlations to a lactone carbonyl which was assigned as C-15 $\left(\delta_{\mathrm{C}} 174.2\right)$ completing a butenolide moiety (Figure 2.2, substructure C). The NMR data for this butenolide substructure were consistent with the chemical shifts reported for the butenolide of raspailodane B (33). ${ }^{16}$

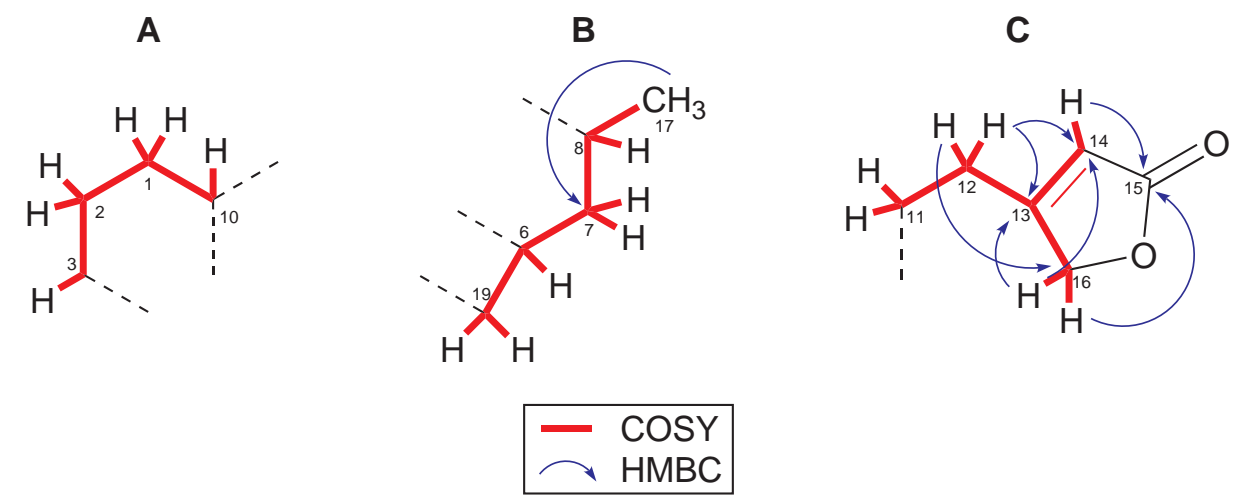

Figure 2.2 Selected COSY and HMBC correlations establishing substructures of raspailodane $\mathrm{F}(\mathbf{4 0})$.

These three substructures were connected through the observation of HMBC correlations from methyl singlet protons $\mathrm{H}_{3}-20\left(\delta_{\mathrm{C}} 21.7, \delta_{\mathrm{H}} 0.96\right)$ to a quaternary carbon $(\mathrm{C}-9$ : $\left.\delta_{\mathrm{C}} 37.5\right)$, methine $\mathrm{C}-8$, methine $\mathrm{C}-10$ and methylene $\mathrm{C}-11$. As the only quaternary centre, C-9 must be directly bonded to C-8, C-10, C-11 and C-20 (Figure 2.3).

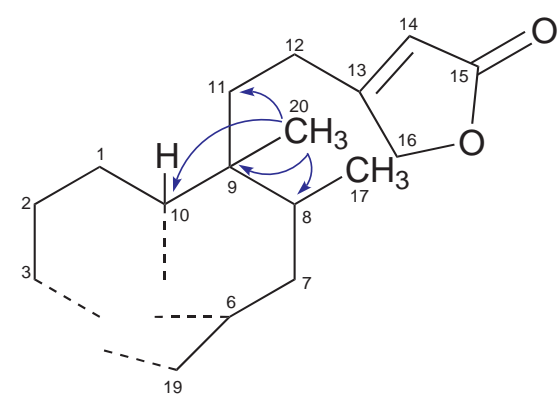

Figure 2.3 HMBC correlations connecting the substructures of raspailodane $\mathrm{F}(\mathbf{4 0})$.

The remaining features to be assigned to the structure were an ester/lactone carbon, a nonprotonated olefinic carbon, a further quaternary carbon and the oxymethyl group. The final connections in the structure were made through the observation of a further series of HMBC correlations. Methine H-10 showed HMBC correlations to the remaining olefinic carbon $\mathrm{C}-4\left(\delta_{\mathrm{C}} 136.7\right)$, a quaternary carbon $\mathrm{C}-5\left(\delta_{\mathrm{C}} 20.6\right)$ and methylene carbon C-19 
indicating that C-5 was connected to each of C-4, C-10 and C-19. HMBC correlations observed from H-19a and H-19b to C-5 and from H-3 to C-5 supported this assignment. The fourth substituent of the trisubstituted olefinic system was determined to be C-18 $\left(\delta_{\mathrm{C}}\right.$ 167.7) through the observation of an HMBC correlation from H-3 to C-18. An HMBC correlation from an oxymethyl group $\left(\mathrm{C}-21: \delta_{\mathrm{C}} 51.6, \delta_{\mathrm{H}} 3.65\right)$ to $\mathrm{C}-18$ showed this moiety to be a methyl ester. The ${ }^{13} \mathrm{C}$ chemical shifts of $\mathrm{C}-3$ and $\mathrm{C}-4$ are consistent with the polarising effect of the neighbouring carbonyl. With the molecular formula accounted for in the substructure and two double bond equivalents unaccounted for, a connection between C-5 and C-6 is proposed to form a tricyclo[5.4.0.0 $\left.0^{1,3}\right]$ undecane system containing a cyclopropyl ring. This proposal is supported by the unusual chemical shifts of methylene protons $\mathrm{H}-19 \mathrm{a}$ and $\mathrm{H}-19 \mathrm{~b}\left(\delta_{\mathrm{H}} 1.26,0.54\right)$. The observed ${ }^{1} J_{\mathrm{CH}}$ coupling constants for positions 6 and 19 (both $161 \mathrm{~Hz}$ ) are also consistent with a cyclopropyl moiety. ${ }^{42}$ Finally, weak HMBC correlations from H-6 to C-4, C-5 and C-10 provide further evidence for this assignment. The presence of the cyclopropyl group is likely to distort the chair conformation of ring B forcing a number of the bond angles in the molecule into conformations which do not produce strong NMR correlations. The HMBC correlations used to determine the final structure are shown in Figure 2.4.

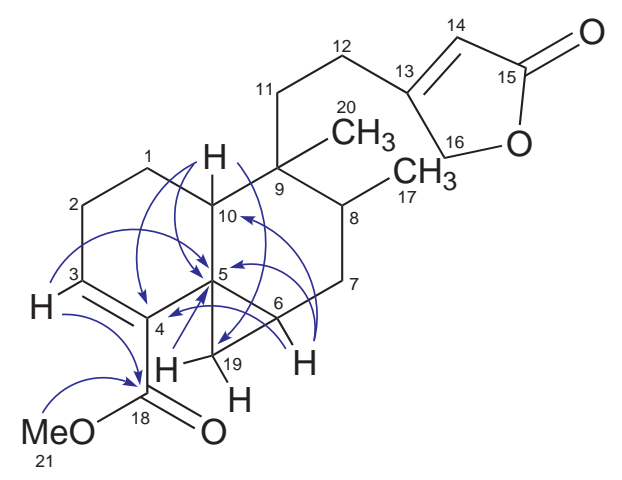

Figure 2.4 HMBC correlations establishing the structure of raspailodane F (40).

The relative configuration of $\mathbf{4 0}$ was assigned on the basis of NOE enhancements observed in a series of 1D-NOESY experiments and a ROESY experiment. Selective excitation of methyl protons $\mathrm{H}_{3}-17$ showed NOE enhancements to $\mathrm{H}-10$ and $\mathrm{H}-19 \mathrm{~b}$, while selective excitation of $\mathrm{H}-19 \mathrm{~b}$ revealed NOE enhancements to its geminal partner $\mathrm{H}-19 \mathrm{a}, \mathrm{H}-10$ and methyl protons $\mathrm{H}_{3}-17$. Selective excitation of $\mathrm{H}-19$ a on the other hand only revealed an NOE enhancement to H-19b. From these observations, H-10 and methyl C-17 were 
determined to be in a 1,3-diaxial arrangement which places $\mathrm{C}$-1 equatorial to ring $\mathrm{B}$. The observation of three further correlations in the ROESY spectrum completed the stereochemical assignment. NOE enhancements between methyl protons $\mathrm{H}_{3}-17$ and $\mathrm{H}-$ $7 \beta$ indicated that $\mathrm{H}-7 \beta$ was placed equatorial to the ring thus placing $\mathrm{H}-7 \alpha$ in an axial position on the opposite face of the ring. Methyl protons $\mathrm{H}_{3}-20$ showed two 1,3-diaxial NOE enhancements to $\mathrm{H}-7 \alpha$ and $\mathrm{H}-1 \alpha$ respectively placing these three groups axial on the $\alpha$ face of the ring. This is corroborated by the observation of a weak COSY correlation between $\mathrm{H}_{3}-20$ and $\mathrm{H}-10$ indicating long-range W-coupling between these protons. With C-20 axial, C-11 must be equatorial. The observation of independent 1,3-diaxial NOE enhancements on both faces of the ring would seem to indicate that ring B exists in a chair conformation (Figure 2.5). It is likely however, that the chair is quite distorted due to the tortional strain introduced by the cyclopropyl ring.
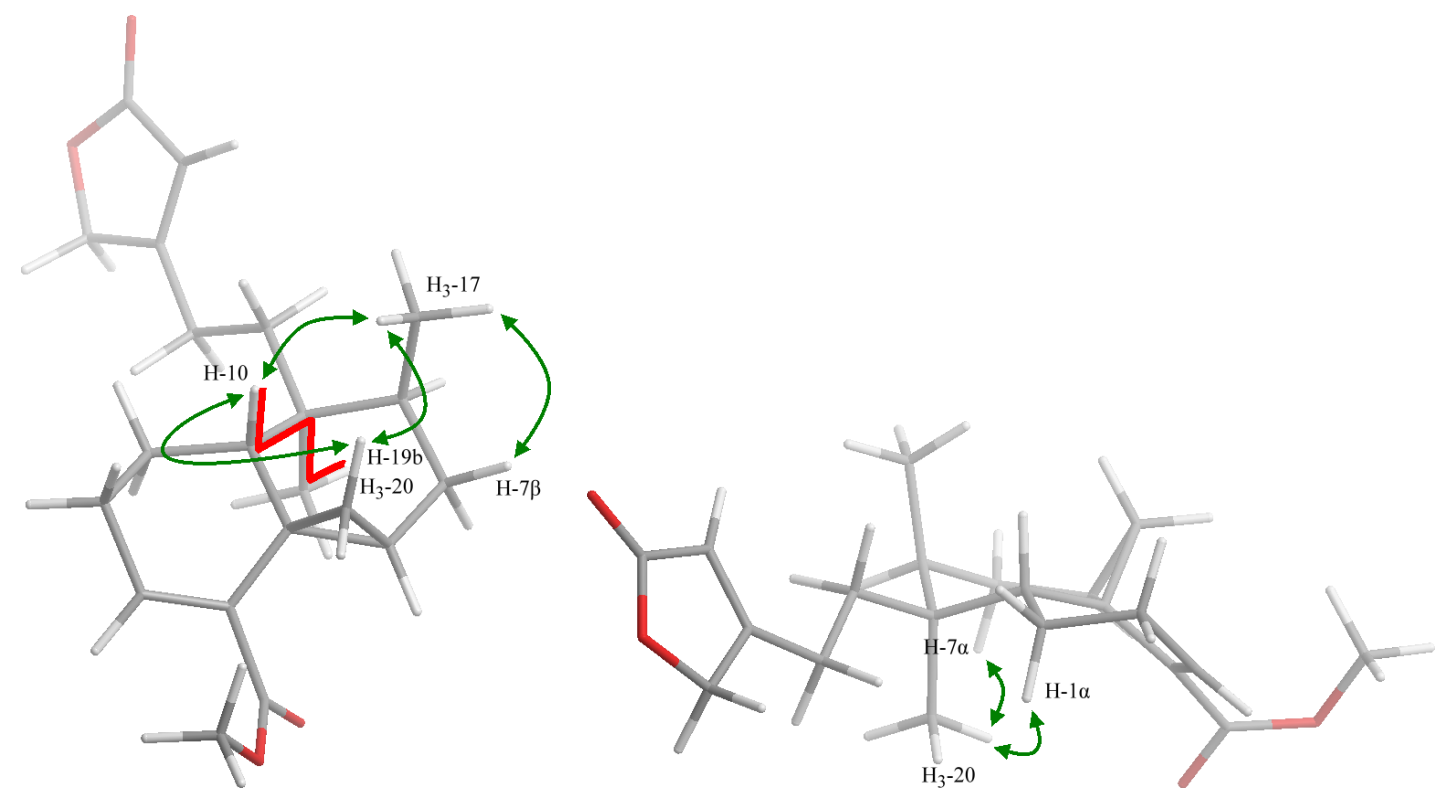

Figure 2.5 COSY W-coupling and selected NOE enhancements used to determine the relative configuration of raspailodane $\mathrm{F}(\mathbf{4 0})$.

Raspailodane F (40) is similar to raspailodane B (33) possessing a modified furan side chain, formally a butenolide. The characteristic that distinguishes $\mathbf{4 0}$ is the cyclopropyl moiety created by a new carbon-carbon bond between C-6 and C-19. In all other respects it is identical to 33 . NMR data for raspailodane $\mathrm{F}(\mathbf{4 0})$ is presented in Table 2.2.

The presence of a cyclopropyl ring in diterpenes is certainly not without precedence. Several terrestrial diterpenes have been reported with a cyclopropyl group such as the timber-isolated devadaran- $1 \beta, 11 \beta, 15 \xi, 16$-tetrol (42). ${ }^{43}$ However, there are only 


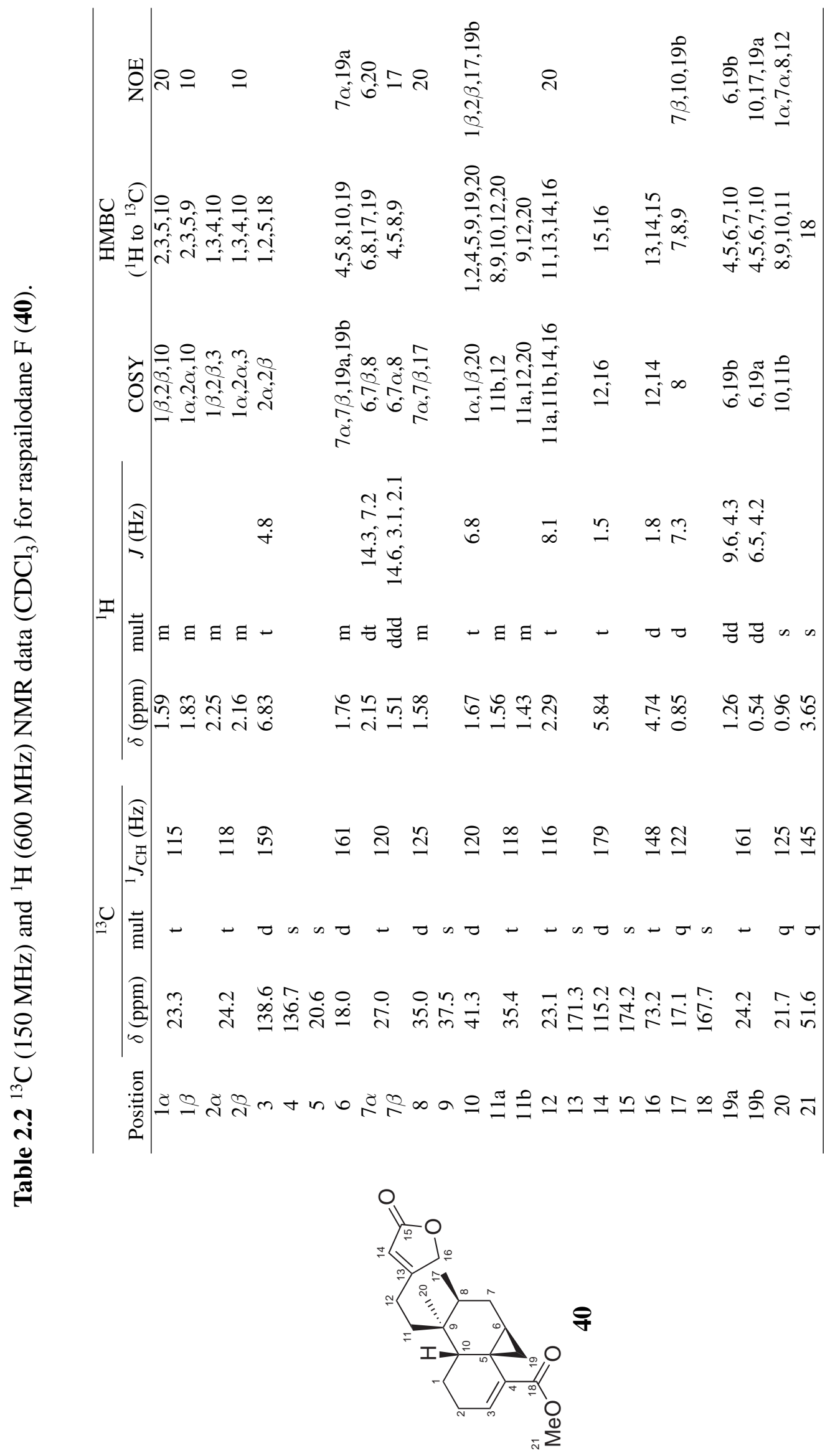


four reported clerodanes containing cyclopropyl moieties, all derived from the marine environment. These are asmarines I and J (26-27) and the tunicate-derived dytesinins A and B (43-44). ${ }^{44}$ In each case the cyclopropyl ring connects carbons C-4, C-5 and C-19, the formation of which can potentially be accounted for by the mechanism depicted in Scheme 2.3. ${ }^{36}$ Raspailodane $\mathrm{F}$ is unusual in that it is the first reported clerodane diterpene with a C-5, C-6, C-19 cyclopropyl moiety the formation of which likely occurs after the 1,2-methyl shift between C-4 and C-5.

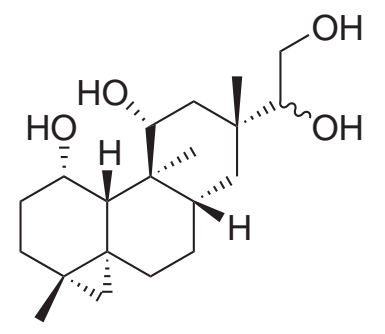

42<smiles>[R]C12OC(=O)C=C1CC[C@H]1[C@@H]2CC[C@]2(C)[C@@H](C)CCC[C@H]12</smiles>

$43 \mathrm{R}=\mathrm{OH}$

$44 \mathrm{R}=\mathrm{H}$
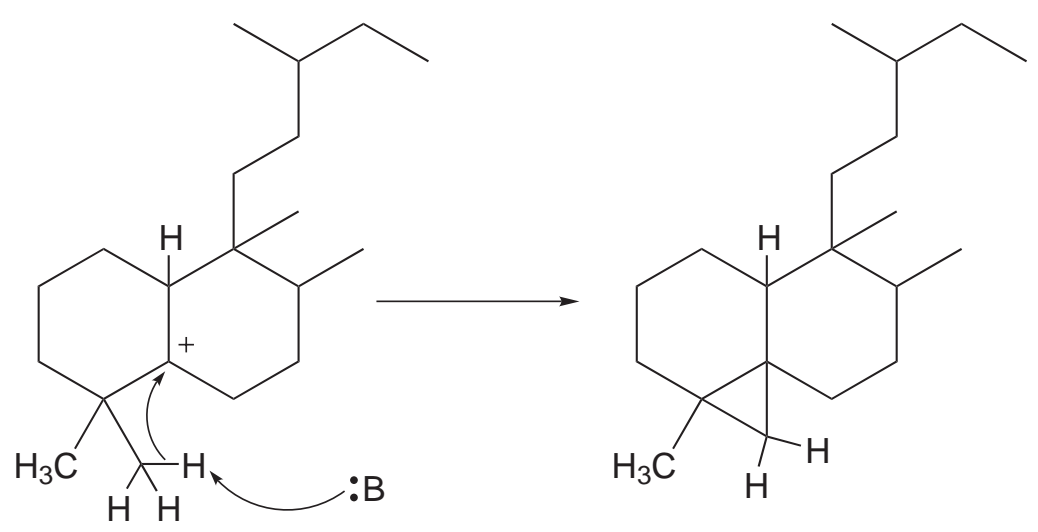

Scheme 2.3 A proposed biogenesis of the C-4, C-5, C-19 cyclopropyl moiety in clerodanes. $^{36}$ 


\subsection{Raspailodane G}

Raspailodane G (41) was isolated as a colourless oil, the NMR data of which were similar to those of raspailodanes C-E (34-36). ${ }^{16}$ HRESIMS data indicated the presence of a pseudomolecular ion at $m / z 345.1704\left([\mathrm{M}+\mathrm{H}]^{+}, \Delta 2.1 \mathrm{ppm}\right)$ representing a molecular formula of $\mathrm{C}_{20} \mathrm{H}_{24} \mathrm{O}_{5}$, requiring nine double bond equivalents. The ${ }^{13} \mathrm{C}$ NMR spectrum revealed 20 resonances and a multiplicity edited HSQC experiment confirmed that all 24 hydrogens were attached to carbon, consistent with this molecular formula. Two carbonyl carbons were identified, the first an unsaturated ketone $\left(\delta_{\mathrm{C}} 193.4\right)$ and the other an ester/lactone function $\left(\delta_{\mathrm{C}}\right.$ 170.6). In addition, three non-protonated olefinic carbons $\left(\delta_{\mathrm{C}} 160.6,131.1\right.$ and 128.9), three protonated olefinic carbons $\left(\delta_{\mathrm{C}} 146.9,144.5\right.$, and 108.7), a non-protonated acetal carbon $\left(\delta_{\mathrm{C}} 105.6\right)$, a further quaternary carbon $\left(\delta_{\mathrm{C}} 43.0\right)$, an oxymethyl group $\left(\delta_{\mathrm{C}} 50.1, \delta_{\mathrm{H}} 3.15\right)$, a tertiary methyl $\left(\delta_{\mathrm{C}} 21.4, \delta_{\mathrm{H}} 1.04\right)$ and a secondary methyl $\left(\delta_{\mathrm{C}} 15.9, \delta_{\mathrm{H}} 1.08\right)$ were noted.

As with raspailodane $\mathrm{F}(\mathbf{4 0})$, three substructures were constructed using a combination of COSY, HMBC, TOCSY and HSQC-TOCSY correlations. Analysis of the ${ }^{1} \mathrm{H}$ and ${ }^{13} \mathrm{C}$ NMR data of $\mathbf{4 1}$ revealed the presence of three methines in the downfield region $(\mathrm{C}-14$ : $\delta_{\mathrm{C}} 108.7, \delta_{\mathrm{H}} 6.74, \mathrm{C}-15: \delta_{\mathrm{C}} 144.5, \delta_{\mathrm{H}} 7.44$ and C-16: $\left.\delta_{\mathrm{C}} 146.9, \delta_{\mathrm{H}} 8.01\right)$ consistent with a keto-furan substructure (Figure 2.6, substructure A). This assignment was confirmed by the observation of HMBC correlations from H-14 to a carbonyl (C-12: $\left.\delta_{\mathrm{C}} 193.4\right)$, a non-protonated carbon $\left(\mathrm{C}-13: \delta_{\mathrm{C}} 128.9\right), \mathrm{C}-15$ and $\mathrm{C}-16$. Further HMBC correlations from $\mathrm{H}-15$ to $\mathrm{C}-13, \mathrm{C}-14$, and $\mathrm{C}-16$ and $\mathrm{H}-16$ to $\mathrm{C}-13, \mathrm{C}-14$ and $\mathrm{C}-15$ supported this assignment. The large ${ }^{1} J_{\mathrm{CH}}$ coupling constants measured for C-15 $(209 \mathrm{~Hz})$ and C-16 $(207 \mathrm{~Hz})$ are indicative of the attachment of oxygen at these centres. The chemical shifts of this substructure are consistent with those of keto-furan side chain similar to that of 36. ${ }^{16}$

A second substructure was constructed from series of COSY correlations between methyl protons $\mathrm{H}_{3}-17\left(\delta_{\mathrm{C}} 15.9, \delta_{\mathrm{H}} 1.08\right)$ and $\mathrm{H}-8\left(\delta_{\mathrm{C}} 35.6, \delta_{\mathrm{H}} 2.45\right)$ then between $\mathrm{H}-8$ and methylene protons $\mathrm{H}-7 \alpha$ and $\mathrm{H}-7 \beta\left(\delta_{\mathrm{C}} 37.4, \delta_{\mathrm{H}} 2.20,1.99\right)$ indicating the attachment of C7 to C-8 to C-17 (Figure 2.6, substructure B). This assignment was confirmed by selective 
excitation of protons $\mathrm{H}_{3}-17$ in a series of 1D-TOCSY experiments with increasing mixing times which sequentially revealed $\mathrm{H}-8$ then $\mathrm{H}-7 \alpha$ and $\mathrm{H}-7 \beta$.

A final substructure was constructed from a series of COSY correlations indicating the linear arrangement of C-10 $\left(\delta_{\mathrm{C}} 37.6, \delta_{\mathrm{H}} 2.64\right), \mathrm{C}-1\left(\delta_{\mathrm{C}} 22.3, \delta_{\mathrm{H}} 1.93,1.53\right), \mathrm{C}-2\left(\delta_{\mathrm{C}} 21.7\right.$, $\left.\delta_{\mathrm{H}} 1.93,1.53\right)$ and $\mathrm{C}-3\left(\delta_{\mathrm{C}} 20.0, \delta_{\mathrm{H}} 2.33,2.10\right)$ (Figure 2.6 , substructure C). Due to the spectral overlap between the protons of C-1 and C-2, the substructure was resolved by a series of HSQC-TOCSY experiments with increasing mixing times. The HSQC-TOCSY experiment can resolve overlapping proton resonances by presenting the data with respect to the carbon to which the proton exhibits an HSQC correlation. In this case, since C1 and C-2 are distinct ( $\delta_{\mathrm{C}} 22.3$ and 21.7 respectively), TOCSY correlations to H-1a,b and $\mathrm{H}-2 \mathrm{a}, \mathrm{b}$ can be resolved. At a short mixing time $(20 \mathrm{~ms})$ strong correlations were observed between H-10 and H-1a,b, and between H-3a,b and H-2a,b. With longer mixing times both H-10 and H-3a,b showed similar correlations to H-1a,b and H-2a,b. Finally, selective excitation of $\mathrm{H}-10$ in a series of 1D-TOCSY experiments with increasing mixing times sequentially revealed $\mathrm{H}-1 \mathrm{a}, \mathrm{b}$ and $\mathrm{H}-2 \mathrm{a}, \mathrm{b}$ then $\mathrm{H}-3 \mathrm{a}, \mathrm{b}$. These data indicate the linear arrangement of C-10 to C-1 to C-2 to C-3.

A

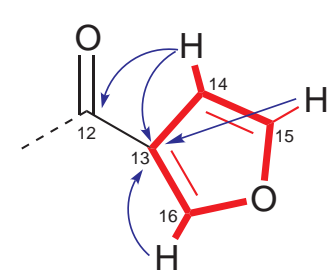

B

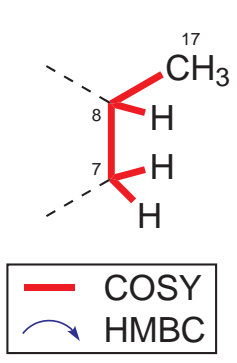

C

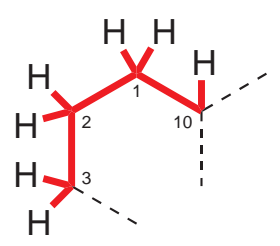

Figure 2.6 Selected COSY and HMBC correlations establishing substructures of raspailodane $G \mathbf{( 4 1 )}$.

A series of $\mathrm{HMBC}$ correlations from methyl singlet protons $\mathrm{H}_{3}-19\left(\delta_{\mathrm{C}} 21.4, \delta_{\mathrm{H}} 1.04\right)$ to $\mathrm{C}-8$, quaternary carbon $\mathrm{C}-9\left(\delta_{\mathrm{C}} 43.0\right), \mathrm{C}-10$, and methylene $\mathrm{C}-11\left(\delta_{\mathrm{C}} 46.5, \delta_{\mathrm{H}} 2.89\right)$ established the connection of C-19 to C-9 and C-9 to C-8, C-10 and C-11. HMBC correlations observed from H-11a,b to C-12 established the final connection between the three substructures (Figure 2.7).

At this stage the remaining unassigned functions in the molecule were an ester/lactone 


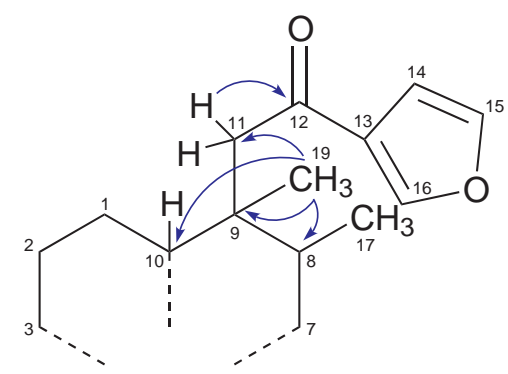

Figure 2.7 HMBC correlations connecting the substructures of raspailodane G (41).

carbonyl, two non-protonated olefinic carbons, a non-protonated acetal carbon and an oxymethyl group. Another series of HMBC correlations were observed to complete the structure of raspailodane G (Figure 2.8). H-8 showed an HMBC correlation to the acetal carbon (C-6: $\left.\delta_{\mathrm{C}} 105.6\right)$ indicating the attachment of C-6 to C-7. This was confirmed by the observation of HMBC correlations from $\mathrm{H}-7 \alpha$ and $\mathrm{H}-7 \beta$ to C-6. A highly polarised tetrasubstituted double bond $\left(\mathrm{C}-4: \delta_{\mathrm{C}} 131.1\right.$ and C-5: $\delta_{\mathrm{C}}$ 160.6) was placed between C-3, C-6 and $\mathrm{C}-10$ on the basis of HMBC correlations from $\mathrm{H}-7 \beta$ to $\mathrm{C}-5, \mathrm{H}-3 \mathrm{a}$ and $\mathrm{H}-3 \mathrm{~b}$ to both $\mathrm{C}-4$ and $\mathrm{C}-5$, and $\mathrm{H}-10$ to both $\mathrm{C}-4$ and $\mathrm{C}-5$. The fourth substituent of the double bond was determined to be carbonyl carbon C-18 $\left(\delta_{\mathrm{C}} 170.6\right)$ by the observation of an HMBC correlation between $\mathrm{H}-3 \mathrm{a}$ and $\mathrm{C}-18$. The assignment of $\mathrm{C}-18$ is consistent with the polarised nature of the C-4, C-5 double bond. An HMBC correlation between an oxymethyl group $\left(\mathrm{C}-20: \delta_{\mathrm{C}} 50.1, \delta_{\mathrm{H}} 3.15\right)$ and C-6 determined the attachment of the oxymethyl group to the acetal centre C-6. With all carbons and protons accounted for and one double bond equivalent left to assign, C-18 and C-6 were determined to be connected by a lactone linkage. This is consistent with the ${ }^{13} \mathrm{C}$ chemical shift of $\mathrm{C}-18$ and accounts for all the elements of the molecular formula. Comparison of the ${ }^{1} \mathrm{H}$ and ${ }^{13} \mathrm{C}$ NMR data of $\mathbf{4 1}$ with that of $\mathbf{3 4}$ confirmed the presence of the same decalin ring moiety. ${ }^{16}$

The relative configuration of $\mathbf{4 1}$ was resolved in a series of 1D-NOESY experiments. Selective excitation of methyl protons $\mathrm{H}_{3}-17$ revealed 1,3-diaxial enhancements to methine $\mathrm{H}-10$ and methyl protons $\mathrm{H}_{3}-20$. The axial orientation of $\mathrm{H}-10$ indicates that C-1 must be equatorial to ring B. An NOE enhancement between methyl protons $\mathrm{H}_{3}$ 17 and methylene proton $\mathrm{H}-7 \beta$ indicated that $\mathrm{H}-7 \beta$ was placed equatorial and $\mathrm{H}-7 \alpha$ must be axial on the opposite face of the ring to methyl C-17. This conclusion is supported by the observation of a long-range COSY W-correlation between $\mathrm{H}_{3}-17$ and 
$\mathrm{H}-7 \alpha$ which indicates that $\mathrm{C}-17$ and $\mathrm{H}-7 \alpha$ are arranged in a 1,2-diaxial conformation. The measured coupling constants between $\mathrm{H}-8$ and $\mathrm{H}-7 \alpha$ and $\mathrm{H}-8$ and $\mathrm{H}-7 \beta$ (5.5 and $2.8 \mathrm{~Hz}$ respectively) are consistent with the expected equatorial/axial and equatorial/equatorial interactions. Selective excitation of methyl protons $\mathrm{H}_{3}-19$ produced a 1,3-diaxial enhancement of $\mathrm{H}-7 \alpha$ placing methyl C-19 axial on the $\alpha$ face of ring B and indicating that C-11 must be equatorial. The independent observation of 1,3-diaxial NOE enhancements on both faces of ring B indicate that it must exist in a chair conformation (Figure 2.9).

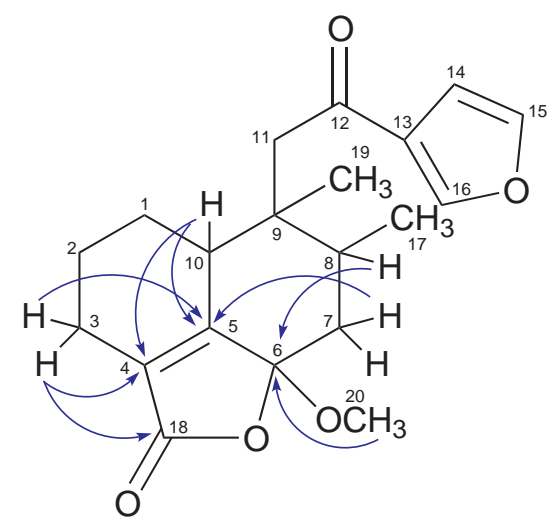

Figure 2.8 Selected HMBC correlations completing the structure of raspailodane G (41).

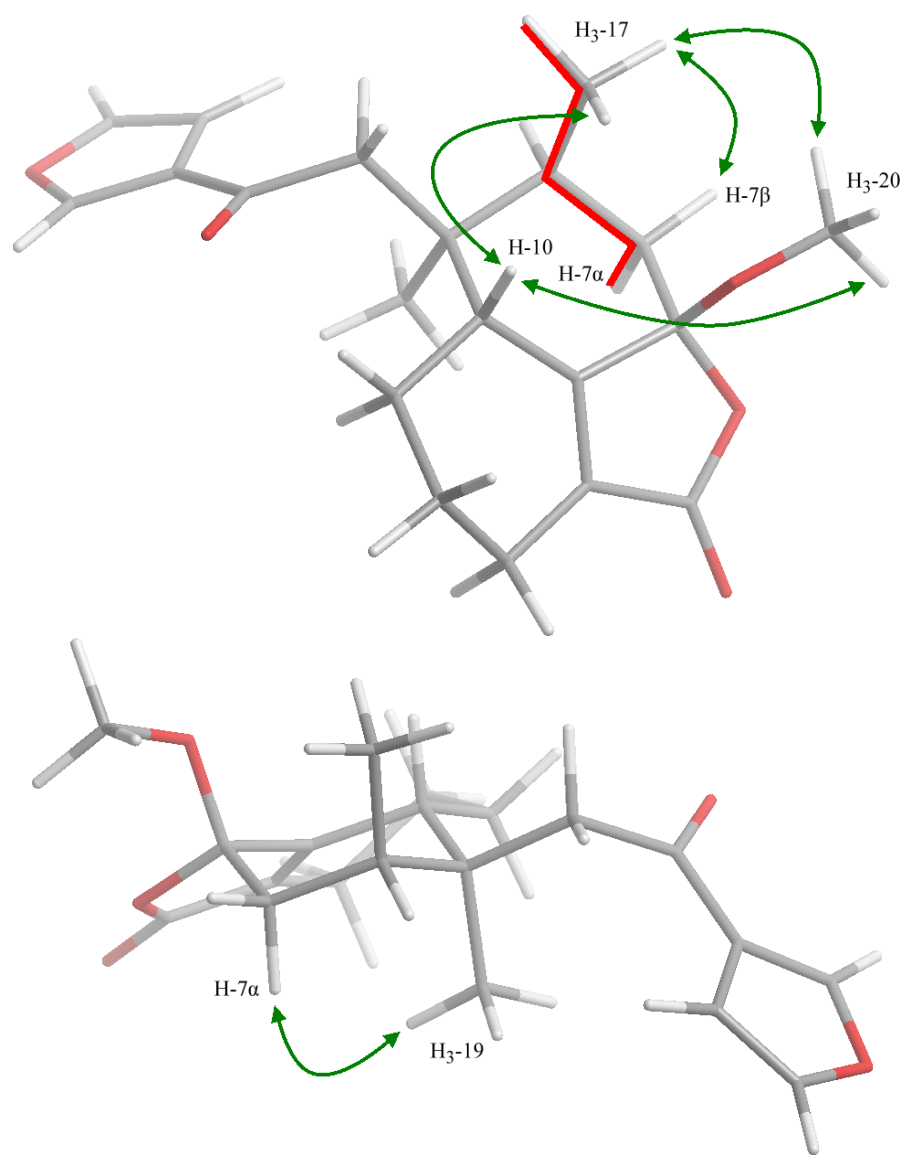

Figure 2.9 COSY W-coupling and selected NOE enhancements establishing the relative configuration of raspailodane $\mathrm{G}(\mathbf{4 1})$. 
Raspailodane G (41) is a 19-norclerodane similar to raspailodanes C-E. The isolation of 41 completes the set of four structures $(\mathbf{3 4 - 3 6}, \mathbf{4 1})$ where C-6 is found either as a ringjunction oxymethine or as a methoxy-acetal and C-12 is either a methylene or a ketone. NMR data for raspailodane G (41) is presented in Table 2.3.

There have been no reported natural products isolated specifically from $R$. topsenti beyond those already mentioned here. Other natural products from the genus Raspailia are reported in the literature in only seven papers. In 1986 the acetylenic enol ether glyceride raspailyne-A (45) was reported from Raspailia pumila ${ }^{45}$ followed shortly thereafter by a further 10 related raspailynes (46-55) isolated from $R$. pumila and $R$. ramosa ${ }^{46}$ In 1995 Faulkner et al. reported the isolation of the raspailols A and B (56-57) from an unidentified species of the Raspailia subgenus Raspaxilla. ${ }^{47,48}$ The diterpenes zaatirin (58) and chelodane (15) were co-isolated from Raspailia sp. with asmarines AF and the steroid methyl-3-oxocholan-24-oate (59) in 2000. ${ }^{34}$ More recently, a known synthetic acetylcholine mimetic, esmodil (60), was isolated from an Australian collection of Raspailia (Raspailia) sp. along with the two known metabolites phorboxazoles A and B (61-62). ${ }^{49}$ Finally, the diterpenes barekol (63), barekoxide (64) ${ }^{35}$ and nosyberkol $(\mathbf{6 5})^{36}$ were co-isolated with asmarines G-K. The presence of okadaic acid (66) and dinophysistoxin-3 (DTX3) (67) has also been reported in collections of R. agminata from Fiordland, New Zealand, although it is implied that these metabolites were isolated as a result of the sponge being exposed to toxic dinoflagellates. ${ }^{50}$

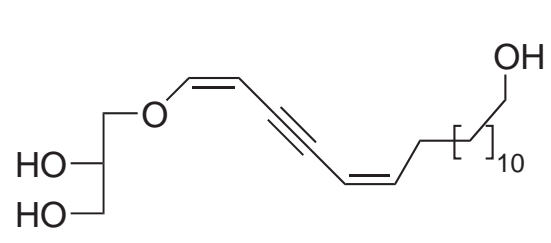

45

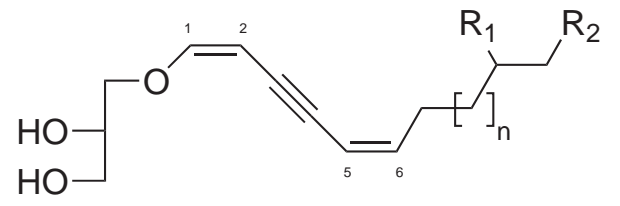

$46 \quad \mathrm{n}=5 \quad \mathrm{R}_{1}=\mathrm{Me} \quad \mathrm{R}_{2}=\mathrm{H} \quad \Delta_{5-6}=(E)$

$47 \quad \mathrm{n}=5 \quad \mathrm{R}_{1}=\mathrm{H} \quad \mathrm{R}_{2}=\mathrm{H} \quad \Delta_{1-2}=(E)$

$\begin{array}{llll}48 & \mathrm{n}=7 & \mathrm{R}_{1}=\mathrm{H} & \mathrm{R}_{2}=\mathrm{OH}\end{array}$

$49 \mathrm{n}=9 \quad \mathrm{R}_{1}=\mathrm{OH} \quad \mathrm{R}_{2}=\mathrm{H}$

$50 \quad \mathrm{n}=4 \quad \mathrm{R}_{1}=\mathrm{H} \quad \mathrm{R}_{2}=\mathrm{H}$

$51 \quad \mathrm{n}=5 \quad \mathrm{R}_{1}=\mathrm{H} \quad \mathrm{R}_{2}=\mathrm{H}$

$52 \mathrm{n}=6 \quad \mathrm{R}_{1}=\mathrm{H} \quad \mathrm{R}_{2}=\mathrm{H}$

$53 \mathrm{n}=5 \quad \mathrm{R}_{1}=\mathrm{Me} \quad \mathrm{R}_{2}=\mathrm{H}$

$54 \mathrm{n}=4 \quad \mathrm{R}_{1}=\mathrm{Me} \quad \mathrm{R}_{2}=\mathrm{H}$

$55 \mathrm{n}=5 \quad \mathrm{R}_{1}=\mathrm{H} \quad \mathrm{R}_{2}=\mathrm{H} \quad \Delta_{5-6}=(E)$ 


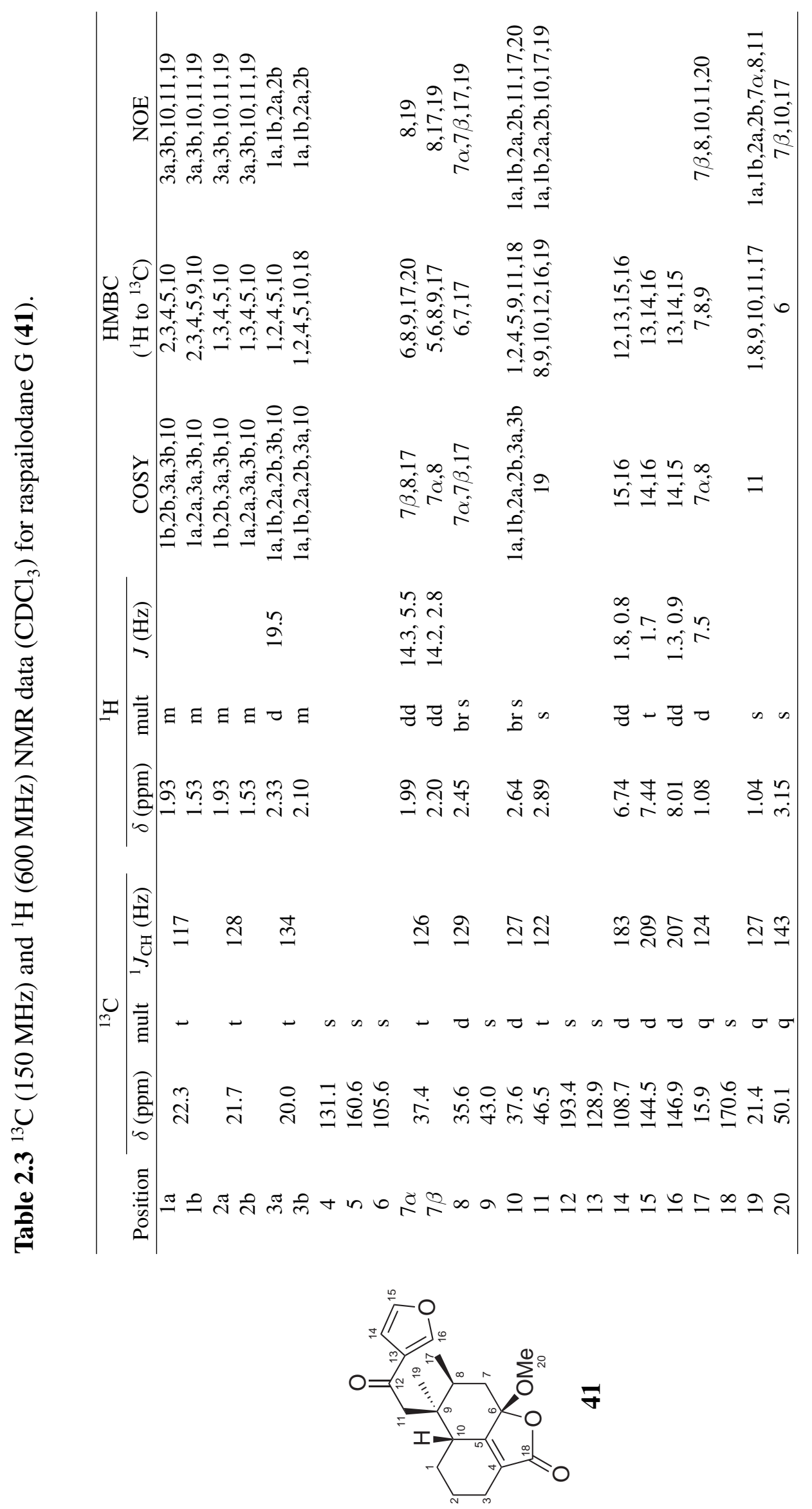




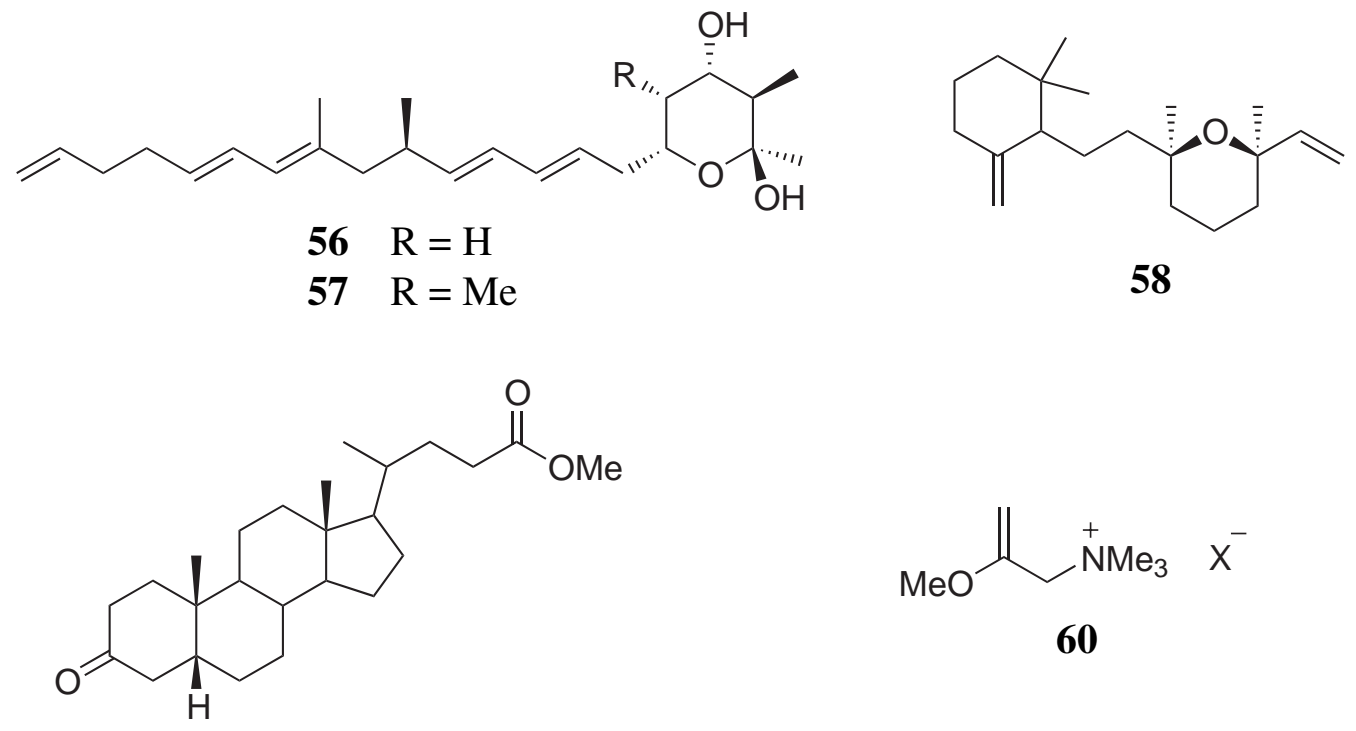

59

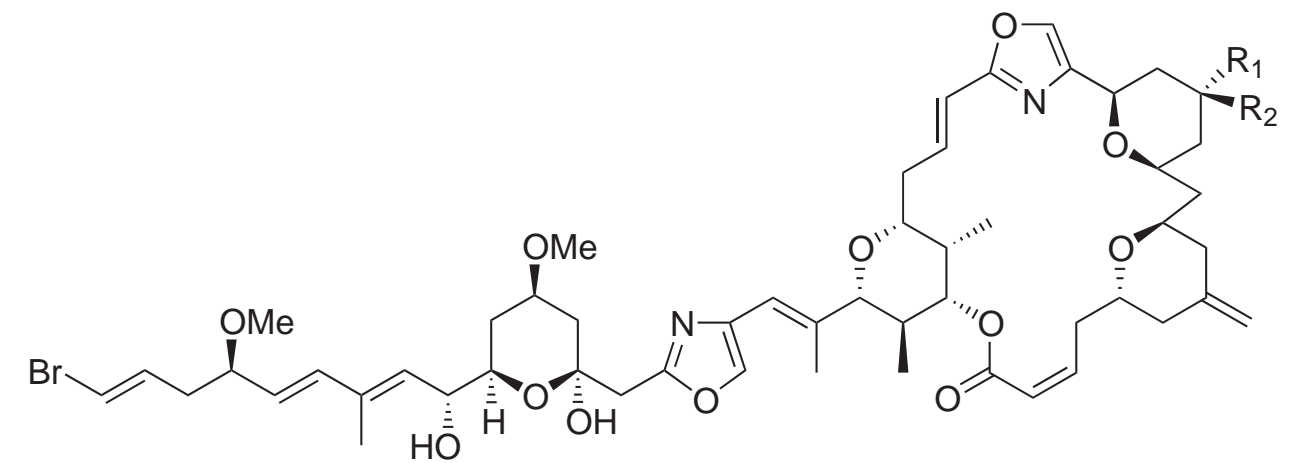

$$
\begin{array}{lll}
\mathbf{6 1} & \mathrm{R}_{1}=\mathrm{OH} & \mathrm{R}_{2}=\mathrm{H} \\
\mathbf{6 2} & \mathrm{R}_{1}=\mathrm{H} & \mathrm{R}_{2}=\mathrm{OH}
\end{array}
$$

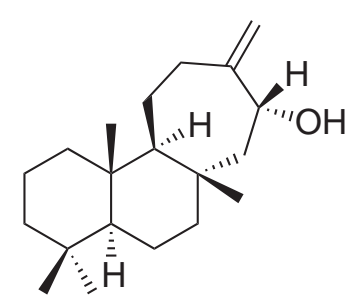

63

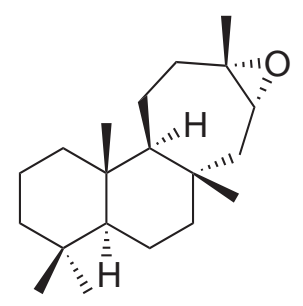

64

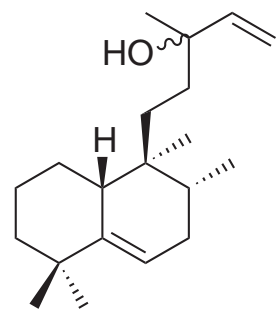

65

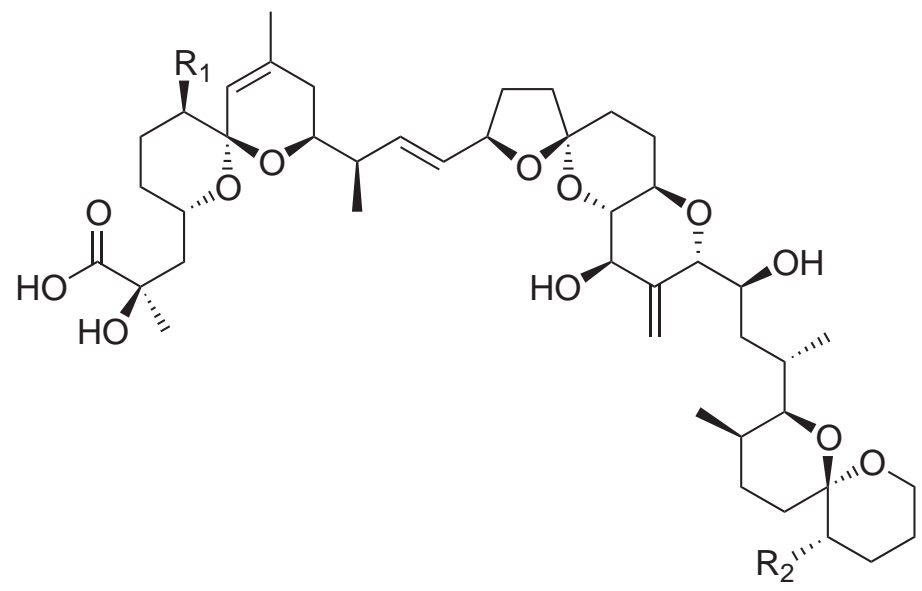

$66 \quad \mathrm{R}_{1}=\mathrm{OH} \quad \mathrm{R}_{2}=\mathrm{H}$

$67 \mathrm{R}_{1}=$ OAcyl $\mathrm{R}_{2}=\mathrm{CH}_{3}$ 


\subsection{Summary}

The extraction of a new collection of Raspailia topsenti collected from the Three Kings Islands, New Zealand resulted in the isolation and characterisation of two new clerodane diterpenes, raspailodanes $\mathrm{F}(\mathbf{4 0})$ and $\mathrm{G}(\mathbf{4 1})$. Raspailodane $\mathrm{F}$ is particularly interesting because it is based upon a cyclopropyl containing tricyclo[5.4.0.0 $\left.0^{1,3}\right]$ undecane system, a structural feature not previously seen in clerodane diterpenes. Raspailodane $\mathrm{G}$ is notable in that it completes a subset of four related raspailodanes with differing functionality at positions 6 and 12. The isolation of these two new clerodanes extends the scope of interesting chemistry found in metabolites of Raspailia topsenti. 


\section{Chapter 3}

\section{Screening Methods}

\subsection{Cyclic Loading}

Biological extracts contain a wide range of compounds with varying degrees of polarity, from polar amino acids and sugars to non-polar lipids and steroids. This property makes these extracts challenging to work with as they are usually difficult to concentrate due to solubility problems. The wide range of polarity also causes problems with the chromatographic separation of the extract using standard procedures. This problem is overcome in our laboratory by loading an extract on to a column of HP20 by means of a method known as cyclic loading. ${ }^{16}$ This technique involves passing an extract through a column followed by repeated dilution of the eluent and subsequent re-passage through the column until all compounds of interest have adsorbed to the stationary phase (usually measured by a percentage dilution - typically $25 \%$ of the original concentration). This occurs because as the eluent is progressively made more polar by dilution, more compounds will preferentially adsorb to the stationary phase. The procedure for cyclic loading a biological extract is depicted in Figure 3.1.

The biological activity of many secondary metabolites requires them to be easily transported across cell membranes and other biological barriers. One means for them to achieve this is to possess both lipophilic and hydrophilic moieties within their structures. This causes the overall polarity of many secondary metabolites to be of an intermediate nature. The polarities of the components of an extract can therefore be thought of as belonging to one of three groups: the polar metabolites consisting of amino acids and sugars at one extreme, the non-polar metabolites consisting of steroids and lipids at the other extreme, and the intermediate polarity metabolites which bridge the two extremes. Since surprisingly few primary metabolites are of an intermediate polarity this "mass window" can be targeted to achieve a crude separation of primary and secondary metabolites at a very early stage of purification. 


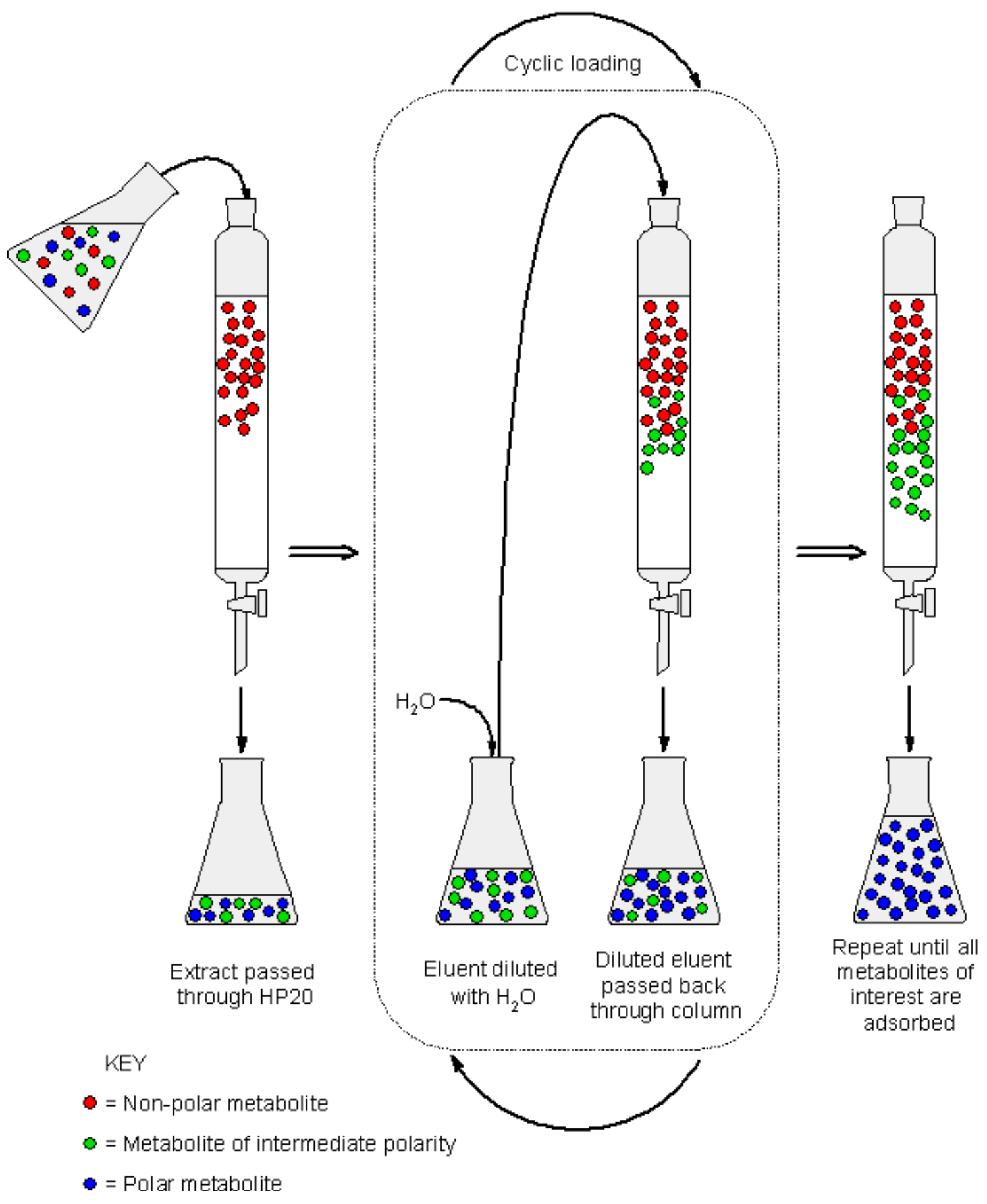

Figure 3.1 Cyclic loading. 
To achieve this in practise, an extract adsorbed to the column is eluted with selected concentrations of organic modifier. Typically for a sponge extract, eluents of water, $30 \%$ acetone in water, $75 \%$ acetone in water and acetone are used. These concentrations of organic modifier are chosen to elute the intermediate range metabolites and by extension, the "mass window" containing the highest concentration of secondary metabolites, into the $75 \%$ acetone fraction. Figure 3.2 depicts an idealised plot of mass $v s$. polarity for the adsorbed components of a biological extract. Obviously this is a very broad generalisation and in practice the $75 \%$ acetone in water fraction will be contaminated to some degree with metabolites from adjacent fractions. Clearly, not all extracts will exhibit a mass profile such as that in Figure 3.2. Nonetheless, analysis of the $75 \%$ acetone in water fraction provides a useful insight into the secondary metabolite composition of the extract as a whole.

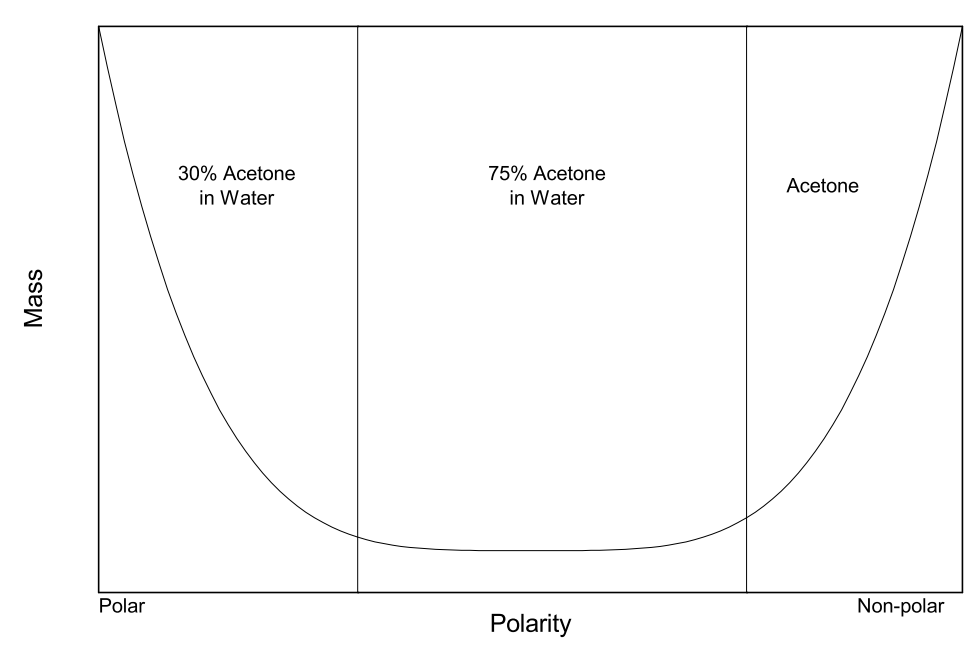

Figure 3.2 Idealised mass $v s$. polarity for the adsorbed components of a biological extract.

\subsection{Screening History}

Our laboratory's screening of marine sponge extracts for secondary metabolites began with the analysis of the $75 \%$ acetone/water fractions dissolved in deuterated chloroform by ${ }^{1} \mathrm{H}$ NMR spectroscopy. ${ }^{16}$ While this method proved fruitful initially, the observation of interesting NMR signals potentially attributable to secondary metabolites was hampered by strong, broad signals associated with residual fats present in the sample. 
A more robust screening protocol was devised which used a combination of ${ }^{1} \mathrm{H}$ NMR with COSY and HSQC 2D correlation spectra. Solubility of the $75 \%$ acetone fraction of the extract in chloroform was not always guaranteed so the NMR solvent of choice was also changed to deuterated methanol in which a wider range of semi-purified sponge extracts proved soluble. ${ }^{51}$ The use of two-dimensional NMR spectra resolved the overlap between residual lipids and many interesting correlations potentially associated with secondary metabolites. Through the analysis of a number of sponge extracts, a "mask" was developed for both the COSY and HSQC spectra which indicated correlations occurring regularly throughout a large number of spectra. These correlations were deemed to be due to common metabolites of little interest. Spectra of further screens were compared with these masks to determine whether a significant number of unusual correlations were present and assigned a hit score on a scale of $1-10 .{ }^{51}$

This NMR screening technique was later modified to include spiking the NMR sample of the $75 \%$ acetone fraction with an internal standard. The standard compound chosen was 1,3,5-tribromobenzene which exhibits a sharp singlet resonance at $\delta_{\mathrm{H}} 7.74$ in $\mathrm{CD}_{3} \mathrm{OD}$. The relative height of the standard peak to the other peaks in the ${ }^{1} \mathrm{H}$ spectrum was used as an indication of the concentration of any interesting signals. Analysis of the ${ }^{1} \mathrm{H}$ spectra of the other fractions of the screen (using $\mathrm{CD}_{3} \mathrm{OD}$ as the NMR solvent for the $30 \%$ acetone in water fraction and $\mathrm{CDCl}_{3}$ for the acetone fraction) was included in the protocol. In an effort to reduce the subjectivity of the hit score, the ranking system for the analysis of the screens was also revised and split into four 10 point categories - hit strength, number of peaks, uniqueness, mass available - and one four point category - recollectability.

The hit strength rating is based upon the intensity of any interesting signals in the ${ }^{1} \mathrm{H}$ spectrum with respect to the intensity of the 1,3,5-tribromobenzene internal standard peak. In general, if the spectrum contains interesting signals with intensities greater than or equal to half that of the standard, it scores a 10 . Intensities from $45 \%-50 \%$ of the height score a nine and so on down. The number of interesting (unmasked) correlations in the HSQC spectrum are then counted. More than 20 correlations scores 10 . The uniqueness rating remains the most subjective. A score is assigned based on how different the screen appears to be from any others. The mass available rating is simply the mass (in kilograms) 
of available material multiplied by a factor of 10 (rounded to the nearest integer). If more than $1 \mathrm{~kg}$ of material is available a 10 is scored. The recollectability score is assigned based on the ease of recollection. At present, a four is scored if the sponge was collected locally, two if it was collected from d'Urville Island and a one is scored otherwise.

One advantage of the new ranking system is the ability to weight a particular category. For example, the recollectability scores could be scaled to weight in favour of d'Urville Island collections if a dive trip to d'Urville Island were planned in the near future. Any hits could then be targeted for recollection.

At this stage, the screening protocol was formalised and is presented in Appendix A.

\subsection{Sponge Screening}

In this study, a total of 56 sponges were screened using this protocol. Twelve of those screens (PTN2_45C, PTN2_45E, PTN2_45H, PTN2_46B, PTN2_46C, PTN2_47J, PTN2_48B, PTN2_49D, PTN2_58A, PTN2_63B, PTN2_65D and PTN2_69D) have not yet been scored under either the old or the new ranking systems. Of the remaining screens, 15 were immediately discontinued on the basis of their low score. One further screen (PTN2_13E) was discontinued after being re-ranked using the new system. Of the remaining 28 screens, nine were further analysed while 19 were put aside at the time and still await further analysis. Table 3.1 summarises these data.

Nine screens were analysed in detail. Three of these led to the isolation of novel compounds and are detailed in later chapters (MNP960, see Chapter 4, PTN2_50E, see Chapter 5, PTN2_72C, see Chapter 6). The remaining six screens are discussed briefly here. 
Table 3.1 Screening statistics.

\begin{tabular}{|c|c|c|c|c|c|c|c|c|}
\hline \multirow[b]{2}{*}{ Sponge \# } & \multirow[b]{2}{*}{ Status } & \multirow[b]{2}{*}{ Old Hit \# } & \multicolumn{6}{|c|}{ New Hit \# } \\
\hline & & & $\mathrm{HS}^{\mathrm{a}}$ & $\mathrm{NP}^{\mathrm{b}}$ & $\mathrm{U}^{\mathrm{c}}$ & $\mathrm{MA}^{\mathrm{d}}$ & $\mathrm{R}^{\mathrm{e}}$ & Total \\
\hline KAH9901/43-3 & Discontinued & 1 & & & & & & \\
\hline MKB1744 & Discontinued & 4 & & & & & & \\
\hline MKB1757 & Awaiting analysis & 7 & & & & & & \\
\hline MKB1811 & Discontinued & 3 & & & & & & \\
\hline MKB1824 & Awaiting analysis & 6 & & & & & & \\
\hline MKB1839 & Awaiting analysis & 7 & & & & & & \\
\hline MNP649 & Awaiting analysis & 7 & & & & & & \\
\hline MNP653 & Discontinued & 2 & & & & & & \\
\hline MNP654 & Discontinued & 4 & & & & & & \\
\hline MNP728 & Awaiting analysis & 8 & & & & & & \\
\hline MNP823 & Awaiting analysis & 6 & & & & & & \\
\hline MNP825 & Analysed and discontinued & 5 & & & & & & \\
\hline MNP960 & Completed & 7 & 9 & 5 & 7 & 10 & 2 & 33 \\
\hline MNP961 & Discontinued & 3 & 3 & 2 & 2 & 10 & 2 & 19 \\
\hline MNP962 & Awaiting analysis & 6 & 6 & 5 & 5 & 10 & 2 & 28 \\
\hline MNP963 & Discontinued & 4 & & & & & & \\
\hline MNP965 & Analysed and discontinued & 6 & & & & & & \\
\hline MNP968 & Discontinued & 3 & & & & & & \\
\hline MNP969 & Analysed and discontinued & 8 & & & & & & \\
\hline MNP970 & Discontinued & 4 & & & & & & \\
\hline MNP972 & Discontinued & 2 & & & & & & \\
\hline MNP973 & Discontinued & 4 & & & & & & \\
\hline MNP974 & Completed & 7 & & & & & & \\
\hline MNP975 & Discontinued & 3 & 3 & 3 & 5 & 7 & 2 & 20 \\
\hline MNP980 & Awaiting analysis & 6 & 4 & 3 & 4 & 10 & 2 & 23 \\
\hline MNP981 & Awaiting analysis & 6 & 5 & 5 & 6 & 10 & 2 & 28 \\
\hline MNP986 & Awaiting analysis & 8 & 7 & 7 & 6 & 5 & 2 & 27 \\
\hline MNP988 & Discontinued & 2 & 2 & 1 & 0 & 1 & 2 & 6 \\
\hline MNP989 & Awaiting analysis & 7 & 6 & 6 & 7 & 10 & 2 & 31 \\
\hline MNP990 & Awaiting analysis & 7 & 5 & 7 & 8 & 3 & 2 & 25 \\
\hline MNP991 & Analysed and discontinued & 8 & 7 & 9 & 9 & 6 & 2 & 33 \\
\hline MNP992 & Awaiting analysis & 8 & 8 & 9 & 9 & 3 & 2 & 31 \\
\hline MNP993 & Awaiting analysis & 5 & 7 & 7 & 8 & 6 & 2 & 30 \\
\hline MNP994 & Awaiting analysis & 7 & 7 & 7 & 8 & 4 & 2 & 28 \\
\hline MNP995 & Awaiting analysis & 7 & 6 & 7 & 7 & 6 & 2 & 28 \\
\hline PTN2_8A & Completed & 8 & & & & & & \\
\hline PTN2_9A & Discontinued & 4 & 2 & 7 & 7 & 10 & 1 & 27 \\
\hline PTN2_12C & Awaiting analysis & 6 & 4 & 5 & 5 & 1 & 4 & 19 \\
\hline PTN2_12D & Awaiting analysis & 6 & 7 & 6 & 7 & 1 & 4 & 25 \\
\hline PTN2_13A & Discontinued & 4 & 1 & 2 & 2 & 1 & 4 & 10 \\
\hline PTN2_13D & Awaiting analysis & 6 & 7 & 6 & 7 & 1 & 4 & 25 \\
\hline PTN2_13E & Discontinued & 6 & 2 & 2 & 3 & 1 & 4 & 12 \\
\hline PTN2_50E & Completed & & 10 & 10 & 9 & 2 & 1 & 32 \\
\hline PTN2_72C & Completed & & 10 & 10 & 10 & 1 & 1 & 32 \\
\hline
\end{tabular}

a Hit Strength

b Number of Peaks

${ }^{c}$ Uniqueness

${ }^{d}$ Mass Available

${ }^{\mathrm{e}}$ Recollectability 


\section{MNP825}

The screen spectra of this unidentified sponge (121.8 $\mathrm{g}$ ) indicated the presence of interesting aromatic resonances. Partial purification of the extract led to the conclusion that these resonances belonged to a simple anisaldehyde-based structure, possibly anisaldehyde itself. No further purification was performed.

\section{MNP965}

An unidentified sponge of the genus Callyspongia (51.7 g) collected from Victory Island, near d'Urville Island, New Zealand. The screen spectra contained resonances attributed to aromatics, oxymethines and tertiary (singlet) methyls. Upon further purification, a number of these resonances were identified as belonging to phenylalanine or similar substructures. Analysis was discontinued.

\section{MNP969}

An unidentified sponge of the genus Haliclona (49.9 g) collected from Victory Island, near d'Urville Island, New Zealand. The screen spectra contained a number of interesting resonances largely attributed to oxymethines. A second, larger extraction of the sponge (103.7 g) was performed. Subsequent analysis of this extract showed no evidence of the interesting resonances and no further analysis was performed.

\section{MNP974}

An unidentified sponge of the genus Dysidea (73.0 g) collected from Stephen's Island, near d'Urville Island, New Zealand. A number of strong aromatic resonances, in addition to readily identified methyl signals were present in the screen spectra. A large-scale 
extraction of the sponge was performed $(227 \mathrm{~g})$. From a combination of the screen and bulk extracts, $24.1 \mathrm{mg}$ of the known compound avarol (68) was isolated. Avarol was originally isolated in 1974 from Dysidea avara alongside its corresponding quinone, avarone (69). ${ }^{52}$ Avarol has also been reported from a New Zealand collection of Dysidea sp. ${ }^{53}$ As compound $\mathbf{6 8}$ accounted for a significant number of the interesting correlations present in the screen spectra, analysis of these extracts was discontinued.

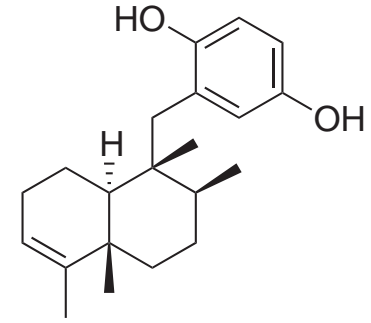

68

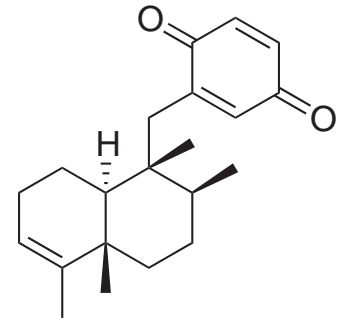

69

\section{MNP991}

An unidentified axinellid sponge (100.1 g) collected from Nelson's Rock, d'Urville Island, New Zealand. The screen spectra contained a large number of very strong aromatic resonances. A large-scale extraction of the sponge (331.4 g) was performed. It was noted that spectra obtained from the large-scale extraction did not match the screen spectra. Analysis of the sponge material itself led to the conclusion that the large-scale extract was of a different sponge from the screen. Due to the confusion surrounding the identity of the sponge, no further analysis was performed.

\section{PTN2 8A}

An unidentified calcareous sponge possibly belonging to the genus Leucetta (102 $\mathrm{g}$ ) collected from Island Bay, Wellington, New Zealand. The screen spectra contained a series of interesting resonances in the olefinic and oxymethine regions. A large-scale extraction of the sponge was performed $(514 \mathrm{~g})$. Purification of a combination of the screen and large-scale extracts led to the isolation of the known peroxysteroid $5 \alpha, 8 \alpha$ - 
epidioxy-24R-ethylcholesta-6,22(E)-dien-3 $\beta$-ol (70). ${ }^{54}$ Originally reported in 2000 from the marine sponge Luffariella cf. variabilis, compound $\mathbf{7 0}$ was also recently isolated in our laboratory from a collection of Biemna sp. collected near the northern tip of the North Island of New Zealand. ${ }^{51}$ Exhaustive analysis of fractions generated during this isolation did not indicate the presence of any further compounds of interest and analysis of the extracts was discontinued.

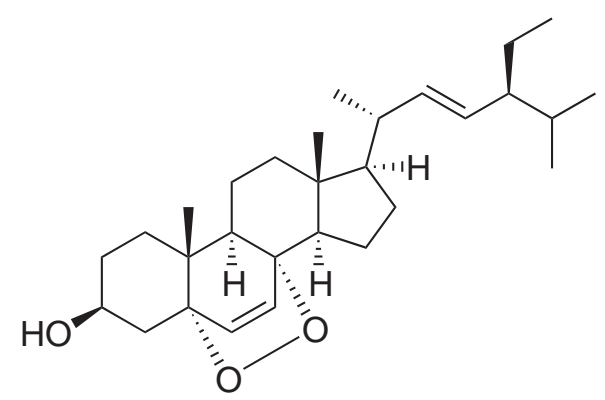

70

\subsection{Dereplication}

While this newly developed screening protocol proved very effective for differentiating secondary metabolites from primary metabolites, the analyst still had to determine whether a series of unusual signals belonged to an as yet undiscovered secondary metabolite or one which may already have been reported in the literature. The examples of avarol (68) and 5 $\alpha, 8 \alpha$-epidioxy-24R-ethylcholesta-6,22(E)-dien-3 $\beta$-ol (70) described above highlight this problem. Dereplication of known compounds is an ongoing problem in the search for new structures and it is obviously of utmost importance to the efficacy of the isolation of new compounds that known ones are identified and treated appropriately as quickly as possible.

During the course of this study, two different methods were developed for streamlining the identification and dereplication of compounds from screen spectra. The first involved using the raw NMR data acquired from each screen to develop a computer-based mask which would enable a quicker determination of the hit ranking of a screen. It would also provide the means to compare one screen with another and indicate any similarities between correlations of interest. In addition to improving the efficiency of identifying 
interesting screen spectra, the ability to compare correlations between screens provides a means to quickly dereplicate compounds which may have been identified in previous screens. The second method involved compiling a database of NMR correlations of known compounds with which to compare the data acquired from the extracts. Such a database would assist in the rapid identification of the structural class of any unknown compound, possibly even identifying specific compounds without the need to purify the extract further. Each is discussed in further detail below. While the development of these two techniques has only approached completion towards the end of this study and have thus been of limited use in the analysis of the screens described herein, it is hoped that in the future they will be useful tools in the dereplication of known compounds and the identification of unknown structures. 


\subsection{Computer-based Screen}

The task of manual analysis of individual screen spectra is menial and repetitive and often there is a significant delay between a sponge being screened and the screen being ranked. While some degree of human input is required to adequately rate a screen, the initial masking of known peaks from the spectra is a job well suited to a computer. The manual COSY and HSQC masks were compiled by comparing a number of screen spectra and noting correlations that appeared regularly. ${ }^{51}$ The computer-based screen was approached in a similar manner, although at this stage the analysis has been restricted to the less complex HSQC spectra. A summation of all the screen HSQC spectra collected to date would result in a single spectrum in which the correlations which were common throughout the individual spectra would have stacked up while the signals which were of interest to us would be insignificant in comparison. By taking such a summed spectrum and excluding all correlations which did not reach an arbitrary intensity threshold, a mask spectrum would be produced. If that mask were then normalised and subtracted from a given screen spectrum, the result would be a screen spectrum in which the common signals would be absent (or negative in intensity) and the remaining (positive) correlations would be those in which we were interested. A similar technique has been reported very recently which utilises graphical processing of COSY spectra to screen a fungal extract library. ${ }^{55}$

A number of problems were identified as we began to implement this strategy. The referencing of each individual screen spectrum needed to be revisited to ensure that there was consistency across all the included spectra. In order to achieve this, the methanol correlation in each spectrum was referenced to $\delta_{\mathrm{C}} 49.0, \delta_{\mathrm{H}} 3.31$. Also, a number of legacy screen HSQC spectra had been acquired using different pulse sequences (notably multiplicity-edited HSQC) which meant that not all of the spectra would consist entirely of positive intensity correlations. This would pose problems during the summation as some spectra would contribute a cancelling effect rather than an enhancing effect for some signals. Further, some of these legacy spectra had been acquired with different spectral windows in one or both $\mathrm{F}_{2}$ and $\mathrm{F}_{1}$ which would require further processing to account for. 
Finally, we discovered that the software available to us for the direct summation of spectra was unsuitable for our requirements.

To resolve a number of these issues, we decided to process the data outside of the NMR software package itself. The first task was to export the individual screen data in a format that we could further process. While the HSQC spectrum itself was available in a binary format, we ultimately decided that the simplest method would be to export a text file containing a list of the $\mathrm{F}_{2}$ and $\mathrm{F}_{1}$ coordinates for each correlation in the spectrum. The NMR software included the capability to export such a list but required that some threshold was established above which correlations would be identified. For our purposes, this threshold needed to be set as close to the noise bed of the spectrum as possible.

To ensure uniform treatment of each individual screen spectrum, a macro was written which attempted to identify where the threshold needed to be set. Two regions of the HSQC spectrum which should be devoid of any real correlations were identified (region A: 7 ppm to $8.5 \mathrm{ppm}$ in $\mathrm{F}_{2}$ by $60 \mathrm{ppm}$ to $100 \mathrm{ppm}$ in $\mathrm{F}_{1}$ and region $\mathrm{B}: 2.5 \mathrm{ppm}$ to $3.5 \mathrm{ppm}$ in $\mathrm{F}_{2}$ by $100 \mathrm{ppm}$ to $140 \mathrm{ppm}$ in $\mathrm{F}_{1}$, see Figure 3.3 ). The macro proceeded by repeatedly adjusting the magnitude of the $2 \mathrm{D}$ landscape down by $5 \%$ until region $\mathrm{A}$ contained a minimum (non-zero) number of signals. If region B still contained more than 5 signals, the magnitude was further reduced in 5\% steps until less than 5 signals were observed. Once a suitable threshold was set, a list of correlations within the region $0.5 \mathrm{ppm}$ to $8.5 \mathrm{ppm}$ in $\mathrm{F}_{2}$ by $0 \mathrm{ppm}$ to $160 \mathrm{ppm}$ in $\mathrm{F}_{1}$ was exported as a text file.

In order to be useful to us, the format of the text file needed to be altered. This was also seen as an opportunity to filter the list of correlations for any which were likely to be caused by $\mathrm{F}_{1}$ axial displacement of ${ }^{1} \mathrm{H}$ resonances attached to ${ }^{12} \mathrm{C}$ which occur at the centre of $F_{2}$ and the edges of $F_{1}$. To achieve this, a program entitled "Peaks" was written using Microsoft Visual C++. This simple utility would process an entire directory of input files outputting the data in the format we required. At the same time, it checks the coordinates of each correlation and discards any which lie between 4 ppm and 6 ppm in $\mathrm{F}_{2}$ and either higher than $150 \mathrm{ppm}$ or lower than $15 \mathrm{ppm}$ in $\mathrm{F}_{1}$. For a correlation to be accepted, it must also lie inside the range $0.5 \mathrm{ppm}$ to $8.5 \mathrm{ppm}$ in $\mathrm{F}_{2}$ and $0 \mathrm{ppm}$ to $160 \mathrm{ppm}$ 
in $F_{1}$. The regions of the spectrum from which correlations are rejected are indicated in Figure 3.3. The relevant functions of the Peaks program are presented in Appendix B.

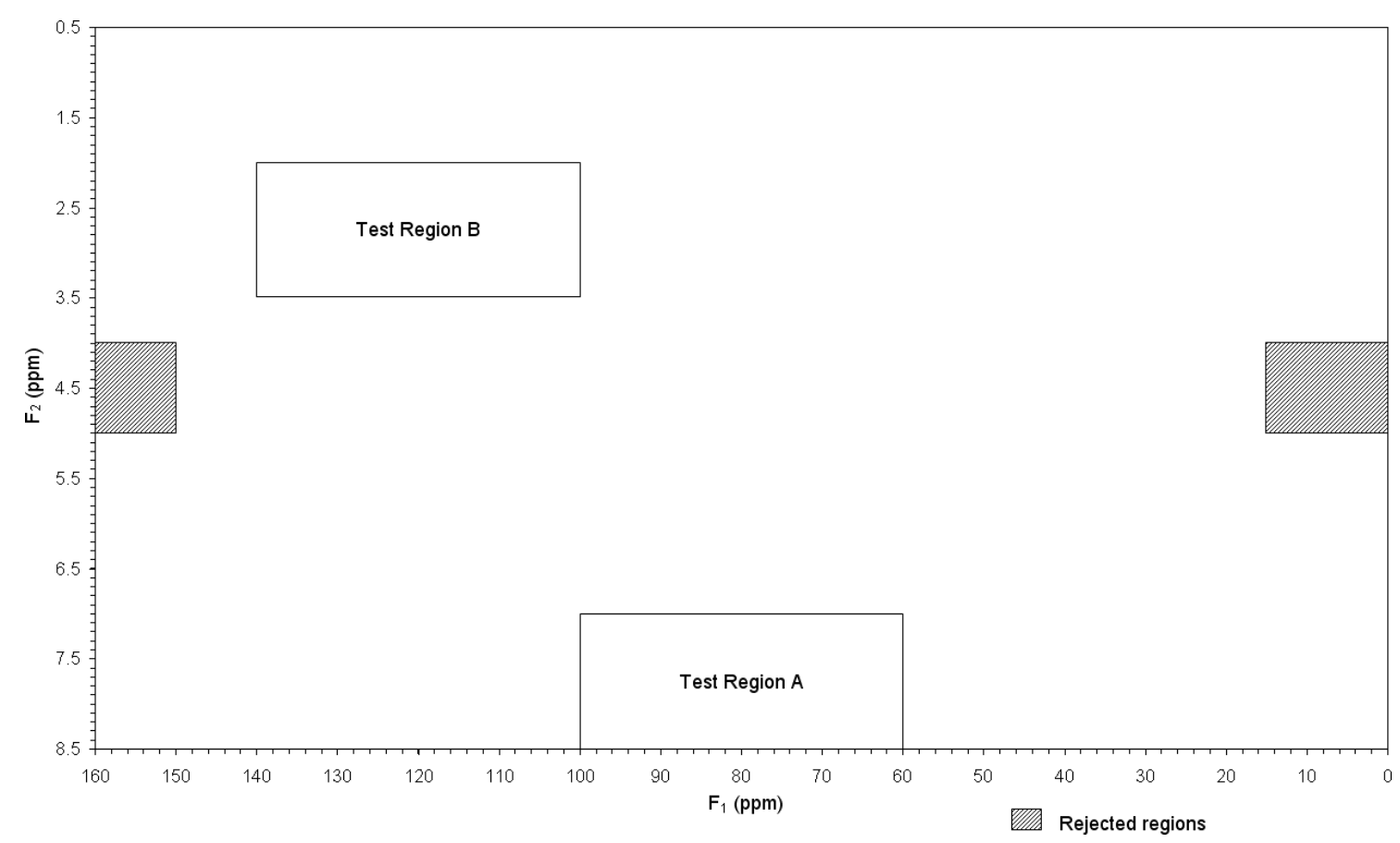

Figure 3.3 A representation of an HSQC spectrum indicating regions of significance to the selection of correlations.

With the correlation data in a form which was convenient for processing, the task of compiling the data into a suitable mask came to bear. Our tool of choice for handling large arrays of data was Matlab - a powerful program for the manipulation and plotting of large data sets. Matlab is also very flexible as it offers its own macro programming language which we were able to utilise to automate a significant portion of our analysis. A series of macros were written to build two different masks which could be applied to any given screen. The salient features of these macros are highlighted here (the macros are presented in full in Appendix C).

The next issue we encountered was that of resolution. The data from the individual screens needed to be reduced to a matrix representation in order to perform any practical analysis. We opted to use an array of 80 data points in $F_{2}$ and 160 data points in $F_{1}$. This equates to a resolution of $0.1 \mathrm{ppm}$ in $\mathrm{F}_{2}$ and $1 \mathrm{ppm}$ in $\mathrm{F}_{1}$ which was considered high enough to achieve a reasonable level of peak differentiation while keeping the total size of the array to a workable level (12800 points).

The formation of the mask was approached in two ways. The first, as explained above, 
would sum up the intensities of the correlations of the individual screen spectra. The second approach was to reduce each screen spectrum to a binary format, that is, simply a " 1 " if a correlation is present in a given cell and a " 0 " otherwise, and to sum the binary spectra to create a mask which indicated the frequency of occurrence of correlations rather than the overall intensity.

The Matlab macro "Initialise" starts the process of creating the masks. The task of running the "Peaks" program was incorporated into the Matlab macros in order to reduce the number of manual steps required in transitioning from NMR spectra to screen masks. After checking if "Peaks" needs to be executed, "Initialise" runs the "CreateMasks" macro. This macro recursively loads each screen correlation list in the input directory, converts the spectrum to an $80 \times 160$ array then adds the intensities to the amplitude mask and appropriately increments the relevant fields of the frequency mask. Finally, an arbitrary threshold is applied to the frequency mask below which any correlations are discarded. For the purposes of this discussion, a threshold of 5\% was selected.

In trialling this method, a subset of 50 screen spectra was used. The masks generated from these 50 screens with this protocol are presented in both $2 \mathrm{D}$ and $3 \mathrm{D}$ representations in Figures 3.4 and 3.5. Thus, the amplitude mask simply represents a summation of the amplitudes of every correlation from the 50 screens and the frequency mask represents only those correlations which occurred in three (technically 2.5) or more individual spectra.

As exemplified by the correlation at ca. $48 \times 130$ (equating to ca. $\delta_{\mathrm{H}} 5.3, \delta_{\mathrm{C}} 130$ ) in

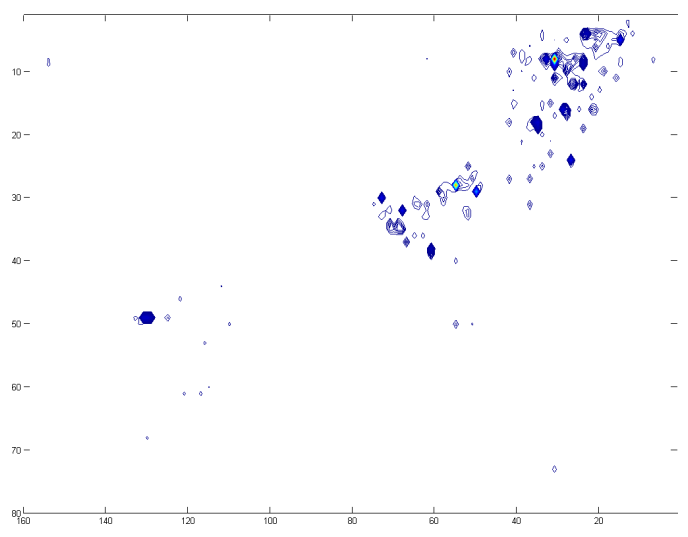

(a)

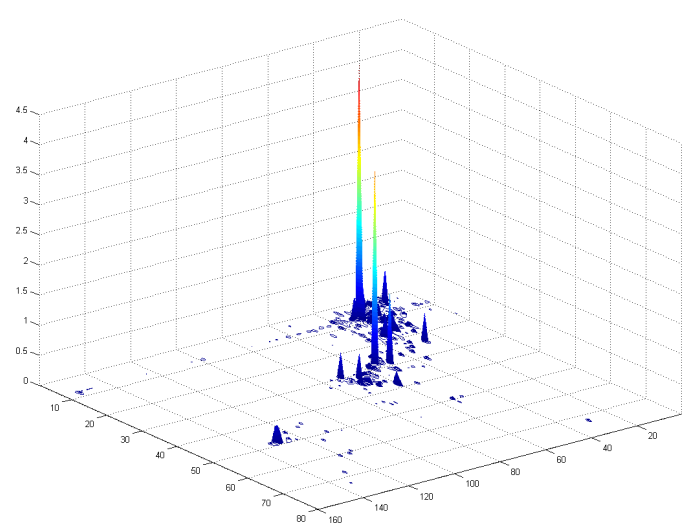

(b)

Figure 3.4 The amplitude mask. 


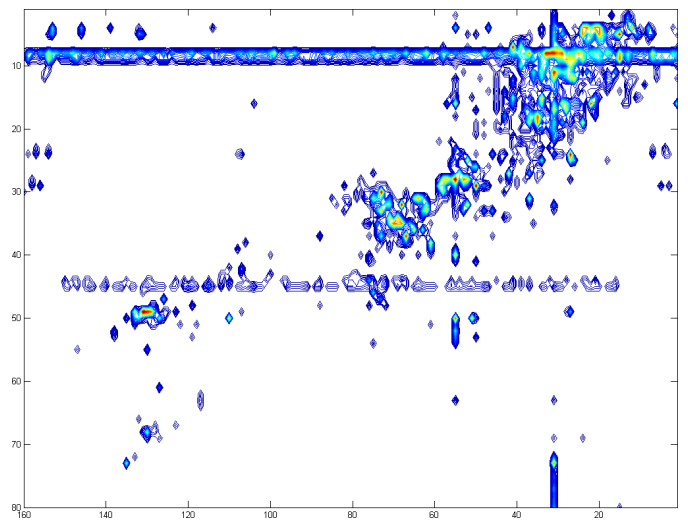

(a)

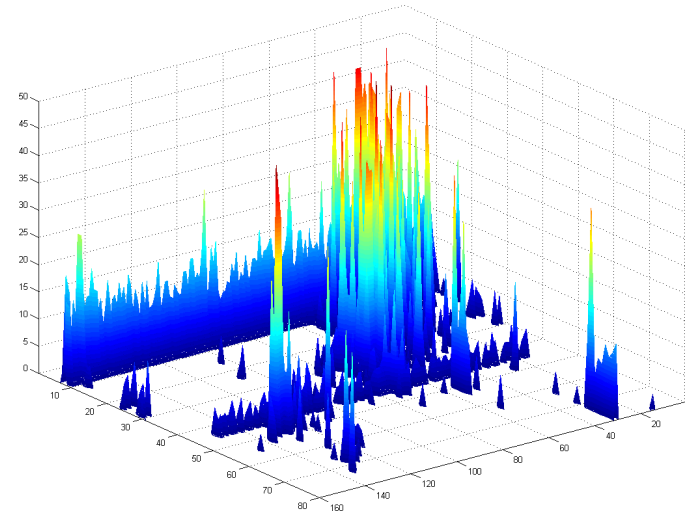

(b)

Figure 3.5 The frequency mask.

Figures 3.4 and 3.5, some correlations which occur at a high frequency throughout the 50 screens do not necessarily sum up to a particularly high intensity which justifies the use of both the amplitude and frequency masks. The frequency mask is also much more sensitive to $\mathrm{T}_{1}$ noise which arises from any very intense resonances.

These masks were then applied to each of the contributing screen spectra. The macro "MaskScreen" was used for this purpose. The application of the amplitude mask is achieved by subtracting the mask, which was first normalised by the number of contributing screens and reduced to 5\%, from the HSQC spectrum. Any correlations which still have a positive amplitude are retained (at their original amplitude) and the rest are discarded. The application of the frequency mask simply removes any correlations which match those of the mask. Finally, the amplitude mask and the frequency mask were applied sequentially to generate a doubly-masked spectrum. The results of masking three selected screens are presented here.

\section{MNP993}

The screen of MNP993 was selected as an example of a moderately ranked screen. It was originally ranked at 5/10 which formed the basis for its selection. Under the new ranking system it scored a total of 30 (see Table 3.1) which would be considered above-average but it is nonetheless used as an example here. The HSQC spectrum of the screen before masking is presented in $2 \mathrm{D}$ and $3 \mathrm{D}$ representations in Figure 3.6. Application of the 
amplitude mask resulted in the spectrum presented in Figure 3.7, while the application of the frequency mask resulted in the spectrum presented in Figure 3.8. Finally, both masks were sequentially applied resulting in the spectrum presented in Figure 3.9. Chemical analysis of this extract has not yet been performed but these results are in keeping with the hit ranking of this screen.

\section{MNP988}

The screen of MNP988 was chosen as an example of a particularly low ranking screen. Originally ranked at 2/10, it later scored a total of 6 under the new ranking system (see Table 3.1). The HSQC spectrum of the screen before masking is presented in $2 \mathrm{D}$ and 3D representations in Figure 3.10. The application of either the amplitude or frequency masks to this spectrum resulted in no correlations, justifying the low ranking scored by this screen.

\section{PTN2 50E}

The screen of PTN2_50E was selected as an example of a highly ranked screen. While it was not ranked under the original system, it scored a total of 32 under the new system (see Table 3.1). Again, the HSQC spectra of the screen are presented prior to masking (Figure 3.11), after application of the amplitude mask (Figure 3.12), after application of the frequency mask (Figure 3.13) and after sequential application of both masks (Figure 3.14). Clearly, a large number of correlations remain unmasked.

These three examples demonstrate the ability of the computer-based mask to reduce the amount of information present in a screen spectrum thereby enabling the analyst to more quickly evaluate and rank the data. In the three examples given, PTN2_50E clearly dominates as the screen with the most significant number of unusual correlations. This is consistent with the chemical composition of PTN2_50E which was identified as Dendrilla rosea and examined in detail (see Chapter 5). The masked screen of MNP988 clearly 


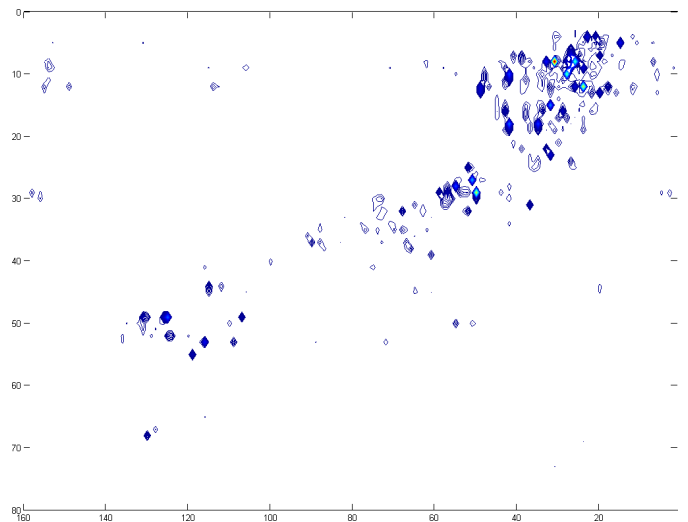

(a)

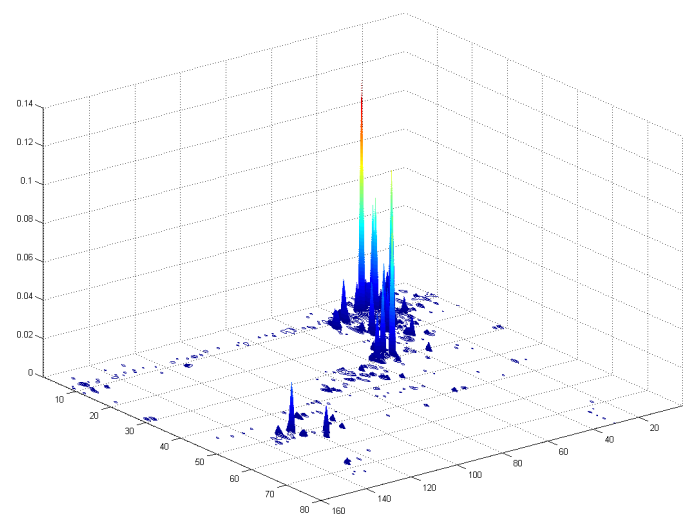

(b)

Figure 3.6 The HSQC spectrum of the screen of MNP993.

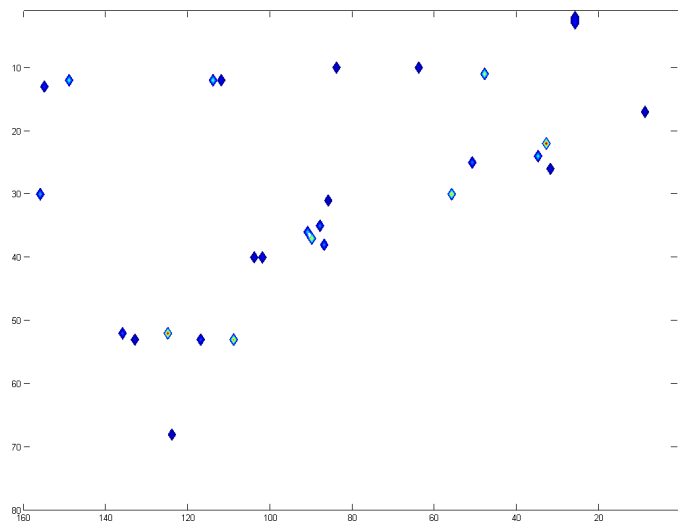

(a)

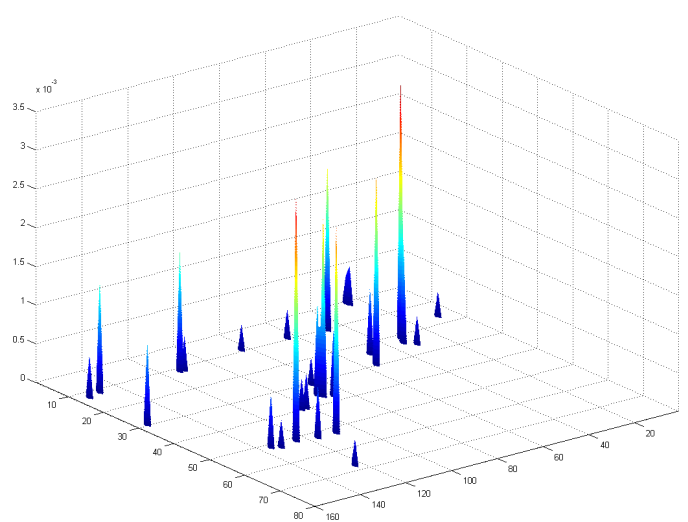

(b)

Figure 3.7 The amplitude-masked HSQC spectrum of the screen of MNP993.

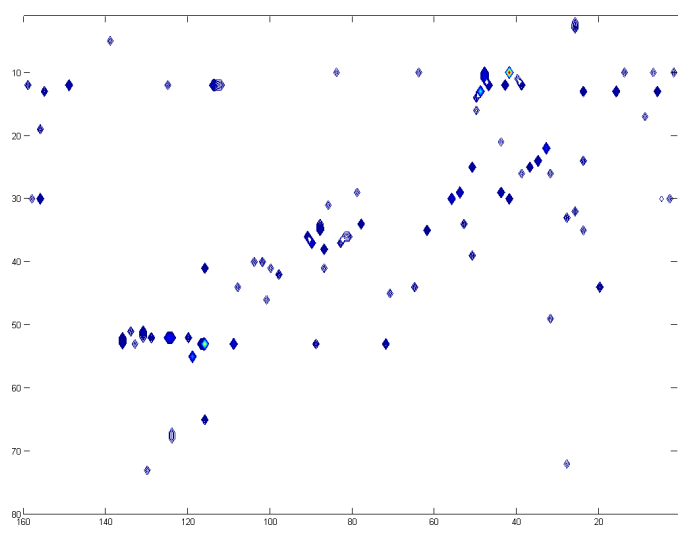

(a)

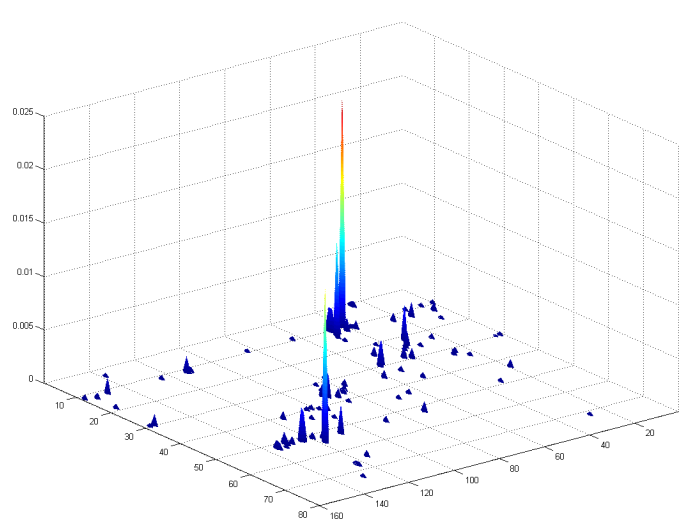

(b)

Figure 3.8 The frequency-masked HSQC spectrum of the screen of MNP993. 


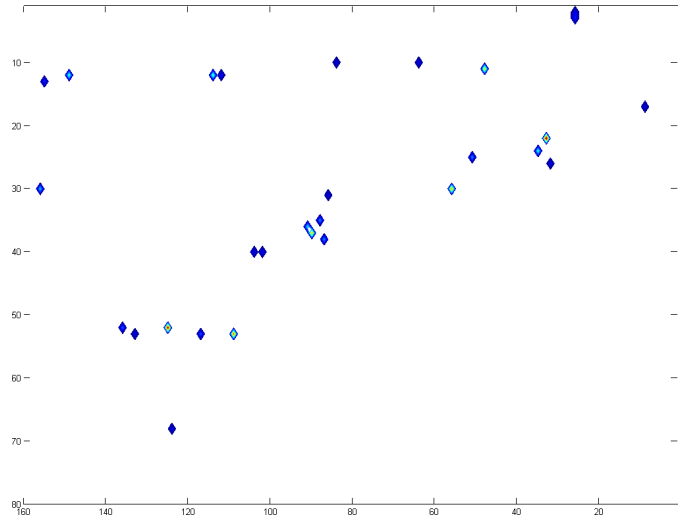

(a)

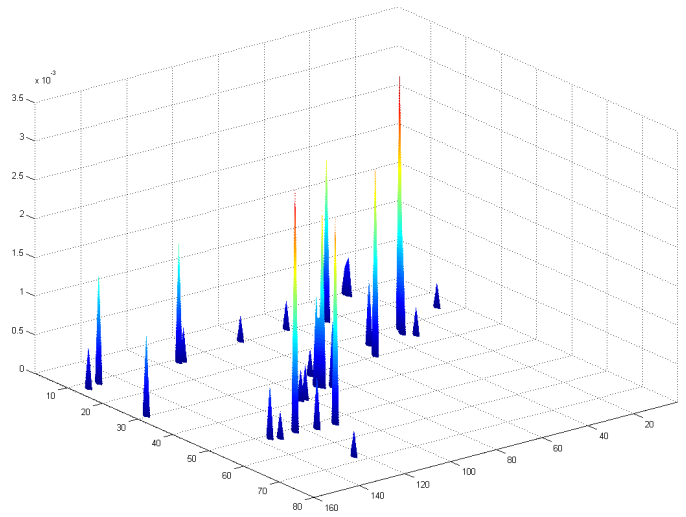

(b)

Figure 3.9 The combination amplitude-frequency-masked HSQC spectrum of the screen of MNP993.

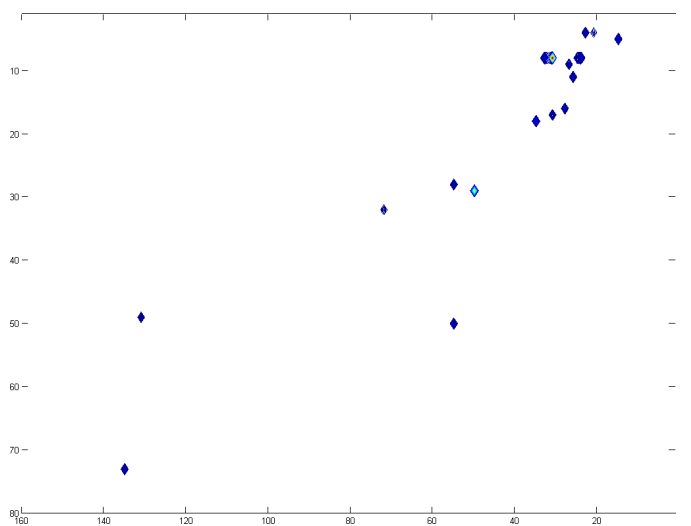

(a)

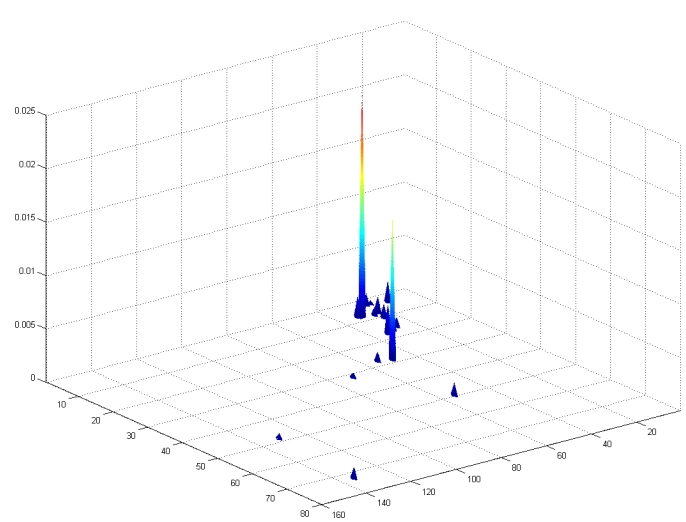

(b)

Figure 3.10 The HSQC spectrum of the screen of MNP988.

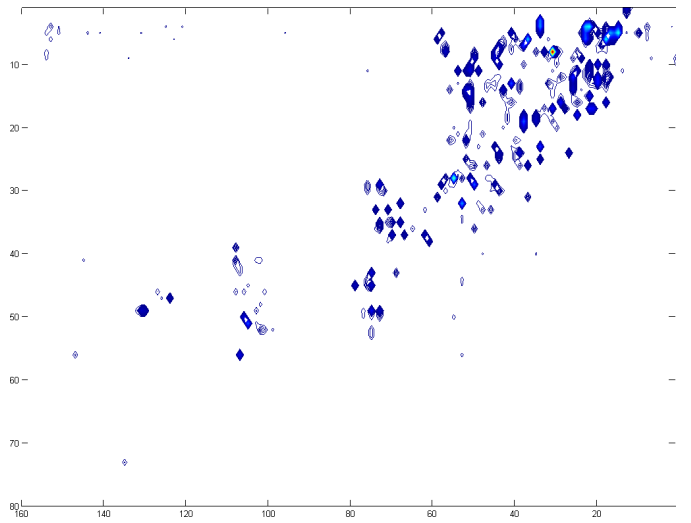

(a)

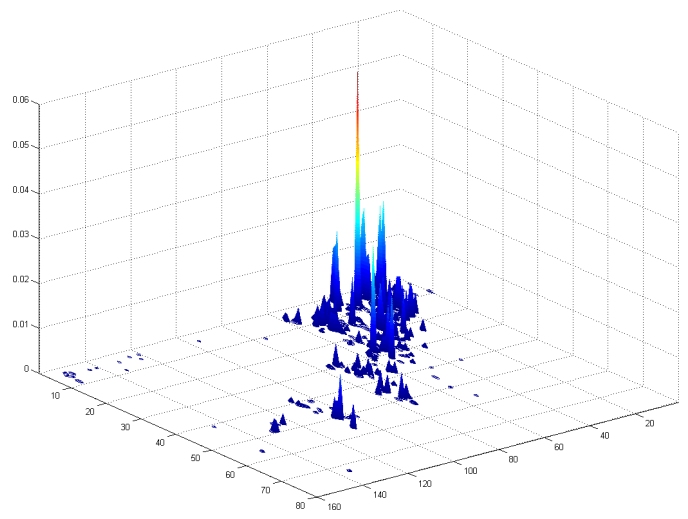

(b)

Figure 3.11 The HSQC spectrum of the screen of PTN2_50E. 


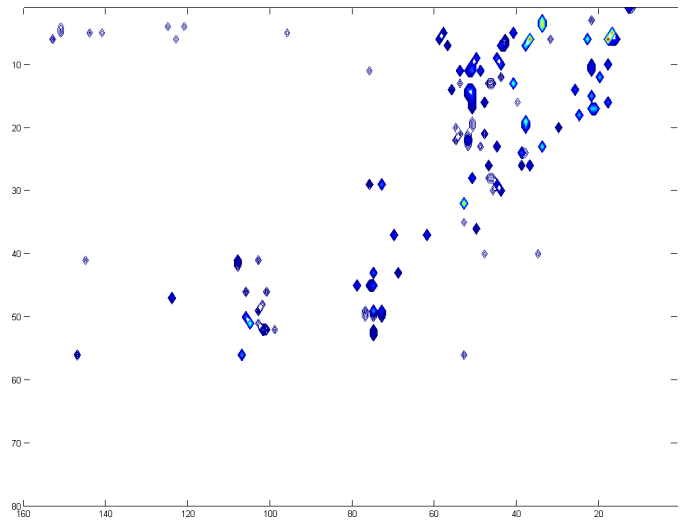

(a)

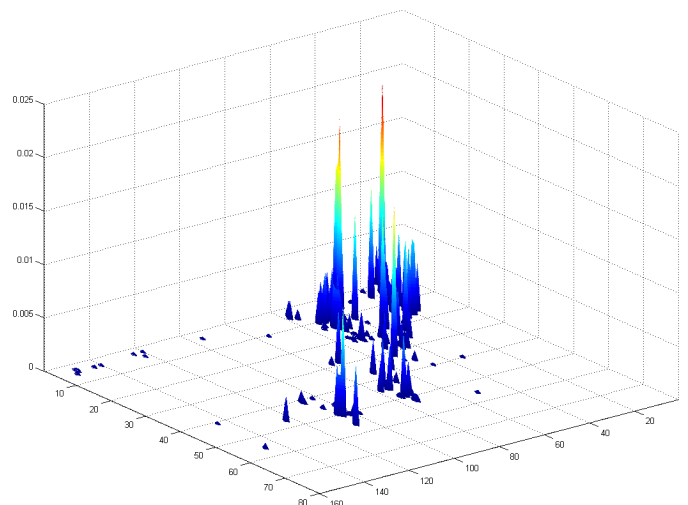

(b)

Figure 3.12 The amplitude-masked HSQC spectrum of the screen of PTN2_50E.

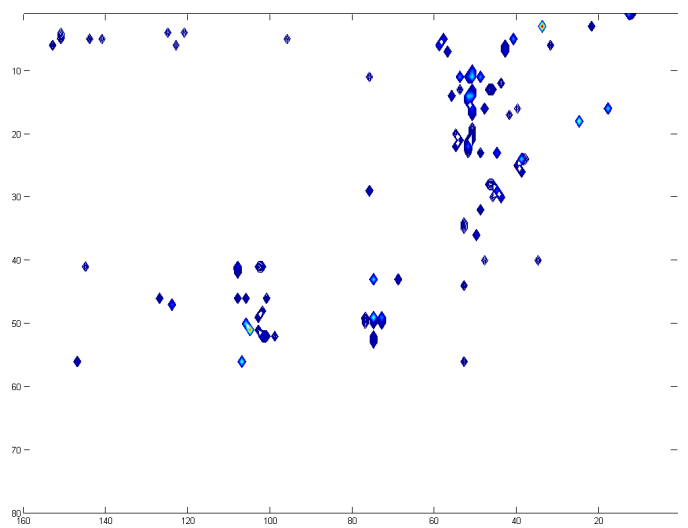

(a)

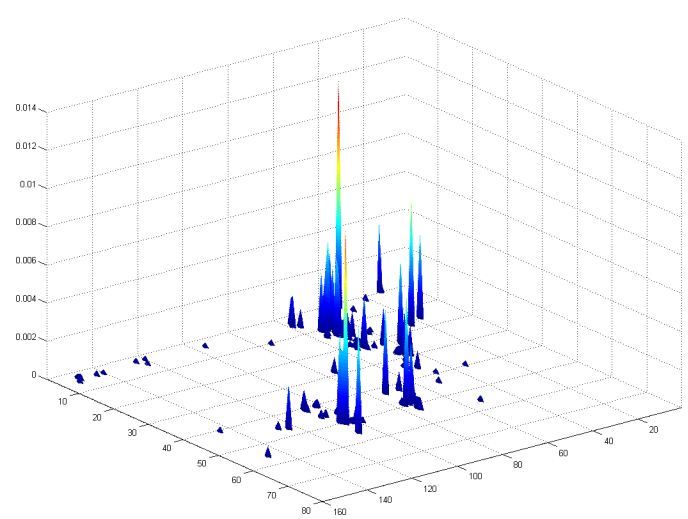

(b)

Figure 3.13 The frequency-masked HSQC spectrum of the screen of PTN2_50E.

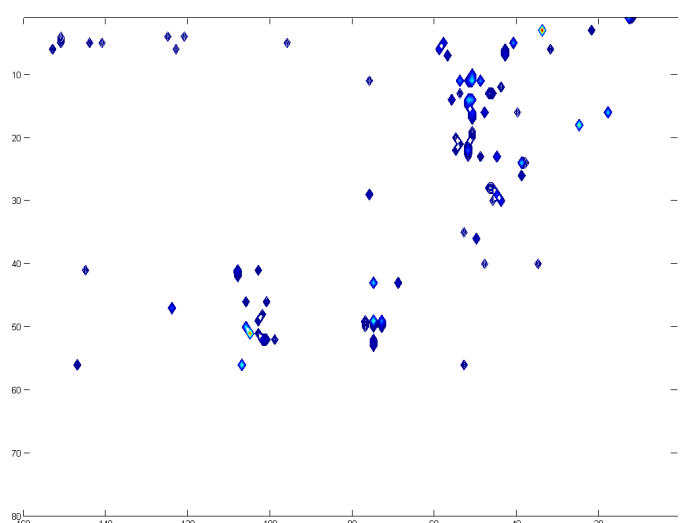

(a)

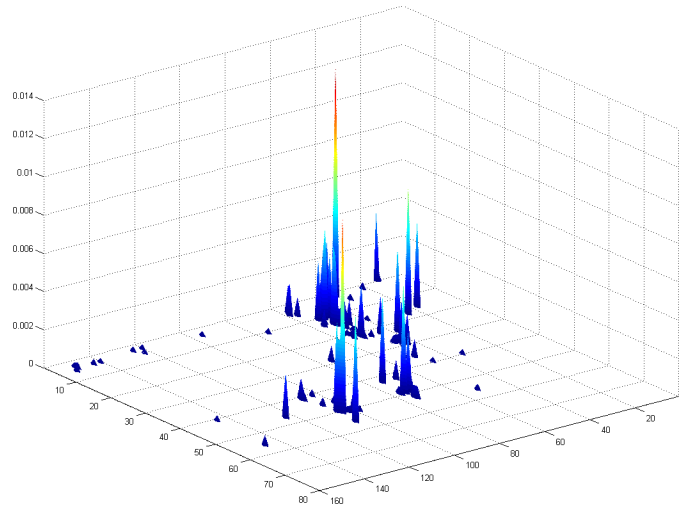

(b)

Figure 3.14 The combination amplitude-frequency-masked HSQC spectrum of the screen of PTN2_50E. 
indicated that there was little value in examining the extract further. The masked spectra of MNP993 indicate that some interesting correlations are certainly present. To date, this screen has not yet been examined further. 


\subsection{HSQC Correlation Database}

The second approach to improving the efficacy of our screening protocol was to construct a database of 2D NMR correlations. Initially, COSY spectra were deemed too complicated to be readily converted to a database form so HSQC spectra with their relatively simple ${ }^{1} \mathrm{H}-{ }^{13} \mathrm{C}$ correlation data were chosen. A number of considerations needed to be made before the compilation of the data was started. We first needed to decide what data we would require in the database. The critical data required were the ${ }^{1} \mathrm{H}$ and ${ }^{13} \mathrm{C}$ chemical shifts of the observed correlation and a description of the chemical environment which brought about the observed signal. An index field to uniquely identify each correlation was also required. Since correlations would be grouped by compound, another field to identify the associated compound was added. A field for the ${ }^{1} J_{\mathrm{CH}}$ of the HSQC correlation (if such data were available) was also included.

We quickly noted that some information about the associated compound would also be useful. The molecular mass, the structure, the name of the compound, its formula, the NMR solvent used when acquiring the HSQC and a reference for the original source of the data were all considered important. The database itself was then split into a compound database and a correlation database which were cross-referenced by compound number. This is depicted schematically in Figure 3.15.

The next hurdle was to develop a systematic means of describing the chemical environment of the position giving rise to the HSQC correlation. A number of such systems already exist, the most well-known of which is probably the SMILES system which was developed in 1988 to describe simple chemical structures ${ }^{56}$ and has since evolved

\begin{tabular}{|c|c|}
\hline Compound Database & Correlation Database \\
\hline Compound Number & Correlation Number \\
\hline Compound Name & Compound Number \\
\hline Molecular Formula & Position \\
\hline Molecular Mass & ${ }^{13} \mathrm{C}$ Chemical Shift \\
\hline NMR Solvent & ${ }^{1} \mathrm{H}$ Chemical Shift \\
\hline Source Reference & ${ }^{1} J_{\mathrm{CH}}$ Coupling Constant \\
\hline Structure & Description \\
\hline
\end{tabular}

Figure 3.15 Schematic representation of the initial layout of the dual database. 
to describe stereochemistry and reactions. From our perspective, the disadvantage of SMILES and any other systems of chemical description was the difficulty of searching for structural motifs within a complex structure. For example, a search for the presence of a secondary methyl in either methylcyclohexane or 1-ethyl-4-methylcyclohexane is not trivial as the SMILES representations are $\mathrm{CC} 1 \mathrm{CCCCC} 1$ and $\mathrm{CCC} 1 \mathrm{CCC}(\mathrm{C}) \mathrm{CC} 1$ respectively. As a result, we determined that a new system of description would need to be developed, tailored towards describing HSQC correlations, which provided a number of readily searchable fields.

Initially, the description of a correlation was subdivided into two fields. The first, denoted class, described the overall type of environment (e.g. methylene, O-methine [oxymethine], aldehyde) while the second, called adjacent, indicated what type of environments were connected to the position. It was quickly determined that an additional field was needed to classify the subclass of the environment - for example to distinguish a hydroxyl oxymethine from the oxymethine of an ether. Thus in this case, the subclass field was used to indicate connectivity though hetero-atoms while the adjacent field implied carbon-carbon connectivity. For methyls, the subclass field was used to designate primary, secondary or tertiary. Some examples are given in Table 3.2. In compiling the tables, adjacent positions were listed in approximate order of the deshielding influence they would have on the position in question. Finally it should be noted that no attempt was made to include stereochemistry in the position descriptions during the construction of this database.

Table 3.2 Some examples of the use of the class, subclass and adjacent fields.

\begin{tabular}{ccccc} 
& Position & Class & Subclass & Adjacent \\
\cline { 2 - 5 } & 2 & methyl & $2^{\circ}$ & methine \\
3 & methine & & methylene, methylene, methyl \\
& 4 & $O$-methine & $O H$ & $O$-methine, methine \\
& 5 & $O$-methine, methylene & $O$-methyl & $O$-methine, methylene \\
& 6 & methylene & & $O$-methine, methylene \\
& 7 & methylene & & methine, methylene \\
& & $O$-methyl & $O$-methine & \\
\hline
\end{tabular}

Methyls are particularly useful in structural determination as their HMBC correlations generally give rise to significant substructures but the data given in Table 3.2 for the 
methyls is less useful than was considered ideal. To resolve this lack of detail for the special case of a methyl, the subclass field would be used to describe the attachment carbon and the adjacent field would describe positions adjacent to the attachment carbon (excluding the methyl itself). Further, for the case of $O$-methyls, since the subclass field would describe the heteroatom bonded position, the adjacent field could similarly be used to describe the positions adjacent to that position. The designation of primary, secondary or tertiary was retained despite a certain redundancy as it provides a useful search key. We felt that this treatment of methyls would ultimately be much more useful when searching the database for structural information. Redundancy of information also provides a means of maintaining the accuracy of the data in the database as errors of omission are more easily located if multiple search keys are available.

A number of additional descriptors for the subclass of a position were developed during the course of compiling a database of correlations. A methyl which is part of a geminal dimethyl pair is designated as gemdi. The descriptors 3ring, 4ring, and 5ring designate a position which is part of a three- four- or five-membered ring respectively while ringjunc is used to denote a position which is part of multiple rings. Six-membered rings and larger were considered ubiquitous enough to be ignored. It is also debatable whether enough ring-strain exists to significantly impact upon the chemical shifts in these larger rings. A more complex series of examples are presented in Table 3.3. Note that position 9 is not described as it does not have an associated HSQC correlation.

Table 3.3 Further examples of describing chemical environments.

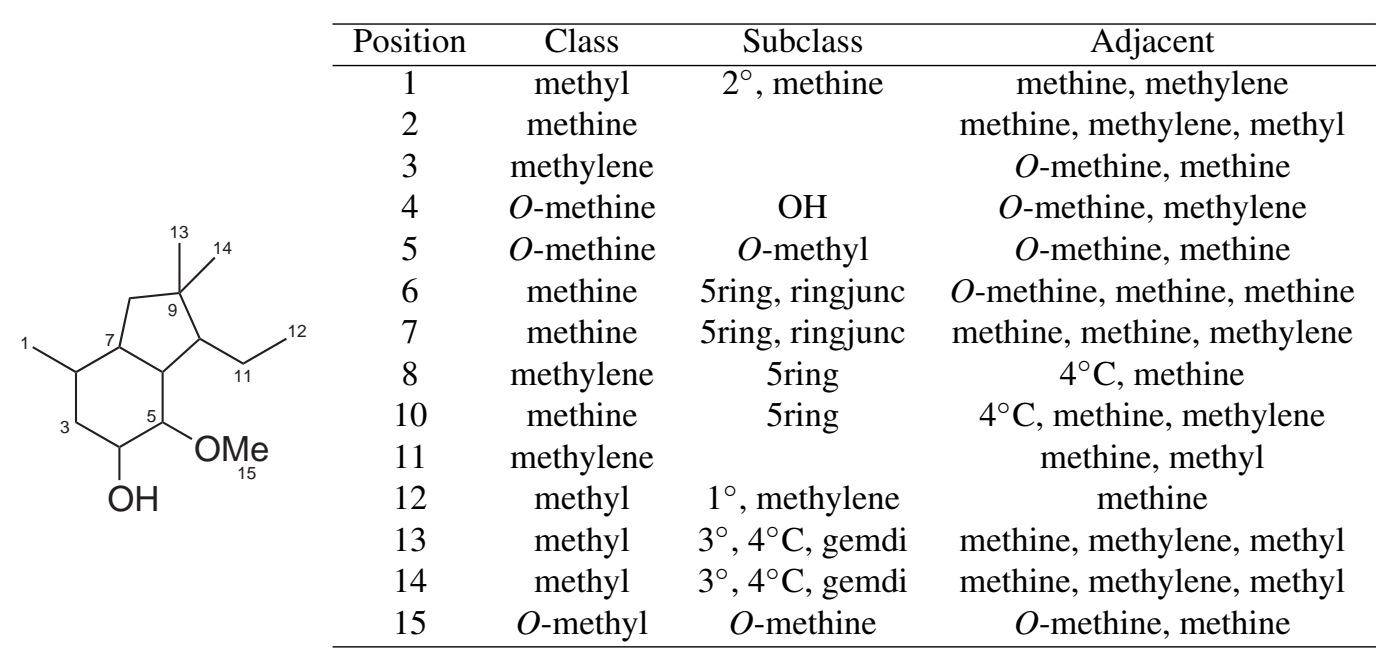


As is evident from Table 3.3, a lot of structural information can be gleaned from a single database entry. The entry for position 12 , for example, seems simple enough but it clearly implies an ethyl branch from a more complex structure. Should the spectra of an unknown compound readily identify an ethyl branch then an appropriate search of the database will list all compounds containing ethyl chains. Couple this data with the chemical shifts of the positions in question and it may be that you can quickly determine the class of compounds to which the unknown compound belongs.

Olefins and acetylenes remained to be classified in the database. The class of a double bond is described with the position in question listed first. Substitution of the olefin with carbons is indicated by omission of any other element. For example, $H C=C$ indicates an olefin tri-substituted with carbon while $\mathrm{OHC}=\mathrm{CH}$ indicates a double bond with an oxygen substituent at the end in question and a carbon substituent at the other. The configuration of double bonds was too important to omit so it was necessary to develop a means to describe the geometry in full. Thus the adjacent field describes the current position as $\alpha$ to $x, \beta$ cis to $y, \beta$ trans to $z$ as appropriate. Alkynes were very easy to classify as, unless we are describing the molecule ethyne, any alkyne which gives rise to an HSQC correlation must take the form $H C \equiv C(X)$ where $X$ represents possible substitution with a heteroatom.

Additional descriptors became necessary as the database grew in size and complexity. While most are self-explanatory, the distinction between the classifications ester and $\mathrm{O}$ acyl (or amide and $\mathrm{N}-a c y l$ ) as used in the database is worth noting. Using ethyl propanoate $\left(\mathrm{CH}_{3} \mathrm{CH}_{2} \mathrm{COOCH}_{2} \mathrm{CH}_{3}\right)$ as an example, the methylene of the acid side of the propanoate would be described as class methylene, subclass -, adjacent ester, methyl. The methylene of the ethyl group on the other hand would be described as class O-methylene, subclass O-acyl, adjacent methyl. The terms ester or amide are used to designate the carbonyl from the "acid" side of the ester or amide while the terms O-acyl or $\mathrm{N}$-acyl are used to designate the carbonyl as connected through the heteroatom of the functional group. Acetate groups are worthy of mention here since they represent simple esters. As methyls are treated specially, so too are acetates such that the adjacent field is used to represent the group to which the ester carbonyl is attached. The entry for the methyl of ethyl 
acetate $\left(\mathrm{CH}_{3} \mathrm{COOCH}_{2} \mathrm{CH}_{3}\right)$ would be described as class methyl, subclass ester, adjacent O-methylene. There is some argument for dropping the $O$ - from the description of the methylene in the adjacent field as it is already implied by the subclass field but we decided that the redundancy would ultimately improve the efficacy of searching the data.

Table 3.4 contains a complete description of peloruside A (71), a potent microtubule stabilising agent presently undergoing pre-clinical trials for the treatment of cancer. ${ }^{57,58}$

As the database developed it became apparent that being able to compare the data for larger moieties with one another would be useful. Amino acid residues and sugars were the two groups of compounds for which this would be most useful. To accomplish this, a new field designated residue was created. Independent of all the other data, the residue entry would contain the name of the amino acid or sugar to which the position belonged (e.g. tyrosine or glucopyranose). Acetate groups were also considered important enough to describe in the residue field.

Several functional groups remained difficult to classify using the rules thus far developed. Initially, problematic groups included such moieties as furans and thiazoles; in fact, most of the problematic structures turned out to be five-membered heteroaromatic rings. In order to describe these structures one last field, substructure, was introduced. To describe a substructure, the substructure moiety itself is first numbered in the same manner as is normally used in organic nomenclature - that is, lactones and lactams are numbered from the carbonyl, while heteroaromatic rings are numbered from the highest atomic weight heteroatom. Note that the numbering of the substructure may change depending on how it is substituted in the molecule in question. This numbering scheme is used to describe the substitution of the substructure. In the case of 3-ethylfuran for example, the structure is obviously described as substituted with a methylene at C-3. The description of any given position in the substructure is then constructed in the following manner: the substructure field is populated with the name of the substructure in question, the class field is filled in as normal, which is to say it describes the nature of the position in question, the subclass field describes the position of the substructure which is presently being described (e.g. C2) along with any additional descriptors (e.g. ringjunc), and the adjacent field describes the 

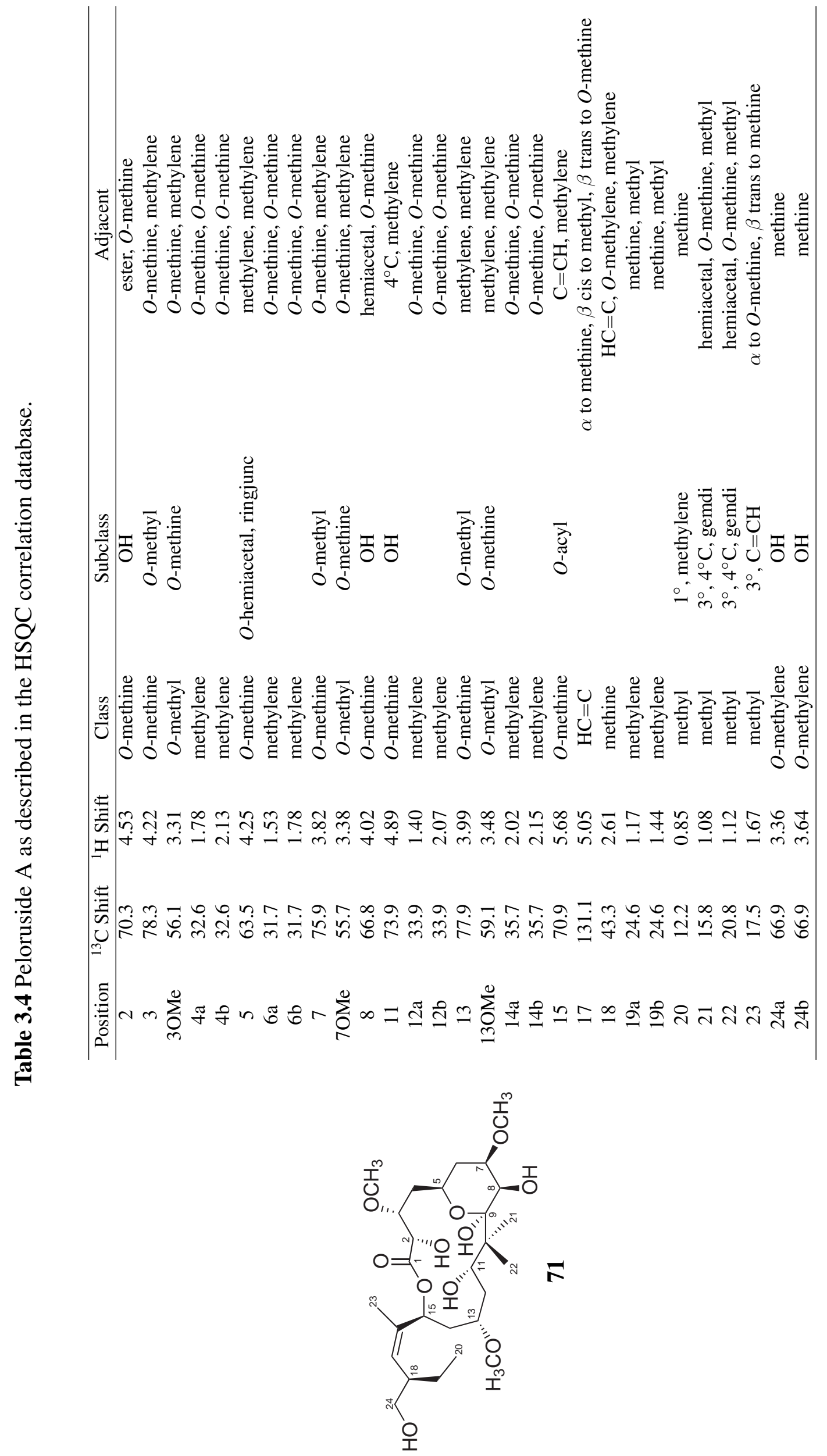
substitution of the whole substructure. For example, the description of the C-2 position of the furan in 3-ethylfuran would read residue -, substructure furan, class $O H C=C$, subclass $C 2$, adjacent $C 3$-methylene. Over the course of developing the database to date, 13 substructures have been recognised (Figure 3.16).

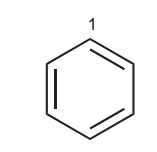

benzene<smiles>O=C1C=C[CH]O1</smiles>

butenolide

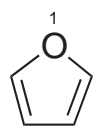

furan

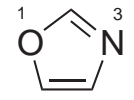

oxazole<smiles>O=C1CCCN1</smiles>

butanamide<smiles>C1=[N+]OCC1</smiles>

4,5-dihydroisoxazole

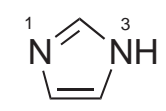

imidazole

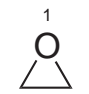

oxirane

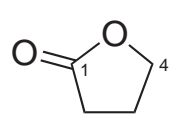

butanolide

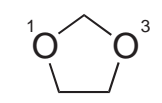

dioxolane

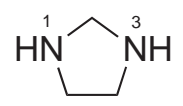

imidazolidine

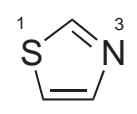

thiazole

Figure 3.16 The 13 substructures used in the HSQC correlation database to date.

The assigned substructure is also used in the adjacent field when required. In the case of 3-ethylfuran, the methylene moiety would be described as class methylene, subclass -, adjacent $C 3$-furan, methyl indicating that it is adjacent to the $\mathrm{C} 3$ position of a furan and the methyl group. In this example, the methyl entry would contain a lot of information; class methyl, subclass $1^{\circ}$, methylene, adjacent C3-furan. This one entry essentially describes the whole molecule in this example, but might otherwise indicate a significant substructure of a larger molecule.

One further point to note involves the describing of benzene moieties. By definition, the position of the double bonds is not fixed as is implied by the drawn structure, ergo when describing the class of a position, the alternative arrangement of the double bonds must be considered and the higher priority description used. For example, 3-bromotoluene can be drawn with the bond arrangement in two ways (Figure 3.17). The class entry for position 2 could be described as either $H C=C B r$ or $H C=C$. Similarly, position 4 can be 
described as $H C=C H$ or $H C=C B r$. In each case, the correct entry is $H C=C B r$ as bromine has a higher atomic mass than either carbon or hydrogen.<smiles>Cc1cccc(Br)c1</smiles><smiles>Cc1cccc(Br)c1</smiles>

Figure 3.17 Differently drawn structures of 3-bromotoluene.

A complete description of the cytotoxic depsipeptide obyanamide (72) which was reported in 2002 from the cyanobacterium Lyngbya confervoides ${ }^{59}$ is presented here as an example of the use of the residue and substructure fields (Table 3.5).

At this stage of development, the system of describing structures is capable of dealing with most structural types found in the literature. One notable exception are compounds containing polyaromatic moieties which are presently very difficult to describe. Further development of the HSQC correlation database will need to address describing compounds of this type.

The current structure of the HSQC correlation database is presented in Figure 3.18.

\begin{tabular}{|c|c|}
\hline Compound Database & Correlation Database \\
\hline Compound Number & Correlation Number \\
\hline Compound Name & Compound Number \\
\hline Molecular Formula & Position \\
\hline Molecular Mass & ${ }^{13} \mathrm{C}$ Chemical Shift \\
\hline NMR Solvent & ${ }^{1} \mathrm{H}$ Chemical Shift \\
\hline Source Reference & ${ }^{1} J_{\mathrm{CH}}$ Coupling Constant \\
\hline \multirow[t]{5}{*}{ Structure } & Residue \\
\hline & Substructure \\
\hline & Class \\
\hline & Subclass \\
\hline & Adjacent \\
\hline
\end{tabular}

Figure 3.18 Schematic representation of the current layout of the dual database.

In compiling the database, the question of which compounds to include was considered very important. It is not unusual for literature data to contain errors, either in logic or simply typographical. The compounds selected for the database were chosen based upon the reliability of the source, the thoroughness of the presented structural elucidation and the diversity of structural features that they would contribute to the database. To date, the 


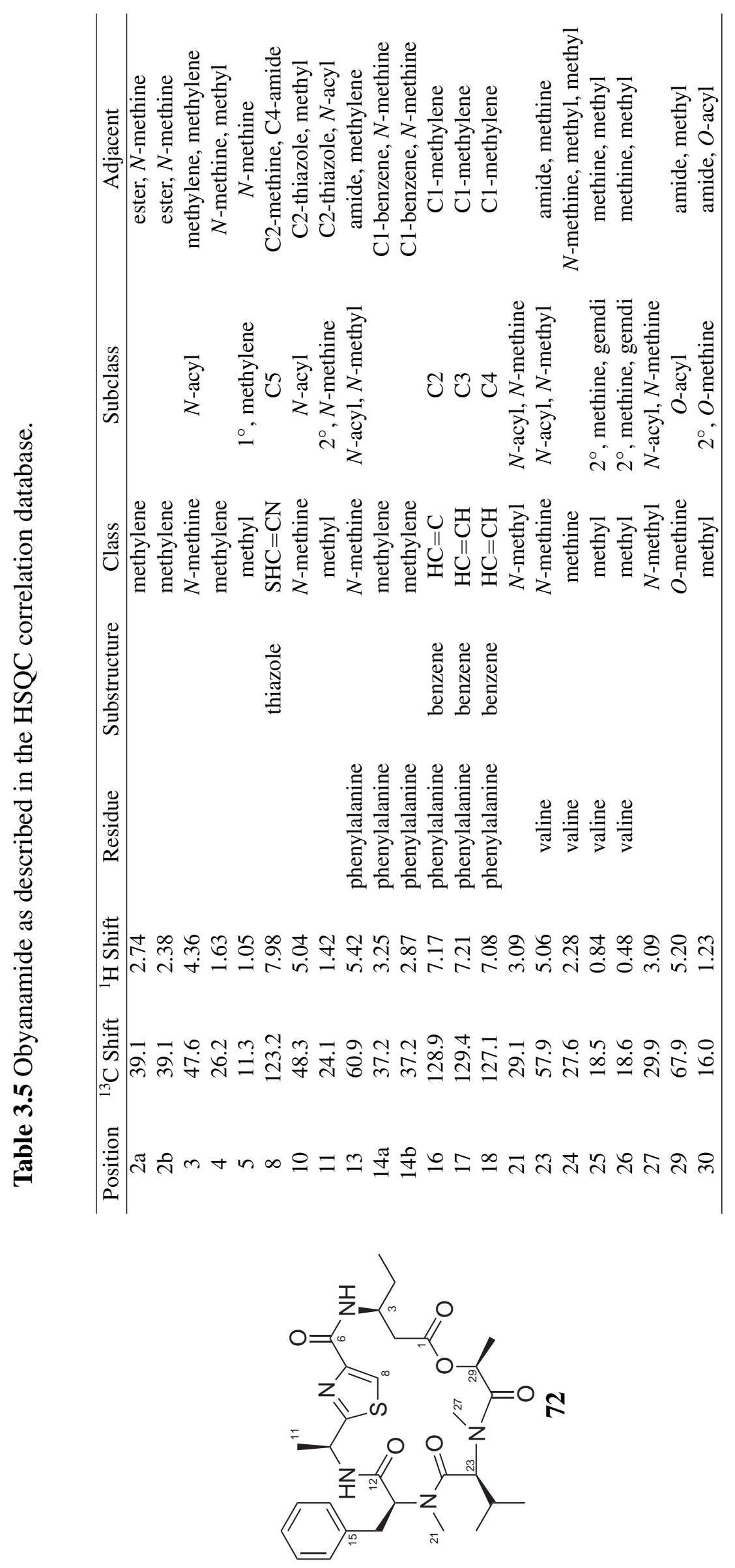


91 compounds listed in Table 3.6 have been included in the HSQC correlation database (citations refer to the source of NMR data rather than the original isolation). These data represent a total of over 2500 described HSQC correlations which represent significant diversity of structure.

The usefulness of the database remains limited, but as new compounds are added and the number of HSQC correlations increases it will become a powerful tool in the dereplication of natural products. The validity of the database in its present form is explored here by searching the database for elements of raspailodane F (40) (see Chapter 2). In this example, searches are constructed with relatively narrow margins of error $\left(\delta_{\mathrm{C}} \pm 2.5 \mathrm{ppm}\right.$ and $\left.\delta_{\mathrm{H}} \pm 0.05 \mathrm{ppm}\right)$.

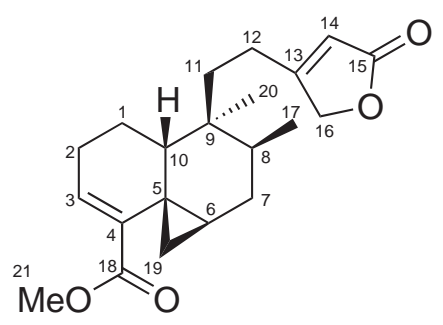

40

A search for the methyl singlet at position $20\left(\delta_{\mathrm{C}} 21.7, \delta_{\mathrm{H}} 0.96\right)$ of $\mathbf{4 0}$ is constructed by searching for $\delta_{\mathrm{C}} 24.2 \geqslant x \geqslant 19.2, \delta_{\mathrm{H}} 1.01 \geqslant x \geqslant 0.91$, class contains methyl, subclass contains $3^{\circ}$. These criteria limit the results to eight correlations. Two belong to geminal dimethyl signals of mycalamides $\mathrm{A}\left(\delta_{\mathrm{C}} 23.0, \delta_{\mathrm{H}} 0.98\right)$ and $\mathrm{E}\left(\delta_{\mathrm{C}} 22.9, \delta_{\mathrm{H}} 0.97\right)$, two belong to ring junction methyls of the triterpenoids stelletin $\mathrm{H}\left(\delta_{\mathrm{C}} 23.3, \delta_{\mathrm{H}} 1.01\right)$ and $\mathrm{I}\left(\delta_{\mathrm{C}} 23.3\right.$, $\delta_{\mathrm{H}} 1.01$ ), two belong to tertiary methyls of the sesquiterpenes 2-hydroxymicrocionin-2 butenolide $\left(\delta_{\mathrm{C}} 20.3, \delta_{\mathrm{H}} 0.92\right)$ and 1,2-dehydromicrocionin-4 hydroxybutenolide $\left(\delta_{\mathrm{C}} 21.6\right.$, $\left.\delta_{\mathrm{H}} 0.96\right)$, one belongs to the $\mathrm{C}-20$ tertiary methyl of raspailodane $\mathrm{A}\left(\delta_{\mathrm{C}} 21.6, \delta_{\mathrm{H}} 0.98\right)$ and the final correlation arises from a geminal dimethyl of cinnamolide $\left(\delta_{\mathrm{C}} 21.3, \delta_{\mathrm{H}} 0.94\right)$.

To refine the pool of suspect compounds, a search for the olefinic methine at position 14 $\left(\delta_{\mathrm{C}} 115.2, \delta_{\mathrm{H}} 5.84\right)$ of $\mathbf{4 0}$ is performed $\left(\delta_{\mathrm{C}} 117.5 \geqslant x \geqslant 112.5, \delta_{\mathrm{H}} 5.89 \geqslant x \geqslant 5.79\right.$, class contains $H C=C$ ). Two results are returned on this occasion - the olefinic methine at position 14 of raspailodane $\mathrm{B}\left(\delta_{\mathrm{C}} 115.5, \delta_{\mathrm{H}} 5.82\right)$ and an aromatic methine from the peptide renieramide $\left(\delta_{\mathrm{C}} 116.3, \delta_{\mathrm{H}} 5.85\right) .^{\dagger}$

\footnotetext{
${ }^{\dagger} \mathrm{NMR}$ data for renieramide is available in $\mathrm{CD}_{3} \mathrm{OD}$ and $\mathrm{d}_{6}$-DMSO but only the $\mathrm{d}_{6}$-DMSO data matched.
} 


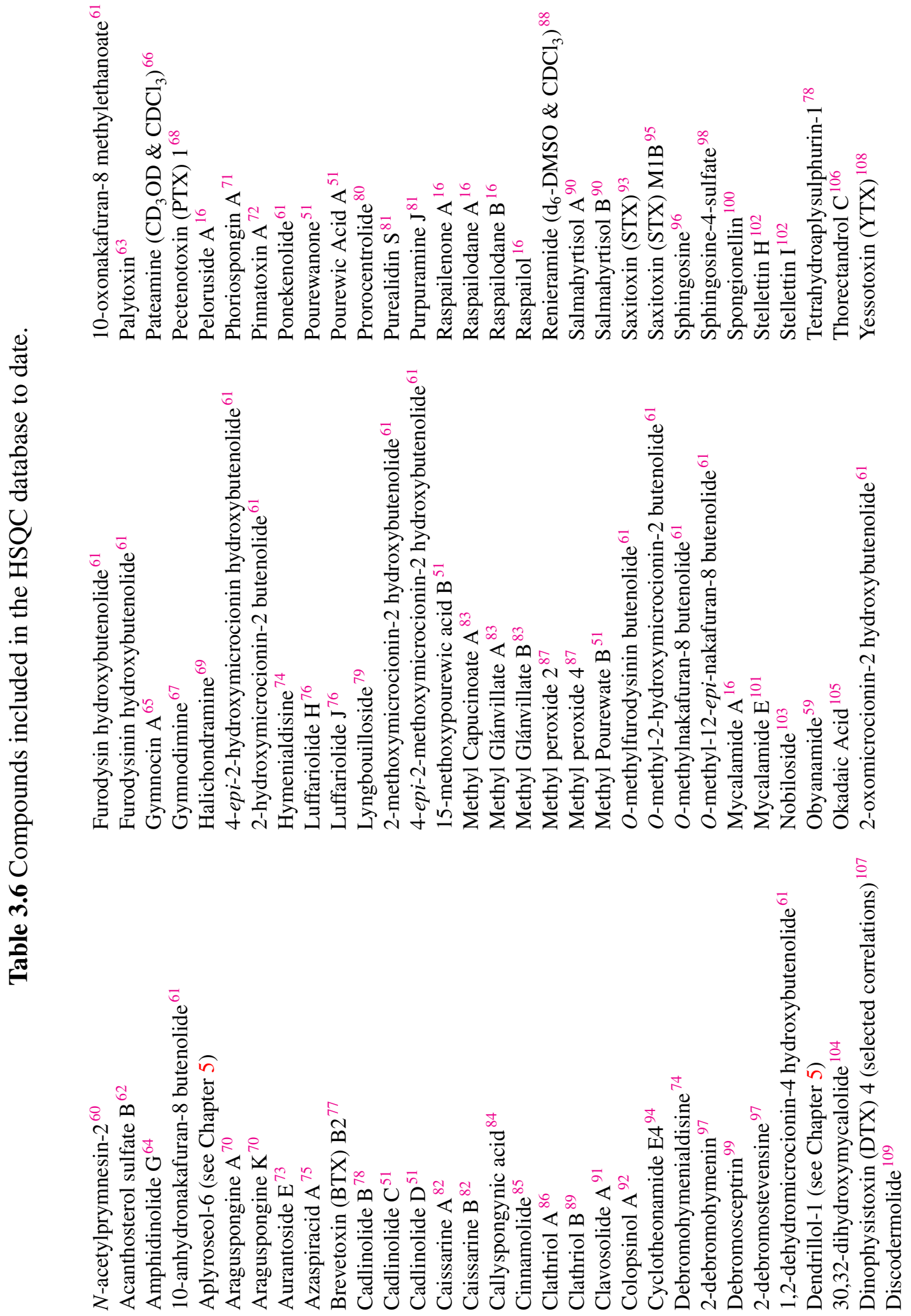


Finally, searches for the olefinic methine at position $3\left(\delta_{\mathrm{C}} 138.6, \delta_{\mathrm{H}} 6.83\right)$ and the methylene at position $16\left(\delta_{\mathrm{C}} 73.2, \delta_{\mathrm{H}} 4.74\right)$ of $\mathbf{4 0}\left(\delta_{\mathrm{C}} 141.1 \geqslant x \geqslant 136.1, \delta_{\mathrm{H}} 6.88 \geqslant x \geqslant\right.$ 6.78, class contains $H C=C$ and $\delta_{\mathrm{C}} 75.7 \geqslant x \geqslant 70.7, \delta_{\mathrm{H}} 4.79 \geqslant x \geqslant 4.69$, class contains methylene respectively) returned hits for position 3 of raspailodane $\mathrm{A}$ and an olefinic methine of cinnamolide in the first instance, and a single hit for the olefinic methine at position 14 of raspailodane $\mathrm{B}$ in the second.

The combination of these searches would seem to indicate some structural similarity to raspailodanes $\mathrm{A}$ and $\mathrm{B}$. Although this example is somewhat contrived, it serves to illustrate that the HSQC correlation database is a useful tool in the identification of similar structural motifs.

\subsection{Summary}

Fifty-six sponges were screened for interesting secondary metabolites over the course of this study. Of these, several led to the isolation of new metabolites which are discussed in subsequent chapters. A significant amount of work was spent isolating two known compounds, avarol (68) and $5 \alpha, 8 \alpha$-epidioxy-24R-ethylcholesta-6,22(E)-dien-3 $\beta$ ol (70) which highlights one of the most significant problems facing the modern natural products chemist; dereplication of known compounds from those which have not yet been discovered.

This study approached the problem of dereplication in two ways. First, a method for the partial automated analysis of screens of biological extracts was developed. This computer-based screen works to reduce the volume of extraneous information which is presented to the analyst by masking out correlations in HSQC spectra which are of little or no interest due to their repeated occurrence in extracts. At the same time, a database of HSQC correlations was constructed which, as it grows in size, will become a powerful tool for the efficient identification of structural motifs of compounds in a complex mixture. 


\section{Petrosianoic Acid: A New $\mathrm{C}_{19}$ Fatty Acid from the New Zealand Marine Sponge Petrosia sp.}

\subsection{Background}

Marine sponges of class Demospongiae are known to produce a variety of fatty acids. ${ }^{110}$ These compounds possess long chains of carbon atoms which exhibit varying levels of saturation. Related to these fatty acids are the polyacetylenes, compounds which are characteristic metabolites of marine sponges which belong to the demospongian order Haplosclerida. ${ }^{111}$ Polyacetylenes are produced by a number of families in this order including Petrosiidae (more specifically genera Xestospongia and Petrosia) from which the majority of the isolated polyacetylenes have been reported. ${ }^{111}$ The polyacetylenic and fatty acid constituents of the genus Petrosia (taxonomy see Table 4.1) are herein explored.

Table 4.1 Taxonomic classification of genus Petrosia from order Haplosclerida as presented by Hooper and van Soest. ${ }^{5}$

\begin{tabular}{|c|c|c|c|}
\hline Order & Sub-order & Family & Genus \\
\hline \multirow{15}{*}{ Haplosclerida } & \multirow{3}{*}{ Haplosclerina } & Callyspongiidae & $\ldots$ \\
\hline & & Chalinidae & $\ldots$ \\
\hline & & Niphatidae & $\ldots$ \\
\hline & \multirow{6}{*}{ Petrosina } & Calcifibrospongiidae & $\ldots$ \\
\hline & & \multirow{4}{*}{ Petrosiidae } & Acanthostrongylophora \\
\hline & & & Neopetrosia \\
\hline & & & Petrosia \\
\hline & & & Xestospongia \\
\hline & & Phloeodyctyidae & $\ldots$ \\
\hline & \multirow{6}{*}{ Spongilina } & Lubomirskiidae & $\ldots$ \\
\hline & & Malawispongiidae & $\ldots$ \\
\hline & & Metaniidae & $\ldots$ \\
\hline & & Metschnikowiidae & $\ldots$ \\
\hline & & Potamolepidae & $\ldots$ \\
\hline & & Spongillidae & $\ldots$ \\
\hline
\end{tabular}

Polyacetylenes are generally long straight-chain molecules of varying chain length which include a diverse range of degrees of saturation, olefinic geometries and oxidation states at a variety of positions. Two examples of polyacetylenes from Petrosia include petrosynol 
(73), isolated from a Red Sea collection of an unidentified species of Petrosia, ${ }^{112}$ and petroformyne-1 (74) reported with a series of related compounds from a Mediterranean collection of Petrosia ficiformis. ${ }^{113-115}$

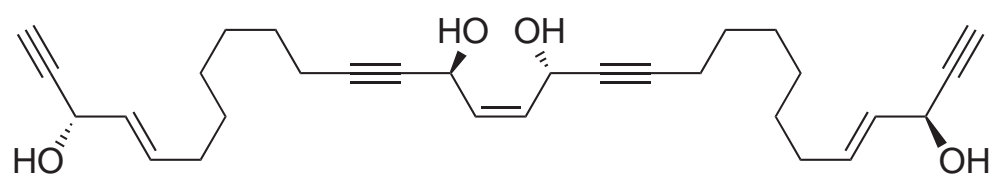

73

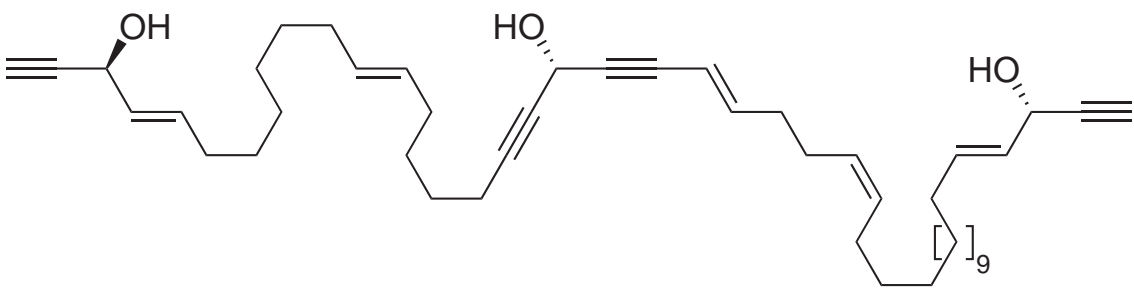

74

Polyacetylenic acids and their esters form a smaller subset of reported polyacetylenes. There are 22 reported polyacetylenic acid derivatives from petrosid sponges. ${ }^{114-122}$ These compounds are exemplified by the compounds petroformyne A and B (75-76) from $P$. ficiformis, ${ }^{114,115}$ the $\mathrm{C}_{18}$ brominated acetylenic acid (77) from $P$. volcano, ${ }^{117}$ petrosolic acid (78) from Petrosia sp., ${ }^{118}$ corticatic acid A and B (79-80) from P. corticata, ${ }^{119}$ petroformynic acid (81) from P. ficiformis ${ }^{120}$ and aztèquynol A (82) from an unidentified species of Petrosia. ${ }^{121}$<smiles>C#C[C@H](O)/C=C/CPC/C=C\C#CC(=O)OC</smiles>

$75 \mathrm{R}=\mathrm{C}_{31} \mathrm{H}_{56}$

$76 \mathrm{R}=\mathrm{C}_{33} \mathrm{H}_{60}$

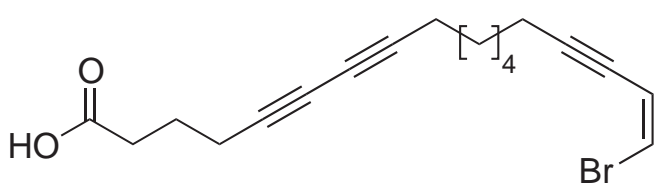

77

Polyacetylenes also display a wide range of biological activities. ${ }^{111}$ The above examples show some indication of this diversity - petroformynes A and B (75-76) are active in the $\mu \mathrm{g} / \mathrm{mL}$ range in a brine shrimp (Artemia salina) lethality assay, ${ }^{114}$ the $\mathrm{C}_{18}$ brominated acetylenic acid (77) and corticatic acids A and B (79-80) display antifungal activity against Mortierella ramanniana ${ }^{117,119}$ and petrosolic acid (78) inhibits RNA-dependent DNA polymerase, DNA-dependent DNA polymerase and RNAase $\mathrm{H}$ activities of HIV-1 reverse transcriptase at $1.2,6.2$ and $39.5 \mu \mathrm{M}$ concentrations respectively. ${ }^{118}$

One reported compound from an unidentified Korean species of Petrosia is the acetylenic methyl ester petrynol (83). ${ }^{123}$ This compound possesses only one acetylenic moiety 


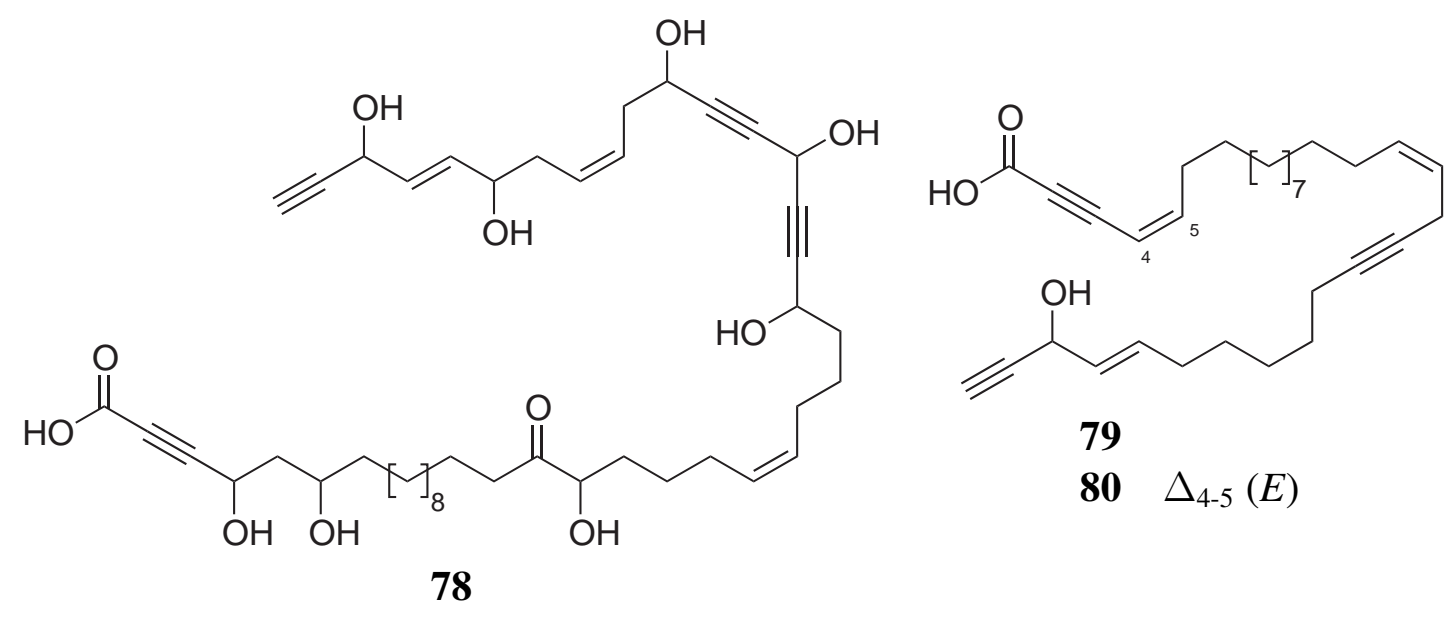

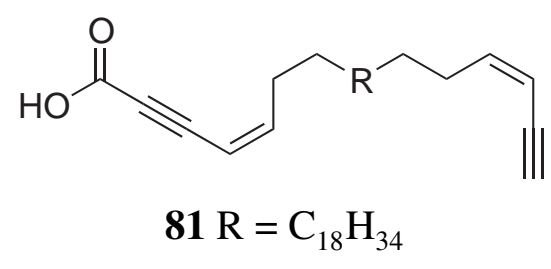

$81 \mathrm{R}=\mathrm{C}_{18} \mathrm{H}_{34}$<smiles>C#CC(O)/C=C/CCCCC(C)C</smiles>

82

(thereby excluding it from being classed as a polyacetylene) and is interesting as it may represent an intermediate biosynthetic stage between the polyacetylenes and fatty acids.<smiles>C#C[C@H](O)/C=C/CCCCCCC(=O)OC</smiles>

83

In 1982 Djerassi et al. reported the isolation of 30 fatty acids (84-113) from Petrosia ficiformis, six of which were previously unreported structures (see Table 4.2). ${ }^{124}$ Since that time, only eight further fatty acids have been reported from the genus Petrosia. In 1984 the brominated acids (5Z,9Z)-6-bromo-25-methylhexacosa-5,9-dienoic acid (114) and (5Z,9Z)-6-bromo-24-methylhexacosa-5,9-dienoic acid (115) isolated from collections of Petrosia ficiformis and Petrosia hebes were reported. ${ }^{125}$ Petrosia pellasarca was the source of three further fatty acids, (5Z,9Z)-triaconta-5,9-dienoic acid (116), (19Z,22Z,25Z,28Z,31Z)-tetratriaconta-19,22,25,28,31-pentaenoic acid (117) and 27-methyloctacosanoic acid (118) reported in 1990. ${ }^{110}$ Finally, in 1993 three additional brominated acids, (5E,9Z)-6-bromoheptacosa-5,9-dienoic acid (119), (5E,9Z)-6-bromooctacosa-5,9-dienoic acid (120) and (Z)-heptacos-19-enoic acid (121) were reported from an unidentified Caribbean species of Petrosia. ${ }^{126}$ No biological activity has been reported from any of these 38 compounds. 
Table 4.2 Fatty acid composition of Petrosia ficiformis as reported by Djerassi et al. ${ }^{124}$

\begin{tabular}{|c|c|}
\hline Compound & Fatty Acid \\
\hline 84 & 12-methyltridecanoic (iso-14:0) \\
\hline 85 & Tetradecanoic ( $n-14: 0 ;$ myristic) \\
\hline 86 & 4,8,12-trimethyltridecanoic (4-Me,8-Me,12-Me-13:0) \\
\hline 87 & 13-methyltetradecanoic (iso-15:0) \\
\hline 88 & 12-methyltetradecanoic (anteiso-15:0) \\
\hline 89 & Pentadecanoic $(n-15: 0)$ \\
\hline 90 & 14-methylpentadecanoic (iso-16:0) \\
\hline 91 & 13-methylpentadecanoic (anteiso-16:0) \\
\hline 92 & Hexadec-9-enoic $\left(\Delta^{9}-16: 1 ;\right.$ palmitoleic $)$ \\
\hline 93 & Hexadecanoic ( $n-16: 0 ;$ palmitic) \\
\hline 94 & 15-methylhexadec-9-enoic ( $\Delta^{9}$-iso-17:1) \\
\hline 95 & 10-methylhexadecanoic (10-Me-16:0) \\
\hline 96 & 15-methylhexadecanoic (iso-17:0) \\
\hline 97 & 14-methylhexadecanoic (anteiso-17:0) \\
\hline 98 & Heptadecenoic $(17: 1)^{\dagger}$ \\
\hline 99 & Heptadecanoic $(n-17: 0)$ \\
\hline 100 & Octadecenoic $(18: 1)^{\dagger}$ \\
\hline 101 & Octadec-11-enoic ( $\Delta^{11}-18: 1 ;$ vaccenic $)$ \\
\hline 102 & Octadecanoic $(n-18: 0)$ \\
\hline 103 & 11-methyloctadecanoic (11-Me-18:0) \\
\hline 104 & Nonadecenoic $(19: 1)^{\dagger}$ \\
\hline 105 & Docosa-7,13,16-trienoic $\left(\Delta^{7,13,16}-22: 3\right)^{\ddagger}$ \\
\hline 106 & Docosa-7,13-dienoic $\left(\Delta^{7,13}-22: 2\right)$ \\
\hline 107 & 15-methyltriacosanoic $(15-\mathrm{Me}-23: 0)^{\ddagger}$ \\
\hline 108 & 15-methyltetracosanoic $(15-\mathrm{Me}-24: 0)^{\ddagger}$ \\
\hline 109 & Tetracos-17-enoic $\left(\Delta^{17}-24: 1\right)$ \\
\hline 110 & 24-methylpentacosa-5,9-dienoic $\left(\Delta^{5,9}-26: 2\right)^{\ddagger}$ \\
\hline 111 & Pentacosa-5,9-dienoic $\left(\Delta^{5,9}-26: 2\right)$ \\
\hline 112 & 25-methylhexacosa-5,9-dienoic $\left(\Delta^{5,9} \text {-iso- } 27: 2\right)^{\ddagger}$ \\
\hline 113 & 24-methylhexacosa-5,9-dienoic $\left(\Delta^{5,9} \text {-anteiso- } 27: 2\right)^{\ddagger}$ \\
\hline
\end{tabular}

$\dagger$ Double bond position not determined.

$\ddagger$ Newly described structure.<smiles>[R]C(C)C(Br)CCC=CCCC(Br)=CCCCC(=O)O</smiles>

$114 \quad \mathrm{R}_{1}=\mathrm{H} \quad \mathrm{R}_{2}=\mathrm{Me}$

$115 \mathrm{R}_{1}=\mathrm{Me} \quad \mathrm{R}_{2}=\mathrm{H}$<smiles>CCCCCCCC/C=C\CCCCC(=O)O</smiles>

116<smiles>CC/C=C\C/C=C\C/C=C\C/C=C\C/C=C\C(=O)O</smiles>

117 
<smiles>CC(C)[14CH2]C(=O)O</smiles>

118<smiles>CCCCC=CCCC(Br)=CCCCC(=O)O</smiles>

$119 \mathrm{n}=14$

$120 \mathrm{n}=15$

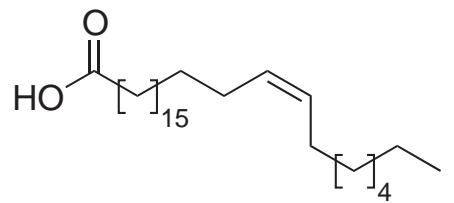

121

During the course of routine sponge screening, NMR spectra of an extract of an unidentified species of the genus Petrosia (MNP960) collected from the Marlborough Sounds, New Zealand, showed the presence of interesting NMR resonances in the aromatic/olefinic region. A large scale extraction of $840 \mathrm{~g}$ of the sponge material was performed. Repeated reversed-phase chromatography using HP20 and Amberchrom resins was followed by normal-phase chromatography using DIOL. Final purification by $\mathrm{C}_{18}$ reversed-phase HPLC led to the isolation of a new nonadecanoic acid derivative formally called $(5 E, 7 E)$-4,17-dioxononadeca-5,7-dienoic acid, here named petrosianoic acid (122) (Scheme 4.1).

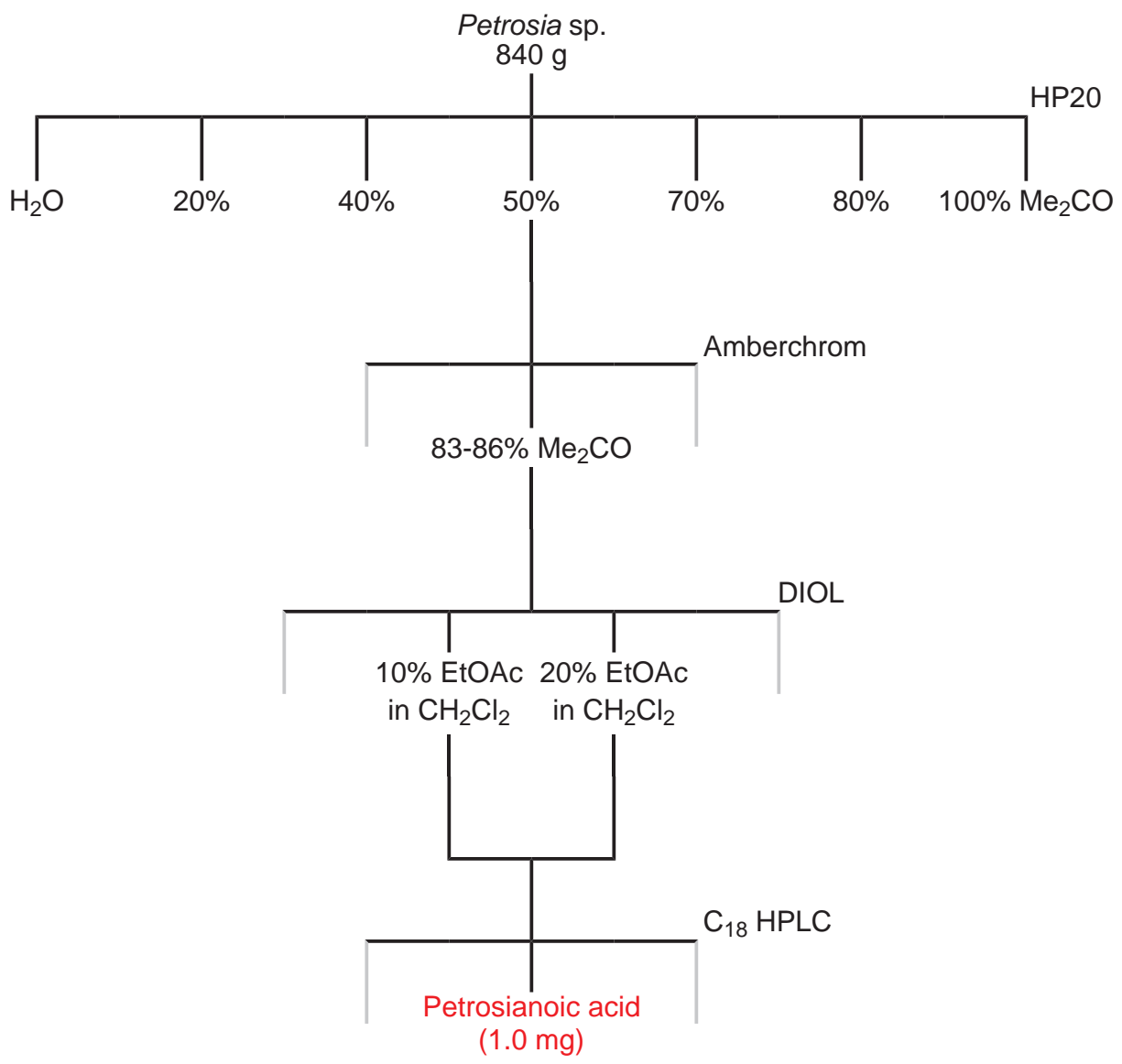

Scheme 4.1 The isolation procedure for petrosianoic acid (122) from Petrosia sp. 


\subsection{Petrosianoic Acid}

The observation of pseudo-molecular ions by HRESIMS indicated a molecular formula of $\mathrm{C}_{19} \mathrm{H}_{30} \mathrm{O}_{4}$ for petrosianoic acid $\left(323.2210[\mathrm{M}+\mathrm{H}]^{+}, \Delta 2.3 \mathrm{ppm}\right.$ and $321.2060[\mathrm{M}-\mathrm{H}]^{-}$, $\Delta 0.5 \mathrm{ppm}$ in positive- and negative-ion modes respectively) requiring five double-bond equivalents. The ${ }^{13} \mathrm{C}$ NMR spectrum of 122 contained 19 distinct resonances while the ${ }^{1} \mathrm{H}$ NMR spectrum accounted for 29 of the 30 protons. A multiplicity-edited HSQC experiment confirmed the attachment of these 29 protons to carbon indicating the presence of one exchangeable proton. Identifiable features in the ${ }^{13} \mathrm{C}$ NMR spectrum included three carbonyl resonances $\left(\delta_{\mathrm{C}} 212.3,198.5\right.$ and 177.7), four olefinic resonances $\left[\left(\delta_{\mathrm{C}} 146.6\right.\right.$, $\left.\delta_{\mathrm{H}} 6.19\right),\left(\delta_{\mathrm{C}} 144.0, \delta_{\mathrm{H}} 7.18\right),\left(\delta_{\mathrm{C}} 128.9, \delta_{\mathrm{H}} 6.20\right)$ and $\left.\left(\delta_{\mathrm{C}} 127.3, \delta_{\mathrm{H}} 6.11\right)\right]$ and a methyl $\left(\delta_{\mathrm{C}} 8.0, \delta_{\mathrm{H}} 1.05\right)$. The three carbonyl resonances could be further distinguished as likely being a saturated ketone, an unsaturated ketone and an acid or ester function. This is consistent with the chemical shifts observed for the four olefinic resonances which likely represent two polarised double bonds. The UV spectrum of 122 showed a $\lambda_{\max }$ of $275 \mathrm{~nm}$ ( $\epsilon$ 21500) which provided further evidence for the presence of an $\alpha, \beta, \gamma, \delta$-unsaturated ketone. $^{127}$

Determination of the structure of petrosianoic acid began with the observation of an $\mathrm{AB}$ spin system of two methylenes $\left[\left(\mathrm{C}-2: \delta_{\mathrm{C}} 28.0, \delta_{\mathrm{H}} 2.69\right)\right.$ and $\left(\mathrm{C}-3: \delta_{\mathrm{C}} 34.7\right.$, $\left.\left.\delta_{\mathrm{H}} 2.90\right)\right]$ in the analysis of the COSY spectrum of 122. Each methylene showed HMBC correlations to both the unsaturated carbonyl (C-4: $\left.\delta_{\mathrm{C}} 198.5\right)$ and the acid/ester function $\left(\mathrm{C}-1: \delta_{\mathrm{C}} 177.2\right)$ although how these functionalities were connected was not immediately obvious. A COSY correlation between H-5 $\left(\delta_{\mathrm{C}} 127.3, \delta_{\mathrm{H}} 6.10\right)$ and H-6 $\left(\delta_{\mathrm{C}}\right.$ 144.0, $\delta_{\mathrm{H}}$ 7.18) indicated the attachment of these two olefinic carbons in a polarised double bond. HMBC correlations to the unsaturated carbonyl C-4 were observed from $\mathrm{H}-5$ and H-6 placing C-5 and C-6 adjacent to C-4. H-5 also showed an HMBC correlation to C3 indicating the linear connectivity of C-3, C-4 and C-5. The assignment of C-4 as the unsaturated carbonyl defined $\mathrm{C}-1$ as the acid/ester function. The ${ }^{13} \mathrm{C}$ chemical shifts for positions C-5 and C-6 are consistent with a polarised double bond. Spectral overlap in the ${ }^{1} \mathrm{H}$ spectrum of olefinic protons $\mathrm{H}-7\left(\delta_{\mathrm{C}} 128.9, \delta_{\mathrm{H}} 6.19\right)$ and $\mathrm{H}-8\left(\delta_{\mathrm{C}} 146.7, \delta_{\mathrm{H}} 6.19\right)$ 
made the assignment of their position more difficult. Protons $\mathrm{H}-7 / \mathrm{H}-8$ showed HMBC correlations to C-5 and C-6 indicating the linear connection of C-7 and C-8 to C-6. The attachment of C-7 to C-6 and C-8 to C-7 was made on the basis of their ${ }^{13} \mathrm{C}$ shifts which are consistent with the expected shifts of an $\alpha, \beta, \gamma, \delta$-unsaturated ketone. Observed COSY correlations from $\mathrm{H}-7 / \mathrm{H}-8$ to both $\mathrm{H}-6$ and $\mathrm{H}_{2}-9$ were consistent with this assignment. An HMBC correlation from methylene protons $\mathrm{H}_{2}-9\left(\delta_{\mathrm{C}} 33.3, \delta_{\mathrm{H}} 2.18\right)$ to $\mathrm{C}-7$ extended this substructure by a further methylene unit. Finally, a COSY correlation between methylene protons $\mathrm{H}_{2}-10\left(\delta_{\mathrm{C}} 28.7, \delta_{\mathrm{H}} 1.42\right)$ and $\mathrm{H}_{2}-9$, supported by an HMC correlation noted between $\mathrm{H}_{2}-10$ and $\mathrm{C}-8$ indicated the attachment of C-10 to C-9 completing this substructure (Figure 4.1, substructure A).

Another substructure was constructed from the methyl terminus (C-19: $\left.\delta_{\mathrm{C}} 8.0, \delta_{\mathrm{H}} 1.05\right)$. A COSY correlation between $\mathrm{H}_{3}-19$ and a methylene $\left(\mathrm{C}-18: \delta_{\mathrm{C}} 36.0, \delta_{\mathrm{H}} 2.42\right)$ completed a simple spin system. HMBC correlations from both $\mathrm{H}_{3}-19$ and $\mathrm{H}_{2}-18$ to the saturated ketone $\left(\mathrm{C}-17: \delta_{\mathrm{C}} 212.3\right)$ indicated its attachment to C-18 consistent with the downfield shift of $\mathrm{H}_{2}-18$. Two further HMBC correlations from another deshielded methylene (C-16: $\left.\delta_{\mathrm{C}} 42.5, \delta_{\mathrm{H}} 2.39\right)$ to $\mathrm{C}-17$ and $\mathrm{C}-18$ extended the substructure by a methylene group. The substructure (Figure 4.1, substructure B) was completed by the observation of a COSY correlation from $\mathrm{H}_{2}-16$ to another methylene (C-15: $\left.\delta_{\mathrm{C}} 24.0, \delta_{\mathrm{H}} 1.56\right)$. This assignment was supported by noting an HMBC correlation from $\mathrm{H}-15$ to C-17.

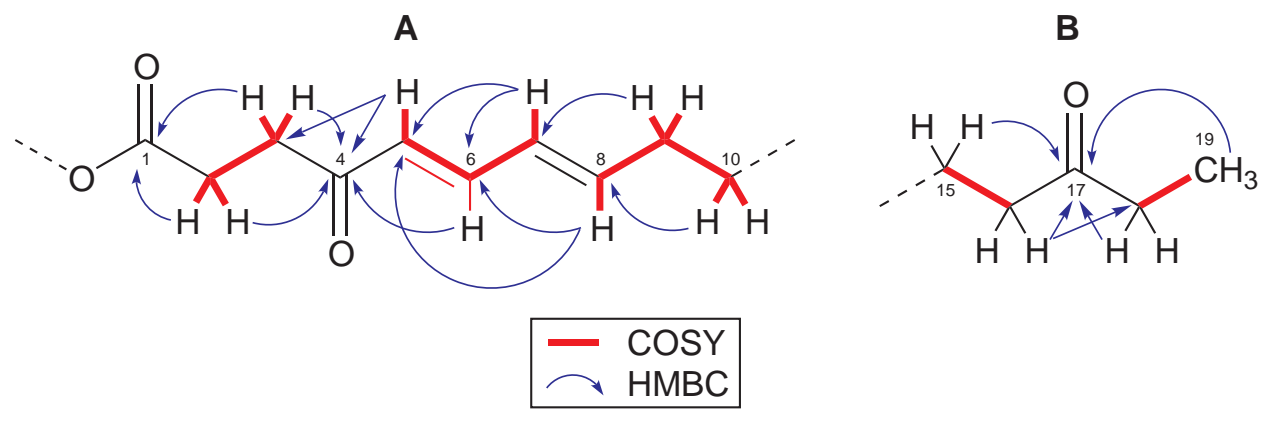

Figure 4.1 Selected COSY and HMBC correlations establishing substructures of petrosianoic acid (122).

Four methylene pairs remained unaccounted for in the structure. The chemical shifts of each of these methylenes were very similar $\left(\delta_{\mathrm{C}} 29.2-29.4, \delta_{\mathrm{H}} 1.28\right)$ and indicative of a short unresolved alkyl chain. The resonance at $\delta_{\mathrm{H}} 1.28$ integrated for a relative eight protons consistent with a chain of four methylenes. COSY correlations observed between 
$\delta_{\mathrm{H}} 1.28$ and both $\mathrm{H}_{2}-10$ and $\mathrm{H}_{2}-15$ suggested that substructures $\mathrm{A}$ and $\mathrm{B}$ were connected via this alkyl chain. This proposal is supported by the observation of HMBC correlations from $\mathrm{H}_{2}-9, \mathrm{H}_{2}-10, \mathrm{H}_{2}-15$ and $\mathrm{H}_{2}-16$ to resonances at $\delta_{\mathrm{C}} 29.2-29.4$. On the basis of this evidence C-11, C-12, C-13 and C-14 were assigned interchangeably as $\left(\delta_{\mathrm{C}} 29.4, \delta_{\mathrm{H}} 1.28\right)$, $\left(\delta_{\mathrm{C}} 29.4, \delta_{\mathrm{H}} 1.28\right),\left(\delta_{\mathrm{C}} 29.3, \delta_{\mathrm{H}} 1.28\right)$ and $\left(\delta_{\mathrm{C}} 29.2, \delta_{\mathrm{H}} 1.28\right)$. To further support the assignment of the alkyl chain between $\mathrm{C}-10$ and $\mathrm{C}-15$, selective excitation of $\mathrm{H}_{2}-9$ in a series of 1D-TOCSY experiments with increasing mixing times sequentially revealed $\mathrm{H}_{2}-10,\left[\mathrm{H}_{2}-11, \mathrm{H}_{2}-12, \mathrm{H}_{2}-13\right.$ and $\left.\mathrm{H}_{2}-14\right], \mathrm{H}_{2}-15$ then $\mathrm{H}_{2}-16$.

With the molecular formula accounted for except for a single proton, position C-1 was proposed to be a carboxylic acid moiety. NMR data for petrosianoic acid $\mathbf{1 2 2}$ is presented in Table 4.3.

The assignment of the geometry of the double bonds in petrosianoic acid was challenging due to the spectral overlap of H-7 and H-8. The geometry of $\Delta_{5-6}$ was assigned as $(E)$ on the basis of the observed ${ }^{1} \mathrm{H}^{-}{ }^{1} \mathrm{H}$ coupling constant between $\mathrm{H}-5$ and $\mathrm{H}-6$ of $15.6 \mathrm{~Hz}$. In order to determine the value of ${ }^{3} J_{\mathrm{HH}}$ between $\mathrm{H}-7$ and $\mathrm{H}-8$, an HSQC experiment was performed with an extended acquisition time of approximately one second, in the absence of broadband ${ }^{13} \mathrm{C}$ decoupling. The increased acquisition time increases the resolution obtained in $\mathrm{F}_{2}$ to allow accurate measurement of the ${ }^{3} J_{\mathrm{HH}}$ values from 1D traces of the 2D HSQC spectrum. The absence of ${ }^{13} \mathrm{C}$ decoupling causes the ${ }^{1} \mathrm{H}$ signals to be split by the ${ }^{1} J_{\mathrm{CH}}$ coupling constant. Strongly coupled spin systems of the form ${ }^{1} \mathrm{H}-{ }^{12} \mathrm{C}-{ }^{12} \mathrm{C}-{ }^{1} \mathrm{H}$ (which would be the dominant isotopomer observed in a ${ }^{1} \mathrm{H}$ spectrum) will generally no longer exhibit strong coupling when one carbon is a ${ }^{13} \mathrm{C}$; that is, of the form ${ }^{1} \mathrm{H}-{ }^{13} \mathrm{C}-{ }^{12} \mathrm{C}-{ }^{1} \mathrm{H}$ (which would be the dominant isotopomer observed in an HSQC experiment). This technique has been reported for the measurement of ${ }^{3} J_{\mathrm{HH}}$ coupling constants in symmetrical systems. ${ }^{128}$ The $1 \mathrm{D}$ trace at $\delta_{\mathrm{C}} 128.9(\mathrm{C}-7)$ (Figure 4.2) indicates a doublet of doublets with coupling constants of $15.8 \mathrm{~Hz}$ and $11.1 \mathrm{~Hz}$. The 1D trace at $\delta_{\mathrm{C}} 146.7$ (C-8) (Figure 4.3) indicates a doublet of triplets with coupling constants of 15.0 Hz and 7.4 Hz. The observed $11.1 \mathrm{~Hz}$ doublet for $\mathrm{H}-7$ is consistent with the $9.8 \mathrm{~Hz}$ doublet observed for H-6 as measured from the ${ }^{1} \mathrm{H}$ spectrum. Similarly, the observed 7.4 Hz triplet for $\mathrm{H}-8$ is consistent with the coupling constant measured for $\mathrm{H}_{2}-9(6.8 \mathrm{~Hz})$. 


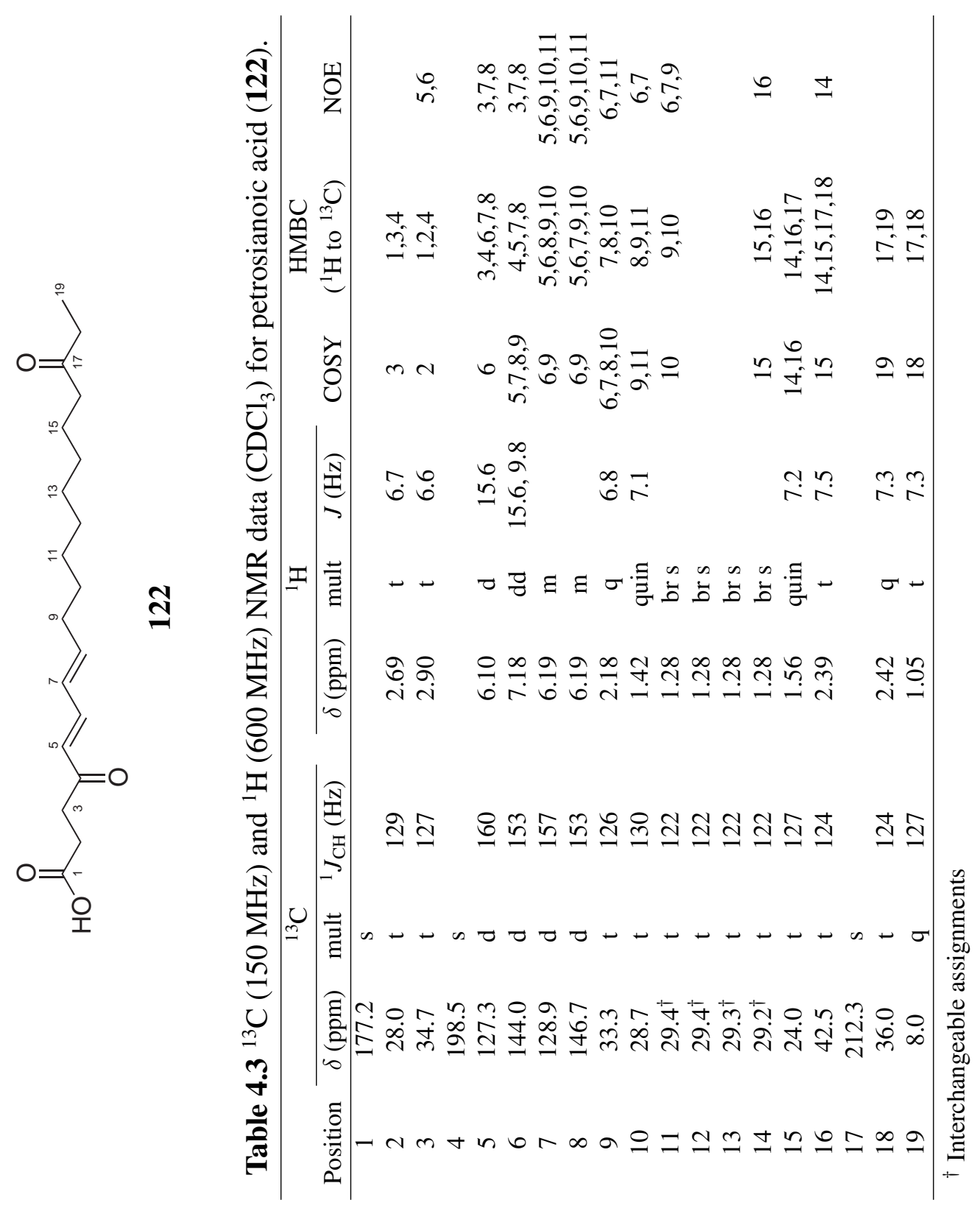


These data indicate that the coupling constants of $15.8 \mathrm{~Hz}$ for $\mathrm{H}-7$ and $15.0 \mathrm{~Hz}$ for $\mathrm{H}-8$ represent their mutual coupling defining $\Delta_{7-8}$ as $(E)$.

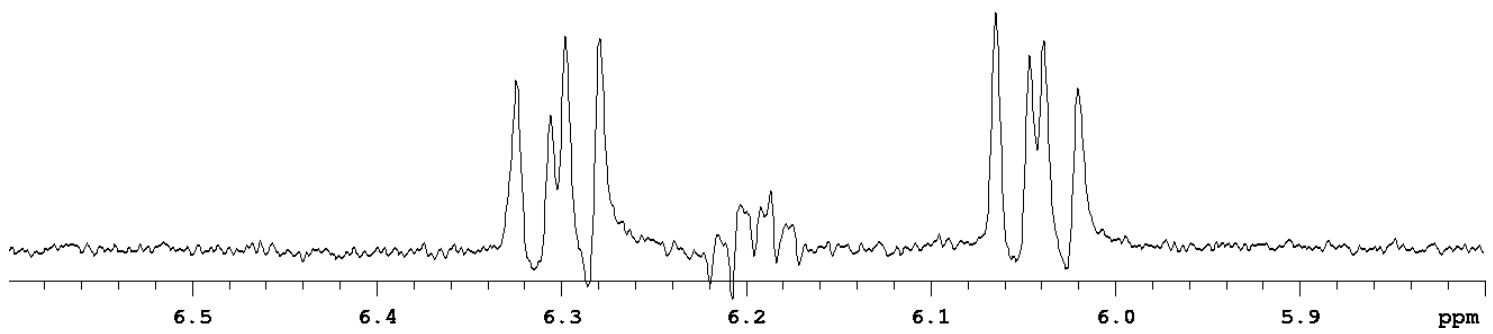

Figure 4.2 1D trace at $\delta_{\mathrm{C}} 128.9$ of a 2D HSQC experiment showing dd(15.8, $\left.11.1 \mathrm{~Hz}\right)$ coupling.

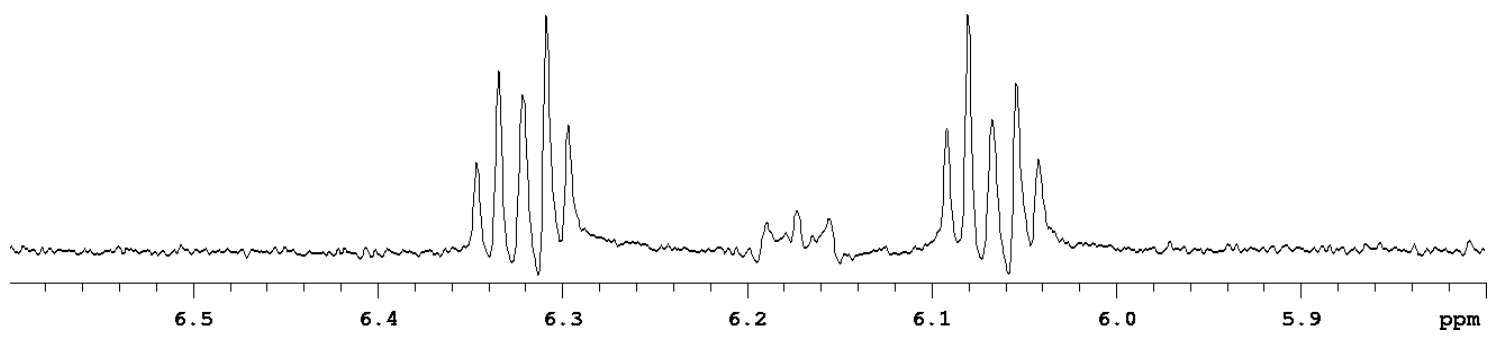

Figure 4.3 1D trace at $\delta_{\mathrm{C}} 146.7$ of a 2D HSQC experiment showing $\operatorname{dt}(15.0,7.4 \mathrm{~Hz})$ coupling. 


\subsection{Methylpetrosianoate}

In order to prove the presence of the carboxylic acid moiety, petrosianoic acid was subjected to ethereal $\mathrm{CH}_{3} \mathrm{~N}_{2}$ for several hours. The NMR spectra of the product of the reaction were largely identical to those of $\mathbf{1 2 2}$ with the additional presence of an oxymethyl signal $\left(\mathrm{C}-20: \delta_{\mathrm{C}} 52.0, \delta_{\mathrm{H}} 3.68\right)$ and a slight upfield shift of C-1 to $\delta_{\mathrm{C}} 173.6$ consistent with the formation of a methyl ester. An HMBC correlation observed from $\mathrm{H}_{3}-20$ to $\mathrm{C}-1$ confirmed the structure as methylpetrosianoate (123). NMR data for $\mathbf{1 2 3}$ are presented in Table 4.4 .<smiles>CCC(=O)CCCCCC=CCCC=CC=CC(=O)CCC(=O)OC</smiles>

123

Table 4.4 ${ }^{13} \mathrm{C}(150 \mathrm{MHz})$ and ${ }^{1} \mathrm{H}(600 \mathrm{MHz}) \mathrm{NMR}$ data $\left(\mathrm{CDCl}_{3}\right)$ for methylpetrosianoate (123).

\begin{tabular}{|c|c|c|c|c|c|c|c|c|c|}
\hline \multirow[b]{2}{*}{ Position } & \multicolumn{3}{|c|}{${ }^{13} \mathrm{C}$} & \multicolumn{3}{|c|}{${ }^{1} \mathrm{H}$} & \multicolumn{3}{|c|}{ HMBC } \\
\hline & $\delta(\mathrm{ppm})$ & mult & ${ }^{1} J_{\mathrm{CH}}(\mathrm{Hz})$ & $\delta(\mathrm{ppm})$ & mult & $J(\mathrm{~Hz})$ & COSY & $\left({ }^{1} \mathrm{H}\right.$ to $\left.{ }^{13} \mathrm{C}\right)$ & NOE \\
\hline 1 & 173.6 & $\mathrm{~s}$ & & & & & & & \\
\hline 2 & 28.0 & $\mathrm{t}$ & 129 & 2.64 & $\mathrm{t}$ & 6.8 & 3 & $1,3,4$ & \\
\hline 3 & 34.9 & $\mathrm{t}$ & 126 & 2.90 & $\mathrm{t}$ & 6.8 & 2 & $1,2,4$ & 5,6 \\
\hline 4 & 198.5 & $\mathrm{~s}$ & & & & & & & \\
\hline 5 & 127.5 & $\mathrm{~d}$ & 157 & 6.10 & $\mathrm{~d}$ & 15.6 & 6 & $3,4,7$ & $3,7,8$ \\
\hline 6 & 143.7 & $\mathrm{~d}$ & 153 & 7.18 & $\mathrm{dd}$ & $15.6,9.8$ & $5,7,8$ & $4,7,8$ & $3,7,8$ \\
\hline 7 & 128.9 & $\mathrm{~d}$ & 157 & 6.18 & $\mathrm{~m}$ & & 6,9 & $5,6,8,9$ & 5,6 \\
\hline 8 & 146.3 & $\mathrm{~d}$ & 153 & 6.18 & $\mathrm{~m}$ & & 6,9 & $5,6,7,9$ & 5,6 \\
\hline 9 & 33.3 & $\mathrm{t}$ & 122 & 2.17 & $\mathrm{q}$ & 6.7 & $7,8,10$ & $7,8,10$ & 11 \\
\hline 10 & 28.8 & $\mathrm{t}$ & 134 & 1.42 & quin & 6.9 & 9,11 & $8,9,11$ & \\
\hline 11 & $29.5^{\dagger}$ & $\mathrm{t}$ & 117 & 1.27 & br s & & 10 & 9,10 & 9 \\
\hline 12 & $29.4^{\dagger}$ & $\mathrm{t}$ & 117 & 1.27 & br s & & & & \\
\hline 13 & $29.4^{\dagger}$ & $\mathrm{t}$ & 117 & 1.27 & br s & & & & \\
\hline 14 & $29.2^{\dagger}$ & $\mathrm{t}$ & 117 & 1.27 & br s & & 15 & 15,16 & 16 \\
\hline 15 & 24.0 & $\mathrm{t}$ & 122 & 1.56 & quin & 6.6 & 14,16 & $14,16,17$ & \\
\hline 16 & 42.6 & $\mathrm{t}$ & 124 & 2.39 & $\mathrm{t}$ & 7.5 & 15 & $14,15,17,18$ & 14 \\
\hline 17 & 212.2 & $\mathrm{~s}$ & & & & & & & \\
\hline 18 & 36.0 & $\mathrm{t}$ & 123 & 2.41 & $q$ & 7.4 & 19 & 17,19 & \\
\hline 19 & 8.0 & $\mathrm{q}$ & 127 & 1.05 & $\mathrm{t}$ & 7.3 & 18 & 17,18 & \\
\hline 20 & 52.0 & $\mathrm{q}$ & 148 & 3.68 & $\mathrm{~s}$ & & & 1 & \\
\hline
\end{tabular}

$\dagger$ Interchangeable assignments

\subsection{Summary}

To the best of our knowledge only two nonadecanoic acid derivatives, the incompletely characterised nonadecenoic acid (104) from Petrosia ficiformis and (Z)-nonadec-6-enoic acid (124) from Geodia gibberosa, ${ }^{129}$ have been reported from the marine environment 
making 122 an unusual natural product.<smiles>CCCC/C=C\CCCCC(=O)O</smiles>

124

The ${ }^{1} \mathrm{H}, \mathrm{COSY}$ and HSQC NMR spectra of petrosianoic acid contain all the interesting olefinic resonances which drew our attention in the original screen spectra. The intensity of the signals in the screen spectra imply that $\mathbf{1 2 2}$ exists in greater volumes than those isolated. A review of the spectra of fractions obtained throughout the isolation indicated that a quantity of $\mathbf{1 2 2}$ was present in the more polar $20 \%$ and $40 \% \mathrm{Me}_{2} \mathrm{CO}$ in $\mathrm{H}_{2} \mathrm{O}$ fractions. As enough petrosianoic acid was isolated for our purposes, these fractions were not purified any further. 


\section{Chapter 5}

\section{A Novel Polyacetylenic Nitrile and Other Constituents of the New Zealand Marine Sponge Dendrilla rosea}

\subsection{Dendrilla rosea}

As mentioned previously, the taxonomic classification of some sponges is still an area of dispute. The orders Dictyoceratida and Dendroceratida exemplify this conflict in part due to the lack of either siliceous or calcareous spicules to use as taxonomic markers. ${ }^{6}$ Many sponges in these orders have been repeatedly re-classified and appear in the literature under a number of pseudonyms. There are also reports of researchers incorrectly identifying a sponge specimen due to the similar morphology of many sponges in these orders. ${ }^{130}$ As a result the literature pertaining to these orders is difficult to follow. In this study, an extract of the New Zealand marine sponge Dendrilla rosea (Lendenfeld) (Figure 5.1, taxonomy see Table 5.1) was examined.

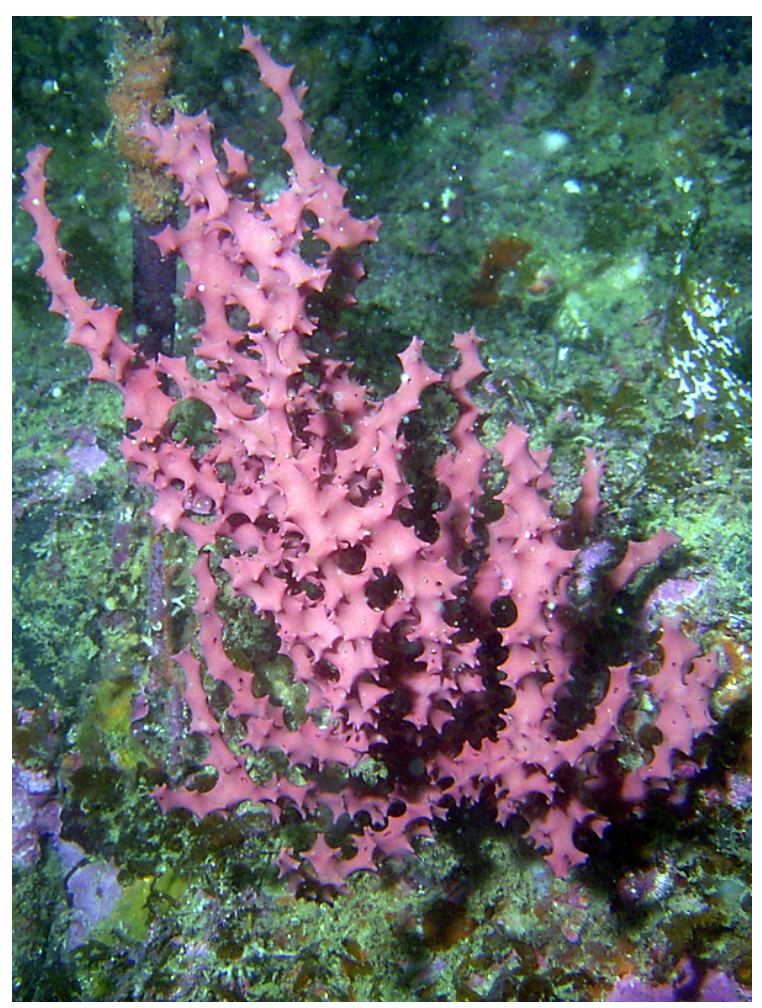

Figure 5.1 Dendrilla rosea. 
Table 5.1 Taxonomic classification of genus Dendrilla from order Dendroceratida as presented by Hooper and van Soest. ${ }^{5}$

\begin{tabular}{l|l|l}
\multirow{2}{*}{ Order } & Family & Genus \\
\hline \hline \multirow{4}{*}{ Dendroceratida } & \multirow{4}{*}{ Darwinellidae } & Aplysilla \\
\cline { 3 - 3 } & & Chelonaplysilla \\
\cline { 3 - 3 } & & Darwinella \\
\cline { 3 - 3 } & & Dendrilla \\
\cline { 2 - 3 } & Dictyodendrillidae & $\ldots$ \\
\hline
\end{tabular}

Dendrilla rosea is a large, erect, digitate sponge which grows up to $30 \mathrm{~cm}$ in height. It is coloured bright rose-pink throughout. ${ }^{5}$ While Dendrilla rosea is described as erect, all Dendroceratids at some stages of their life cycle will also appear in an encrusting form. ${ }^{5}$ Unfortunately, two other similar species, Aplysilla rosea (Barrois) and Darwinella gardineri (Topsent), are often mistaken for Dendrilla rosea ${ }^{130}$ Aplysilla rosea is a strictly encrusting sponge which occurs in a variety of colours including rose-pink. ${ }^{5}$ There is some doubt that the genus Aplysilla has ever been collected from New Zealand waters. ${ }^{130}$ Darwinella gardineri is also an encrusting sponge but it may form irregular upright lobes. Specimens are also a rose-pink colour throughout the tissue. ${ }^{130}$ The colours of Darwinella gardineri and Dendrilla rosea are almost identical but distinguishable. Other points of difference are that Dendrilla rosea is found at a slightly greater depth and generally grows taller than Darwinella gardineri. Differences in the fibre structure of the sponge material more distinctly identify the two species but are not useful for identifying specimens in the field. ${ }^{130}$

The only report of compounds specifically from Dendrilla rosea describes dendrillols- 1 to -4 (125-128) which were isolated in 1986 from collections of sponge material from near Leigh and the Poor Knights marine reserve off the north-east coast of New Zealand. ${ }^{131}$ These compounds were co-isolated with the known metabolites ambliofuran (129) $)^{132}$ and aplyroseols- 1 to -3 and -5 to $-7(\mathbf{1 3 0}-\mathbf{1 3 2}, \mathbf{1 3 4}-\mathbf{1 3 6}) .{ }^{133-135}$ The structure of dendrillol-1 was determined by X-ray analysis. ${ }^{131}$ Interestingly, the structure described for aplyroseol7 (136) in this report differed from the original structure which was reported from an Australian collection of Aplysilla rosea as 137. ${ }^{134}$ A further paper published a decade later reported the re-isolation of aplyroseol-7 from another Australian collection of Aplysilla rosea and confirmed the structure as $\mathbf{1 3 7}{ }^{136}$ It is probable that the Dendrilla rosea paper 
contained a typographical error although no mention of this is made in the later Aplysilla rosea report.

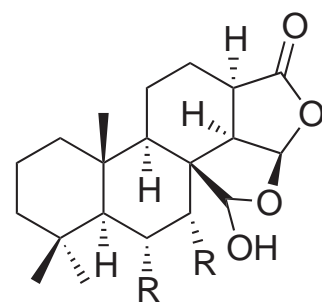

$125 \mathrm{R}=\mathrm{H}$

$126 \mathrm{R}=\mathrm{OAc}$

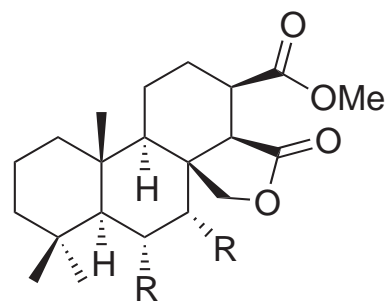

$127 \mathrm{R}=\mathrm{H}$

$128 \mathrm{R}=\mathrm{OH}$

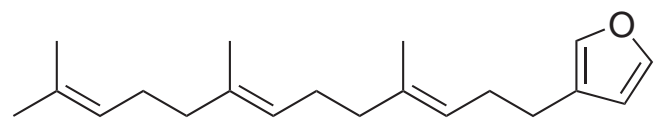

129

Three of the metabolites isolated from $D$. rosea have been synthesised along with two derivatives. In 1991 the stereoselective synthesis of (-)-dendrillol-1 (125) was performed. ${ }^{137,138}$ Shortly thereafter, the same group reported the stereoselective synthesis of aplyroseols-1 and -2 (130-131) alongside the derivative deacetylaplyroseol-2 (138) confirming the absolute configuration of $\mathbf{1 3 0}$ and 131. ${ }^{139}$ Strangely, four years later the absolute configuration of aplyroseol-1 (130) was again reported based on an Xray analysis. ${ }^{140}$ Finally, in 2002, the stereoselective synthesis of the derivative (-)acetyldendrillol-1 (139) was reported. ${ }^{141}$

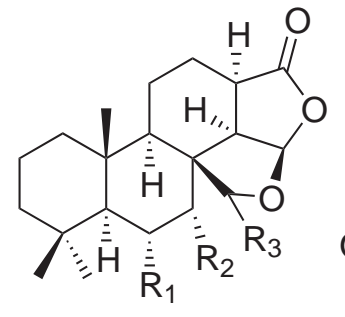

$130 \quad \mathrm{R}_{1}=\mathrm{H}$

$131 \mathrm{R}_{1}=\mathrm{H}$

$\mathrm{R}_{2}=\mathrm{OB}$

$132 \mathrm{R}_{1}=\mathrm{OH}$

$\mathrm{R}_{2}=\mathrm{OA}$

$\mathrm{R}_{2}=\mathrm{OBu}$

$133 \mathrm{R}_{1}=\mathrm{OAc}$

$\mathrm{R}_{2}=\mathrm{OBu}$

$\mathrm{R}_{2}=\mathrm{OB}$

$\mathrm{R}_{2}=\mathrm{OH}$

$\mathrm{R}_{2}=\mathrm{OAc}$
$\mathrm{R}_{2}=\mathrm{OH}$

$\mathrm{R}_{2}=\mathrm{H}$

$139 \mathrm{R}_{1}=\mathrm{H}$
$\mathrm{R}_{3}=\mathrm{OH}$<smiles>CCCC(=O)O</smiles>

$\mathrm{R}_{3}=\mathrm{OH}$

$\mathrm{R}_{3}=\mathrm{OH}$

$\mathrm{R}_{3}=\mathrm{OH}$

$\mathrm{R}_{3}=\mathrm{OH}$

$\mathrm{R}_{3}=\mathrm{OH}$

$\mathrm{R}_{3}=\mathrm{OH}$

$\mathrm{R}_{3}=\mathrm{OAc}$

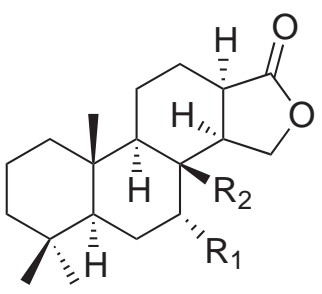

$136 \mathrm{R}_{1}=\mathrm{CH}_{2} \mathrm{OAc} \quad \mathrm{R}_{2}=\mathrm{H}$

$137 \mathrm{R}_{1}=\mathrm{OAc}$

$\mathrm{R}_{2}=\mathrm{CH}_{3}$

The aplyroseols and the dendrillols are spongian diterpenes derived from the basic spongian skeleton (140). Spongian and rearranged spongian diterpenes are an extensive class of secondary metabolites and a complete examination is beyond the scope of this 
report. A recent review describes over 150 spongian and related diterpenes isolated from marine sponges up to the end of 2004. ${ }^{142}$ Since that time only the new rearranged spongian diterpenes omriolides A and B (141-142) from Dictyodendrilla aff. retiara have been reported from marine sponges.

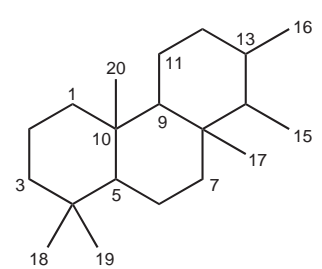

140

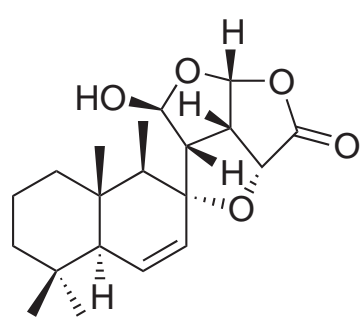

141

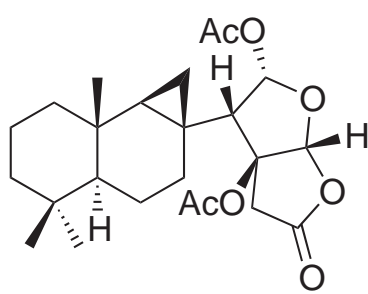

142

A total of 18 aplyroseols, four dendrillols and one related lactone have been isolated from a variety of sources. Aplyroseols-1 and -2 (130-131) were originally isolated in 1985 from Igernella notabilis collected from the U.S. Virgin Islands. ${ }^{133}$ Aplyroseols-1 and 2 were again reported as new compounds in 1986 when they were isolated alongside aplyroseols-3 to -7 (132-137) and a related lactone (143) from Aplysilla rosea collected from North Bondi, Sydney, Australia. ${ }^{134}$ Aplyroseol-3 (132) was concurrently reported from a separate Australian collection of Aplysilla sp. from Port Phillip Bay, Melbourne, Australia. ${ }^{135}$ The dendrillols-1 to $-4(\mathbf{1 2 5}-\mathbf{1 2 8})$ were then reported from the New Zealand collection of Dendrilla rosea. Finally, in 1997, aplyroseols-8 to -18 (144-154) were reported from a second collection of Aplysilla rosea from North Bondi. ${ }^{136}$ To complicate matters, this paper also states that they isolated the same lactone as reported in 1986 (143) from Aplysilla rosea, however, the structure is inexplicably assigned as the 17-des-acetyl derivative (155). Further, a recent stereoselective synthesis of aplyroseol-14 (150) led to a reassignment of the structure as the unusual $\delta$-lactone $156 .{ }^{141}$ The implications of this reassignment on the related structures 143/155 and 151-152 are unknown.

Biological testing has only been reported for four of these compounds. Aplyroseol1 (130) exhibited an $\mathrm{ED}_{50}$ of $6.5 \mu \mathrm{g} / \mathrm{mL}$ against in vitro lymphocytic leukæmia. ${ }^{133}$ Aplyroseol-2 (131) was cytotoxic to both murine lymphoma L1210 ( $\left.\mathrm{IC}_{50} 1.9 \mu \mathrm{g} / \mathrm{mL}\right)$ and human epidermoid carcinoma $\mathrm{KB}\left(\mathrm{IC}_{50} 2.5 \mu \mathrm{g} / \mathrm{mL}\right)$ cells but showed no significant anti-tumour activity against P388 in vivo. ${ }^{143}$ The synthetically prepared dendrillol-1 (125) which was determined to be active against HeLa (human cervix epitheloid carcinoma 


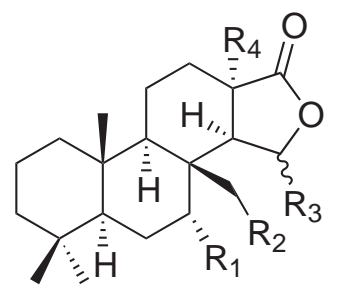

$143 \quad \mathrm{R}_{1}=\mathrm{OAc} \quad \mathrm{R}_{2}=\mathrm{OAc} \quad \mathrm{R}_{3}=\mathrm{H}$

$150 \mathrm{R}_{1}=\mathrm{H}$

$\mathrm{R}_{2}=\mathrm{OAc} \quad \mathrm{R}_{3}=\mathrm{H}$

$151 \mathrm{R}_{1}=\mathrm{OAc}$

$152 \mathrm{R}_{1}=\mathrm{OAc}$

$\mathrm{R}_{2}=\mathrm{H}$

$\mathrm{R}_{3}=\mathrm{OH}$

$\mathrm{R}_{3}=\mathrm{H}$

$\mathrm{R}_{2}=\mathrm{OAc}$

$\mathrm{R}_{3}=\mathrm{H}$
$\mathrm{R}_{2}=\mathrm{OH}$

$155 \mathrm{R}_{1}=\mathrm{OAc}$
$\mathrm{R}_{4}=\mathrm{H}$

$\mathrm{R}_{4}=\mathrm{H}$

$\mathrm{R}_{4}=\mathrm{H}$

$\mathrm{R}_{4}=\mathrm{OH}$

$\mathrm{R}_{4}=\mathrm{H}$

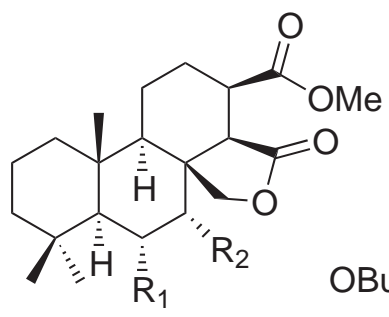

$144 \quad \mathrm{R}_{1}=\mathrm{H} \quad \mathrm{R}_{2}=\mathrm{OBu}$

$145 \mathrm{R}_{1}=\mathrm{OAc} \quad \mathrm{R}_{2}=\mathrm{H}$

$146 \quad \mathrm{R}_{1}=\mathrm{OBu} \quad \mathrm{R}_{2}=\mathrm{OH}$

$147 \quad \mathrm{R}_{1}=\mathrm{OBu} \quad \mathrm{R}_{2}=\mathrm{OAc}$

$148 \mathrm{R}_{1}=\mathrm{OAc} \quad \mathrm{R}_{2}=\mathrm{OBu}$

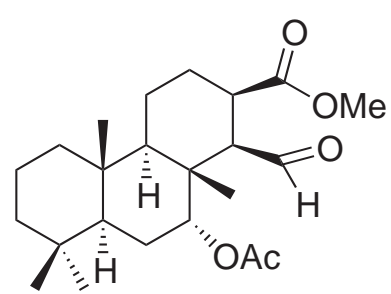

149

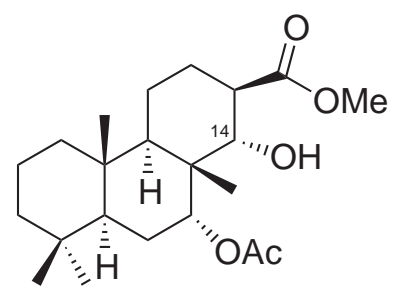

153

15414 epi

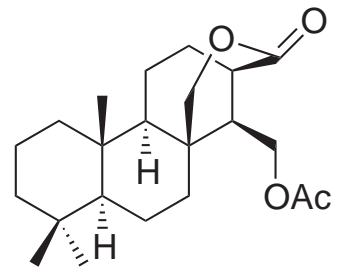

156 
cells), HEp-2 (human larynx carcinoma cells) and Cricetulus griseus Chinese hamster ovary cells with $50 \%$ toxic concentrations of $14.8,3.5$ and $5.1 \mu \mathrm{g} / \mathrm{mL}$ respectively. The derivative acetyldendrillol-1 (139) showed no significant activity in the same assays. ${ }^{144}$

In this study, a number of specimens of Dendrilla rosea were collected from the north-east coast of the North Island of New Zealand. The screen spectra of D. rosea (PTN2_50E) displayed a large number of very prominent signals which were attributed to acetal moieties, methoxy groups and a large number of alkyl methyls. The purification of the screen extract and two further bulk extracts of $D$. rosea by a series of reversedphase (HP20 or HP20SS resins) and normal-phase (DIOL or silica gel stationary phases) chromatographic separations ultimately led to the isolation of the known compounds dendrillol-1 (125), aplyroseol-6 (135) and the steroid 24-nor-5 $\alpha$-cholesta-7,22(E)-diene$3 \beta, 6 \alpha$-diol (157) which was originally isolated from the marine sponge Spongia gracilis in 1989. ${ }^{145}$ This is the first time either $\mathbf{1 3 5}$ or $\mathbf{1 5 7}$ have been isolated from D. rosea. An unusual polyacetylenic nitrile, here named dendronitrile (158), was also isolated. The structure elucidation of $\mathbf{1 5 8}$ will be discussed in detail. An overview of the isolation procedures for these four metabolites is presented in Scheme 5.1.

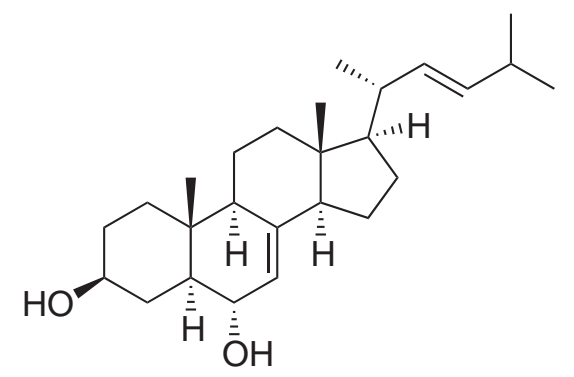

157

Our initial focus in this work with $D$. rosea was the isolation of new spongian-related diterpenes. Due to the large number of compounds known from D. rosea and the even larger pool of related compounds from related sponges, we investigated a new technique to identify unknown compounds in a complex mixture using HMBC spectra. Given that NMR data for all the aplyroseols and dendrillols were available in the literature we believed we would be able to identify and eliminate HMBC correlations which belonged to known compounds. This in turn would allow us to identify correlations which arose from new compounds in a spectrum of a mixture of these related compounds. Figure 5.2 depicts an HMBC spectrum of such a mixture with a selection of correlations attributed 

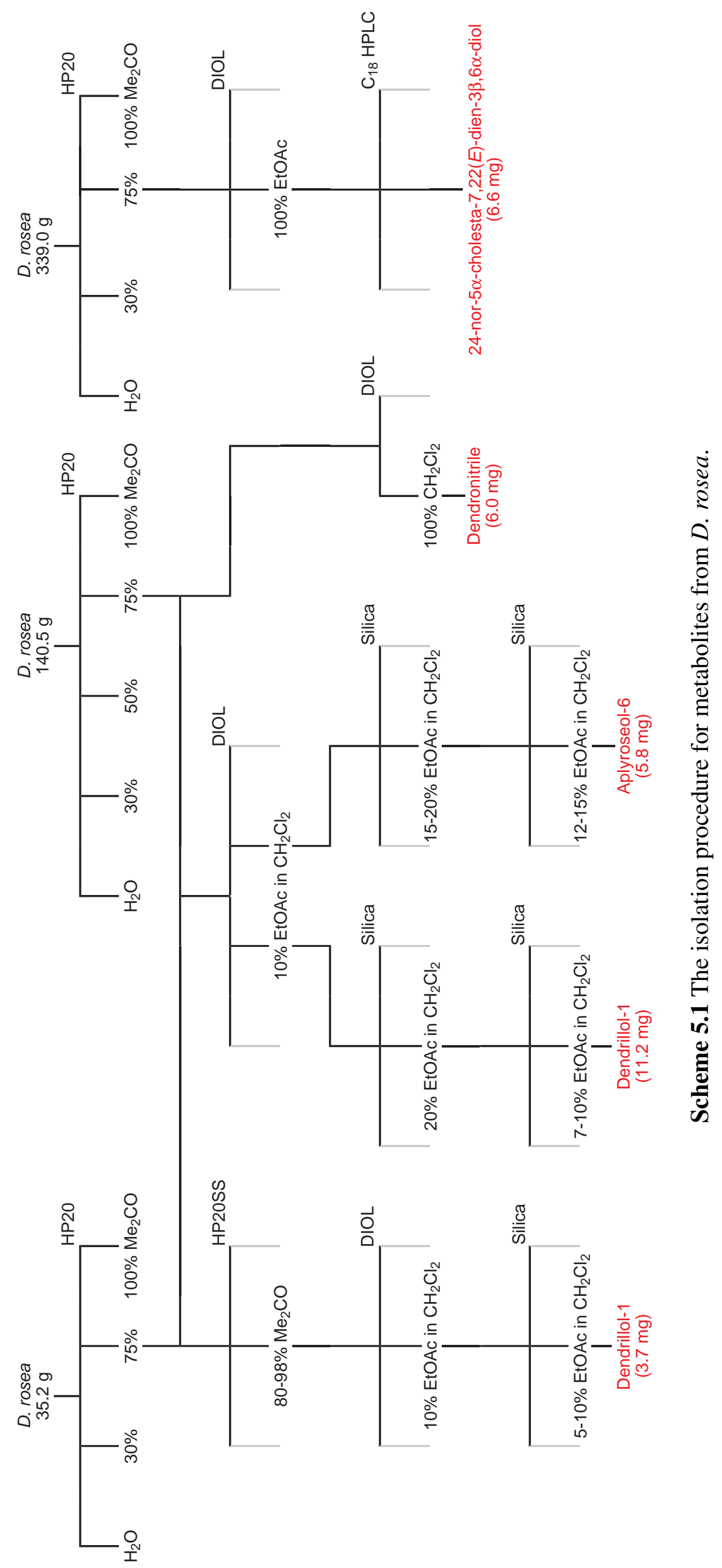


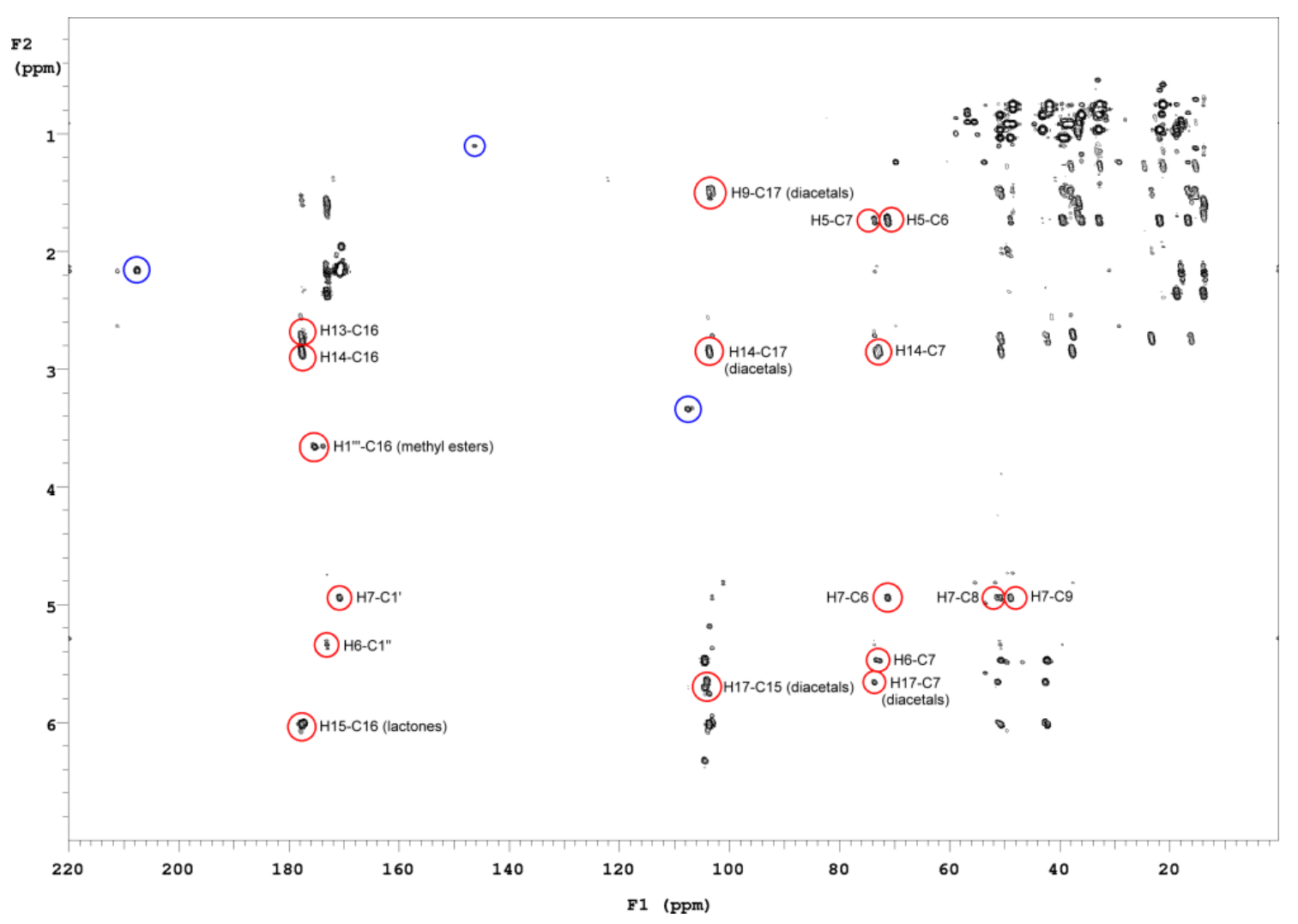

Figure 5.2 An HMBC spectrum of a complex mixture of spongian-type diterpenes.

to known spongian diterpenes labelled in red and three unidentified correlations labelled in blue.

Unfortunately, while we acquired a number of HMBC data sets and were able to identify a large number of correlations, we were hampered by the literature data which were available. A number of issues arose when we attempted to compile the literature data into a usable database of correlations. The first problem was that the data were reported in a number of different solvents. In and of itself this was not an insurmountable problem as the effect of a change in solvent on chemical shift is generally small and as the majority of the available data was presented in $\mathrm{CDCl}_{3}$, we elected to ignore the effect. The second issue was the resolution of the available data. In many cases, broad ranges of the ${ }^{1} \mathrm{H}$ spectrum were assigned as multiplets representing as many as 16 protons. This unfortunately limited the data we could reliably use to those signals which were readily identified and reported in each case. Broadly speaking and with a number of exceptions, this limited us to concentrating on the methyl resonances. Fortunately, there was no shortage of available methyl resonances (there are between three and six methyl groups on each of the known structures) and HMBC correlations from methyls are strong 
and reliable. However, analysis of the HMBC correlations of the singlet methyl groups associated with the highly conserved positions C-18, C-19 and C-20 led to the realisation that in some cases the literature assignments of positions C-5 and C-9 were incorrect. Finally, the report of the reassignment of the structure of aplyroseol-14 from $\mathbf{1 5 0}$ to $\mathbf{1 5 6}^{141}$ threw into doubt the reliability of a significant portion of the available NMR data. Ultimately, we were forced to abandon this approach. Nonetheless, we believe this technique may prove useful for the analysis of other mixtures of known and unknown compounds where the literature data are more reliable.

During the course of this work dendrillol-1 (125) and aplyroseol-6 (135) were purified and both were found to have incorrectly assigned NMR data. In order to clarify the literature, the reassigned NMR data are presented here. 


\subsection{Dendrillol-1}

The assignment of the ${ }^{1} \mathrm{H}$ and ${ }^{13} \mathrm{C}$ NMR spectra of dendrillol-1 (125) was published in 1986. ${ }^{131}$ Unfortunately, the available ${ }^{1} \mathrm{H}$ NMR data were very limited in resolution and few resonances were specifically assigned - one multiplet encompassed the resonances attributable to 16 protons $(\mathrm{H}-1 \alpha, \beta, \mathrm{H}-2 \alpha, \beta, \mathrm{H}-3 \alpha, \beta, \mathrm{H}-5, \mathrm{H}-6 \alpha, \beta, \mathrm{H}-7 \alpha, \beta, \mathrm{H}-9, \mathrm{H}-11 \alpha, \beta$ and $\mathrm{H}-12 \mathrm{a}, \mathrm{b})$. When 125 was synthesised, the assignment of the ${ }^{13} \mathrm{C}$ NMR data was revisited and the assignments of C-5, C-9, C-13 and C-14 were interchanged (although the paper reports that they interchanged the assignments of C-3, C-5, C-7 and C-9 which is incorrect). ${ }^{138}$ Unfortunately the proton assignments of these four methines were not corrected except by inference. Figure 5.3 shows the critical HMBC correlations used to correct the original spectral assignments. In order to clarify the literature, the complete spectral assignment of dendrillol-1 (125) is presented in Table 5.2.

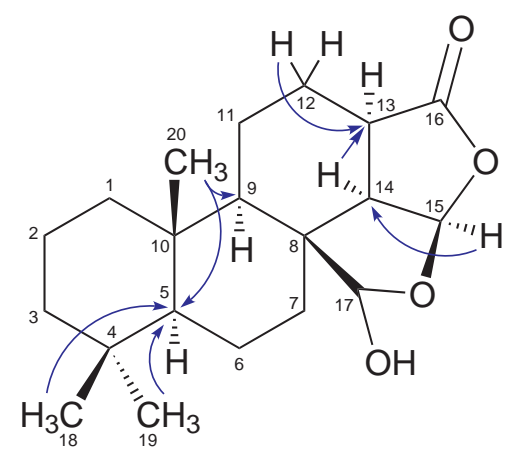

Figure 5.3 HMBC correlations used to correctly assign the chemical shifts of dendrillol-1 (125). 


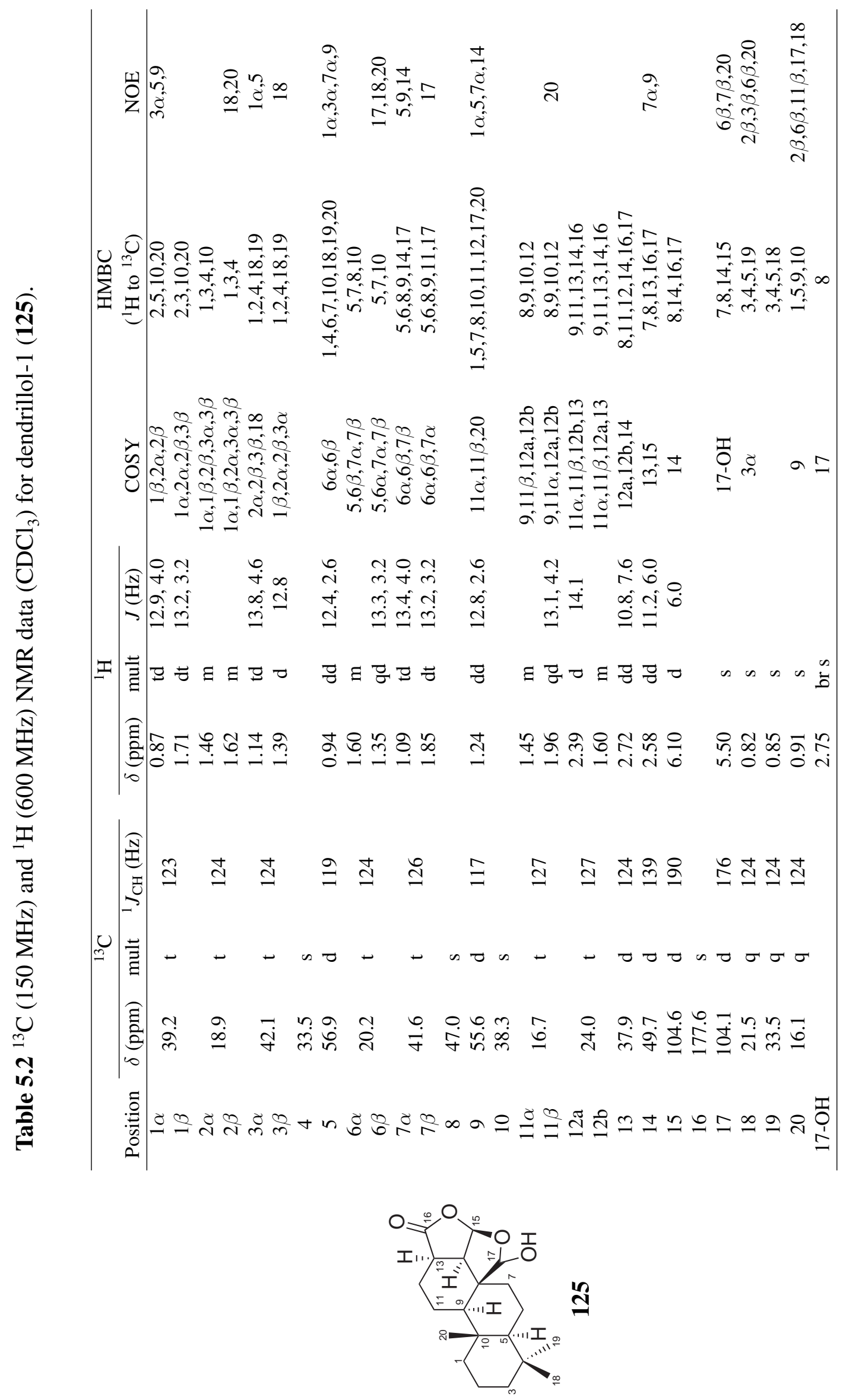




\subsection{Aplyroseol-6}

Aplyroseol-6 (135) was also reported with a complete assignment of the ${ }^{1} \mathrm{H}$ and ${ }^{13} \mathrm{C}$ NMR data. ${ }^{134}$ In this case, the ${ }^{1} \mathrm{H}$ spectrum afforded enough resolution to assign most of the resonances, however the assignment of H-9 was omitted in error. The assignment of the ${ }^{13} \mathrm{C}$ resonances is revisited here inverting both the assignments of methines $\mathrm{C}-5$ and $\mathrm{C}$ 9 and the assignments of methylenes $\mathrm{C}-2$ and C- $3^{\prime}$. The assignment of the ${ }^{1} \mathrm{H}$ shift of H-5 remains unchanged, $\mathrm{H}_{2}-2$ and $\mathrm{H}_{2}-3^{\prime}$ are now resolved and the chemical shift of $\mathrm{H}-9$ is now reported. Key HMBC correlations used to assign the relevant shifts are shown in Figure 5.4. The complete spectral assignment of aplyroseol-6 (135) is presented in Table 5.3.

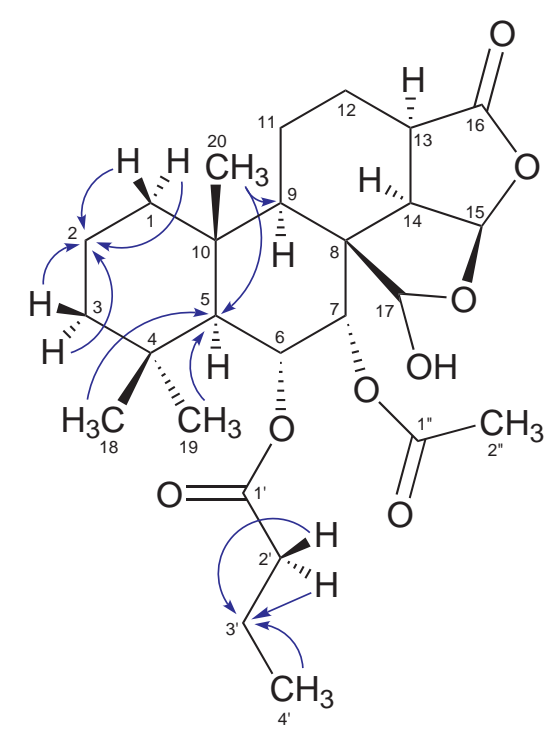

Figure 5.4 HMBC correlations used to correctly assign the chemical shifts of aplyroseol-6 (135). 


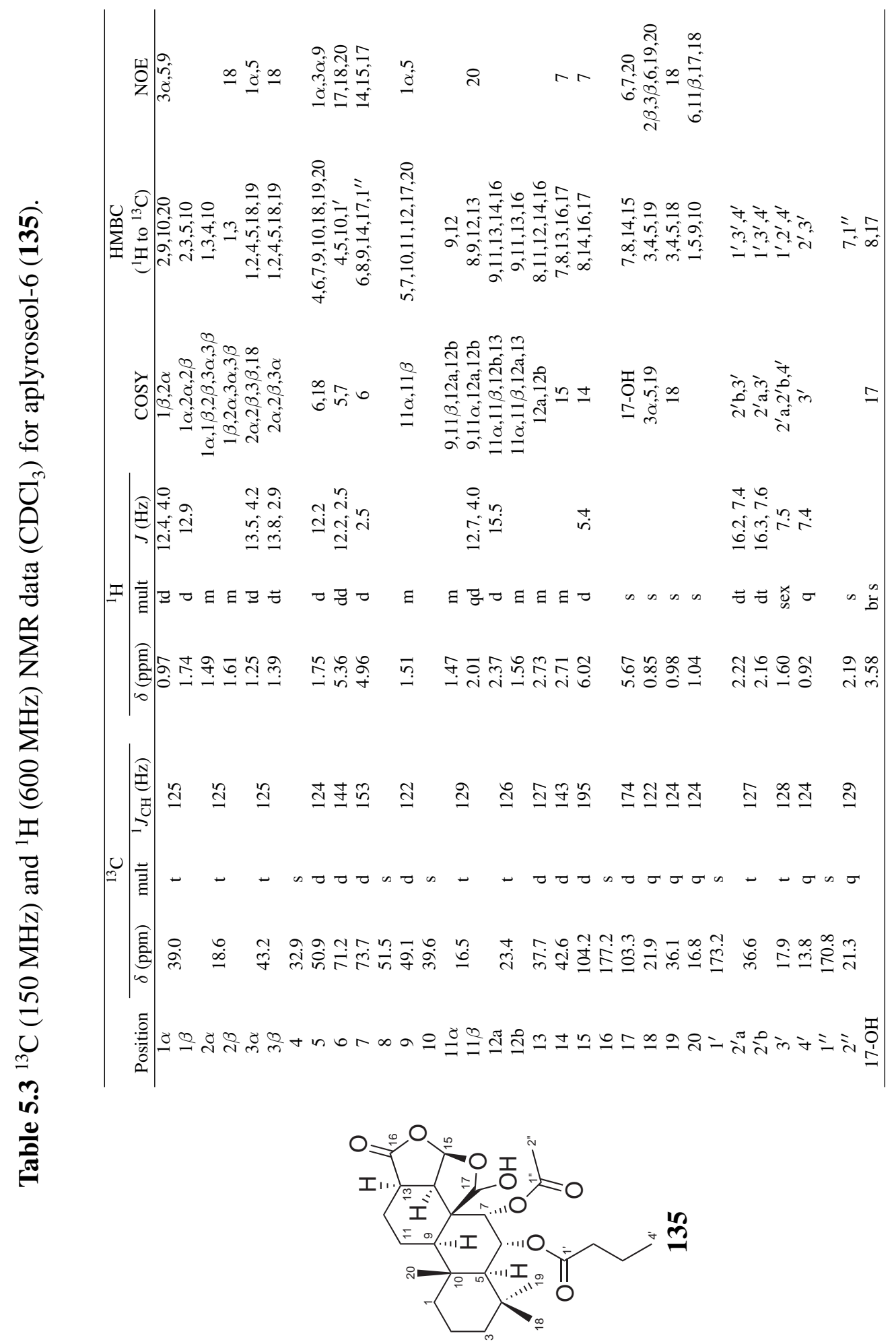




\subsection{Dendronitrile}

Dendronitrile (158) was isolated as an amorphous white solid in only two steps from the crude sponge extract. It is highly non-polar and was readily separated from other extractable components of the sponge on a normal-phase DIOL column. Despite repeated attempts in both positive and negative ion modes, no intelligible signal was observed by HRESIMS which presented an additional challenge in the structure elucidation of 158. Analysis of ${ }^{13} \mathrm{C}$ NMR data revealed the presence of 13 carbon resonances, three of which appeared to be olefinic, four in the acetylenic region, one attributable to a methyl and five in the methine/methylene region. Signals in the ${ }^{1} \mathrm{H}$ NMR spectrum included two olefinic resonances and a methyl triplet. In total, the ${ }^{1} \mathrm{H}$ spectrum integrated for 15 protons or some multiple thereof. A multiplicity edited HSQC experiment confirmed correlations between all observed proton resonances and carbon resonances indicating that all protons were attached to carbon. The HSQC experiment also suggested that five of the carbon resonances belonged to non-protonated carbons as no correlations to protons were observed. The chemical shifts of four of these non-protonated resonances were typical of acetylenic carbons $\left(\delta_{\mathrm{C}} 66.3,72.7,77.8\right.$ and 82.9). The fifth non-protonated resonance $\left(\delta_{\mathrm{C}} 119.5\right)$ seemed typical of an olefinic carbon. Two further olefinic methines were identified $\left(\delta_{\mathrm{C}} 149.9, \delta_{\mathrm{H}} 6.06\right.$ and $\left.\delta_{\mathrm{C}} 107.4, \delta_{\mathrm{H}} 5.44\right)$ but no further olefinic carbon could be identified to complete a second double bond. With most of the spectral elements identified, only one terminus of the molecule (a methyl triplet) had been accounted for.

The presence of four acetylenic carbon resonances directed us towards UV analysis as conjugated acetylenes are known to exhibit characteristic sharp UV spectra. The UV spectrum of 158 (Figure 5.5) shows a "chicken-foot" shape characteristic of a conjugated enediyne [ $\lambda_{\max } 212 \mathrm{~nm}(\epsilon$ 62800), $240 \mathrm{~nm}(\epsilon$ 9220), $254 \mathrm{~nm}(\epsilon 16400), 266 \mathrm{~nm}(\epsilon 23200)$, $282 \mathrm{~nm}(\epsilon 18700)]$ which compares well with the literature $\left[\lambda_{\max } 210 \mathrm{~nm}, 238 \mathrm{~nm}, 251 \mathrm{~nm}\right.$, $264 \mathrm{~nm}, 280 \mathrm{~nm}] .{ }^{146}$

Two substructures were constructed on the basis of the analysis of 2D NMR spectra of 158. The first of these, beginning from the methyl terminus, was constructed on the basis of a series of COSY correlations from the methyl triplet $\left(\mathrm{C}-14: \delta_{\mathrm{C}} 13.5, \delta_{\mathrm{H}} 1.02\right)$ to a 


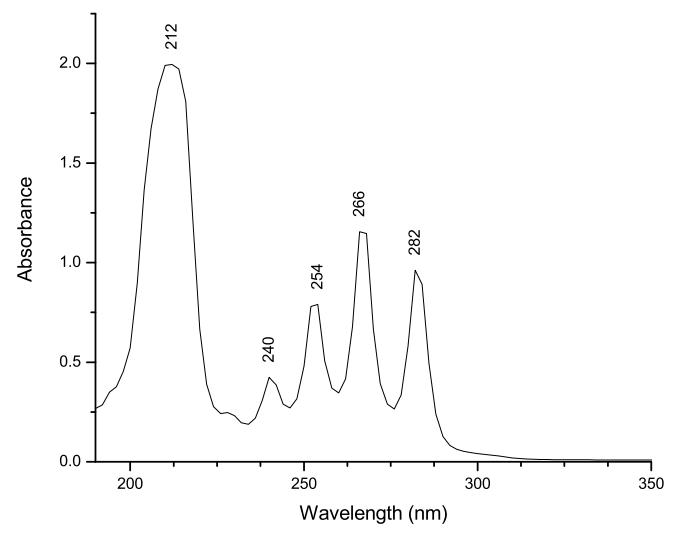

Figure 5.5 The UV spectrum of dendronitrile (158).

methylene $\left(\mathrm{C}-13: \delta_{\mathrm{C}} 24.3, \delta_{\mathrm{H}} 2.34\right)$ to an olefinic methine $\left(\mathrm{C}-12: \delta_{\mathrm{C}} 149.9, \delta_{\mathrm{H}} 6.06\right)$ to a second olefinic methine $\left(\mathrm{C}-11: \delta_{\mathrm{C}} 107.4, \delta_{\mathrm{H}} 5.44\right)$ (Figure 5.6, substructure A). The geometry of the double bond was determined to be $(Z)$ on the basis of the observed coupling constant between $\mathrm{H}-11$ and $\mathrm{H}-12(10.8 \mathrm{~Hz})$.

The second substructure, consisting of a chain of four methylenes, C-3 $\left(\delta_{\mathrm{C}} 16.9\right.$, $\left.\delta_{\mathrm{H}} 2.40\right), \mathrm{C}-4\left(\delta_{\mathrm{C}} 24.5, \delta_{\mathrm{H}} 1.82\right), \mathrm{C}-5\left(\delta_{\mathrm{C}} 27.1, \delta_{\mathrm{H}} 1.71\right)$ and C-6 ( $\left.\delta_{\mathrm{C}} 19.0, \delta_{\mathrm{H}} 2.42\right)$, was constructed through the observation of COSY correlations between their respective protons resonances (Figure 5.6, substructure B).

A<smiles>CC=CC(C)C</smiles>

B<smiles>CCCCC</smiles>

Figure 5.6 COSY correlations establishing the substructures of dendronitrile (158).

With these two substructures in hand, the only features not yet accounted for were the four acetylenic carbons and the one remaining apparently olefinic carbon. The observation of HMBC correlations from both $\mathrm{H}_{2}-3$ and $\mathrm{H}_{2}-4$ to the olefinic resonance indicated that $\mathrm{C}-2$ $\left(\delta_{\mathrm{C}} 119.5\right)$ was attached to $\mathrm{C}-3$. A series of $\mathrm{HMBC}$ correlations from $\mathrm{H}_{2}-6$ to all four acetylenic carbons and from $\mathrm{H}-11$ to two acetylenic carbons $\left(\delta_{\mathrm{C}} 66.3,77.8\right)$ indicated that the diyne system was situated between C-6 and C-11 connecting the substructures. The connection of the substructures through the diyne moiety is supported in part by the observation of a weak, long-range, seven-bond COSY correlation between $\mathrm{H}_{2}-6$ and $\mathrm{H}-11$. Long-range ${ }^{1} \mathrm{H}-{ }^{1} \mathrm{H}$ spin coupling of this nature has been observed in other 
enediyne systems. ${ }^{147}$ The order of the four acetylenic carbons was determined through the observation of further HMBC correlations. Methylene $\mathrm{H}_{2}-5$ showed a correlation to C-7 $\left(\delta_{\mathrm{C}} 82.9\right)$ indicating the attachment of C-7 to C-6. Similarly, $\mathrm{H}_{2}-13$ showed a correlation to $\mathrm{C}-10\left(\delta_{\mathrm{C}} 72.7\right)$ connecting $\mathrm{C}-10$ and $\mathrm{C}-11 . \mathrm{H}-11$ did not display an HMBC correlation to $\mathrm{C}-10$ but rather to both $\mathrm{C}-8\left(\delta_{\mathrm{C}} 66.3\right)$ and $\mathrm{C}-9\left(\delta_{\mathrm{C}} 77.8\right)$. The correlation to $\mathrm{C}-8$ was quite weak relative to C-9 and was used to determine the order of connectivity from C-7 to $\mathrm{C}-10$ (Figure 5.7).

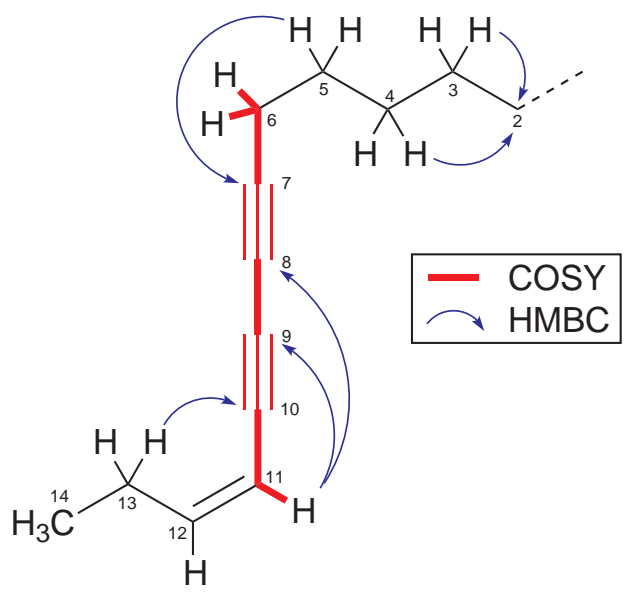

Figure 5.7 COSY and HMBC correlations extending the substructure of dendronitrile (158).

A comparison of the assigned ${ }^{13} \mathrm{C}$ chemical shifts for the enediyne system of $\mathbf{1 5 8}$ with those of other enediynes in the literature raised some confusion. A number of similar aliphatically substituted enediynes were examined and little or no consistency in the assignment of the acetylenic chemical shifts was observed. Table 5.4 shows the ${ }^{13} \mathrm{C}$ NMR data for the enediyne systems of dendronitrile and four further analogous compounds - (Z)-hexadec-11-en-7,9-diynoic acid (159), ${ }^{146}$ (9Z,17E)-18-bromooctadeca-9,17-diene5,7,15-triynoic acid (160), ${ }^{117}$ methyl $(9 E, 17 E)$-18-bromooctadeca-9,17-diene-5,7,15-triynoate (161) $)^{148}$ and carduusyne E ethyl ester (162). ${ }^{147}$ While these data are not consistent, we are confident in our assignment of the ${ }^{13} \mathrm{C}$ chemical shifts of the enediyne system of dendronitrile.

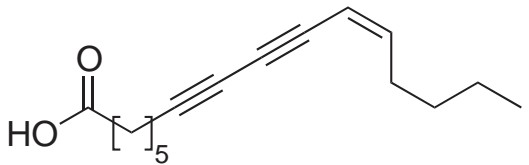

159

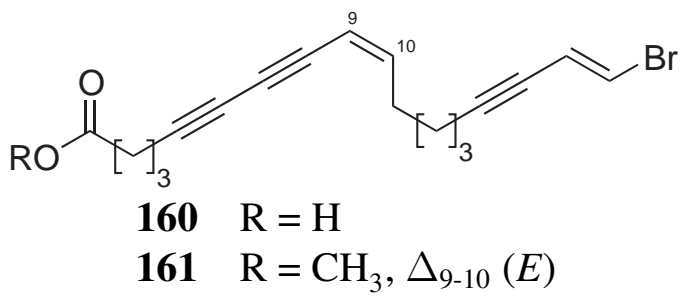




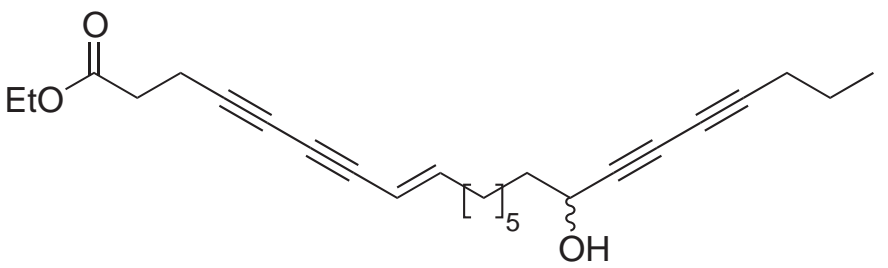

162

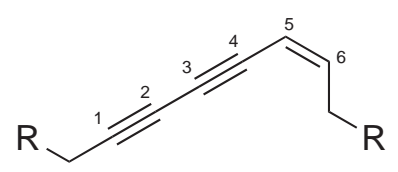

Table 5.4 ${ }^{13} \mathrm{C}$ NMR data for the enediyne systems of selected compounds.

\begin{tabular}{cccccc}
\hline Position & $\mathbf{1 5 8}$ & $\mathbf{1 5 9}$ & $\mathbf{1 6 0}$ & $\mathbf{1 6 1}$ & $\mathbf{1 6 2}$ \\
& $\delta_{\mathrm{C}}\left(\mathrm{CDCl}_{3}\right)$ & $\delta_{\mathrm{C}}\left(\mathrm{CDCl}_{3}\right)$ & $\delta_{\mathrm{C}}\left(\mathrm{CDCl}_{3}\right)$ & $\delta_{\mathrm{C}}\left(\mathrm{CDCl}_{3}\right)$ & $\delta_{\mathrm{C}}\left(\mathrm{C}_{6} \mathrm{D}_{6}\right)$ \\
\hline 1 & 82.9 & 65.5 & $\dagger$ & 82.8 & 81.0 \\
2 & 66.3 & $72.3^{\ddagger}$ & 72.3 & 67.1 & 65.9 \\
3 & 77.8 & $78.2^{\ddagger}$ & 66.2 & 74.7 & 72.5 \\
4 & 72.7 & 84.3 & 78.1 & 74.2 & 74.6 \\
5 & 107.4 & 108.1 & 108.5 & 109.5 & 108.5 \\
6 & 149.9 & 147.8 & 147.2 & 147.5 & 148.5 \\
\hline
\end{tabular}

$\dagger$ Not assigned. Believed to be beneath the $\mathrm{CDCl}_{3}$ signal at ca. $\delta_{\mathrm{C}} 77$. $\ddagger$ Interchangeable assignments.

At this stage the proposed structure accounted for all the elements of the NMR data. Without mass spectral data to give any clear indication of the molecular formula, three structures were proposed - two symmetrical tetra-substituted olefinic compounds, one halogenated with a $\mathrm{C}_{2}$ axis of symmetry, and one with a $\mathrm{C}_{4}$ axis of symmetry, or a nitrile with $\mathrm{C}_{1}$ symmetry (Figure 5.8).

The next recourse was to examine the IR spectrum of the compound. IR analysis of dendronitrile revealed a weak-to-moderate band absorbing at $2247 \mathrm{~cm}^{-1}$. Absorptions in

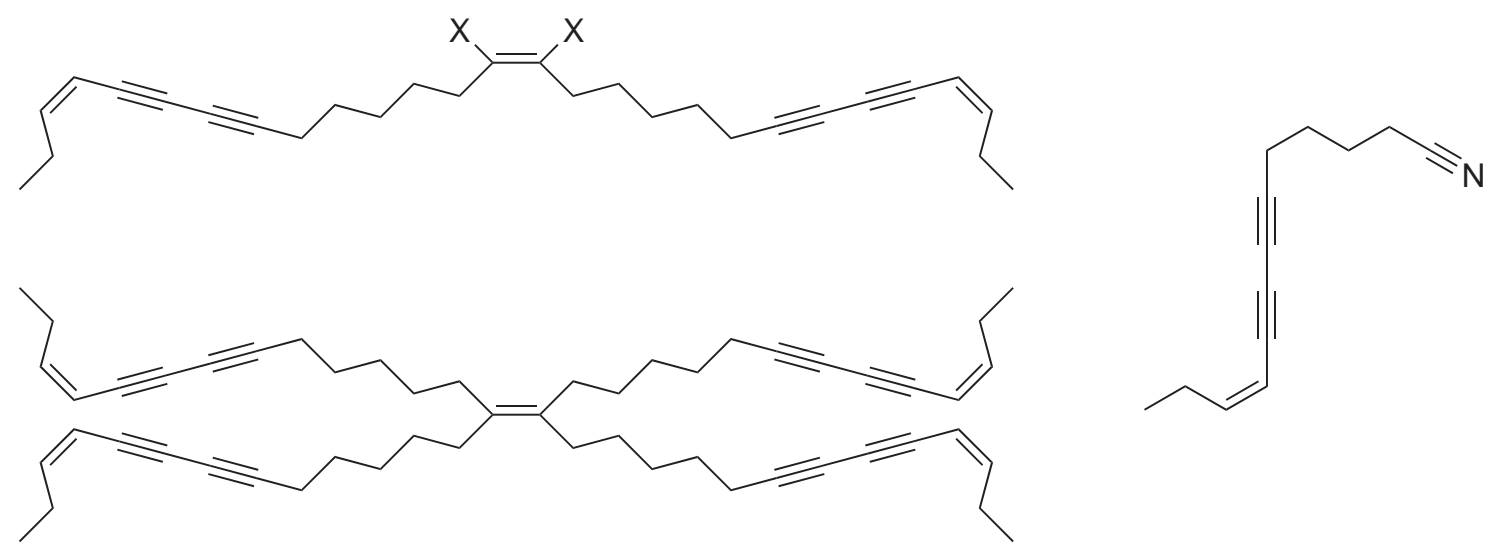

Figure 5.8 The proposed possible structures for dendronitrile. 
the region of the spectrum between 2000 and $2400 \mathrm{~cm}^{-1}$ are generally attributed to carbon dioxide (which was also observed at 2361-2342 $\mathrm{cm}^{-1}$ ), acetylenes and nitriles. ${ }^{149}$ The absorption band generated in an IR spectrum by acetylenes is caused by $\mathrm{C} \equiv \mathrm{C}$ stretching and is generally very weak in substituted alkynes. Conversely, the absorption band generated by the stretching of the $\mathrm{C} \equiv \mathrm{N}$ bond of nitriles is significantly stronger. ${ }^{149}$ In our case, the evidence was reasonably indicative of the presence of a nitrile moiety but given that there was no evidence of a separate weak acetylenic band, the possibility remained that the absorption at $2247 \mathrm{~cm}^{-1}$ was an abnormally strong acetylene band.

In Raman spectroscopy, selection rules are reversed relative to IR spectroscopy. Substituted acetylenic $\mathrm{C} \equiv \mathrm{C}$ stretching generates a moderately strong Raman band while the less symmetric $\mathrm{C} \equiv \mathrm{N}$ stretching is only weakly observed. Excitation of dendronitrile with a green laser $(514 \mathrm{~nm})$ produced a Raman spectrum with a moderate absorption band at $2241 \mathrm{~cm}^{-1}$ which was attributed to the acetylenic moieties.

Closer examination of both the Raman and the IR spectra led us to conclude that the structure of dendronitrile was in fact 158. The absorption band in the IR spectrum exhibited a small unresolved shoulder on the lower wavenumber side which was attributed to the weak acetylenic absorption (Figure 5.9). In counterpoint, a shoulder was also observed on the higher wavenumber side of the Raman band $\left(2263 \mathrm{~cm}^{-1}\right)$ which arose from the weak nitrile absorption (Figure 5.10). While neither method of analysis was enough to justify the assignment of the structure on its own, the combination of the two methods seemed justification enough to conclude that both nitrile and acetylene moieties were present.

With a putative structure of dendronitrile in hand, another attempt at obtaining a mass spectrum was made. Given the proposed presence of a nitrile moiety, a small amount of silver chloride was added to the sample for mass spectral analysis. Silver ions are well known for their affinity to $\pi$-systems ${ }^{150}$ and therefore the expectation arose that dendronitrile would complex with silver ions under MS electrospray ionisation conditions and produce $[\mathrm{M}+\mathrm{Ag}]^{+}$or $[2 \mathrm{M}+\mathrm{Ag}]^{+}$pseudomolecular ions.

When this analysis was performed a pseudomolecular ion cluster at $\mathrm{m} / \mathrm{z} 189$ and 191 


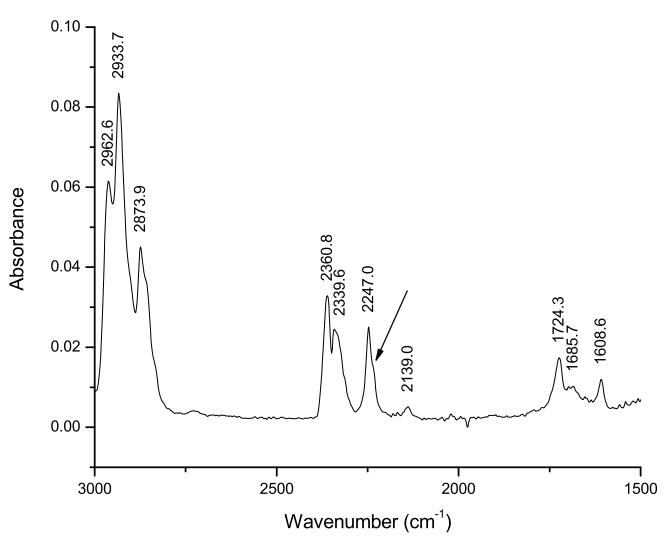

Figure 5.9 The IR spectrum of dendronitrile (158).

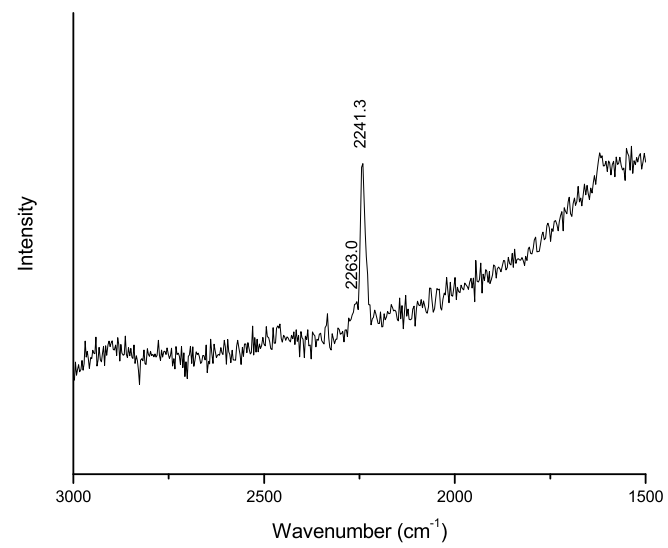

Figure 5.10 The Raman spectrum of dendronitrile (158).

was observed unexpectedly. This cluster was attributed to the pseudomolecular ion $\left[\mathrm{Ag}+\left(\mathrm{CH}_{3} \mathrm{CN}\right)_{2}\right]^{+}$which had arisen from complexation of the acetonitrile carrier solvent with the silver ions. At this stage it became apparent that the observation of a nitrile compound which was present in a relatively low concentration in a solvent consisting almost entirely of nitrile functions was highly unlikely! The carrier solvent was changed to methanol and the analysis of neat dendronitrile (no silver chloride) was performed. The observation of pseudomolecular ions at $m / z 203.1552\left[\mathrm{M}+\mathrm{NH}_{4}\right]^{+}\left(\mathrm{C}_{13} \mathrm{H}_{19} \mathrm{~N}_{2}^{+}\right.$requires 203.1543, $\Delta 4.5 \mathrm{ppm})$ and $m / z$ 208.1100 $[\mathrm{M}+\mathrm{Na}]^{+}\left(\mathrm{C}_{13} \mathrm{H}_{15} \mathrm{NNa}^{+}\right.$requires 208.1097, $\Delta$ $1.3 \mathrm{ppm}$ ) confirmed the molecular formula of dendronitrile (158) as $\mathrm{C}_{13} \mathrm{H}_{15} \mathrm{~N}$ consistent with the proposed structure.

Finally, when the instrumentation became available to acquire a ${ }^{15} \mathrm{~N}-\mathrm{HMBC}$ spectrum of dendronitrile, an $\mathrm{HMBC}$ correlation observed from $\mathrm{H}_{2}-3$ to $\mathrm{N}-1\left(\delta_{\mathrm{N}}-134.7\right)$ provided final confirmation of the structure. The observed chemical shift of N-1 is consistent with a nitrile moiety which typically occur between -110 and -140 ppm. ${ }^{13}$ Complete NMR data for $\mathbf{1 5 8}$ are presented in Table 5.5.

As discussed in Chapter 4, polyacetylenes are characteristic metabolites of the sponge order Haplosclerida. In fact, a series of polyacetylenes, carduusynes A-E (163-167), which were isolated from the axinellid sponge Phakellia carduus, ${ }^{147}$ comprise the only other reported incidence of polyacetylenes outside of Haplosclerida. The isolation of a polyacetylene from a Dendroceratid sponge is unprecedented. 


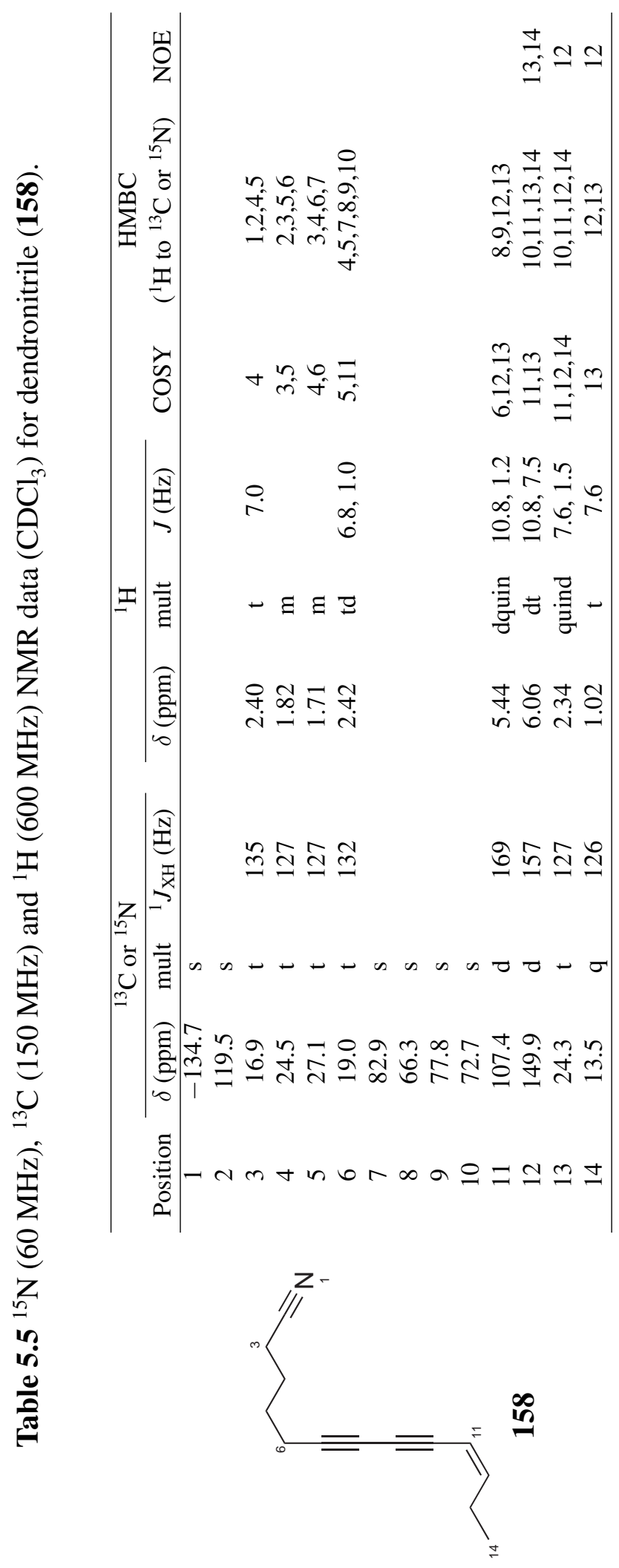


<smiles>CCCC#CCCCC/C=C/C=C\C#CCCC(=O)O</smiles>

163

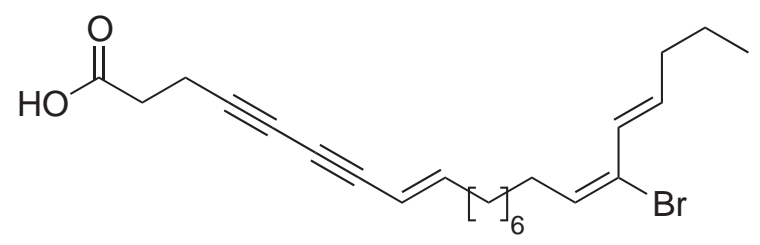

164
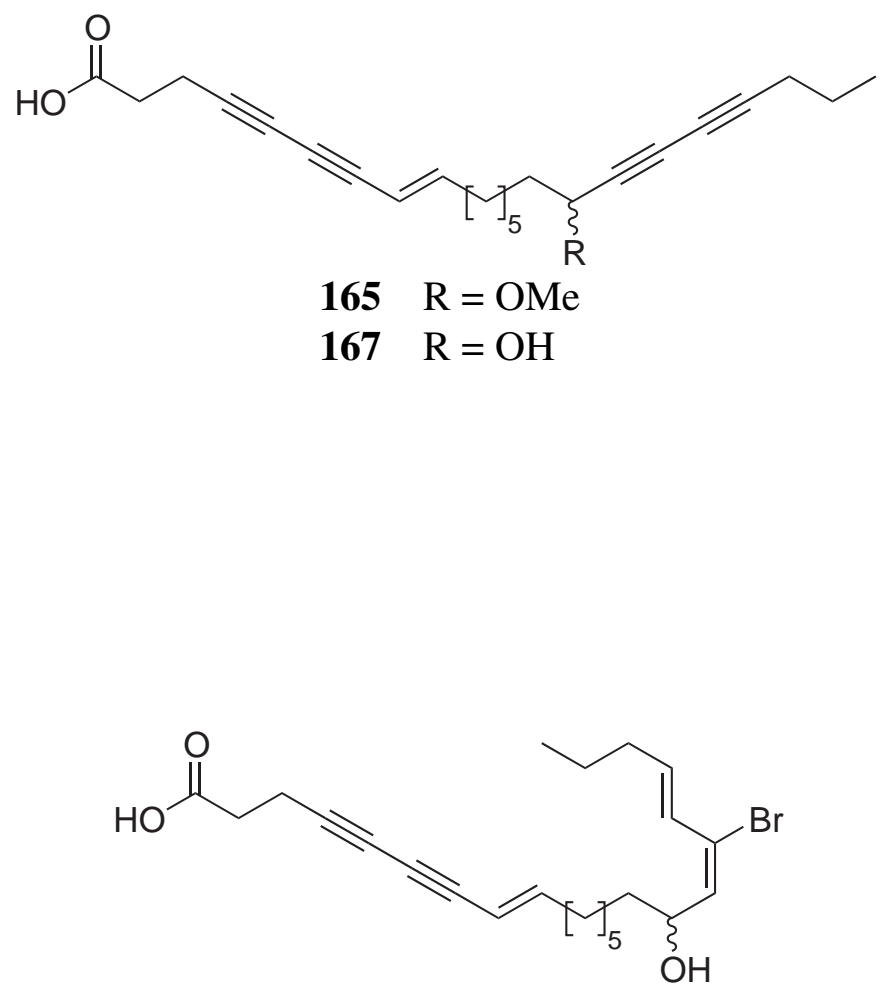

166 
Nitriles are reasonably uncommon in natural products and very much more so in sponges. Only some 50 nitrile-containing compounds have been reported from phylum Porifera and again, none from the Dendroceratid order. ${ }^{151}$

Dendronitrile (158) is exceptionally interesting as it contains both a conjugated enediyne moiety and a nitrile group. As far as we have been able to determine, only two acetylenic nitriles have ever been reported as natural products. The first was isolated in 1946 from the culture medium of the basidiomycete Tricholoma nudum (called nudic acid B) ${ }^{152}$ and again in 1952 from the fungus Clitocybe diatreta (called diatretyne-2). ${ }^{153}$ In 1955 the structure of each was determined to be $\mathbf{1 6 8},{ }^{154}$ at which stage the pseudonym nudic acid B was dropped. ${ }^{152}$ In 1974 another acetylenic nitrile (169) was co-isolated with 168 from the fungus Lepista glaucocana. ${ }^{155}$ In each case, the nitrile moiety is conjugated to the acetylene moieties. Thus, to the best of our knowledge, $\mathbf{1 5 8}$ is the only the third polyacetylenic nitrile ever reported and the only reported occurrence from a marine source. It is also the first example of a natural product with both nitrile and acetylene moieties which are not conjugated.

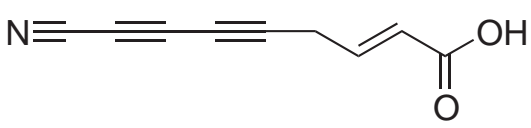

168

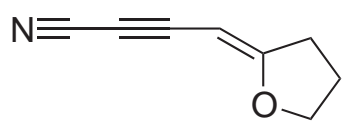

169

\subsection{Summary}

The novel natural product dendronitrile (158) was isolated from the New Zealand marine sponge Dendrilla rosea during the pursuit of new compounds believed primarily to belong to the spongian diterpene family. Unfortunately, no new spongian diterpenes were isolated as a result of this study, in part due to a lack of rigour in the literature. Reassigned NMR data for the previously reported compounds dendrillol-1 (125) and aplyroseol-6 (135) were presented here in an attempt to clarify existing reports.

A re-examination of the original screen spectra of Dendrilla rosea revealed that dendronitrile was in part evident in the crude extract. Most of the resonances of $\mathbf{1 5 8}$ were occluded by other signals, but the ${ }^{1} \mathrm{H}$ resonance of the olefinic methine at position 12 was 
evident in the screen ${ }^{1} \mathrm{H}$ spectrum. In addition, the HSQC spectrum of the screen also revealed the correlation for position 12 at $\delta_{\mathrm{C}} 149.9, \delta_{\mathrm{H}} 6.06$. Finally, an examination of the masked HSQC spectra of the screen of Dendrilla rosea revealed the same correlation at approximately $56 \times 149$ (see Figures 5.11, 3.12, 3.13 and 3.14). That this correlation was not masked out, and that it appears relatively stronger in the masked spectra than in the original screen HSQC, provides supporting evidence for the validity of the computerbased masking technique.

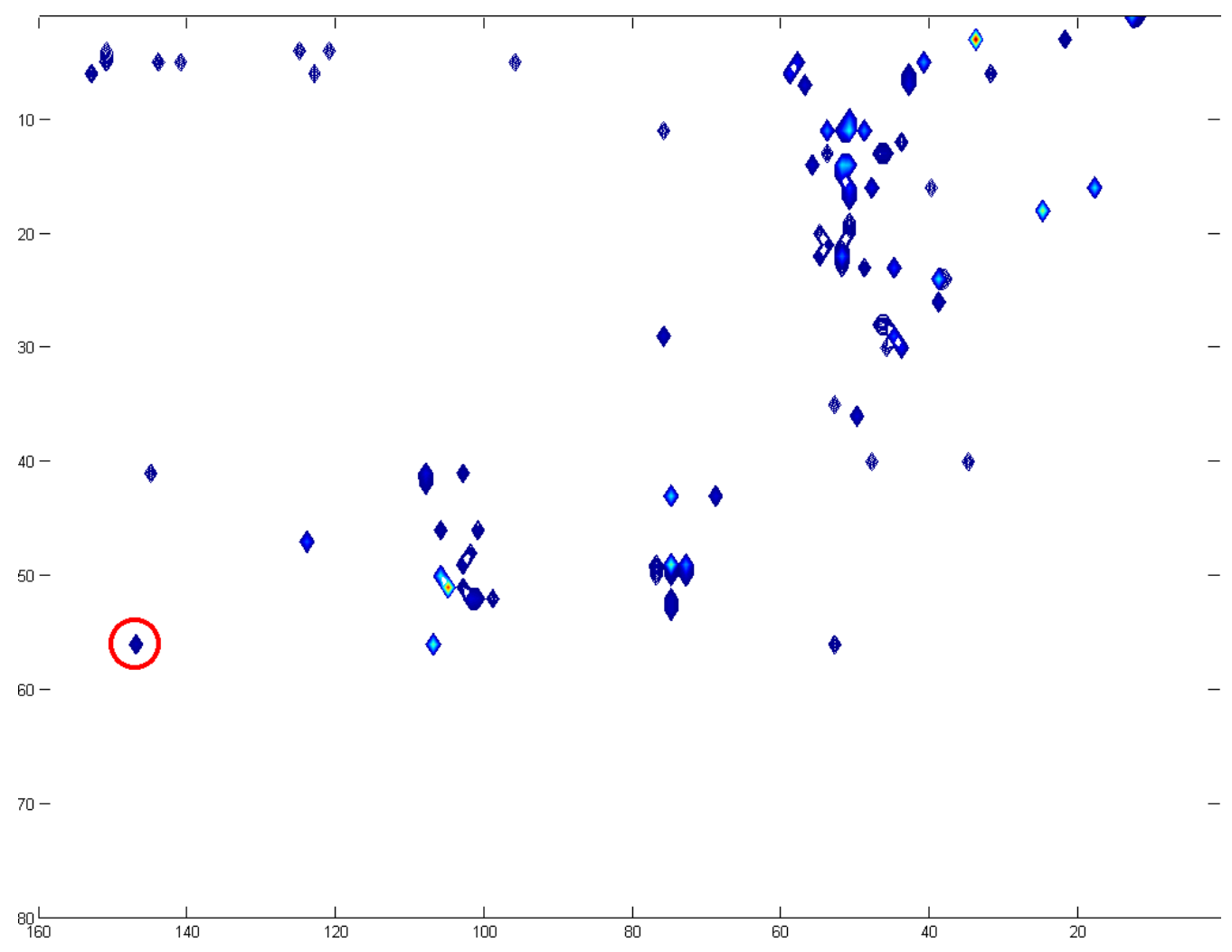

Figure 5.11 The combination amplitude-frequency-masked HSQC spectrum of the screen of Dendrilla rosea. 


\section{Chapter 6}

\section{New Lamellarins from the New Zealand Marine Sponge Dictyodendrilla dendyi}

\subsection{Dictyodendrilla dendyi}

A recent collection of the marine sponge Dictyodendrilla dendyi (Bergquist) (Figure 6.1, taxonomy see Table 6.1) collected near Cape Brett, off the north-east coast of the North Island of New Zealand, was examined in this study. D. dendyi is a very distinctive deep blue, almost black sponge with a soft reticulated fibrous skeleton. The spectra obtained from screening D. dendyi (PTN2_72C) with our standard protocol were immediately recognised as being exceptional on account of the presence of a large number of aromatic moieties with little or no aliphatic complement. Of particular note was the intensity of aromatic signals in the more polar $30 \%$ acetone in water fraction of the screen. Figure 6.2 shows the ${ }^{1} \mathrm{H}$ NMR spectra of the $30 \%$ and $75 \%$ acetone in water fractions of the screen of $D$. dendyi alongside the ${ }^{1} \mathrm{H}$ NMR spectra of the same fractions of the screen of sponge MNP993 (see Chapter 3). The spectra obtained from MNP993 would be considered more "typical" and serve to illustrate the remarkable nature of the $D$. dendyi screen.

There have been no compounds reported to date specifically from Dictyodendrilla dendyi.

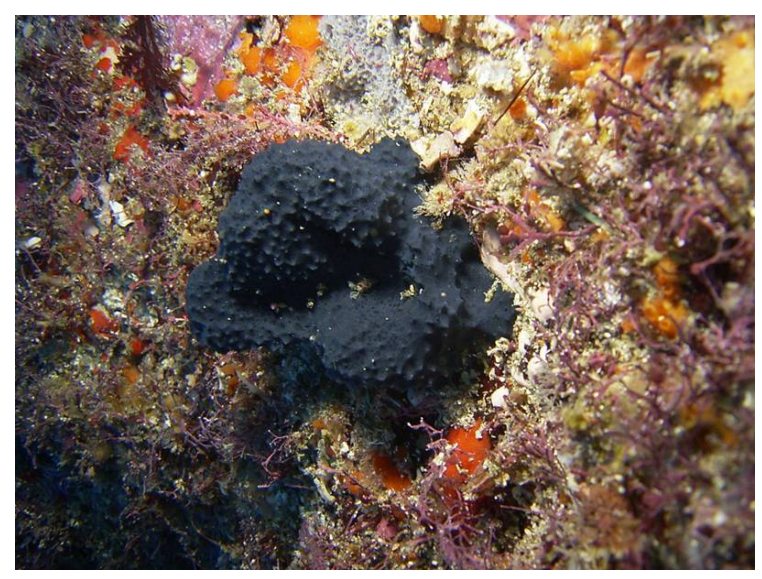

Figure 6.1 Dictyodendrilla dendyi. 
Table 6.1 Taxonomic classification of genus Dictyodendrilla from order Dendroceratida as presented by Hooper and van Soest. ${ }^{5}$

\begin{tabular}{l|l|l} 
Order & Family & Genus \\
\hline \hline \multirow{4}{*}{ Dendroceratida } & Darwinellidae & $\ldots$ \\
\cline { 2 - 3 } & \multirow{3}{*}{ Dictyodendrillidae } & Acanthodendrilla \\
\cline { 3 - 3 } & & Dictyodendrilla \\
\cline { 3 - 3 } & & Igernella \\
\cline { 3 - 3 } & & Spongionella \\
\hline
\end{tabular}

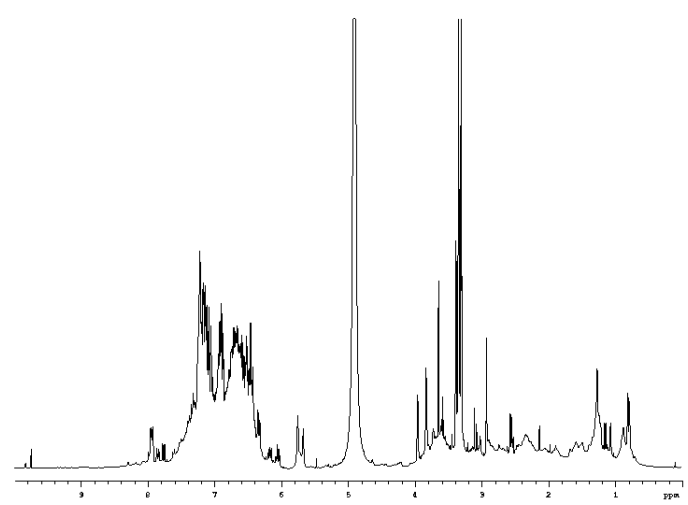

(a) D. dendyi (30\% acetone in water)

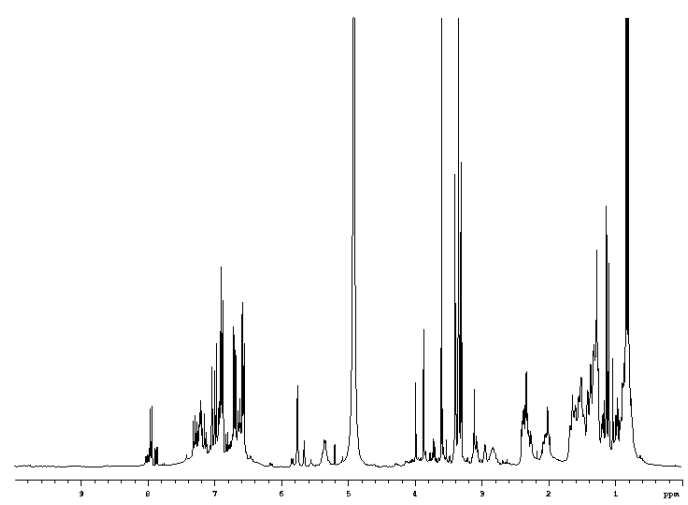

(c) D. dendyi ( $75 \%$ acetone in water)

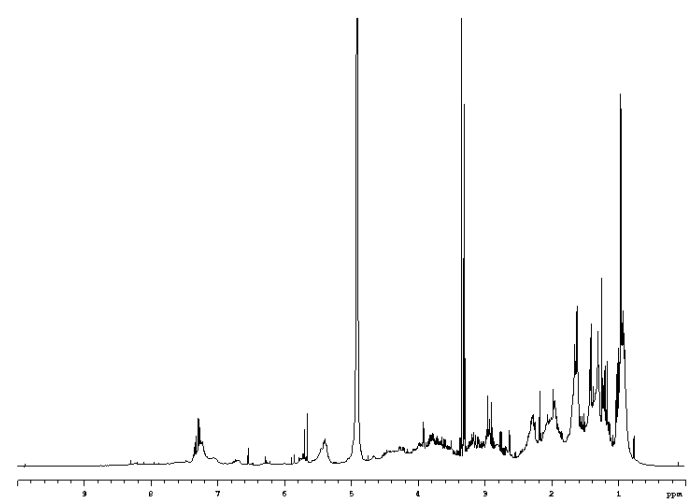

(b) MNP993 (30\% acetone in water)

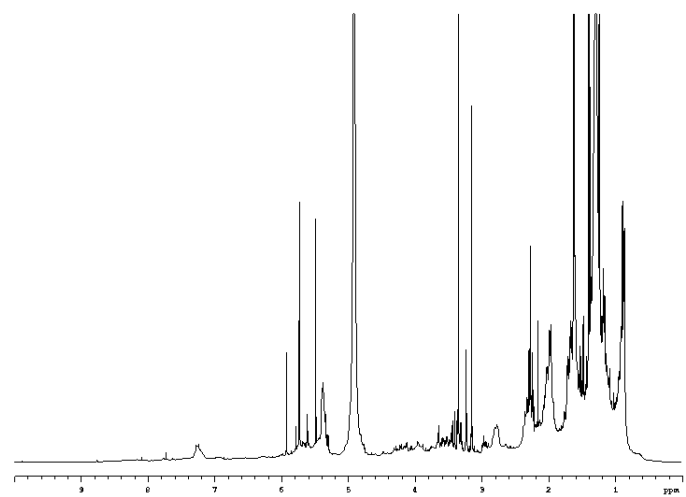

(d) MNP993 (75\% acetone in water)

Figure 6.2 ${ }^{1} \mathrm{H}$ NMR spectra of $D$. dendyi and MNP993 extracts. 
Natural products from the genus Dictyodendrilla are represented in only eight papers. In 1987 the furanosesquiterpene pallescensone (170) was reported as isolated from $D$. cavernosa. ${ }^{156}$ The same group published two further papers; one in 1988 detailing the isolation of a diterpene, dictyodendrillolide (171), from an unidentified Dictyodendrilla species ${ }^{157}$ and a second in 1990 reporting two additional diterpenes from D. cavernosa, namely spongian-16-one (172) and spongia-15,16-dione (173). ${ }^{158}$ In 1993 a Japanese group reported three aromatic alkaloid aldose reductase inhibitors 174-176 from an unidentified species of Dictyodendrilla. ${ }^{159}$ In 1995 three new oxygenated sesquiterpenes, dictyodendrillins A-C (177-179) were isolated from another unidentified species of Dictyodendrilla along with the known sesquiterpene dendrolasin (180), originally isolated from Spongia officinalis. ${ }^{160}$ More recently, five new alkaloids, dictyodendrins A-E (181185) and the two known aldose reductase inhibitors 174 and 176 (the latter as the sodium salt) were reported in 2003 isolated from D. verongiformis. ${ }^{161}$ In 2005 the isolation of the bisindole alkaloid dendridine A (186) was reported from an Okinawan collection of an unidentified species of Dictyodendrilla. ${ }^{162}$ Finally, also in 2005, the rearranged spongian diterpenes omriolide A (141) and B (142) were reported as isolated from a Kenyan collection of D. aff. retiara. ${ }^{163}$<smiles>C=C1CCCC(C)(C)C1CC(=O)c1ccoc1</smiles>

170

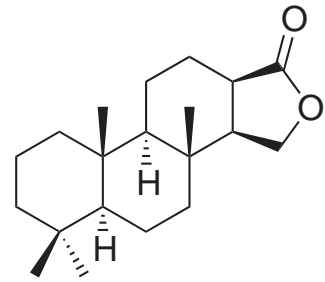

172<smiles>CC(=O)OC1C=C(CCC=C(C)CCC=C(C)CCC=C(C)C)C(=O)O1</smiles>

171

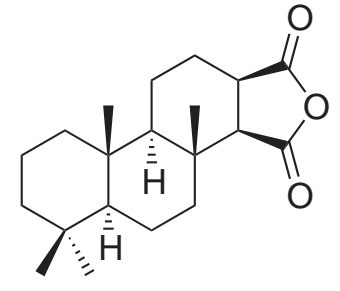

173

In this study, approximately $50 \mathrm{~g}$ of $D$. dendyi was initially extracted. Reversedphase column chromatography using HP20 and HP20S resins followed by normal-phase chromatography using DIOL resulted in the isolation of $4.2 \mathrm{mg}$ of a new compound belonging to the lamellarin family of alkaloids, here named lamellarin $\theta$ (187). The lamellarin family will be discussed in detail in Section 6.12. 
<smiles>COc1cccc2c3c([nH]c12)C(=O)C(c1ccc(O)cc1)=C1C3=C(c2ccc(O)cc2)C2(c3ccc(O)cc3)OC(=O)C2(OC(=O)CO)N1CCc1ccc(O)cc1</smiles>

$174 \mathrm{R}=\mathrm{SO}_{3} \mathrm{Na}$

$175 \mathrm{R}=\mathrm{SO}_{3} \mathrm{H}$<smiles>COC(=O)/C(c1ccc(O)cc1)=c1/c(-c2ccc(O)cc2)c2c(n1CCc1ccc(O)cc1)=C(c1ccc(O)cc1)C(=O)c1[nH]c3c(OC(C)C)cccc3c1-2</smiles>

176<smiles>CC(C)=CCC/C(C)=C/CCC1C(=O)OC2OC21</smiles>

177<smiles>CC(C)=CCC/C(C)=C/CCC1=CC(=O)O[C@H]1O</smiles>

178<smiles>CC(C)=CCC/C(C)=C/CCC1CC(O)OC1=O</smiles>

179<smiles>CC(C)=CCC/C(C)=C/CCc1ccoc1</smiles>

180<smiles>COC(=O)C(c1ccc(O)cc1)c1c(-c2ccc(O)cc2)c2c3c([nH]c4c(OS(C)(=O)=O)cccc43)c(O)c(-c3ccc(O)cc3)c2n1CCc1ccc(O)cc1</smiles>

181<smiles>CS(=O)(=O)Oc1cccc2c1[nH]c1c(O)c(-c3ccc(O)cc3)c3c(c(-c4ccc(O)cc4)c(C(=O)c4ccc(O)cc4)n3CCc3ccc(O)cc3)c12</smiles>

182<smiles></smiles>

$183 \mathrm{R}=\mathrm{H}$

$184 \mathrm{R}=\mathrm{SO}_{3} \mathrm{Na}$<smiles>CS(=O)(=O)Oc1cccc2c3c([nH]c12)C(=O)C(c1ccc(O)cc1)=c1c-3c(-c2ccc(O)cc2)c(=Cc2ccc(O)cc2)n1CCc1ccc(O)cc1</smiles>

185 
<smiles>NCCc1c[nH]c2c(O)cc(Br)c(-c3c(Br)cc(O)c4[nH]cc(CCN)c34)c12</smiles>

186

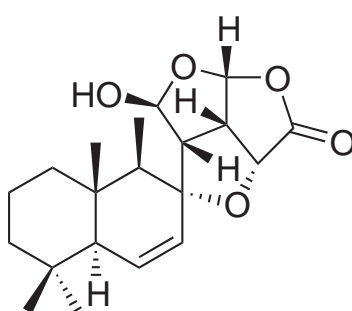

141

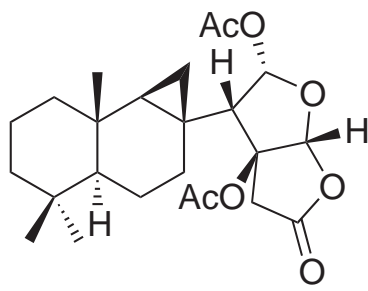

142

Following this initial success, a large-scale extraction of approximately $650 \mathrm{~g}$ of $D$. dendyi was performed. During purification of this bulk extract, side fractions of the original extract were integrated as appropriate. A combination of bench-top reversedphase (HP20) and normal-phase (DIOL) chromatography with final purification by HPLC $\left(\mathrm{C}_{18}\right)$ resulted in the isolation of a second new lamellarin, lamellarin $\kappa(\mathbf{1 8 8})$, one previously reported lamellarin, lamellarin $\mathrm{O}(\mathbf{1 8 9}),{ }^{164}$ five new sulfated lamellarin derivatives, lamellarin $\theta 4^{\prime \prime}, 4^{\prime \prime \prime}$-disulfate (190), lamellarin $\mathrm{O} 4^{\prime \prime}$-sulfate (191) and $4^{\prime \prime}, 4^{\prime \prime \prime}$ disulfate (192) and lamellarin $\kappa 4^{\prime \prime}$-sulfate (193) and $4^{\prime \prime}, 4^{\prime \prime \prime}$-disulfate (194), the known compounds dictyodendrins $\mathrm{C}(\mathbf{1 8 3})$ and D (184) and one compound previously only reported as the hydrolysis product of the naturally occurring dictyodendrins, ${ }^{161}$ here named dictyodendrin F (195). The polar nature of the sulfated dictyodendrin (183184) and lamellarin (190-194) derivatives necessitated the use of a source of $\mathrm{Na}^{+}$ions during HPLC chromatography to improve resolution. Either $\mathrm{NaCl}$ or a $\mathrm{NaOAc}$ buffer $\mathrm{pH}$ adjusted to 7.0 was employed to facilitate this. Desalting of subsequent fractions was achieved by cyclic loading, eluting any salts with several column-volumes of water, then elution of the column with an organic solvent (generally $\mathrm{MeOH}$ ). 


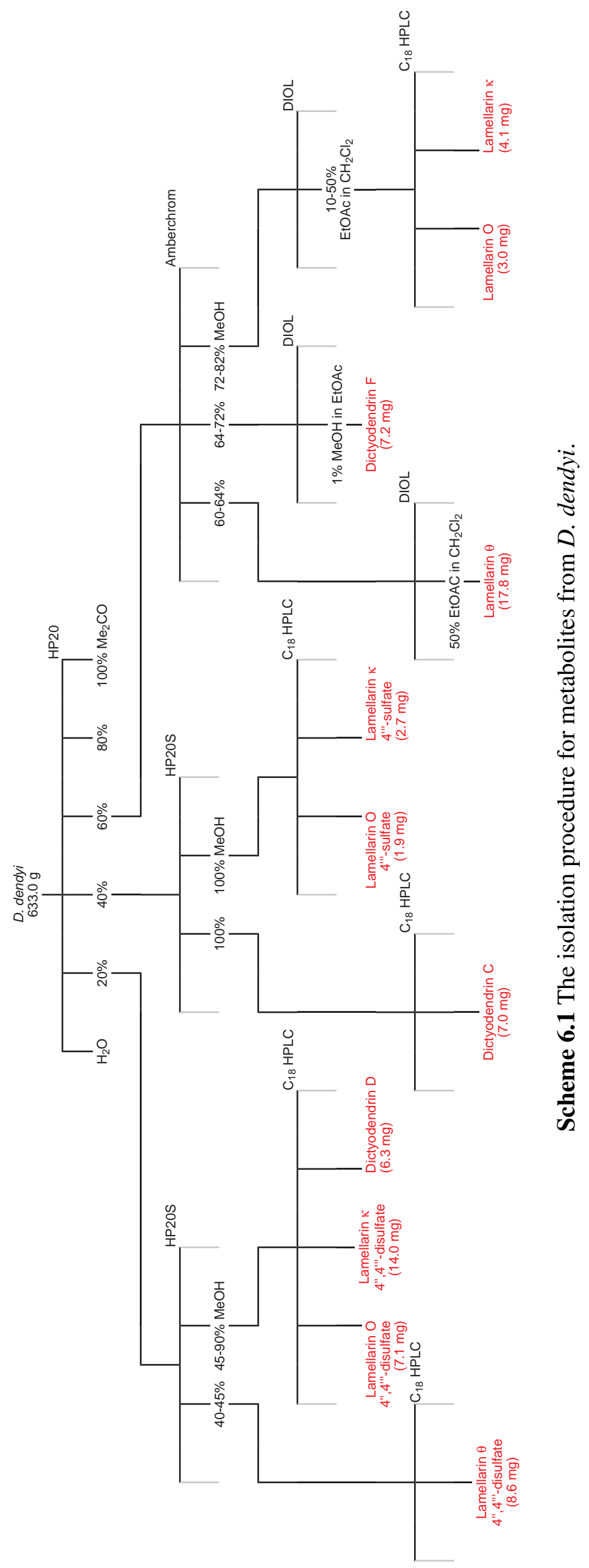




\subsection{Lamellarin $\theta$}

Negative-ion mode HRESIMS analysis of lamellarin $\theta(\mathbf{1 8 7})$ gave rise to a single pseudomolecular ion indicative of a molecular formula of $\mathrm{C}_{26} \mathrm{H}_{21} \mathrm{NO}_{6}\left(442.1272[\mathrm{M}-\mathrm{H}]^{-}\right.$, $\Delta 2.9 \mathrm{ppm})$. The ${ }^{1} \mathrm{H}$ NMR spectrum of $\mathbf{1 8 7}$ in $\mathrm{CD}_{3} \mathrm{OD}$ accounted for only 18 protons indicating the likely presence of three exchangeable protons. This was confirmed by the observation of 21 protons when the ${ }^{1} \mathrm{H}$ spectrum was recorded in $\mathrm{d}_{6}$-DMSO. The integration ratios of the observed signals indicated the presence of symmetry in the molecule assigned to three 1,4-disubstituted benzene rings. The ${ }^{13} \mathrm{C}$ NMR spectrum supported this hypothesis with evidence for only 20 distinct carbon resonances. A multiplicity-edited HSQC spectrum indicated that all 18 non-exchangeable protons were attached to carbons. The proposed molecular formula corresponds to a structure containing 17 double bond equivalents. The presence of three benzene rings account for 12 equivalents and a $13^{\text {th }}$ is indicated by the presence of a ketone resonance in the ${ }^{13} \mathrm{C}$ NMR spectrum $\left(\delta_{\mathrm{C}}\right.$ 194.8). Other significant moieties include an oxymethyl group $\left(\delta_{\mathrm{C}} 51.0, \delta_{\mathrm{H}} 3.41\right)$, an aromatic or olefinic methine $\left(\delta_{\mathrm{C}} 128.7, \delta_{\mathrm{H}} 7.08\right)$ and a strongly deshielded methylene $\left(\delta_{\mathrm{C}} 56.7, \delta_{\mathrm{H}} 5.81\right)$.

Analysis of the COSY and HMBC spectra of $\mathbf{1 8 7}$ led to the construction of three paradisubstituted benzene substructures. COSY correlations from an aromatic methine (C$\left.2^{\prime}\left[6^{\prime}\right]: \delta_{\mathrm{C}} 131.8, \delta_{\mathrm{H}} 7.98\right)$ to a second aromatic methine $\left(\mathrm{C}-3^{\prime}\left[5^{\prime}\right]: \delta_{\mathrm{C}} 116.5, \delta_{\mathrm{H}} 6.90\right)$, each of which integrated in the ${ }^{1} \mathrm{H}$ spectrum for two proton equivalents, established one 1,4disubstituted benzene ring. HMBC correlations from $\mathrm{H}-2^{\prime}\left[6^{\prime}\right]$ to a non-protonated carbon $\left(\mathrm{C}-4^{\prime}: \delta_{\mathrm{C}} 164.3\right)$ and $\mathrm{H}-3^{\prime}\left[5^{\prime}\right]$ to a further non-protonated carbon $\left(\mathrm{C}-1^{\prime}: \delta_{\mathrm{C}} 128.1\right)$ assigned the remaining two carbons in the ring. The strongly deshielded nature of C- $4^{\prime}$ is consistent with oxygen attachment at this position. This is supported by the relatively shielded nature of both the proton and carbon resonances of position $3^{\prime}\left[5^{\prime}\right]$. An HMBC correlation from the resonances of protons $\mathrm{H}-2^{\prime}\left[6^{\prime}\right]$ to the carbonyl $\left(\mathrm{C}-7: \delta_{\mathrm{C}} 194.8\right)$ indicated the attachment of the carbonyl to C-1'. The relatively deshielded chemical shift observed for $\mathrm{H}-2^{\prime}\left[6^{\prime}\right]$ is consistent with this assignment. Finally, an HMBC correlation from methylene protons $\mathrm{H}_{2}-6\left(\delta_{\mathrm{C}} 56.7, \delta_{\mathrm{H}} 5.81\right)$ to $\mathrm{C}-1^{\prime}$ established the position of the methylene adjacent 
to the carbonyl (Figure 6.3, substructure A). This assignment partially accounts for the deshielded nature of C-6 although the observed ${ }^{1} \mathrm{H}$ and ${ }^{13} \mathrm{C}$ shifts could not be entirely explained on this basis.

The remaining two benzene substructures were identified in a similar fashion. The first was constructed from the observation of COSY correlations between aromatic methines $\mathrm{C}-2^{\prime \prime}\left[6^{\prime \prime}\right]\left(\delta_{\mathrm{C}} 130.4, \delta_{\mathrm{H}} 6.91\right)$ and $\mathrm{C}-3^{\prime \prime}\left[5^{\prime \prime}\right]\left(\delta_{\mathrm{C}} 115.8, \delta_{\mathrm{H}} 6.58\right)$ establishing a second 1,4disubstituted benzene ring. HMBC correlations from $\mathrm{H}-2^{\prime \prime}\left[6^{\prime \prime}\right]$ to non-protonated carbon C-4" $\left(\delta_{\mathrm{C}} 156.6\right)$ and from $\mathrm{H}-3^{\prime \prime}\left[5^{\prime \prime}\right]$ to non-protonated carbon $\mathrm{C}-1^{\prime \prime}\left(\delta_{\mathrm{C}} 127.5\right)$ established the remainder of the ring. The downfield shift of C- $4^{\prime \prime}$ and the relatively shielded nature of the resonances of position $3^{\prime \prime}\left[5^{\prime \prime}\right]$ were consistent with oxygen attachment at position $4^{\prime \prime}$. The observation of HMBC correlations from $\mathrm{H}-2^{\prime \prime}\left[6^{\prime \prime}\right]$ to another non-protonated aromatic carbon $\left(\mathrm{C}-4: \delta_{\mathrm{C}} 125.9\right)$ indicated that the ring was attached to an extended aromatic system (Figure 6.3, substructure B). The third substructure was constructed in an identical fashion. COSY correlations observed between aromatic methines C-2 $2^{\prime \prime \prime}\left[6^{\prime \prime \prime}\right]\left(\delta_{\mathrm{C}} 132.9\right.$, $\delta_{\mathrm{H}}$ 7.00) and C- $3^{\prime \prime \prime}\left[5^{\prime \prime \prime}\right]\left(\delta_{\mathrm{C}} 115.3, \delta_{\mathrm{H}} 6.71\right)$ established a 1,4-disubstituted benzene ring. HMBC correlations from $\mathrm{H}-2^{\prime \prime \prime}\left[6^{\prime \prime \prime}\right]$ to non-protonated carbon C-4"' $\left(\delta_{\mathrm{C}} 157.2\right)$ and from $\mathrm{H}-3^{\prime \prime \prime}\left[5^{\prime \prime \prime}\right]$ to non-protonated carbon C-1"' $\left(\delta_{\mathrm{C}} 128.5\right)$ completed the assignment of the ring. The deshielded nature of C-4"' and the relatively upfield shifts of the resonances of position $3^{\prime \prime \prime}\left[5^{\prime \prime \prime}\right]$ were consistent with oxygen attachment at $C-4^{\prime \prime \prime}$. Substructure $C$ was completed by the observation of HMBC correlations from $\mathrm{H}-2^{\prime \prime \prime}\left[6^{\prime \prime \prime}\right]$ to another nonprotonated aromatic carbon $\left(\mathrm{C}-3: \delta_{\mathrm{C}} 132.7\right)$ indicating that this ring was also attached to an extended aromatic system (Figure 6.3, substructure C).

These substructures account for 22 of the 26 carbons, 14 of the 21 protons and four of the six oxygens of the molecular formula. The remaining unassigned carbons were the oxymethyl carbon, one further non-protonated aromatic carbon, an ester carbonyl carbon which was initially misinterpreted as an oxygenated non-protonated aromatic carbon and the aromatic/olefinic methine which we now decided must be aromatic as no further olefinic carbons were available. The confusion over the ester carbonyl arose on account of its unusually upfield ${ }^{13} \mathrm{C}$ chemical shift of $163.9 \mathrm{ppm}$ which is in fact more shielded than oxygenated non-protonated carbon C-4'. An HMBC correlation observed 
A

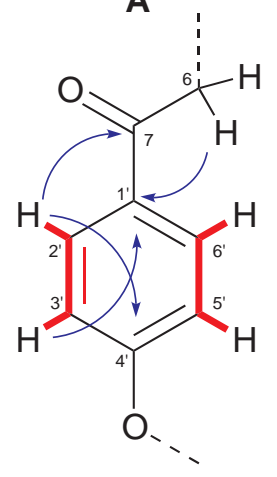

B

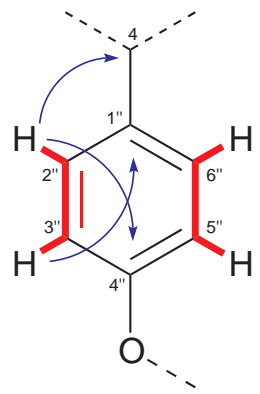

$\longrightarrow$ COSY
C

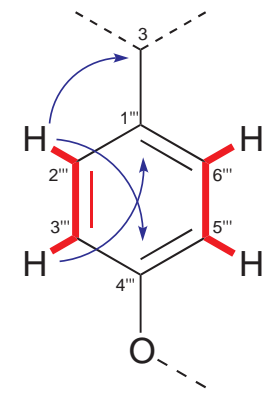

Figure 6.3 Selected COSY and HMBC correlations establishing substructures of lamellarin $\theta$ (187).

from the oxymethyl group to this carbon indicated their attachment to one another. Its nature as an ester was only correctly interpreted as a result of the subsequent isolation of the known compound lamellarin O (189) (see Section 6.4) which possesses a similar unusually shielded methyl ester carbon.

The presence of nitrogen was confirmed by ${ }^{1} \mathrm{H}_{-}{ }^{15} \mathrm{~N}$ HMBC analysis which showed correlations to ${ }^{15} \mathrm{~N}$ at $\delta_{\mathrm{N}}-228.1$. Specifically, the spectra revealed correlations between methylene protons $\mathrm{H}_{2}-6$ (substructure $\left.\mathrm{A}\right)$ and $\mathrm{N}-1\left(\delta_{\mathrm{N}}-228.1\right)$ and the aromatic methine proton $\left(\mathrm{C}-5: \delta_{\mathrm{C}} 128.7, \delta_{\mathrm{H}} 7.08\right)$ and $\mathrm{N}-1$. These data indicate the connection of $\mathrm{N}-1$ to both C-5 and C-6. The deshielded nature of methylene C-6 is consistent with it being sandwiched between nitrogen N-1 and carbonyl C-7. Both a long-range COSY correlation and an NOE enhancement were also observed between $\mathrm{H}-5$ and $\mathrm{H}_{2}-6$ consistent with this assignment. Finally, HMBC correlations observed from methylene $\mathrm{H}_{2}-6$ to $\mathrm{C}-5$ and the unassigned non-protonated aromatic carbon C-2 $\left(\delta_{\mathrm{C}} 120.8\right)$ provided more evidence for the connection of $\mathrm{C}-5$ to $\mathrm{N}-1$ and suggested that $\mathrm{C}-2$ was also attached to $\mathrm{N}-1$ (see Figure 6.4).

Further HMBC analysis indicated that the aromatic methine proton $\mathrm{H}-5$ correlated to $\mathrm{C}-2$ and methylene C-6 consistent with the above assignment. Additional correlations to two non-protonated aromatic carbons, C-3 (substructure C) and C-4 (substructure B), were observed along with a strong correlation to the ester carbonyl $\left(\delta_{\mathrm{C}} 163.9\right)$. Long-range HMBC correlations from $\mathrm{H}-5$ to $\mathrm{C}-1^{\prime \prime}$ (substructure $\mathrm{B}$ ) and $\mathrm{C}-1^{\prime \prime \prime}$ (substructure C) were 
also observed. This information, coupled with the observation of an NOE enhancement between methine $\mathrm{H}-5$ and methine protons $\mathrm{H}-2^{\prime \prime}\left[6^{\prime \prime}\right]$ indicated the connection of C-4 to C-5. The long-range HMBC correlation from $\mathrm{H}-5$ to $\mathrm{C}-1^{\prime \prime \prime}$ confirmed that $\mathrm{C}-3$ must be attached to C-4 (see Figure 6.4).

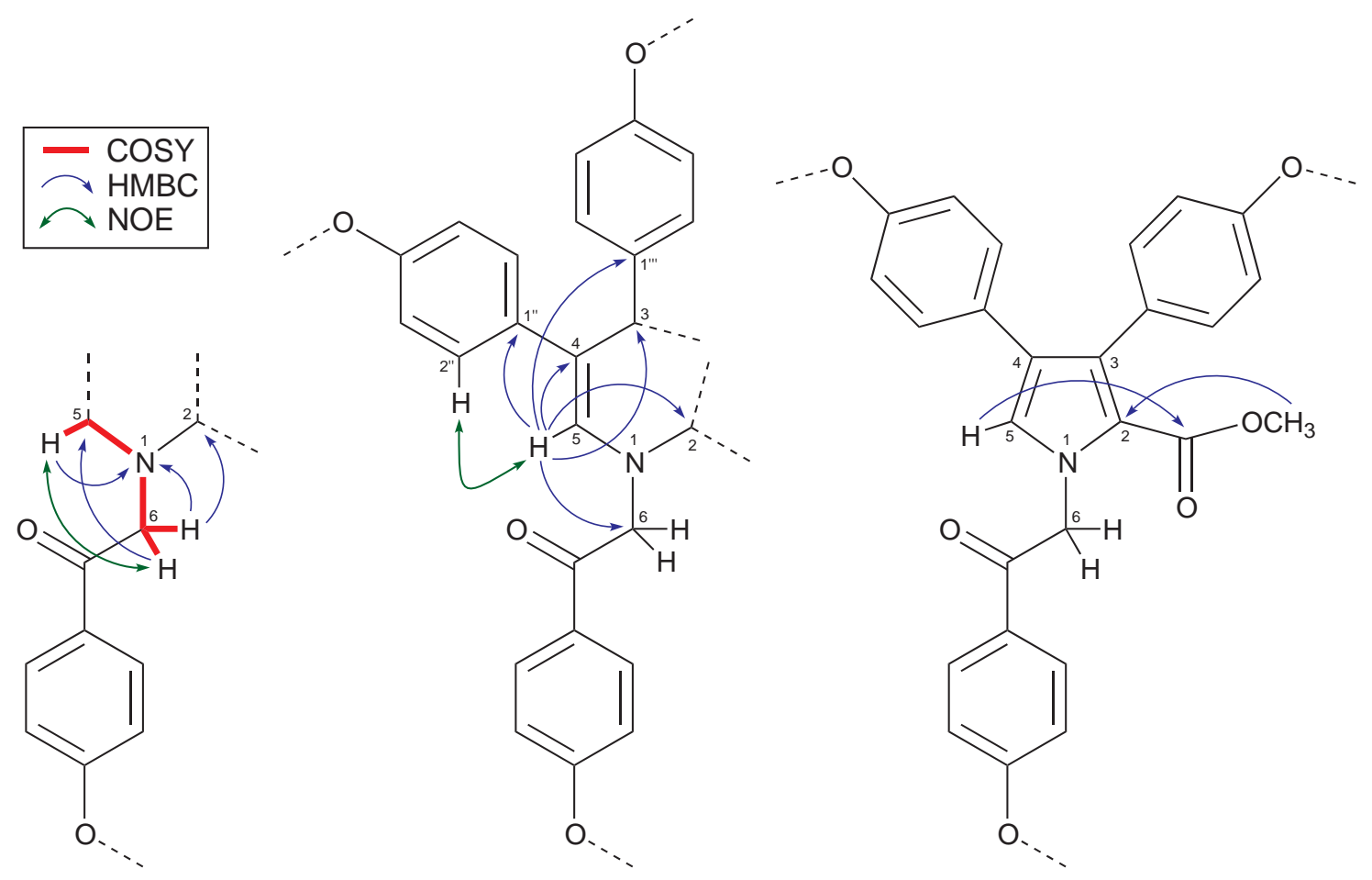

Figure 6.4 Correlations connecting the substructures of lamellarin $\theta(\mathbf{1 8 7})$.

As all detected carbon resonances were now assigned, the connection of aromatic carbons C-2 and C-3 was indicated completing a pyrrole group and satisfying three further double bond equivalents. The observed chemical shift of $\mathrm{N}-1\left(\delta_{\mathrm{N}}-228.1\right)$ is consistent with a pyrrole nitrogen which generally occur in the range of -230 to $-260 \mathrm{ppm} .{ }^{13}$ In addition, the large observed ${ }^{1} J_{\mathrm{CH}}$ of $187 \mathrm{~Hz}$ for C-5 is consistent with those reported for position C-2 of pyrroles. ${ }^{42}$ Finally, the attachment of the methyl ester to $\mathrm{C}-2$ provided the $17^{\text {th }}$ and final double bond equivalent. Initially the only HMBC correlation observed from the oxymethyl group $\left(\delta_{\mathrm{C}} 51.0, \delta_{\mathrm{H}} 3.41\right)$ was to the ester carbonyl carbon. The structure could be confirmed only when spectra were re-acquired on a NMR spectrometer equipped with a cryogenic probe. The increased sensitivity of the cryogenic probe allowed the observation of a long-range $\mathrm{HMBC}$ correlation from the oxymethyl group to $\mathrm{C}-2$ confirming the attachment of the ester carbonyl at this position (see Figure 6.4). Interestingly, this structure requires that the strong HMBC correlation observed between H-5 and the ester carbonyl is actually a long-range four-bond correlation. While the strength of this 
correlation is unusual, it is consistent with the corresponding HMBC correlation observed for the known compound lamellarin O (189). ${ }^{164}$

With only three protons from the molecular formula unaccounted for in the substructure, positions C-4', C-4" and C-4"' were proposed as hydroxylated accounting for the exchangeable protons signals observed when the ${ }^{1} \mathrm{H}$ NMR spectrum was acquired in $\mathrm{d}_{6}$ DMSO. This assignment was supported by the observation of HMBC correlations from exchangeable protons $4^{\prime \prime}-\mathrm{OH}$ and $4^{\prime \prime \prime}-\mathrm{OH}$ to their respective attachment points when the HMBC spectrum was acquired in $\mathrm{d}_{6}$-DMSO. The $4^{\prime}$-OH resonance afforded no similar correlation to $\mathrm{C}-4^{\prime}$ presumably due to the higher rate of proton exchange at this position indicated by the very broad resonance observed in the ${ }^{1} \mathrm{H}$ NMR spectrum. The final structure of lamellarin $\theta$ is therefore proposed to be $\mathbf{1 8 7}$. NMR data for $\mathbf{1 8 7}$ is presented in both $\mathrm{CD}_{3} \mathrm{OD}$ (Table 6.2) and $\mathrm{d}_{6}$-DMSO (Table 6.3).

The initial misinterpretation of the nature of the ester carbonyl carbon as an oxygenated non-protonated aromatic carbon led to the proposal of a quite different structure during our early attempts to elucidate lamellarin $\theta$. Specifically, the strong HMBC correlation observed between H-5 and the "oxygenated non-protonated aromatic carbon" (in addition to the three aromatic carbons, C-2, C-3 and C-4) led to the proposal of a pyridine as the cyclic core of the structure. As this new structure now lacked one oxygen, a pyridine $N$-oxide was originally proposed as the final structure (see Figure 6.5). The HMBC correlation observed from H-5 to the misidentified carbon is now only required to be a three-bond correlation which seemed more consistent with the strength of the signal. This proposed structure was consistent with almost all aspects of the elucidation described for lamellarin $\theta$. Only three points of difference were noted; first, the HMBC correlations observed from both methylene $\mathrm{H}_{2}-6$ and methine $\mathrm{H}-5$ to $\mathrm{N}-1$ would, of necessity, be fourbond correlations; second, the ${ }^{15} \mathrm{~N}$ chemical shift was not typical of a pyridine $N$-oxide (which would in theory be observed significantly further downfield than $-228.1 \mathrm{ppm}$ ); and third, the deshielded nature of methylene $\mathrm{H}_{2}-6$ was less readily explained with the pyridine $\mathrm{N}$-oxide structure. However, none of these three problems were definitive four-bond correlations to N-1 were unlikely, but not impossible, especially given that no two- or three-bond correlations were available with which to compare the intensity; 


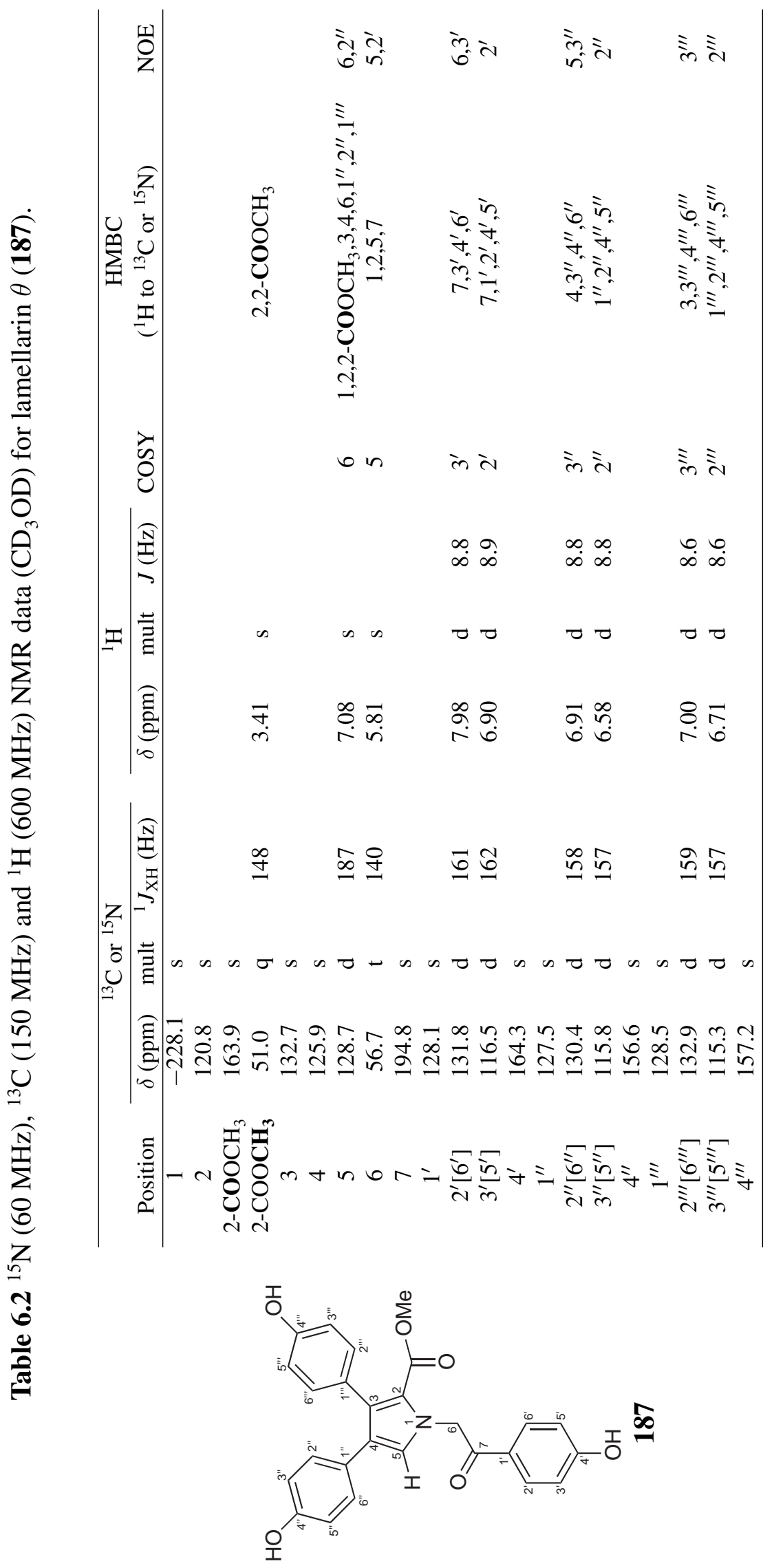




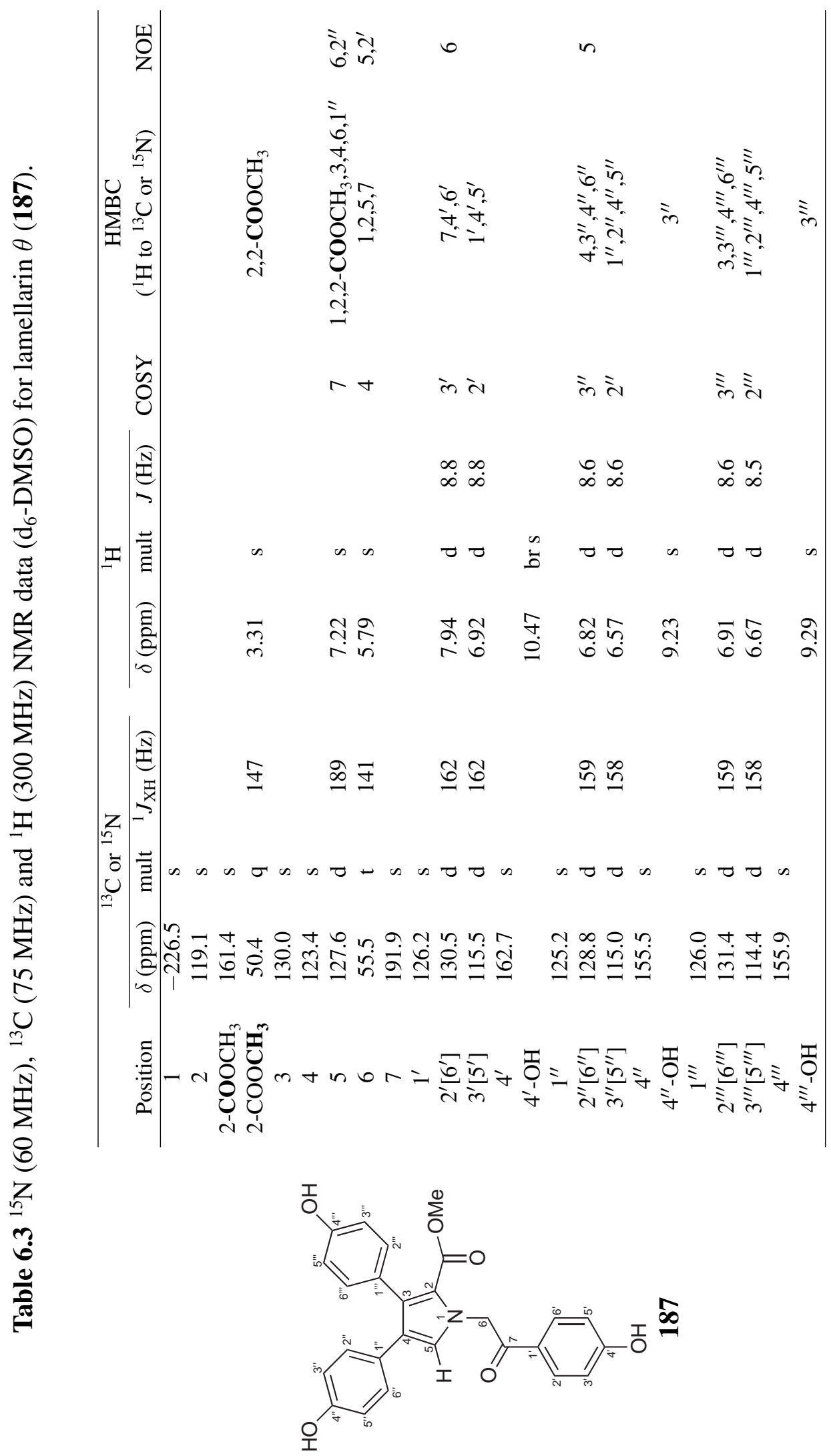


the ${ }^{15} \mathrm{~N}$ chemical shift of $\mathrm{N}-1$ was atypical of an $N$-oxide, but little or no ${ }^{15} \mathrm{~N}$ NMR data from analogous structures were available for comparison; and similarly, perhaps the $N$-oxide was withdrawing electrons from C-6 through the extended conjugation of the molecule accounting for its deshielded nature. Since the proposal of an $N$-oxide was unusual and based on quite circumstantial evidence, great pains were taken to test the hypothesis. Section 6.3 describes the exhaustive derivatisation of lamellarin $\theta$. In a somewhat diabolical twist of fate, every single derivative produced was also consistent with the $N$-oxide structure. Only the subsequent isolation of the known compound lamellarin O (189) (see Section 6.4) and the plausibility of biogenesis of a pyrrole-based alkaloid over a pyridine-based alkaloid (see Section 6.15) ultimately ruled out the $N$-oxide structure. An analysis of the literature NMR data for lamellarin O (189) ${ }^{164}$ revealed one key NOE enhancement between the methyl ester protons and $\mathrm{H}-2^{\prime \prime \prime}\left[6^{\prime \prime \prime}\right]$ which aided the original structural elucidation. Had the corresponding NOE enhancement been observed in the spectra of lamellarin $\theta$, the correct structure might more quickly have been identified as this correlation would have immediately ruled out the proposed pyridine $N$-oxide structure.

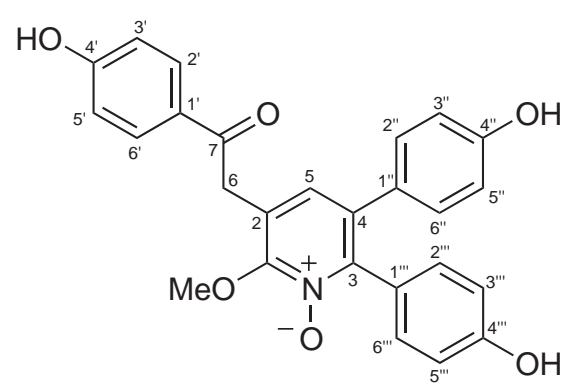

Figure 6.5 The initially proposed pyridine $N$-oxide structure for lamellarin $\theta$.

In order to determine whether lamellarin $\theta(\mathbf{1 8 7})$ was methoxylated in vivo or as an artefact of isolation in $\mathrm{MeOH}$, the extraction and isolation was repeated replacing $\mathrm{MeOH}$ by EtOH at each stage. From a sample of approximately $63 \mathrm{~g}$ of sponge material a further $3.8 \mathrm{mg}$ of lamellarin $\theta$ was isolated. The methyl ester moiety was still present confirming that 187 is a true natural product.

Lamellarin $\theta$ was submitted to the School of Biological Sciences at Victoria University of Wellington for biological testing in a P388 murine leukæmia assay. The result was positive with cytotoxic activity in the $1 \mu \mathrm{M}$ range. 


\subsection{Synthetic Derivatives of Lamellarin $\theta$}

\section{$N$-Methylation of Lamellarin $\theta$ (187)}

In order to confirm that the proposed structure of lamellarin $\theta$ was correct, a number of synthetic derivatives were prepared. While still under the misapprehension that the structure was a pyridine $\mathrm{N}$-oxide (and uncertain even of that) an attempt was made to $\mathrm{N}$ methylate 187 using MeI. Control reactions with pyridine and pyridine $N$-oxide were also performed. As expected, pyridine was readily methylated to produce $N$-methylpyridinium iodide while pyridine $N$-oxide yielded pyridinium $N$-methoxide iodide. However, no reaction was observed with $\mathbf{1 8 7}$. The methylation reaction was performed in an NMR tube in order to monitor the reaction by ${ }^{1} \mathrm{H}$ NMR spectroscopy. Interestingly, the presence of MeI appeared to catalyse the exchange of the aromatic methine proton H-5 with deuterons from the solvent - in this case $\mathrm{CD}_{3} \mathrm{OD}$. After 24 hours, the protons of $\mathrm{H}$ 5 had completely exchanged for deuterons and the corresponding resonance was absent from the ${ }^{1} \mathrm{H}$ spectrum. A proposed mechanism for this transformation is based on an initial reaction between $\mathrm{CD}_{3} \mathrm{OD}$ and MeI producing catalytic quantities of deuteroiodic acid (DI) which provides an acidic source of deuterium ions for an electrophilic aromatic substitution mechanism (Scheme 6.2). The presence of methyl iodide is necessary to catalyse this exchange; lamellarin $\theta$ left sitting for an equivalent period of time in $\mathrm{CD}_{3} \mathrm{OD}$ in the absence of methyl iodide did not undergo this transformation. Fortunately, a sample of deuterated 187 could be re-protonated by standing in a solution of MeI in $\mathrm{CH}_{3} \mathrm{OH}$ overnight. The lack of methylation is more consistent with the pyrrole structure but steric hindrance could also explain the lack of methylation of the $N$-oxide structure.

\section{Acetylation of Lamellarin $\theta$ (187)}

To prove that the three broad resonances observed in the ${ }^{1} \mathrm{H}$ spectrum of $\mathbf{1 8 7}$ in $\mathrm{d}_{6}$ DMSO were due to exchangeable $\mathrm{OH}$ protons (in particular the resonance assigned to 4'-OH which lacked an HMBC correlation to its attachment point C-4'), an acetylation of lamellarin $\theta$ was carried out with acetic anhydride in pyridine. The positive-ion 


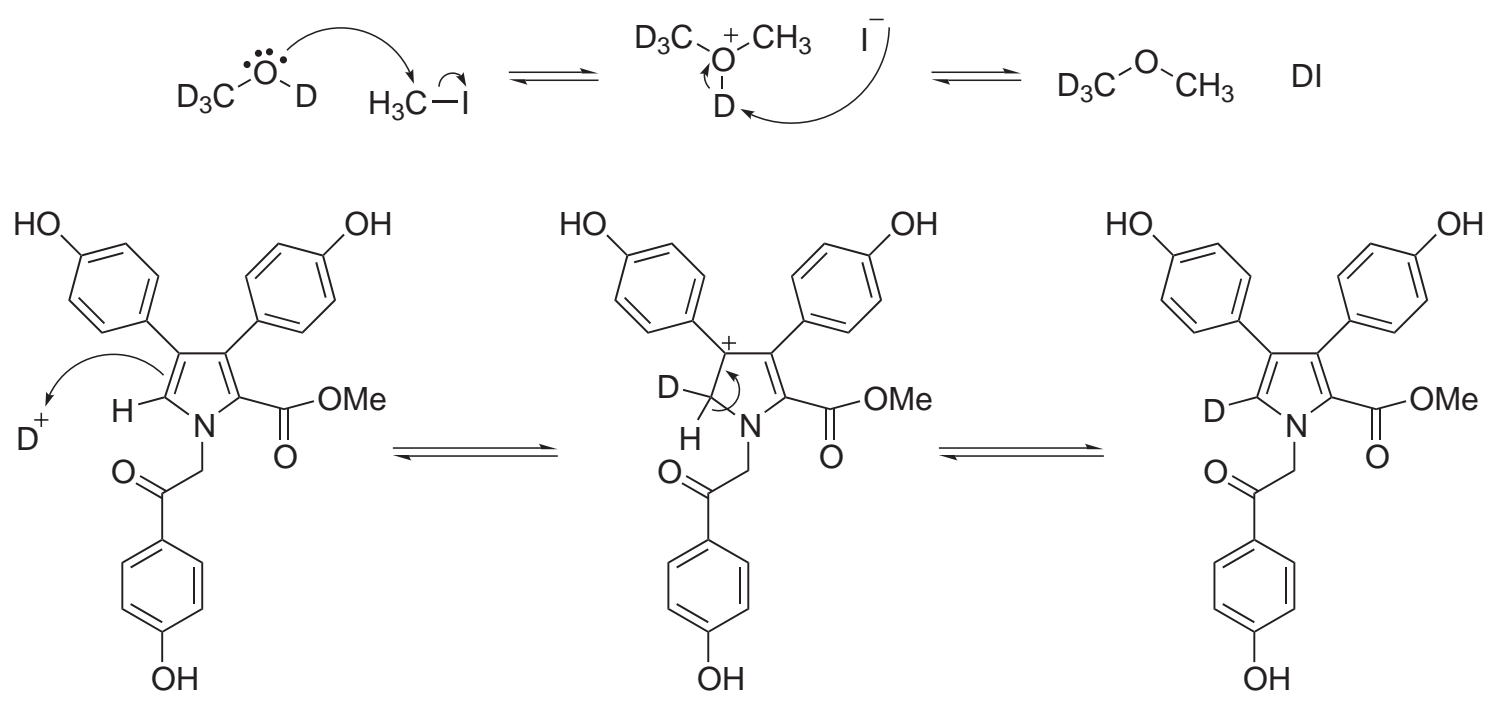

Scheme 6.2 Proposed mechanism of deuterium exchange at C-5.

HRESIMS of the reaction product gave rise to a pseudo-molecular ion indicative of a formula of $\mathrm{C}_{32} \mathrm{H}_{27} \mathrm{NO}_{9}\left(592.1558[\mathrm{M}+\mathrm{Na}]^{+}, \Delta 3.3 \mathrm{ppm}\right)$. The increase in mass of $126 \mathrm{Da}$ is consistent with triacetylation. The ${ }^{1} \mathrm{H}$ and ${ }^{13} \mathrm{C}$ NMR spectra of the acetylation product indicated additional signals attributable to the three acetate groups - three methyl singlets in the ${ }^{1} \mathrm{H}$ spectrum and in the ${ }^{13} \mathrm{C}$ spectrum, three non-protonated carbonyl resonances and three methyl resonances. The observed change in the chemical shifts of the associated benzene rings is entirely consistent with acetylation at centres $\mathrm{C}-4^{\prime}, \mathrm{C}-4^{\prime \prime}$ and C-4"' . NMR data for $4^{\prime}, 4^{\prime \prime}, 4^{\prime \prime \prime}$-triacetyllamellarin $\theta(\mathbf{1 9 6})$ is presented in Table 6.4 .

\section{Ketone Reduction of $\mathbf{4}^{\prime}, \mathbf{4}^{\prime \prime}, \mathbf{4}^{\prime \prime \prime}$-triacetyllamellarin $\theta$ (196)}

The high index of hydrogen deficiency of $\mathbf{1 8 7}$ led to a limited amount of information about the structure being obtained through ${ }^{1} \mathrm{H}-{ }^{13} \mathrm{C}$ correlation spectroscopy. It was therefore proposed to reduce the ketone in order to afford additional protons which might exhibit new correlations reinforcing the proposed structure. Standard reduction conditions with $\mathrm{NaBH}_{4}$ are quite basic and the presence of phenolic protons was considered a concern. A protected form of $\mathbf{1 8 7}$ was deemed required and as the triacetylated derivative was already available, a reduction of 196 was attempted. Unfortunately, under $\mathrm{NaBH}_{4}$ reduction conditions some hydrolysis of the acetyl groups occurred resulting in an unresolvable mixture of products. 


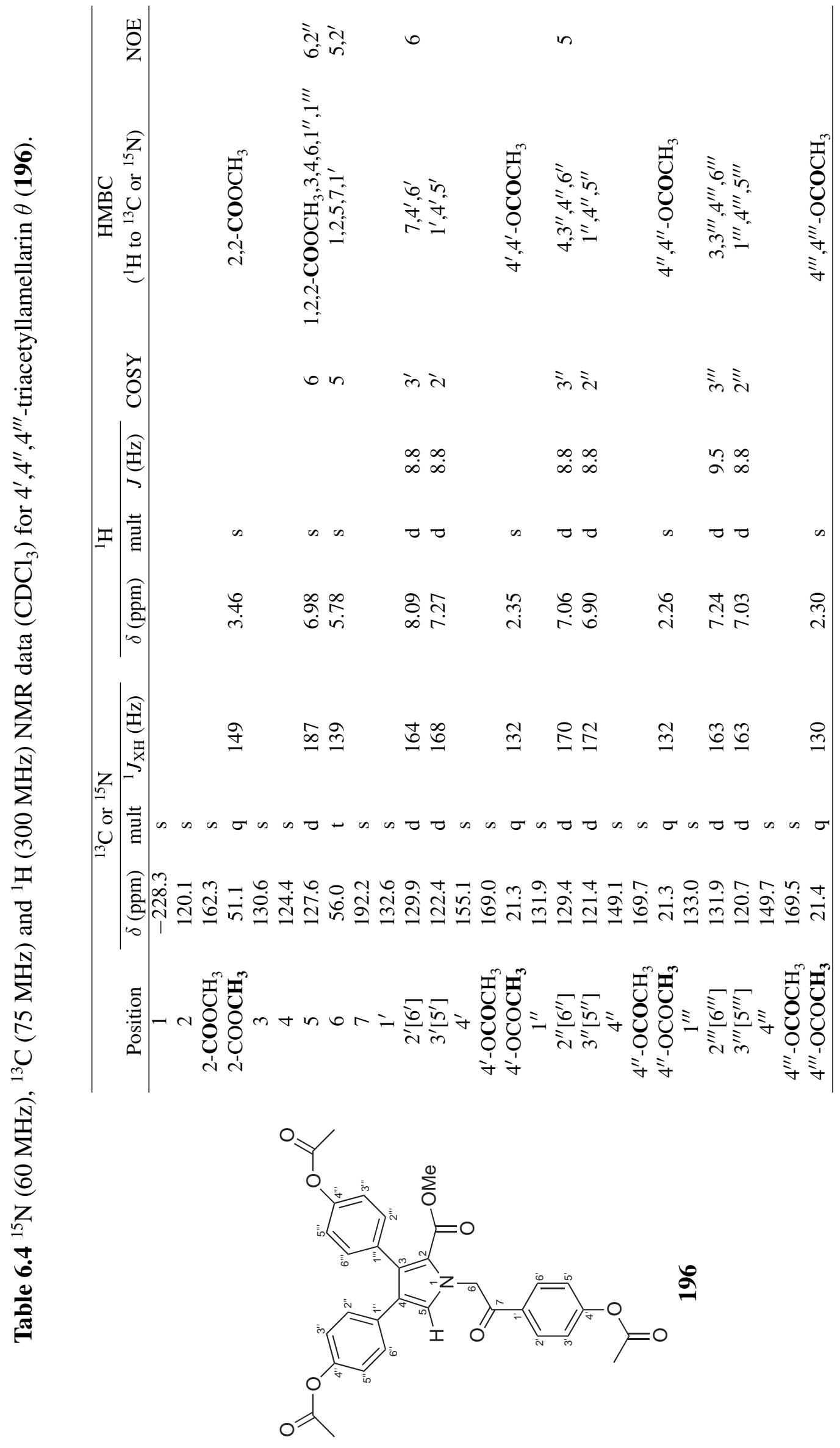




\section{$O$-Methylation of Lamellarin $\theta$ (187)}

In light of the previous result, methylation of $\mathbf{1 8 7}$ was considered the best option for protecting the molecule. Lamellarin $\theta$ was therefore subjected to $\mathrm{CH}_{2} \mathrm{~N}_{2}$ in $\mathrm{Et}_{2} \mathrm{O}$ for several hours. Four products were identified from this reaction, two of which could be separated and characterised. The first was identified as $4^{\prime}$-methoxylamellarin $\theta$, which was recognised as the known structure lamellarin O (189), ${ }^{164}$ from the observation of a new oxymethyl resonance in both the ${ }^{13} \mathrm{C}$ and ${ }^{1} \mathrm{H}$ NMR spectra $\left(\delta_{\mathrm{C}} 56.1, \delta_{\mathrm{H}} 3.90\right)$ and an $\mathrm{HMBC}$ correlation from the new oxymethyl group to $\mathrm{C}-4^{\prime}$. Lamellarin $\mathrm{O}$ was later isolated and characterised as a secondary metabolite produced by the sponge (see Section 6.4). The other product isolated was $4^{\prime}, 4^{\prime \prime}, 4^{\prime \prime \prime}$-trimethoxylamellarin $\theta$ (197). The positive-ion HRESIMS of 197 showed a pseudo-molecular ion corresponding to a molecular formula of $\mathrm{C}_{29} \mathrm{H}_{27} \mathrm{NO}_{6}\left(508.1744[\mathrm{M}+\mathrm{Na}]^{+}, \Delta 2.6 \mathrm{ppm}\right)$ indicating the addition of three methyl groups. The ${ }^{1} \mathrm{H}$ and ${ }^{13} \mathrm{C}$ NMR spectra were consistent with this conclusion showing three additional oxymethyl resonances $\left(4^{\prime}-\mathrm{OCH}_{3}: \delta_{\mathrm{C}} 56.1, \delta_{\mathrm{H}} 3.90,4^{\prime \prime}-\mathrm{OCH}_{3}: \delta_{\mathrm{C}} 55.7, \delta_{\mathrm{H}} 3.72\right.$ and $\left.4^{\prime \prime \prime}-\mathrm{OCH}_{3}: \delta_{\mathrm{C}} 55.7, \delta_{\mathrm{H}} 3.80\right)$. $\mathrm{HMBC}$ correlations from $4^{\prime}-\mathrm{OCH}_{3}$ to $\mathrm{C}-4^{\prime}, 4^{\prime \prime}-\mathrm{OCH}_{3}$ to $\mathrm{C}-4^{\prime \prime}$ and $4^{\prime \prime \prime}-\mathrm{OCH}_{3}$ to $\mathrm{C}-4^{\prime \prime \prime}$ confirmed the locations of the additional methyl moieties. Table 6.5 contains full NMR data for $4^{\prime}, 4^{\prime \prime}, 4^{\prime \prime \prime}$-trimethoxylamellarin $\theta$.

The remaining two inseparable products appeared to be $4^{\prime}, 4^{\prime \prime}$-dimethoxylamellarin $\theta$ and $4^{\prime}, 4^{\prime \prime \prime}$-dimethoxylamellarin $\theta$. It is interesting to note that all of the isolated products were methoxylated at C- $4^{\prime}$ indicating the facile methylation of this site. This is consistent with the placement of the carbonyl para to the hydroxyl as resonance structures indicate that this would cause a decrease in the $\mathrm{pK}_{\mathrm{a}}$ of the hydroxyl group (see Scheme 6.3). Diazomethane is known to methylate acidic hydroxyls with greater ease than neutral or basic hydroxyls. ${ }^{165}$ It would also appear that the rate of methylation of the other two hydroxyls is virtually equivalent as the mixture of the two dimethylated derivatives was not clearly dominated by either product. The mixture of dimethylated derivatives was resubjected to $\mathrm{CH}_{2} \mathrm{~N}_{2}$ to produce a further quantity of 197. All of these observations are consistent with the proposed structure of $\mathbf{1 8 7}$. 


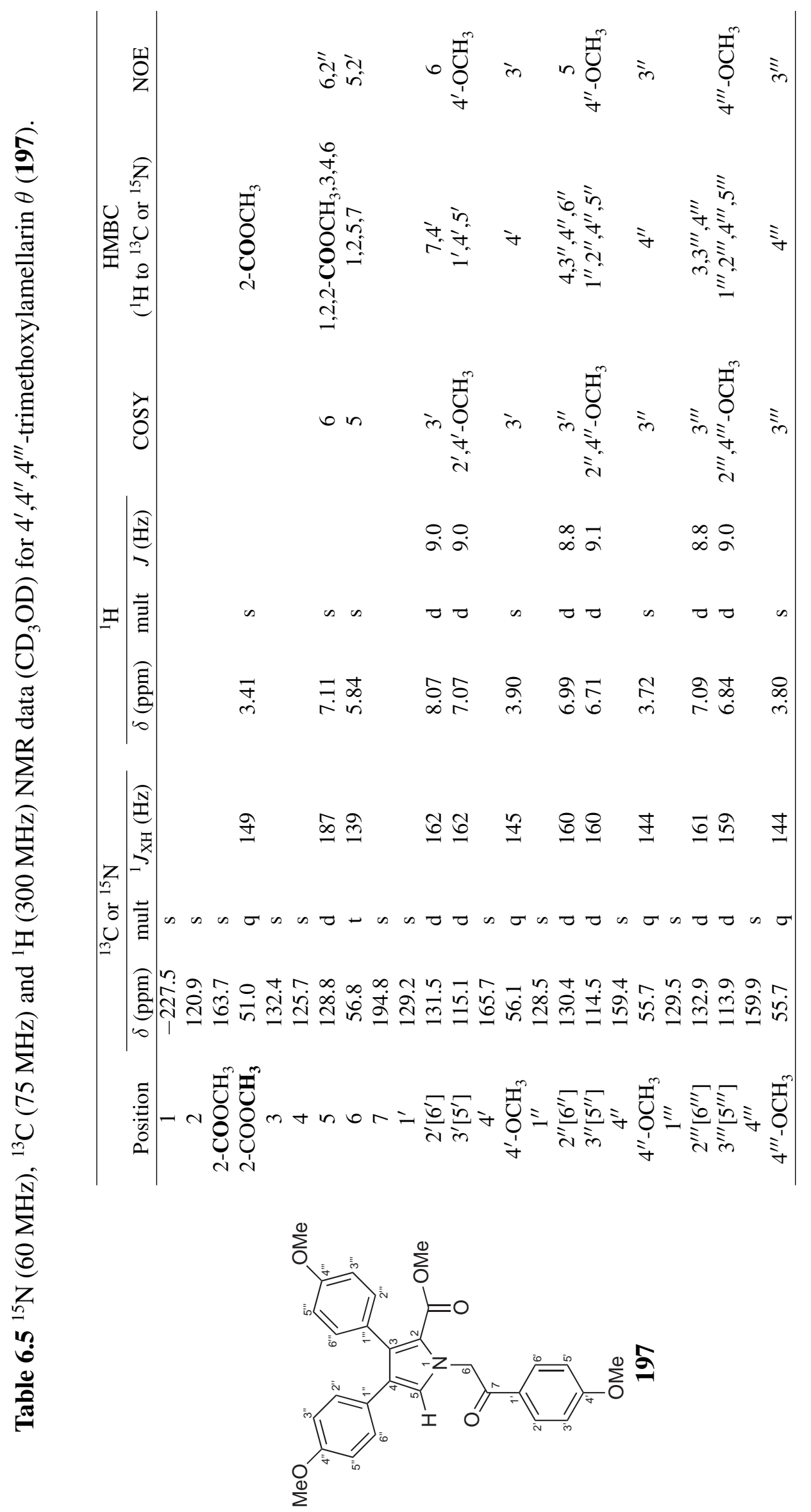




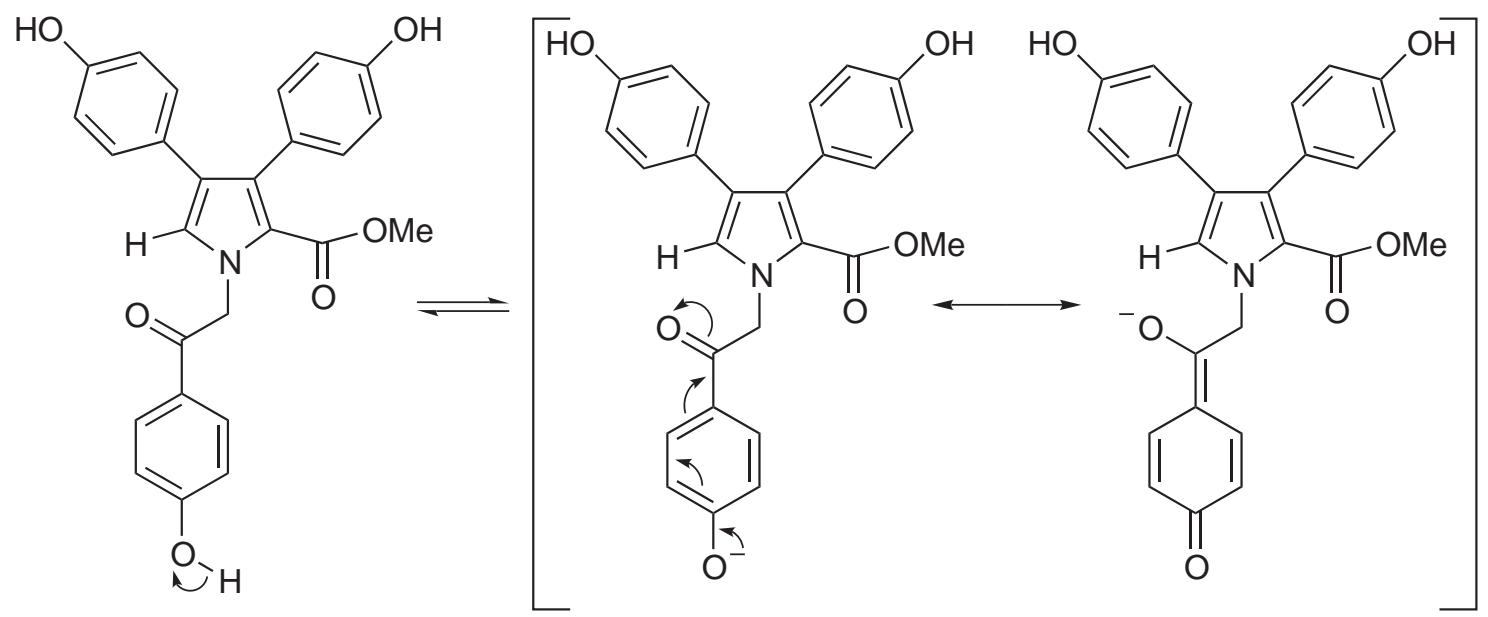

Scheme 6.3 Increased acidity of the $4^{\prime}-\mathrm{OH}$ position in lamellarin $\theta(\mathbf{1 8 7})$.

\section{Ketone Reduction of $\mathbf{4}^{\prime}, \mathbf{4}^{\prime \prime}, \mathbf{4}^{\prime \prime \prime}$-trimethoxylamellarin $\theta(197)$}

With a protected derivative of $\mathbf{1 8 7}$ in hand, reduction of the carbonyl was attempted. A sample of 197 was treated overnight with $\mathrm{NaBH}_{4}$ in $\mathrm{MeOH}$. Unexpectedly, two products were isolated from the reaction. Interestingly, the major product was not the expected reduced derivative; instead the molecule had undergone lactonisation with loss of methanol to form a derivative of lukianol A (198), a known natural product which was originally isolated in 1992 from a tunicate of undetermined genus collected from Palmyra atoll in the Pacific Ocean. ${ }^{166}$

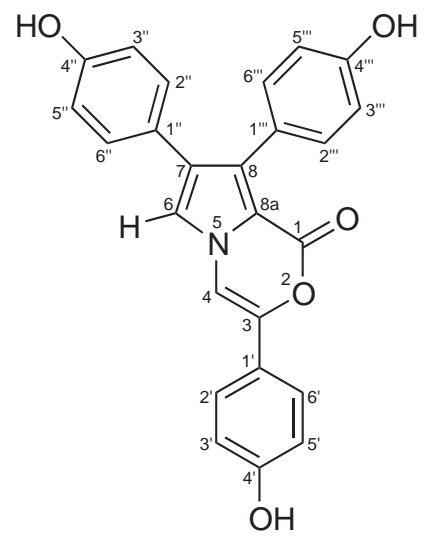

198

The lactone product gave rise to a pseudo-molecular ion in the HRESIMS corresponding to a formula of $\mathrm{C}_{28} \mathrm{H}_{25} \mathrm{NO}_{5}\left(456.1848[\mathrm{M}+\mathrm{H}]^{+}, \Delta 9.3 \mathrm{ppm}\right)$ and indicating the loss of $\mathrm{CH}_{2} \mathrm{O}$ relative to 197 . The ${ }^{1} \mathrm{H}$ and ${ }^{13} \mathrm{C}$ NMR spectra were consistent with reduction of the ketone at C-3 (previously C-7 under the lamellarin numbering system) to a secondary alcohol $\left(\delta_{\mathrm{C}} 79.6, \delta_{\mathrm{H}} 5.75\right)$ and a corresponding change in the shifts of the adjacent 
methylene C-4 (previously C-6) $\left(\delta_{\mathrm{C}} 49.6, \delta_{\mathrm{H}} 4.48,4.34\right)$. Notably absent from the ${ }^{1} \mathrm{H}$ and ${ }^{13} \mathrm{C}$ NMR spectra were resonances associated with the oxymethyl group of the methyl ester. An HMBC correlation between oxymethine $\mathrm{H}-3$ and oxygenated carbon C1 (previously 2- $\mathrm{COOCH}_{3}$ ) suggested the formation of a new six-membered ring linking C-1 and C-3 through an oxygen bridge. The product was therefore identified as 3,4dihydro-4',4", $4^{\prime \prime \prime}$-trimethoxylukianol A (199) (see Table 6.6 for NMR data). With no stereochemical control involved in the reaction, the product is assumed to be a racemic mixture of C-3 epimers.

The mechanism of this transformation is proposed to take place via an intramolecular nucleophilic attack by the initially formed alkoxide ion on the methyl ester with concomitant re-establishment of the carbonyl and ejection of a methoxide ion (see Scheme 6.4).<smiles></smiles><smiles>COC(=O)c1c(-c2ccc(OC)cc2)c(-c2ccc(OC)cc2)c2n1O[C@H](c1ccc(OC)cc1)OC2=O</smiles>

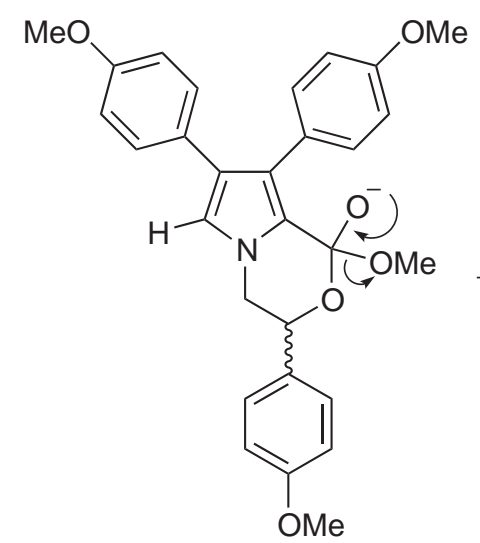<smiles></smiles>

Scheme 6.4 The proposed mechanism for the formation of 3,4-dihydro-4', $4^{\prime \prime}, 4^{\prime \prime \prime}$-trimethoxylukianol A (199).

Interestingly, the originally proposed $\mathrm{N}$-oxide structure could in theory have undergone a similar transformation via an intramolecular nucleophilic aromatic substitution mechanism. Under this mechanism, the positive charge on the nitrogen would provide a 


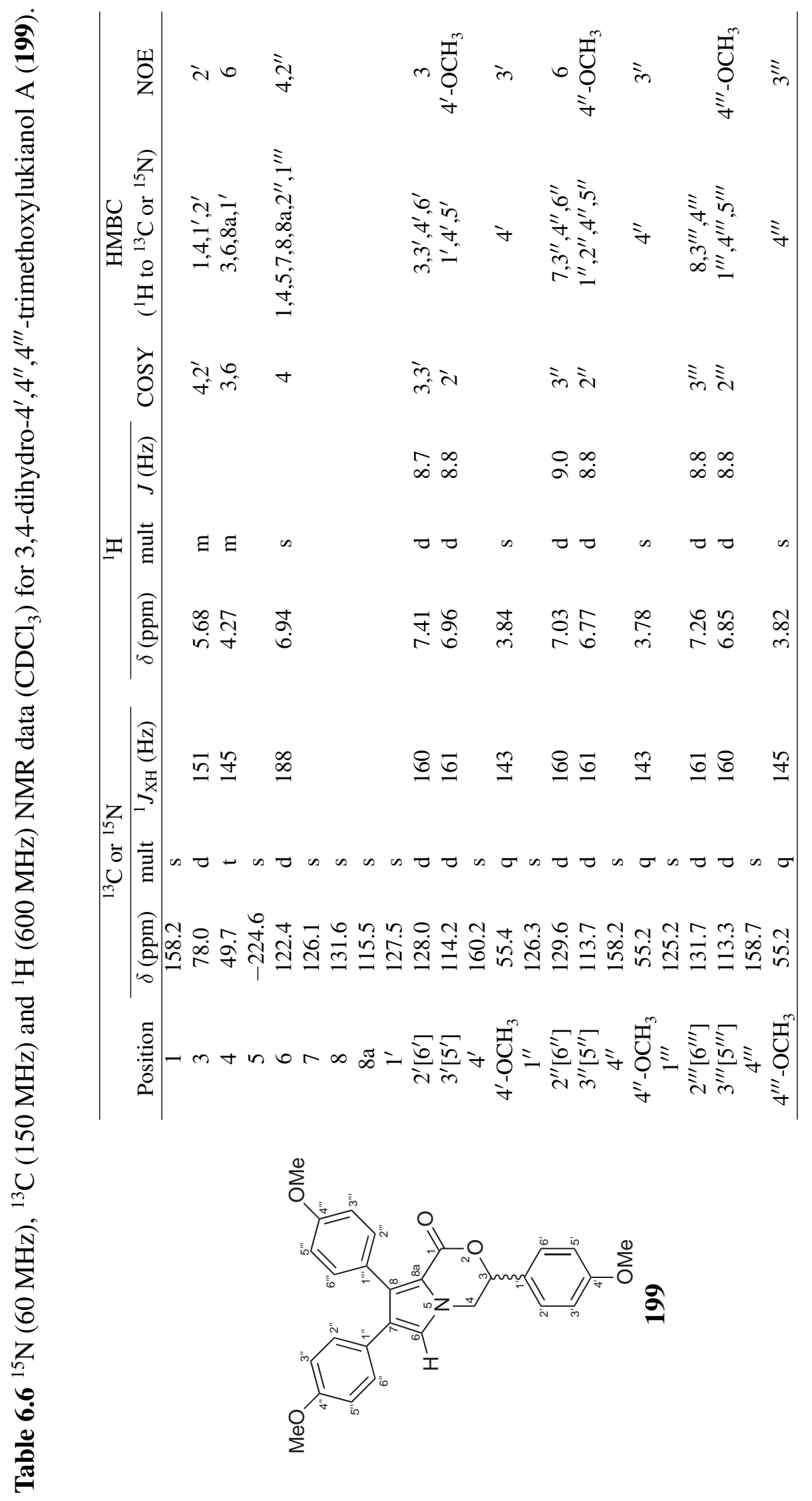


convenient electron sink for the incoming nucleophile (see Scheme 6.5). The fact that this transformation was so plausible was a significant factor in our original assumption that the pyridine $N$-oxide structure was correct.<smiles>COc1ccc(C(=O)Cc2cc(-c3ccc(OC)cc3)c(-c3ccc(OC)cc3)[n+]([O-])c2OC)cc1</smiles><smiles></smiles>

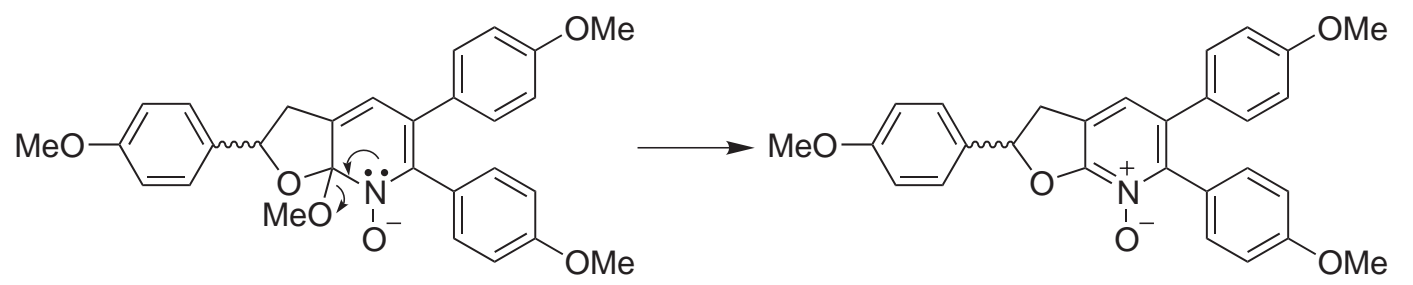

Scheme 6.5 The proposed mechanism for the cyclisation of the pyridine $N$-oxide structure.

It has been suggested that the lamellarins are structurally related to the lukianols. ${ }^{166}$ This hypothesis was supported by the isolation of lamellarin $\mathrm{O}$ which was proposed to be a ring-opened analogue of lukianol A. ${ }^{164}$ The observed lactonisation of $4^{\prime}, 4^{\prime \prime}, 4^{\prime \prime \prime}-$ trimethoxylamellarin $\theta$ under reductive conditions further suggests that the lamellarins may in fact be biosynthetic precursors to the lukianols.

Under the assumption that the increased basicity of the reaction medium due to the presence of methoxide ions generated from $\mathrm{MeOH}$ by $\mathrm{NaBH}_{4}$ was a factor in driving the transformation to completion, the reduction was repeated using THF as the solvent. In this instance, the only isolated product was the expected reduced lamellarin $\theta$ derivative (200) which was isolated in good yield (ca. 95\%).

The positive-ion HRESIMS of $\mathbf{2 0 0}$ gave rise to pseudo-molecular ions corresponding to a molecular formula of $\mathrm{C}_{29} \mathrm{H}_{29} \mathrm{NO}_{6}\left(470.1974\left[\mathrm{M}-\mathrm{H}_{2} \mathrm{O}+\mathrm{H}\right]^{+}, \Delta 2.6 \mathrm{ppm}\right.$ and 488.2110 $\left.[\mathrm{M}+\mathrm{H}]^{+}, \Delta 8.7 \mathrm{ppm}\right)$ indicating an increase of 2 Da over 197. Similar to the lactone 199, ${ }^{1} \mathrm{H}$ and ${ }^{13} \mathrm{C}$ chemical shift changes of positions $\mathrm{C}-6\left(\delta_{\mathrm{C}} 57.6, \delta_{\mathrm{H}} 4.62,4.34\right)$ and C-7 $\left(\delta_{\mathrm{C}} 74.1, \delta_{\mathrm{H}} 4.96\right)$ indicated reduction of the ketone. In this case, the reduction of the ketone moiety accounted entirely for the change in mass of the compound indicating 
that lactonisation had not occurred. As in the case of the lactone, the product is assumed to be a racemate of C-7 epimers. Unfortunately, a complete NMR analysis of $\mathbf{2 0 0}$ was not performed soon enough and the sample of $\mathbf{2 0 0}$ degraded into the same lukianol A derivative isolated from the reduction in $\mathrm{MeOH}$. As a result, ${ }^{13} \mathrm{C}$ chemical shifts for 200 have only been identified by indirect ${ }^{1} \mathrm{H}-{ }^{13} \mathrm{C}$ HMBC correlations, ${ }^{1} J_{\mathrm{CH}}$ data was unobtainable and no ${ }^{15} \mathrm{~N}$ data was able to be collected. All available NMR data for 7hydroxy-4', $4^{\prime \prime}, 4^{\prime \prime \prime}$-trimethoxylamellarin $\theta(\mathbf{2 0 0})$ is presented in Table 6.7.

\section{Summary}

A series of five derivatives of lamellarin $\theta$ (187) were prepared and characterised. In each case, the product was consistent with the proposed structure of $\mathbf{1 8 7}$. The triacetyl and trimethoxy derivatives confirm the presence of three hydroxyls and the reduction and lactonisation products are consistent with a ketone at C-6. The presence of the nitrogen is confirmed by NMR spectroscopy and the measured ${ }^{15} \mathrm{~N}$ chemical shift for position N-1 is consistent with a pyrrole nitrogen. ${ }^{13}$ The reactivity of lamellarin $\theta$ is also consistent with the pyrrole moiety; we were unable to methylate the pyrrole nitrogen, instead observing H/D exchange at position C-5, the mechanism of which can be accounted for by electrophilic aromatic substitution. While we initially considered a pyridine $N$-oxide based structure, the combined weight of all this evidence forces us to conclude that the structure of lamellarin $\theta$ is definitely the pyrrole based 187 . 


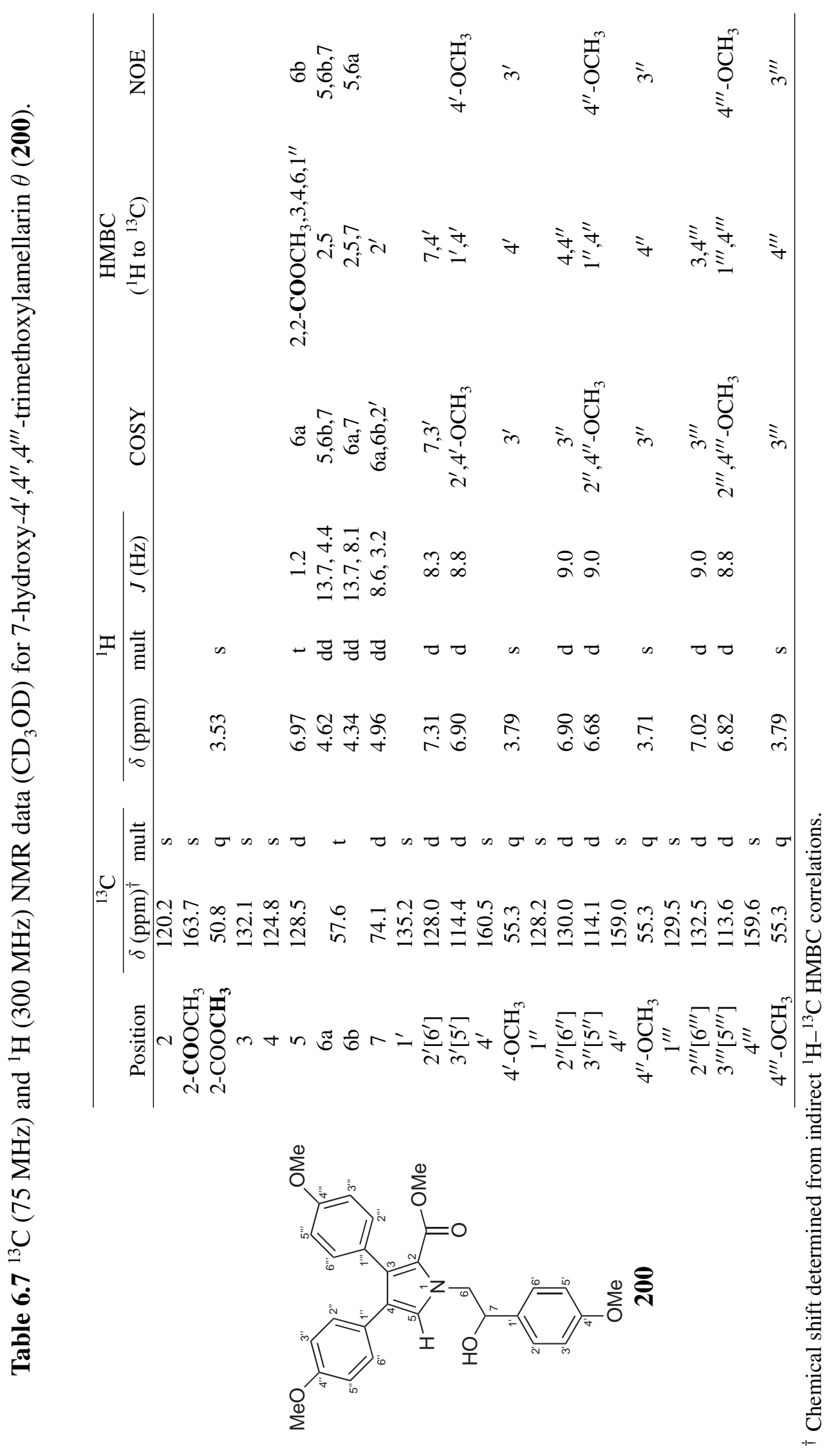




\subsection{Lamellarin O}

Positive-ion mode HRESIMS analysis of lamellarin O (189) gave rise to pseudomolecular ions indicative of a molecular formula of $\mathrm{C}_{27} \mathrm{H}_{23} \mathrm{NO}_{6}\left(480.1443[\mathrm{M}+\mathrm{Na}]^{+}, \Delta\right.$ $5.3 \mathrm{ppm}$ and $\left.937.2988[2 \mathrm{M}+\mathrm{Na}]^{+}, \Delta 4.8 \mathrm{ppm}\right)$. Lamellarin $\mathrm{O}$ showed obvious spectral similarities to lamellarin $\theta(\mathbf{1 8 7})$ with the addition of resonances attributable to an extra oxymethyl group $\left(4^{\prime}-\mathrm{OCH}_{3}: \delta_{\mathrm{C}} 56.1, \delta_{\mathrm{H}} 3.90\right)$. The proposed molecular formula differs from that of lamellarin $\theta$ by $14 \mathrm{Da}$ or $\mathrm{CH}_{2}$ which is accounted for by the replacement of a hydroxyl group with an oxymethyl group. An HMBC correlation from the new oxymethyl singlet $4^{\prime}-\mathrm{OCH}_{3}$ to $\mathrm{C}-4^{\prime}$ confirmed the attachment point. Lamellarin $\mathrm{O}$ was therefore identified as $4^{\prime}$-methoxylamellarin $\theta$. The mass spectra and ${ }^{1} \mathrm{H}$ and ${ }^{13} \mathrm{C} \mathrm{NMR}$ data for lamellarin $\mathrm{O}$ were entirely consistent with those of the synthetically derived 4'methoxylamellarin $\theta$ (see Section 6.3) and the previously reported natural product. ${ }^{164}$ NMR data for lamellarin O (189) is presented in Table 6.8.

In order to exclude the possibility that the methoxylation of lamellarin $\mathrm{O}(\mathbf{1 8 9})$ at $\mathrm{C}-4^{\prime}$ was a result of extraction in $\mathrm{MeOH}$, the isolation of a quantity of $\mathbf{1 8 9}$ from the EtOH extract was performed, again substituting $\mathrm{EtOH}$ for $\mathrm{MeOH}$ during each chromatographic step. A further $0.7 \mathrm{mg}$ of $\mathbf{1 8 9}$ was successfully isolated indicating that lamellarin $\mathrm{O}$ (189) is also a true natural product. 


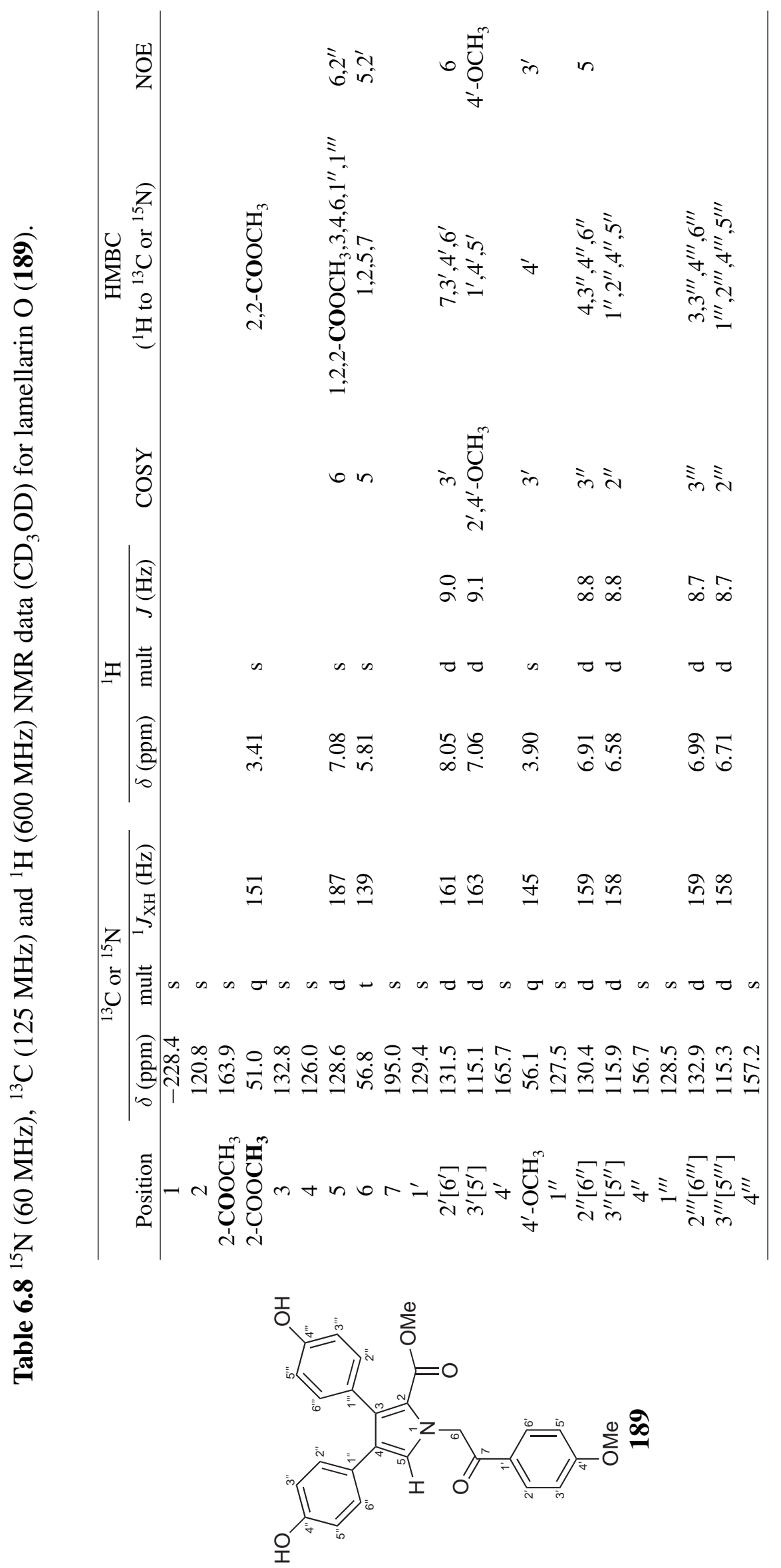




\subsection{Lamellarin $\theta \mathbf{4}^{\prime \prime}, \mathbf{4}^{\prime \prime \prime}$-disulfate}

Negative-ion mode HRESIMS of lamellarin $\theta 4^{\prime \prime}, 4^{\prime \prime \prime}$-disulfate (190) showed a single pseudo-molecular ion indicative of the molecular formula $\mathrm{C}_{26} \mathrm{H}_{19} \mathrm{NO}_{12} \mathrm{~S}_{2} \mathrm{Na}_{2}(300.5172$ $\left.[\mathrm{M}-2 \mathrm{Na}]^{2-}, \Delta 2.6 \mathrm{ppm}\right)$. The structure of $\mathbf{1 9 0}$ was elucidated in the same fashion as lamellarin $\theta$ (187). The molecular formula of 190 differs from 187 by the loss of 2 protons and the addition of $\mathrm{S}_{2} \mathrm{O}_{6} \mathrm{Na}_{2}$ (twice $\mathrm{SO}_{3} \mathrm{Na}$ ) which is consistent with lamellarin $\theta$ $4^{\prime \prime}, 4^{\prime \prime \prime}$-disulfate representing the sodium salt of a disulfate of $\mathbf{1 8 7}$. The ${ }^{1} \mathrm{H}$ NMR spectrum of 190 accounted for 18 of the 19 protons in the structure which is consistent with the loss of two exchangeable protons due to sulfation. The integration pattern of the ${ }^{1} \mathrm{H}$ NMR spectrum was identical to that of $\mathbf{1 8 7}$. The ${ }^{13} \mathrm{C}$ NMR spectrum of $\mathbf{1 9 0}$ indicated 20 distinct carbon environments consistent with three symmetrically disubstituted benzene rings as observed in lamellarin $\theta$. The molecular formula of $\mathbf{1 9 0}$ requires 25 doublebond equivalents. Again, 12 are accounted for by the benzene rings, a $13^{\text {th }}$ by a ketone resonance $\left(\delta_{\mathrm{C}} 194.5\right)$ and a further 8 by the two sulfate groups. Other identifiable moieties included an aromatic methine integrating for one proton $\left(\delta_{\mathrm{C}} 129.2, \delta_{\mathrm{H}} 7.19\right)$, a downfieldshifted methylene $\left(\delta_{\mathrm{C}} 56.8, \delta_{\mathrm{H}} 5.85\right)$ and an oxymethyl group $\left(\delta_{\mathrm{C}} 51.1, \delta_{\mathrm{H}} 3.42\right)$, all consistent with those observed in $\mathbf{1 8 7 .}$

Analysis of 2D NMR spectra of $\mathbf{1 9 0}$ allowed the construction of three substructures (Figure 6.6). COSY correlations between an aromatic methine (C-2' $\left[6^{\prime}\right]: \delta_{\mathrm{C}} 131.7$, $\left.\delta_{\mathrm{H}} 7.99\right)$ to a second aromatic methine $\left(\mathrm{C}-3^{\prime}\left[5^{\prime}\right]: \delta_{\mathrm{C}} 116.5, \delta_{\mathrm{H}} 6.91\right)$ indicated a $1,4-$ disubstituted benzene ring. HMBC correlations from $\mathrm{H}-2^{\prime}\left[6^{\prime}\right]$ to the carbonyl $\mathrm{C}-7$ $\left(\delta_{\mathrm{C}} 194.5\right)$ and non-protonated carbon C-4' $\left(\delta_{\mathrm{C}} 164.3\right)$ and from $\mathrm{H}-3^{\prime}\left[5^{\prime}\right]$ to non-protonated carbon $\mathrm{C}-1^{\prime}\left(\delta_{\mathrm{C}} 128.1\right)$ extended the first substructure. Finally a strong HMBC correlation from the methylene protons $\left(\mathrm{C}-6: \delta_{\mathrm{C}} 56.8, \delta_{\mathrm{H}} 5.85\right)$ to $\mathrm{C}-7$ indicated the connection between C-6 and C-7.

The second two substructures were assembled in parallel. COSY correlations between an aromatic methine $\left(\mathrm{C}-2^{\prime \prime}\left[6^{\prime \prime}\right]: \delta_{\mathrm{C}} 129.9, \delta_{\mathrm{H}} 7.07\right)$ and another aromatic methine $\left(\mathrm{C}-3^{\prime \prime}\left[5^{\prime \prime}\right]\right.$ : $\left.\delta_{\mathrm{C}} 122.2, \delta_{\mathrm{H}} 7.11\right)$ indicated one 1,4-disubstituted benzene ring while COSY correlations between another aromatic methine $\left(\mathrm{C}-2^{\prime \prime \prime}\left[6^{\prime \prime \prime}\right] \delta_{\mathrm{C}} 132.5, \delta_{\mathrm{H}} 7.17\right)$ and a final aromatic 
methine $\left(\mathrm{C}-3^{\prime \prime \prime}\left[5^{\prime \prime \prime}\right]: \delta_{\mathrm{C}} 121.4, \delta_{\mathrm{H}} 7.25\right)$ identified a second identically substituted benzene ring. HMBC correlations from $\mathrm{H}-2^{\prime \prime}\left[6^{\prime \prime}\right]$ to non-protonated carbons $\mathrm{C}-4\left(\delta_{\mathrm{C}} 125.2\right)$ and C-4" $\left(\delta_{\mathrm{C}} 152.2\right)$ and from $\mathrm{H}-3^{\prime \prime}\left[5^{\prime \prime}\right]$ to non-protonated carbon C-1" $\left(\delta_{\mathrm{C}} 132.6\right)$ completed one substructure while HMBC correlations from $\mathrm{H}-2^{\prime \prime \prime}\left[6^{\prime \prime \prime}\right]$ to non-protonated carbons $\mathrm{C}$ $3\left(\delta_{\mathrm{C}} 131.8\right)$ and $\mathrm{C}-4^{\prime \prime \prime}\left(\delta_{\mathrm{C}} 152.9\right)$ and from H-3 $3^{\prime \prime \prime}\left[5^{\prime \prime \prime}\right]$ to non-protonated carbon C- $1^{\prime \prime \prime}$ $\left(\delta_{\mathrm{C}} 133.7\right)$ completed the other.
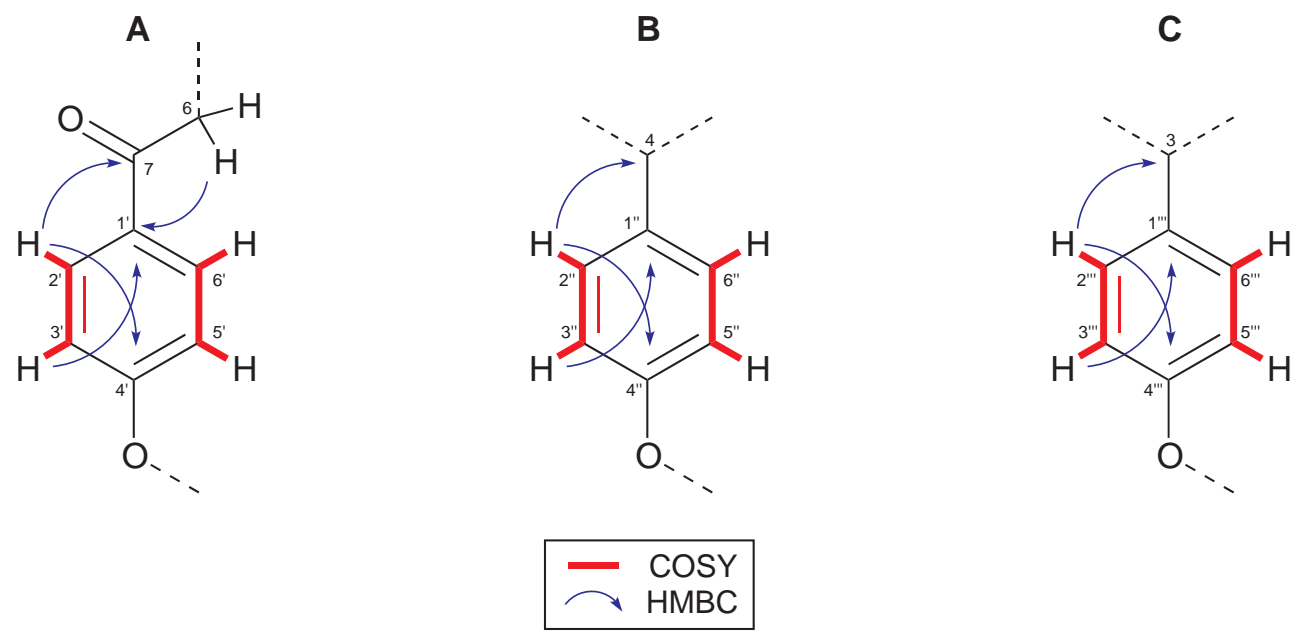

Figure 6.6 Selected COSY and HMBC correlations establishing substructures A-C of lamellarin $\theta 4^{\prime \prime}, 4^{\prime \prime \prime}$-disulfate (190).

Methylene $\mathrm{H}_{2}-6$ (substructure A) exhibited HMBC correlations to the nitrogen (N-1: $\left.\delta_{\mathrm{N}}-226.1\right)$, the aromatic methine $\left(\mathrm{C}-5: \delta_{\mathrm{C}} 129.2, \delta_{\mathrm{H}} 7.19\right)$ and a non-protonated aromatic carbon $\left(\mathrm{C}-2: \delta_{\mathrm{C}} 121.3\right)$ indicating the attachment of $\mathrm{C}-6$ to $\mathrm{N}-1$ and $\mathrm{N}-1$ to both $\mathrm{C}-2$ and C-5. HMBC correlations observed from the oxymethyl group to an ester carbonyl $\left(\delta_{\mathrm{C}}\right.$ 163.6) and C-2 suggested its nature as a methyl ester attached to C-2 and accounting for a $22^{\text {nd }}$ double bond equivalent. Aromatic methine H-5 displayed HMBC correlations to $\mathrm{N}-1$ (supporting the above assignment), C-4 (substructure B) and C-3 (substructure C). An NOE enhancement between $\mathrm{H}-5$ and $\mathrm{H}-2^{\prime \prime}\left[6^{\prime \prime}\right]$ necessitated the attachment of C-4 to C-5. The observed HMBC correlation from H-5 to C-3 in turn indicated the attachment of C-3 to C-4. With no further carbon resonances to assign, the structure was completed by connecting C-2 and C-3 forming a pyrrole core accounting for the remaining three double bond equivalents. Figure 6.7 shows the extended substructure of lamellarin $\theta$ $4^{\prime \prime}, 4^{\prime \prime \prime}$-disulfate.

A comparison of the shifts of the benzene rings of lamellarin $\theta$ (187) and lamellarin $\theta$ 


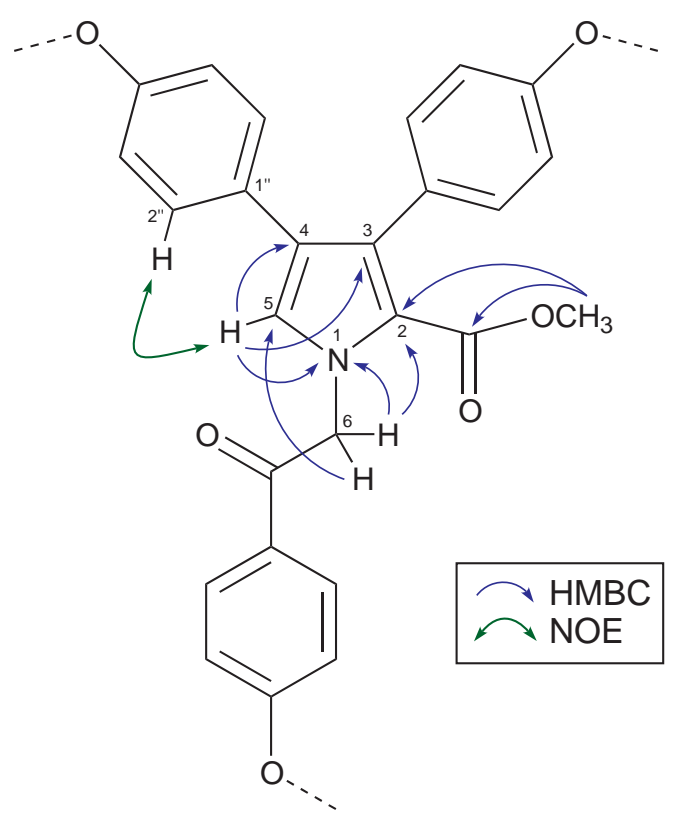

Figure 6.7 Selected correlations connecting the substructures of lamellarin $\theta$ $4^{\prime \prime}, 4^{\prime \prime \prime}$-disulfate (190).

$4^{\prime \prime}, 4^{\prime \prime \prime}$-disulfate (190) showed strong similarities between the shifts of ring A while rings $\mathrm{B}$ and $\mathrm{C}$ differed in a consistent manner (see Table 6.9). These data support the placement of the sulfate groups at positions $4^{\prime \prime}$ and $4^{\prime \prime \prime}$ and a hydroxyl at position $4^{\prime}$. The observed chemical shift changes were also consistent with the corresponding differences between the reported chemical shifts of the known compounds dictyodendrin $C(\mathbf{1 8 3})$ and D (184), which differ only by sulfation of a 4-hydroxybenzene moiety. ${ }^{161}$ NMR data for lamellarin $\theta 4^{\prime \prime}, 4^{\prime \prime \prime}$-disulfate (190) is presented in Table 6.10.

Table 6.9 Chemical shift differences between selected NMR data $\left(\mathrm{CD}_{3} \mathrm{OD}\right)$ for lamellarins $\theta(\mathbf{1 8 7})$ and $\theta 4^{\prime \prime}, 4^{\prime \prime \prime}$-disulfate (190).

\begin{tabular}{|c|c|c|c|c|c|c|}
\hline \multirow{3}{*}{ Position } & \multicolumn{2}{|c|}{ Lamellarin $\theta$} & \multicolumn{2}{|c|}{ Lamellarin $\theta 4^{\prime \prime}, 4^{\prime \prime \prime}$-disulfate } & \multicolumn{2}{|c|}{ Difference } \\
\hline & ${ }^{13} \mathrm{C}$ & ${ }^{1} \mathrm{H}$ & ${ }^{13} \mathrm{C}$ & ${ }^{1} \mathrm{H}$ & ${ }^{13} \mathrm{C}$ & ${ }^{1} \mathrm{H}$ \\
\hline & $\delta(\mathrm{ppm})$ & $\delta(\mathrm{ppm})$ & $\delta(\mathrm{ppm})$ & $\delta(\mathrm{ppm})$ & $\Delta \delta(\mathrm{ppm})$ & $\Delta \delta(\mathrm{ppm})$ \\
\hline $1^{\prime}$ & 128.1 & & 128.1 & & 0.0 & \\
\hline $2^{\prime}\left[6^{\prime}\right]$ & 131.8 & 7.98 & 131.7 & 7.99 & -0.1 & +0.01 \\
\hline $3^{\prime}\left[5^{\prime}\right]$ & 116.5 & 6.90 & 116.5 & 6.91 & 0.0 & +0.01 \\
\hline $4^{\prime}$ & 164.3 & & 164.3 & & 0.0 & \\
\hline $1^{\prime \prime}$ & 127.5 & & 132.6 & & +5.1 & \\
\hline $2^{\prime \prime}\left[6^{\prime \prime}\right]$ & 130.4 & 6.91 & 129.9 & 7.07 & -0.5 & +0.16 \\
\hline $3^{\prime \prime}\left[5^{\prime \prime}\right]$ & 115.8 & 6.58 & 122.2 & 7.11 & +6.4 & +0.53 \\
\hline $4^{\prime \prime}$ & 156.6 & & 152.2 & & -4.4 & \\
\hline $1^{\prime \prime \prime}$ & 128.5 & & 133.7 & & +5.2 & \\
\hline $2^{\prime \prime \prime}\left[6^{\prime \prime \prime}\right]$ & 132.9 & 7.00 & 132.5 & 7.17 & -0.4 & +0.17 \\
\hline $3^{\prime \prime \prime}\left[5^{\prime \prime \prime}\right]$ & 115.3 & 6.71 & 121.4 & 7.25 & +6.1 & +0.54 \\
\hline $4^{\prime \prime \prime}$ & 157.2 & & 152.9 & & -4.3 & \\
\hline
\end{tabular}




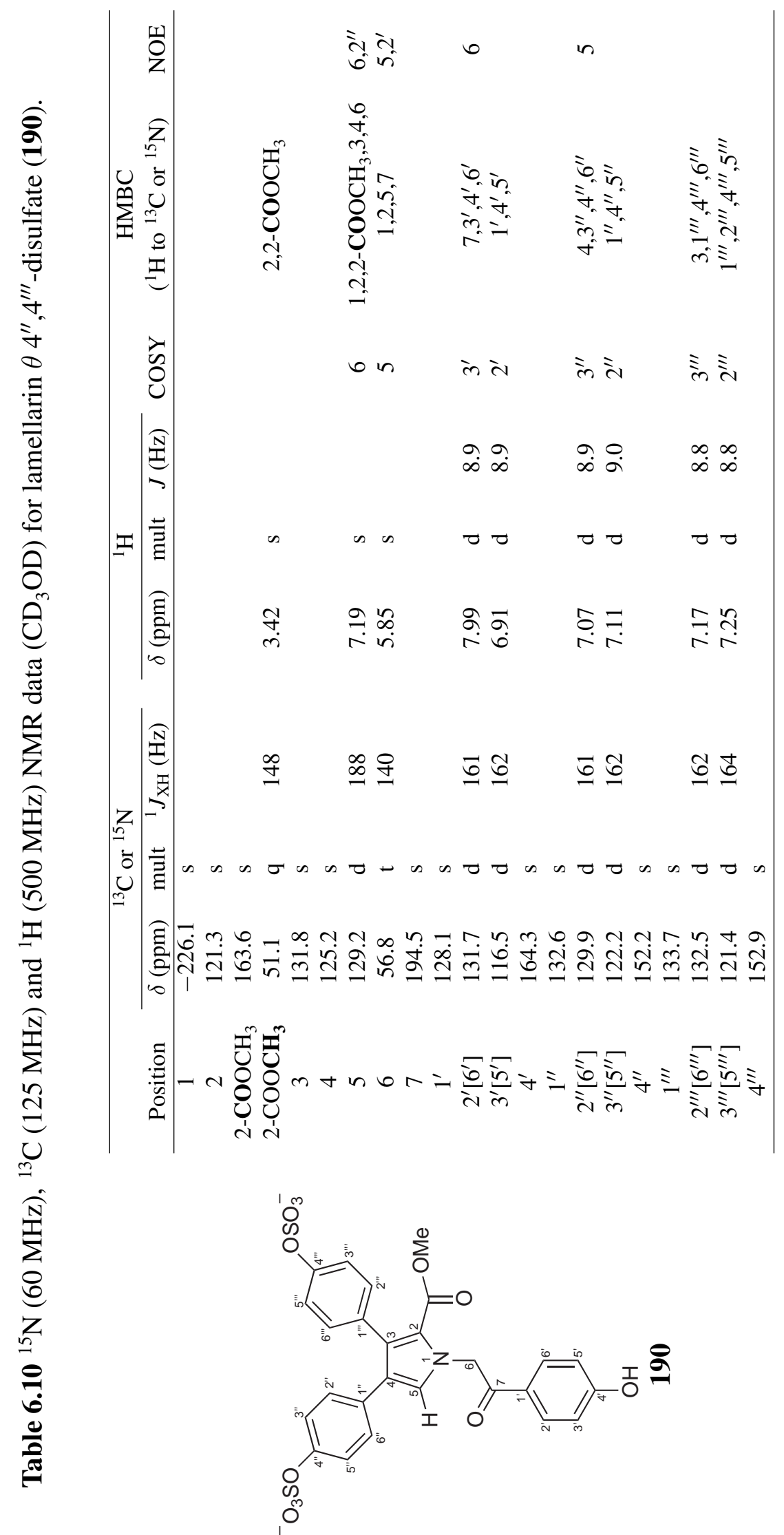




\subsection{Synthetic Derivatives of Lamellarin $\theta \mathbf{4}^{\prime \prime}, \mathbf{4}^{\prime \prime \prime}$-disulfate}

\section{Reaction of Lamellarin $\theta \mathbf{4}^{\prime \prime}, \mathbf{4}^{\prime \prime \prime}$-disulfate (190) with Barium Chloride}

As a simple test for the presence of sulfate groups, a few drops of $\mathrm{BaCl}_{2}$ were added to a small volume of $\mathbf{1 9 0}$ in $\mathrm{MeOH}$. The formation of a milky precipitate, attributable to the formation of the barium salt of $\mathbf{1 9 0}$, was observed.

\section{Desulfation of Lamellarin $\theta \mathbf{4}^{\prime \prime}, \mathbf{4}^{\prime \prime \prime}$-disulfate (190)}

In order to prove that 190 was a sulfated derivative of $\mathbf{1 8 7}$, an acidic desulfation was performed. Lamellarin $\theta 4^{\prime \prime}, 4^{\prime \prime \prime}$-disulfate was subjected to an excess of $p$-toluenesulfonic acid for one hour. The product isolated from the reaction mixture was spectrally identical to lamellarin $\theta$. 


\subsection{Lamellarin $O 4^{\prime \prime \prime}$-sulfate}

Negative-ion mode HRESIMS analysis of lamellarin O $4^{\prime \prime \prime}$-sulfate (191) gave rise to a single pseudo-molecular ion indicative of a molecular formula of $\mathrm{C}_{27} \mathrm{H}_{22} \mathrm{NO}_{9} \mathrm{SNa}$ $\left(536.1006[\mathrm{M}-\mathrm{Na}]^{-}, \Delta 0.7 \mathrm{ppm}\right)$. The molecular formula of lamellarin $\mathrm{O} 4^{\prime \prime \prime}$-sulfate differs from lamellarin $\mathrm{O}$ by the loss of one proton and the addition of $\mathrm{SO}_{3} \mathrm{Na}$ which is consistent with lamellarin $\mathrm{O} 4^{\prime \prime \prime}$-sulfate representing the sodium salt of a monosulfate of 189. The ${ }^{1} \mathrm{H}$ and ${ }^{13} \mathrm{C}$ NMR spectra of lamellarin $\mathrm{O} 44^{\prime \prime \prime}$-sulfate differ from those of lamellarin $\mathrm{O}$ only in resonances attributable to ring $\mathrm{C}$ and the observed chemical shift changes are consistent with sulfation at position $4^{\prime \prime \prime}$ (see Table 6.11). The observed chemical shifts for ring $C$ are consistent with those recorded for lamellarin $\theta 4^{\prime \prime}, 4^{\prime \prime \prime}$ disulfate which is also sulfated at position $4^{\prime \prime \prime}$. NMR data for lamellarin $\mathrm{O} 4^{\prime \prime \prime}$-sulfate (191) is presented in Table 6.12.

Table 6.11 Chemical shift differences between selected NMR data $\left(\mathrm{CD}_{3} \mathrm{OD}\right)$ for lamellarins $\mathrm{O}(\mathbf{1 8 9})$ and $\mathrm{O} 4^{\prime \prime \prime}$-sulfate (191).

\begin{tabular}{|c|c|c|c|c|c|c|}
\hline \multirow{3}{*}{ Position } & \multicolumn{2}{|c|}{ Lamellarin $\mathrm{O}$} & \multicolumn{2}{|c|}{ Lamellarin O $4^{\prime \prime \prime}$-sulfate } & \multicolumn{2}{|c|}{ Difference } \\
\hline & ${ }^{13} \mathrm{C}$ & ${ }^{1} \mathrm{H}$ & ${ }^{13} \mathrm{C}$ & ${ }^{1} \mathrm{H}$ & ${ }^{13} \mathrm{C}$ & ${ }^{1} \mathrm{H}$ \\
\hline & $\delta(\mathrm{ppm})$ & $\delta(\mathrm{ppm})$ & $\delta(\mathrm{ppm})$ & $\delta(\mathrm{ppm})$ & $\Delta \delta(\mathrm{ppm})$ & $\Delta \delta(\mathrm{ppm})$ \\
\hline $1^{\prime}$ & 129.4 & & 129.3 & & -0.1 & \\
\hline $2^{\prime}\left[6^{\prime}\right]$ & 131.5 & 8.05 & 131.5 & 8.08 & 0.0 & +0.03 \\
\hline $3^{\prime}\left[5^{\prime}\right]$ & 115.1 & 7.06 & 115.1 & 7.09 & 0.0 & +0.03 \\
\hline $4^{\prime}$ & 165.7 & & 165.7 & & 0.0 & \\
\hline $1^{\prime \prime}$ & 127.5 & & 127.0 & & -0.5 & \\
\hline $2^{\prime \prime}\left[6^{\prime \prime}\right]$ & 130.4 & 6.91 & 130.5 & 6.90 & -0.1 & -0.01 \\
\hline $3^{\prime \prime}\left[5^{\prime \prime}\right]$ & 115.9 & 6.58 & 116.0 & 6.58 & +0.1 & 0.00 \\
\hline $4^{\prime \prime}$ & 156.7 & & 156.9 & & +0.2 & \\
\hline $1^{\prime \prime \prime}$ & 128.5 & & 134.0 & & +5.5 & \\
\hline $2^{\prime \prime \prime}\left[6^{\prime \prime \prime}\right]$ & 132.9 & 6.99 & 132.6 & 7.15 & -0.3 & +0.16 \\
\hline $3^{\prime \prime \prime}\left[5^{\prime \prime \prime}\right]$ & 115.3 & 6.71 & 121.3 & 7.23 & +6.0 & +0.52 \\
\hline $4^{\prime \prime \prime}$ & 157.2 & & 152.8 & & -4.4 & \\
\hline
\end{tabular}




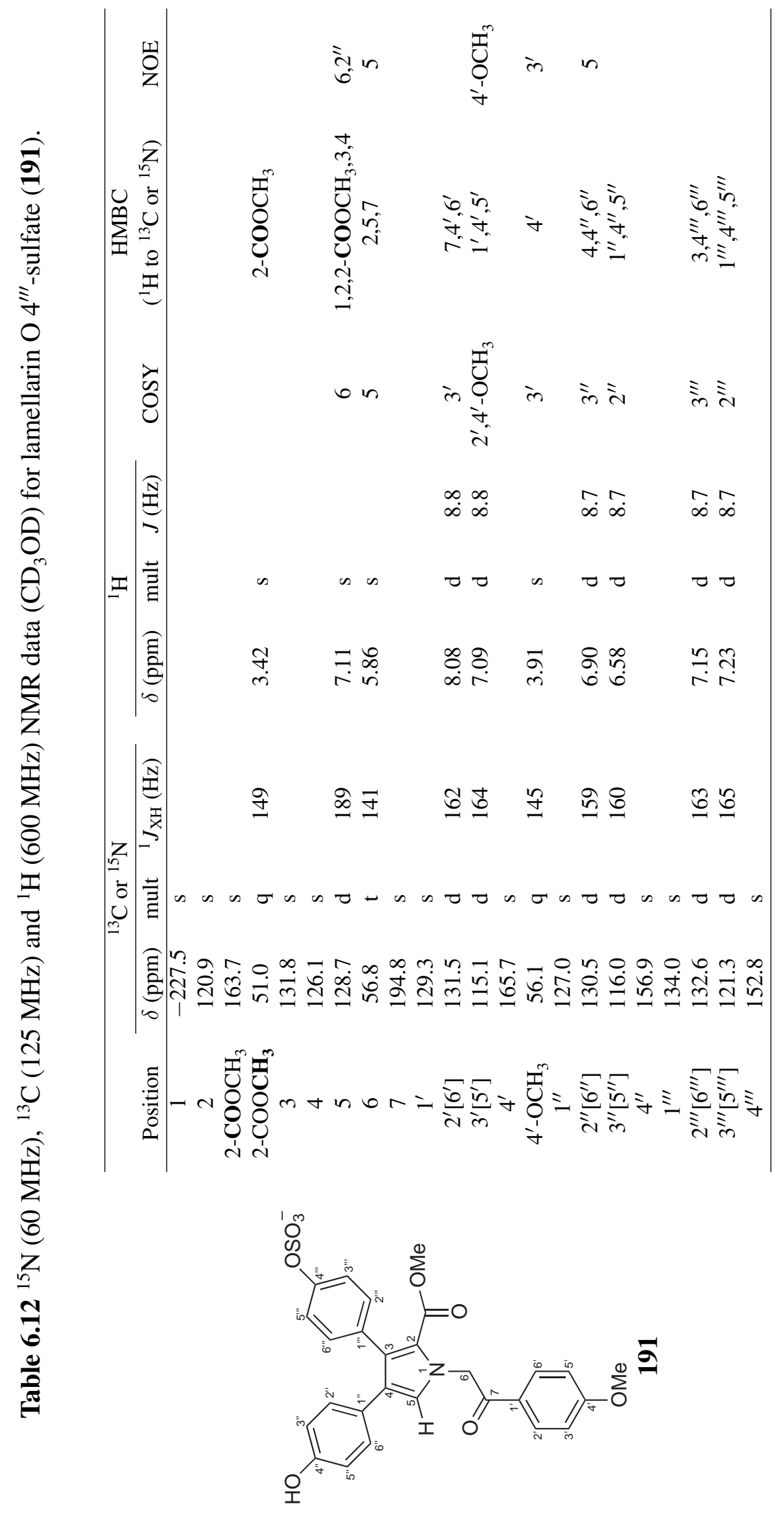




\subsection{Lamellarin $04^{\prime \prime}, 4^{\prime \prime \prime}$-disulfate}

Negative-ion mode HRESIMS analysis of lamellarin O $4^{\prime \prime}, 4^{\prime \prime \prime}$-disulfate (192) gave rise to a single pseudo-molecular ion indicative of a molecular formula of $\mathrm{C}_{27} \mathrm{H}_{21} \mathrm{NO}_{12} \mathrm{~S}_{2} \mathrm{Na}_{2}$ $\left(307.5256[\mathrm{M}-2 \mathrm{Na}]^{2-}, \Delta 0.6 \mathrm{ppm}\right)$. The molecular formula of lamellarin $\mathrm{O} 4^{\prime \prime}, 4^{\prime \prime \prime}-$ disulfate differs from lamellarin $\mathrm{O}$ by the loss of two protons and the addition of $\mathrm{S}_{2} \mathrm{O}_{6} \mathrm{Na}_{2}$ (twice $\mathrm{SO}_{3} \mathrm{Na}$ ) which is consistent with lamellarin $\mathrm{O} 4^{\prime \prime}, 4^{\prime \prime \prime}$-disulfate representing the sodium salt of a disulfate of 189. The ${ }^{1} \mathrm{H}$ and ${ }^{13} \mathrm{C}$ NMR spectra of lamellarin $\mathrm{O} 44^{\prime \prime}, 4^{\prime \prime \prime}-$ disulfate show chemical shift changes relative to lamellarin $\mathrm{O}$ which are indicative of sulfation at positions $4^{\prime \prime}$ and $4^{\prime \prime \prime}$ (see Table 6.13). Again, the observed chemical shifts for rings $\mathrm{B}$ and $\mathrm{C}$ are consistent with those recorded for lamellarin $\theta 4^{\prime \prime}, 4^{\prime \prime \prime}$-disulfate which is also sulfated at positions $4^{\prime \prime}$ and $4^{\prime \prime \prime}$. NMR data for lamellarin $\mathrm{O} 4^{\prime \prime}, 4^{\prime \prime \prime}$-disulfate (192) is presented in Table 6.14 .

Table 6.13 Chemical shift differences between selected NMR data $\left(\mathrm{CD}_{3} \mathrm{OD}\right)$ for lamellarins $\mathrm{O}(\mathbf{1 8 9})$ and $\mathrm{O} 4^{\prime \prime}, 4^{\prime \prime \prime}$-disulfate (192).

\begin{tabular}{|c|c|c|c|c|c|c|}
\hline \multirow{3}{*}{ Position } & \multicolumn{2}{|c|}{ Lamellarin $\mathrm{O}$} & \multicolumn{2}{|c|}{ Lamellarin $\mathrm{O} 4^{\prime \prime}, 4^{\prime \prime \prime}$-disulfate } & \multicolumn{2}{|c|}{ Difference } \\
\hline & ${ }^{13} \mathrm{C}$ & ${ }^{1} \mathrm{H}$ & ${ }^{13} \mathrm{C}$ & ${ }^{1} \mathrm{H}$ & ${ }^{13} \mathrm{C}$ & ${ }^{1} \mathrm{H}$ \\
\hline & $\delta(\mathrm{ppm})$ & $\delta(\mathrm{ppm})$ & $\delta(\mathrm{ppm})$ & $\delta(\mathrm{ppm})$ & $\Delta \delta(\mathrm{ppm})$ & $\Delta \delta(\mathrm{ppm})$ \\
\hline $1^{\prime}$ & 129.4 & & 129.2 & & -0.2 & \\
\hline $2^{\prime}\left[6^{\prime}\right]$ & 131.5 & 8.05 & 131.5 & 7.99 & 0.0 & +0.03 \\
\hline $3^{\prime}\left[5^{\prime}\right]$ & 115.1 & 7.06 & 115.1 & 6.91 & 0.0 & +0.02 \\
\hline $4^{\prime}$ & 165.7 & & 165.7 & & 0.0 & \\
\hline $1^{\prime \prime}$ & 127.5 & & 132.6 & & +5.1 & \\
\hline $2^{\prime \prime}\left[6^{\prime \prime}\right]$ & 130.4 & 6.91 & 129.9 & 7.07 & -0.5 & +0.16 \\
\hline $3^{\prime \prime}\left[5^{\prime \prime}\right]$ & 115.9 & 6.58 & 122.2 & 7.11 & +6.3 & +0.53 \\
\hline $4^{\prime \prime}$ & 156.7 & & 152.2 & & -4.5 & \\
\hline $1^{\prime \prime \prime}$ & 128.5 & & 133.7 & & +5.2 & \\
\hline $2^{\prime \prime \prime}\left[6^{\prime \prime \prime}\right]$ & 132.9 & 6.99 & 132.6 & 7.17 & -0.3 & +0.18 \\
\hline $3^{\prime \prime \prime}\left[5^{\prime \prime \prime}\right]$ & 115.3 & 6.71 & 121.4 & 7.25 & +6.1 & +0.54 \\
\hline $4^{\prime \prime \prime}$ & 157.2 & & 152.9 & & -4.3 & \\
\hline
\end{tabular}




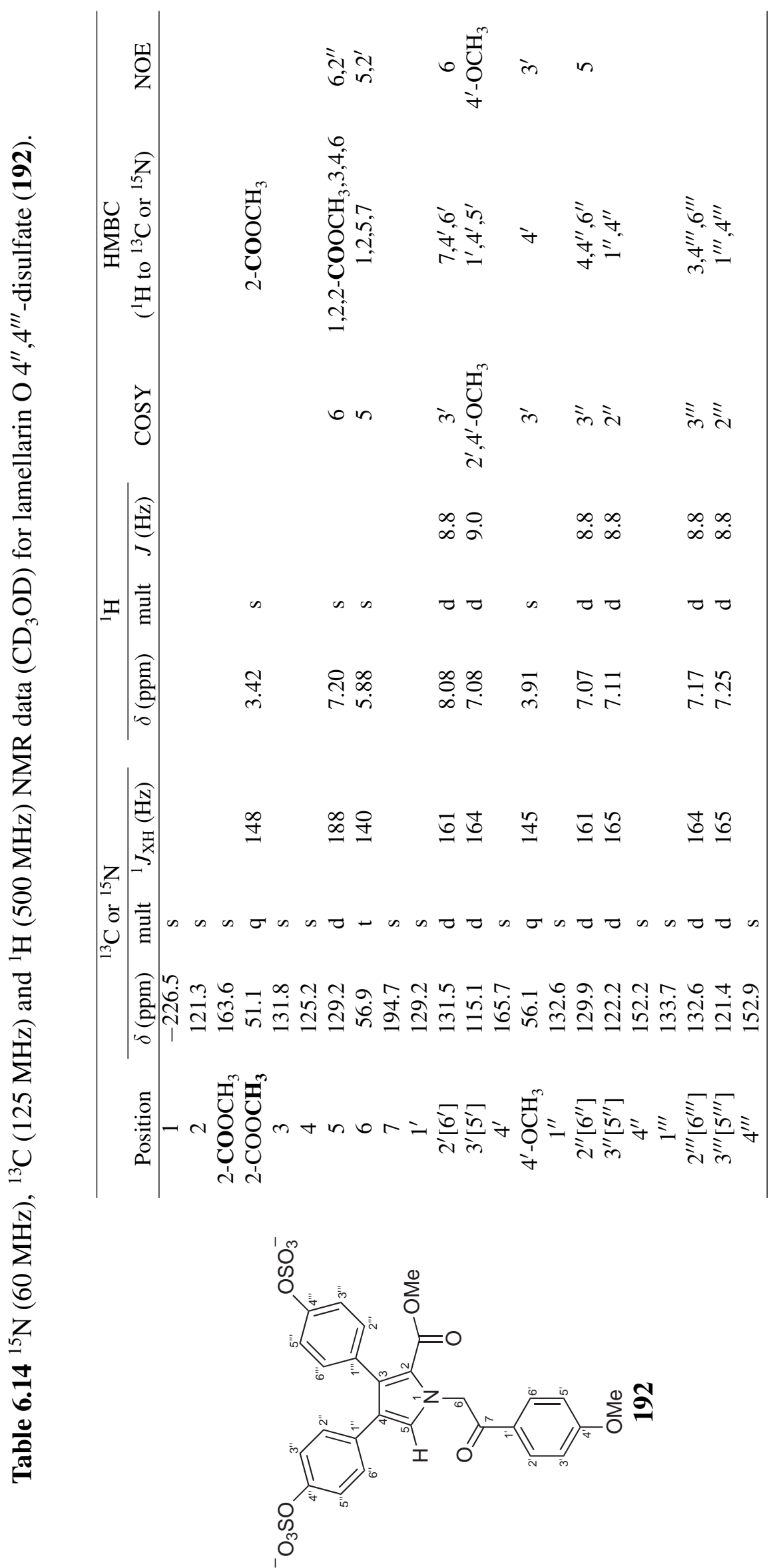




\subsection{Lamellarin $\kappa$}

Positive-ion mode HRESIMS analysis of lamellarin $\kappa(\mathbf{1 8 8})$ gave rise to a single pseudomolecular ion indicative of a molecular formula of $\mathrm{C}_{28} \mathrm{H}_{25} \mathrm{NO}_{7}\left(488.1682[\mathrm{M}+\mathrm{H}]^{+}, \Delta\right.$ $4.5 \mathrm{ppm})$. The molecular formula of 188 differs from lamellarin $\theta(\mathbf{1 8 7})$ by $44 \mathrm{Da}$ or $\mathrm{C}_{2} \mathrm{H}_{4} \mathrm{O}$. The most noticeable difference in the NMR spectra of lamellarin $\kappa$ is the loss of symmetry of one of the benzene rings. Three aromatic proton resonances $\left(\delta_{\mathrm{H}} 7.79\right.$, $6.74,6.69)$, each integrating for one proton, were observed suggesting a trisubstituted benzene moiety. Also present in the NMR spectra were resonances attributable to two new oxymethyl groups $\left(\delta_{\mathrm{C}} 56.0, \delta_{\mathrm{H}} 3.99\right.$ and $\left.\delta_{\mathrm{C}} 55.7, \delta_{\mathrm{H}} 3.88\right)$. All other spectral features of lamellarin $\theta$ were still present.

Analysis of the COSY and HMBC spectra of $\mathbf{1 8 8}$ led to the construction of a new ring A substructure. COSY correlations between aromatic methine doublet $\mathrm{H}-3^{\prime}\left(\delta_{\mathrm{C}} 98.4\right.$, $\left.\delta_{\mathrm{H}} 6.74\right)$ and $\mathrm{H}-5^{\prime}\left(\delta_{\mathrm{C}} 106.6, \delta_{\mathrm{H}} 6.69\right)$ and $\mathrm{H}-5^{\prime}$ and $\mathrm{H}-6^{\prime}\left(\delta_{\mathrm{C}} 132.1, \delta_{\mathrm{H}} 7.79\right)$ established a trisubstituted benzene ring. The measured coupling constant between $\mathrm{H}-3^{\prime}$ and $\mathrm{H}-$ $5^{\prime}$ of $2.3 \mathrm{~Hz}$ is consistent with meta-coupling while the coupling constant of $8.8 \mathrm{~Hz}$ measured between $\mathrm{H}-5^{\prime}$ and $\mathrm{H}-6^{\prime}$ places them ortho to one another. HMBC correlations observed from $\mathrm{H}-3^{\prime}$ to two oxygenated non-protonated aromatic carbons $\left(\delta_{\mathrm{C}} 164.9\right.$, $161.3)$ and one further non-protonated aromatic carbon $\left(\delta_{\mathrm{C}} 117.7\right)$ completed the benzene ring. Methine $\mathrm{H}-3^{\prime}$ displayed weak long-range COSY correlations to both oxymethyl resonances suggesting that positions $2^{\prime}$ and $4^{\prime}$ were methoxy-substituted. The observation of NOE enhancements between oxymethyl protons $4^{\prime}-\mathrm{OCH}_{3}\left(\delta_{\mathrm{C}} 55.7, \delta_{\mathrm{H}} 3.88\right)$ and methines $\mathrm{H}-3^{\prime}$ and $\mathrm{H}-5^{\prime}$ and between oxymethyl protons $2^{\prime}-\mathrm{OCH}_{3}\left(\delta_{\mathrm{C}} 56.0, \delta_{\mathrm{H}} 3.99\right)$ and $\mathrm{H}-3^{\prime}$ confirmed this assessment. This information combined with HMBC correlations observed from $2^{\prime}-\mathrm{OCH}_{3}$ to $\mathrm{C}-2^{\prime}\left(\delta_{\mathrm{C}} 161.3\right)$ and from $4^{\prime}-\mathrm{OCH}_{3}$ to $\mathrm{C}-4^{\prime}\left(\delta_{\mathrm{C}} 164.9\right)$ confirmed the linear sequence of $\mathrm{C}-2^{\prime}, \mathrm{C}-3^{\prime}, \mathrm{C}-4^{\prime}$ and $\mathrm{C}-5^{\prime}$. The remaining non-protonated aromatic carbon was assigned as $\mathrm{C}-1^{\prime}\left(\delta_{\mathrm{C}}\right.$ 117.7). An $\mathrm{HMBC}$ correlation from $\mathrm{H}-6^{\prime}$ to $\mathrm{C}-7$ $\left(\delta_{\mathrm{C}}\right.$ 192.2) indicated the attachment of $\mathrm{C}-7$ to $\mathrm{C}-1^{\prime}$. Finally, an HMBC correlation observed from methylene protons $\mathrm{H}_{2}-6\left(\delta_{\mathrm{C}} 59.5, \delta_{\mathrm{H}} 5.62\right)$ to $\mathrm{C}-7$ completed the new ring $\mathrm{A}$ substructure (Figure 6.8). 


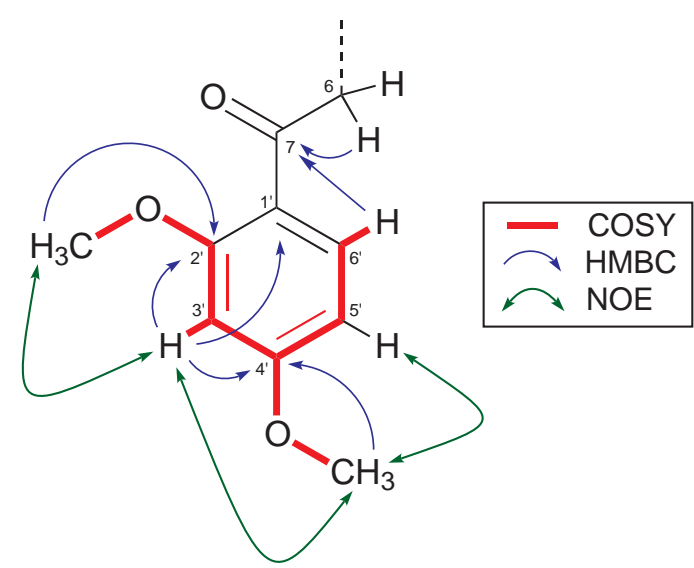

Figure 6.8 Selected COSY and HMBC correlations establishing the ring A substructure of lamellarin $\kappa(\mathbf{1 8 8})$.

With the new ring A substructure accounting for the extra $\mathrm{C}_{2} \mathrm{H}_{4} \mathrm{O}$ in the molecular formula, the remainder of the structure of $\mathbf{1 8 8}$ was constructed in an identical fashion to that of lamellarin $\theta$. NMR data for lamellarin $\kappa(\mathbf{1 8 8})$ is presented in Table 6.15. 


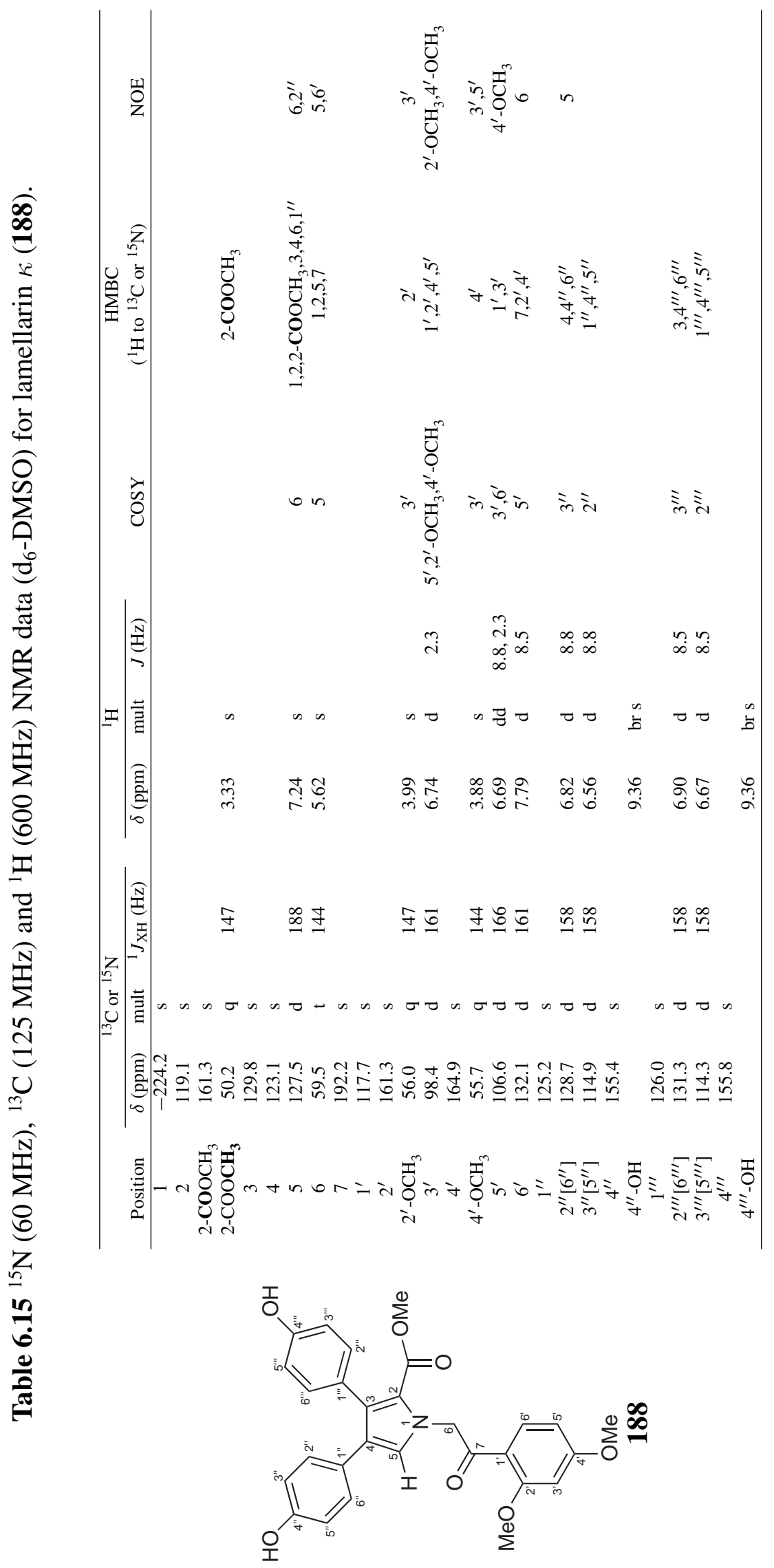




\subsection{Lamellarin $\kappa 4^{\prime \prime \prime}$-sulfate}

Negative-ion mode HRESIMS analysis of lamellarin $\kappa 4^{\prime \prime \prime}$-sulfate (193) gave rise to

a single pseudo-molecular ion indicative of a molecular formula of $\mathrm{C}_{28} \mathrm{H}_{24} \mathrm{NO}_{10} \mathrm{SNa}$ $\left(566.1110[\mathrm{M}-\mathrm{Na}]^{-}, \Delta 0.9 \mathrm{ppm}\right)$. The molecular formula of 193 differs from lamellarin $\kappa$ by the loss of one proton and the addition of $\mathrm{SO}_{3} \mathrm{Na}$ which is consistent with lamellarin $\kappa 4^{\prime \prime \prime}$-sulfate representing the sodium salt of a monosulfate of $\mathbf{1 8 8}$. As with lamellarins $\mathrm{O}$ and $\mathrm{O} 4{ }^{\prime \prime \prime}$-sulfate, the ${ }^{1} \mathrm{H}$ and ${ }^{13} \mathrm{C}$ NMR spectra of lamellarin $\kappa 4^{\prime \prime \prime}$-sulfate differ from those of lamellarin $\kappa$ only in resonances attributable to ring $\mathrm{C}$ and the observed chemical shift changes are consistent with sulfation at position $4^{\prime \prime \prime}$ (see Table 6.16). NMR data for lamellarin $\kappa 4^{\prime \prime \prime}$-sulfate $(\mathbf{1 9 3})$ is presented in both $\mathrm{CD}_{3} \mathrm{OD}$ (Table 6.17) and $\mathrm{d}_{6^{-}}$ DMSO (Table 6.18).

Table 6.16 Chemical shift differences between selected NMR data $\left(\mathrm{d}_{6}\right.$-DMSO) for lamellarins $\kappa \mathbf{( 1 8 8 )}$ and $\kappa 4^{\prime \prime \prime}$-sulfate (193).

\begin{tabular}{|c|c|c|c|c|c|c|}
\hline \multirow{3}{*}{ Position } & \multicolumn{2}{|c|}{ Lamellarin $\kappa$} & \multicolumn{2}{|c|}{ Lamellarin $\kappa 4^{\prime \prime \prime}$-sulfate } & \multicolumn{2}{|c|}{ Difference } \\
\hline & ${ }^{13} \mathrm{C}$ & ${ }^{1} \mathrm{H}$ & ${ }^{13} \mathrm{C}$ & ${ }^{1} \mathrm{H}$ & ${ }^{13} \mathrm{C}$ & ${ }^{1} \mathrm{H}$ \\
\hline & $\delta(\mathrm{ppm})$ & $\delta(\mathrm{ppm})$ & $\delta(\mathrm{ppm})$ & $\delta(\mathrm{ppm})$ & $\Delta \delta(\mathrm{ppm})$ & $\Delta \delta(\mathrm{ppm})$ \\
\hline $1^{\prime}$ & 117.7 & & 117.7 & & 0.0 & \\
\hline $2^{\prime}$ & 161.3 & & 161.4 & & +0.1 & \\
\hline $3^{\prime}$ & 98.4 & 6.74 & 98.4 & 6.74 & 0.0 & 0.00 \\
\hline $4^{\prime}$ & 164.9 & & 165.0 & & +0.1 & \\
\hline $5^{\prime}$ & 106.6 & 6.69 & 106.6 & 6.69 & 0.0 & 0.00 \\
\hline $6^{\prime}$ & 132.1 & 7.79 & 132.2 & 7.80 & +0.1 & +0.01 \\
\hline $1^{\prime \prime}$ & 125.2 & & 125.1 & & -0.1 & \\
\hline $2^{\prime \prime}\left[6^{\prime \prime}\right]$ & 128.7 & 6.82 & 128.8 & 6.81 & -0.1 & -0.01 \\
\hline $3^{\prime \prime}\left[5^{\prime \prime}\right]$ & 114.9 & 6.56 & 115.0 & 6.57 & +0.1 & +0.01 \\
\hline $4^{\prime \prime}$ & 155.4 & & 155.6 & & +0.2 & \\
\hline $1^{\prime \prime \prime}$ & 126.0 & & 129.9 & & +3.9 & \\
\hline $2^{\prime \prime \prime}\left[6^{\prime \prime \prime}\right]$ & 131.3 & 6.90 & 130.7 & 7.00 & -0.6 & +0.10 \\
\hline $3^{\prime \prime \prime}\left[5^{\prime \prime \prime}\right]$ & 114.3 & 6.67 & 118.8 & 7.07 & +4.5 & +0.40 \\
\hline $4^{\prime \prime \prime}$ & 155.8 & & 152.2 & & -3.6 & \\
\hline
\end{tabular}




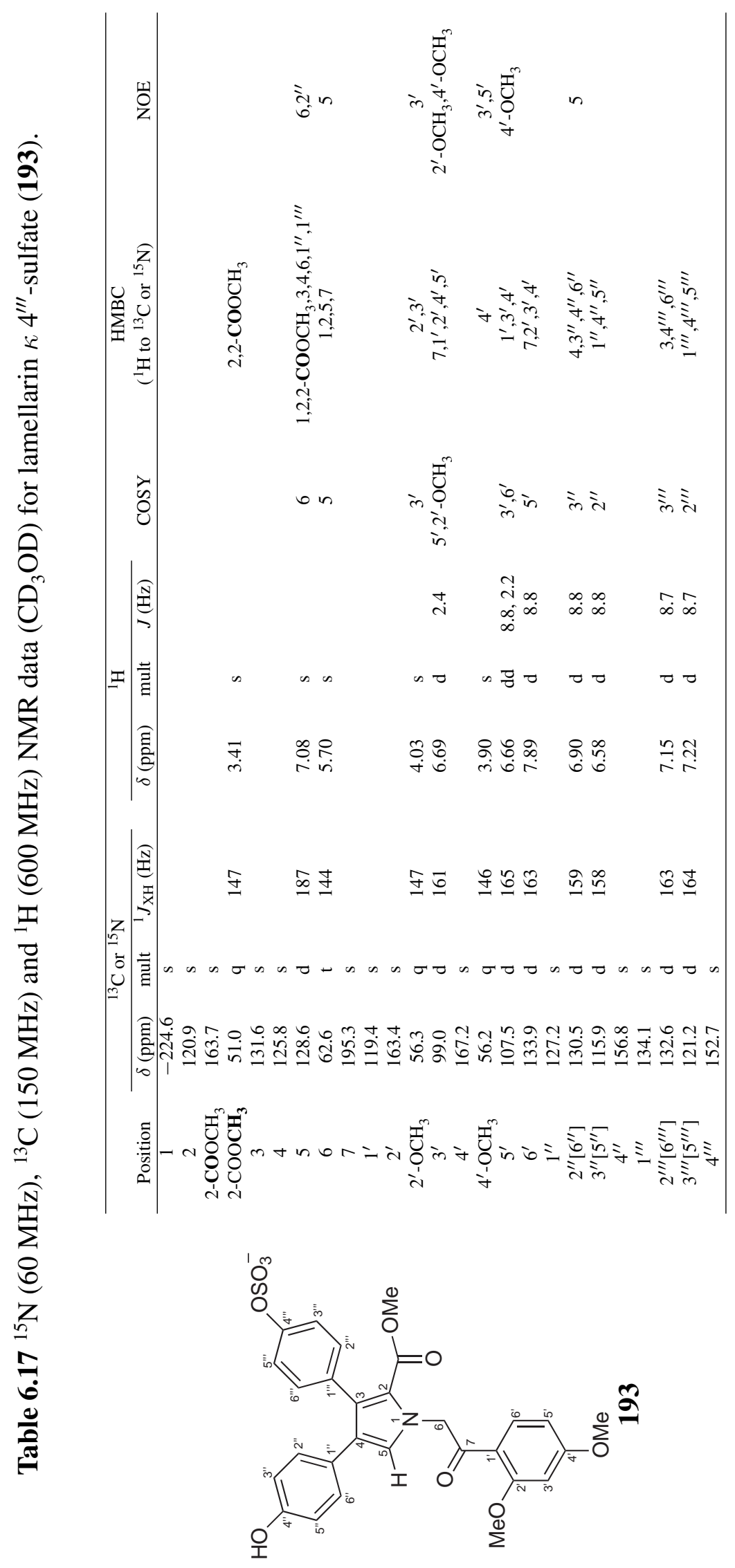




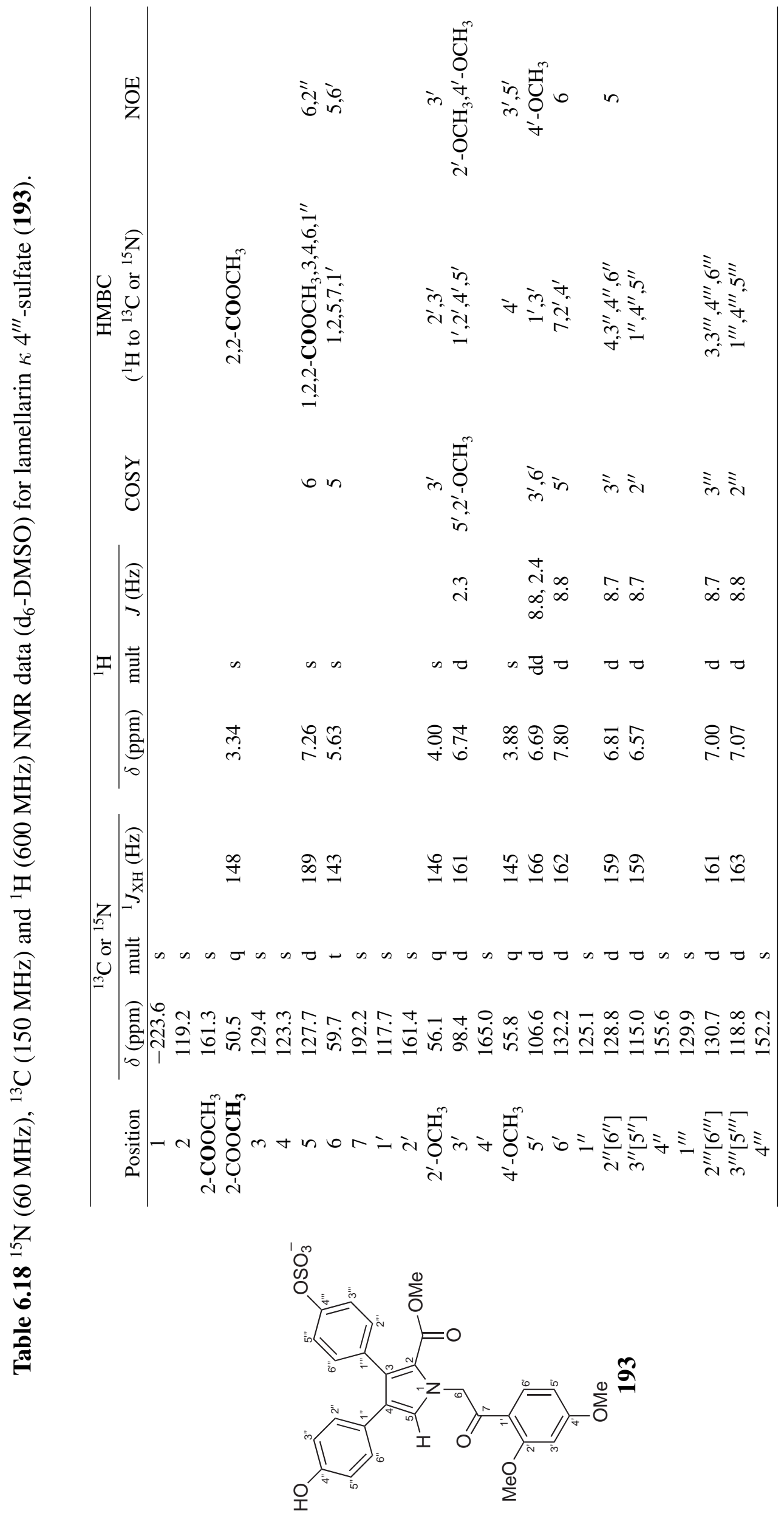




\subsection{Lamellarin $\kappa \mathbf{4}^{\prime \prime}, \mathbf{4}^{\prime \prime \prime}$-disulfate}

Negative-ion mode HRESIMS analysis of lamellarin $\kappa 4^{\prime \prime}, 4^{\prime \prime \prime}$-disulfate (194) gave rise to a single pseudo-molecular ion indicative of a molecular formula of $\mathrm{C}_{28} \mathrm{H}_{23} \mathrm{NO}_{13} \mathrm{~S}_{2} \mathrm{Na}_{2}$ $\left(322.5323[\mathrm{M}-2 \mathrm{Na}]^{2-}, \Delta 3.6 \mathrm{ppm}\right)$. The molecular formula of lamellarin $\kappa 4^{\prime \prime}, 4^{\prime \prime \prime}-$ disulfate differs from lamellarin $\kappa$ by the loss of two protons and the addition of $\mathrm{S}_{2} \mathrm{O}_{6} \mathrm{Na}_{2}$ (twice $\mathrm{SO}_{3} \mathrm{Na}$ ) which is consistent with lamellarin $\kappa 4^{\prime \prime}, 4^{\prime \prime \prime}$-disulfate representing the sodium salt of a disulfate of $\mathbf{1 8 8}$. As with lamellarins $\mathrm{O}$ and $\mathrm{O} 4^{\prime \prime}, 4^{\prime \prime \prime}$-disulfate, the ${ }^{1} \mathrm{H}$ and ${ }^{13} \mathrm{C}$ NMR spectra of lamellarin $\kappa 4^{\prime \prime}, 4^{\prime \prime \prime}$-disulfate show chemical shift changes relative to lamellarin $\kappa$ which are indicative of sulfation at positions $4^{\prime \prime}$ and $4^{\prime \prime \prime}$ (see Table 6.19). NMR data for lamellarin $\kappa 4^{\prime \prime}, 4^{\prime \prime \prime}$-disulfate (194) is presented in both $\mathrm{CD}_{3} \mathrm{OD}$ (Table 6.20) and $\mathrm{d}_{6}$-DMSO (Table 6.21).

Table 6.19 Chemical shift differences between selected NMR data $\left(\mathrm{d}_{6}\right.$-DMSO) for lamellarins $\kappa \mathbf{( 1 8 8 )}$ and $\kappa 4^{\prime \prime}, 4^{\prime \prime \prime}$-disulfate (194).

\begin{tabular}{|c|c|c|c|c|c|c|}
\hline \multirow{3}{*}{ Position } & \multicolumn{2}{|c|}{ Lamellarin $\kappa$} & \multicolumn{2}{|c|}{ Lamellarin $\kappa 4^{\prime \prime}, 4^{\prime \prime \prime}$-disulfate } & \multicolumn{2}{|c|}{ Difference } \\
\hline & ${ }^{13} \mathrm{C}$ & ${ }^{1} \mathrm{H}$ & ${ }^{13} \mathrm{C}$ & ${ }^{1} \mathrm{H}$ & ${ }^{13} \mathrm{C}$ & ${ }^{1} \mathrm{H}$ \\
\hline & $\delta(\mathrm{ppm})$ & $\delta(\mathrm{ppm})$ & $\delta(\mathrm{ppm})$ & $\delta(\mathrm{ppm})$ & $\Delta \delta(\mathrm{ppm})$ & $\Delta \delta(\mathrm{ppm})$ \\
\hline $1^{\prime}$ & 117.7 & & 117.7 & & 0.0 & \\
\hline $2^{\prime}$ & 161.3 & & 161.4 & & +0.1 & \\
\hline $3^{\prime}$ & 98.4 & 6.74 & 98.4 & 6.75 & 0.0 & +0.01 \\
\hline $4^{\prime}$ & 164.9 & & 165.0 & & +0.1 & \\
\hline $5^{\prime}$ & 106.6 & 6.69 & 106.7 & 6.69 & +0.1 & 0.00 \\
\hline $6^{\prime}$ & 132.1 & 7.79 & 132.3 & 7.80 & +0.2 & +0.01 \\
\hline $1^{\prime \prime}$ & 125.2 & & 129.3 & & +4.1 & \\
\hline $2^{\prime \prime}\left[6^{\prime \prime}\right]$ & 128.7 & 6.82 & 127.9 & 6.92 & -0.8 & +0.10 \\
\hline $3^{\prime \prime}\left[5^{\prime \prime}\right]$ & 114.9 & 6.56 & 120.2 & 6.98 & +5.3 & +0.42 \\
\hline $4^{\prime \prime}$ & 155.4 & & 151.6 & & -3.8 & \\
\hline $1^{\prime \prime \prime}$ & 126.0 & & 129.8 & & +3.8 & \\
\hline $2^{\prime \prime \prime}\left[6^{\prime \prime \prime}\right]$ & 131.3 & 6.90 & 130.7 & 7.04 & -0.6 & +0.14 \\
\hline $3^{\prime \prime \prime}\left[5^{\prime \prime \prime}\right]$ & 114.3 & 6.67 & 119.0 & 7.11 & +4.7 & +0.44 \\
\hline $4^{\prime \prime \prime}$ & 155.8 & & 152.2 & & -3.6 & \\
\hline
\end{tabular}




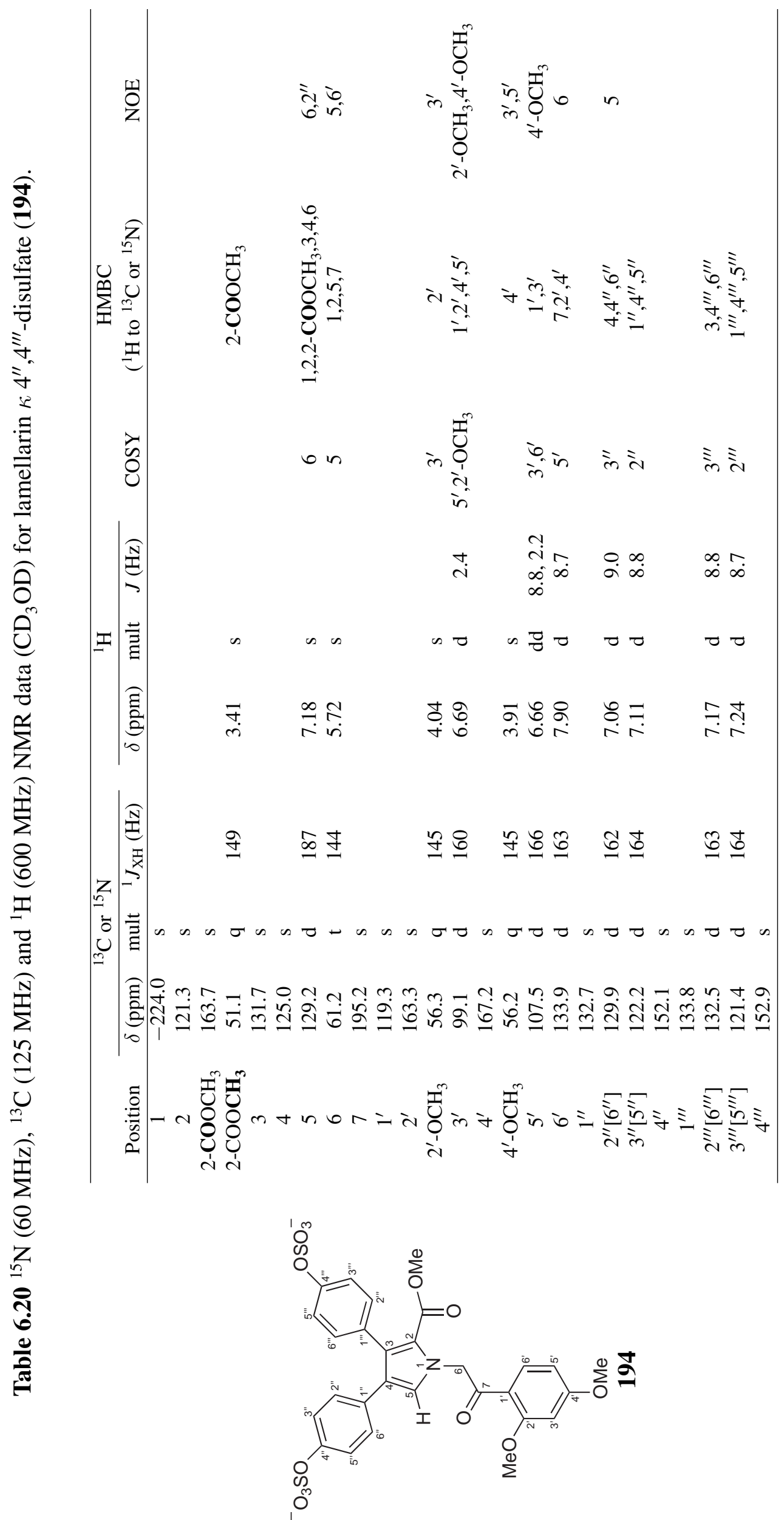




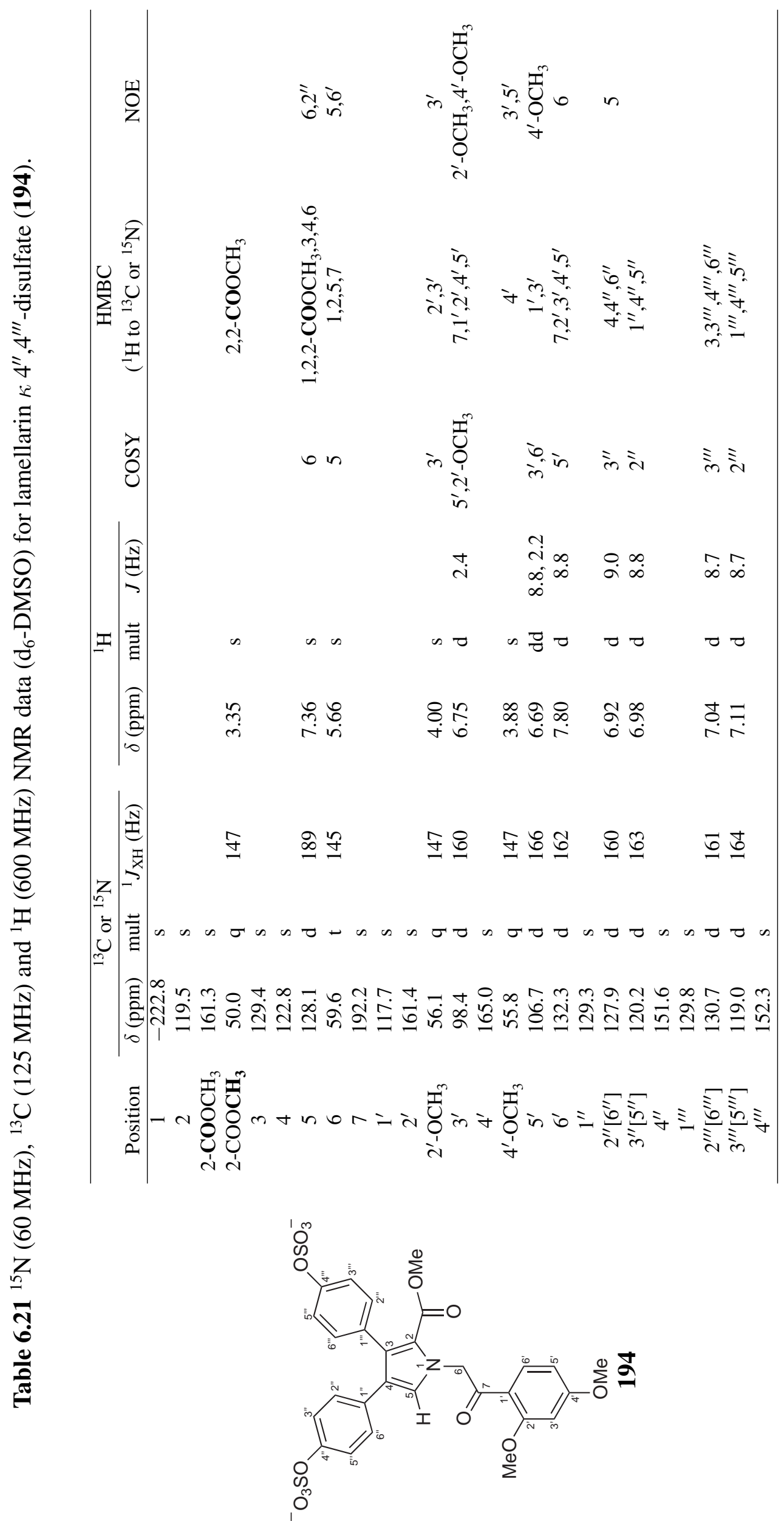




\subsection{Summary}

The lamellarins are one of the most extensive families of natural products known. Including those described herein, the family consists of 49 naturally occurring members and numerous synthetic and semi-synthetic derivatives. The first lamellarins, A-D (201-204) were reported in 1985 from a Palauan collection of the mollusc Lamellaria sp. ${ }^{167}$ In 1988 four further lamellarins, E-H (205-208) were isolated from the marine tunicate Didemnum chartaceum collected from the Republic of Seychelles. ${ }^{168}$ Family Lamellariidae is known to predate upon tunicates and as a result, the lamellarins isolated from Lamellaria sp. were suggested to have been sequestered from the mollusc's prey. ${ }^{168}$ Six further lamellarins, I-M (209-213) and N (214) (the latter as the 8,13,20-triacetate on account of peracetylation during isolation) were reported in 1993 isolated from an unknown species of genus Didemnum. ${ }^{169}$ Lamellarins A-D (201-204) were also reisolated from the same extraction of Didemnum sp. lending support to the hypothesis that Lamellaria sp. obtained these metabolites from its food source. ${ }^{169}$ In 1994 lamellarins $\mathrm{O}$ (189) and P (215) were reported from an Australian collection of the marine sponge Dendrilla cactos. ${ }^{164}$ These were followed a year later by lamellarins Q (216) and R (217) isolated from a separate Australian collection of the same species. ${ }^{170}$ Excluding the lamellarins described herein from Dictyodendrilla dendyi, the latter four compounds represent the only members of the lamellarin family which have been isolated from sponges. Lamellarin S (218) was reported in 1996 isolated from an Australian collection of Didemnum sp. ${ }^{171}$ The extraction of an unidentified tunicate collected from the Arabian Sea, near Thiruvananthapuram (formerly Trivandrum), India in 1997 led to the isolation of an underivatised lamellarin N (214), lamellarins T-X (219-223) and 20-sulfate derivatives of lamellarins T-V (224-226) and Y (227). ${ }^{172}$ Lamellarin Y itself has never been isolated as a natural product. In 1999 lamellarin Z (228), the 20-sulfates of lamellarins B (229), C (230) and L (231), and lamellarin G 8-sulfate (232) were reported from an Australian collection of Didemnum chartaceum. ${ }^{173}$ Later that same year, lamellarin $\alpha 20$-sulfate (233) was described from the same collection of the unidentified tunicate from the Arabian Sea as previously reported. ${ }^{174}$ An unidentified species of Didemnum collected from the Indian Ocean yielded lamellarin $\beta$ (234). ${ }^{175}$ In 2004 an underivatised lamellarin $\alpha$ 
(235) and lamellarins $\gamma(\mathbf{2 3 6})$ and $\epsilon^{\dagger}$ (237) were reported from a sample of the tunicate Didemnum obscurum collected near Tiruchendur, India. ${ }^{176}$ Finally, in 2005, a different Indian collection of Didemnum obscurum gave rise to four further lamellarins, $\zeta(\mathbf{2 3 8})$, $\eta$ (239), $\Phi(\mathbf{2 4 0})$ and $\chi(\mathbf{2 4 1}) .{ }^{177}$ It is not clear why the compounds were not named in Greek alphabetical order - that is, $\zeta, \eta, \theta$ and $\kappa^{\ddagger}$ The new lamellarins described herein (187, 188 and 190-194) are all related to lamellarins $O$ and $P$.

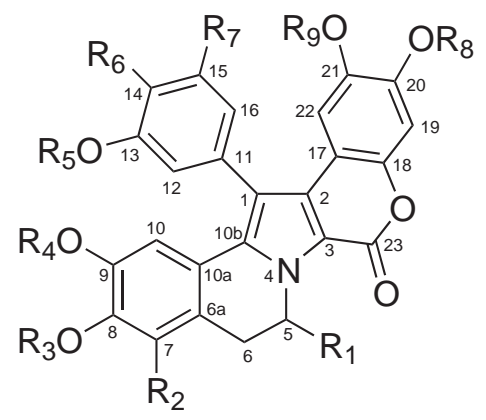

\begin{tabular}{|c|c|c|c|c|c|c|c|c|c|c|}
\hline & Lamellarin & $\mathrm{R}_{1}$ & $\mathrm{R}_{2}$ & $\mathrm{R}_{3}$ & $\mathrm{R}_{4}$ & $\mathrm{R}_{5}$ & $\mathrm{R}_{6}$ & $\mathrm{R}_{7}$ & $\mathrm{R}_{8}$ & $\mathrm{R}_{9}$ \\
\hline 201 & $\mathrm{~A}$ & $\mathrm{OH}$ & $\mathrm{OMe}$ & $\mathrm{Me}$ & $\mathrm{Me}$ & $\mathrm{Me}$ & $\mathrm{OH}$ & $\mathrm{H}$ & $\mathrm{H}$ & $\mathrm{Me}$ \\
\hline 203 & $\mathrm{C}$ & $\mathrm{H}$ & $\mathrm{OMe}$ & $\mathrm{Me}$ & $\mathrm{Me}$ & $\mathrm{Me}$ & $\mathrm{OH}$ & $\mathrm{H}$ & $\mathrm{H}$ & $\mathrm{Me}$ \\
\hline 230 & C 20-sulfate & $\mathrm{H}$ & $\mathrm{OMe}$ & $\mathrm{Me}$ & $\mathrm{Me}$ & $\mathrm{Me}$ & $\mathrm{OH}$ & $\mathrm{H}$ & $\mathrm{SO}_{3} \mathrm{Na}$ & $\mathrm{Me}$ \\
\hline 205 & $\mathrm{E}$ & $\mathrm{H}$ & $\mathrm{OH}$ & $\mathrm{Me}$ & $\mathrm{Me}$ & $\mathrm{H}$ & $\mathrm{OMe}$ & $\mathrm{H}$ & $\mathrm{H}$ & $\mathrm{Me}$ \\
\hline 206 & $\mathrm{~F}$ & $\mathrm{H}$ & $\mathrm{OH}$ & $\mathrm{Me}$ & $\mathrm{Me}$ & $\mathrm{Me}$ & $\mathrm{OMe}$ & $\mathrm{H}$ & $\mathrm{H}$ & $\mathrm{Me}$ \\
\hline 207 & G & $\mathrm{H}$ & $\mathrm{H}$ & $\mathrm{H}$ & $\mathrm{Me}$ & $\mathrm{H}$ & $\mathrm{OMe}$ & $\mathrm{H}$ & $\mathrm{Me}$ & $\mathrm{H}$ \\
\hline 232 & G 8-sulfate & $\mathrm{H}$ & $\mathrm{H}$ & $\mathrm{SO}_{3} \mathrm{Na}$ & $\mathrm{Me}$ & $\mathrm{H}$ & $\mathrm{OMe}$ & $\mathrm{H}$ & $\mathrm{Me}$ & $\mathrm{H}$ \\
\hline 209 & I & $\mathrm{H}$ & $\mathrm{OMe}$ & $\mathrm{Me}$ & $\mathrm{Me}$ & $\mathrm{Me}$ & $\mathrm{OMe}$ & $\mathrm{H}$ & $\mathrm{H}$ & $\mathrm{Me}$ \\
\hline 210 & $\mathrm{~J}$ & $\mathrm{H}$ & $\mathrm{H}$ & $\mathrm{H}$ & $\mathrm{Me}$ & $\mathrm{Me}$ & $\mathrm{OMe}$ & $\mathrm{H}$ & $\mathrm{H}$ & $\mathrm{Me}$ \\
\hline 211 & K & $\mathrm{H}$ & $\mathrm{OH}$ & $\mathrm{Me}$ & Мe & $\mathrm{Me}$ & $\mathrm{OH}$ & $\mathrm{H}$ & $\mathrm{H}$ & $\mathrm{Me}$ \\
\hline 212 & $\mathrm{~L}$ & $\mathrm{H}$ & $\mathrm{H}$ & $\mathrm{H}$ & $\mathrm{Me}$ & $\mathrm{H}$ & $\mathrm{OMe}$ & $\mathrm{H}$ & $\mathrm{H}$ & $\mathrm{Me}$ \\
\hline 231 & 20-sulfa & $\mathrm{H}$ & $\mathrm{H}$ & $\mathrm{H}$ & $\mathrm{Me}$ & $\mathrm{H}$ & $\mathrm{OMe}$ & $\mathrm{H}$ & $\mathrm{O}_{3} \mathrm{Na}$ & $\mathrm{Me}$ \\
\hline 218 & $\mathrm{~S}$ & $\mathrm{H}$ & $\mathrm{H}$ & $\mathrm{H}$ & $\mathrm{Me}$ & $\mathrm{H}$ & $\mathrm{OH}$ & $\mathrm{H}$ & $\mathrm{H}$ & $\mathrm{H}$ \\
\hline 219 & $\mathrm{~T}$ & $\mathrm{H}$ & $\mathrm{OMe}$ & $\mathrm{Me}$ & $\mathrm{Me}$ & $\mathrm{H}$ & $\mathrm{OMe}$ & $\mathrm{H}$ & $\mathrm{H}$ & $\mathrm{Me}$ \\
\hline 224 & T 20-sulfate & $\mathrm{H}$ & $\mathrm{OMe}$ & $\mathrm{Me}$ & $\mathrm{Me}$ & $\mathrm{H}$ & $\mathrm{OMe}$ & $\mathrm{H}$ & $\mathrm{O}_{3} \mathrm{Na}$ & $\mathrm{Me}$ \\
\hline 220 & $\mathrm{U}$ & $\mathrm{H}$ & $\mathrm{H}$ & $\mathrm{Me}$ & $\mathrm{Me}$ & $\mathrm{H}$ & $\mathrm{OMe}$ & $\mathrm{H}$ & $\mathrm{H}$ & $\mathrm{Me}$ \\
\hline 225 & U 20-sulfate & $\mathrm{H}$ & $\mathrm{H}$ & $\mathrm{Me}$ & $\mathrm{Me}$ & $\mathrm{H}$ & $\mathrm{OMe}$ & $\mathrm{H}$ & $\mathrm{SO}_{3} \mathrm{Na}$ & $\mathrm{Me}$ \\
\hline 221 & V & $\mathrm{OH}$ & $\mathrm{OMe}$ & $\mathrm{Me}$ & $\mathrm{Me}$ & $\mathrm{H}$ & $\mathrm{OMe}$ & $\mathrm{H}$ & $\mathrm{H}$ & $\mathrm{Me}$ \\
\hline 226 & V 20-sulfate & $\mathrm{OH}$ & $\mathrm{OMe}$ & $\mathrm{Me}$ & $\mathrm{Me}$ & $\mathrm{H}$ & $\mathrm{OMe}$ & $\mathrm{H}$ & $\mathrm{SO}_{3} \mathrm{Na}$ & $\mathrm{Me}$ \\
\hline 227 & Y 20-sulfate & $\mathrm{H}$ & $\mathrm{H}$ & $\mathrm{Me}$ & $\mathrm{H}$ & $\mathrm{H}$ & $\mathrm{OMe}$ & $\mathrm{H}$ & $\mathrm{SO}_{3} \mathrm{Na}$ & $\mathrm{Me}$ \\
\hline 228 & $\mathrm{Z}$ & $\mathrm{H}$ & $\mathrm{H}$ & $\mathrm{H}$ & $\mathrm{Me}$ & $\mathrm{H}$ & $\mathrm{OH}$ & $\mathrm{H}$ & $\mathrm{Me}$ & $\mathrm{H}$ \\
\hline 234 & $\beta$ & $\mathrm{H}$ & $\mathrm{H}$ & $\mathrm{H}$ & $\mathrm{H}$ & $\mathrm{H}$ & $\mathrm{OMe}$ & $\mathrm{H}$ & $\mathrm{H}$ & $\mathrm{H}$ \\
\hline 236 & $\gamma$ & $\mathrm{H}$ & $\mathrm{OH}$ & $\mathrm{Me}$ & $\mathrm{Me}$ & $\mathrm{Me}$ & $\mathrm{H}$ & $\mathrm{OMe}$ & $\mathrm{H}$ & $\mathrm{Me}$ \\
\hline 241 & $\chi$ & $\mathrm{H}$ & $\mathrm{H}$ & Ac & $\mathrm{Me}$ & $\mathrm{Me}$ & OAc & $\mathrm{H}$ & Ac & $\mathrm{Me}$ \\
\hline
\end{tabular}

Lamellarins O-R (189 and 215-217) form an interesting subset within the lamellarin family whose members not only represent the only lamellarins isolated from marine

\footnotetext{
${ }^{\dagger}$ The Greek letter " $\delta$ " was omitted presumably to avoid confusion with NMR nomenclature.

†The Greek letter “ $\iota$ ” was omitted to avoid confusion with the Latin letter "i”.
} 


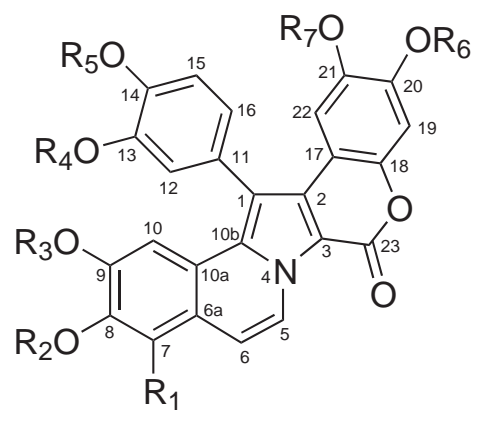

\begin{tabular}{|c|c|c|c|c|c|c|c|c|}
\hline & Lamellarin & $\mathrm{R}_{1}$ & $\mathrm{R}_{2}$ & $\mathrm{R}_{3}$ & $\mathrm{R}_{4}$ & $\mathrm{R}_{5}$ & $\mathrm{R}_{6}$ & $\mathrm{R}_{7}$ \\
\hline 202 & B & $\mathrm{OMe}$ & $\mathrm{Me}$ & $\mathrm{Me}$ & $\mathrm{Me}$ & $\mathrm{H}$ & $\mathrm{H}$ & $\mathrm{Me}$ \\
\hline 229 & B 20-sulfate & $\mathrm{OMe}$ & $\mathrm{Me}$ & $\mathrm{Me}$ & $\mathrm{Me}$ & $\mathrm{H}$ & $\mathrm{SO}_{3} \mathrm{Na}$ & $\mathrm{Me}$ \\
\hline 204 & $\mathrm{D}$ & $\mathrm{H}$ & $\mathrm{H}$ & $\mathrm{Me}$ & $\mathrm{Me}$ & $\mathrm{H}$ & $\mathrm{H}$ & $\mathrm{Me}$ \\
\hline 208 & $\mathrm{H}$ & $\mathrm{H}$ & $\mathrm{H}$ & $\mathrm{H}$ & $\mathrm{H}$ & $\mathrm{H}$ & $\mathrm{H}$ & $\mathrm{H}$ \\
\hline 213 & M & $\mathrm{OH}$ & $\mathrm{Me}$ & $\mathrm{Me}$ & $\mathrm{Me}$ & $\mathrm{H}$ & $\mathrm{H}$ & $\mathrm{Me}$ \\
\hline 214 & $\mathrm{~N}$ & $\mathrm{H}$ & $\mathrm{H}$ & $\mathrm{Me}$ & $\mathrm{H}$ & $\mathrm{Me}$ & $\mathrm{H}$ & $\mathrm{Me}$ \\
\hline 222 & $\mathrm{~W}$ & $\mathrm{OMe}$ & $\mathrm{Me}$ & $\mathrm{Me}$ & $\mathrm{H}$ & $\mathrm{Me}$ & $\mathrm{H}$ & $\mathrm{Me}$ \\
\hline 223 & $X$ & $\mathrm{H}$ & $\mathrm{Me}$ & $\mathrm{Me}$ & $\mathrm{H}$ & $\mathrm{Me}$ & $\mathrm{H}$ & $\mathrm{Me}$ \\
\hline 235 & $\alpha$ & $\mathrm{H}$ & $\mathrm{Me}$ & $\mathrm{Me}$ & $\mathrm{H}$ & $\mathrm{Me}$ & $\mathrm{H}$ & $\mathrm{Me}$ \\
\hline 233 & $\alpha 20$-sulfate & $\mathrm{H}$ & $\mathrm{Me}$ & $\mathrm{Me}$ & $\mathrm{H}$ & $\mathrm{Me}$ & $\mathrm{SO}_{3} \mathrm{Na}$ & $\mathrm{Me}$ \\
\hline 237 & $\epsilon$ & $\mathrm{OH}$ & $\mathrm{Me}$ & $\mathrm{Me}$ & $\mathrm{Me}$ & $\mathrm{Me}$ & $\mathrm{H}$ & $\mathrm{Me}$ \\
\hline 238 & $\zeta$ & $\mathrm{OMe}$ & $\mathrm{Me}$ & $\mathrm{Me}$ & $\mathrm{Me}$ & $\mathrm{Me}$ & $\mathrm{H}$ & $\mathrm{Me}$ \\
\hline 239 & $\eta$ & $\mathrm{H}$ & $\mathrm{Me}$ & $\mathrm{Me}$ & $\mathrm{Me}$ & $\mathrm{Me}$ & $\mathrm{H}$ & $\mathrm{Me}$ \\
\hline 240 & $\Phi$ & $\mathrm{OMe}$ & $\mathrm{Me}$ & Ac & $\mathrm{Me}$ & $\mathrm{Ac}$ & Ac & $\mathrm{Me}$ \\
\hline
\end{tabular}

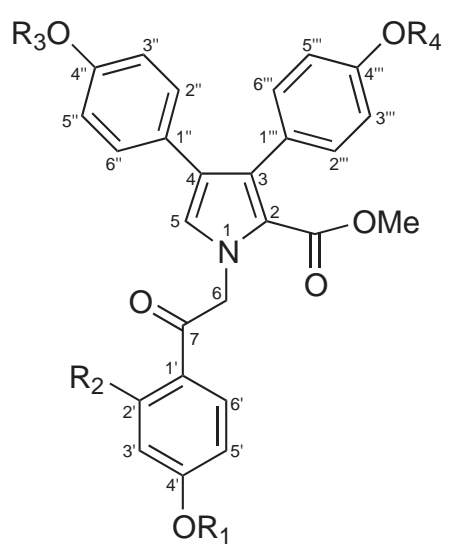

\begin{tabular}{lccccc}
\hline & Lamellarin & $\mathrm{R}_{1}$ & $\mathrm{R}_{2}$ & $\mathrm{R}_{3}$ & $\mathrm{R}_{4}$ \\
\hline $\mathbf{1 8 9}$ & $\mathrm{O}$ & $\mathrm{Me}$ & $\mathrm{H}$ & $\mathrm{H}$ & $\mathrm{H}$ \\
$\mathbf{1 9 1}$ & $\mathrm{O} 4^{\prime \prime \prime}$-sulfate & $\mathrm{Me}$ & $\mathrm{H}$ & $\mathrm{H}$ & $\mathrm{SO}_{3} \mathrm{Na}$ \\
$\mathbf{1 9 2}$ & $\mathrm{O}^{\prime \prime}, 4^{\prime \prime \prime}$-disulfate & $\mathrm{Me}$ & $\mathrm{H}$ & $\mathrm{SO}_{3} \mathrm{Na}$ & $\mathrm{SO}_{3} \mathrm{Na}$ \\
$\mathbf{2 1 5}$ & $\mathrm{P}$ & $\mathrm{Me}$ & $\mathrm{OH}$ & $\mathrm{H}$ & $\mathrm{H}$ \\
$\mathbf{1 8 7}$ & $\theta$ & $\mathrm{Me}$ & $\mathrm{H}$ & $\mathrm{H}$ & $\mathrm{H}$ \\
$\mathbf{1 9 0}$ & $\theta 4^{\prime \prime}, 4^{\prime \prime \prime}$-disulfate & $\mathrm{H}$ & $\mathrm{H}$ & $\mathrm{SO}_{3} \mathrm{Na}$ & $\mathrm{SO}_{3} \mathrm{Na}$ \\
$\mathbf{1 8 8}$ & $\kappa$ & $\mathrm{Me}$ & $\mathrm{OMe}$ & $\mathrm{H}$ & $\mathrm{H}$ \\
$\mathbf{1 9 3}$ & $\kappa 4^{\prime \prime \prime}$-sulfate & $\mathrm{Me}$ & $\mathrm{OMe}$ & $\mathrm{H}$ & $\mathrm{SO}_{3} \mathrm{Na}$ \\
$\mathbf{1 9 4}$ & $\kappa 4^{\prime \prime}, 4^{\prime \prime \prime}$-disulfate & $\mathrm{Me}$ & $\mathrm{OMe}$ & $\mathrm{SO}_{3} \mathrm{Na}$ & $\mathrm{SO}_{3} \mathrm{Na}$ \\
\hline
\end{tabular}




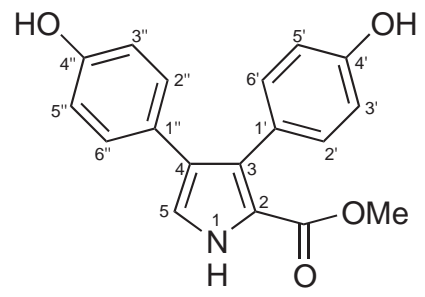

$216 \mathrm{Q}$

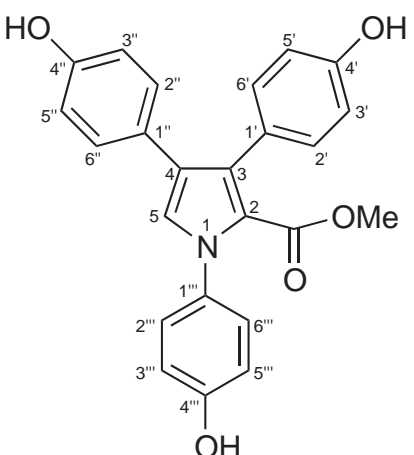

$217 \quad \mathrm{R}$

sponges prior to this report, but whose structures also differ from the other structures with respect to the general carbon skeleton. Based on these two observations, it is the author's opinion that lamellarins O-R should not have been labelled as lamellarins but rather classed as lukianols as they share the same carbon skeleton as both known members of this class. While lukianols $\mathrm{A}$ and $\mathrm{B}$ were isolated from a tunicate, ${ }^{166}$ much less is known about this class of metabolites to suggest a trend such as the one which occurs in the lamellarin class; it is possible that the tunicate and sponges in question share a related bacterial symbiont or food source. Nonetheless, for the purposes of this discussion, the established precedent is recognised and the new compounds described herein are classed as lamellarins.

A comprehensive discussion of the varied biological activities attributed to the lamellarins is beyond the scope of this report. Two reviews, one discussing the isolation and activities of lamellarins $\mathrm{A}-\beta,{ }^{178}$ and one discussing bioactive marine alkaloids in general with a section on lamellarin bioactivity ${ }^{179}$ were published in 2000 . Some of the more significant findings include the activities of lamellarins I, K, L, N and $\beta$, and the 20-sulfate derivatives of $\mathrm{U}, \mathrm{V}$ and $\alpha$. Lamellarins I (209), K (211) and L (212) showed significant cytotoxic activity against P388 and A549 cell lines each with an $\mathrm{IC}_{50}$ of $0.25 \mu \mathrm{g} / \mathrm{mL} .{ }^{169}$ Lamellarin N (214) was active against the SK-MEL-5 and UACC-62 cell lines in the NCI 60 cell-line panel with $\mathrm{LC}_{50}$ s of $187 \mathrm{nM}$ and $9.88 \mu \mathrm{M}$ respectively. ${ }^{172}$ Lamellarin $\beta$ (234) was found to be cytotoxic against HL-60 cells with an $\mathrm{IC}_{50}$ of $4.8 \mu \mathrm{g} / \mathrm{mL} .{ }^{175}$ Probably the most significant result was the activity of the 20-sulfate derivatives of lamellarins U (225), V (226) and $\alpha$ (233) against HIV-1 integrase. All three showed significant inhibition of the terminal cleavage and strand transfer activities of HIV-1 
integrase at micromolar concentrations while displaying only moderate cytotoxicity in an MTT assay. ${ }^{174}$ Lamellarin $\alpha 20$-sulfate was the most active and least toxic compound with a terminal cleavage $\mathrm{IC}_{50}$ of $16 \mu \mathrm{M}$, a strand transfer $\mathrm{IC}_{50}$ of $22 \mu \mathrm{M}$ and a cytotoxic $\mathrm{LD}_{50}$ of $274 \mu \mathrm{M}$. Some non-sulfated lamellarins were also tested in the same assay and while they possessed similar inhibitory activities, they were significantly more cytotoxic. ${ }^{174}$

The most significant biological activity reported for the lamellarins isolated since the literature was reviewed in 2000 concerns lamellarins $\zeta, \eta, \Phi$ and $\chi$ which all exhibited inhibitory activity against the colorectal cancer cell line COLO-205 at low micromolar concentrations. ${ }^{177}$

No activities have been reported for the sponge-derived lamellarins O-R although lamellarins $\mathrm{Q}$ and $\mathrm{R}$ were shown not to possess antibiotic activity. ${ }^{170}$ Consequently, there is considerable interest in the potential activities of the sulfated sponge-derived lamellarins in this report. 


\subsection{Dictyodendrins C, D and F}

Also isolated from these extractions of Dictyodendrilla dendyi were the known natural products dictyodendrin $\mathrm{C}(\mathbf{1 8 3})$ and $\mathrm{D}(\mathbf{1 8 4})$ and the new natural product dictyodendrin $\mathrm{F}$ (195). Dictyodendrin F has previously been reported as the product of hydrolysis of dictyodendrins A-E (181-185). ${ }^{161}$

All spectral data for compounds $\mathbf{1 8 3}$ and $\mathbf{1 8 4}$ were in agreement with those reported previously. ${ }^{161}$ The NMR data for both dictyodendrin C and D are presented here complete with ${ }^{15} \mathrm{~N}$ assignments and ${ }^{1} J_{\mathrm{CH}} /{ }^{1} J_{\mathrm{NH}}$ coupling constants in $\mathrm{CD}_{3} \mathrm{OH}(\mathbf{1 8 3}$ : Table 6.22, 184: Table 6.24) and $\mathrm{CD}_{3} \mathrm{OD}(\mathbf{1 8 3}$ : Table 6.23, 184: Table 6.25). In addition, the chemical shift of C-13 of dictyodendrin C which was previously unreported has also been assigned.

Negative-ion mode HRESIMS analysis of dictyodendrin F (195) gave rise to a single pseudo-molecular ion indicative of a molecular formula of $\mathrm{C}_{34} \mathrm{H}_{24} \mathrm{~N}_{2} \mathrm{O}_{6}(555.1519$ $[\mathrm{M}-\mathrm{H}]^{-}, \Delta 5.8 \mathrm{ppm}$ ). All ${ }^{1} \mathrm{H} \mathrm{NMR}$ data (in $\mathrm{CD}_{3} \mathrm{OH}$ ) for 195 were consistent with those reported. ${ }^{161} \mathrm{NMR}$ data is presented here in $\mathrm{CD}_{3} \mathrm{OH}$ (Table 6.26) and $\mathrm{d}_{6}$-DMSO (Table 6.27).

Dictyodendrins A-E (181-185) have been reported to exhibit complete inhibition of telomerase activity at a concentration of $50 \mu \mathrm{g} / \mathrm{mL}$. Dictyodendrin F (195) was inactive in the same assay suggesting that the presence of at least one sulfate group was required for activity. ${ }^{161}$ 


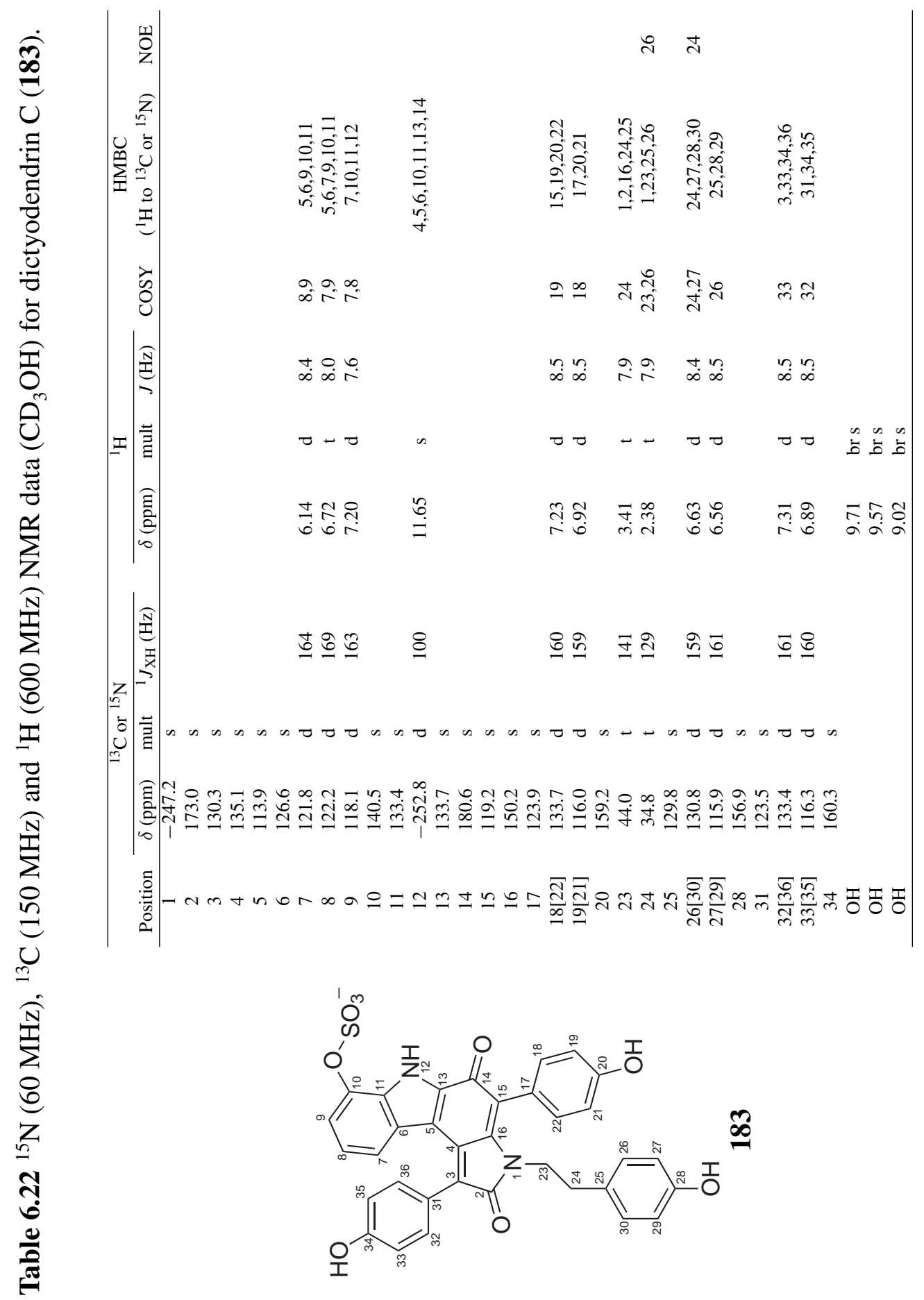




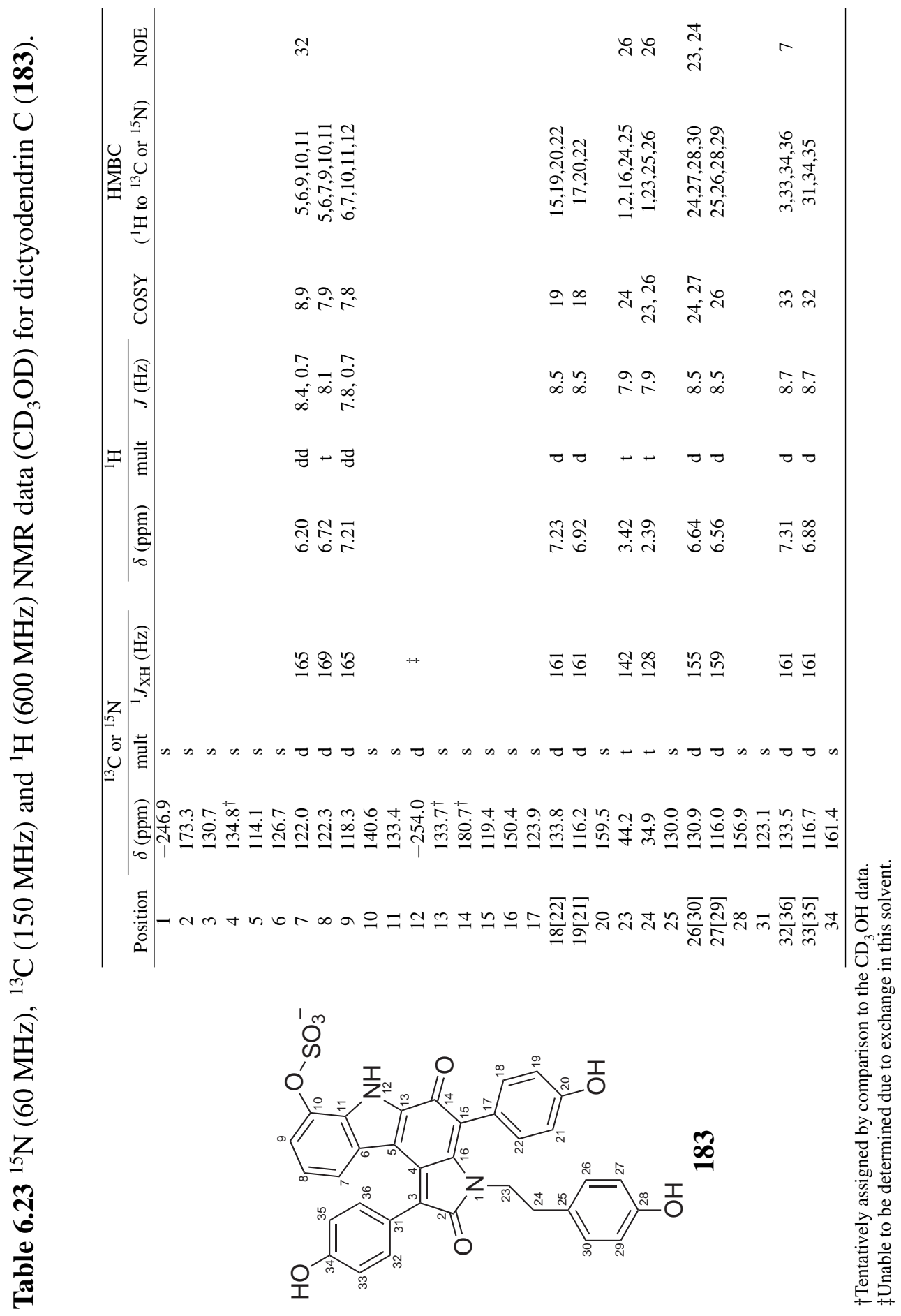




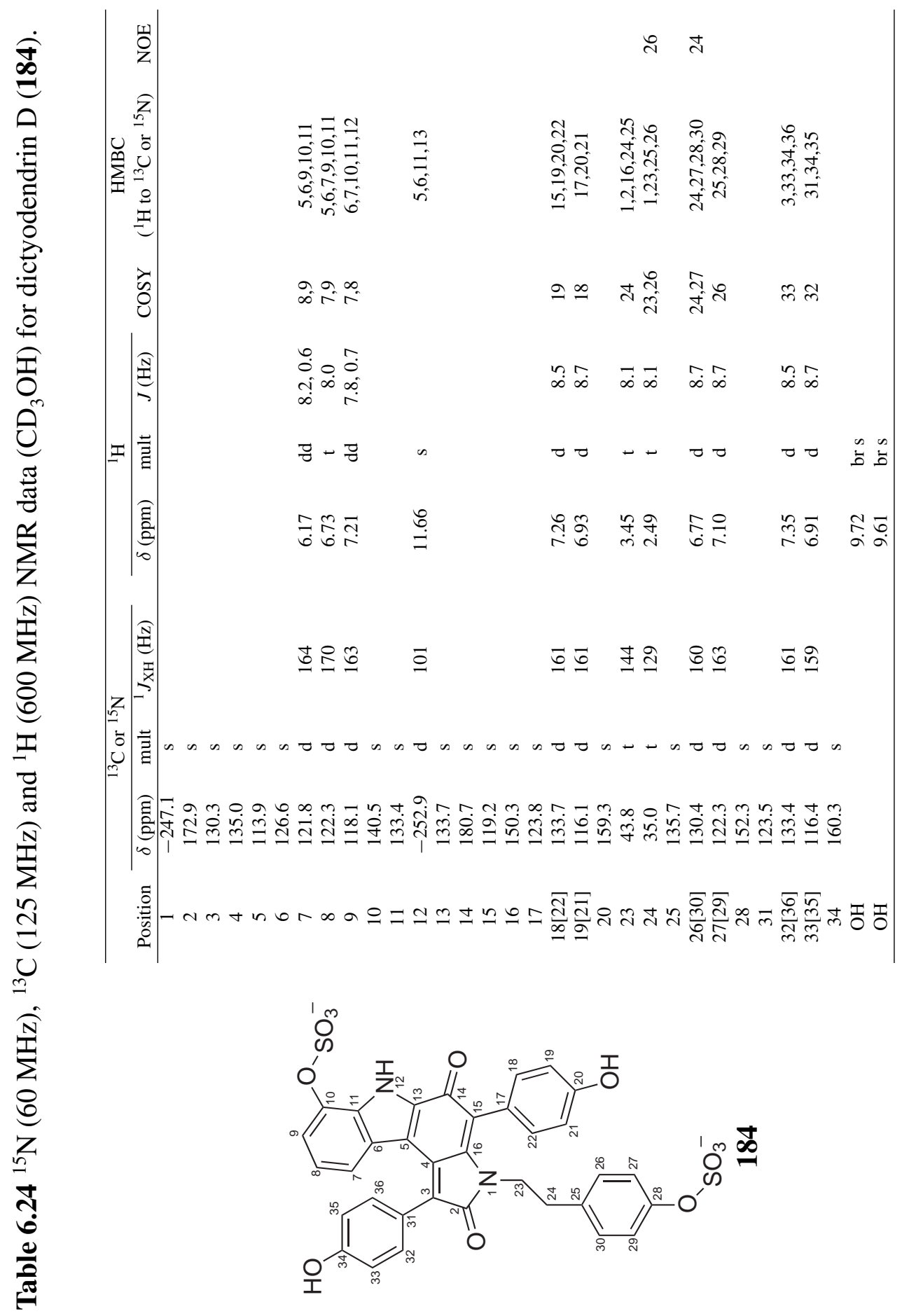




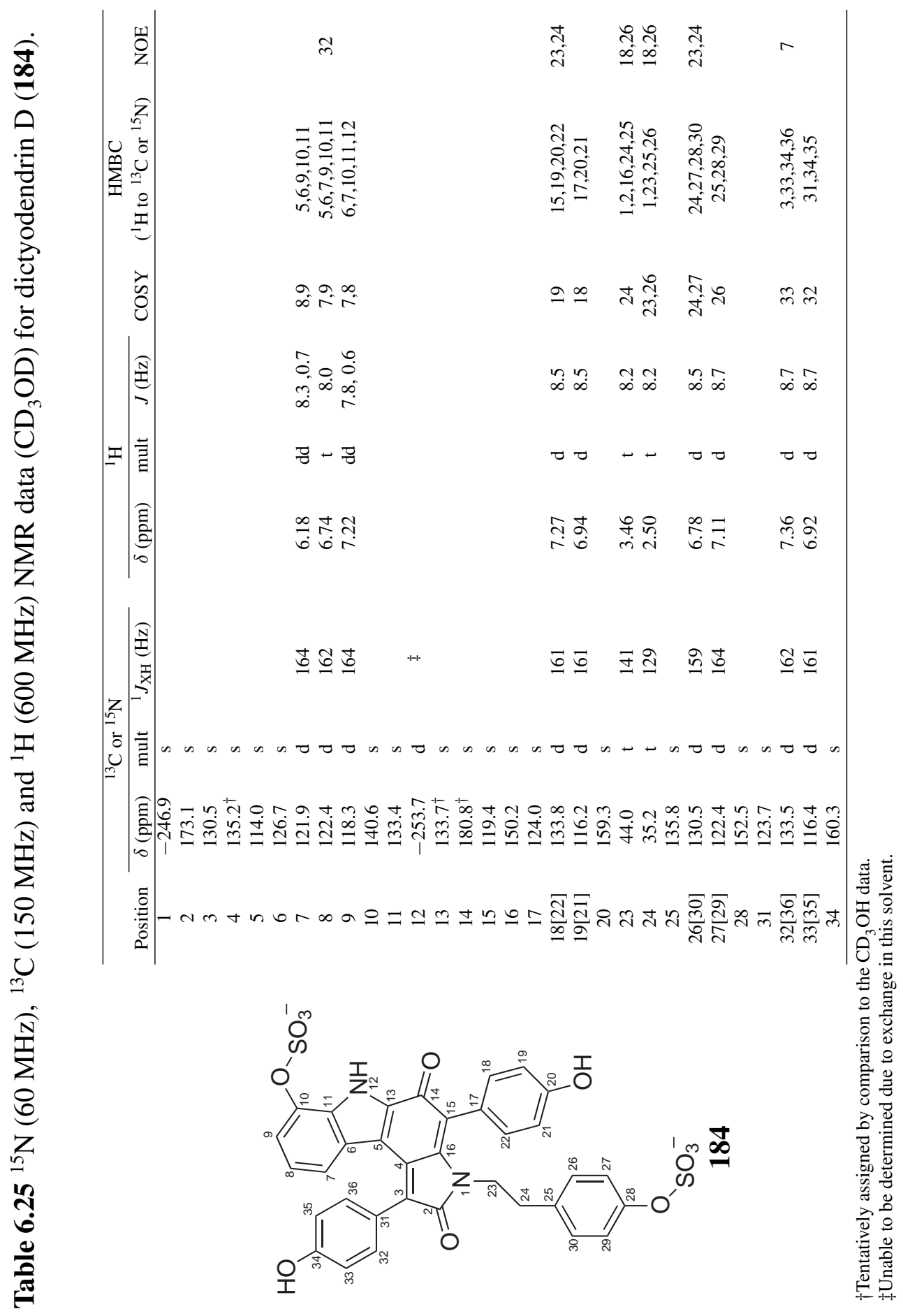




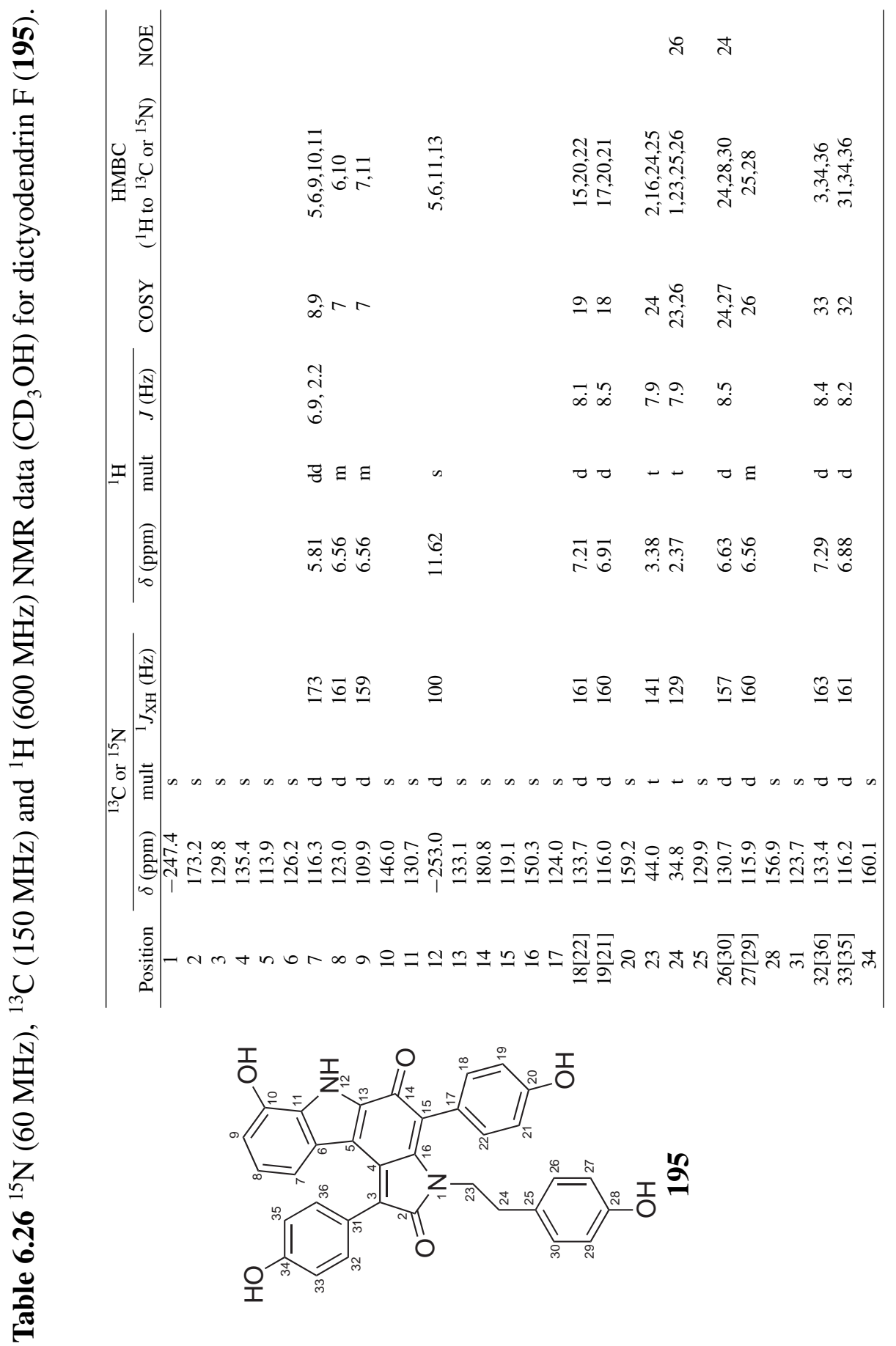




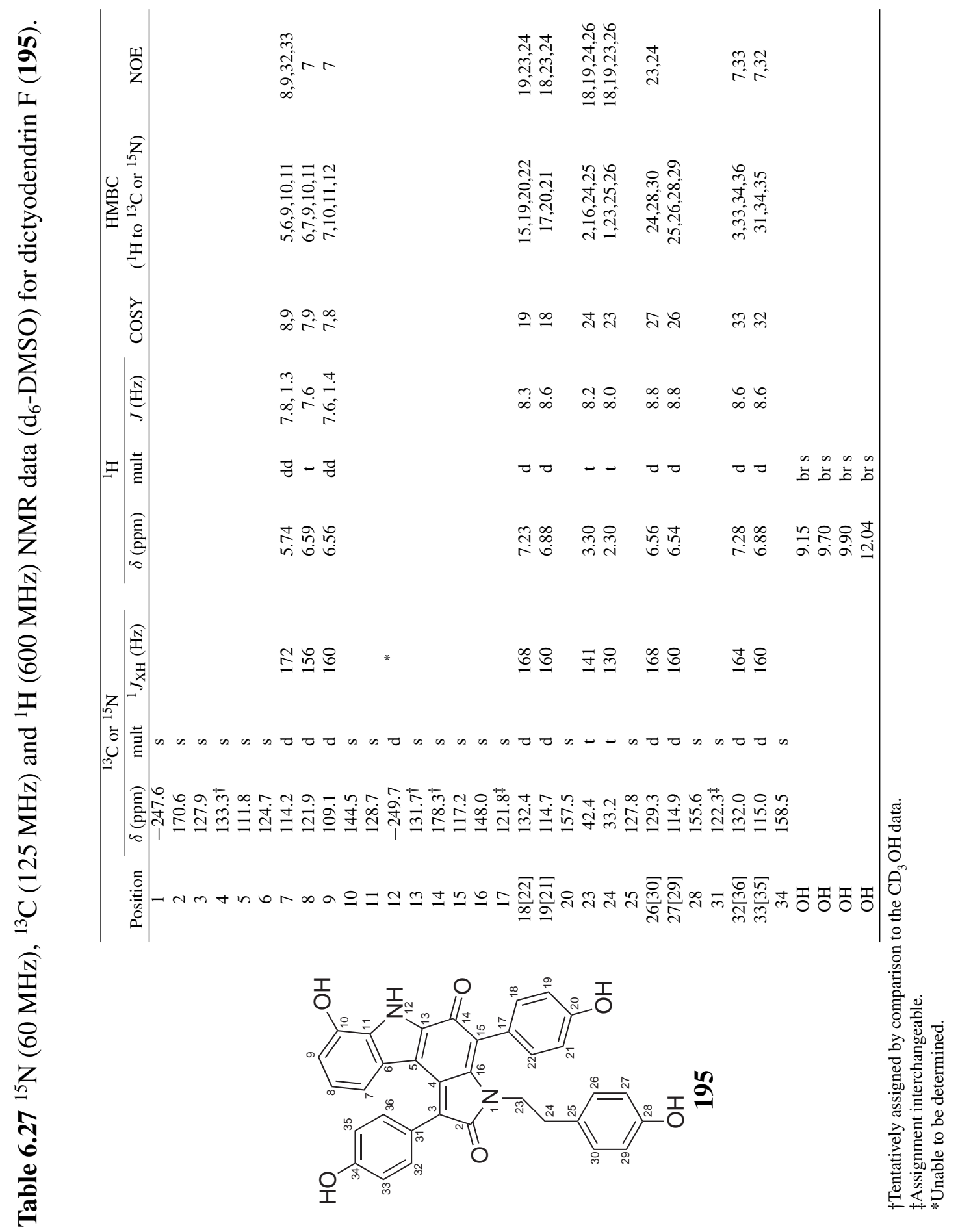




\subsection{Polyaromatic Pyrrole Alkaloids}

Both the lamellarins and the dictyodendrins belong to a class of amino acid-derived polyaromatic pyrrole alkaloids which in addition, include the rigidins, lukianols, polycitones, polycitrins, storniamides, ningalins, purpurone, and the unnamed aldose reductase inhibitors previously mentioned. The structurally simplest family, the rigidins, started with the isolation of rigidin A (242) from the Okinawan tunicate Eudistoma cf. rigida in 1990. ${ }^{180}$ Rigidins B-D (243-245) followed in 2003 isolated from another Okinawan tunicate, this time of the genus Cystodytes. ${ }^{181}$ Rigidin E (246) was reported in the same year from an unidentified species of Eudistoma. ${ }^{182}$ Ningalins A-D (247-250), reported in 1997 from an Australian Didemnum species of tunicate, are a family of tyrosinederived metabolites which are formed by the condensation of two, three, four and five tyrosine (or dopa) units respectively. ${ }^{183}$ Purpurone (251), isolated in 1993 from a Palauan collection of the marine sponge Iotrochota sp., ${ }^{184}$ is structurally related to $\mathbf{2 5 0}$. Lukianols A (198) and B (252) were isolated from an unidentified tunicate collected from Palmyra atoll. ${ }^{166}$ Lukianol B is unusual in this class of metabolites as it is the only known iodinecontaining structure. The polycitrins, A (253) and B (254) were reported co-isolated with polycitone A (255) from a tunicate of the genus Polycitor collected from Sodwana Bay, South Africa. ${ }^{185}$ More recently, polycitone B (256) was isolated from a Madagascaran collection of Polycitor africanus. ${ }^{186}$ In 1996 storniamides A-D (257-260) were reported from a Patagonian collection of an unidentified species of the sponge genus Cliona. ${ }^{187}$ Finally, as previously discussed (see Section 6.1), the aldose reductase inhibitors 174176 were isolated from a collection of the marine sponge Dictyodendrilla sp. in 1993.

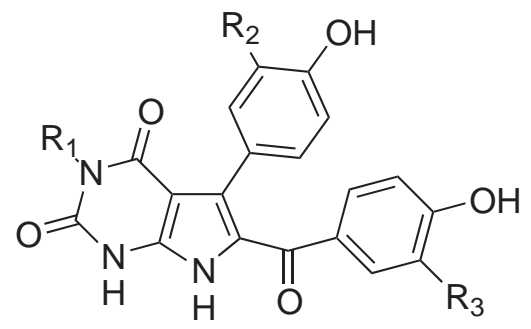

$$
\begin{array}{llll}
\mathbf{2 4 2} & \mathrm{R}_{1}=H & \mathrm{R}_{2}=H & \mathrm{R}_{3}=\mathrm{H} \\
\mathbf{2 4 3} & \mathrm{R}_{1}=\mathrm{H} & \mathrm{R}_{2}=\mathrm{H} & \mathrm{R}_{3}=\mathrm{OMe} \\
\mathbf{2 4 4} & \mathrm{R}_{1}=\mathrm{H} & \mathrm{R}_{2}=\mathrm{OMe} & \mathrm{R}_{3}=\mathrm{H} \\
\mathbf{2 4 5} & \mathrm{R}_{1}=\mathrm{H} & \mathrm{R}_{2}=\mathrm{OMe} & \mathrm{R}_{3}=\mathrm{OMe} \\
\mathbf{2 4 6} & \mathrm{R}_{1}=\mathrm{Me} & \mathrm{R}_{2}=\mathrm{H} & \mathrm{R}_{3}=\mathrm{H}
\end{array}
$$

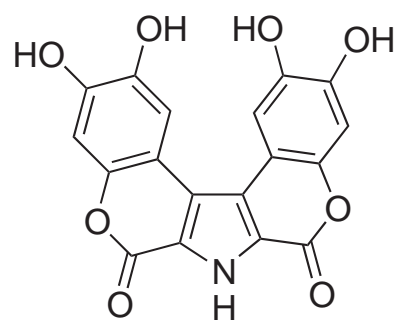

247 


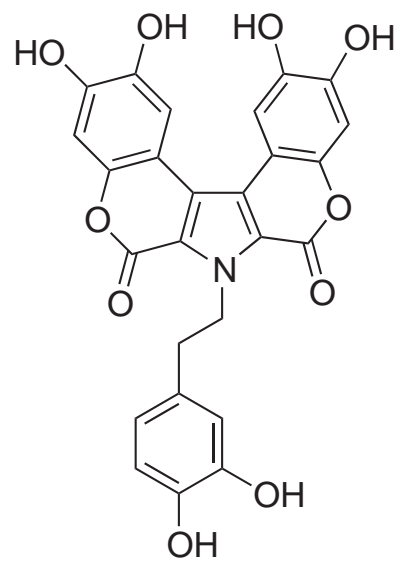

248

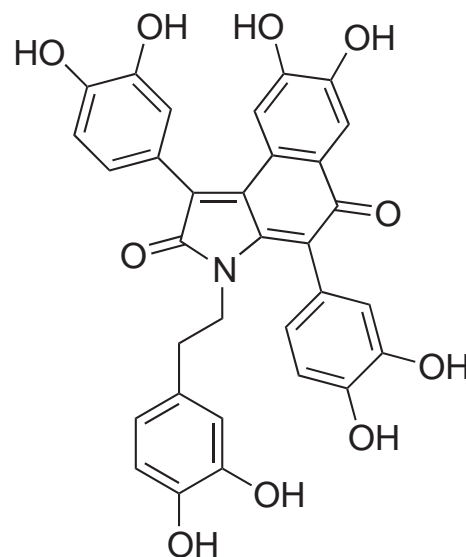

249
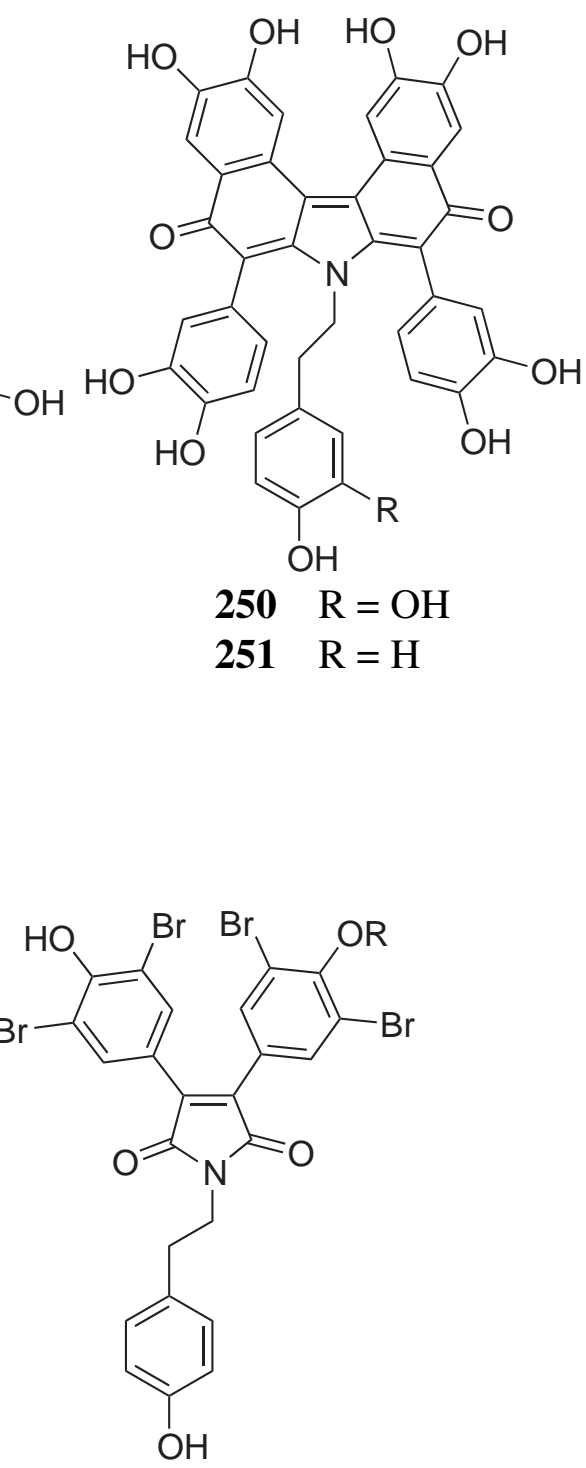

$253 \mathrm{R}=\mathrm{H}$

$254 \mathrm{R}=\mathrm{Me}$<smiles>O=C(c1cc(Br)c(O)c(Br)c1)c1c(-c2cc(Br)c(O)c(Br)c2)c(-c2cc(Br)c(O)c(Br)c2)c(C(=O)c2cc(Br)c(O)c(Br)c2)n1CCc1ccc(O)cc1</smiles>

255<smiles>O=C(c1cc(Br)c(O)c(Br)c1)c1[nH]c(C(=O)c2cc(Br)c(O)c(Br)c2)c(-c2cc(Br)c(O)c(Br)c2)c1-c1cc(Br)c(O)c(Br)c1</smiles>

256 


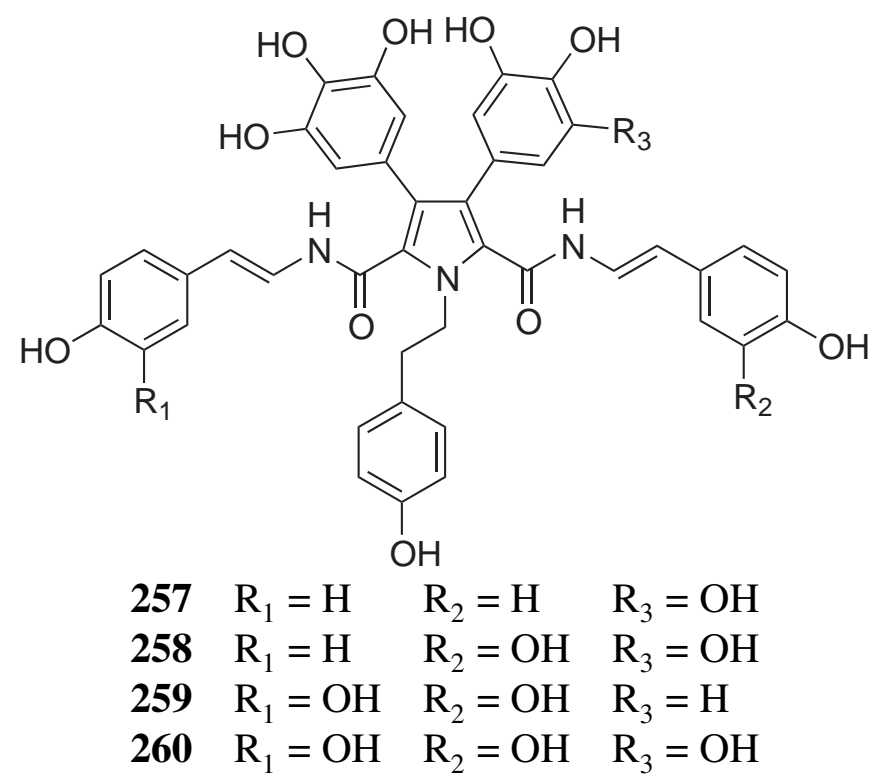

The bioactivity of these compounds is varied. Rigidin A (242) was reported to have potent calmodulin antagonistic activity with an $\mathrm{IC}_{50}$ of $50 \mu \mathrm{M} .{ }^{180} \mathrm{In}$ a preliminary study, rigidins B-D (243-245) were cytotoxic to murine leukæmia L1210 cells. ${ }^{181}$ Rigidins A (242) and E (246) were tested against human colon and human epidermoid carcinoma cell lines and found to show minimal inhibition of each. ${ }^{182}$ Purpurone (251) inhibited the activity of ATP-citrate lyase with an $\mathrm{IC}_{50}$ of $7 \mu \mathrm{M} .{ }^{184}$ Lukianol A (198) showed weak cytotoxicity against a KB-derived cell line while lukianol B (252) was inactive in the same assay. ${ }^{166}$ Polycitone A (255) was discovered to be the major contributor to inhibitory activity in a retroviral reverse transcriptase and cellular DNA polymerase bioassay-guided isolation. ${ }^{186}$ All four storniamides (257-260) were reported to possess antibiotic activity against the Gram-positive bacteria Staphylococcus aureus, Bacillus subtilis and Micrococcus luteus at $50 \mathrm{ng} /$ disc. No activity was observed against Gramnegative bacteria or Candida albicans. ${ }^{187}$ Finally, the aldose reductase inhibitors 174-176 inhibited bovine lens aldose reductase with 50\% inhibitory concentrations of 49, 125 and $112 \mathrm{nM}$ respectively. ${ }^{159}$ No activity has been reported for the ningalins or the polycitrins.

In general, the activity of many of these polyaromatic pyrrole alkaloids seems to be towards DNA manipulating enzymes. This hypothesis, raised initially with regard to only the lamellarins, ${ }^{178}$ can potentially be extended to encompass other members of this class of compounds based on the reverse transcriptase and cellular DNA polymerase inhibitory activity of polycitone A and the telomerase inhibitory activity of the dictyodendrins. 
<smiles>[R]Oc1cccc2c1[nH]c1c(-c3ccc(O)cc3)c3c(c(-c4ccc(O)cc4)c12)C(=O)C1(OC(=O)C(O)=C1c1ccc(O)cc1)N3CCc1ccc(O)cc1</smiles>

$174 \mathrm{R}=\mathrm{SO}_{3} \mathrm{Na}$

$175 \mathrm{R}=\mathrm{SO}_{3} \mathrm{H}$<smiles>COC(=O)/C(c1ccc(O)cc1)=c1/c(-c2ccc(O)cc2)c2c(n1CCc1ccc(O)cc1)=C(c1ccc(O)cc1)C(=O)c1[nH]c3c(OS(=O)(=O)O)cccc3c1-2</smiles>

176

\subsection{Biogenesis of Polyaromatic Pyrrole Alkaloids}

The biogenesis of this class of compounds has long been proposed to be through the condensation of tyrosine (or dopa) units. ${ }^{179}$ The inclusion of the dictyodendrins and the aldose reductase inhibitors necessitates the inclusion of tryptophan as a building block to these molecules. Certainly, the biogenesis of the core of all the compounds described above (with the exception of the rigidins) can theoretically be described by the dimerisation of two pyruvate derivatives followed by the formation of a pyrrole through the dual nucleophilic attack of a primary amine. Further inclusion of pyruvate groups through oxidative decarboxylations followed by simple halogenation, methylation or oxidation steps can describe almost every member of this class.

Tyrosine and tryptophan are both essential amino acids produced in plants, fungi and bacteria via the shikimate pathway. ${ }^{188}$ As animals, sponges are unable to synthesise these aromatic amino acids themselves and must acquire them from their food supply.

The biogenesis of lamellarin $\theta(\mathbf{1 8 7})$ is proposed to follow the above mechanism. Three tyrosine-based building blocks are required, one molecule of tyramine and two molecules of 3-(4-hydroxyphenyl)pyruvate, both of which are known enzymatic products of tyrosine (see Scheme 6.6). The proposed mechanism begins in the manner described above with conjugation of the two pyruvates and subsequent dual nucleophilic attack by the tyramine to form the pyrrole core. Oxidative decarboxylation of one of the carboxylates followed by methylation of the other and oxidation of the tyramine chain results in the formation 
of 187 (see Scheme 6.7). Of course, the order of events is flexible - for example, it is entirely plausible that the oxidation of the tyramine group occurs before the nucleophilic attack.<smiles>NCCc1ccc(O)cc1</smiles>

Tyramine

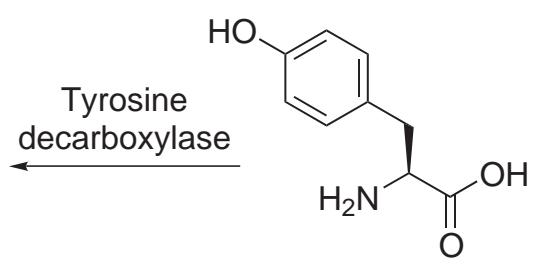

Tyrosine

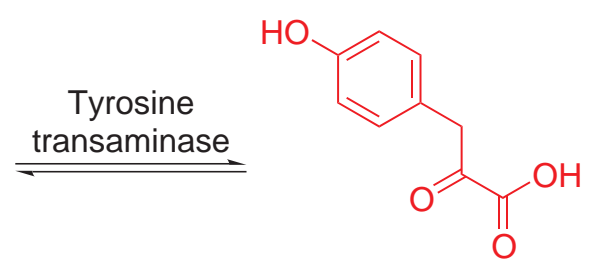

3-(4-hydroxyphenyl)pyruvate

Scheme 6.6 Formation of tyramine and 3-(4-hydroxyphenyl)pyruvate.
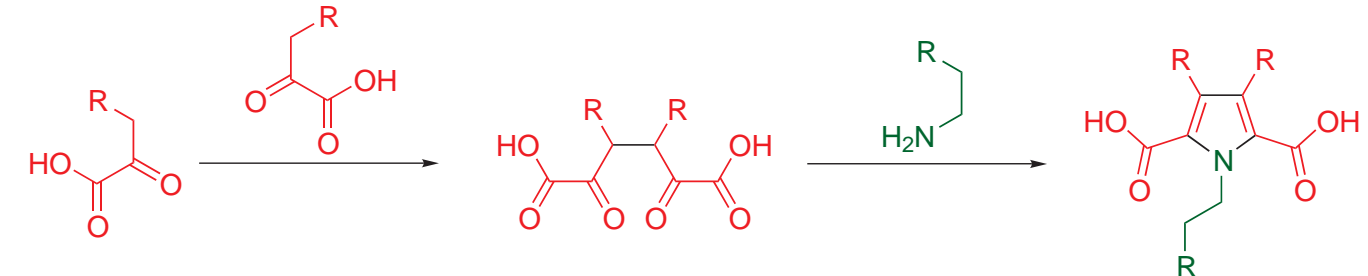

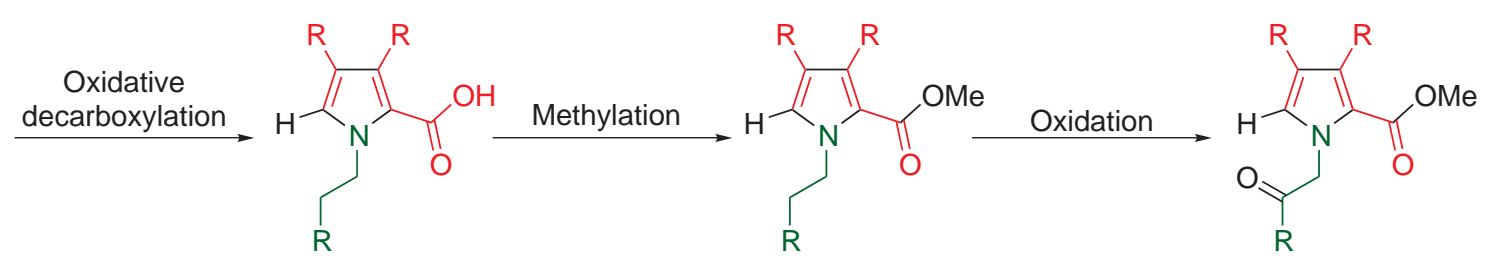

Scheme 6.7 A proposed biogenesis of lamellarin $\theta(\mathbf{1 8 7}) . \mathrm{R}=4$-hydroxybenzene.

While the exact biosynthetic mechanism of the dimerisation of the pyruvate groups is not clear, the laboratory equivalent can be performed through the use of umpolung chemistry. A report from 1995 of the biomimetic total synthesis of polycitrin A (253) performs a one-pot, three-step reaction between two molecules of 3-(4-methoxyphenyl)pyruvic acid and ammonia to produce the corresponding pyrrole. ${ }^{189}$ The reaction uses butyllithium to abstract both the carboxylic acid proton and an acidic methylene proton from 3-(4methoxyphenyl)pyruvate. The addition of half an equivalent of iodine results in the formation of 3-iodo-3-(4-methoxyphenyl)pyruvate which, now behaving as a electrophile, is attacked by the anionic methylene of the remaining unreacted pyruvate. The system is then saturated with ammonia gas before half an equivalent of $\mathrm{TiCl}_{4}$ is added. This results in the formation of the pyrrole through nucleophilic attack on one of the pyruvate ketone carbonyls and subsequent intramolecular nucleophilic attack on the other pyruvate ketone carbonyl (see Scheme 6.8). The by-products of the reaction are ammonium chloride and 
titanium dioxide, the formation of the latter providing a significant driving force.<smiles>COc1ccc(CC(=O)C(=O)O)cc1</smiles>

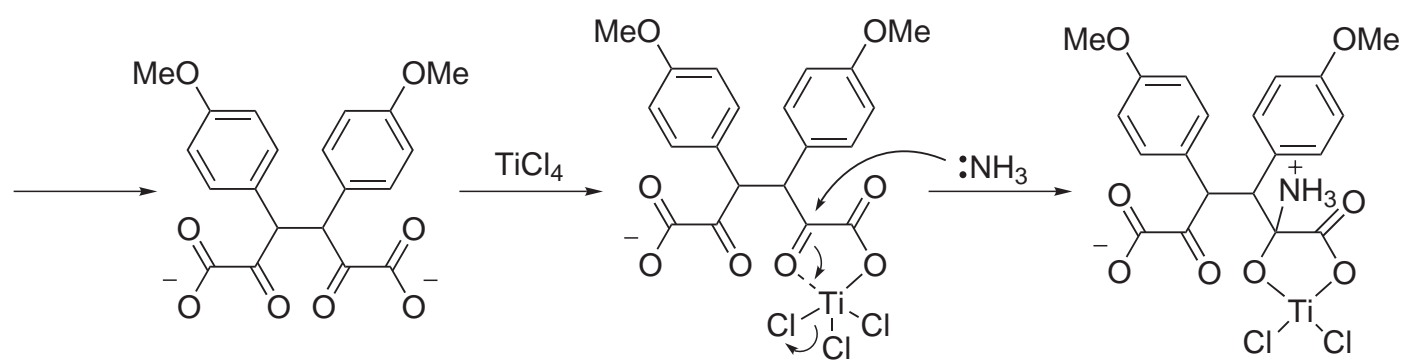

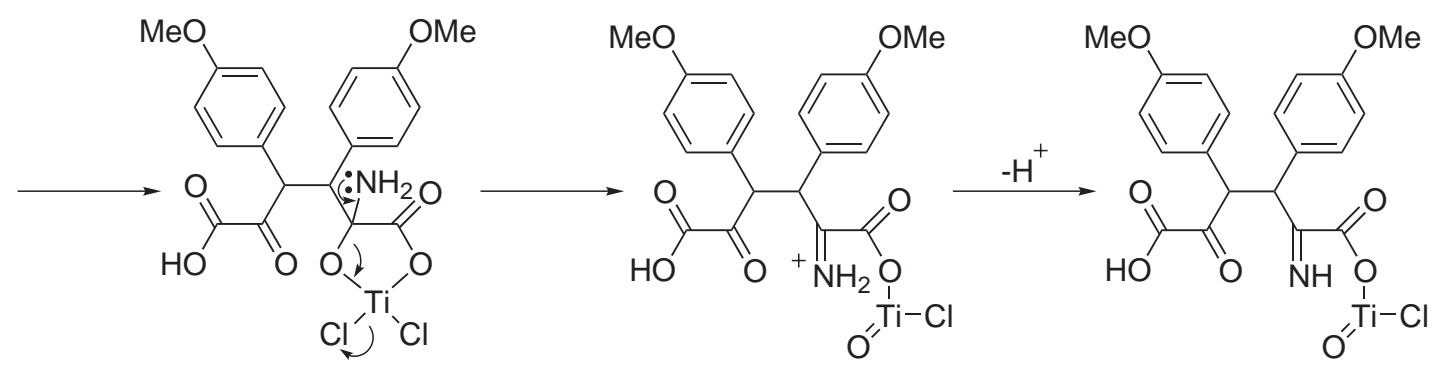

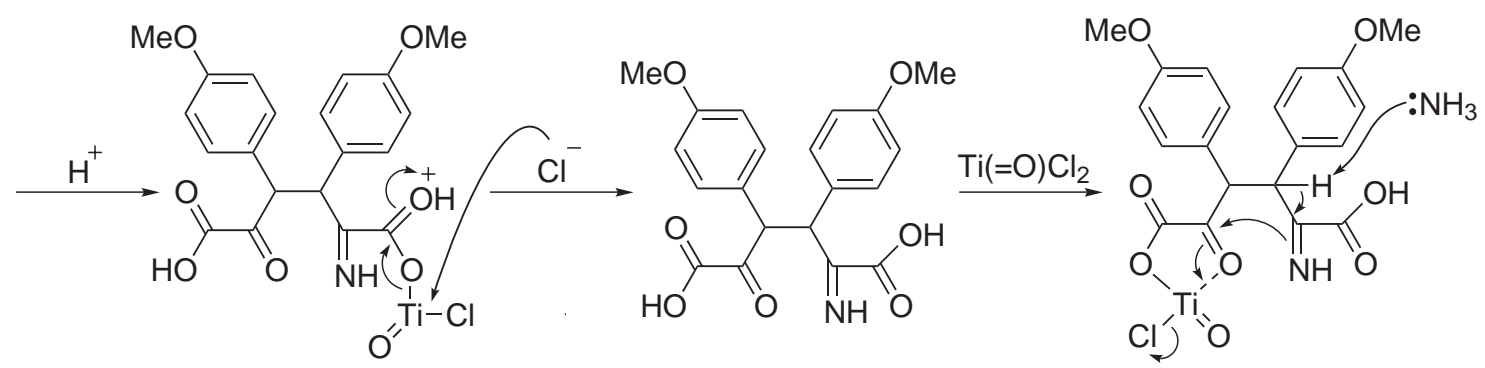

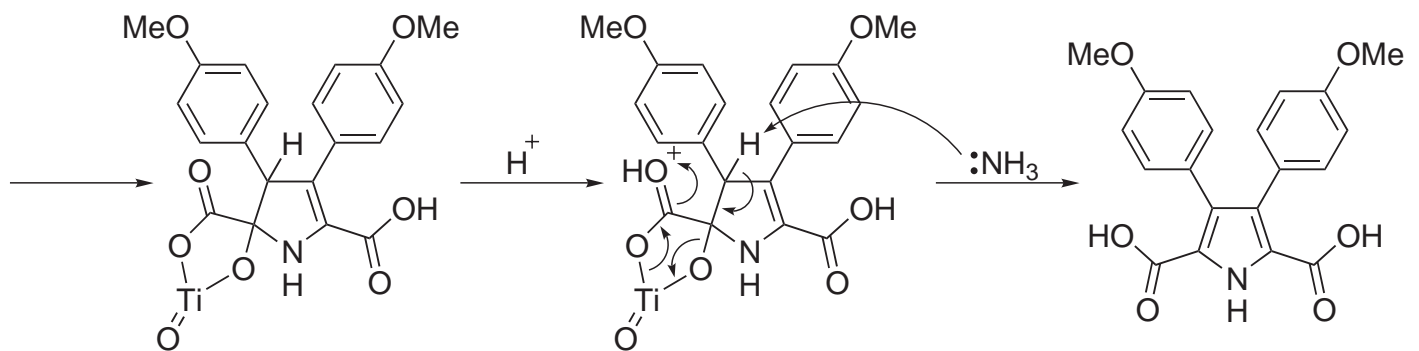

Scheme 6.8 A biomimetic synthesis of the pyrrole core. ${ }^{189}$

With the exception of lamellarins $\mathrm{Q}$ and $\mathrm{R}$, all the remaining sponge-derived lamellarins can be formed from lamellarin $\theta$ through a variety of oxidation, methylation and sulfation modifications. Lamellarin Q (216) is most likely formed by the inclusion of ammonia instead of tyramine in the biosynthetic pathway. Lamellarin $\mathrm{R}(\mathbf{2 1 7})$ may be formed by the substitution of 4-methoxyaniline for the tyramine unit. 
The formation of dictyodendrin $F$ (195) is proposed to occur in the same fashion. In this case, five building blocks are required - three 3-(4-hydroxyphenyl)pyruvates, one tyramine and a tryptophan-derived indole-3-pyruvic acid (see Scheme 6.9). The formation proceeds via conjugation of the indole-3-pyruvic acid and one 3-(4-hydroxy)pyruvate. Subsequent dual nucleophilic attack by tyramine results in the formation of the pyrrole core. Nucleophilic attack by a second 3-(4-hydroxy)pyruvate and the resulting decarboxylation installs the third amino acid group. Electrophilic aromatic substitution by the pyruvate carbonyl and corresponding decarboxylation results in the formation of a new six-membered ring. The enol form of the carbonyl is then oxidised to restore the aromaticity of the system. Installation of the last 3-(4-hydroxy)pyruvate group occurs in the same fashion with decarboxylation of the remaining carboxylate moiety. Finally, oxidation to restore conjugation throughout the molecule, methylation of the acid and oxidation of the indole to install the hydroxyl moiety completes the formation of a dictyodendrin precursor (see Scheme 6.10). Again, the exact order of events is flexible. The formation of dictyodendrin $\mathrm{F}$ from this precursor was proposed by Warabi et al. in their original discussion of the dictyodendrins (see Scheme 6.11). ${ }^{161}$<smiles>N[C@@H](Cc1c[nH]c2ccccc12)C(=O)O</smiles>

Tryptophan
Tryptophan dehydrogenase

Scheme 6.9 Formation of indole-3-pyruvic acid. 
<smiles>[R]CC(=O)C(=O)OC</smiles><smiles>[R]C(C(=O)O)C(C(=O)C(=O)O)c1c[nH]c2ccccc12</smiles><smiles>[R]CCn1c(C(=O)O)c([2H])c(-c2c[nH]c3ccccc23)c1C(=O)O</smiles><smiles>[R]CC(=O)C(O)COC</smiles><smiles>[R]c1c(-c2c[nH]c3ccccc23)c(C(=O)C(=O)O)n(CCP)c1C(=O)O</smiles>

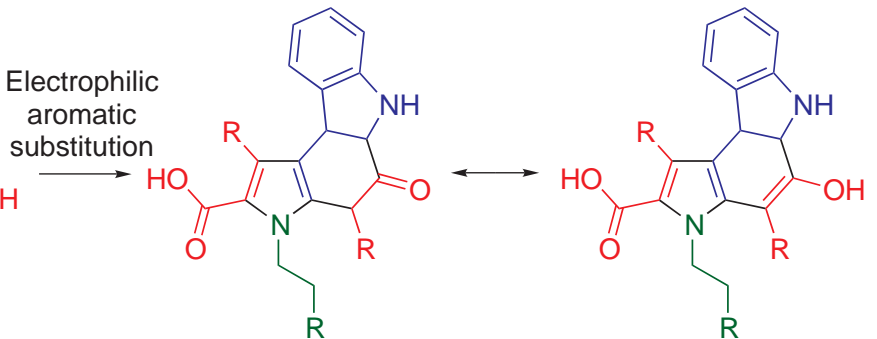<smiles>[R]CCn1c(C(=O)OC)c([R])c2c([R])c(O)c3[nH]c4ccccc4c3c21</smiles><smiles>[R]CC(=O)C(=O)O</smiles><smiles></smiles><smiles>[2H]C(C(=O)O)=c1c([2H])c2c(n1CCP)=C([2H])C(=O)c1[nH]c3ccccc3c1-2</smiles><smiles></smiles><smiles>[2H]c1c(C(=O)O)c([2H])c2c(c1[2H])c([2H])c(C(=O)OC)n2CCP</smiles>

Scheme 6.10 A proposed biogenesis of a dictyodendrin precursor. $\mathrm{R}=$ 4-hydroxybenzene.

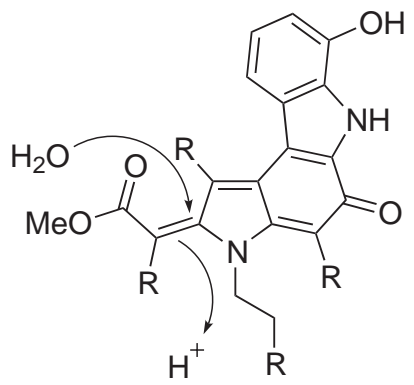<smiles>CI</smiles>

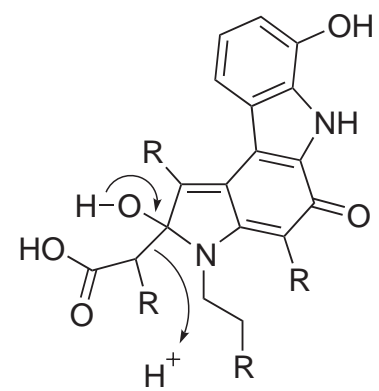<smiles></smiles>

Scheme 6.11 Formation of dictyodendrin $\mathrm{F}(\mathbf{1 9 5})$ as proposed by Warabi et al. ${ }^{161}$ $\mathrm{R}=$ 4-hydroxybenzene. 


\section{Chapter 7}

\section{Conclusion}

Over the course of this study, 12 new chemical structures from four different species of marine sponge were described. A number of interesting modern NMR techniques were applied during the elucidation of these structures. In addition, significant advances were made to the means by which our laboratory examines crude extracts and subsequently dereplicates known compounds.

The marine sponge Raspailia topsenti from which our group has previously described several new clerodanes has given rise to two further related diterpenes. The inclusion of a tricyclo[5.4.0.0 $\left.0^{1,3}\right]$ undecane framework in one of these structures is unprecedented in the clerodane family.

The new nonadecanoic acid derivative isolated from Petrosia sp. and the acetylenic nitrile isolated from Dendrilla rosea are both straight-chain acid derivatives. Each presented its own challenges during structure elucidation and it was only the use of some advanced NMR techniques that brought them to resolution; measuring ${ }^{3} J_{\mathrm{HH}}$ coupling constants from 1D traces of an HSQC experiment acquired without broadband ${ }^{13} \mathrm{C}$ decoupling in the former case, and the use of a ${ }^{1} \mathrm{H}-{ }^{15} \mathrm{~N}$ HMBC experiment in the latter. Each of these two compounds is unusual, most notably dendronitrile which includes nonconjugated nitrile and acetylene moieties.

The isolation of a new series of lamellarins, in particular five new sulfated compounds, from Dictyodendrilla dendyi is significant. While the lamellarins are a very large family of compounds, the observation that sponge-derived lamellarins differ from the rest of the family places these compounds at the very least in a subset with only four of the known lamellarins. The analysis of the biological activity of many of these compounds is ongoing. In particular, the tendency for lamellarin-type alkaloids to exhibit activity towards DNA-modifying enzymes requires that the new compounds isolated herein are tested appropriately. The sulfate derivatives are of particular interest as the polar nature 
of these compounds may assist in the delivery of these molecules in biological systems.

Significant advances were made in the development of an automated software based screening system. The ability to generate a screen mask directly from the NMR data of a series of extracts and its subsequent application to a number of individual screen spectra was successfully demonstrated. Now that the concept has been shown to work, further development will still be required to turn the software screen into a "hands-on" tool.

Similarly, the database of HSQC correlations is an ongoing development. Its usefulness will increase as the number and diversity of compounds included expands. The new means of describing a chemical environment has proved to be quite versatile but is not yet capable of describing the full gamut of chemical variability. This issue will have to be addressed before the database will demonstrate its full potential. 


\section{Chapter 8}

\section{Experimental}

\subsection{General Methods}

NMR spectra were recorded using a Varian Unity Inova $300\left(300 \mathrm{MHz}\right.$ for ${ }^{1} \mathrm{H}$ and $75 \mathrm{MHz}$ for $\left.{ }^{13} \mathrm{C}\right)$, a Varian Unity Inova $500\left(500 \mathrm{MHz}\right.$ for ${ }^{1} \mathrm{H}$ and $125 \mathrm{MHz}$ for $\left.{ }^{13} \mathrm{C}\right)$, or a Varian DirectDrive $600\left(600 \mathrm{MHz}\right.$ for ${ }^{1} \mathrm{H}, 150 \mathrm{MHz}$ for ${ }^{13} \mathrm{C}$ and $60 \mathrm{MHz}$ for $\left.{ }^{15} \mathrm{~N}\right)$ spectrometer. The $600 \mathrm{MHz}$ instrument was equipped with a Varian inverse-detected triple-resonance $\mathrm{HCN}$ cold probe operating at $25 \mathrm{~K}$. Both the 300 and $500 \mathrm{MHz}$ instruments had normaland inverse-detected broadband probes available. All direct-detected ${ }^{1} \mathrm{H}$ and ${ }^{13} \mathrm{C}$ chemical shifts $(\delta)$ were referenced to the residual solvent peak. ${ }^{190}$ Indirectly-detected ${ }^{13} \mathrm{C}$ and ${ }^{15} \mathrm{~N}$ shifts were referenced to the unified TMS scale with $\Xi$ ratios of 25.145020 and 10.136767 respectively. ${ }^{14}$ All HRESIMS data were obtained using a PE Biosystem Mariner 5158 TOF mass spectrometer. Infrared spectra were recorded on a Biorad FTS-7 spectrometer or a Bruker Tensor 27 spectrometer accurate to $2 \mathrm{~cm}^{-1}$. Raman spectra were acquired using a Jobin Yvon LabRam confocal spectrometer working in backscattering configuration with holographic notch filters. The spectrometer is attached to an Olympus BX2 microscope with a long working distance $(\times 50)$ achromatic filter. UV/vis spectra were obtained using a Hewlett-Packard 8452 diode array spectrometer or a Varian Cary 100 spectrometer accurate to $2 \mathrm{~nm}$. Optical rotations were recorded on a Perkin-Elmer 241 polarimeter.

MPLC and HPLC were performed using a Rainin Dynamax SD-200 HPLC system or a Varian SD-1 HPLC system equipped with a Rainin UV-1 detector or a Varian ProStar 335 Diode Array detector. MPLC solvents were either HPLC grade or glass-distilled prior to use. All HPLC was performed with HPLC grade solvents. $\mathrm{H}_{2} \mathrm{O}$ used for MPLC or HPLC was glass-distilled and deionised using a MilliQ system. All solvent mixtures are reported as \% vol/vol. Reversed-phase HPLC was performed using a Phenomenex Prodigy $\mathrm{C}_{18}$ column (analytical $[25 \times 0.46 \mathrm{~cm}]$ or semi-preparative $[25 \times 1.0 \mathrm{~cm}]$ ). Normal- 
phase HPLC was performed using a custom-packed Phenomenex DIOL column $(25 \times$ $0.40 \mathrm{~cm}$ ). TLC analyses were performed using either Merck Kieselgel (Alufoilen) 60 $\mathrm{F}_{254}$ or Machery-Nagel Alugram Sil G/UV 254 plates. TLC plates were visualised by one or more of (1) fluorescence quenching under UV light ( $\lambda=254 \mathrm{~nm})$, (2) fluorescence under UV light ( $\lambda=350 \mathrm{~nm}$ ), (3) spraying with $50 \% \mathrm{H}_{2} \mathrm{SO}_{4} / \mathrm{MeOH}$ then heating, (4) dipping in $5 \% \mathrm{H}_{2} \mathrm{SO}_{4} / \mathrm{MeOH}$ then heating, or (5) dipping in $5 \% \mathrm{H}_{2} \mathrm{SO}_{4} / \mathrm{MeOH}$ then spraying with $1 \%$ vanillin/ $\mathrm{MeOH}$ then heating. Reversed-phase chromatography on PSDVB was performed using HP20 (Mitsubishi), HP20S or HP20SS (Supelco), or Amberchrom CG-

161M (Tosohaas). Normal-phase chromatography was performed using Kieselgel 60 (230-400 mesh ASTM) or DIOL from International Sorbent Technologies or YMC.

Cyclic loading was performed by passing an extract through a PSDVB column. The eluent was then diluted with a volume of $\mathrm{H}_{2} \mathrm{O}$ (usually halving the concentration of the eluent) and passed back through the same column. This procedure was repeated until all desired material adsorbed to the column.

Backloading was performed either by cyclic loading or by dilution. The cyclic loading method involves cyclic loading an eluent to $25 \%$ of its original concentration then eluting the column with an organic solvent to strip all material from the stationary phase. The dilution method involves adding some volume of stationary phase to the eluent then diluting the eluent to $25 \%$ of its original concentration while stirring vigourously. The mixture is then filtered and the stationary phase placed in a column and eluted with an organic solvent to strip all material from the resin.

Desalting was performed by cyclic loading a sample on to a PSDVB column. The column was then eluted with a substantial quantity of $\mathrm{H}_{2} \mathrm{O}$ (ca. 15 column-volumes). The column was then eluted with an organic solvent to afford a desalted sample.

\section{Preparation of diazomethane solution}

To a solution of $\mathrm{KOH}(5.06 \mathrm{~g}, 90 \mathrm{mmol})$ in $\mathrm{H}_{2} \mathrm{O}(8 \mathrm{~mL})$ and $\mathrm{EtOH}(10 \mathrm{~mL})$ maintained at $65^{\circ} \mathrm{C}$ in a diazomethane distillation apparatus with smooth glass joints, diazald $(1.018 \mathrm{~g}$, 
$4.8 \mathrm{mmol})$ in $\mathrm{Et}_{2} \mathrm{O}(11 \mathrm{~mL})$ was added drop-wise. Distilled ethereal $\mathrm{CH}_{2} \mathrm{~N}_{2}$ was collected in a flask maintained at $0{ }^{\circ} \mathrm{C}$. Excess diazald was rinsed from the dropping funnel into the reaction vessel with $\mathrm{Et}_{2} \mathrm{O}$ until the distillate was clear. 


\subsection{Isolation of Raspailodane F (40) and G (41) from Raspailia topsenti}

Raspailia topsenti (500 g wet weight) was extracted for $18 \mathrm{hr}$ in $1.25 \mathrm{~L}$ of $\mathrm{MeOH}$. The extract was filtered and the sponge material re-extracted for $18 \mathrm{hr}$ with a further $1.25 \mathrm{~L}$ of $\mathrm{MeOH}$. The second extract was passed through a $200 \mathrm{~mL}$ column of HP20. The first extract was then passed through the same column and the eluents combined. The combined eluents were then diluted with $2.5 \mathrm{~L}$ of $\mathrm{H}_{2} \mathrm{O}$ (now $50 \% \mathrm{MeOH}$ in $\mathrm{H}_{2} \mathrm{O}$ ) and passed back through the column. The eluent was diluted again with $5 \mathrm{~L}$ of $\mathrm{H}_{2} \mathrm{O}$ (now $25 \% \mathrm{MeOH}$ in $\mathrm{H}_{2} \mathrm{O}$ ) and the resulting $10 \mathrm{~L}$ eluent was passed through the column a final time. The column was then eluted sequentially with $250 \mathrm{~mL}$ fractions of solvent $\left(\mathrm{H}_{2} \mathrm{O}\right.$, $40 \%, 75 \%$ and $85 \% \mathrm{Me}_{2} \mathrm{CO}$ in $\mathrm{H}_{2} \mathrm{O}$ and $\mathrm{Me}_{2} \mathrm{CO}$ ). The $75 \% \mathrm{Me}_{2} \mathrm{CO}$ in $\mathrm{H}_{2} \mathrm{O}$ elution was backloaded on to a $80 \mathrm{~mL}$ HP20 column and eluted with $250 \mathrm{~mL}$ of $\mathrm{Me}_{2} \mathrm{CO}$. The $\mathrm{Me}_{2} \mathrm{CO}$ eluent was concentrated under reduced pressure. The resulting material was cyclic loaded on to $30 \mathrm{~mL}$ of HP20S which was transferred to the top of a prepacked $45 \times 2.5 \mathrm{~cm}$ internal diameter HP20S column and eluted at a flow rate of $8 \mathrm{~mL} / \mathrm{min}$ from $50 \% \mathrm{Me}_{2} \mathrm{CO}$ in $\mathrm{H}_{2} \mathrm{O}$ to $100 \% \mathrm{Me}_{2} \mathrm{CO}$ with a solvent gradient of $0.4 \% / \mathrm{min}$. Twenty-five fractions were collected over $125 \mathrm{~min}$.

Fractions 19 and 20 of the $25\left(87 \%\right.$ to $90 \% \mathrm{Me}_{2} \mathrm{CO}$ in $\left.\mathrm{H}_{2} \mathrm{O}\right)$ were combined and cyclic loaded on to $2 \mathrm{~mL}$ of Amberchrom which was transferred to the top of a $30 \times 1.1 \mathrm{~cm}$ internal diameter prepacked Amberchrom column and eluted at a flow rate of $5 \mathrm{~mL} / \mathrm{min}$ from $50 \%$ to $64 \% \mathrm{Me}_{2} \mathrm{CO}$ in $\mathrm{H}_{2} \mathrm{O}$ with a solvent gradient of $1 \% / \mathrm{min}, 64 \%$ to $76 \% \mathrm{Me}_{2} \mathrm{CO}$ in $\mathrm{H}_{2} \mathrm{O}$ with a solvent gradient of $0.5 \% / \mathrm{min}$ and $76 \% \mathrm{Me}_{2} \mathrm{CO}$ in $\mathrm{H}_{2} \mathrm{O}$ to $100 \% \mathrm{Me}_{2} \mathrm{CO}$ with a solvent gradient of $1 \% / \mathrm{min}$. Thirty-one fractions were collected over $62 \mathrm{~min}$. Fractions 16 to $18\left(73 \%\right.$ to $75 \% \mathrm{Me}_{2} \mathrm{CO}$ in $\left.\mathrm{H}_{2} \mathrm{O}\right)$ were combined and chromatographed on a semi-preparative $\mathrm{C}_{18}$ reversed-phase HPLC column with $70 \% \mathrm{MeCN}$ in $\mathrm{H}_{2} \mathrm{O}$ as the mobile phase at a flow rate of $3 \mathrm{~mL} / \mathrm{min}$ to afford raspailodane $\mathrm{F}(\mathbf{4 0})(1.1 \mathrm{mg})$ and raspailodane B (33) (0.1 mg) with retention times of 16.3 and $21.3 \mathrm{~min}$ respectively.

Fractions 17 and 18 of the $25\left(83 \%\right.$ to $86 \% \mathrm{Me}_{2} \mathrm{CO}$ in $\left.\mathrm{H}_{2} \mathrm{O}\right)$ were combined and 
cyclic loaded on to $2 \mathrm{~mL}$ of Amberchrom which was transferred to the top of a $30 \times$ $1.1 \mathrm{~cm}$ internal diameter prepacked Amberchrom column and eluted at a flow rate of $5 \mathrm{~mL} / \mathrm{min}$ from $50 \%$ to $64 \% \mathrm{Me}_{2} \mathrm{CO}$ in $\mathrm{H}_{2} \mathrm{O}$ with a solvent gradient of $1 \% / \mathrm{min}, 64 \%$ to $76 \% \mathrm{Me}_{2} \mathrm{CO}$ in $\mathrm{H}_{2} \mathrm{O}$ with a solvent gradient of $0.5 \% / \mathrm{min}$ and $76 \% \mathrm{Me}_{2} \mathrm{CO}$ in $\mathrm{H}_{2} \mathrm{O}$ to $100 \% \mathrm{Me}_{2} \mathrm{CO}$ with a solvent gradient of $1 \% / \mathrm{min}$. Thirty-one fractions were collected over 62 min. Fractions 11 to $13\left(67 \%\right.$ to $69 \% \mathrm{Me}_{2} \mathrm{CO}$ in $\left.\mathrm{H}_{2} \mathrm{O}\right)$ were combined and chromatographically separated on a semi-preparative $\mathrm{C}_{18}$ reversed-phase HPLC column with $70 \% \mathrm{MeCN}$ in $\mathrm{H}_{2} \mathrm{O}$ as the mobile phase at a flow rate of $3 \mathrm{~mL} / \mathrm{min}$ to afford raspailodane $\mathrm{G}(\mathbf{4 1})(13.7 \mathrm{mg})$ and raspailol (29) (2.6 $\mathrm{mg})$ with retention times of 10.0 and $10.8 \mathrm{~min}$ respectively.

\section{Raspailodane F (40)}

Colourless oil; UV (MeOH) $\lambda_{\max } 212 \mathrm{~nm}$ ( $\epsilon$ 29000); NMR data see Table 2.2; HRESIMS, obsd. $m / z$ 345.2074 $[\mathrm{M}+\mathrm{H}]^{+}, \mathrm{C}_{21} \mathrm{H}_{29} \mathrm{O}_{4}^{+}$requires 345.2060, $\Delta 4.0 \mathrm{ppm}$.

\section{Raspailodane G (41)}

Colourless oil; $[\alpha]_{\mathrm{D}}+156\left(25^{\circ} \mathrm{C}\right)$; UV (MeOH) $\lambda_{\max } 236 \mathrm{~nm}(\epsilon 11500)$; IR (KBr) $\nu_{\max }$ 2920, 2855, 1760, $1384 \mathrm{~cm}^{-1}$; NMR data see Table 2.3; HRESIMS, obsd. $\mathrm{m} / z$ 345.1704 $[\mathrm{M}+\mathrm{H}]^{+}, \mathrm{C}_{20} \mathrm{H}_{25} \mathrm{O}_{5}^{+}$requires $345.1703, \Delta 2.1 \mathrm{ppm}$. 


\subsection{Isolation of Petrosianoic Acid (122) from Petrosia sp.}

Petrosia sp. (840 g wet weight) was extracted for $18 \mathrm{hr}$ in $2 \mathrm{~L}$ of $\mathrm{MeOH}$. The extract was filtered and the sponge material re-extracted for $18 \mathrm{hr}$ with a further $2 \mathrm{~L}$ of $\mathrm{MeOH}$. The second extract was passed through a $300 \mathrm{~mL}$ column of HP20. The first extract was then passed through the same column and the eluents combined. The combined eluent was then diluted with $4 \mathrm{~L}$ of $\mathrm{H}_{2} \mathrm{O}$ (now $50 \% \mathrm{MeOH}$ in $\mathrm{H}_{2} \mathrm{O}$ ) and passed back through the column. The eluent was diluted again with $8 \mathrm{~L}$ of $\mathrm{H}_{2} \mathrm{O}$ (now $25 \% \mathrm{MeOH}$ in $\mathrm{H}_{2} \mathrm{O}$ ) and the resulting $16 \mathrm{~L}$ eluent was passed through the column a final time. The column was then eluted sequentially with $1 \mathrm{~L}$ fractions of solvent $\left(\mathrm{H}_{2} \mathrm{O}, 20 \%, 30 \%, 50 \%, 70 \%\right.$ and $80 \% \mathrm{Me}_{2} \mathrm{CO}$ in $\mathrm{H}_{2} \mathrm{O}$ and $\mathrm{Me}_{2} \mathrm{CO}$ ). The $50 \% \mathrm{Me}_{2} \mathrm{CO}$ in $\mathrm{H}_{2} \mathrm{O}$ elution was backloaded on to a $50 \mathrm{~mL} \mathrm{HP} 20$ column and eluted with $250 \mathrm{~mL}$ of $\mathrm{MeOH}$. The $\mathrm{Me}_{2} \mathrm{CO}$ eluent was concentrated under reduced pressure to yield $116 \mathrm{mg}$ of material. This material was cyclic loaded on to $1.5 \mathrm{~mL}$ of Amberchrom which was transferred to the top of a $30 \times 1.1 \mathrm{~cm}$ internal diameter prepacked Amberchrom column and eluted at a flow rate of $5 \mathrm{~mL} / \mathrm{min}$ from $20 \% \mathrm{Me}_{2} \mathrm{CO}$ in $\mathrm{H}_{2} \mathrm{O}$ to $100 \% \mathrm{Me}_{2} \mathrm{CO}$ with a solvent gradient of $2 \% / \mathrm{min}$. Forty fractions were collected over $40 \mathrm{~min}$.

Fractions 32 to 33 of the $40\left(83 \%\right.$ to $86 \% \mathrm{Me}_{2} \mathrm{CO}$ in $\left.\mathrm{H}_{2} \mathrm{O}\right)$ were combined and passed through a normal-phase column (DIOL, $3 \mathrm{~mL}$ ) eluted successively with $10 \mathrm{~mL}$ volumes of $\mathrm{CH}_{2} \mathrm{Cl}_{2}, 2 \%, 5 \%, 10 \%, 20 \%$, and $50 \%$ EtOAc in $\mathrm{CH}_{2} \mathrm{Cl}_{2}, \mathrm{EtOAc}, 5 \%, 10 \%$ and $50 \% \mathrm{MeOH}$ in EtOAc, and $\mathrm{MeOH}$. The $10 \%$ and $20 \%$ EtOAc in $\mathrm{CH}_{2} \mathrm{Cl}_{2}$ fractions were combined and chromatographically separated on an analytical $\mathrm{C}_{18}$ reversed-phase HPLC column with $70 \% \mathrm{MeCN}$ in $0.1 \mathrm{M} \mathrm{HCOOH}$ as the mobile phase at a flow rate of $1 \mathrm{~mL} / \mathrm{min}$ to afford petrosianoic acid (122) (1.0 $\mathrm{mg})$ with a retention time of $17.8 \mathrm{~min}$.

Fractions 27 to 31 and fractions 34 to 36 of the 40 (73\% to $82 \%$ and $87 \%$ to $92 \%$ $\mathrm{Me}_{2} \mathrm{CO}$ in $\mathrm{H}_{2} \mathrm{O}$ respectively) were combined and passed through a normal-phase column (DIOL, $10 \mathrm{~mL}$ ) eluted successively with $10 \mathrm{~mL}$ volumes of $5 \%$ and $20 \%$ EtOAc in $\mathrm{CH}_{2} \mathrm{Cl}_{2}$, EtOAc, and $50 \% \mathrm{MeOH}$ in EtOAc. The 20\% EtOAc in $\mathrm{CH}_{2} \mathrm{Cl}_{2}$ fraction was chromatographically separated on a semi-preparative $\mathrm{C}_{18}$ reversed-phase HPLC column with $70 \% \mathrm{MeCN}$ in $0.1 \mathrm{M} \mathrm{HCOOH}$ as the mobile phase at a flow rate of $4.7 \mathrm{~mL} / \mathrm{min}$ to 
afford petrosianoic acid (122) (1.6 mg) with a retention time of $20.1 \mathrm{~min}$.

\section{Methylation of 122}

To a sample of $122(1.0 \mathrm{mg}, 3.1 \mu \mathrm{mol})$, ca. $4.5 \mathrm{~mL}$ of ethereal $\mathrm{CH}_{2} \mathrm{~N}_{2}$ was added. The resulting solution was left to sit at $0{ }^{\circ} \mathrm{C}$ for $1 \mathrm{hr}$, then at RT for $30 \mathrm{~min}$ and finally in a tepid water bath for $1 \mathrm{hr}$. The solution was then evaporated to dryness under reduced pressure to afford $123(1.9 \mathrm{mg})$.

\section{Petrosianoic Acid (122)}

Amorphous white solid; UV (MeOH) $\lambda_{\max } 275$ nm ( $\epsilon$ 21500); IR (neat) $\nu_{\max }$ 2917, 2848, 1705, 1683, $1636 \mathrm{~cm}^{-1}$; NMR data see Table 4.3; HRESIMS, obsd. $\mathrm{m} / \mathrm{z}$ $321.2059[\mathrm{M}-\mathrm{H}]^{-}, \mathrm{C}_{19} \mathrm{H}_{29} \mathrm{O}_{4}^{-}$requires 321.2060, $\Delta$ 0.5 ppm, obsd. $323.2210[\mathrm{M}+\mathrm{H}]^{+}$, $\mathrm{C}_{19} \mathrm{H}_{31} \mathrm{O}_{4}^{+}$requires 323.2217, $\Delta 2.3 \mathrm{ppm}$.

\section{Methylpetrosianoate (123)}

Amorphous white solid; UV (MeOH) $\lambda_{\max } 276$ nm ( $\epsilon$ 25900); NMR data see Table 4.4; HRESIMS, obsd. $m / z 337.2386[\mathrm{M}+\mathrm{H}]^{+}, \mathrm{C}_{20} \mathrm{H}_{33} \mathrm{O}_{4}^{+}$requires 337.2373, $\Delta 3.7 \mathrm{ppm}$, obsd. $m / z 359.2200[\mathrm{M}+\mathrm{Na}]^{+}, \mathrm{C}_{20} \mathrm{H}_{32} \mathrm{O}_{4} \mathrm{Na}^{+}$requires 359.2193, $\Delta 2.1 \mathrm{ppm}$. 


\subsection{Isolation of Metabolites from Dendrilla rosea}

\section{Initial Extraction of $D$. rosea}

Dendrilla rosea (35.2 g wet weight) was extracted for $18 \mathrm{hr}$ in $400 \mathrm{~mL}$ of $\mathrm{MeOH}$. The extract was filtered and the sponge material re-extracted for $18 \mathrm{hr}$ with a further $400 \mathrm{~mL}$ of $\mathrm{MeOH}$. The extracts were combined and cyclic loaded to $25 \%$ of the original concentration on to an $80 \mathrm{~mL}$ HP20 column. The column was eluted successively with $250 \mathrm{~mL}$ volumes of $\mathrm{H}_{2} \mathrm{O}, 30 \%$ and $75 \% \mathrm{Me}_{2} \mathrm{CO}$ in $\mathrm{H}_{2} \mathrm{O}$ and $\mathrm{Me}_{2} \mathrm{CO}$. The $75 \% \mathrm{Me}_{2} \mathrm{CO}$ in $\mathrm{H}_{2} \mathrm{O}$ elution was backloaded on to a $40 \mathrm{~mL}$ HP20 column and eluted with $150 \mathrm{~mL}$ of $\mathrm{Me}_{2} \mathrm{CO}$. The $\mathrm{Me}_{2} \mathrm{CO}$ eluent was concentrated under reduced pressure to yield $189 \mathrm{mg}$ of material. Approximately half $(94 \mathrm{mg}$ ) of this material was cyclic loaded on to $2 \mathrm{~mL}$ of HP20SS which was transferred to the top of a $30 \times 1.1 \mathrm{~cm}$ internal diameter prepacked HP20SS column. The column was eluted at a flow rate of $5 \mathrm{~mL} / \mathrm{min}$ with $20 \% \mathrm{Me}_{2} \mathrm{CO}$ in $\mathrm{H}_{2} \mathrm{O}$ for $10 \mathrm{~min}$, then gradient eluted from $20 \% \mathrm{Me}_{2} \mathrm{CO}$ in $\mathrm{H}_{2} \mathrm{O}$ to $\mathrm{Me}_{2} \mathrm{CO}$ over $40 \mathrm{~min}$ (2\%/min), and finally with $\mathrm{Me}_{2} \mathrm{CO}$ for $14 \mathrm{~min}$. A total of 64 fractions were collected over the entire run at a rate of 1 fraction/min. Fractions 40 to 49 (80\% to $98 \% \mathrm{Me}_{2} \mathrm{CO}$ in $\mathrm{H}_{2} \mathrm{O}$ ) were combined and concentrated under reduced pressure. The resulting material was divided in half and passed through two $10 \mathrm{~mL}$ DIOL columns each eluted successively with $30 \mathrm{~mL}$ volumes of $\mathrm{CH}_{2} \mathrm{Cl}_{2}, 10 \%$ and $50 \%$ EtOAc in $\mathrm{CH}_{2} \mathrm{Cl}_{2}$, EtOAc, $10 \% \mathrm{MeOH}$ in EtOAc and $\mathrm{MeOH}$. The $10 \%$ EtOAc in $\mathrm{CH}_{2} \mathrm{Cl}_{2}$ fractions were combined and passed through a $20 \mathrm{~mL}$ silica column eluted successively with $75 \mathrm{~mL}$ of $\mathrm{CH}_{2} \mathrm{Cl}_{2}, 5 \%, 10 \%$ and $15 \%$ EtOAc in $\mathrm{CH}_{2} \mathrm{Cl}_{2}$. Sixty fractions were collected (ca. $5 \mathrm{~mL} /$ fraction). Fractions $27-$ 36 (5\% to $10 \%$ EtOAc in $\mathrm{CH}_{2} \mathrm{Cl}_{2}$ ) were combined to afford dendrillol-1 (125) (3.7 mg).

\section{Large-scale Extraction of $D$. rosea}

Dendrilla rosea (140.5 g wet weight) was extracted for $18 \mathrm{hr}$ in $500 \mathrm{~mL}$ of $\mathrm{MeOH}$. The extract was filtered and the sponge material re-extracted for $18 \mathrm{hr}$ with a further $500 \mathrm{~mL}$ of $\mathrm{MeOH}$. The extracts were combined and cyclic loaded to $25 \%$ of the original concentration on to a $150 \mathrm{~mL}$ HP20 column. The column was eluted successively with 
$500 \mathrm{~mL}$ volumes of $\mathrm{H}_{2} \mathrm{O}, 30 \%, 50 \%$ and $75 \% \mathrm{Me}_{2} \mathrm{CO}$ in $\mathrm{H}_{2} \mathrm{O}$ and $\mathrm{Me}_{2} \mathrm{CO}$. The $75 \%$ $\mathrm{Me}_{2} \mathrm{CO}$ in $\mathrm{H}_{2} \mathrm{O}$ elution was backloaded on to a $40 \mathrm{~mL}$ HP20 column and eluted with $150 \mathrm{~mL}$ of $\mathrm{Me}_{2} \mathrm{CO}$. The $\mathrm{Me}_{2} \mathrm{CO}$ eluent was concentrated under reduced pressure to yield $375 \mathrm{mg}$ of material. Approximately half $(187 \mathrm{mg})$ of this material was combined with the remaining $94 \mathrm{mg}$ of the $75 \% \mathrm{Me}_{2} \mathrm{CO}$ in $\mathrm{H}_{2} \mathrm{O}$ fraction from the previous extraction and injected on to a prepacked $45 \times 2.5 \mathrm{~cm}$ internal diameter DIOL column which was eluted at a flow rate of $8 \mathrm{~mL} / \mathrm{min}$ with successive $640 \mathrm{~mL}$ volumes of $\mathrm{CH}_{2} \mathrm{Cl}_{2}, 10 \%, 50 \%$ EtOAc in $\mathrm{CH}_{2} \mathrm{Cl}_{2}$, EtOAc, $10 \% \mathrm{MeOH}$ in EtOAc and $\mathrm{MeOH}$. A total of 12 fractions were collected at a rate of 1 fraction/40 min.

Fraction 3 of the $12\left(10 \%\right.$ EtOAc in $\left.\mathrm{CH}_{2} \mathrm{Cl}_{2}\right)$ was passed through a $30 \mathrm{~mL}$ silica column eluted successively with $100 \mathrm{~mL}$ volumes of $50 \% \mathrm{CH}_{2} \mathrm{Cl}_{2}$ in petroleum ether, $\mathrm{CH}_{2} \mathrm{Cl}_{2}$, $2 \%, 20 \%$ and $50 \%$ EtOAc in $\mathrm{CH}_{2} \mathrm{Cl}_{2}$. A total of 80 fractions were collected (ca. $6.25 \mathrm{~mL} /$ fraction). Fractions 53-58 (20\% EtOAc in $\left.\mathrm{CH}_{2} \mathrm{Cl}_{2}\right)$ were combined and passed through a $30 \mathrm{~mL}$ silica column succesively eluted with $60 \mathrm{~mL}$ volumes of $\mathrm{CH}_{2} \mathrm{Cl}_{2}, 5 \%$, $7 \%, 10 \%, 15 \%$ and $20 \%$ EtOAc in $\mathrm{CH}_{2} \mathrm{Cl}_{2}$. A total of 48 fractions were collected (ca. $7.5 \mathrm{~mL} /$ fraction). Fractions $14-26$ (7\% to $10 \%$ EtOAc in $\mathrm{CH}_{2} \mathrm{Cl}_{2}$ ) were combined to afford dendrillol-1 (125) (11.2 mg).

Fraction 4 of the $12\left(10 \%\right.$ EtOAc in $\left.\mathrm{CH}_{2} \mathrm{Cl}_{2}\right)$ was divided in half and passed through two $30 \mathrm{~mL}$ silica columns each eluted successively with $60 \mathrm{~mL}$ volumes of $7 \%, 10 \%$, $15 \%, 20 \%$ and $50 \%$ EtOAc in $\mathrm{CH}_{2} \mathrm{Cl}_{2}$. Forty-eight fractions were collected (ca. $6.25 \mathrm{~mL} /$ fraction) from each column. Fractions 35-37 (15\% to $20 \%$ EtOAc in $\mathrm{CH}_{2} \mathrm{Cl}_{2}$ ) from each run were combined and passed through a $30 \mathrm{~mL}$ silica column succesively eluted with $120 \mathrm{~mL}$ volumes of $10 \%, 12 \%$ and $15 \%$ EtOAc in $\mathrm{CH}_{2} \mathrm{Cl}_{2}$. A total of 60 fractions were collected (ca. $6 \mathrm{~mL} /$ fraction). Fractions $36-60$ (12\% to $15 \%$ EtOAc in $\mathrm{CH}_{2} \mathrm{Cl}_{2}$ ) were combined to afford aplyroseol-6 (135) (5.8 mg).

The remaining $187 \mathrm{mg}$ of the original $75 \% \mathrm{Me}_{2} \mathrm{CO}$ in $\mathrm{H}_{2} \mathrm{O}$ fraction was passed through a $100 \mathrm{~mL}$ DIOL column eluted successively with $320 \mathrm{~mL}$ volumes of $\mathrm{CH}_{2} \mathrm{Cl}_{2}, 10 \%$ and $50 \%$ EtOAc in $\mathrm{CH}_{2} \mathrm{Cl}_{2}$, EtOAc, $10 \% \mathrm{MeOH}$ in EtOAc and $\mathrm{MeOH}$. A total of 24 fractions were collected (80 mL/fraction). Fraction $1\left(\mathrm{CH}_{2} \mathrm{Cl}_{2}\right)$ was evaporated to dryness under 
reduced pressure to afford dendronitrile $(\mathbf{1 5 8})(6.0 \mathrm{mg})$.

\section{Second Large-scale Extraction of D. rosea}

Dendrilla rosea (339.0 g wet weight) was extracted for $18 \mathrm{hr}$ in $1.5 \mathrm{~L}$ of $\mathrm{MeOH}$. The extract was filtered and the sponge material re-extracted for $18 \mathrm{hr}$ with a further 1.5 $\mathrm{L}$ of $\mathrm{MeOH}$. The extracts were combined and cyclic loaded to $25 \%$ of the original concentration on to a $300 \mathrm{~mL}$ HP20 column. The column was eluted successively with $1 \mathrm{~L}$ volumes of $\mathrm{H}_{2} \mathrm{O}, 30 \%$ and $75 \% \mathrm{Me}_{2} \mathrm{CO}$ in $\mathrm{H}_{2} \mathrm{O}$ and $\mathrm{Me}_{2} \mathrm{CO}$. The $75 \% \mathrm{Me}_{2} \mathrm{CO}$ in $\mathrm{H}_{2} \mathrm{O}$ elution was backloaded on to a $150 \mathrm{~mL} \mathrm{HP} 20$ column and eluted with $500 \mathrm{~mL}$ of $\mathrm{Me}_{2} \mathrm{CO}$. The $\mathrm{Me}_{2} \mathrm{CO}$ eluent was concentrated under reduced pressure to yield $1.30 \mathrm{~g}$ of material. This material was divided into three and each third was injected on to a prepacked 45 $\times 2.5 \mathrm{~cm}$ internal diameter DIOL column which was eluted at a flow rate of $5 \mathrm{~mL} / \mathrm{min}$ with successive $800 \mathrm{~mL}$ volumes of $\mathrm{CH}_{2} \mathrm{Cl}_{2}, 10 \%, 50 \%$ EtOAc in $\mathrm{CH}_{2} \mathrm{Cl}_{2}$, EtOAc, $10 \%$ $\mathrm{MeOH}$ in EtOAc and $\mathrm{MeOH}$. Twelve fractions were collected for each injection at a rate of 1 fraction/80 min. Fractions 7 (100\% EtOAc) from each of the three runs were combined and chromatographically separated on a semi-preparative $\mathrm{C}_{18}$ reversed-phase HPLC column with $60 \%$ THF in $\mathrm{H}_{2} \mathrm{O}$ as the mobile phase at a flow rate of $4.7 \mathrm{~mL} / \mathrm{min}$ to afford 24-nor-5 $\alpha$-cholesta-7,22(E)-diene-3 $\beta, 6 \alpha$-diol (157) (6.6 mg) with a retention time of $6.3 \mathrm{~min}$.

\section{Dendronitrile (158)}

Amorphous white solid; UV (MeOH) $\lambda_{\max } 212 \mathrm{~nm}(\epsilon$ 62800), $240 \mathrm{~nm}(\epsilon$ 9220), $254 \mathrm{~nm}$ ( $\epsilon$ 16400), $266 \mathrm{~nm}$ ( $\epsilon$ 23200), $282 \mathrm{~nm}\left(\epsilon\right.$ 18700); IR (KBr) $\nu_{\max } 2962,2934,2874,2361$, 2342, 2247, 1460, 1426, 912, $733 \mathrm{~cm}^{-1}$; Raman (514 nm) $\nu_{\max } 2263,2241 \mathrm{~cm}^{-1}$; NMR data see Table 5.5; HRESIMS, obsd. $m / z 203.1552\left[\mathrm{M}+\mathrm{NH}_{4}\right]^{+}, \mathrm{C}_{13} \mathrm{H}_{19} \mathrm{~N}_{2}^{+}$requires 203.1543, $\Delta 4.5$ ppm, obsd. $m / z$ 208.1100 $[\mathrm{M}+\mathrm{Na}]^{+}, \mathrm{C}_{13} \mathrm{H}_{15} \mathrm{NNa}^{+}$requires 208.1097, $\Delta$ $1.3 \mathrm{ppm}$. 


\section{Dendrillol-1 (125)}

Colourless oil; NMR data see Table 5.2; HRESIMS, obsd. $\mathrm{m} / \mathrm{z} 352.2496\left[\mathrm{M}+\mathrm{NH}_{4}\right]^{+}$, $\mathrm{C}_{20} \mathrm{H}_{34} \mathrm{NO}_{4}^{+}$requires 352.2482, $\Delta 3.8$ ppm, obsd. $m / z$ 357.2061 $[\mathrm{M}+\mathrm{Na}]^{+}, \mathrm{C}_{20} \mathrm{H}_{30} \mathrm{O}_{4} \mathrm{Na}^{+}$ requires 357.2036, $\Delta 6.8$ ppm, obsd. $m / z 691.4173[2 \mathrm{M}+\mathrm{Na}]^{+}, \mathrm{C}_{40} \mathrm{H}_{60} \mathrm{O}_{8} \mathrm{Na}^{+}$requires 691.4180, $\Delta 1.1 \mathrm{ppm}$.

\section{Aplyroseol-6 (135)}

Colourless oil; NMR data see Table 5.3; HRESIMS, obsd. $m / z 479.2699[\mathrm{M}+\mathrm{H}]^{+}$, $\mathrm{C}_{26} \mathrm{H}_{39} \mathrm{O}_{8}^{+}$requires 479.2639, $\Delta 12.4$ ppm, obsd. $m / z$ 496.2926 $\left[\mathrm{M}+\mathrm{NH}_{4}\right]^{+}, \mathrm{C}_{26} \mathrm{H}_{42} \mathrm{NO}_{8}^{+}$ requires 496.2905, $\Delta 4.1$ ppm, obsd. $m / z$ 501.2473 $[\mathrm{M}+\mathrm{Na}]^{+}, \mathrm{C}_{26} \mathrm{H}_{38} \mathrm{O}_{8} \mathrm{Na}^{+}$requires 501.2459, $\Delta 2.8$ ppm, obsd. $m / z$ 979.5004 $\left[2 \mathrm{M}+\mathrm{Na}^{+}, \mathrm{C}_{52} \mathrm{H}_{76} \mathrm{O}_{16} \mathrm{Na}^{+}\right.$requires 979.5026, $\Delta 2.2 \mathrm{ppm}$.

\section{4-nor-5 $\alpha$-cholesta-7,22(E)-diene-3 $\beta, 6 \alpha$-diol (157)}

White solid; all spectroscopic data were in agreement with those previously reported. ${ }^{145}$ 


\subsection{Isolation of Metabolites from Dictyodendrilla dendyi}

\section{Initial Extraction of D. dendyi}

Dictyodendrilla dendyi (47 g wet weight) was extracted for $18 \mathrm{hr}$ in $200 \mathrm{~mL}$ of $\mathrm{MeOH}$. The extract was filtered and the sponge material re-extracted for $18 \mathrm{hr}$ with a further $200 \mathrm{~mL}$ of $\mathrm{MeOH}$. The extracts were combined and cyclic loaded to $25 \%$ of the original concentration on to an $80 \mathrm{~mL}$ HP20 column. The column was eluted successively with $250 \mathrm{~mL}$ volumes of $\mathrm{H}_{2} \mathrm{O}, 30 \%$ and $75 \% \mathrm{Me}_{2} \mathrm{CO}$ in $\mathrm{H}_{2} \mathrm{O}$ and $\mathrm{Me}_{2} \mathrm{CO}$. The $75 \% \mathrm{Me}_{2} \mathrm{CO}$ in $\mathrm{H}_{2} \mathrm{O}$ elution was backloaded on to a $40 \mathrm{~mL}$ HP20 column and eluted with $100 \mathrm{~mL}$ of $\mathrm{H}_{2} \mathrm{O}$ followed by $130 \mathrm{~mL}$ of $\mathrm{Me}_{2} \mathrm{CO}$. The $\mathrm{Me}_{2} \mathrm{CO}$ eluent was concentrated under reduced pressure to yield $129 \mathrm{mg}$ of material. Approximately half $(66 \mathrm{mg}$ ) of this material was cyclic loaded on to $2 \mathrm{~mL}$ of Amberchrom which was transferred to the top of a $30 \times$ $1.1 \mathrm{~cm}$ internal diameter prepacked Amberchrom column. The column was eluted at a flow rate of $5 \mathrm{~mL} / \mathrm{min}$ with $20 \% \mathrm{MeOH}$ in $\mathrm{H}_{2} \mathrm{O}$ for $10 \mathrm{~min}$, then gradient eluted from $20 \%$ $\mathrm{MeOH}$ in $\mathrm{H}_{2} \mathrm{O}$ to $\mathrm{MeOH}$ over $40 \mathrm{~min}(2 \% / \mathrm{min})$, and finally with $\mathrm{MeOH}$ for $25 \mathrm{~min}$. A total of 75 fractions were collected over the entire run at a rate of 1 fraction/min. Fractions 50 and $51(100 \% \mathrm{MeOH})$ were combined and concentrated under reduced pressure. The resulting material was passed through a normal-phase column (DIOL, $15 \mathrm{~mL}$ ) eluted successively with $30 \mathrm{~mL}$ volumes of $\mathrm{CH}_{2} \mathrm{Cl}_{2}, 1 \%, 2 \%, 5 \%, 10 \%, 20 \%$ and $50 \%$ EtOAc in $\mathrm{CH}_{2} \mathrm{Cl}_{2}$, EtOAc, $1 \%, 2 \%, 5 \%, 10 \%, 20 \%$ and 50\% $\mathrm{MeOH}$ in EtOAc and $\mathrm{MeOH}$. The $50 \%$ EtOAc in $\mathrm{CH}_{2} \mathrm{Cl}_{2}$ fraction was evaporated under reduced pressure to afford lamellarin $\theta$ (187) (4.2 mg). The same procedure was repeated for the second half of the extract to afford a further $4.9 \mathrm{mg}$ of $\mathbf{1 8 7}$.

\section{Large-scale Extraction of $D$. dendyi}

Triplicate samples of Dictyodendrilla dendyi (203 g, 210 g, 220 g wet weight) were extracted for $18 \mathrm{hr}$ with $800 \mathrm{~mL} \mathrm{MeOH}$. The extracts were filtered and the sponge material re-extracted for $18 \mathrm{hr}$ with a further $800 \mathrm{~mL}$ of $\mathrm{MeOH}$. Each pair of extracts was combined 
and cyclic loaded to $25 \%$ of the original concentration on to a $160 \mathrm{~mL}$ HP20 column. Each was eluted successively with $\mathrm{H}_{2} \mathrm{O}, 20 \%, 40 \%, 60 \%$ and $80 \% \mathrm{Me}_{2} \mathrm{CO}$ in $\mathrm{H}_{2} \mathrm{O}$ and $\mathrm{Me}_{2} \mathrm{CO}$.

Each of the $60 \% \mathrm{Me}_{2} \mathrm{CO}$ in $\mathrm{H}_{2} \mathrm{O}$ fractions were backloaded on to $100 \mathrm{~mL}$ of $\mathrm{HP} 20$ by dilution to $25 \%$. The resulting resins were placed in columns and eluted with $300 \mathrm{~mL}$ of $\mathrm{MeOH}$. The three eluents were combined and evaporated to dryness under reduced pressure to afford $246 \mathrm{mg}$ of material. This extract was divided into 4 equal portions which were each cyclic loaded on to $2 \mathrm{~mL}$ of Amberchrom which was transferred to the top of a $30 \times 1.1 \mathrm{~cm}$ internal diameter prepacked Amberchrom column. The columns were eluted at a flow rate of $5 \mathrm{~mL} / \mathrm{min}$ with $20 \% \mathrm{MeOH}$ in $\mathrm{H}_{2} \mathrm{O}$ for $10 \mathrm{~min}$, then gradient

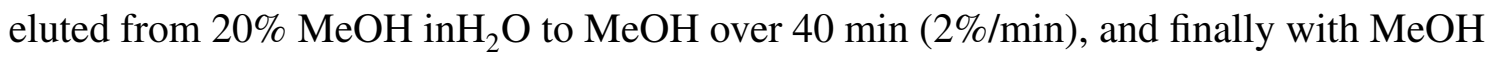
for $25 \mathrm{~min}$. A total of 75 fractions were collected for each run at a rate of 1 fraction/min.

Fractions $30-32,31-32,30-32$ and $30-31(60 \%$ to $64 \%, 62 \%$ to $64 \%, 60 \%$ to $64 \%$ and $60 \%$ to $62 \% \mathrm{MeOH}$ in $\mathrm{H}_{2} \mathrm{O}$ respectively) from each of the runs respectively were combined and evaporated to dryness under reduced pressure. The resulting material was passed through a normal-phase column (DIOL, $30 \mathrm{~mL}$ ) eluted successively with $60 \mathrm{~mL}$ volumes of $\mathrm{CH}_{2} \mathrm{Cl}_{2}, 1 \%, 2 \%, 5 \%, 10 \%, 20 \%$ and $50 \%$ EtOAc in $\mathrm{CH}_{2} \mathrm{Cl}_{2}$, EtOAc and $\mathrm{MeOH}$. The $50 \%$ EtOAc in $\mathrm{CH}_{2} \mathrm{Cl}_{2}$ fraction was evaporated to dryness under reduced pressure to afford lamellarin $\theta$ (187) (17.8 mg).

Fractions $33-35,34-36,33-36$ and $32-35$ (66\% to $70 \%, 68 \%$ to $72 \%, 66 \%$ to $70 \%$ and $64 \%$ to $70 \% \mathrm{MeOH}$ in $\mathrm{H}_{2} \mathrm{O}$ respectively) from each of the runs respectively were combined and evaporated to dryness under reduced pressure. The resulting material was passed through a normal-phase column (DIOL, $30 \mathrm{~mL}$ ) eluted successively with $60 \mathrm{~mL}$ volumes of $20 \%$ and $50 \%$ EtOAc in $\mathrm{CH}_{2} \mathrm{Cl}_{2}$, EtOAc, $1 \%, 2 \%, 5 \% 10 \%$ and $20 \% \mathrm{MeOH}$ in EtOAc and $\mathrm{MeOH}$. The $1 \% \mathrm{MeOH}$ in EtOAc fraction was evaporated to dryness under reduced pressure to afford dictyodendrin F (195) $(7.2 \mathrm{mg})$.

Fractions $36-41,37-41,37-41$ and $36-41(72 \%$ to $82 \%, 74 \%$ to $82 \%, 74 \%$ to $82 \%$ and $72 \%$ to $82 \% \mathrm{MeOH}$ in $\mathrm{H}_{2} \mathrm{O}$ respectively) from each of the runs respectively were combined and evaporated to dryness under reduced pressure. The resulting material was passed through a normal-phase column (DIOL, $30 \mathrm{~mL}$ ) eluted successively with 
$60 \mathrm{~mL}$ volumes of $\mathrm{CH}_{2} \mathrm{Cl}_{2}, 1 \%, 2 \%, 5 \%, 10 \%, 20 \%$ and $50 \% \mathrm{EtOAc}$ in $\mathrm{CH}_{2} \mathrm{Cl}_{2}$, EtOAc, $1 \% \mathrm{MeOH}$ in EtOAc and $\mathrm{MeOH}$. The $10 \%$ and $20 \%$ EtOAc in $\mathrm{CH}_{2} \mathrm{Cl}_{2}$ fractions were chromatographically separated on a semi-preparative $\mathrm{C}_{18}$ reversed-phase HPLC column with $50 \% \mathrm{MeCN}$ in $\mathrm{H}_{2} \mathrm{O}$ as the mobile phase at a flow rate of $4.7 \mathrm{~mL} / \mathrm{min}$ to afford lamellarin O (189) (3.0 mg) and lamellarin $\kappa(\mathbf{1 8 8})(4.1 \mathrm{mg})$ with retention times of 10.0 and 11.8 min respectively.

Each of the $40 \% \mathrm{Me}_{2} \mathrm{CO}$ in $\mathrm{H}_{2} \mathrm{O}$ fractions was backloaded on to $100 \mathrm{~mL}$ of $\mathrm{HP} 20$ by dilution to $25 \%$. The resulting resins were placed in columns and eluted with $300 \mathrm{~mL}$ of $\mathrm{MeOH}$. The three eluents were combined and evaporated to dryness under reduced pressure to afford $1055.4 \mathrm{mg}$ of material. One quarter of this extract was dissolved in a minimum of $0.25 \mathrm{M} \mathrm{NaOAc}$ corrected to a $\mathrm{pH}$ of 7.0 and injected on to a prepacked 45 $\times 2.5 \mathrm{~cm}$ internal diameter HP20S column which was eluted at a flow rate of $10 \mathrm{~mL} / \mathrm{min}$ with $0.25 \mathrm{M} \mathrm{NaOAc}$ corrected to a $\mathrm{pH}$ of 7.0 for $30 \mathrm{~min}$, then gradient eluted from $0.25 \mathrm{M}$ $\mathrm{NaOAc}$ corrected to a $\mathrm{pH}$ of 7.0 to $60 \% \mathrm{MeOH}$ in $0.25 \mathrm{M} \mathrm{NaOAc}$ corrected to a $\mathrm{pH}$ of 7.0 over $120 \mathrm{~min}(0.5 \% / \mathrm{min})$, then from $60 \% \mathrm{MeOH}$ in $0.25 \mathrm{M} \mathrm{NaOAc}$ corrected to a $\mathrm{pH}$ of 7.0 to $\mathrm{MeOH}$ over $40 \mathrm{~min}(1 \% / \mathrm{min})$ and finally with $\mathrm{MeOH}$ for $45 \mathrm{~min}$. A total of 20 fractions were collected from the beginning of the gradient elution at a rate of 1 fraction/10 min.

Fraction 17 of the $20(100 \% \mathrm{MeOH})$ was chromatographically separated on a semipreparative $\mathrm{C}_{18}$ reversed-phase HPLC column with $55 \% \mathrm{MeOH}$ in $0.25 \mathrm{M} \mathrm{NaOAc}$ corrected to a $\mathrm{pH}$ of 7.0 as the mobile phase at a flow rate of $4.7 \mathrm{~mL} / \mathrm{min}$ to afford dictyodendrin C (183) (7.0 mg) with a retention time of $18.9 \mathrm{~min}$.

Fraction 18 of the $20(100 \% \mathrm{MeOH})$ was chromatographically separated on a semipreparative $\mathrm{C}_{18}$ reversed-phase HPLC column with $55 \% \mathrm{MeOH}$ in $0.25 \mathrm{M} \mathrm{NaOAc}$ corrected to a $\mathrm{pH}$ of 7.0 as the mobile phase at a flow rate of $4.7 \mathrm{~mL} / \mathrm{min}$ to afford lamellarin O $4^{\prime \prime \prime}$-sulfate (191) (1.9 mg) and lamellarin $\kappa 4^{\prime \prime \prime}$-sulfate (193) (2.7 mg) with retention times of 12.5 and 17.1 min respectively.

Each of the $20 \% \mathrm{Me}_{2} \mathrm{CO}$ in $\mathrm{H}_{2} \mathrm{O}$ fractions was backloaded on to $100 \mathrm{~mL}$ of $\mathrm{HP} 20$ by dilution to $25 \%$. The resulting resins were placed in columns and eluted with $300 \mathrm{~mL}$ 
of $\mathrm{MeOH}$. The three eluents were combined and evaporated to dryness under reduced pressure to afford $221.2 \mathrm{mg}$ of material. A subsample of $185.6 \mathrm{mg}$ of this extract was dissolved in a minimum of $\mathrm{H}_{2} \mathrm{O}$ and injected on to a prepacked $45 \times 2.5 \mathrm{~cm}$ internal diameter HP20S column which was eluted at a flow rate of $10 \mathrm{~mL} / \mathrm{min}$ with $\mathrm{H}_{2} \mathrm{O}$ for $30 \mathrm{~min}$, then gradient eluted from $\mathrm{H}_{2} \mathrm{O}$ to $60 \% \mathrm{MeOH}$ in $\mathrm{H}_{2} \mathrm{O}$ over $120 \mathrm{~min}(0.5 \% / \mathrm{min})$, then from $60 \% \mathrm{MeOH}$ in $\mathrm{H}_{2} \mathrm{O}$ to $\mathrm{MeOH}$ over $40 \mathrm{~min}(1 \% / \mathrm{min})$ and finally with $\mathrm{MeOH}$ for $45 \mathrm{~min}$. A total of 16 fractions was collected from the beginning of the gradient elution at a rate of 1 fraction/10 $\mathrm{min}$.

Fraction 9 of the $16\left(40 \%-45 \% \mathrm{MeOH}\right.$ in $\left.\mathrm{H}_{2} \mathrm{O}\right)$ was chromatographically separated on a semi-preparative $\mathrm{C}_{18}$ reversed-phase HPLC column with $45 \% \mathrm{MeOH}$ in $0.25 \mathrm{M} \mathrm{NaCl}$ as the mobile phase at a flow rate of $4.7 \mathrm{~mL} / \mathrm{min}$ to afford lamellarin $\theta 4^{\prime \prime}, 4^{\prime \prime \prime}$-disulfate (190) $(8.6 \mathrm{mg})$ with a retention time of $5.1 \mathrm{~min}$.

Fractions $10-15$ of the 16 (45\% to $90 \% \mathrm{MeOH}$ in $\mathrm{H}_{2} \mathrm{O}$ ) were chromatographically separated on a semi-preparative $\mathrm{C}_{18}$ reversed-phase HPLC column with $55 \% \mathrm{MeOH}$ in $0.25 \mathrm{M} \mathrm{NaOAc}$ corrected to a $\mathrm{pH}$ of 7.0 as the mobile phase at a flow rate of $4.7 \mathrm{~mL} / \mathrm{min}$ to afford lamellarin $\mathrm{O} 4^{\prime \prime}, 4^{\prime \prime \prime}$-disulfate (192) (7.1 mg), lamellarin $\kappa 4^{\prime \prime}, 4^{\prime \prime \prime}$-disulfate (194) $(14.0 \mathrm{mg})$ and dictyodendrin $\mathrm{D}(\mathbf{1 8 4})(6.3 \mathrm{mg})$ with retention times of 4.6, 5.4 and $8.2 \mathrm{~min}$ respectively.

\section{Ethanol Extraction of D. dendyi}

Dictyodendrilla dendyi (63 g wet weight) was extracted for $18 \mathrm{hr}$ in $400 \mathrm{~mL}$ of EtOH. The extract was filtered and the sponge material re-extracted for $18 \mathrm{hr}$ with a further $400 \mathrm{~mL}$ of $\mathrm{EtOH}$. The extracts were combined and cyclic loaded to $25 \%$ of the original concentration on to an $80 \mathrm{~mL}$ HP20 column. The column was eluted with $250 \mathrm{~mL}$ volumes of $\mathrm{H}_{2} \mathrm{O}, 30 \%$ and $75 \% \mathrm{Me}_{2} \mathrm{CO}$ in $\mathrm{H}_{2} \mathrm{O}$ and $\mathrm{Me}_{2} \mathrm{CO}$. The $75 \% \mathrm{Me}_{2} \mathrm{CO}$ in $\mathrm{H}_{2} \mathrm{O}$ fraction was backloaded by dilution to $25 \%$ on to $40 \mathrm{~mL}$ of HP20. The resulting resin was placed in a column and eluted with $150 \mathrm{~mL}$ of $\mathrm{Me}_{2} \mathrm{CO}$. This eluent was evaporated under reduced pressure to afford $179 \mathrm{mg}$ of material. Approximately one third of this material $(60 \mathrm{mg}$ ) was cyclic loaded on to $2 \mathrm{~mL}$ of Amberchrom which was transferred to the top of a $30 \times 1.1 \mathrm{~cm}$ 
internal diameter prepacked Amberchrom column. The column was eluted at a flow rate of $1 \mathrm{~mL} / \mathrm{min}$ with $20 \% \mathrm{EtOH}$ in $\mathrm{H}_{2} \mathrm{O}$ for $50 \mathrm{~min}$, then gradient eluted from $20 \% \mathrm{EtOH}$ in $\mathrm{H}_{2} \mathrm{O}$ to $\mathrm{EtOH}$ over $200 \mathrm{~min}(0.4 \% / \mathrm{min})$, and finally with EtOH for $125 \mathrm{~min}$. A total of 45 fractions were collected over 225 min beginning from the start of the gradient elution at a rate of 1 fraction/5 min.

Fractions $21-23$ of the $45\left(80 \%\right.$ to $86 \%$ EtOH in $\left.\mathrm{H}_{2} \mathrm{O}\right)$ were combined and evaporated under reduced pressure. The resulting material was passed through a normal-phase column (DIOL, $30 \mathrm{~mL}$ ) eluted successively with $90 \mathrm{~mL}$ of $10 \%$ EtOAc in $\mathrm{CH}_{2} \mathrm{Cl}_{2}, 60 \mathrm{~mL}$ of $50 \%$ EtOAc in $\mathrm{CH}_{2} \mathrm{Cl}_{2}$ and finally $100 \mathrm{~mL}$ of EtOH. The $50 \%$ EtOAc in $\mathrm{CH}_{2} \mathrm{Cl}_{2}$ fraction was evaporated under reduced pressure to afford lamellarin $\theta$ (187) (3.8 mg).

Fractions $28-40$ of the 45 (94\% to $100 \%$ EtOH in $\mathrm{H}_{2} \mathrm{O}$ ) were combined and evaporated under reduced pressure. The resulting material was passed through a normal-phase column (DIOL, $30 \mathrm{~mL}$ ) eluted successively with $30 \mathrm{~mL}$ of $\mathrm{CH}_{2} \mathrm{Cl}_{2}, 1 \%, 2 \%$ and $5 \%$ EtOAc in $\mathrm{CH}_{2} \mathrm{Cl}_{2}, 60 \mathrm{~mL}$ of $10 \%$ and $20 \%$ EtOAc in $\mathrm{CH}_{2} \mathrm{Cl}_{2}, 30 \mathrm{~mL}$ of EtOAc and finally $60 \mathrm{~mL}$ of EtOH. The $20 \%$ EtOAc in $\mathrm{CH}_{2} \mathrm{Cl}_{2}$ fraction was chromatographically separated on a semi-preparative $\mathrm{C}_{18}$ reversed-phase HPLC column with $50 \% \mathrm{MeCN}$ in $\mathrm{H}_{2} \mathrm{O}$ as the mobile phase at a flow rate of $4.7 \mathrm{~mL} / \mathrm{min}$ to afford lamellarin $\mathrm{O}(\mathbf{1 8 9})(0.7 \mathrm{mg})$ with a retention time of $9.6 \mathrm{~min}$.

\section{$N$-Methylation of 187}

To a sample of $187(1.6 \mathrm{mg}, 3.6 \mu \mathrm{mol})$ in $\mathrm{CD}_{3} \mathrm{OD}(0.7 \mathrm{~mL})$ in a $5 \mathrm{~mm}$ NMR tube, MeI (0.2 mL, $3.2 \mathrm{mmol}$ ) was added. The reaction was maintained at RT for $14 \mathrm{hr}$ and then heated to $40{ }^{\circ} \mathrm{C}$ for a further $46 \mathrm{hr}$ producing only a solution of deuterated 187 .

\section{Acetylation of 187}

A solution of dry $187(2.1 \mathrm{mg}, 4.7 \mu \mathrm{mol})$ in $\mathrm{Ac}_{2} \mathrm{O}(0.5 \mathrm{~mL})$ and pyridine $(0.5 \mathrm{~mL})$ was stirred at RT overnight. The resulting mixture was evaporated under reduced pressure to 
afford $196(3.1 \mathrm{mg})$.

\section{$O$-Methylation of 187}

To a sample of $187(10.3 \mathrm{mg}, 23 \mu \mathrm{mol})$, ca. $4.5 \mathrm{~mL}$ of ethereal $\mathrm{CH}_{2} \mathrm{~N}_{2}$ was added. The resulting solution was left to sit at $0{ }^{\circ} \mathrm{C}$ for $1 \mathrm{hr}$, then at RT for $30 \mathrm{~min}$ and finally in a tepid water bath for $1 \mathrm{hr}$. The solution was then evaporated to dryness under reduced pressure. The resulting material was passed through a normal-phase column (DIOL, $10 \mathrm{~mL}$ ) eluted successively with $30 \mathrm{~mL}$ volumes of $\mathrm{CH}_{2} \mathrm{Cl}_{2}, 1 \%, 2 \%, 5 \%, 10 \%, 20 \%$ and $50 \%$ EtOAc in $\mathrm{CH}_{2} \mathrm{Cl}_{2}$ and $\mathrm{MeOH}$. A total of 42 fractions (ca. $5.3 \mathrm{~mL} /$ fraction) was collected. Fractions 2 and $3\left(\mathrm{CH}_{2} \mathrm{Cl}_{2}\right)$ were combined and evaporated under reduced pressure to afford $\mathbf{1 9 7}$ (5.7 mg). Fractions 4-5 $\left(\mathrm{CH}_{2} \mathrm{Cl}_{2}\right)$ were combined and evaporated under reduced pressure to afford a mixture of two dimethoxylated lamellarin $\theta$ derivatives $(4.7 \mathrm{mg})$. Fractions $20-$ 27 (5\%-10\% EtOAc in $\mathrm{CH}_{2} \mathrm{Cl}_{2}$ ) were combined and evaporated under reduced pressure to afford 189 (3.8 mg). The mixture of dimethoxylated lamellarin $\theta$ derivatives was further treated with ca. $5 \mathrm{~mL}$ of ethereal $\mathrm{CH}_{2} \mathrm{~N}_{2}$ at RT for $18 \mathrm{hr}$. The solution was evaporated to dryness under reduced pressure. The resulting material was passed through a normalphase column (DIOL, $10 \mathrm{~mL}$ ) eluted with $40 \mathrm{~mL}$ of $\mathrm{CH}_{2} \mathrm{Cl}_{2}$. A total of 8 fractions (ca. $5 \mathrm{~mL} /$ fraction) was collected. Fraction 2 was evaporated under reduced pressure to afford an additional quantity of 197 (3.2 $\mathrm{mg})$.

\section{Formation of the barium salt of 190}

To a sample of 190 (ca. $0.5 \mathrm{mg}$ ) in $\mathrm{MeOH}(0.5 \mathrm{~mL}), 1 \mathrm{M} \mathrm{BaCl}_{2}$ (4-5 drops) was added. Upon stirring, the formation of a milky precipitate was noted.

\section{Desulfation of 190}

To a sample of $190(2.0 \mathrm{mg}, 3.1 \mu \mathrm{mol})$ in $\mathrm{Ac}_{2} \mathrm{O}(1 \mathrm{~mL}), p$-TsOH $(350 \mu \mathrm{L}, 2.2 \mathrm{mmol})$ was added. The mixture was stirred at RT for $1 \mathrm{hr}$ then quenched with $\mathrm{H}_{2} \mathrm{O}(400 \mu \mathrm{L}$, 
$22 \mathrm{mmol})$. The reaction mixture was cyclic loaded to $1 \%$ of its original concentration on to a $2 \mathrm{~mL}$ HP20SS column and eluted successively with $25 \mathrm{~mL} \mathrm{H}_{2} \mathrm{O}$, then $10 \mathrm{~mL}$ aliquots of $20 \%, 40 \%, 60 \%$ and $80 \% \mathrm{MeOH}$ in $\mathrm{H}_{2} \mathrm{O}$ and $\mathrm{MeOH}$. The $80 \% \mathrm{MeOH}$ in $\mathrm{H}_{2} \mathrm{O}$ fraction was evaporated under reduced pressure to afford $187(1.4 \mathrm{mg})$.

\section{Ketone Reduction of 196}

To a sample of $196(1.0 \mathrm{mg}, 1.8 \mu \mathrm{mol})$ in $\mathrm{MeOH}(1 \mathrm{~mL}), \mathrm{NaBH}_{4}(5 \mathrm{mg}, 0.1 \mathrm{mmol})$ was added. The reaction was stirred at RT for $2 \mathrm{hr}$ and then quenched with $\mathrm{H}_{2} \mathrm{O}(1 \mathrm{~mL})$. The reaction mixture was cyclic loaded to $10 \%$ of its original concentration on to a $1 \mathrm{~mL}$ HP20SS column and eluted successively with $10 \mathrm{~mL}$ of $\mathrm{H}_{2} \mathrm{O}, 15 \mathrm{~mL}$ of $\mathrm{MeOH}$ and $50 \mathrm{~mL}$ $50 \% \mathrm{CH}_{2} \mathrm{Cl}_{2}$ in $\mathrm{MeOH}$. The $\mathrm{MeOH}$ fraction was evaporated to dryness under reduced pressure to afford $1.3 \mathrm{mg}$ of a complex mixture of reduced lamellarin $\theta$ derivatives with differing degrees of acetylation.

\section{Ketone Reduction of 197}

To a sample of $197(2.0 \mathrm{mg}, 4.1 \mu \mathrm{mol})$ in $\mathrm{MeOH}(1 \mathrm{~mL}), \mathrm{NaBH}_{4}(56.1 \mathrm{mg}, 1.5 \mathrm{mmol})$ was added. The reaction was stirred at RT for $1 \mathrm{hr}$ and then quenched with $\mathrm{H}_{2} \mathrm{O}(3 \mathrm{~mL})$ and $\mathrm{MeOH}(5 \mathrm{~mL})$. The reaction mixture was cyclic loaded to $5 \%$ of its original concentration on to a $1 \mathrm{~mL}$ HP20SS column and eluted successively with $50 \mathrm{~mL}$ of $\mathrm{H}_{2} \mathrm{O}, 10 \mathrm{~mL}$ of $\mathrm{MeOH}$ and $10 \mathrm{~mL} \mathrm{Me}_{2} \mathrm{CO}$. The $\mathrm{MeOH}$ and $\mathrm{Me}_{2} \mathrm{CO}$ fractions were combined and evaporated to dryness under reduced pressure. The resulting material was passed through a normal-phase column (DIOL, $10 \mathrm{~mL}$ ) eluted with $40 \mathrm{~mL}$ of $\mathrm{CH}_{2} \mathrm{Cl}_{2}$. A total of 14 fractions were collected (ca. $2.8 \mathrm{~mL} /$ fraction). Fractions 3 and 4 were combined and evaporated to dryness under reduced pressure. The resulting material injected on to an analytical normal-phase HPLC column (DIOL) which was eluted with 30\% IPA in hexane at a flow rate of $1 \mathrm{~mL} / \mathrm{min}$. Two compounds, with retention times of 4.4 and $7.5 \mathrm{~min}$ respectively, were identified by diode array UV analysis and fractions were collected accordingly. Each fraction was evaporated to dryness under reduced pressure to afford 
$200(0.7 \mathrm{mg})$ and $199(1.2 \mathrm{mg})$ respectively.

To a sample of $197(2.0 \mathrm{mg}, 4.1 \mu \mathrm{mol})$ in THF $(1 \mathrm{~mL}), \mathrm{NaBH}_{4}(50 \mathrm{mg}, 1.5 \mathrm{mmol})$ was added. The mixture was stirred at RT for $2 \mathrm{hr}$ then quenched with $\mathrm{H}_{2} \mathrm{O}(3 \mathrm{~mL})$. The reaction mixture was cyclic loaded to $2 \%$ of its original concentration on to a $1 \mathrm{~mL}$ HP20 column and eluted successively with $50 \mathrm{~mL}$ of $\mathrm{H}_{2} \mathrm{O}, 10 \mathrm{~mL}$ of $\mathrm{MeOH}$ and $10 \mathrm{~mL}$ $\mathrm{Me}_{2} \mathrm{CO}$. The $\mathrm{MeOH}$ fraction was evaporated to dryness under reduced pressure to afford 200 (1.9 mg).

\section{Lamellarin $\theta$ (187)}

Yellow oil; UV (MeOH) $\lambda_{\max } 281 \mathrm{~nm}\left(\epsilon\right.$ 32800); NMR data see Tables $6.2\left(\mathrm{CD}_{3} \mathrm{OD}\right)$ and $6.3\left(\mathrm{~d}_{6}\right.$-DMSO); HRESIMS, obsd. $m / z 442.1272[\mathrm{M}-\mathrm{H}]^{-}, \mathrm{C}_{26} \mathrm{H}_{20} \mathrm{NO}_{6}^{-}$requires $442.1285, \Delta 2.9 \mathrm{ppm}$.

\section{$\mathbf{4}^{\prime}, \mathbf{4}^{\prime \prime}, \mathbf{4}^{\prime \prime \prime}$-triacetyllamellarin $\theta(\mathbf{1 9 6})$}

Amorphous white solid; UV (MeOH) $\lambda_{\max } 253 \mathrm{~nm}(\epsilon$ 39800); NMR data see Table 6.4; HRESIMS, obsd. $m / z 592.1558[\mathrm{M}+\mathrm{Na}]^{+}, \mathrm{C}_{32} \mathrm{H}_{27} \mathrm{NO}_{9} \mathrm{Na}^{+}$requires 592.1578, $\Delta$ $3.3 \mathrm{ppm}$.

\section{$\mathbf{4}^{\prime}, \mathbf{4}^{\prime \prime}, \mathbf{4}^{\prime \prime \prime}$-trimethoxylamellarin $\theta(\mathbf{1 9 7})$}

Amorphous white solid; NMR data see Table 6.5. HRESIMS, obsd. $m / z 508.1744$ $[\mathrm{M}+\mathrm{Na}]^{+}, \mathrm{C}_{29} \mathrm{H}_{27} \mathrm{NO}_{6} \mathrm{Na}^{+}$requires 508.1731, $\Delta 2.6 \mathrm{ppm}$.

\section{3,4-dihydro-4', $\mathbf{4}^{\prime \prime}, \mathbf{4}^{\prime \prime \prime}$-trimethoxylukianol A (199)}

Amorphous yellow solid; UV (MeOH) $\lambda_{\max } 228$ nm ( $\epsilon$ 59700), 291 nm ( $\epsilon$ 30600); NMR data see Table 6.6; HRESIMS, obsd. $m / z 456.1848[\mathrm{M}+\mathrm{H}]^{+}, \mathrm{C}_{28} \mathrm{H}_{26} \mathrm{NO}_{5}^{+}$requires 
456.1806, $\Delta 9.3 \mathrm{ppm}$.

\section{7-hydroxy-4', $\mathbf{4}^{\prime \prime}, \mathbf{4}^{\prime \prime \prime}$-trimethoxylamellarin $\theta(\mathbf{2 0 0})$}

Amorphous white solid; UV (MeOH) $\lambda_{\max } 228 \mathrm{~nm}(\epsilon$ 43100), $252 \mathrm{~nm}(\epsilon 36800)$; NMR data see Table 6.7; HRESIMS, obsd. $m / z$ 470.1974 [M - $\left.\mathrm{H}_{2} \mathrm{O}+\mathrm{H}\right]^{+}, \mathrm{C}_{29} \mathrm{H}_{28} \mathrm{NO}_{5}^{+}$requires 470.1962, $\Delta 2.6$ ppm, obsd. $m / z 488.2110[\mathrm{M}+\mathrm{H}]^{+}, \mathrm{C}_{29} \mathrm{H}_{30} \mathrm{NO}_{6}^{+}$requires 488.2068, $\Delta$ 8.7 ppm.

\section{Lamellarin $\theta \mathbf{4}^{\prime \prime}, \mathbf{4}^{\prime \prime \prime}$-disulfate (190)}

Amorphous grey solid; UV (MeOH) $\lambda_{\max } 279 \mathrm{~nm}(\epsilon$ 37700); NMR data see Table 6.10; HRESIMS, obsd. $m / z 300.5172[\mathrm{M}-2 \mathrm{Na}]^{2-}, \mathrm{C}_{26} \mathrm{H}_{19} \mathrm{NO}_{12} \mathrm{~S}_{2}^{2-}$ requires $300.5180, \Delta$ $2.6 \mathrm{ppm}$.

\section{Lamellarin O (189)}

Orange oil; UV (MeOH) $\lambda_{\max } 274 \mathrm{~nm}(\epsilon$ 31300); NMR data see Table 6.8; HRESIMS, obsd. $m / z 480.1443[\mathrm{M}+\mathrm{Na}]^{+}, \mathrm{C}_{27} \mathrm{H}_{23} \mathrm{NO}_{6} \mathrm{Na}^{+}$requires 480.1418, $\Delta 5.3 \mathrm{ppm}$, obsd. $\mathrm{m} / z$ 937.2988 [2M + Na] $]^{+}, \mathrm{C}_{54} \mathrm{H}_{46} \mathrm{~N}_{2} \mathrm{O}_{12} \mathrm{Na}^{+}$requires 937.2943, $\Delta 4.8 \mathrm{ppm}$.

\section{Lamellarin $04^{\prime \prime \prime}$-sulfate (191)}

Yellow oil; UV (MeOH) $\lambda_{\max } 271 \mathrm{~nm}(\epsilon$ 33200); NMR data see Table 6.12; HRESIMS, obsd. $m / z 536.1006[\mathrm{M}-\mathrm{Na}]^{-}, \mathrm{C}_{27} \mathrm{H}_{22} \mathrm{NO}_{9} \mathrm{~S}^{-}$requires 536.1011, $\Delta 0.7 \mathrm{ppm}$. 


\section{Lamellarin O $4^{\prime \prime}, 4^{\prime \prime \prime}$-disulfate (192)}

Grey oil; UV (MeOH) $\lambda_{\max } 272 \mathrm{~nm}(\epsilon$ 35400); NMR data see Table 6.14; HRESIMS, obsd. $m / z 307.5256[\mathrm{M}-2 \mathrm{Na}]^{2-}, \mathrm{C}_{27} \mathrm{H}_{21} \mathrm{NO}_{12} \mathrm{~S}_{2}^{2-}$ requires 307.5258, $\Delta 0.6 \mathrm{ppm}$.

\section{Lamellarin $\kappa(\mathbf{1 8 8})$}

Amorphous yellow solid; UV (MeOH) $\lambda_{\max } 229$ nm ( $\epsilon$ 27700), 268 nm ( $\epsilon$ 28000); NMR data see Table 6.15; HRESIMS, obsd. $m / z$ 488.1682 $[\mathrm{M}+\mathrm{H}]^{+}, \mathrm{C}_{28} \mathrm{H}_{26} \mathrm{NO}_{7}^{+}$requires 488.1704, $\Delta 4.5 \mathrm{ppm}$.

\section{Lamellarin $\kappa 4^{\prime \prime \prime}$-sulfate (193)}

Yellow oil; UV (MeOH) $\lambda_{\max } 229 \mathrm{~nm}(\epsilon$ 21600), $268 \mathrm{~nm}(\epsilon$ 21700); NMR data see Tables $6.17\left(\mathrm{CD}_{3} \mathrm{OD}\right)$ and $6.18\left(\mathrm{~d}_{6}\right.$-DMSO); HRESIMS, obsd. $m / z 566.1110[\mathrm{M}-\mathrm{Na}]^{-}$, $\mathrm{C}_{28} \mathrm{H}_{24} \mathrm{NO}_{10} \mathrm{~S}^{-}$requires 566.1115, $\Delta 0.9 \mathrm{ppm}$.

\section{Lamellarin $\kappa \mathbf{4}^{\prime \prime}, \mathbf{4}^{\prime \prime \prime}$-disulfate (194)}

Green oil; UV (MeOH) $\lambda_{\max } 226 \mathrm{~nm}(\epsilon 36600), 269 \mathrm{~nm}(\epsilon$ 35400); NMR data see Tables $6.20\left(\mathrm{CD}_{3} \mathrm{OD}\right)$ and $6.21\left(\mathrm{~d}_{6}\right.$-DMSO); HRESIMS, obsd. $m / z 322.5323[\mathrm{M}-2 \mathrm{Na}]^{2-}$, $\mathrm{C}_{28} \mathrm{H}_{23} \mathrm{NO}_{13} \mathrm{~S}_{2}^{2-}$ requires $322.5311, \Delta 3.6 \mathrm{ppm}$.

\section{Dictyodendrin C (183)}

Olive oil; UV (MeOH) $\lambda_{\max } 227 \mathrm{~nm}$ ( $\epsilon$ 41300), $271 \mathrm{~nm}(\epsilon$ 19700), $308 \mathrm{~nm}$ ( $\epsilon$ 14700), $363 \mathrm{~nm}\left(\epsilon\right.$ 9900), $426 \mathrm{~nm}\left(\epsilon\right.$ 9450); NMR data see Tables $6.23\left(\mathrm{CD}_{3} \mathrm{OD}\right)$ and 6.22 $\left(\mathrm{CD}_{3} \mathrm{OH}\right)$; HRESIMS, obsd. $m / z 635.1137[\mathrm{M}-\mathrm{Na}]^{-}, \mathrm{C}_{34} \mathrm{H}_{23} \mathrm{~N}_{2} \mathrm{O}_{9} \mathrm{~S}^{-}$requires 635.1119, $\Delta 2.9 \mathrm{ppm}$. 


\section{Dictyodendrin D (184)}

Olive oil; UV (MeOH) $\lambda_{\max } 222 \mathrm{~nm}(\epsilon$ 44500), $271 \mathrm{~nm}(\epsilon$ 21200), $301 \mathrm{~nm}(\epsilon$ 15800), $352 \mathrm{~nm}\left(\epsilon\right.$ 13000), $416 \mathrm{~nm}\left(\epsilon\right.$ 11200); NMR data see Tables $6.25\left(\mathrm{CD}_{3} \mathrm{OD}\right)$ and 6.24 $\left(\mathrm{CD}_{3} \mathrm{OH}\right)$; HRESIMS, obsd. $m / z 357.0333[\mathrm{M}-2 \mathrm{Na}]^{2-}, \mathrm{C}_{34} \mathrm{H}_{22} \mathrm{~N}_{2} \mathrm{O}_{12} \mathrm{~S}_{2}^{2-}$ requires $357.0302, \Delta 8.8 \mathrm{ppm}$.

\section{Dictyodendrin F (195)}

Green oil; UV (MeOH) $\lambda_{\max } 227 \mathrm{~nm}(\epsilon$ 41800), $281 \mathrm{~nm}(\epsilon$ 20800), $308 \mathrm{~nm}(\epsilon$ 15300), $369 \mathrm{~nm}(\epsilon 10200), 426 \mathrm{~nm}\left(\epsilon\right.$ 9490); NMR data see Tables $6.26\left(\mathrm{CD}_{3} \mathrm{OH}\right)$ and $6.27\left(\mathrm{~d}_{6^{-}}\right.$ DMSO); HRESIMS, obsd. $m / z$ 555.1519 [M $-\mathrm{H}]^{-}, \mathrm{C}_{34} \mathrm{H}_{23} \mathrm{~N}_{2} \mathrm{O}_{6}^{-}$requires 555.1551, $\Delta$ $5.8 \mathrm{ppm}$. 


\section{Appendix A}

\section{Existing Sponge Screening Protocol ${ }^{\dagger}$}

\section{Preparation}

\section{Equipment Needed (per Screen)}

- 1 x Screen column loaded with $80 \mathrm{~mL}$ of HP20 equilibrated in distilled $\mathrm{MeOH}$

- 1 x Backloading column loaded with $40 \mathrm{~mL}$ of $\mathrm{HP} 20$ equilibrated in distilled $\mathrm{MeOH}$

\section{NMR Standard}

Prepare a standard of 1,3,5-tribromobenzene in $\mathrm{CDCl}_{3}$ by dissolving $78.9 \mathrm{mg}$ of 1,3,5tribromobenzene in $5 \mathrm{~mL}$ of $\mathrm{CDCl}_{3}$.

\section{Procedure}

1. Voucher Sample Preparation

- Take a voucher specimen of ca. $10 \mathrm{~g}$ of sponge material ensuring that both the ectoderm and the endoderm are represented.

- Label and store the voucher sample in 75\% IPA in $\mathrm{H}_{2} \mathrm{O}$.

2. Extraction

- Extract ca. $100 \mathrm{~g}$ of sponge material in $400 \mathrm{~mL}$ of distilled $\mathrm{MeOH}$ overnight.

- Filter the first extract and set aside. Re-extract the sponge material (and any filter paper/celite as necessary) in $400 \mathrm{~mL}$ of distilled $\mathrm{MeOH}$ overnight.

${ }^{\dagger}$ Last updated: $13 / 11 / 06$ 
- Filter the second extract.

- Keep all sponge material (and any filter paper/celite as necessary) until the screen is complete at which time it may be discarded.

3. Cyclic Loading

- Pass the second extract through the screen column with a flow rate of ca. $10 \mathrm{~mL} / \mathrm{min}$.

- Pass the first extract through the screen column with a flow rate of ca. $10 \mathrm{~mL} / \mathrm{min}$. Combine the eluent with that of the second extract.

- Dilute the combined eluents with $800 \mathrm{~mL}$ of distilled $\mathrm{H}_{2} \mathrm{O}$. Pass the diluted eluents back through the screen column at a flow rate of ca. $10 \mathrm{~mL} / \mathrm{min}$.

- Dilute the eluent with $1.6 \mathrm{~L}$ of distilled $\mathrm{H}_{2} \mathrm{O}$. Pass the diluted eluent back through the screen column at a flow rate of ca. $10 \mathrm{~mL} / \mathrm{min}$.

- The eluent should be kept until the screen is complete at which time it may be discarded.

4. Elution

- Elute the screen column with $250 \mathrm{~mL}$ of distilled $\mathrm{H}_{2} \mathrm{O}$ at a flow rate of ca. $10 \mathrm{~mL} / \mathrm{min}$. The $\mathrm{H}_{2} \mathrm{O}$ eluent can be discarded immediately.

- Elute the screen column with $250 \mathrm{~mL}$ of $30 \%$ distilled $\mathrm{Me}_{2} \mathrm{CO}$ in distilled $\mathrm{H}_{2} \mathrm{O}\left(75 \mathrm{~mL} \mathrm{Me}_{2} \mathrm{CO}\right.$ to $\left.175 \mathrm{~mL} \mathrm{H}_{2} \mathrm{O}\right)$ at a flow rate of ca. $10 \mathrm{~mL} / \mathrm{min}$.

- Elute the screen column with $250 \mathrm{~mL}$ of $75 \%$ distilled $\mathrm{Me}_{2} \mathrm{CO}$ in distilled $\mathrm{H}_{2} \mathrm{O}\left(187.5 \mathrm{~mL} \mathrm{Me} \mathrm{CO}_{2}\right.$ to $\left.62.5 \mathrm{~mL} \mathrm{H}_{2} \mathrm{O}\right)$ at a flow rate of ca. $10 \mathrm{~mL} / \mathrm{min}$.

- Elute the screen column with $250 \mathrm{~mL}$ of distilled $\mathrm{Me}_{2} \mathrm{CO}$ at a flow rate of ca. $10 \mathrm{~mL} / \mathrm{min}$.

5. Backloading the $75 \%$ Acetone Fraction

- Dilute the $75 \% \mathrm{Me}_{2} \mathrm{CO}$ fraction with $250 \mathrm{~mL}$ of distilled $\mathrm{H}_{2} \mathrm{O}$. Pass the diluted eluent through the backloading column at a flow rate of ca. $8 \mathrm{~mL} / \mathrm{min}$.

- Dilute the eluent with $500 \mathrm{~mL}$ of distilled $\mathrm{H}_{2} \mathrm{O}$. Pass the diluted eluent back through the backloading column at a flow rate of ca. $8 \mathrm{~mL} / \mathrm{min}$. 
- The eluent should be kept until the screen is complete at which time it may be discarded.

- Elute the backloading column with $150 \mathrm{~mL}$ of distilled $\mathrm{Me}_{2} \mathrm{CO}$.

6. Processing the $75 \%$ Acetone Fraction

- Evaporate the $\mathrm{Me}_{2} \mathrm{CO}$ eluent of the backloading column to dryness and transfer to a pre-weighed sample vial. Evaporate to dryness and record the mass.

- Sub-sample approximately $30 \mathrm{mg}$ of material for NMR analysis if necessary.

- Prepare an NMR sample in ca. $700 \mu \mathrm{L}$ of $\mathrm{CD}_{3} \mathrm{OD}$ in a $5 \mathrm{~mm}$ NMR tube.

- Add $10 \mu \mathrm{L}$ of the 1,3,5-tribromobenzene standard (representing $507 \mathrm{nmol}$ of 1,3,5-tribromobenzene) to the NMR tube.

7. NMR Analysis of the $75 \%$ Acetone Fraction

- Run a ${ }^{1} \mathrm{H}$ spectrum of the sample on the $600 \mathrm{MHz}$ instrument using the standard Screen $1 \mathrm{H}$ parameter set. (Experiment time: ca. 4 min)

- Make a note "Standard Added" in the sample text.

- Run a COSY spectrum of the sample using the standard ScreenCOSY parameter set. (Experiment time: ca. $20 \mathrm{~min}$ )

- Run an HSQC spectrum of the sample using the standard ScreenHSQC parameter set. (Experiment time: ca. 4 hr)

- Process and print appropriately.

- Photocopy the full COSY and HSQC spectra on to A3 paper.

- Using a light table, compare the COSY and HSQC blow-ups to the standard screen masks circling any peaks which do not appear in the masks.

8. Assigning Hit Values to the Screen

- Signal strength

- Any peak higher than half the height of the standard peak scores a 10. 
- 0.45-0.5 times the standard peak scores a 9 and so on down (remember to consider the sub-sampling factor if necessary).

- Number of interesting peaks

- Indicates how many peaks have not been masked out in the HSQC. Something exhibiting more than 20 non-masked peaks will score a 10 .

- Uniqueness of interesting peaks

- An arbitrary value indicating whether non-masked peaks represent something interesting.

- Available mass

- The total mass of the available sponge material (including that used for the screen) in $\mathrm{kg}$ is multiplied by 10 and rounded to the nearest integer. If more than $1 \mathrm{~kg}$ of sponge material is available the score is 10 .

- Recollectability

- Collected locally - 4. Collected from d'Urville Island - 2. Other - 1 .

- Sum all 5 hit values. A score of 25 would be considered average.

9. Backloading the $30 \%$ Acetone Fraction

- Dilute the $30 \% \mathrm{Me}_{2} \mathrm{CO}$ fraction with $250 \mathrm{~mL}$ of distilled $\mathrm{H}_{2} \mathrm{O}$. Pass the diluted eluent through the backloading column at a flow rate of ca. $8 \mathrm{~mL} / \mathrm{min}$.

- Dilute the eluent with $500 \mathrm{~mL}$ of distilled $\mathrm{H}_{2} \mathrm{O}$. Pass the diluted eluent back through the backloading column at a flow rate of ca. $8 \mathrm{~mL} / \mathrm{min}$.

- The eluent should be kept until the screen is complete at which time it may be discarded.

- Elute the backloading column with $150 \mathrm{~mL}$ of distilled $\mathrm{MeOH}$.

10. Processing the $30 \%$ Acetone Fraction

- Evaporate the $\mathrm{MeOH}$ eluent of the backloading column to dryness and transfer to a pre-weighed sample vial. Evaporate to dryness and record the mass.

- Sub-sample approximately $30 \mathrm{mg}$ of material for NMR analysis if necessary. 
- Prepare an NMR sample in ca. $700 \mu \mathrm{L}$ of $\mathrm{CD}_{3} \mathrm{OD}$ in a $5 \mathrm{~mm}$ NMR tube.

11. NMR Analysis of the $30 \%$ Acetone Fraction

- Run a ${ }^{1} \mathrm{H}$ spectrum of the sample on the $600 \mathrm{MHz}$ instrument using the standard Screen1H parameter set. (Experiment time: ca. 4 min)

12. Processing the $100 \%$ Acetone Fraction

- Evaporate the $\mathrm{Me}_{2} \mathrm{CO}$ eluent of the screen column to dryness and transfer to a pre-weighed sample vial. Evaporate to dryness and the record mass.

- Sub-sample approximately $30 \mathrm{mg}$ of material for NMR analysis if necessary.

- Prepare an NMR sample in ca. $700 \mu \mathrm{L}$ of $\mathrm{CDCl}_{3}$ in a $5 \mathrm{~mm}$ NMR tube.

13. NMR Analysis of the $100 \%$ Acetone Fraction

- Run a ${ }^{1} \mathrm{H}$ spectrum of the sample on the $600 \mathrm{MHz}$ instrument using the standard Screen1H parameter set. (Experiment time: ca. 4 min) 


\section{Standard NMR Parameter Sets for Screening}

\section{Screen1H (Standard Pulse-acquire)}

$\begin{array}{lll}\text { Acquisition: } & \text { acquisition delay } & 10 \mathrm{~ms} \\ \text { nutation angle } & 60^{\circ} \\ \text { acquisition time } & 4 \mathrm{~s}(38462 \text { complex points }) \\ \text { steady-state scans } & \text { none } \\ \text { number of transients } & 64 \\ \text { temperature } & 20{ }^{\circ} \mathrm{C} \\ \text { spectral width } & 14 \mathrm{ppm} \text { to }-2 \mathrm{ppm} \\ \text { total time } & \text { ca. } 4 \text { min } \\ \text { fourier number } & 65536 \text { complex points } \\ \text { Processing: } & \text { neighting } & \text { none }\end{array}$

\section{ScreenCOSY (Absolute Value Gradient COSY)}

$\begin{array}{lll}\text { Acquisition: } & \text { acquisition delay } & 2 \mathrm{~s} \\ & \text { gradient strength } & 10 \mathrm{Gcm}^{-1} \\ & \text { gradient duration } & 1 \mathrm{~ms} \\ & \text { gradient stabilisation delay } & 500 \mu \mathrm{s} \\ & \text { number of increments } & 512 \\ & \text { acquisition time } & 213 \mathrm{~ms}(1153 \text { complex points }) \\ & \text { steady state scans } & 16 \\ & \text { number of transients } & 1 \\ & \text { temperature } & 20{ }^{\circ} \mathrm{C} \\ & \text { spectral width }\left(\mathrm{F}_{2} \& \mathrm{~F}_{1}\right) & 9 \mathrm{ppm} \text { to } 0 \text { ppm } \\ & \text { total time } & \text { ca. } 20 \text { min } \\ \text { fourier number }\left(\mathrm{F}_{2} \& \mathrm{~F}_{1}\right) & 2048 \text { complex points } \\ \text { Processing: } & \text { sinebell }\end{array}$




\section{ScreenHSQC (Adiabatic Gradient-enhanced HSQC)}

\begin{tabular}{|c|c|c|}
\hline \multirow[t]{21}{*}{ Acquisition: } & steady-state gradient strength & $13 \mathrm{Gcm}^{-1}$ \\
\hline & steady-state gradient duration & $2 \mathrm{~ms}$ \\
\hline & acquisition delay & $1.5 \mathrm{~s}$ \\
\hline & TANGO gradient strength & $10 \mathrm{Gcm}^{-1}$ \\
\hline & TANGO gradient duration & $2 \mathrm{~ms}$ \\
\hline & adiabatic sweep pulse bandwidth & $300 \mathrm{ppm}$ \\
\hline & encoding gradient strength & $10 \mathrm{Gcm}^{-1}$ \\
\hline & encoding gradient time & $4 \mathrm{~ms}$ \\
\hline & decoding gradient strength & $-6 \mathrm{Gcm}^{-1}$ \\
\hline & decoding gradient time & $2.4 \mathrm{~ms}$ \\
\hline & number of increments & 512 \\
\hline & acquisition time & $213 \mathrm{~ms}$ (1153 complex points) \\
\hline & broadband ${ }^{13} \mathrm{C}$ decoupling shape & WURST40 \\
\hline & broadband ${ }^{13} \mathrm{C}$ decoupling bandwidth & 200 ppm \\
\hline & steady state scans & 64 \\
\hline & number of transients & 8 \\
\hline & temperature & $20^{\circ} \mathrm{C}$ \\
\hline & spectral width in $\mathrm{F}_{2}$ & $9 \mathrm{ppm}$ to $0 \mathrm{ppm}$ \\
\hline & spectral width in $\mathrm{F}_{1}$ & $160 \mathrm{ppm}$ to $0 \mathrm{ppm}$ \\
\hline & ${ }^{1} J_{\mathrm{CH}}$ selection & $140 \mathrm{~Hz}$ \\
\hline & total time & ca. $4 \mathrm{hr}$ \\
\hline \multirow[t]{3}{*}{ Processing: } & fourier number in $\mathrm{F}_{2}$ & 2048 complex points \\
\hline & fourier number in $F_{1}$ & 1024 complex points \\
\hline & weighting $\left(\mathrm{F}_{2} \& \mathrm{~F}_{1}\right)$ & gaussian \\
\hline
\end{tabular}




\section{Appendix B}

\section{Selected Functions of Peaks Source Code}

\section{OnInitDialog}

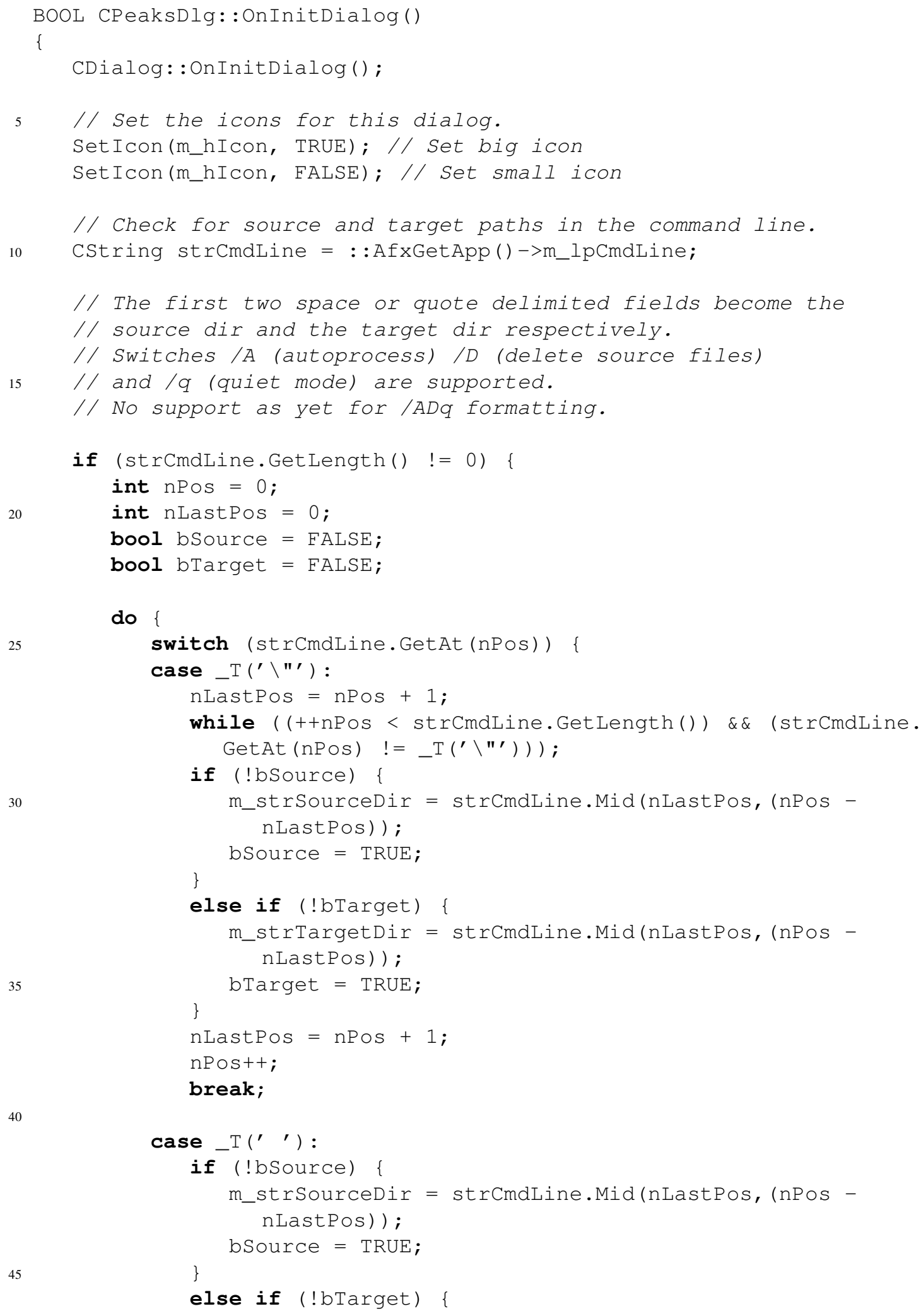




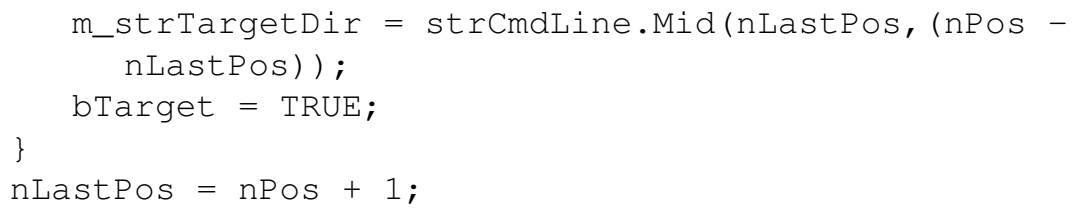

\section{break;}

\}

\} while (++nPos < strCmdLine.GetLength ());

if ( $\mathrm{nPOS}>$ nLastPos) \{

if (!bsource) \{

m_strSourceDir = strCmdLine.Mid(nLastPos, (nPos - nLastPos)) ; bSource = TRUE;

if (m_strTargetDir $!=\ldots$ T(")) \{

if ( (m_strTargetDir.GetLength ()$<3)$ | | (m_strTargetDir.GetAt

(2) $\left.\quad !=-\mathrm{T}\left({ }^{\prime} \backslash \backslash^{\prime}\right)\right)$ )

m_strTargetDir.Insert $\left(0,{ }_{-1} \mathrm{~T}(" \backslash \backslash ")\right)$;

m_strTargetDir.Insert (0, szPath); 


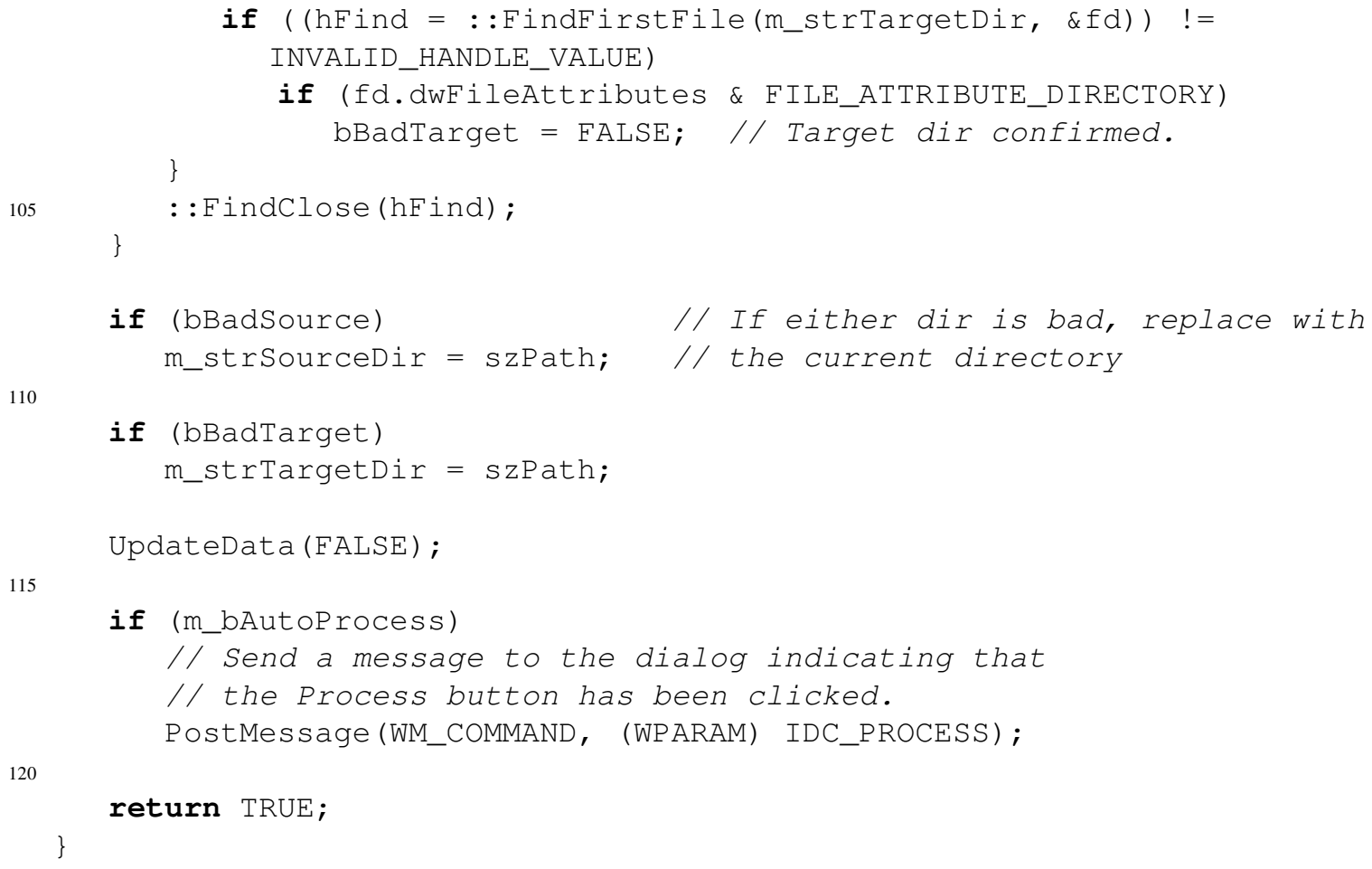

120

return TRUE;

\}

\section{OnSelSource}

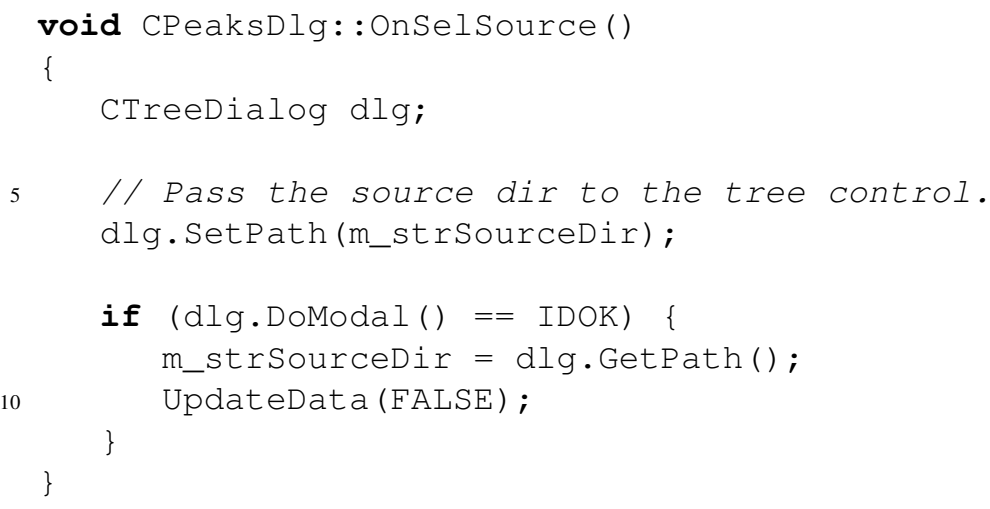

\section{OnSelTarget}

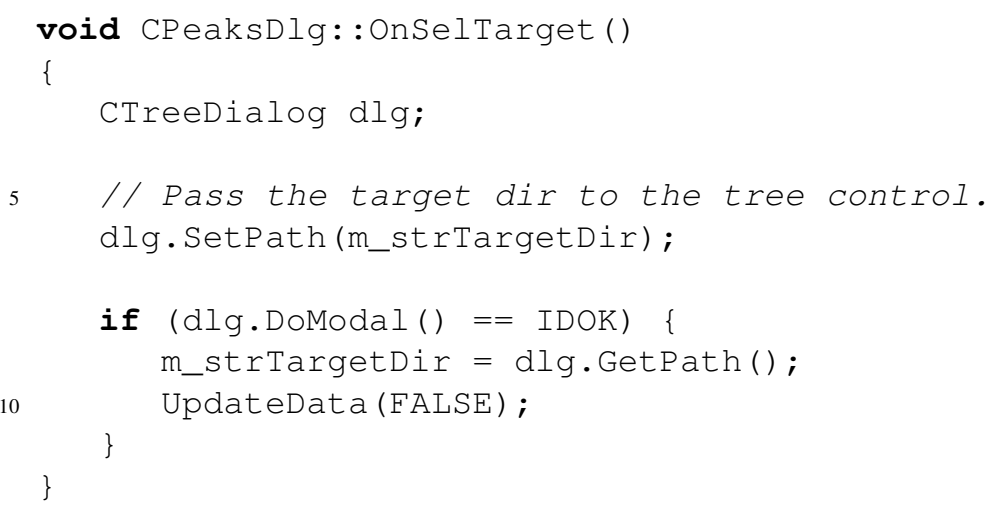

\section{OnProcess}

void CPeaksDlg: : OnProcess ()

\{ 
5 m_ctlSourceDir.EnableWindow(FALSE);

m_ctlTargetDir.Enablewindow (FALSE) ;

m_ctlselsource. Enablewindow (FALSE);

m_ctlSelTarget.EnableWindow (FALSE);

m_ctlDeleteSource.EnableWindow (FALSE);

m_ctlquiet.EnableWindow (FALSE);

m_ctlProcess.Enablewindow (FALSE);

m_ctlcancel.Enablewindow (FALSE);

CWaitCursor curWait;

15

HANDLE hFind;

WIN32_FIND_DATA fd;

int nCount $=0$;

int nWarnings $=0$;

CString strMessage;

CString strSourceDir = m_strSourceDir;

CString strTargetDir = m_strTargetDir;

CString strIdxFileName;

CStdiofile fIdxFile;

25 if (strSourceDir.Right(1) $\quad !={ }^{\mathrm{T}}(" \backslash \backslash ")$ ) // Make sure the source dir ends in a slash strSourceDir = strSourceDir + $\mathrm{T}(" \backslash \backslash ")$;

if (strTargetDir.Right(1) $\quad !={ }^{\mathrm{T}}(" \backslash \backslash ")$ ) // Make sure the target dir ends in a slash strTargetDir = strTargetDir $+\ldots \mathrm{T}(" \backslash \backslash ")$;

// Initialise the index file name strIdxFileName = strTargetDir $+{ }^{\mathrm{T}}($ (Index.dat");

// Enclosed in braces so $E x$ is destroyed if not needed prior I/ to being reused in the main loop below.

\{

CFileException Ex;

if (!) (fIdxFile.Open(strIdxFileName, CFile::modeReadWrite | CFile ::modeCreate | CFile::modeNoTruncate | CFile::shareExclusive, \&Ex)) $\{$ // Open the index file. Ex.ReportError ();

return;

\}

\}

fIdxFile.SeekToEnd(); // Move to the end of the index file.

// Add a file mask for .pks files to the source dir

strSourceDir $+={ }_{-}^{\mathrm{T}}(" * \cdot \mathrm{pks} ")$;

// Check for directory without .pks files

if ( (hFind $=$ : : FindFirstFile (strSourceDir, \&fd)) != INVALID_HANDLE_VALUE) \{

// Remove the *.pks filemask from the source dir. strSourcedir = strSourceDir.Left (strSourceDir.GetLength () - 5);

// Check subitem is not a directory

if (! (fd.dwFileAttributes \& FILE_ATTRIBUTE_DIRECTORY)) do \{

// Get the filename

CString strSourceFile $=$ (LPCTSTR) \&fd.CFileName;

I/ Make the name the same as the source file but 
I/ remove .pks and add. dat

CString strTargetFile = strSourceFile.Left(strSourceFile. GetLength () - 4) + _T (".dat");

// Need to check that file does not already exist in the index.

// Write the name without extension to the index file

fIdxFile.WriteString (strSourceFile. Left (strSourceFile. GetLength () - 4));

// Write a carriage return to the index file

fIdxFile.WriteString (_T ("\n"));

// Insert the source path into the source filename.

strSourcefile.Insert (0, strSourcedir);

// Insert the target path into the target filename.

strTargetFile.Insert (0, strTargetDir);

75

int $\mathrm{nPeaks}=0$;

try \{

CStdiofile fSourceFile(strSourceFile, CFile:modeRead | CFile: : shareDenywrite); CStdiofile fTargetFile(strTargetFile, CFile: modeWrite | CFile::modeCreate | CFile: shareExclusive);

CString strData;

CString stroutput;

for (int $i=0 ; i<6$; $i++$ )

// Throw away the first six lines. fSourceFile.ReadString (strData);

while (fSourceFile.GetPosition() != fSourceFile. GetLength ()) \{

// Throw away the first two lines.

I/ Read in the first line

fSourcefile.ReadString (strData);

// Get the string data from the file

CString strPeakNum = strData.Left (4);

CString strF1 = strData.Mid $(5,15)$;

CString $\operatorname{strF2}=\operatorname{strData} \cdot \operatorname{Mid}(20,15)$;

CString strAmp = strData.Mid $(35,15)$;

100

CString strVol = strData.Mid $(50,15)$;

// Convert the string data to numeric

int nPeakNum = (int) (_tcstod (strPeakNum.GetBuffer (0), NULL) ) ;

double dblF1 = _tcstod(strF1.GetBuffer(0), NULL);

double dblF2 = _tcstod(strF2.GetBuffer(0), NULL);

double dblAmp = _tcstod(strAmp. GetBuffer(0), NULL);

double dblVol = _tcstod (strVol.GetBuffer(0), NULL);

// Read in the second line

fSourcefile.ReadString (strData);

110

// Get the string data from the file

CString strFWHH1 = strData. Left (19);

CString strFWHH2 = strData.Mid $(20,15)$;

// Convert the string data to numeric

double dblFWHH1 = _tcstod(strFWHH1.GetBuffer(0), NULL ) ; 
// Read in the third line fSourceFile.ReadString (strData); // Get the string data from the file

double dblFlmax = _tcstod(strFlmax.GetBuffer(0), NULL );

double dblFlmin = tcstod(strF1min.GetBuffer(0), NULL );

double dblF2max = _tcstod(strF2max.GetBuffer(0), NULL ) ;

double dblF2min = ttcstod(strF2min.GetBuffer(0), NULL )

// Check that the peak is not between 4 and 6 ppm and // over 150 ppm

if $(!(((\mathrm{dblF} 1>150) \& \&(\mathrm{dblF} 2>4) \& \&(\mathrm{dblF} 2<6))$ | |

I/ and it's not between 4 and 6 ppm and under 15 ppm

$((\mathrm{dblF} 1<15) \& \&(\mathrm{dblF} 2>4) \& \&(\mathrm{dblF} 2<6)) \quad \mid$ 
strMessage.Format (_T("\%d files processed."), nCount);

MessageBox (strMessage);

\}

170

m_ctlCancel.EnableWindow (TRUE);

I/ Send a message to the dialog indicating that the Cancel button

I/ has been clicked in order to quit the program.

175

PostMessage (WM_COMMAND, (WPARAM) IDCANCEL); \} 


\section{Appendix C}

\section{Matlab Macros Used to Generate a Screen Mask}

\section{Initialise}

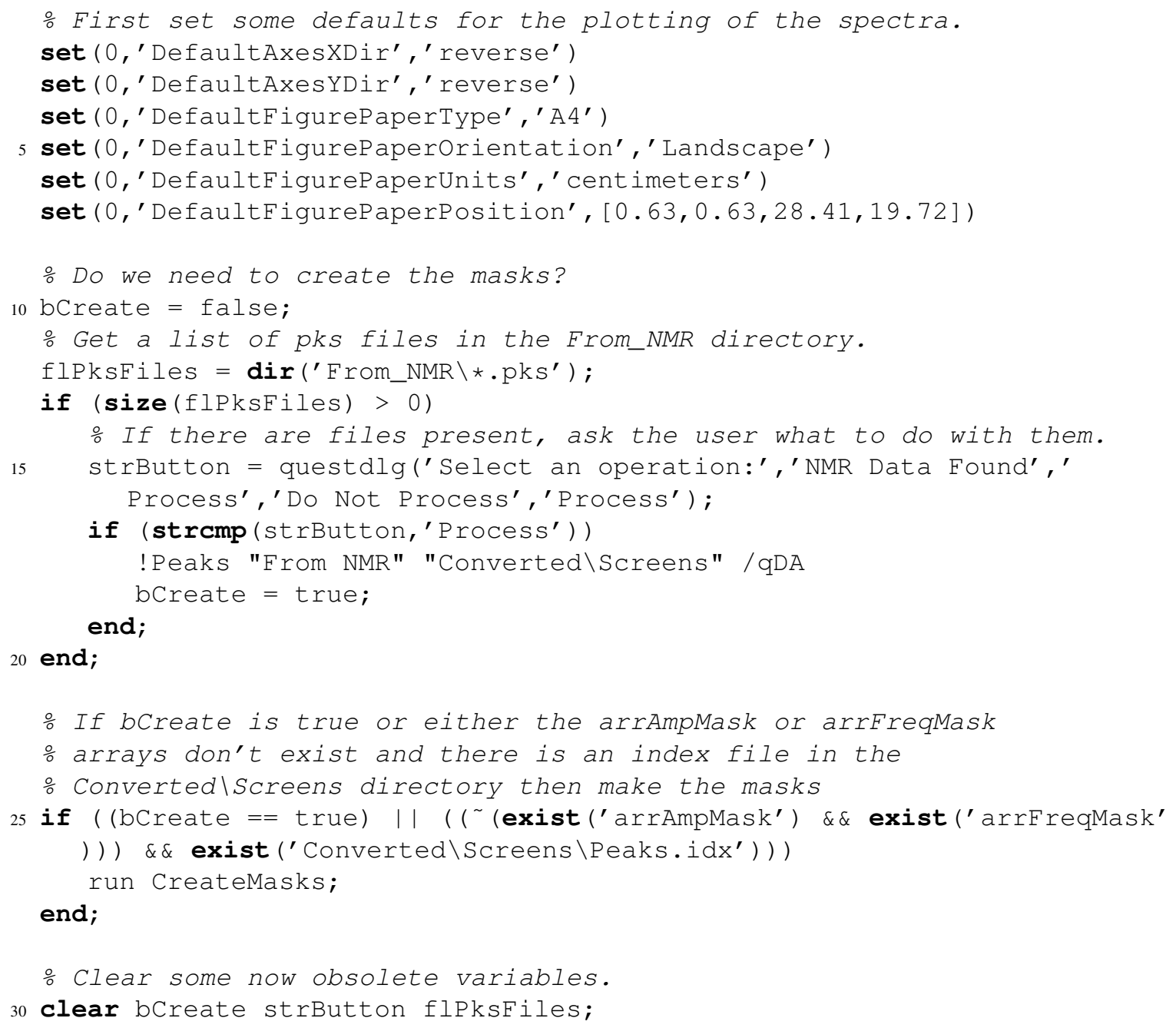

\section{CreateMasks}

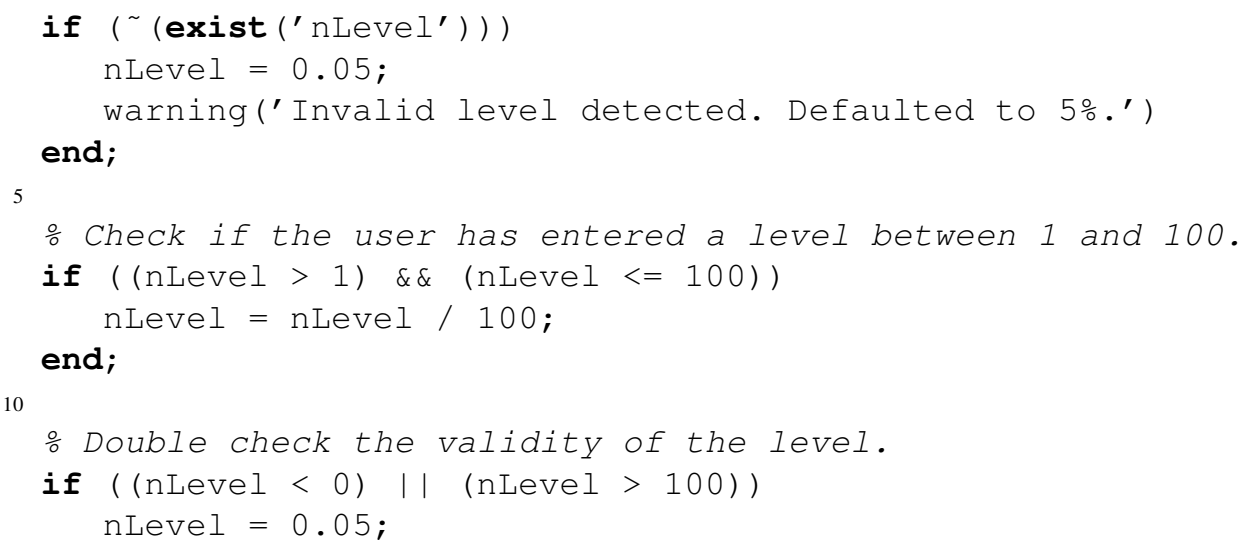


15 end;

warning('Invalid level detected. Defaulted to 5\%.')

응 the list of screens from the index file.

flSampleNames = textread ('Converted $\backslash$ Screens $\backslash$ Peaks.idx',' o $\mathrm{S}^{\prime}$ );

nNumScreens = size (flSampleNames, 1$)$;

20 nCount $=1$;

응 the masks exist, clear them first.

if (exist ('arrAmpMask')) clear arrAmpMask; end;

if (exist ('arrFreqMask')) clear arrFreqMask; end;

25

ㅇ Recreate empty masks.

$\operatorname{arrAmpMask}(80,160)=0$;

arrFreqMask $(80,160)=0$;

$30 \div$ Turn off MATLABS warning for integer to logical conversions

This is necessary for creating the frequency mask!

warning off MATLAB:conversionToLogical

- Create a progress bar for the user.

35 hWaitbar = waitbar (0,'Building Screen Masks');

set (gca (hWaitbar),'Xdir','normal');

ㄴ Loop to work through each screen in the index.

for $j=1:$ nNumScreens

strFileName $=[$ 'Converted $\backslash$ Screens $\backslash$ ' $\operatorname{char}(f l$ SampleNames (j)) '.dat'];

을 the data from the file.

arrInput $=$ csvread(strFileName);

45

ㄴ Loop through the data.

for $k=1$ :size (arrInput, 1 )

arrTempAmpMask (nCount, 1$)=\operatorname{double}(\operatorname{int} 8((\operatorname{arrInput}(k, 3)-0.5) / 0.1)$ $+0.5))$;

$\operatorname{arrTempAmpMask}($ nCount, 2$)=\operatorname{double}(\operatorname{int16}(\operatorname{arrInput}(\mathrm{k}, 2)+0.5))$;

$\operatorname{arrTempAmpMask}($ nCount, 3$)=\operatorname{abs}(\operatorname{arrInput}(\mathrm{k}, 4))$;

$\operatorname{arrTempFreqMask}($ nCount, 1$)=\operatorname{double}(\operatorname{int} 8(((\operatorname{arrInput}(\mathrm{k}, 3)-0.5) / 0.1)$ $+0.5)$ );

50

arrTempFreqMask (nCount, 2$)=\operatorname{double}(\operatorname{int} 16(\operatorname{arrInput}(\mathrm{k}, 2)+0.5))$;

arrTempFreqMask (nCount, 3$)=\operatorname{double}(\operatorname{logical}(\operatorname{arrInput}(\mathrm{k}, 4)))$;

end;

nCount $=$ nCount +1 ;

nCount $=1$;

55

Convert the arrays to full 80 x 160 arrays.

arrTempAmpMask = full (spconvert (arrTempAmpMask));

arrTempFreqMask = double(logical (full (spconvert (arrTempFregMask)) ));

Make sure the size of the arrays is 80 x 160 by upsizing them if

응 necessary.

if ((size (arrTempAmpMask, 1) < 80) || (size (arrTempAmpMask, 2) < 160)) arrTempAmpMask $(80,160)=0$;

end;

65

if $(($ size $(\operatorname{arrTempFreqMask}, 1)<80) \quad||($ size (arrTempFreqMask, 2) < $160)$ )

$\operatorname{arrTempFreqMask}(80,160)=0$;

end;

70 ㅇd the individual arrays to the main arrays.

arrAmpMask = arrAmpMask + arrTempAmpMask;

arrFreqMask = arrFreqMask + arrTempFreqMask; 
- Clear the temporary arrays and update the progress bar.

end;

Apply a percentage threshhold to the frequency mask.

80 for $j=1: 80$

for $k=1: 160$

if (arrFreqMask $(j, k)>$ (nNumScreens * nLevel))

end; $\operatorname{arrTempFreqMask}(j, k)=\operatorname{arrFreqMask}(j, \mathrm{k})$;

85 end;

end;

arrFreqMask = arrTempFreqMask;

clear arrTempFreqMask;

$90 \div$ Close the progress bar.

close (hWaitbar);

- Turn MATLAB logical conversion warnings back on. warning on MATLAB:conversionToLogical

95

- Clear any unnecessary variables.

clear nCount hWaitbar arrInput j k strFileName;

\section{MaskScreen}

을 the level and screen number then mask the screen.

if ( (exist ('nLevel')))

nLevel =0.05;

warning('Invalid level detected. Defaulted to 5\%.')

5 end;

o Check if the user has entered a level between 1 and 100 .

if ( (nLevel > 1) \&\& (nLevel <= 100))

nLevel = nLevel / 100 ;

10 end;

Double check the validity of the level.

if $($ (nLevel < 0$)||$ (nLevel > 100))

nLevel =0.05;

15 warning('Invalid level detected. Defaulted to 5\%.')

end;

\% Check that the user has selected a screen to mask.

if ( (exist ('strToScreen')))

20 warning('Set strToScreen to the name of the screen to mask.'); return;

end;

o Check that the screen exists.

$25 j=1$;

while ( (strcmp (strToScreen, char (flSampleNames (j)))))

$j=j+1$;

if $(j>$ nNumScreens)

warning('No match found.');

30

return;

end;

end;

clear nToScreen; 


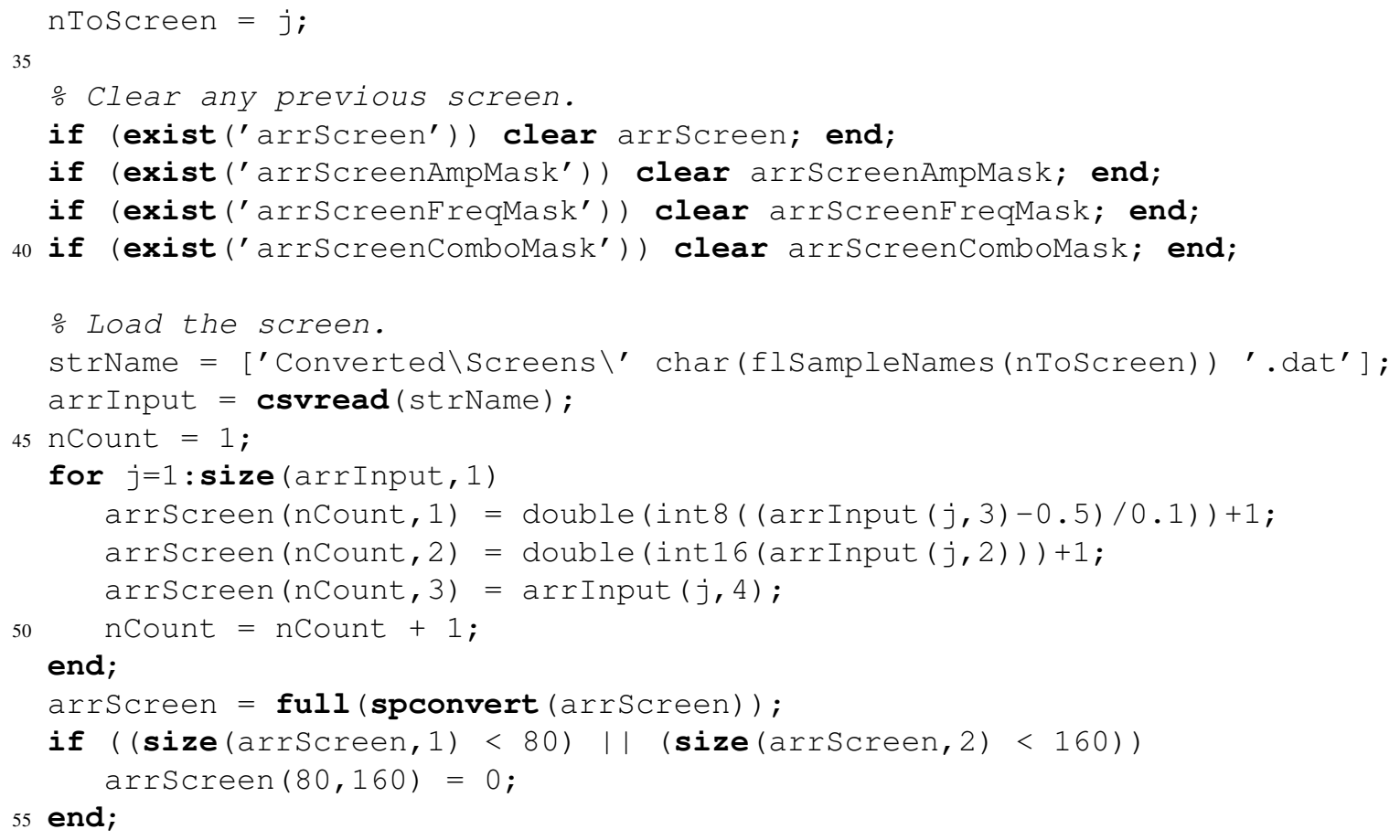

- Clear any unnecessary variables.

clear nCount arrInput j k strName; 


\section{Raspailodane F Spectra}

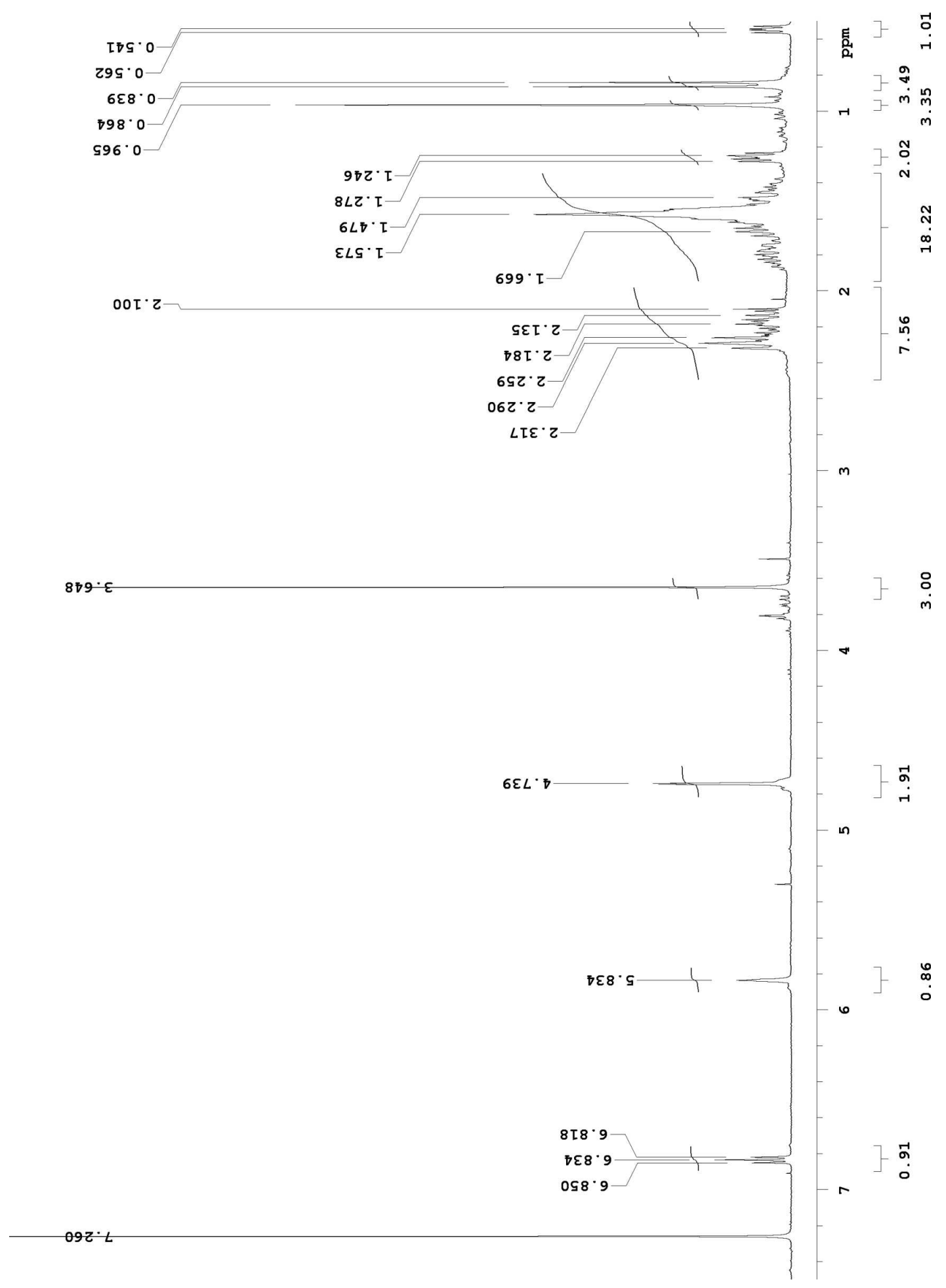

${ }^{1} \mathrm{H}$ NMR spectrum of raspailodane F (40) (300 MHz, $\mathrm{CDCl}_{3}$ ) 


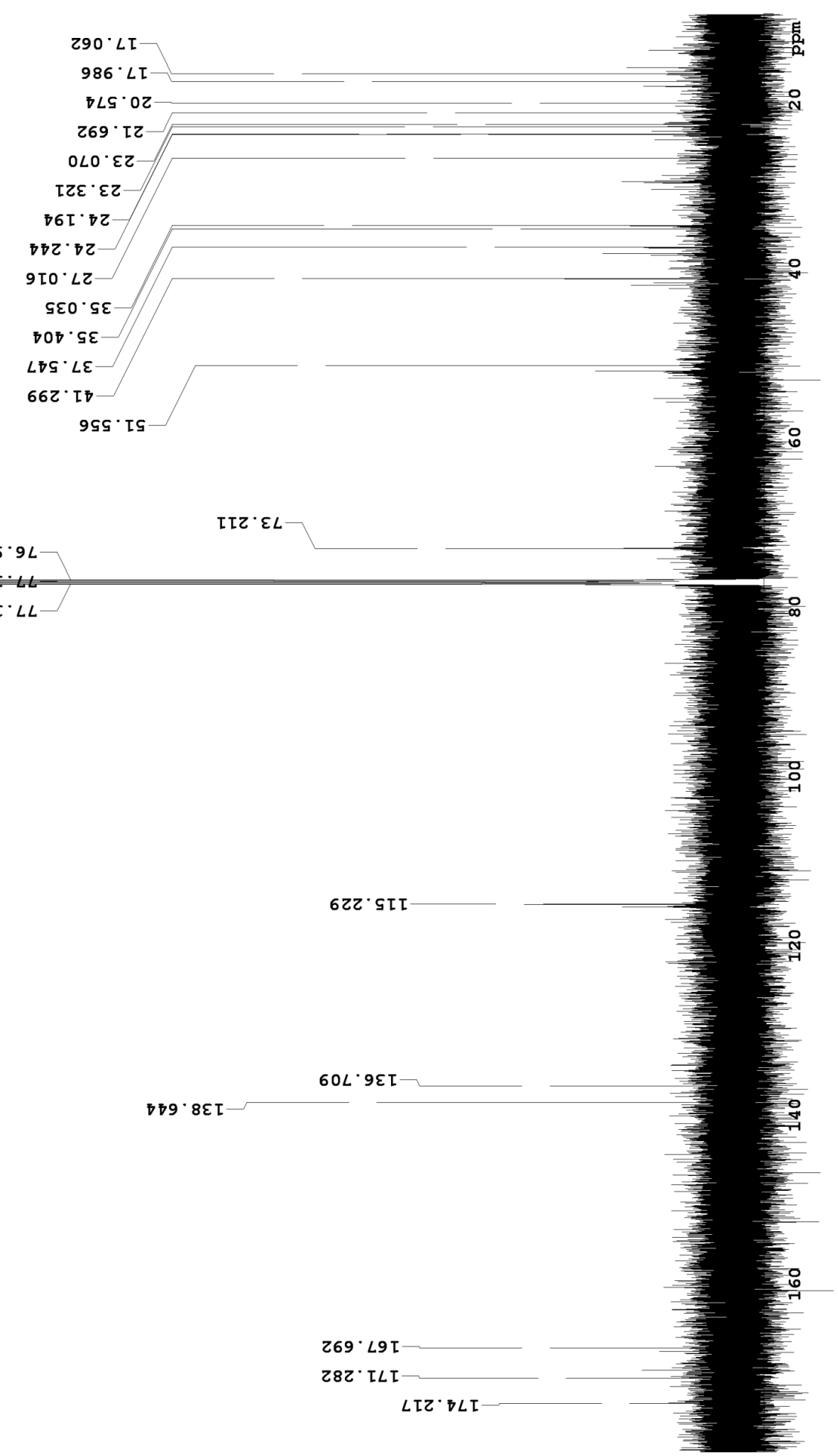

${ }^{13} \mathrm{C}$ NMR spectrum of raspailodane $\mathrm{F}(\mathbf{4 0})\left(600 \mathrm{MHz}, \mathrm{CDCl}_{3}\right)$ 


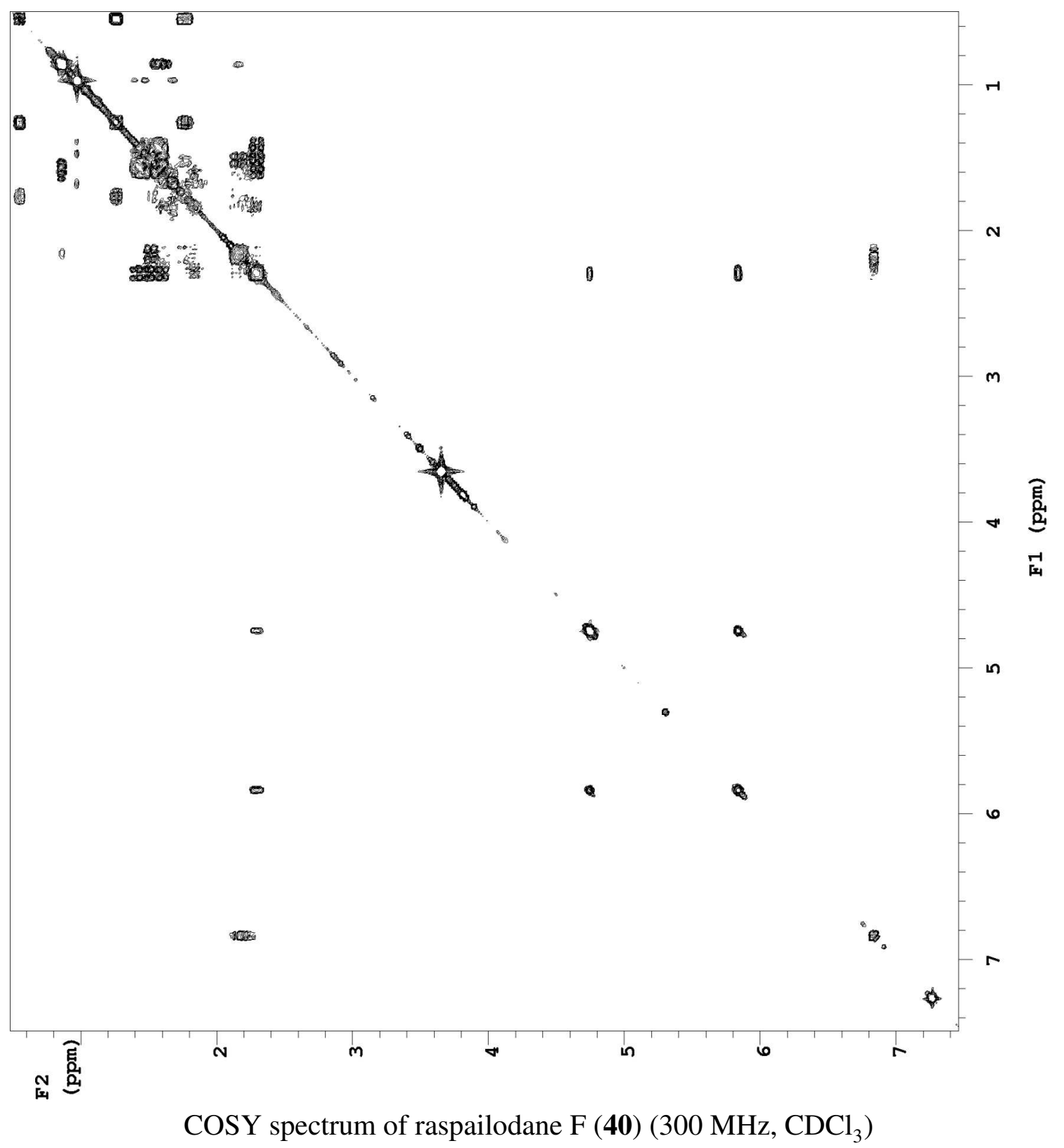




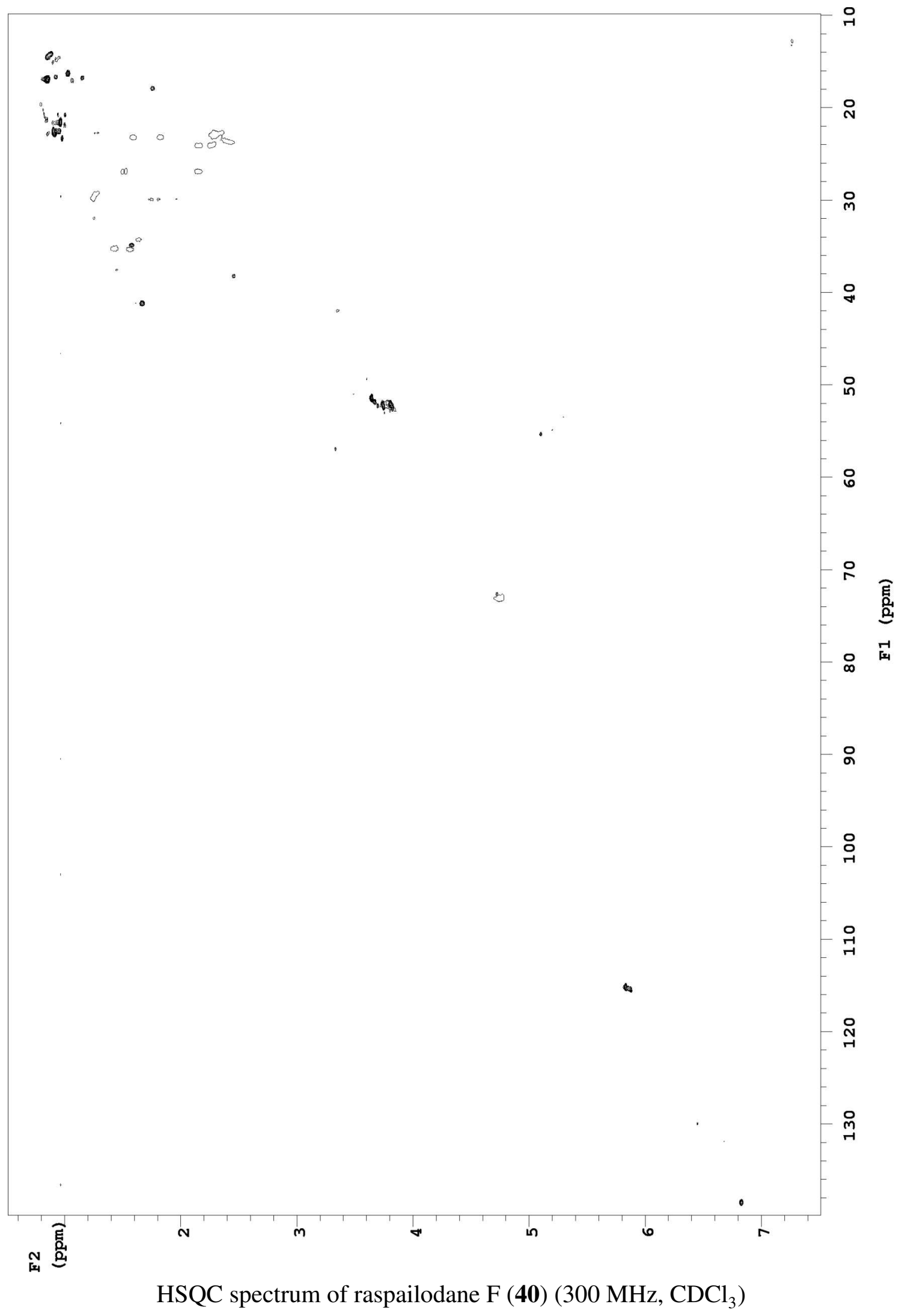




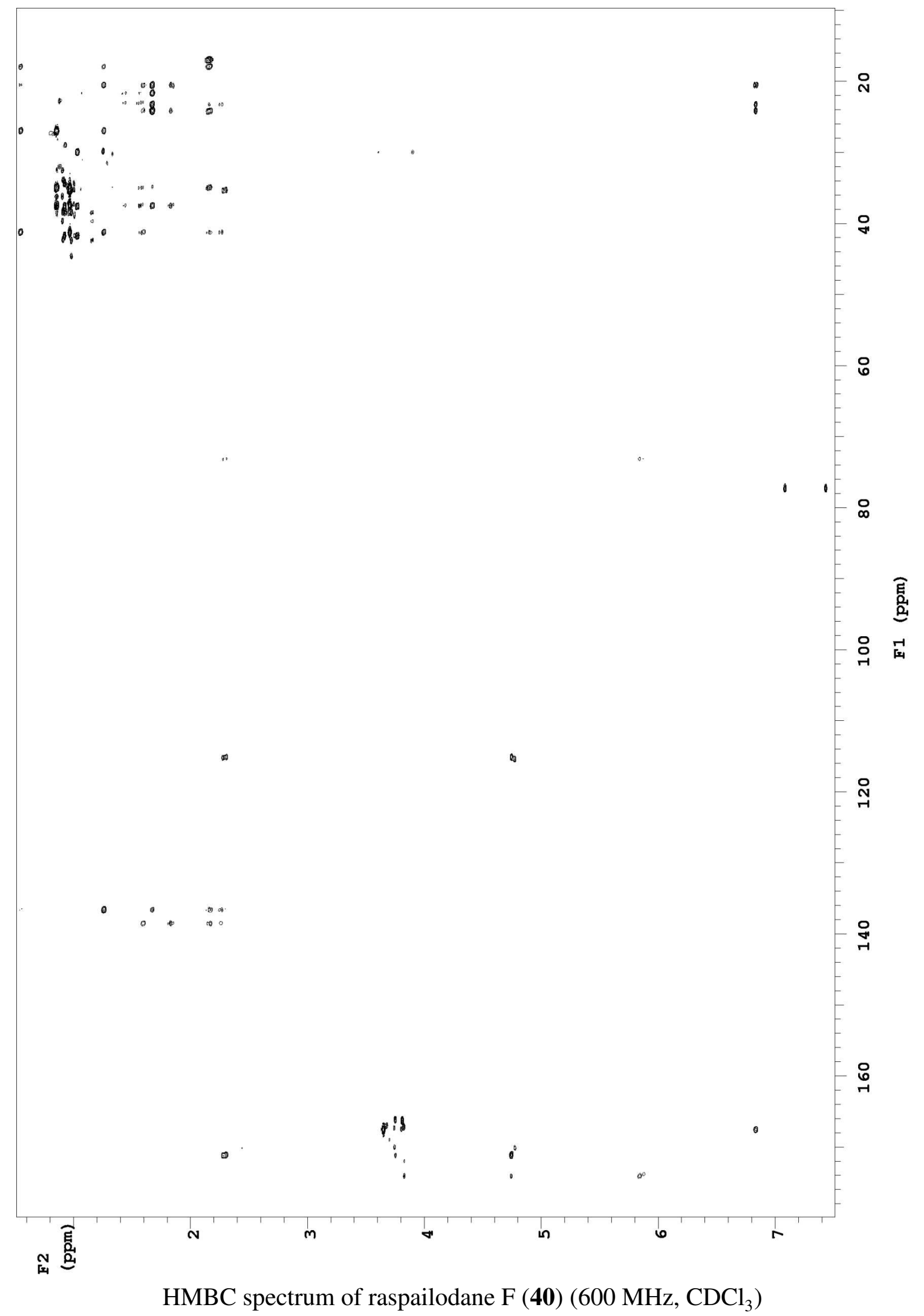




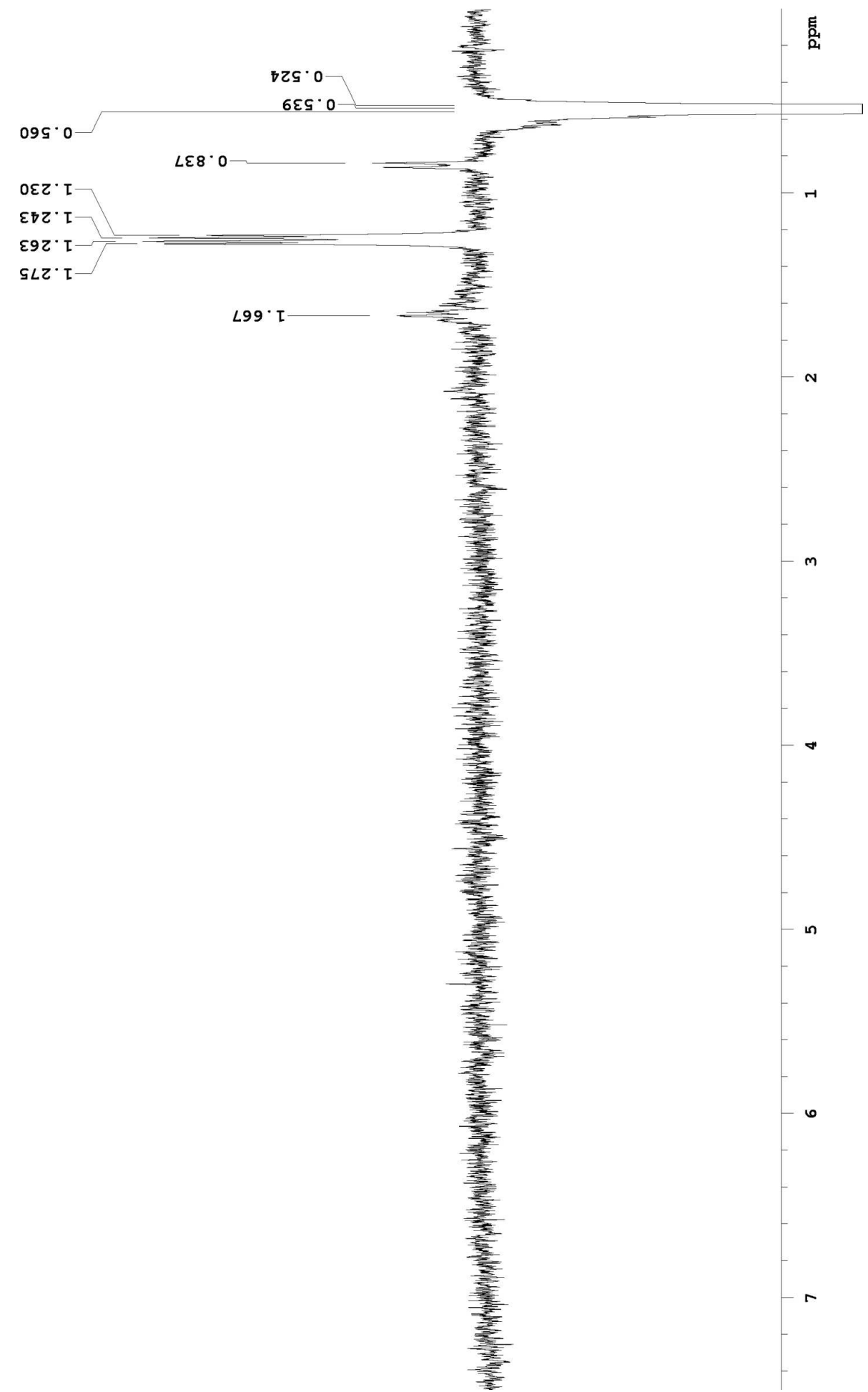

1D NOESY spectrum of raspailodane $F(\mathbf{4 0})$ with selective excitation at $0.54 \mathrm{ppm}\left(300 \mathrm{MHz}, \mathrm{CDCl}_{3}\right)$ 


\section{Raspailodane G Spectra}

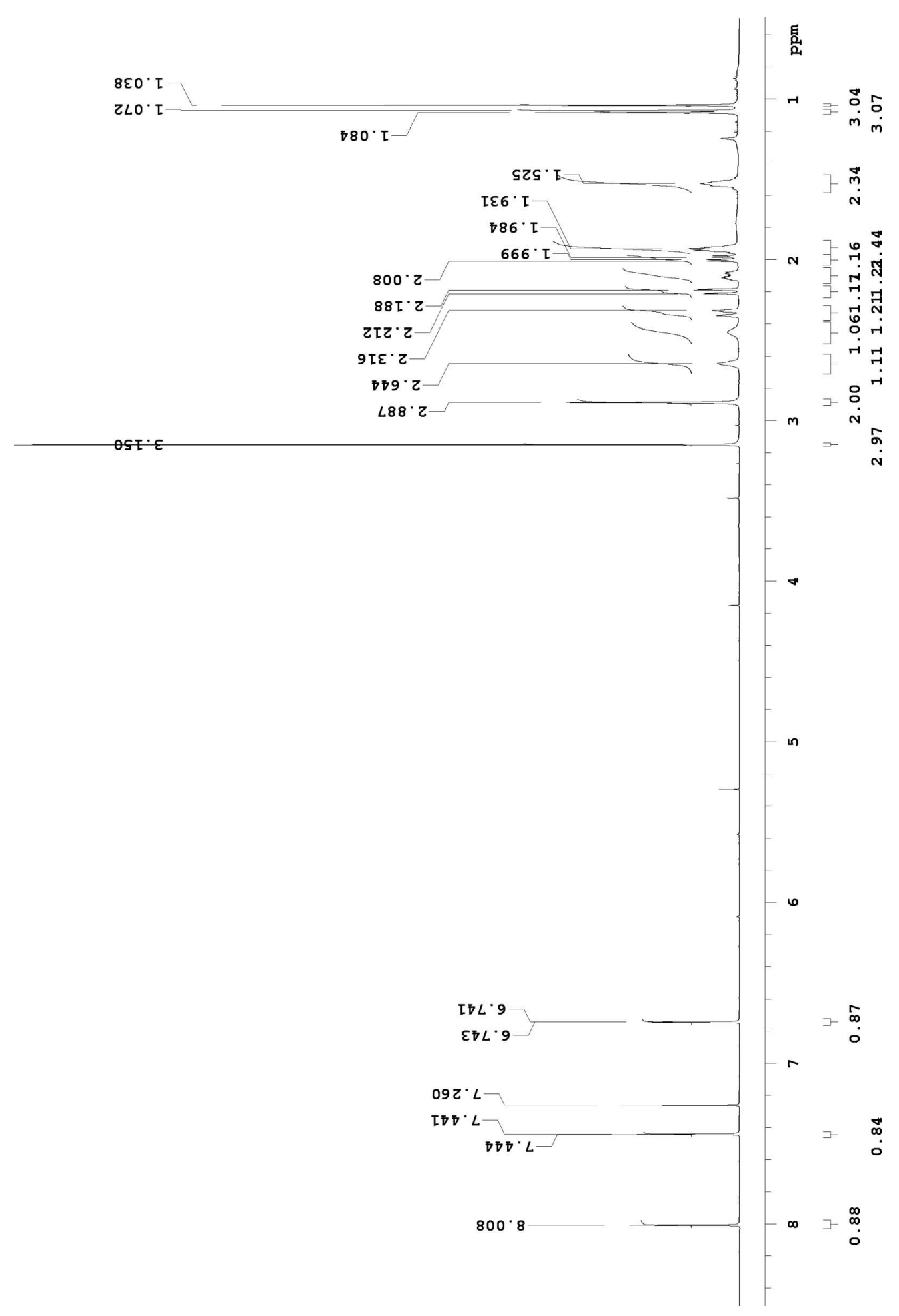

${ }^{1} \mathrm{H}$ NMR spectrum of raspailodane $\mathrm{G}(\mathbf{4 1})\left(600 \mathrm{MHz}, \mathrm{CDCl}_{3}\right)$ 


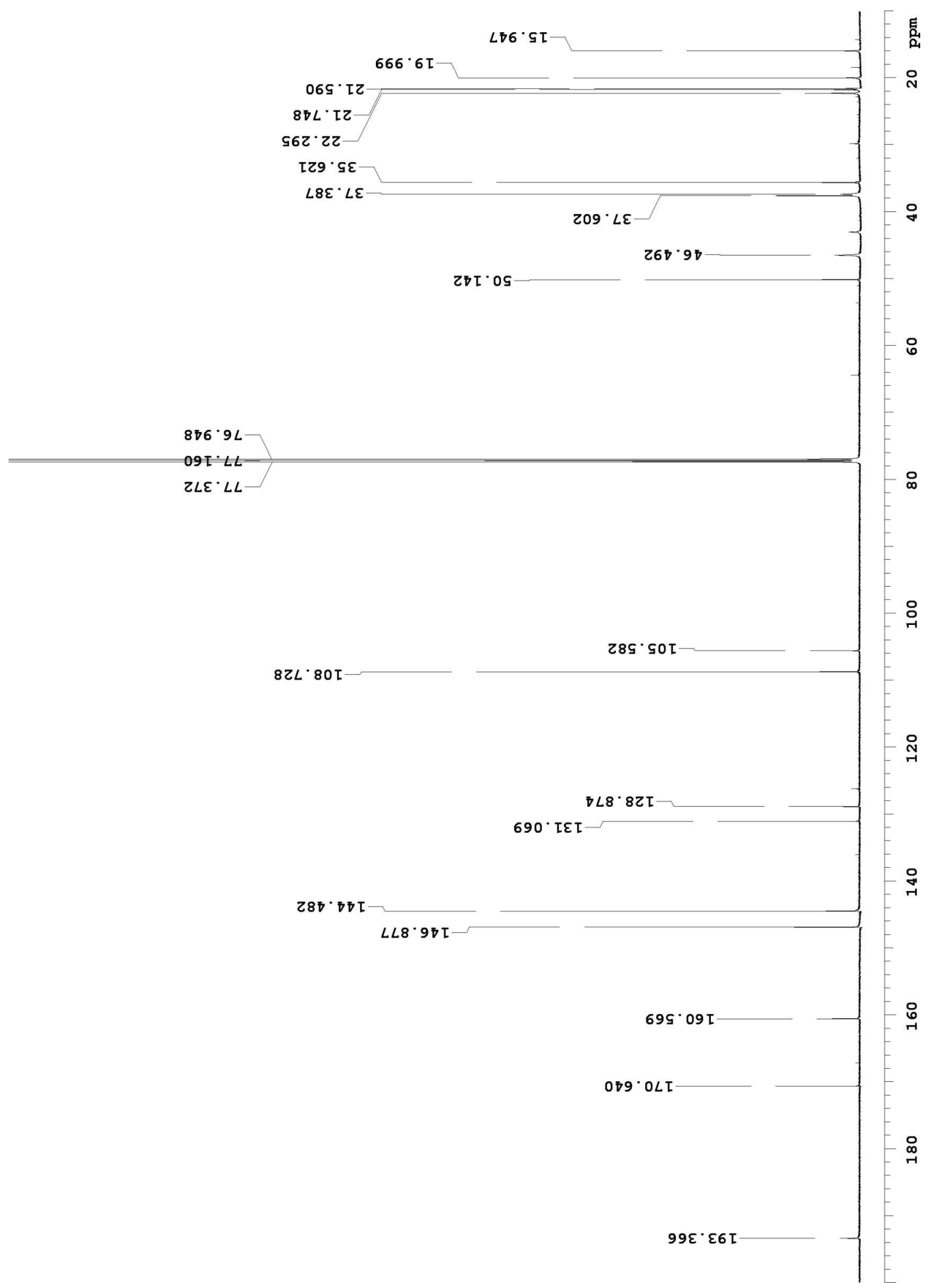

${ }^{13} \mathrm{C}$ NMR spectrum of raspailodane $\mathrm{G}(\mathbf{4 1})\left(600 \mathrm{MHz}, \mathrm{CDCl}_{3}\right)$ 


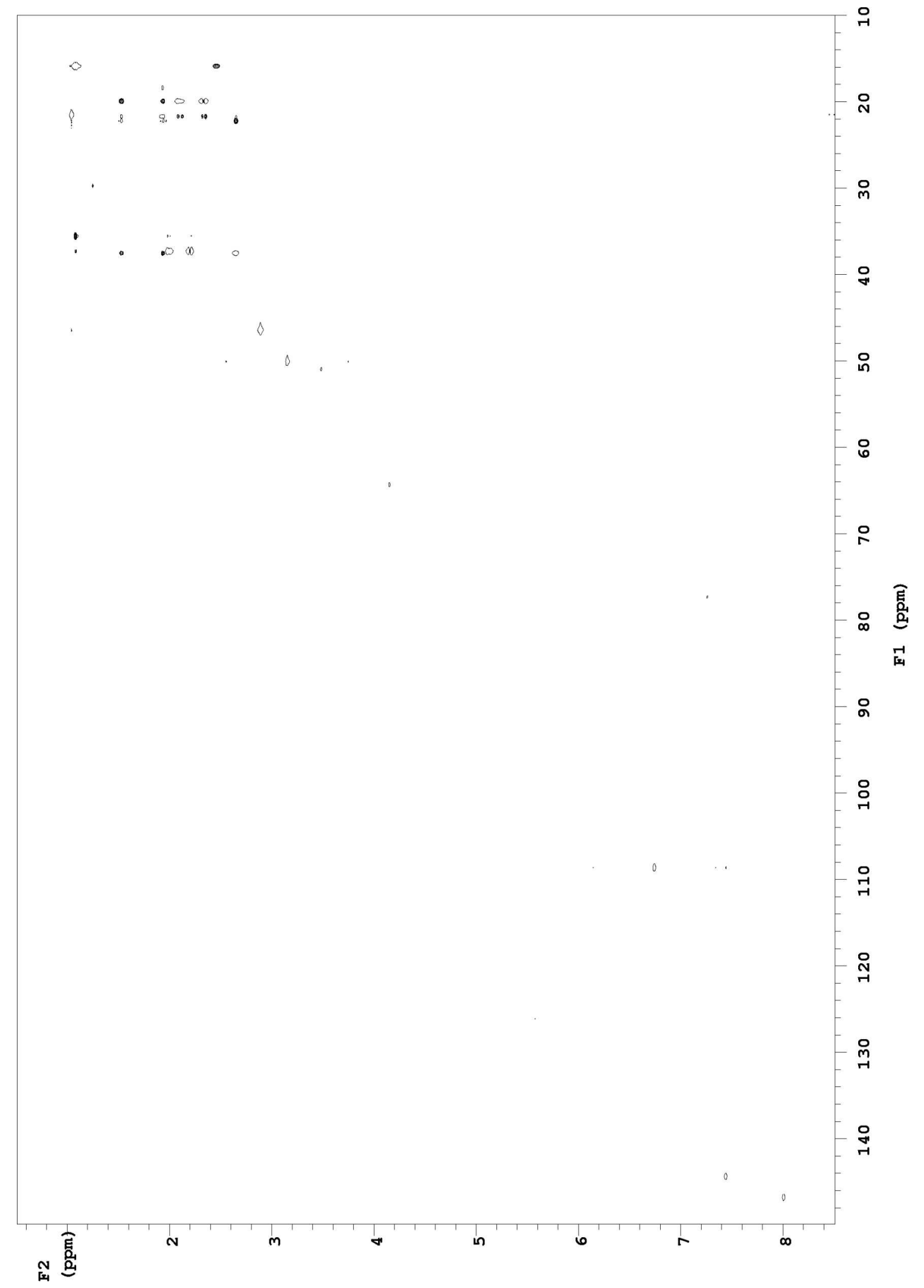

HSQC-TOCSY spectrum of raspailodane G (41) acquired with a $20 \mathrm{~ms}$ mixing time $\left(600 \mathrm{MHz}, \mathrm{CDCl}_{3}\right)$ 


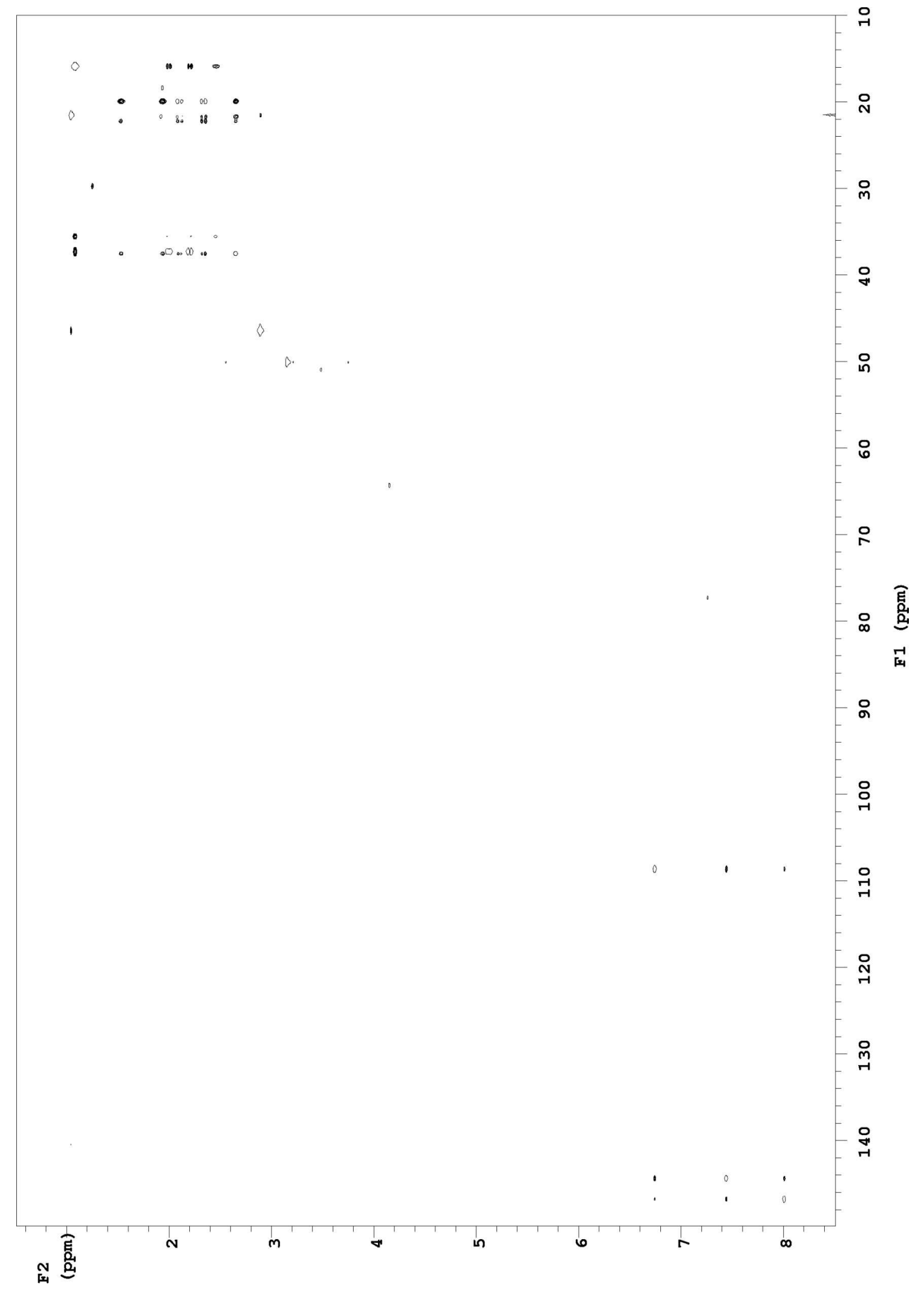

HSQC-TOCSY spectrum of raspailodane G (41) acquired with an $80 \mathrm{~ms}$ mixing time $\left(600 \mathrm{MHz}, \mathrm{CDCl}_{3}\right)$ 


\section{Petrosianoic Acid Spectra}

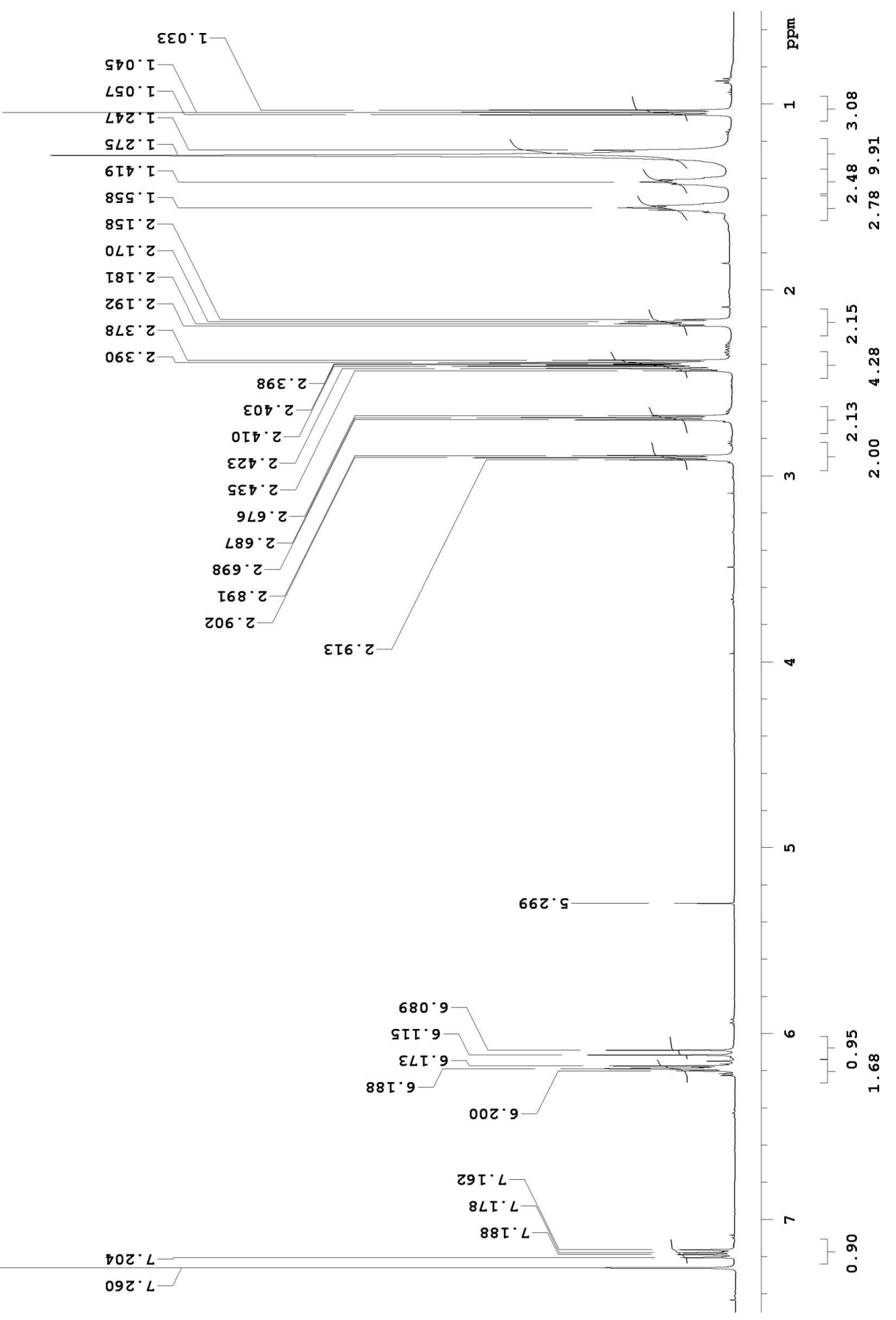

${ }^{1} \mathrm{H}$ NMR spectrum of petrosianoic acid (122) $\left(600 \mathrm{MHz}, \mathrm{CDCl}_{3}\right)$ 


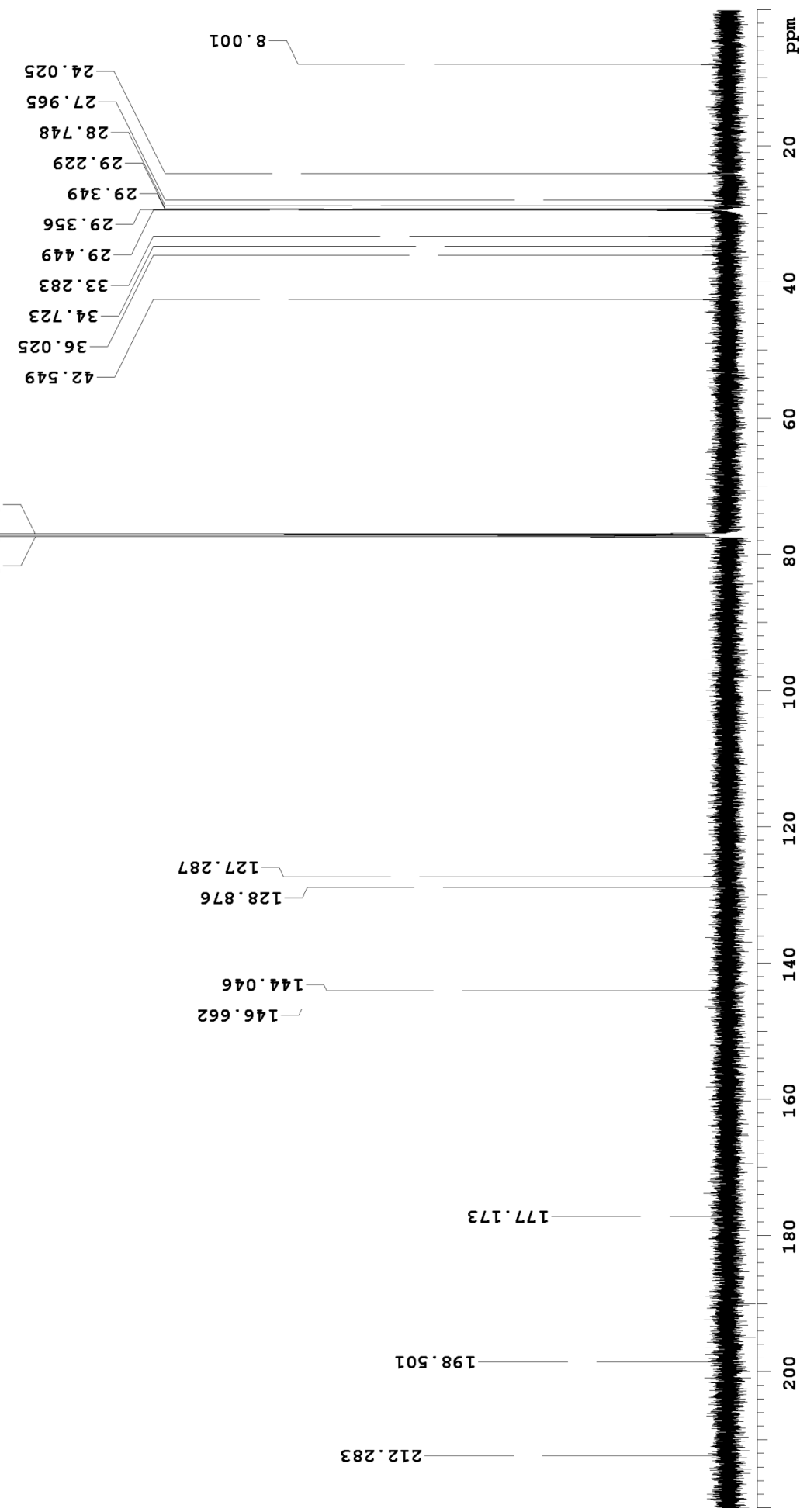

${ }^{13} \mathrm{C}$ NMR spectrum of petrosianoic acid (122) $\left(600 \mathrm{MHz}, \mathrm{CDCl}_{3}\right)$ 


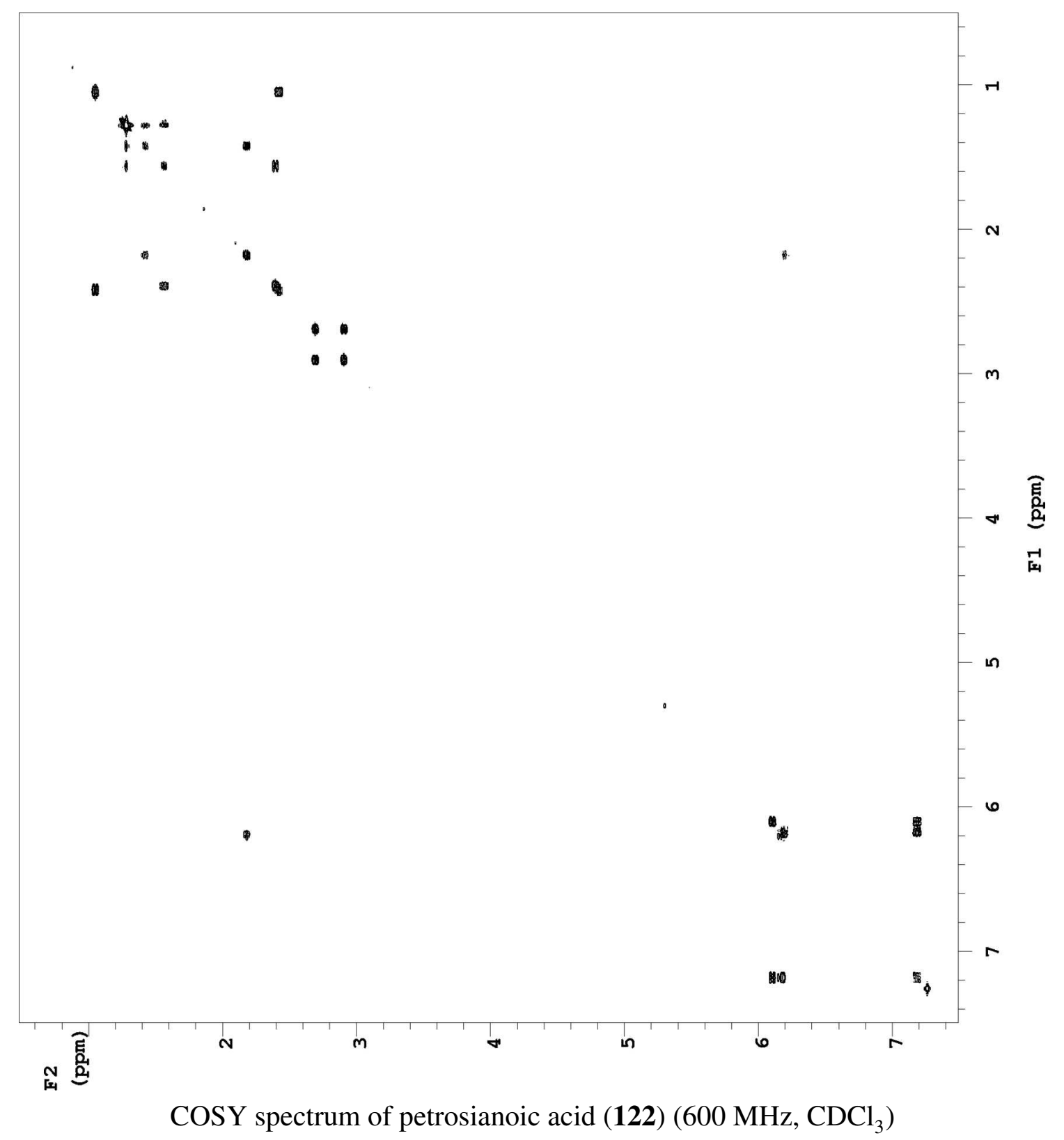




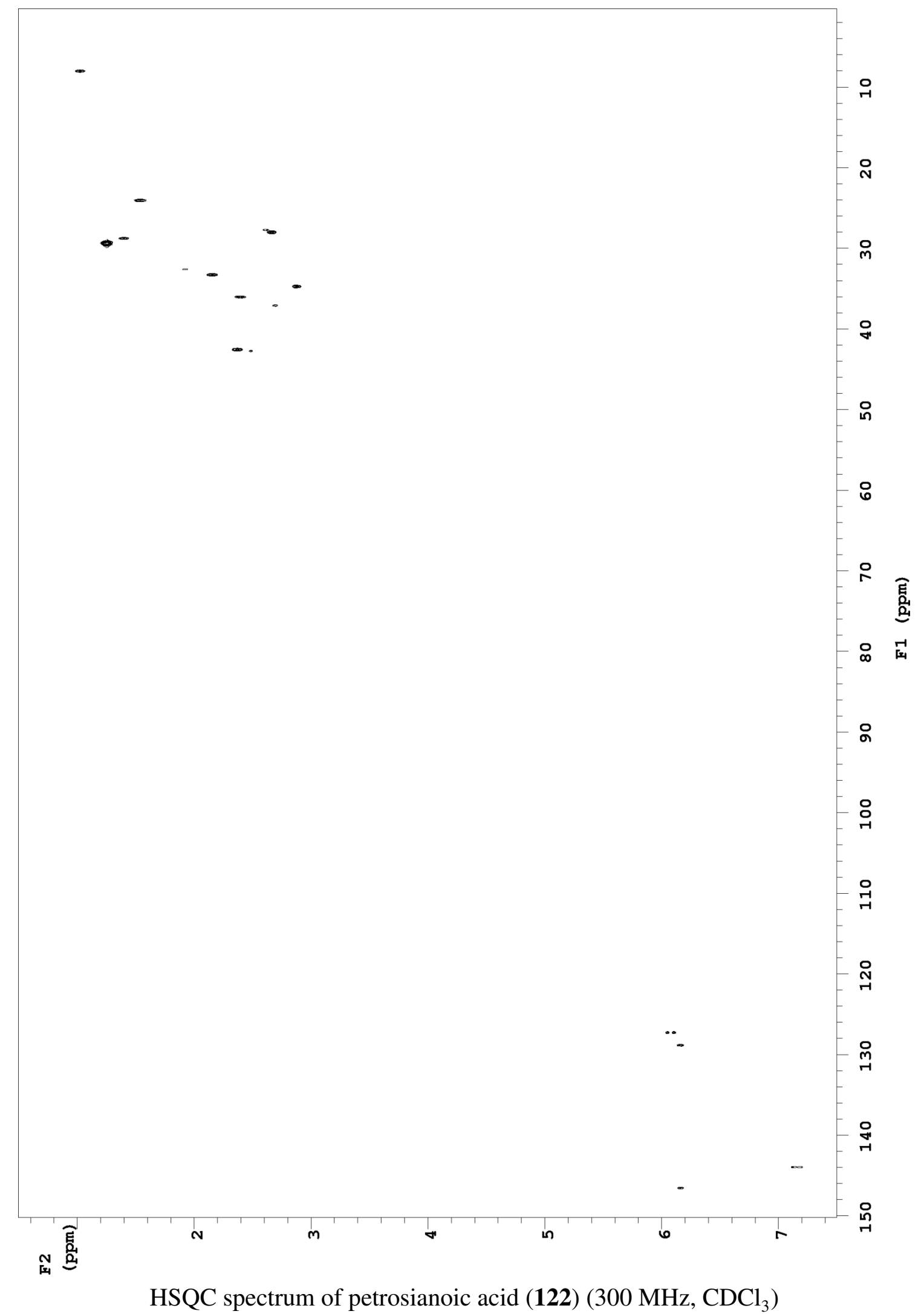




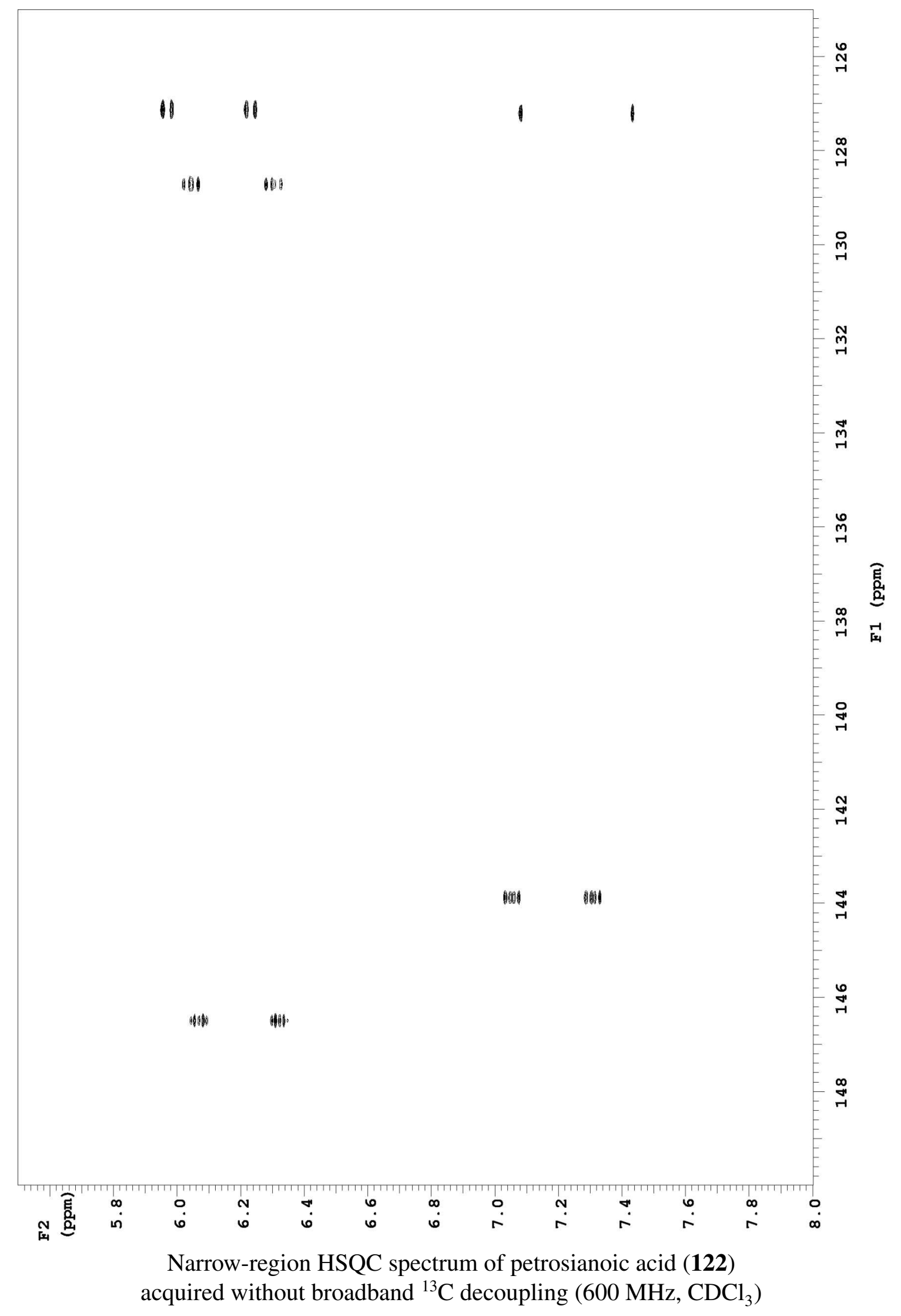




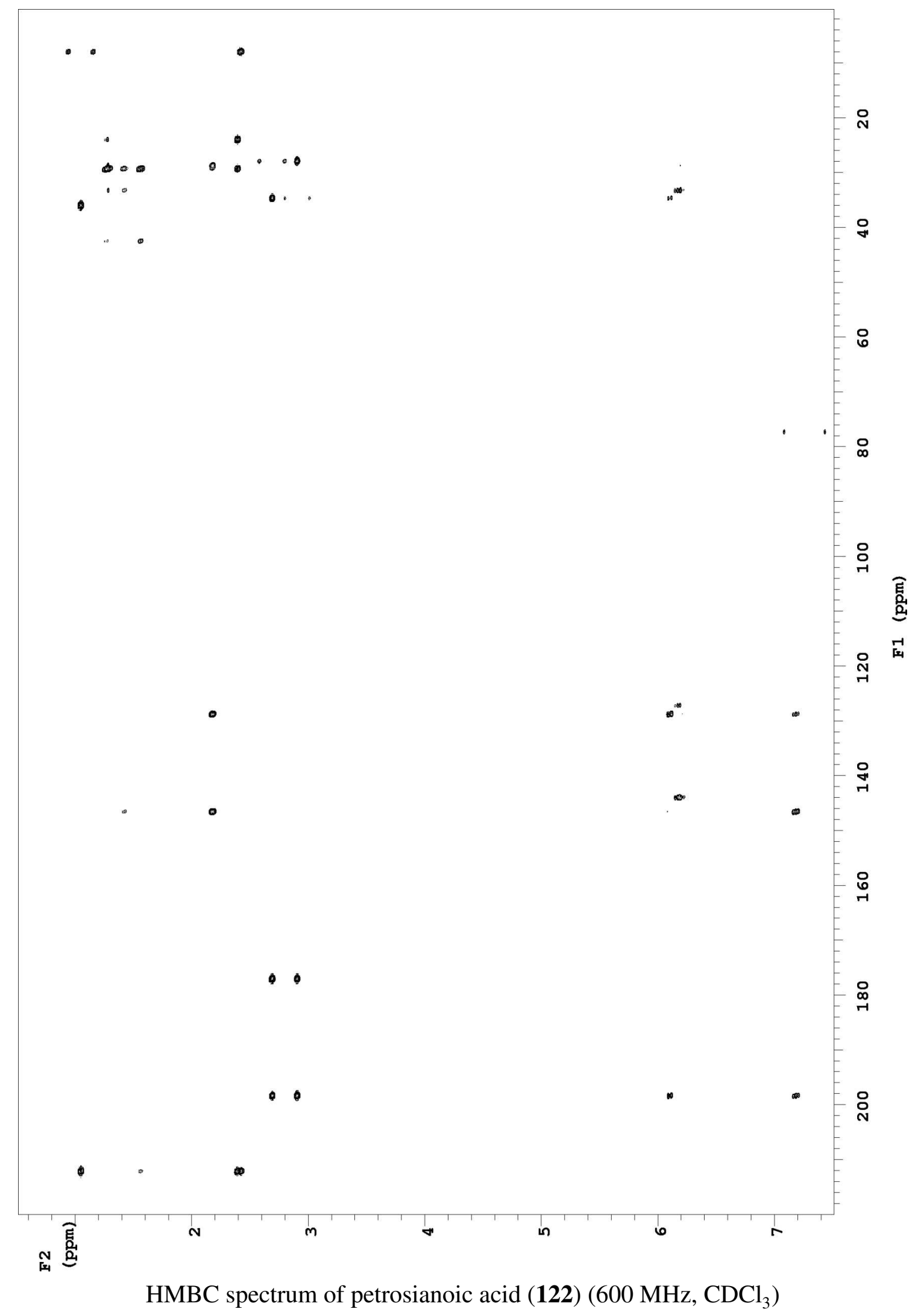




\section{Dendronitrile Spectra}

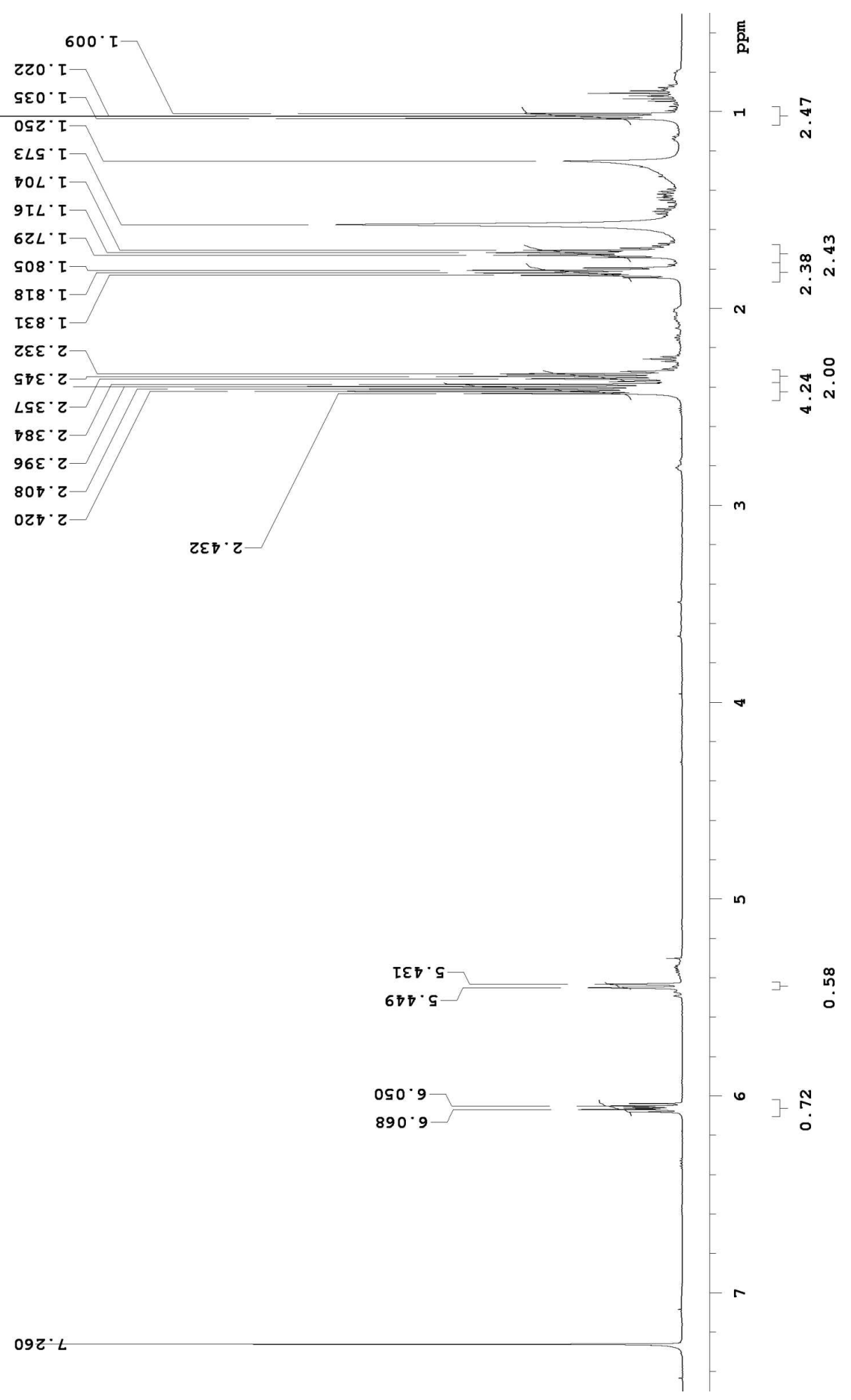

${ }^{1} \mathrm{H}$ NMR spectrum of dendronitrile (158) $\left(600 \mathrm{MHz}, \mathrm{CDCl}_{3}\right)$ 


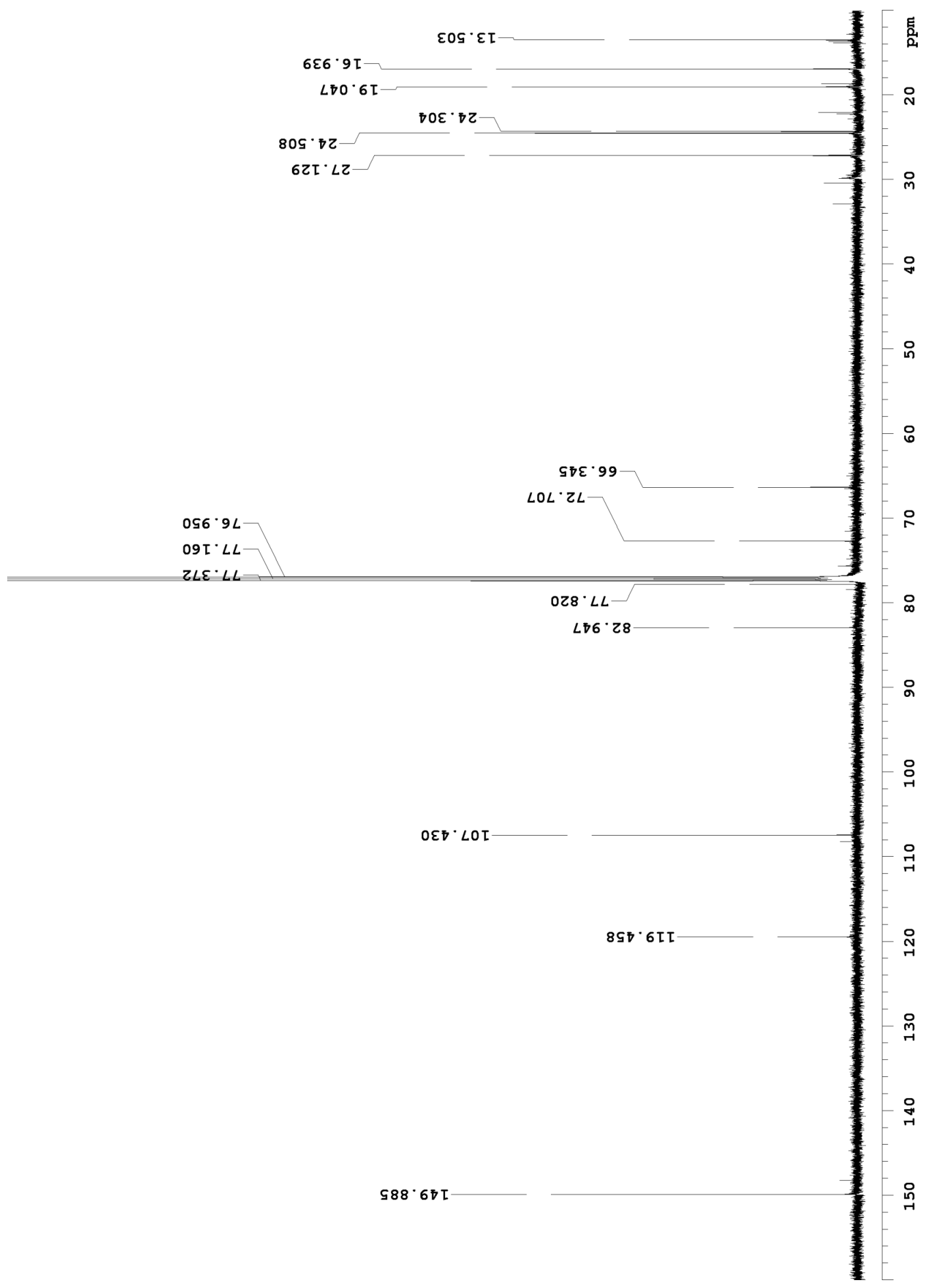

${ }^{13} \mathrm{C}$ NMR spectrum of dendronitrile (158) $\left(600 \mathrm{MHz} \mathrm{CDCl}_{3}\right)$ 


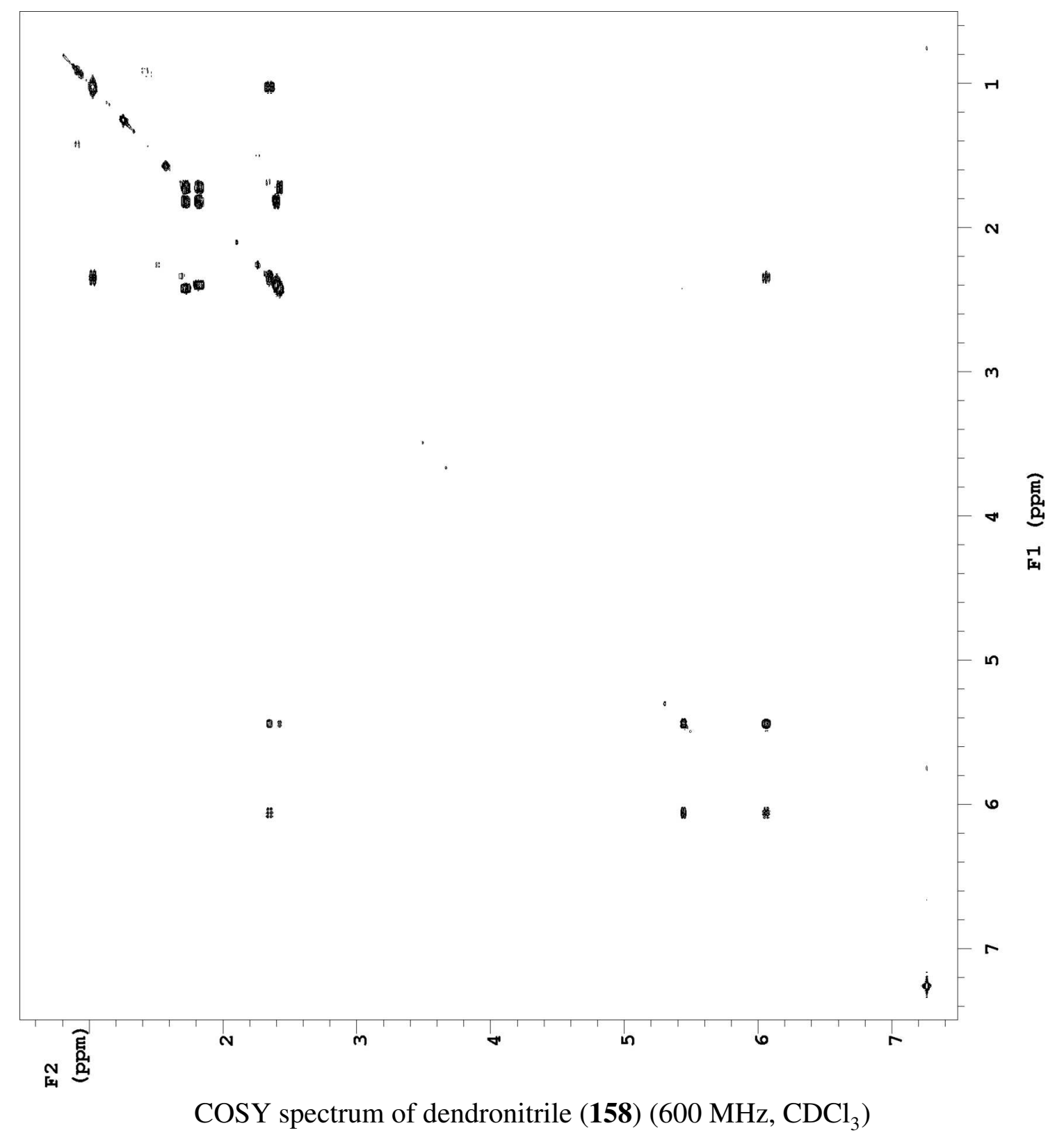




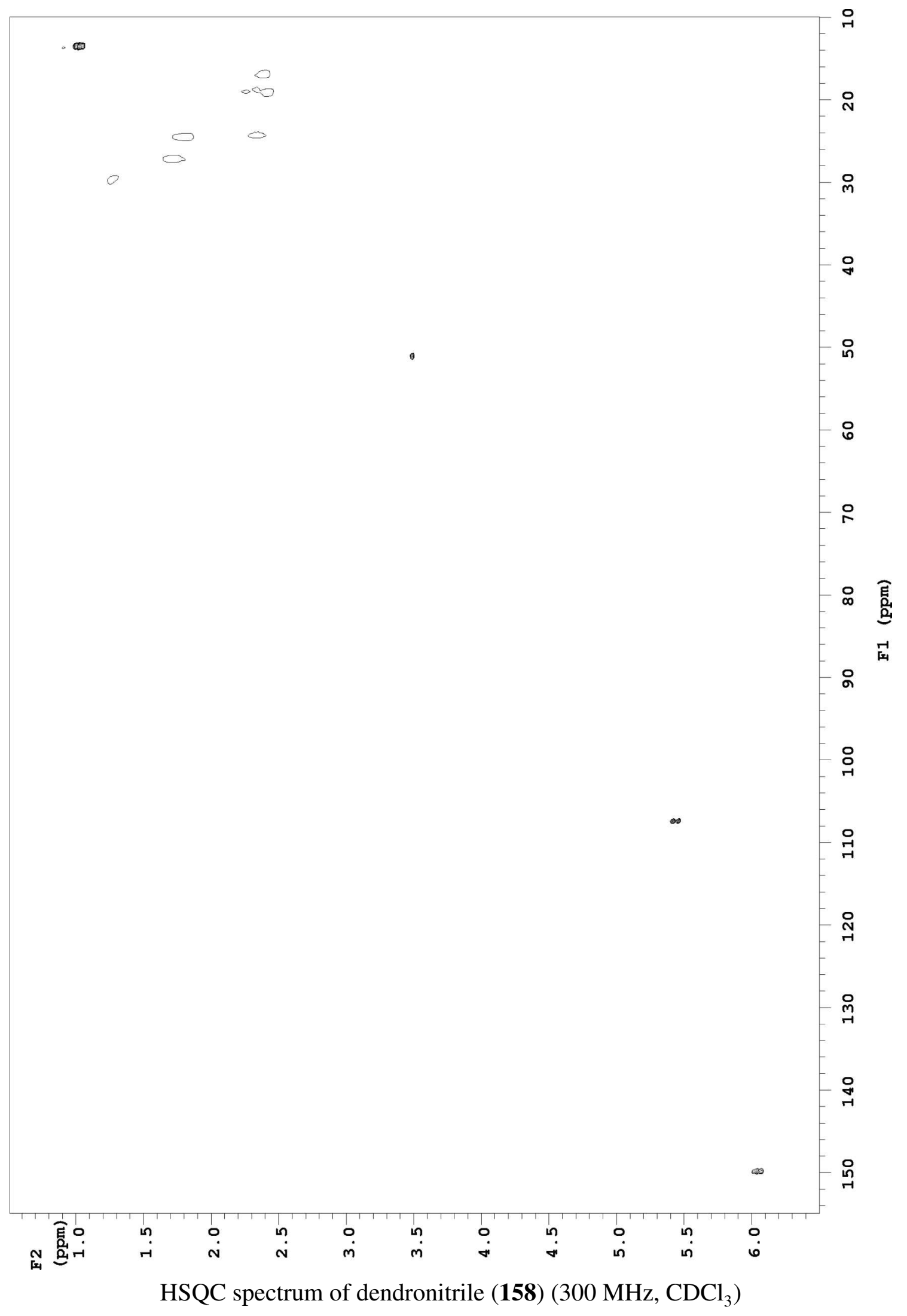




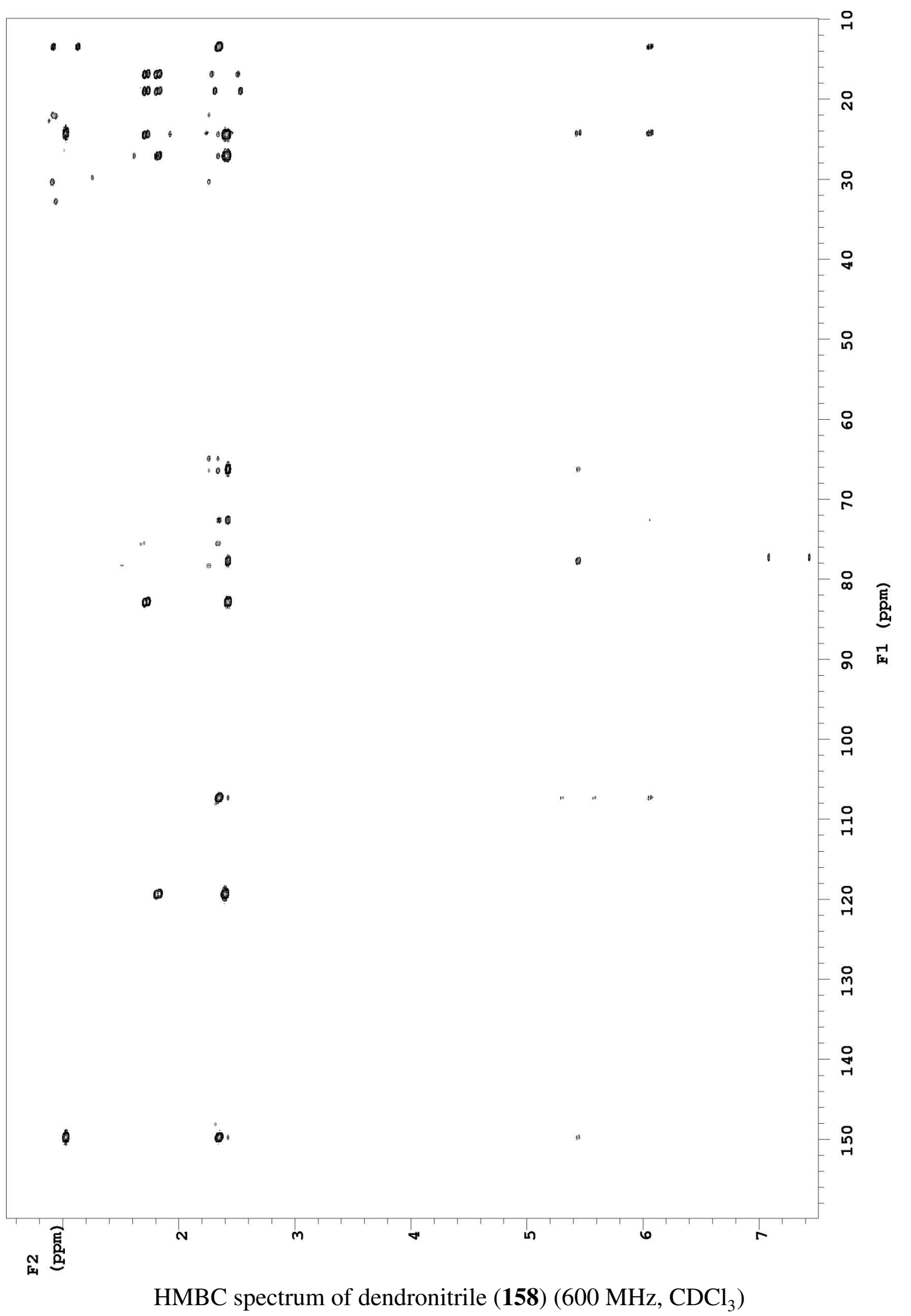




\section{Lamellarin $\theta$ Spectra}

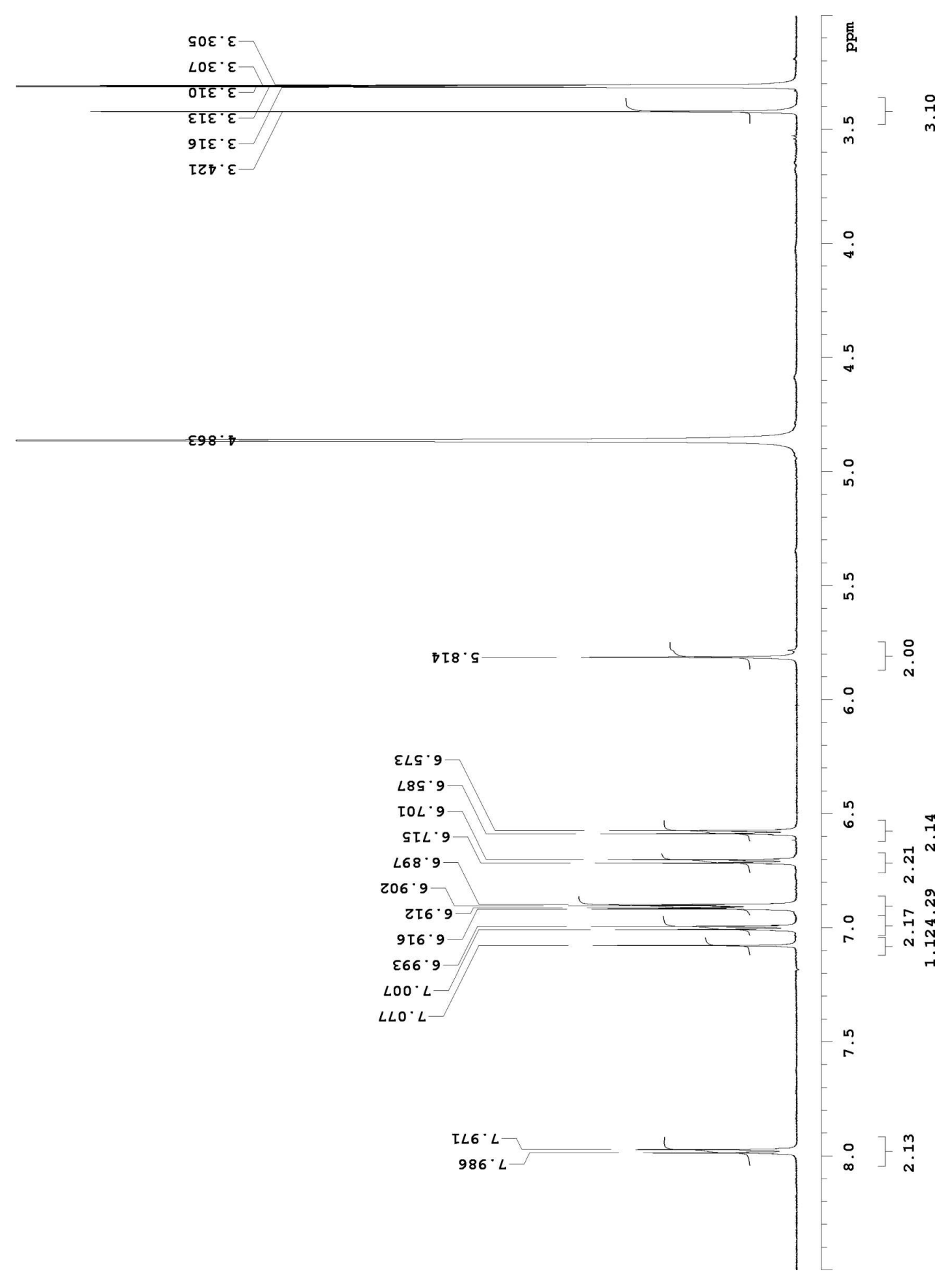

${ }^{1} \mathrm{H}$ NMR spectrum of lamellarin $\theta(\mathbf{1 8 7})\left(600 \mathrm{MHz}, \mathrm{CD}_{3} \mathrm{OD}\right)$ 


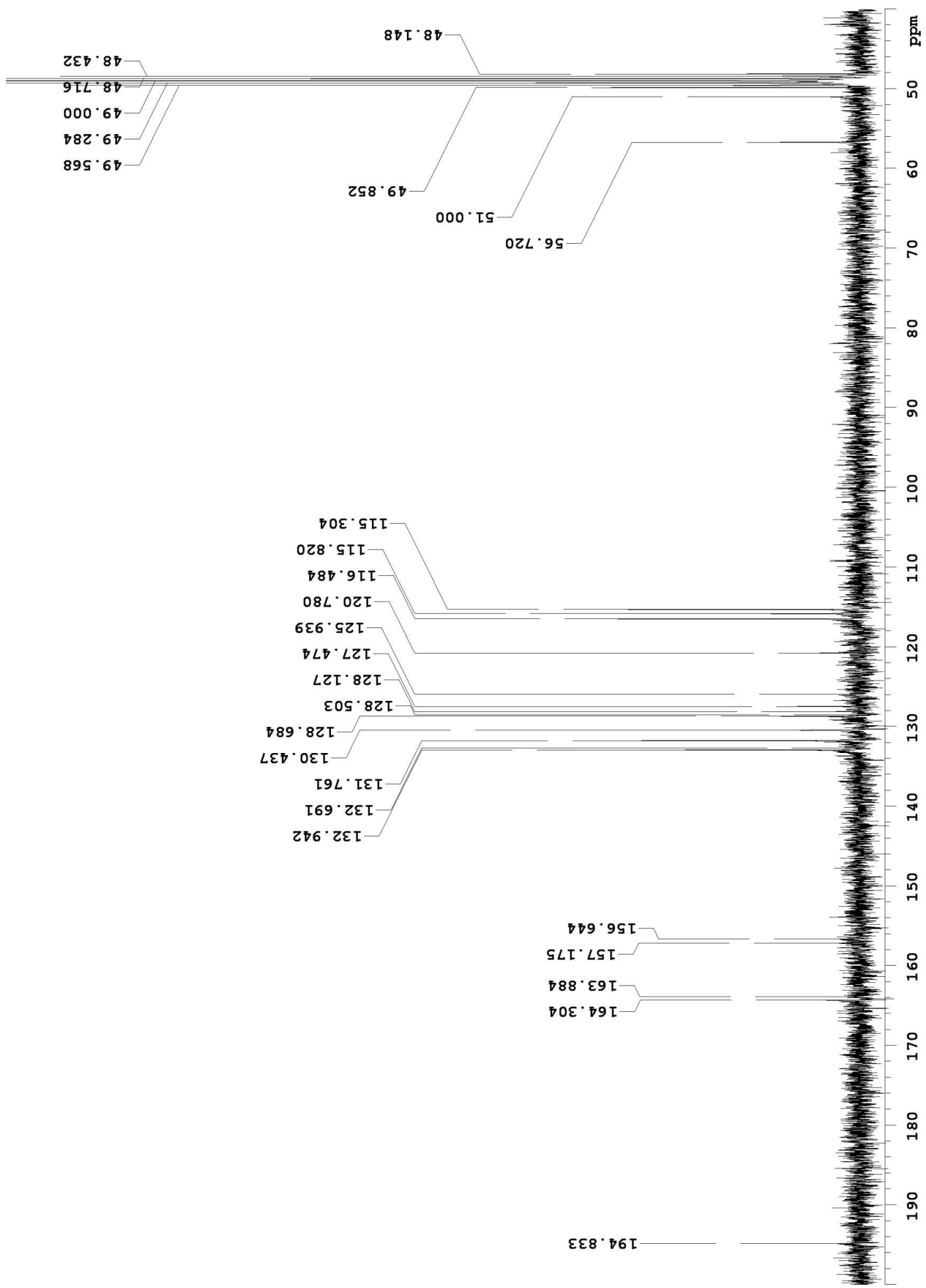

${ }^{13} \mathrm{C}$ NMR spectrum of lamellarin $\theta(\mathbf{1 8 7})\left(300 \mathrm{MHz}, \mathrm{CD}_{3} \mathrm{OD}\right)$ 


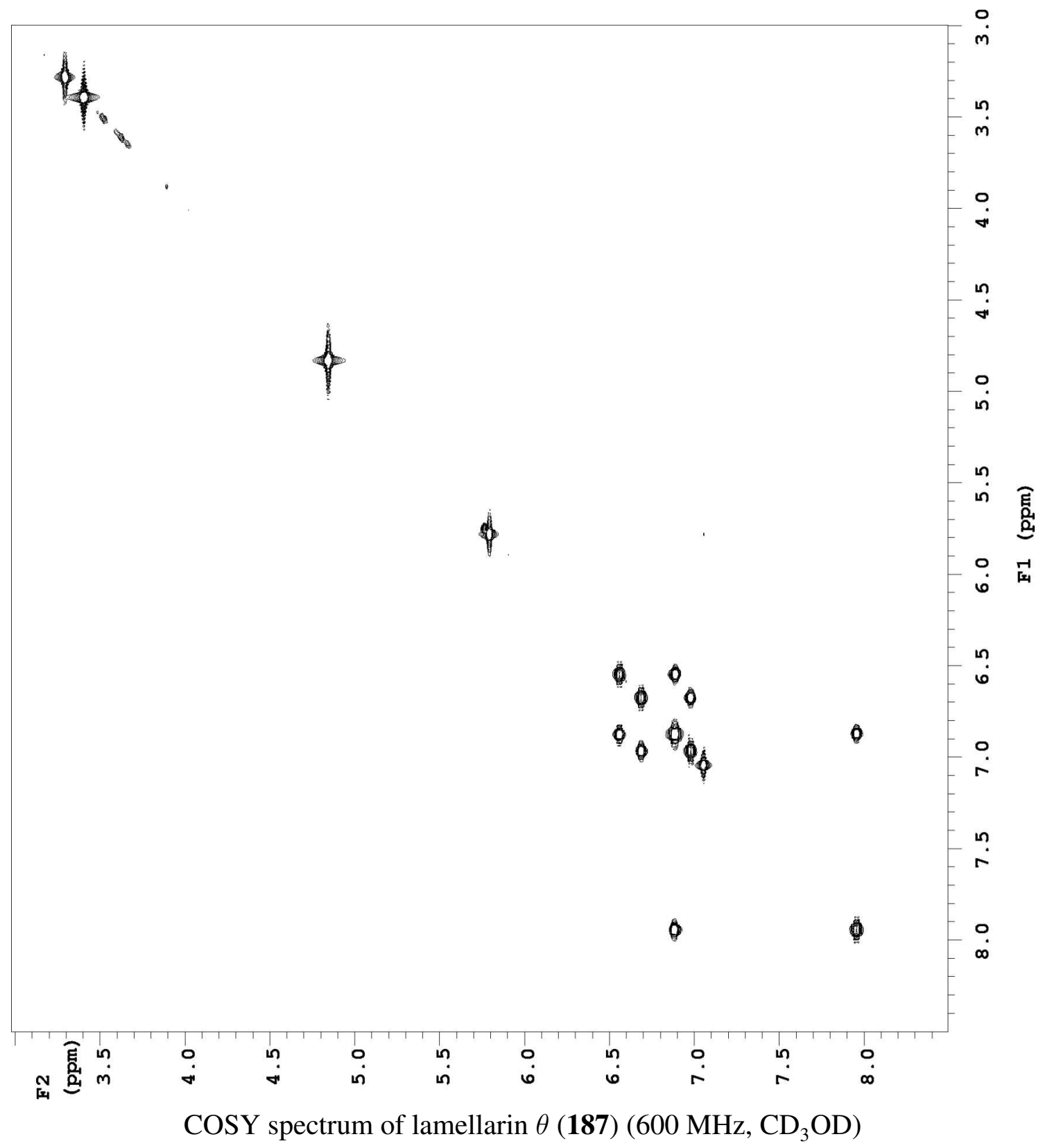




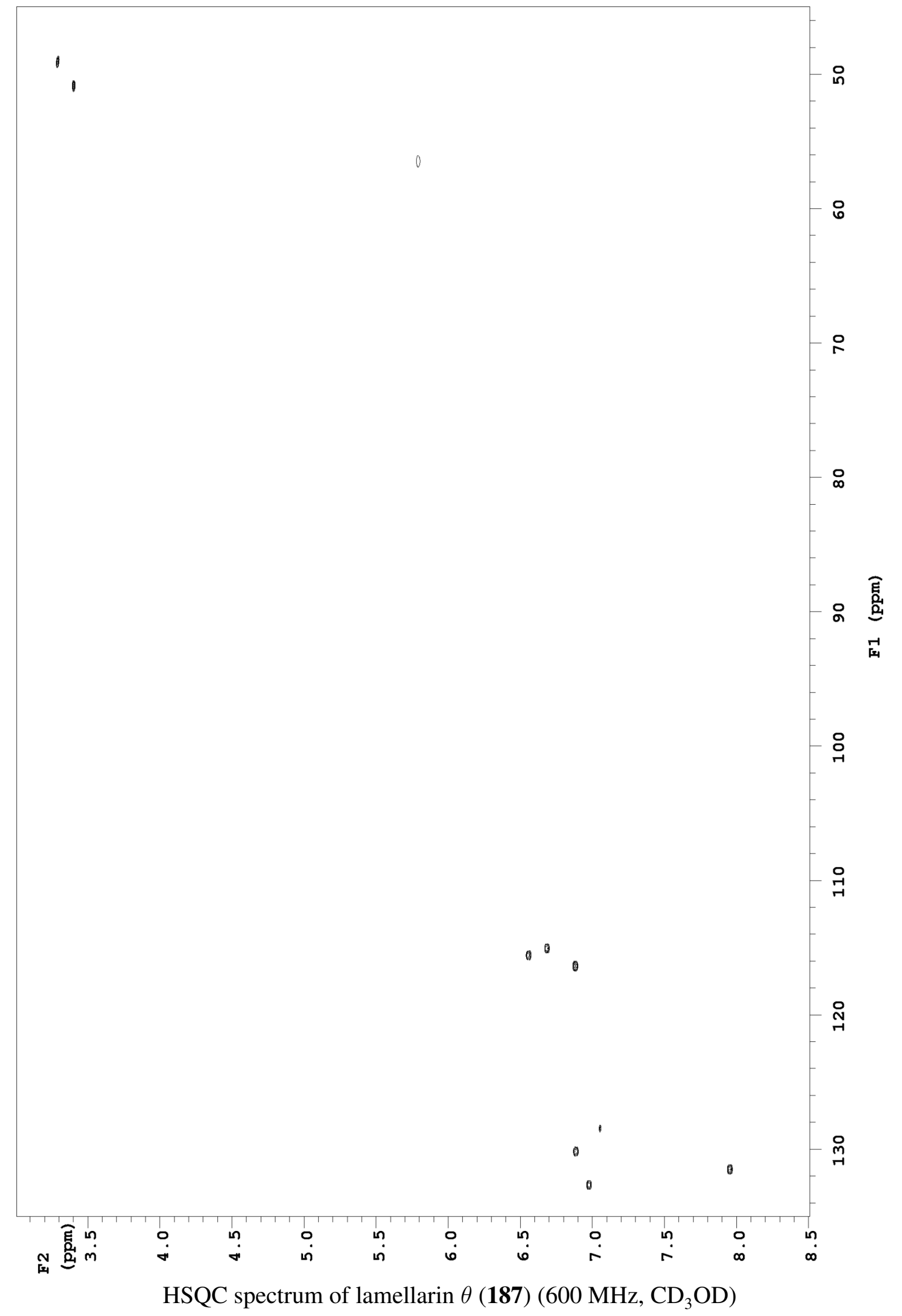




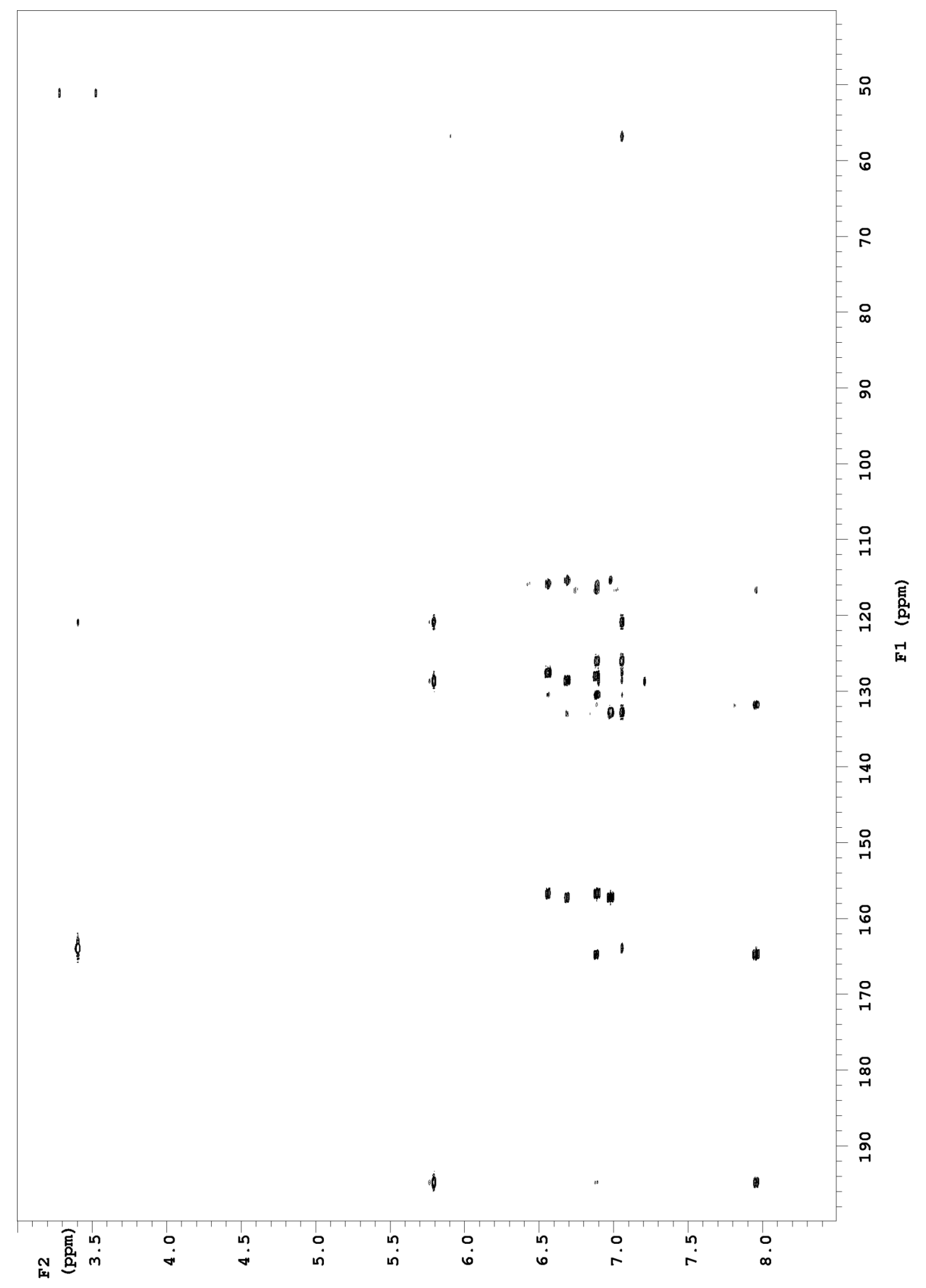

${ }^{1} \mathrm{H}-{ }^{13} \mathrm{C}$ HMBC spectrum of lamellarin $\theta(\mathbf{1 8 7})\left(600 \mathrm{MHz}, \mathrm{CD}_{3} \mathrm{OD}\right)$ 
$\stackrel{\stackrel{n}{N}}{\uparrow}$

$\stackrel{\substack{m \\ i}}{N}$

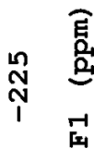

$\stackrel{\text { N }}{\uparrow}$

$\stackrel{\text { ก }}{\stackrel{1}{1}}$

$\stackrel{\text { ㄱ. }}{\text { i }}$

$\stackrel{\text { ก }}{\text { i }}$

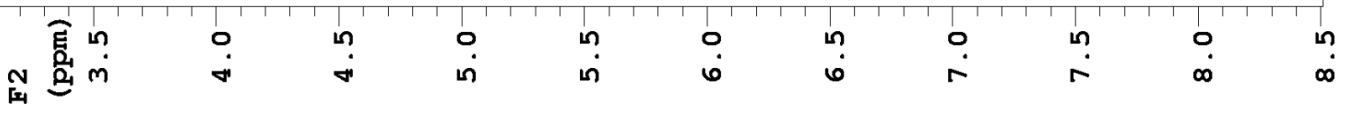

${ }^{1} \mathrm{H}-{ }^{15} \mathrm{~N}$ HMBC spectrum of lamellarin $\theta(\mathbf{1 8 7})\left(600 \mathrm{MHz}, \mathrm{CD}_{3} \mathrm{OD}\right)$ 


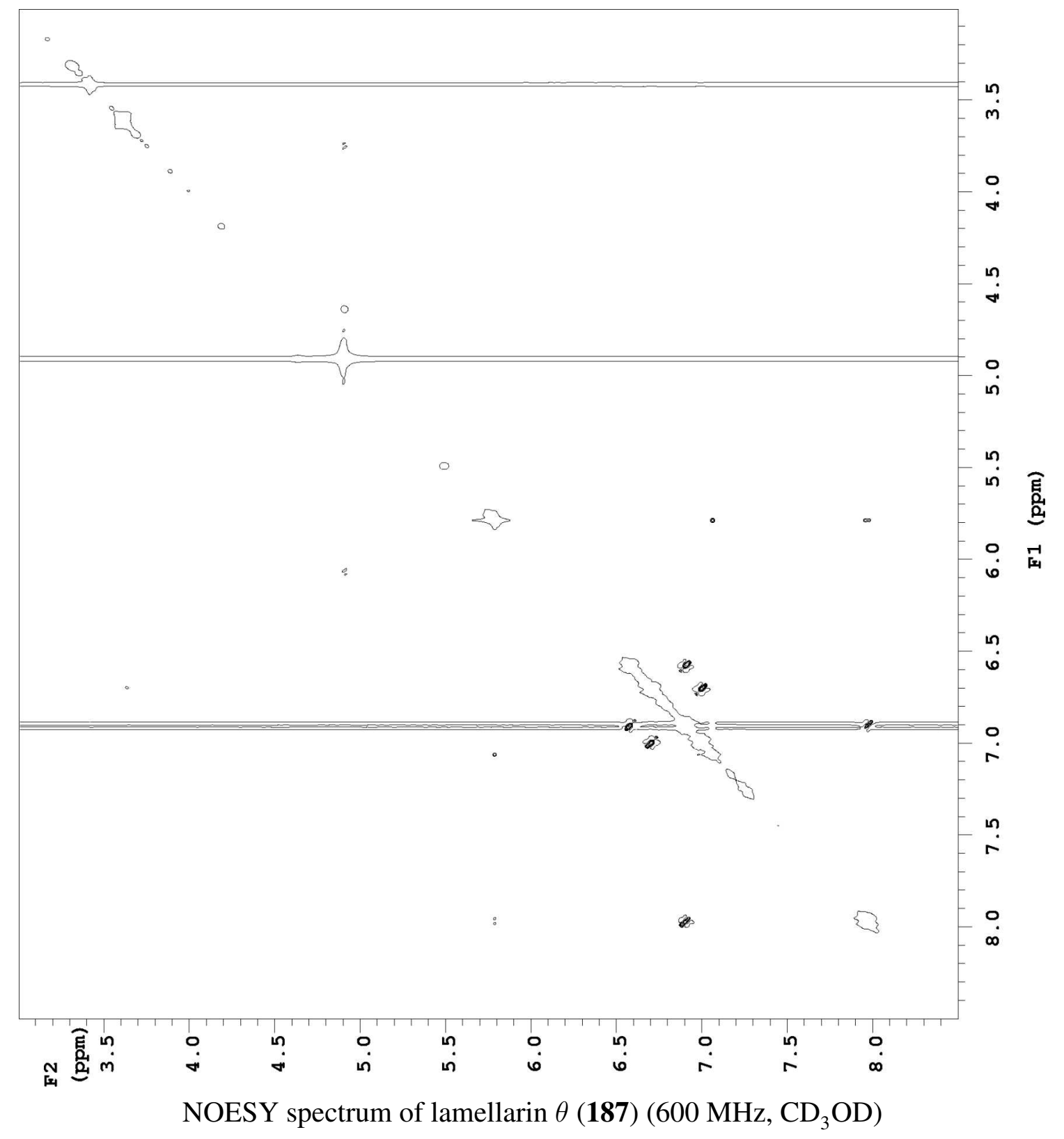




\section{Appendix I}

\section{Lamellarin $\theta \mathbf{4}^{\prime \prime}, \mathbf{4}^{\prime \prime \prime}$-disulfate Spectra}

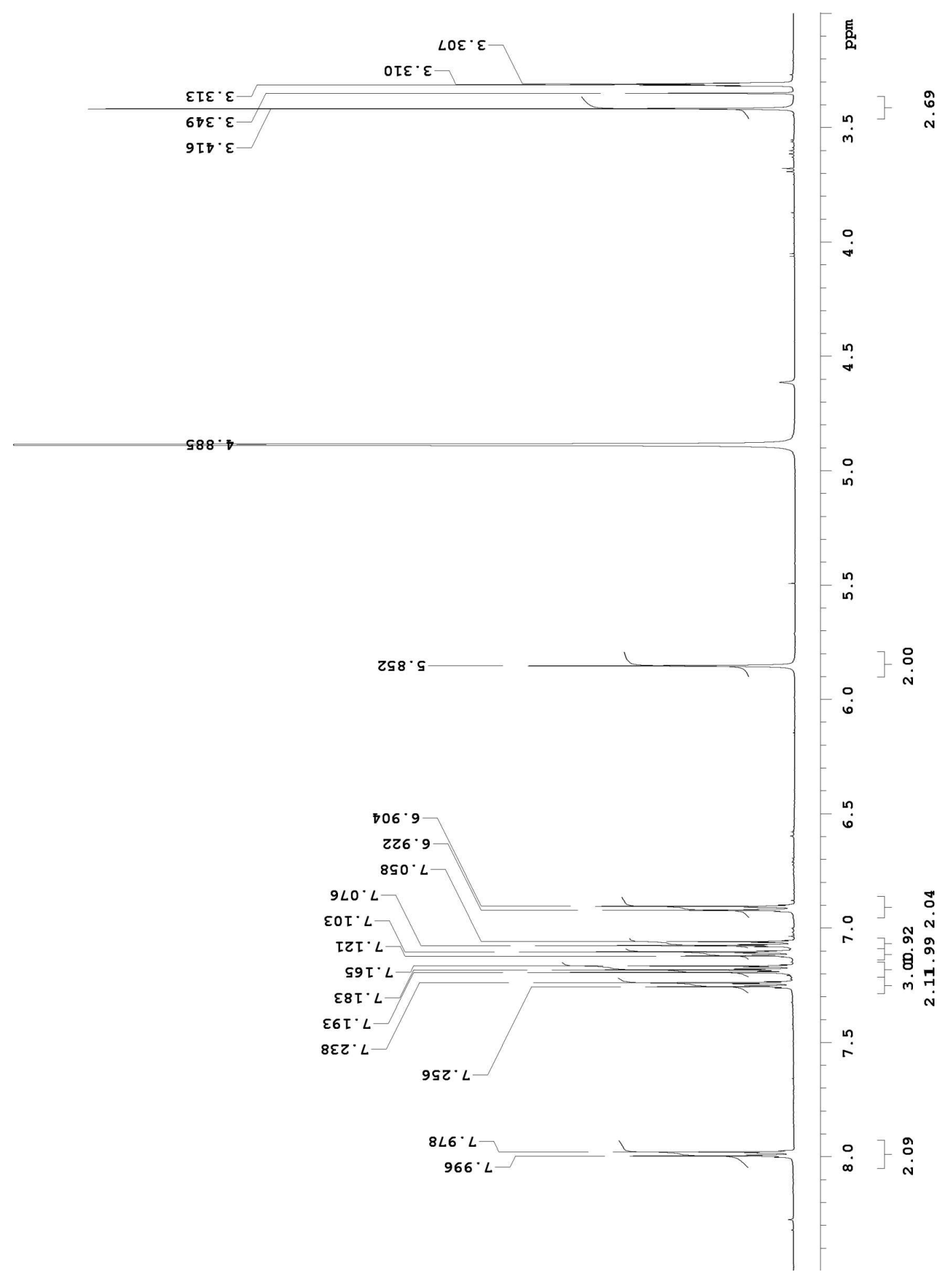

${ }^{1} \mathrm{H}$ NMR spectrum of lamellarin $\theta 44^{\prime \prime}, 4^{\prime \prime \prime}$-disulfate (190) $\left(500 \mathrm{MHz}, \mathrm{CD}_{3} \mathrm{OD}\right)$ 


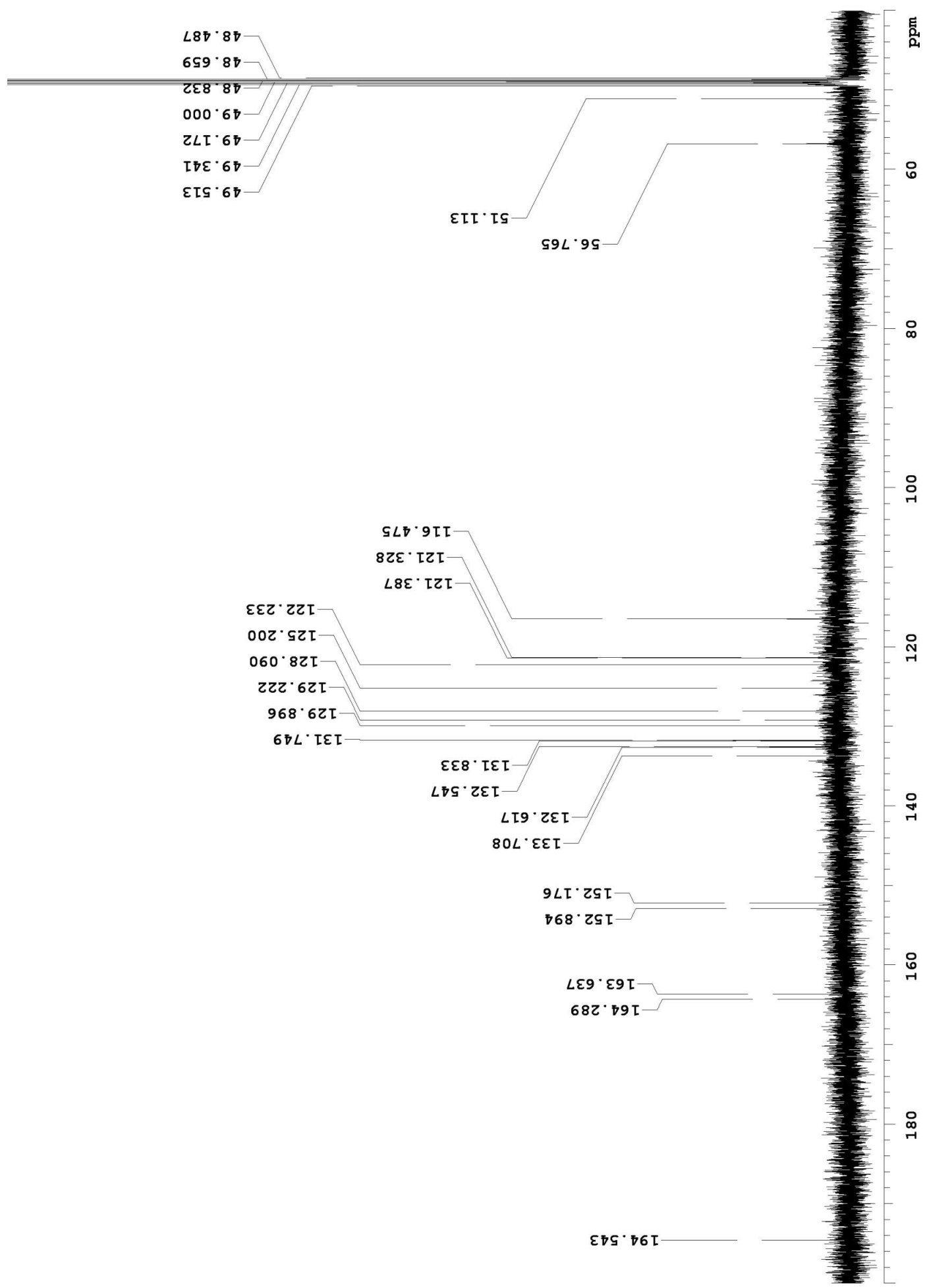

${ }^{13} \mathrm{C}$ NMR spectrum of lamellarin $\theta 4^{\prime \prime}, 4^{\prime \prime \prime}$-disulfate (190) $\left(500 \mathrm{MHz}, \mathrm{CD}_{3} \mathrm{OD}\right)$ 


\section{Lamellarin O 4'"'-sulfate Spectra}

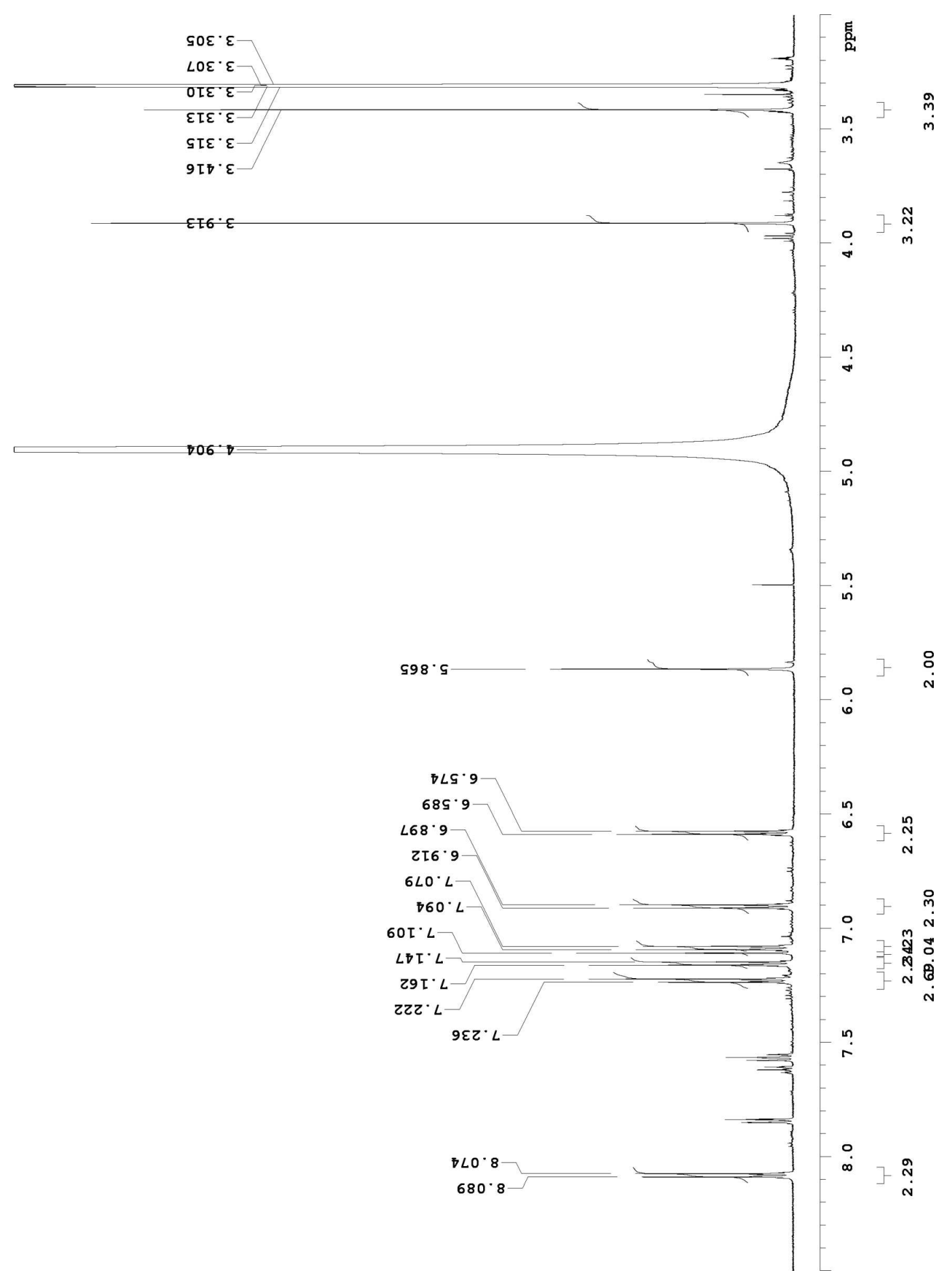

${ }^{1} \mathrm{H}$ NMR spectrum of lamellarin $\mathrm{O} 44^{\prime \prime \prime}$-sulfate (191) $\left(600 \mathrm{MHz}, \mathrm{CD}_{3} \mathrm{OD}\right)$ 


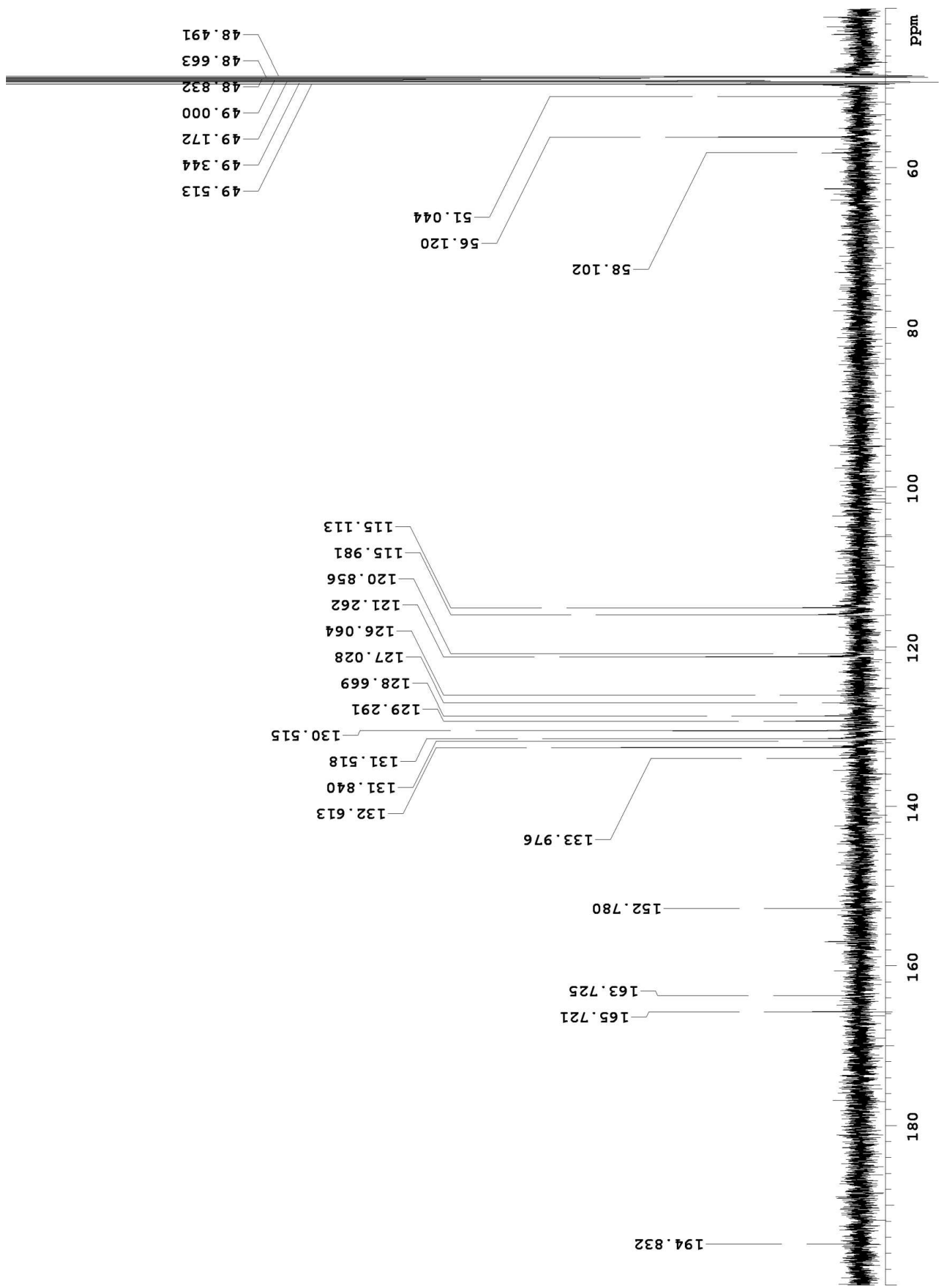

${ }^{13} \mathrm{C}$ NMR spectrum of lamellarin $\mathrm{O} 4$ "'--sulfate (191) $\left(500 \mathrm{MHz}, \mathrm{CD}_{3} \mathrm{OD}\right)$ 


\section{Appendix $K$}

\section{Lamellarin O 4", $4^{\prime \prime \prime}$-disulfate Spectra}

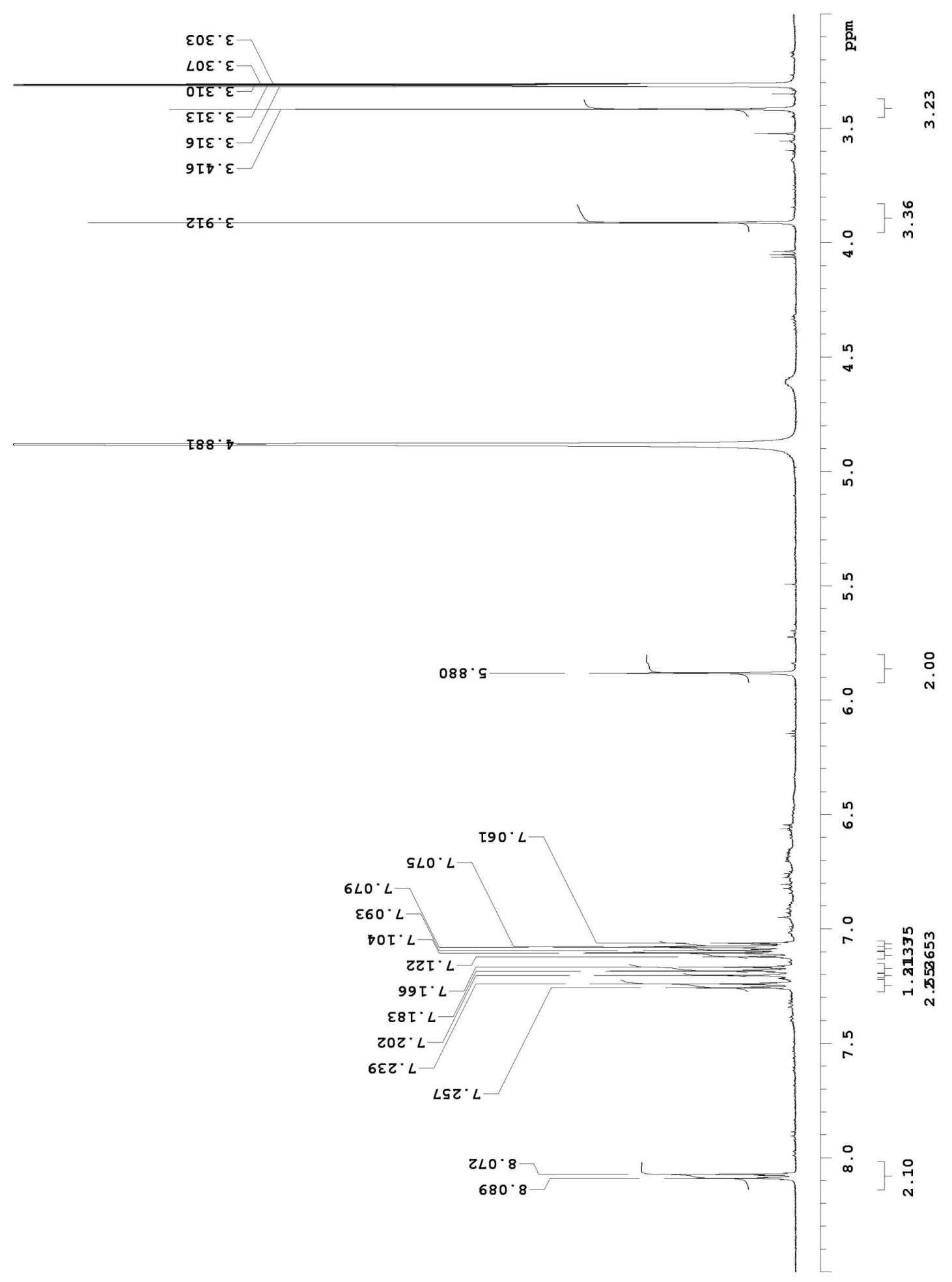

${ }^{1} \mathrm{H}$ NMR spectrum of lamellarin $\mathrm{O} 4^{\prime \prime}, 4^{\prime \prime \prime}$-disulfate (192) $\left(500 \mathrm{MHz}, \mathrm{CD}_{3} \mathrm{OD}\right)$ 


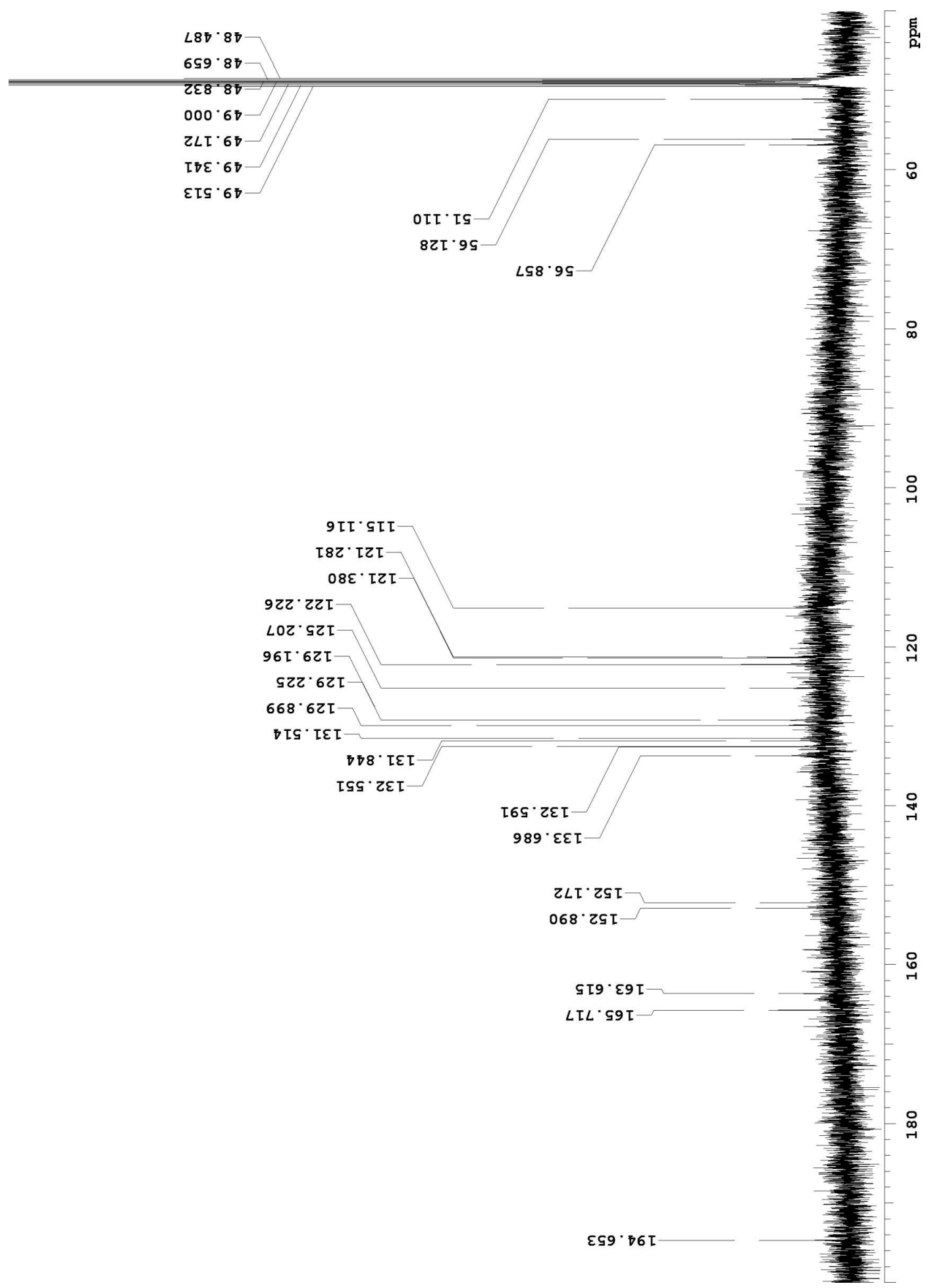

${ }^{13} \mathrm{C}$ NMR spectrum of lamellarin $\mathrm{O} 4^{\prime \prime}, 4^{\prime \prime \prime}$-disulfate (192) $\left(500 \mathrm{MHz}, \mathrm{CD}_{3} \mathrm{OD}\right)$ 


\section{Appendix L}

\section{Lamellarin $\kappa$ Spectra}

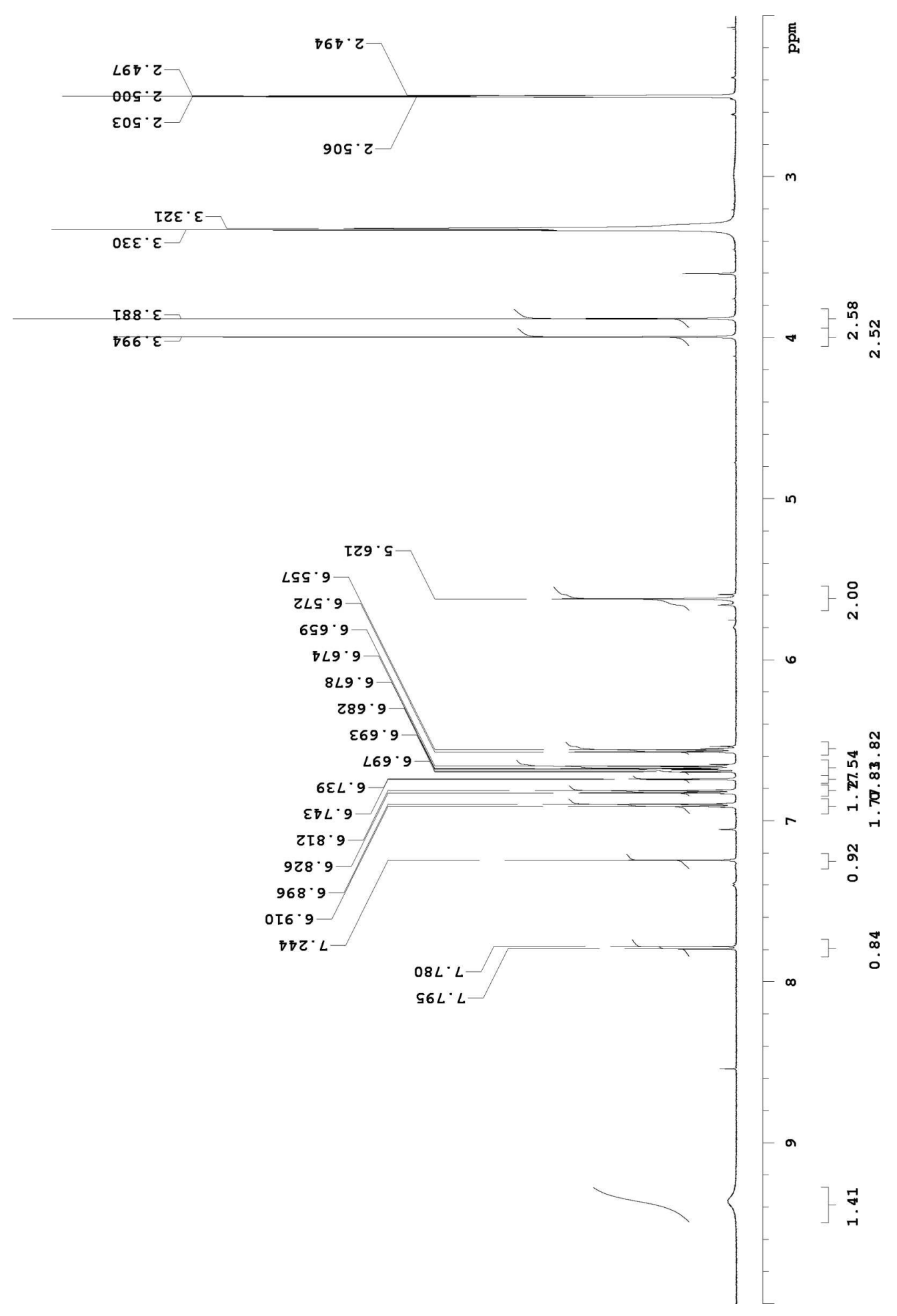

${ }^{1} \mathrm{H}$ NMR spectrum of lamellarin $\kappa(\mathbf{1 8 8})\left(600 \mathrm{MHz}, \mathrm{d}_{6}\right.$-DMSO) 


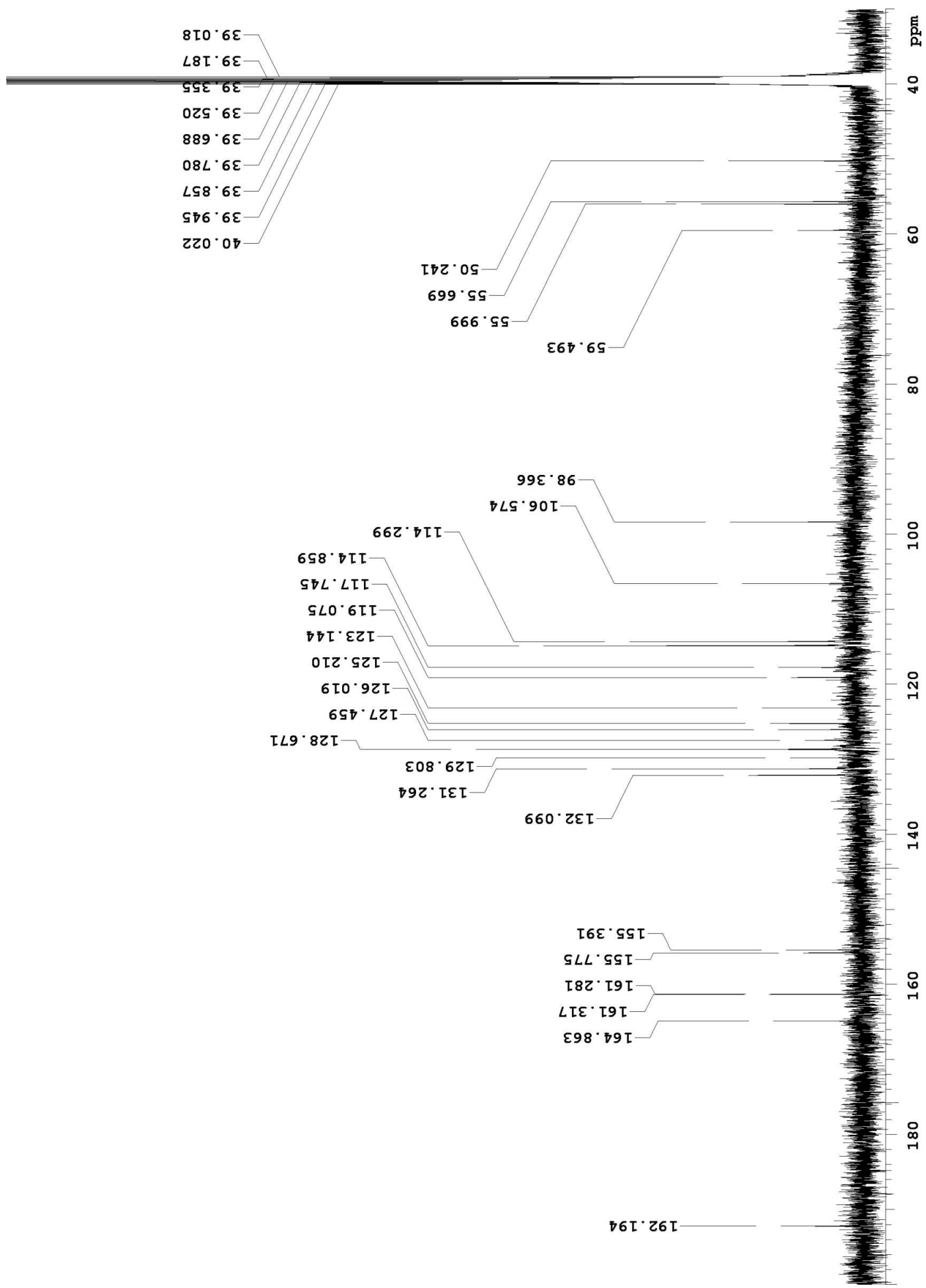

${ }^{13} \mathrm{C}$ NMR spectrum of lamellarin $\kappa(\mathbf{1 8 8})\left(500 \mathrm{MHz}, \mathrm{d}_{6}\right.$-DMSO) 


\section{Lamellarin $\kappa 4^{\prime \prime \prime}$-sulfate Spectra}

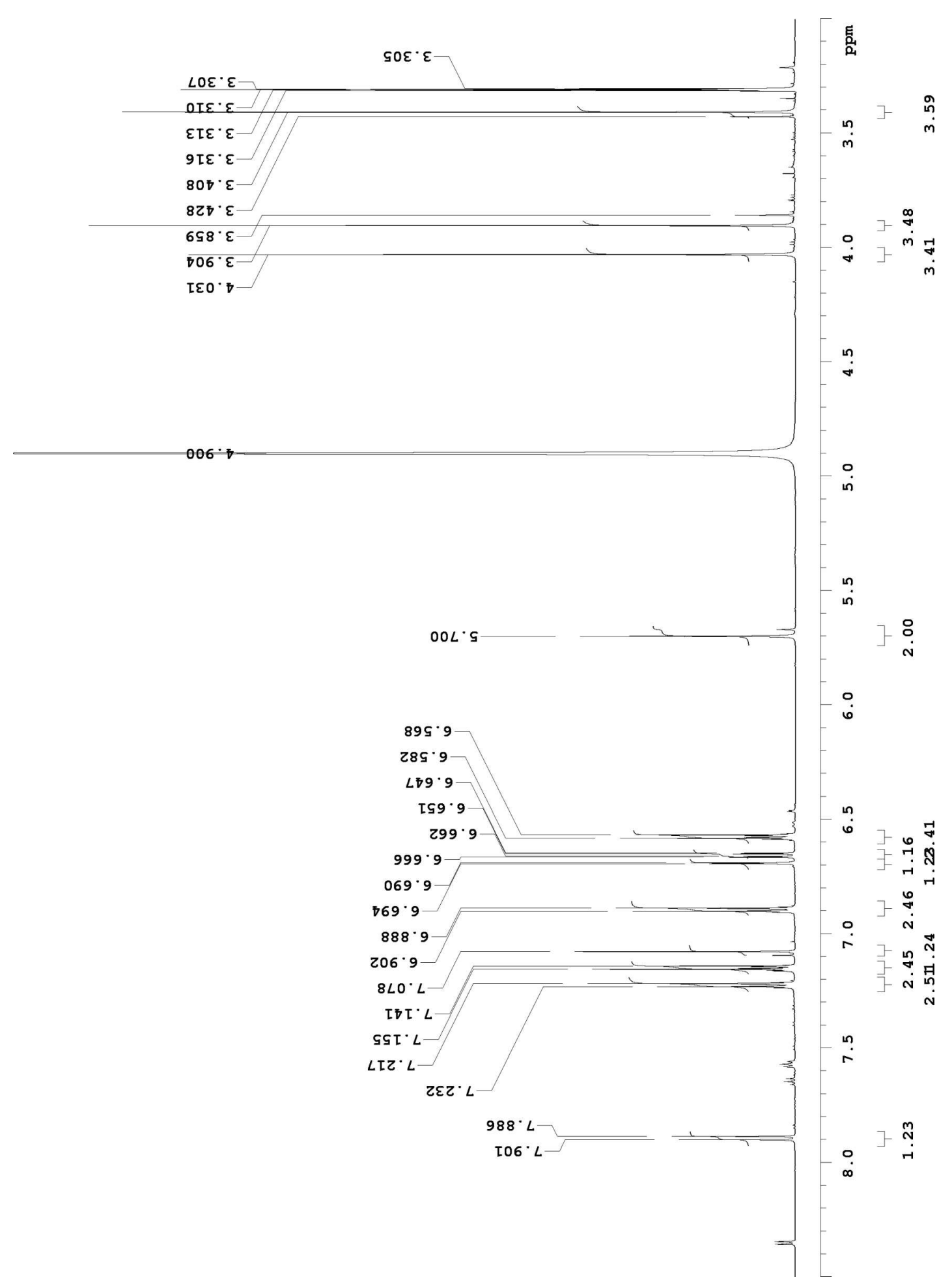

${ }^{1} \mathrm{H}$ NMR spectrum of lamellarin $\kappa 4^{\prime \prime \prime}$-sulfate (193) $\left(600 \mathrm{MHz}, \mathrm{CD}_{3} \mathrm{OD}\right)$ 


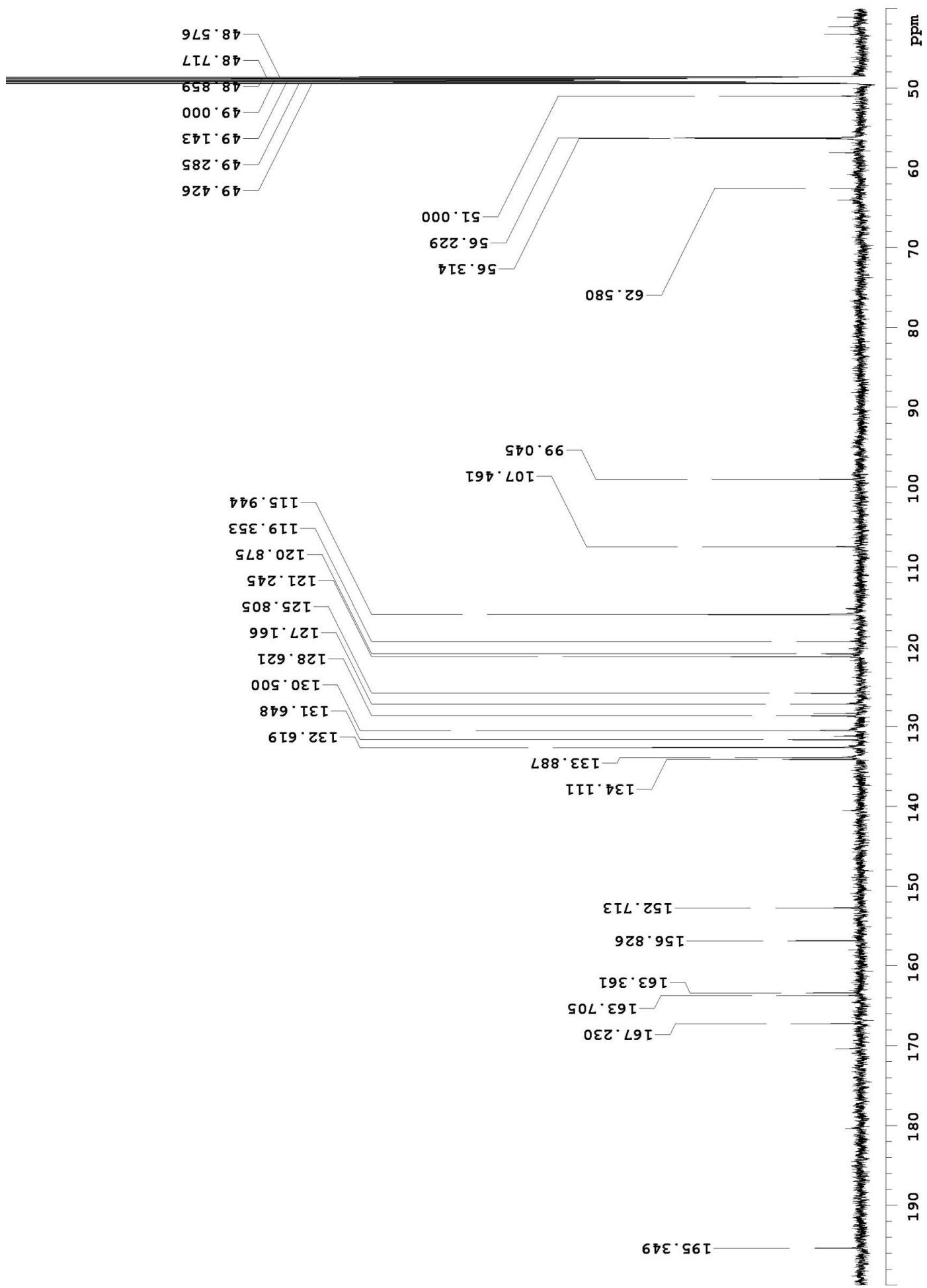

${ }^{13} \mathrm{C}$ NMR spectrum of lamellarin $\kappa 4$ "'I-sulfate $(\mathbf{1 9 3})\left(600 \mathrm{MHz}, \mathrm{CD}_{3} \mathrm{OD}\right)$ 


\section{Lamellarin $\kappa \mathbf{4}^{\prime \prime}, \mathbf{4}^{\prime \prime \prime}$-disulfate Spectra}

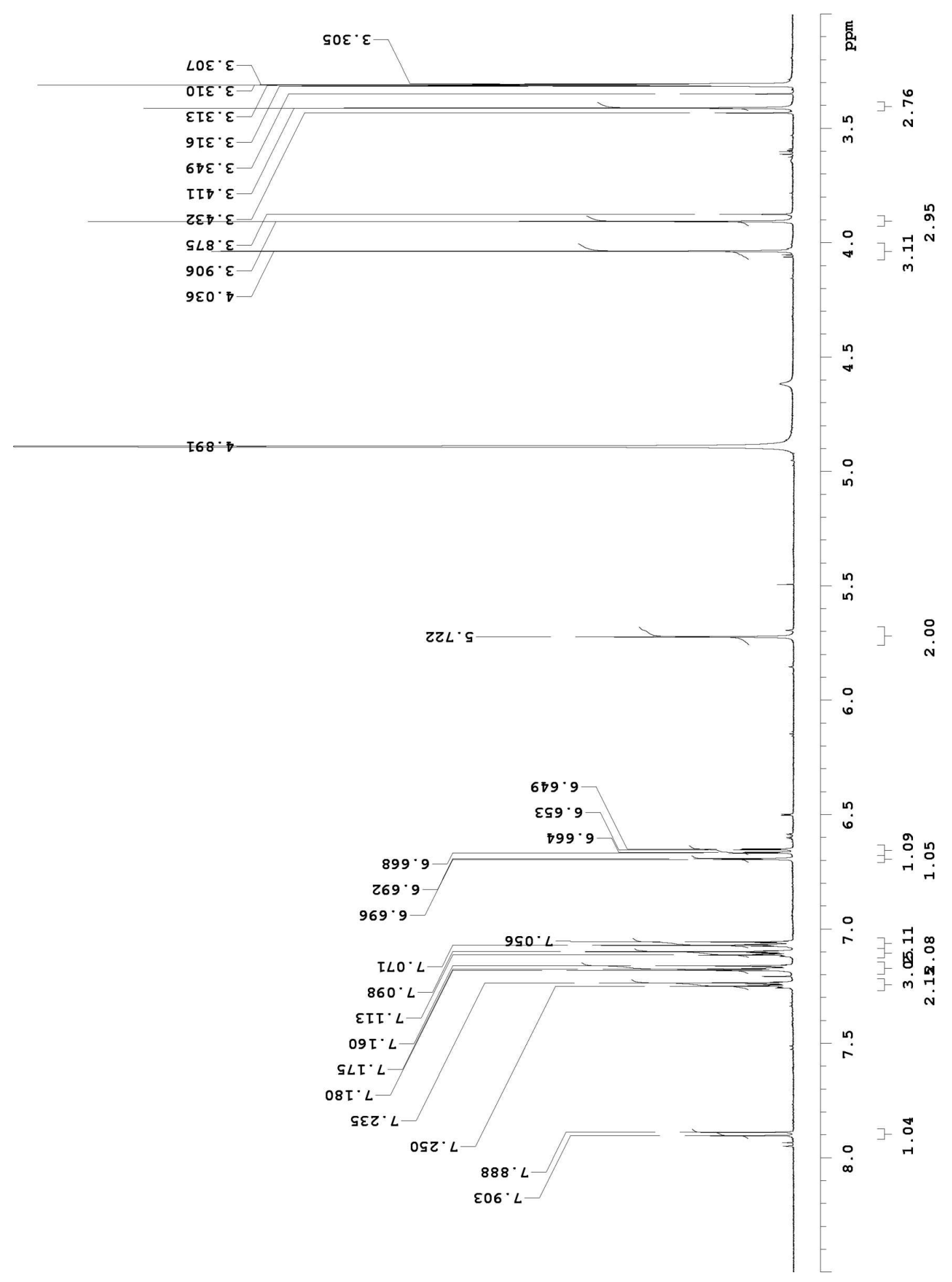

${ }^{1} \mathrm{H}$ NMR spectrum of lamellarin $\kappa 4^{\prime \prime}, 4^{\prime \prime \prime}$-disulfate (194) $\left(600 \mathrm{MHz}, \mathrm{CD}_{3} \mathrm{OD}\right)$ 


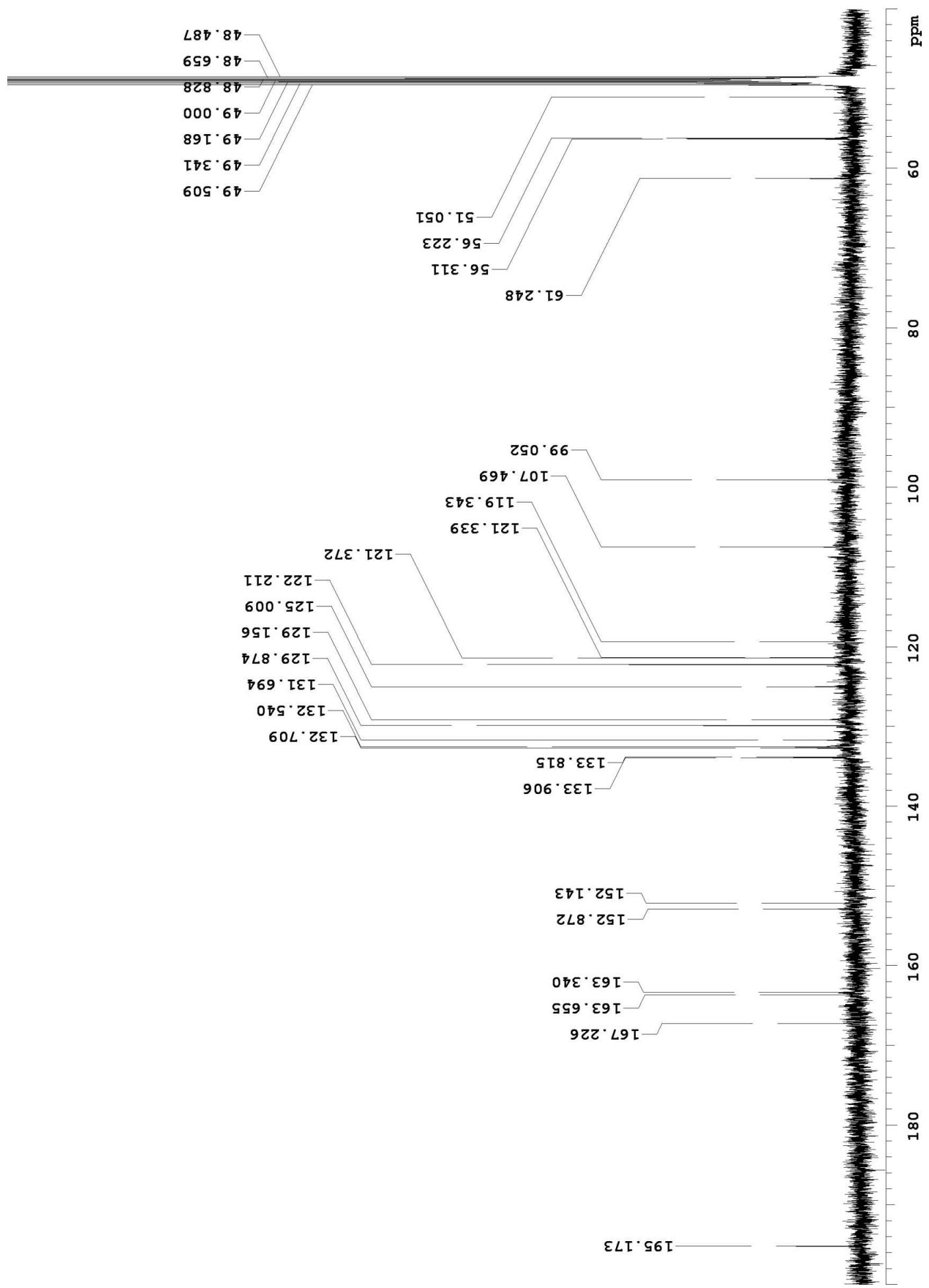

${ }^{13} \mathrm{C}$ NMR spectrum of lamellarin $\kappa 4^{\prime \prime}, 4^{\prime \prime \prime}$-disulfate (194) $\left(500 \mathrm{MHz}, \mathrm{CD}_{3} \mathrm{OD}\right)$ 


\section{Dictyodendrin F Spectra}

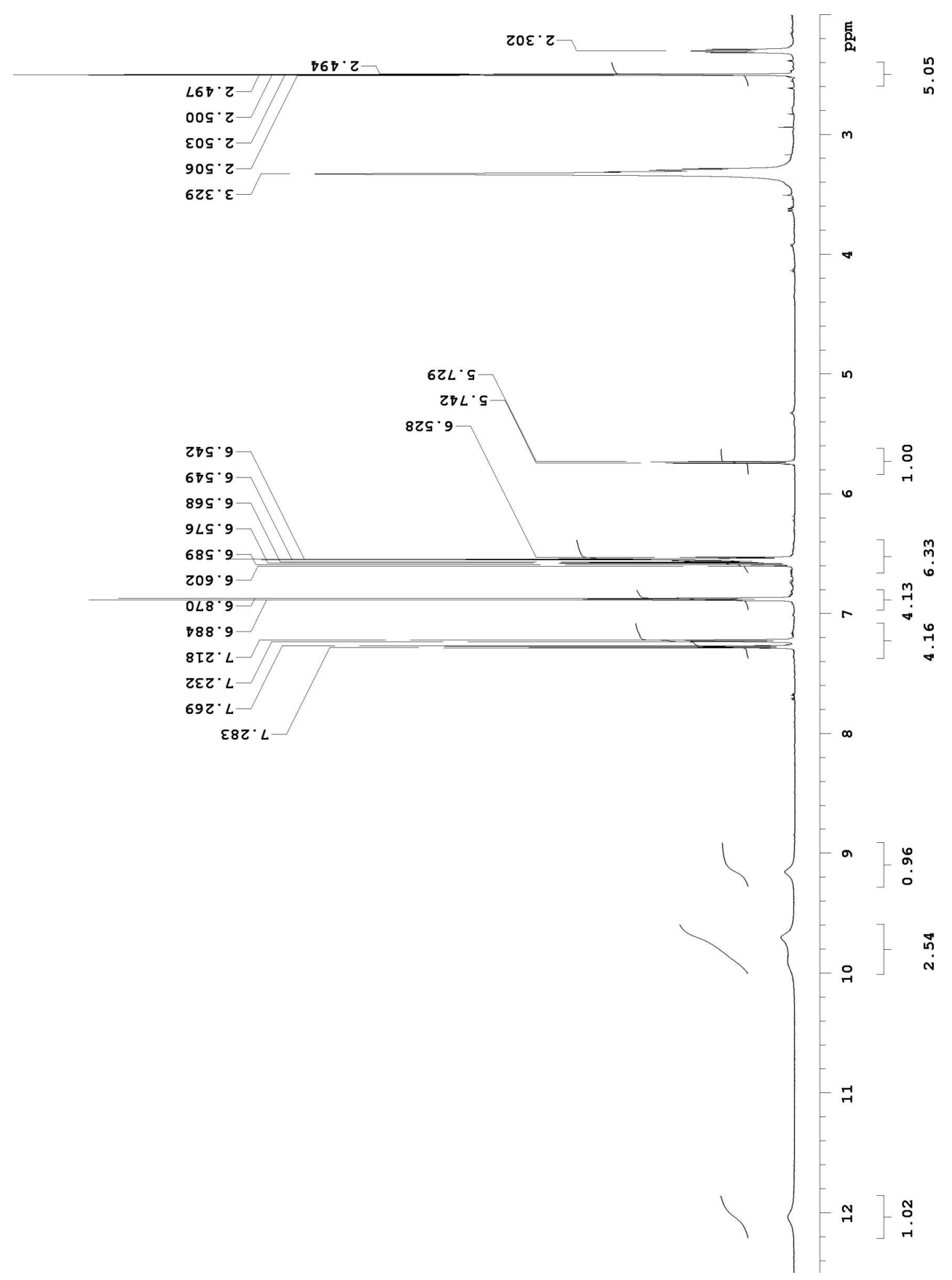

${ }^{1} \mathrm{H}$ NMR spectrum of dictyodendrin $\mathrm{F}(\mathbf{1 9 5})\left(600 \mathrm{MHz}, \mathrm{d}_{6}\right.$-DMSO) 


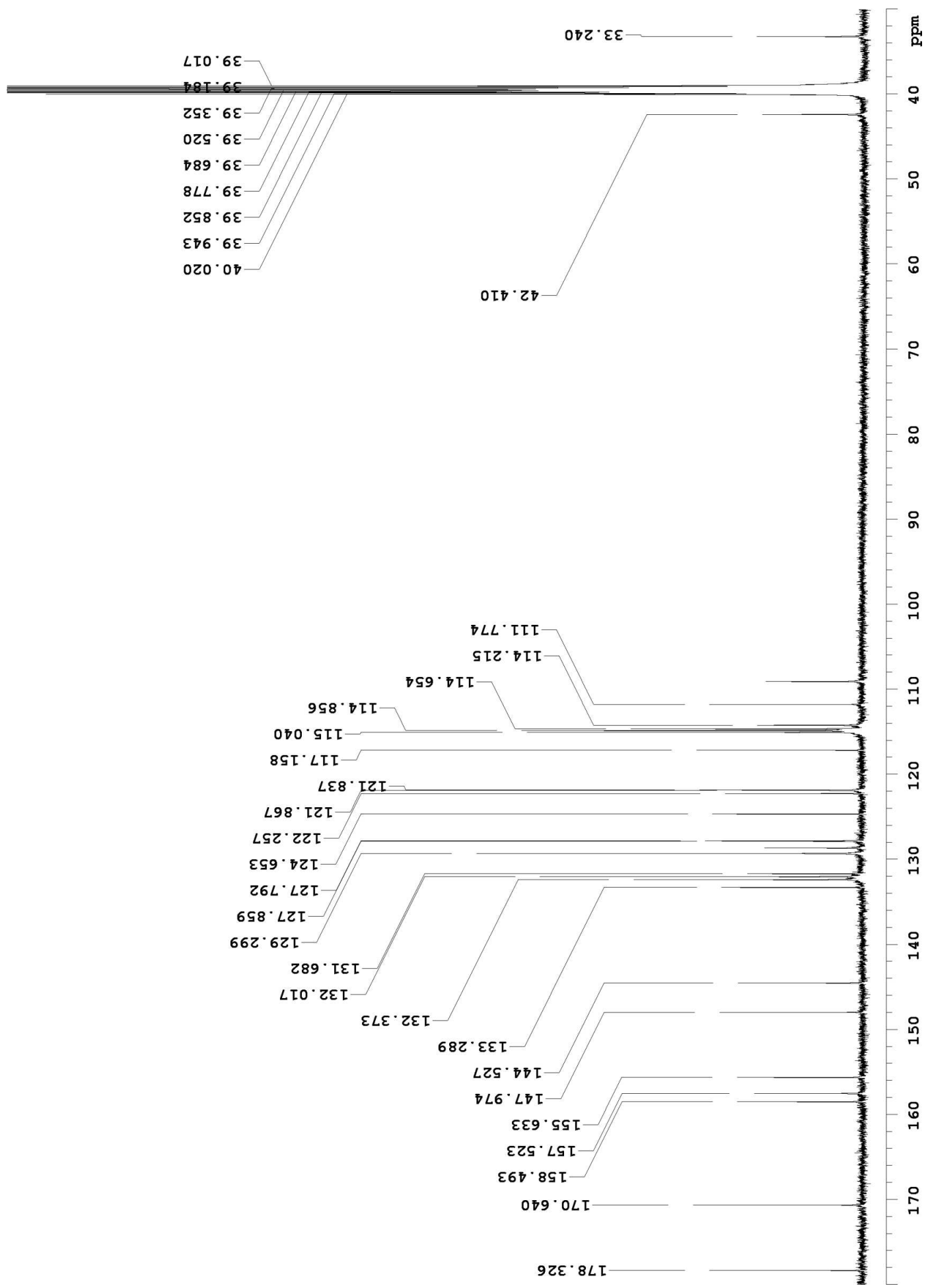

${ }^{13} \mathrm{C}$ NMR spectrum of dictyodendrin $\mathrm{F}(\mathbf{1 9 5})\left(500 \mathrm{MHz}, \mathrm{d}_{6}-\mathrm{DMSO}\right)$ 


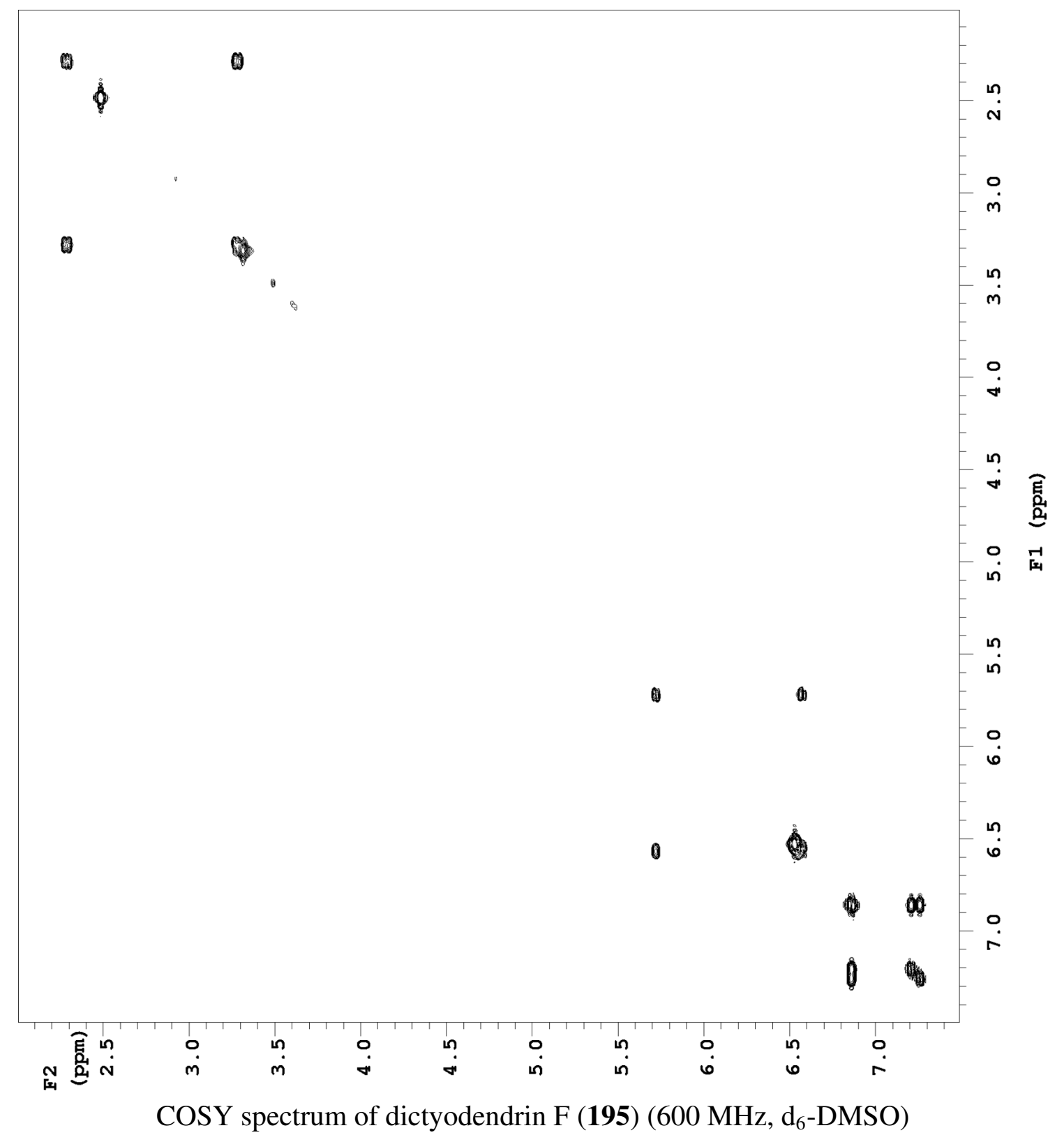




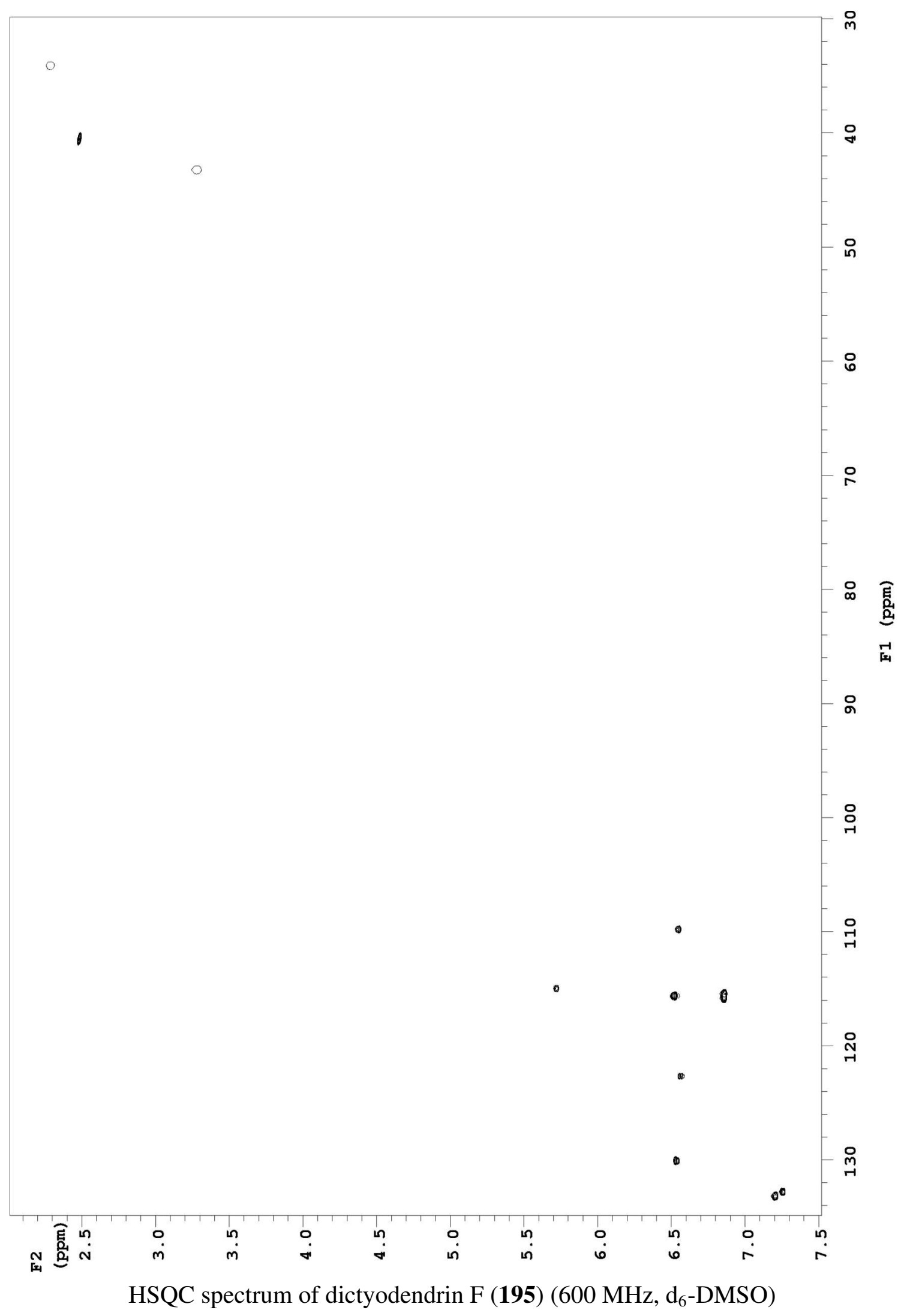




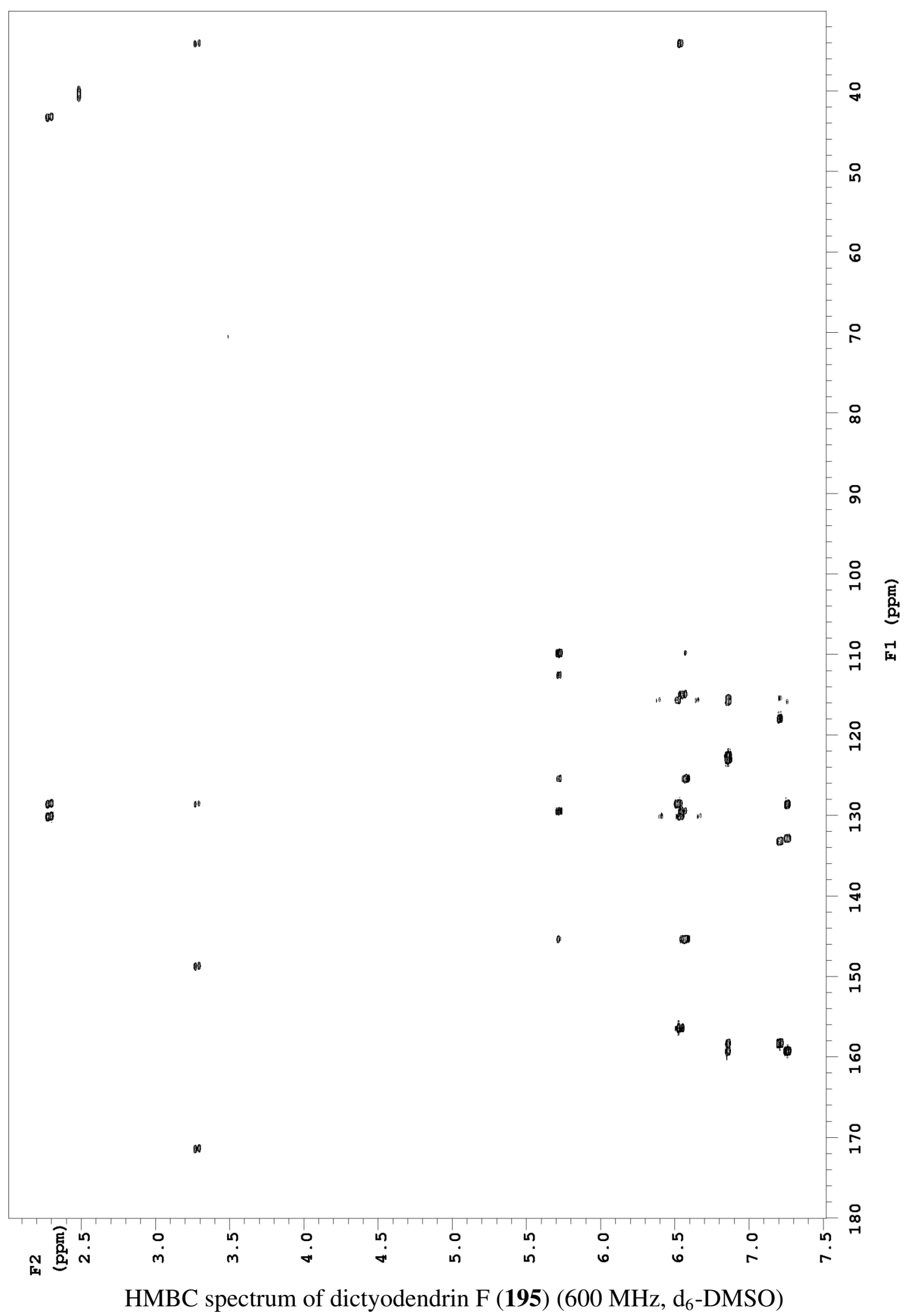




\section{References}

1. Blunt, J. W.; Copp, B. R.; Hu, W.; Munro, M. H.; Northcote, P. T.; Prinsep, M. R. Nat. Prod. Rep. 2007, 24, 31-86. [Cited on page 1]

2. Blunt, J. W.; Copp, B. R.; Munro, M. H.; Northcote, P. T.; Prinsep, M. R. Nat. Prod. Rep. 2003, 20, 1-48. [Cited on page 1]

3. Blunt, J. W.; Copp, B. R.; Munro, M. H.; Northcote, P. T.; Prinsep, M. R. Nat. Prod. Rep. 2004, 21, 1-49. [Cited on page 1]

4. Blunt, J. W.; Copp, B. R.; Munro, M. H.; Northcote, P. T.; Prinsep, M. R. Nat. Prod. Rep. 2005, 22, 15-61. [Cited on pages 1 and 3]

5. Systema Porifera: A Guide to the Classification of Sponges, 1st ed.; Hooper, J. N. A., van Soest, R. W. M., Eds.; Klewer Academic/Plenum: New York, 2002. [Cited on pages 1, 2, 11, 60, 73 and 96]

6. Bergquist, P. R. Sponges; Hutchison \& Co (Publishers) Ltd.: London, 1978. [Cited on pages 1 and 72$]$

7. Andersen, R. J.; Williams, D. E. Pharmaceuticals from the Sea; The Royal Society of Chemistry: London, 2000. [Cited on page 1]

8. Koehn, F. E.; Carter, G. T. Nat. Rev. Drug Discov. 2005, 4, 206-220. [Cited on page 2]

9. Paterson, I.; Anderson, E. A. Science 2005, 310, 451-453. [Cited on pages 2 and 3]

10. Cragg, G. M.; Newman, D. J. Pure Appl. Chem. 2005, 77, 7-24. [Cited on pages 2 and 3]

11. Hirata, Y.; Uemura, D. Pure Appl. Chem. 1986, 58, 701-710. [Cited on page 2]

12. Martin, G. E.; Hadden, C. E. J. Nat. Prod. 2000, 63, 543-585. [Cited on pages 3 and 4]

13. Marek, R.; Lyčka, A. Curr. Org. Chem. 2002, 6, 35-66. [Cited on pages 4, 90, 104 and 118]

14. Harris, R. K.; Becker, E. D.; de Menezes, S. M. C.; Goodfellow, R.; Granger, P. Magn. Reson. Chem. 2002, 40, 489-505. [Cited on pages 4 and 162]

15. West, L. M.; Northcote, P. T.; Battershill, C. N. Aust. J. Chem. 1998, 51, 1097-1102. [Cited on pages 4,8 and 10]

16. West, L. M. The Isolation of Secondary Metabolites from New Zealand Marine Sponges, Ph.D. thesis, Victoria University of Wellington, New Zealand, 2001. [Cited on pages 4, 10, 15, 20, 22, 28, 30 and 58]

17. Moraes, G. Isolation and Structure Elucidation of Novel, Anti-inflammatory Secondary Metabolites from New Zealand Marine Invertebrates, Ph.D. thesis, Victoria University of Wellington, New Zealand, 2006. [Cited on pages 4 and 12]

18. Merritt, A. T.; Ley, S. V. Nat. Prod. Rep. 1992, 243-287. [Cited on pages 6, 7, 9 and 10] 
19. SciFinder Scholar 2006, American Chemical Society. [Cited on page 6]

20. Banerjee, H. N. Science and Culture 1936, 2, 163. [Cited on page 6]

21. Sim, G. A.; Hamor, T. A.; Paul, I. C.; Robertson, J. M. Proc. Chem. Soc. 1961, 75-76. [Cited on page 6]

22. Rogers, D.; Ünal, G. G.; Williams, D. J.; Ley, S. V. J. Chem. Soc., Chem. Commun. 1979, 3, 97-99. [Cited on page 6]

23. Akhila, A.; Rani, K.; Thakur, R. S. Phytochemistry 1991, 30, 2573-2576. [Cited on page 6]

24. Sato, A.; Kurabayashi, M.; Nagai, H.; Ogiso, A.; Mishima, H. Tetrahedron Lett. 1970, 13, 1095-1098. [Cited on page 7]

25. de Pascual Teresa, J.; Urones, J. G.; Marcos, I. S.; Bermejo, F.; Basabe, P. Phytochemistry 1983, 22, 2783-2785. [Cited on page 7]

26. Asakawa, Y.; Lin, X.; Tori, M.; Kondo, K. Phytochemistry 1990, 29, 2597-2603. [Cited on page 7]

27. Capon, R. J.; Faulkner, D. J. J. Am. Chem. Soc. 1984, 106, 1819-1822. [Cited on page 7]

28. Nakamura, H.; Wu, H.; Ohizumi, Y.; Hirata, Y. Tetrahedron Lett. 1984, 25, 29892992. [Cited on pages 7 and 8]

29. Ishida, K.; Ishibashi, M.; Shigemori, H.; Sasaki, T.; Kobayashi, J. Chem. Pharm. Bull. 1992, 40, 766-7. [Cited on page 7]

30. Fu, X.; Schmitz, F. J.; Tanner, R. S.; Kelly-Borges, M. J. Nat. Prod. 1998, 61, 548550. [Cited on page 7]

31. Shoji, N.; Umeyama, A.; Teranaka, M.; Arihara, S. J. Nat. Prod. 1996, 59, 448-450. [Cited on page 7]

32. Rudi, A.; Kashman, Y. J. Nat. Prod. 1992, 55, 1408-1414. [Cited on page 7]

33. Bassett, S.; Ovenden, S. P. B.; Gable, R. W.; Capon, R. J. Aust. J. Chem. 1997, 50, 1137-1143. [Cited on page 7]

34. Yosief, T.; Rudi, A.; Kashman, Y. J. Nat. Prod. 2000, 63, 299-304. [Cited on pages 8 and 24]

35. Rudi, A.; Shalom, H.; Schleyer, M.; Benayahu, Y.; Kashman, Y. J. Nat. Prod. 2004, 67, 106-109. [Cited on pages 8 and 24]

36. Rudi, A.; Aknin, M.; Gaydou, E.; Kashman, Y. J. Nat. Prod. 2004, 67, 1932-1935. [Cited on pages 8, 19 and 24]

37. Northcote, P. T.; West, L. M.; Berridge, M. V. Unpublished data. [Cited on page 9]

38. Tan, A. S.; Berridge, M. V. J. Immunol. Methods 2000, 238, 59-68. [Cited on page 9]

39. Ortega, A.; Blount, J. F.; Manchand, P. S. J. Chem. Soc., Perkin Trans. 1 1982, 10, 2505-2508. [Cited on page 9] 
40. Valdés III, L. J. J. Psychoactive Drugs 1994, 26, 277-283. [Cited on page 9]

41. Roth, B. L.; Baner, K.; Westkaemper, R.; Siebert, D.; Rice, K. C.; Steinberg, S.; Ernsberger, P.; Rothman, R. B. Proc. Natl. Acad. Sci. U.S.A. 2002, 99, 11934 11939. [Cited on page 9]

42. Hansen, P. E. Prog. Nucl. Magn. Reson. Spectrosc. 1981, 14, 175-296. [Cited on pages 16 and 104]

43. Ansell, S. M.; Pegel, K. H.; Taylor, D. A. H. Phytochemistry 1993, 32, 937-943. [Cited on page 17]

44. Shimbo, K.; Tsuda, M.; Fukushi, E.; Kawabata, J.; Kobayashi, J. Tetrahedron 2000, 56, 7923-7926. [Cited on page 19]

45. Guella, G.; Mancini, I.; Pietra, F. J. Chem. Soc., Chem. Commun. 1986, 77-78. [Cited on page 24]

46. Guella, G.; Mancini, I.; Pietra, F. Helv. Chim. Acta 1987, 70, 1050-1062. [Cited on page 24]

47. Cerda-García-Rojas, C. M.; Faulkner, D. J. Tetrahedron 1995, 51, 1087-1092. [Cited on page 24]

48. Czuba, I. R.; Zammit, S.; Rizzacasa, M. A. Org. Biomol. Chem. 2003, 1, 2044-2056. [Cited on page 24]

49. Capon, R. J.; Skene, C.; Liu, E. H.; Lacey, E.; Gill, J. H.; Heiland, K.; Friedel, T. Nat. Prod. Res. 2004, 18, 305-309. [Cited on page 24]

50. Perry, N. B.; Ellis, G.; Blunt, J. W.; Haystead, T. A. J.; Lake, R. J.; Munro, M. H. G. Nat. Prod. Lett. 1998, 11, 305-312. [Cited on page 24]

51. Keyzers, R. A. The Isolation of Biologically Active Secondary Metabolites from New Zealand Marine Organisms, Ph.D. thesis, Victoria University of Wellington, New Zealand, 2003. [Cited on pages 31, 36, 38 and 58]

52. Minale, L.; Riccio, R.; Sodano, G. Tetrahedron Lett. 1974, 38, 3401-3404. [Cited on page 35]

53. de Rosa, S.; Minale, L.; Riccio, R.; Sodano, G. J. Chem. Soc., Perkin Trans. 1 1976, 1408-1414. [Cited on page 35]

54. Gauvin, A.; Smadja, J.; Aknin, M.; Faure, R.; Gaydou, E. Can. J. Chem. 2000, 78, 986-992. [Cited on page 36]

55. Shroeder, F. C.; Gibson, D. M.; Churchill, A. C. L.; Sojikul, P.; Wursthorn, E. J.; Krasnoff, S. B.; Clardy, J. Angew. Chem. Int. Ed. 2007, 46, 901-904. [Cited on page 38]

56. Weininger, D. J. Chem. Inf. Comput. Sci. 1988, 28, 31-36. [Cited on page 48]

57. West, L. M.; Northcote, P. T.; Battershill, C. N. J. Org. Chem. 2000, 65, 445-449. [Cited on page 52]

58. Hood, K. A.; West, L. M.; Rouwé, B.; Northcote, P. T.; Berridge, M. V.; Wakefield, S. J.; Miller, J. H. Cancer Res. 2002, 62, 3356-3360. [Cited on page 52] 
59. Williams, P. G.; Yoshida, W. Y.; Moore, R. E.; Paul, V. J. J. Nat. Prod. 2002, 65, 29-31. [Cited on pages 55 and 58]

60. Igarashi, T.; Satake, M.; Yasumoto, T. J. Am. Chem. Soc. 1999, 121, 8499-8511. [Cited on page 58]

61. Fake, A. D. Sesquiterpenoids from the New Zealand Marine Sponge Dysidea sp., Ph.D. thesis, Victoria University of Wellington, New Zealand, 1999. [Cited on page 58]

62. Tsukamoto, S.; Matsunaga, S.; Fusetani, N.; van Soest, R. W. M. J. Nat. Prod. 1998, 61, 1374-1378. [Cited on page 58]

63. Kan, Y.; Uemura, D.; Hirata, Y.; Ishiguro, M.; Iwashita, T. Tetrahedron Lett. 2001, 42, 3197-3202. [Cited on page 58]

64. Kobayashi, J.; Shigemori, H.; Ishibashi, M.; Yamasu, T.; Hirota, H.; Sasaki, T. J. Org. Chem. 1991, 56, 5221-5224. [Cited on page 58]

65. Satake, M.; Shoji, M.; Oshima, Y.; Naoki, H.; Fujita, T.; Yasumoto, T. Tetrahedron Lett. 2002, 43, 5829-5832. [Cited on page 58]

66. Wojnar, J. M. A Study of the Structure-Activity Relationship of Pateamine, B.Sc. (Hons) Report, Victoria University of Wellington, New Zealand, 2002. [Cited on page 58]

67. Seki, T.; Satake, M.; Mackenzie, L.; Kaspar, H. F.; Yasumoto, T. Tetrahedron Lett. 1995, 36, 7093-7096. [Cited on page 58]

68. Sasaki, K.; Wright, J. L. C.; Yasumoto, T. J. Org. Chem. 1998, 63, 2475-2480. [Cited on page 58]

69. Chill, L.; Yosief, T.; Kashman, Y. J. Nat. Prod. 2002, 64, 1738-1741. [Cited on page 58]

70. Orabi, K. Y.; Sayed, K. A. E.; Hamann, M. T.; Dunbar, D. C.; Al-Said, M. S.; Higa, T.; Kelly, M. J. Nat. Prod. 2002, 65, 1782-1785. [Cited on page 58]

71. Capon, R. J.; Ford, J.; Lacey, E.; Gill, J. H.; Heiland, K.; Friedel, T. J. Nat. Prod. 2002, 65, 358-363. [Cited on page 58]

72. Uemura, D.; Chou, T.; Haino, T.; Nagatsu, A.; Fukuzawa, S.; Zheng, S.; Chen, H. J. Am. Chem. Soc. 1995, 117, 1155-1156. [Cited on page 58]

73. Sata, N. U.; Matsunaga, S.; Fusetani, N.; van Soest, R. W. M. J. Nat. Prod. 1999, 62, 969-971. [Cited on page 58]

74. Supriyono, A.; Schwarz, B.; Wray, V.; Witte, L.; Müller, W. E. G.; van Soest, R.; Sumaryono, W.; Proksch, P.Z. Naturforsch. 1995, 50C, 669-674. [Cited on page 58]

75. Satake, M.; Ofuyi, K.; Naoki, H.; James, K. J.; Furey, A.; McMahon, T.; Silke, J.; Yasumoto, T. J. Am. Chem. Soc. 1998, 120, 9967-9968. [Cited on page 58]

76. Tsuda, M.; Endo, T.; Mikami, Y.; Fromont, J.; Kobayashi, J. J. Nat. Prod. 2002, 65, 1507-1508. [Cited on page 58] 
77. Murata, K.; Satake, M.; Naoki, H.; Kaspar, H. F.; Yasumoto, T. Tetrahedron 1998, $54,735-742$. [Cited on page 58]

78. Tischler, M.; Andersen, R. J.; Choudhary, M. I.; Clardy, J. J. Org. Chem. 1991, 56, 42-47. [Cited on page 58]

79. Tan, L. T.; Márquez, B. L.; Gerwick, W. H. J. Nat. Prod. 2002, 65, 925-928. [Cited on page 58]

80. Torigoe, K.; Murata, M.; Yasumoto, T. J. Am. Chem. Soc. 1988, 110, 7876-7877. [Cited on page 58]

81. Tabudravu, J. N.; Jaspars, M. J. Nat. Prod. 2002, 65, 1798-1801. [Cited on page 58]

82. Saeki, B. M.; Granato, A. C.; Berlinck, R. G. S.; Magalhes, A.; Schefer, A. B.; Ferreira, A. G.; Pinheiro, U. S.; Hajdu, E. J. Nat. Prod. 2002, 65, 796-799. [Cited on page 58]

83. Williams, D. E.; Allen, T. M.; van Soest, R.; Behrisch, H. W.; Andersen, R. J. J. Nat. Prod. 2001, 64, 281-285. [Cited on page 58]

84. Nakao, Y.; Uehara, T.; Matsunaga, S.; Fusetani, N.; van Soest, R. W. M. J. Nat. Prod. 2002, 65, 922-924. [Cited on page 58]

85. Wojnar, J. M. Unpublished data. [Cited on page 58]

86. Keyzers, R. A.; Northcote, P. T.; Webb, V. J. Nat. Prod. 2002, 65, 598-600. [Cited on page 58]

87. Fontana, A.; Ishibashi, M.; Shigemori, H.; Kobayashi, J. J. Nat. Prod. 1998, 61, 1427-1429. [Cited on page 58]

88. Ciasullo, L.; Casapullo, A.; Cutignano, A.; Bifulco, G.; Debitus, C.; Hooper, J.; Gomez-Paloma, L.; Riccio, R. J. Nat. Prod. 2002, 65, 407-410. [Cited on page 58]

89. Keyzers, R. A.; Northcote, P. T.; Berridge, M. V. Aust. J. Chem. 2003, 56, 279-282. [Cited on page 58]

90. Youssef, D. T. A.; Yamaki, R. K.; Kelly, M.; Scheuer, P. J. J. Nat. Prod. 2002, 65, 2-6. [Cited on page 58]

91. Rao, M. R.; Faulkner, D. J. J. Nat. Prod. 2002, 65, 386-388. [Cited on page 58]

92. Kobayashi, J.; Kubota, T.; Takahashi, M.; Ishibashi, M.; Tsuda, M.; Naoki, H. J. Org. Chem. 1999, 64, 1478-1482. [Cited on page 58]

93. Onodera, H.; Satake, M.; Oshima, Y.; Yasumoto, T.; Carmichael, W. W. Nat. Toxins 1997, 5, 146-151. [Cited on page 58]

94. Murakami, Y.; Takei, M.; Shindo, K.; Kitazume, C.; Tanaka, J.; Higa, T.; Fukamachi, H. J. Nat. Prod. 2002, 65, 259-261. [Cited on page 58]

95. Dell'Aversano, C.; Walter, J. A.; Burton, I. W.; Stirling, D. S.; Fattorusso, E.; Quilliam, M. A. Isolation and Structure Elucidation of New and Unusual Saxitoxin Analogues from Mussels. In Harmful Algal Blooms; Intergovernmental Oceonographic Commission of UNESCO: Paris, 2003; pp 189-191. [Cited on page 58] 
96. Meyer, M.; Guyot, M. J. Nat. Prod. 2002, 65, 1722-1723. [Cited on page 58]

97. Eder, C.; Proksch, P.; Wray, V.; Steube, K.; Bringmann, G.; van Soest, R. W. M.; Sudarsono,; Ferdinandus, E.; Pattisina, L. A.; Wiryowidagdo, S.; Moka, W. J. Nat. Prod. 1999, 62, 184-187. [Cited on page 58]

98. Alam, N.; Wang, W.; Hong, J.; Lee, C.; Im, K. S.; Jung, J. H. J. Nat. Prod. 2002, $65,944-945$. [Cited on page 58]

99. Shen, X.; Perry, T. L.; Dunbar, D. C.; Kelly-Borges, M.; Hamann, M. T. J. Nat. Prod. 1998, 61, 1302-1303. [Cited on page 58]

100. Kato, Y.; Fusetani, N.; Matsunaga, S.; Hashimoto, K. Chem. Lett. 1985, 10, 1521. [Cited on page 58]

101. Keyzers, R. Unpublished data. [Cited on page 58]

102. Tasdemir, D.; Mangalindan, G. C.; Concepción, G. P.; Verbitski, S. M.; Rabindran, S.; Miranda, M.; Greenstein, M.; Hooper, J. N. A.; Harper, M. K.; Ireland, C. M. J. Nat. Prod. 2002, 65, 210-214. [Cited on page 58]

103. Takada, K.; Nakao, Y.; Matsunaga, S.; van Soest, R. W. M.; Fusetani, N. J. Nat. Prod. 2002, 65, 411-413. [Cited on page 58]

104. Phuwapraisirisan, P.; Matsunaga, S.; van Soest, R. W. M.; Fusetani, N. J. Nat. Prod. 2002, 65, 942-943. [Cited on page 58]

105. Norte, M.; González, R.; Fernández, J. J.; Rico, M. Tetrahedron 1991, 47, 7437_ 7446. [Cited on page 58]

106. Charan, R. D.; McKee, T. C.; Boyd, M. R. J. Nat. Prod. 2002, 65, 492-495. [Cited on page 58]

107. Hu, T.; Curtis, J. M.; Walter, J. A.; Wright, J. L. C. J. Chem. Soc., Chem. Commun. 1995, 597-599. [Cited on page 58]

108. Murata, M.; Kumagai, M.; Lee, J. S.; Yasumoto, T. Tetrahedron Lett. 1987, 28, 5869-5872. [Cited on page 58]

109. Gunasekera, S. P.; Longley, R. E.; Isbrucker, R. A. J. Nat. Prod. 2002, 65, 18301837. [Cited on page 58]

110. Carballeira, N. M.; Reyes, E. D. J. Nat. Prod. 1990, 53, 836-840. [Cited on pages 60 and 62]

111. Youssef, D. T. A.; Yoshida, W. Y.; Kelly, M.; Scheuer, P. J. J. Nat. Prod. 2000, 63, 1406-1410. [Cited on pages 60 and 61]

112. Fusetani, N.; Shiragaki, T.; Matsunaga, S.; Hashimoto, K. Tetrahedron Lett. 1987, 28, 4313-4314. [Cited on page 61]

113. Cimino, G.; de Giulio, A.; de Rosa, S.; di Marzo, V. Tetrahedron Lett. 1989, 30, 3563-3566. [Cited on page 61]

114. Cimino, G.; de Giulio, A.; de Rosa, S.; di Marzo, V. J. Nat. Prod. 1990, 53, 345-353. [Cited on page 61] 
115. Guo, Y.; Gavagnin, M.; Trivellone, E.; Cimino, G. Tetrahedron 1994, 50, 1326113268. [Cited on page 61]

116. Cimino, G.; de Giulio, A.; de Rosa, S.; de Stefano, S.; Sodano, G. J. Nat. Prod. 1985, 48, 22-27. [Cited on page 61]

117. Fusetani, N.; Li, H.; Tamura, K.; Matsunaga, S. Tetrahedron 1993, 49, 1203-1210. [Cited on pages 61 and 87]

118. Isaacs, S.; Kashman, Y.; Loya, S.; Hizi, A.; Loya, Y. Tetrahedron 1993, 49, 1043510438. [Cited on page 61]

119. Li, H.; Matsunaga, S.; Fusetani, N. J. Nat. Prod. 1994, 57, 1464-1467. [Cited on page 61]

120. Guo, Y.; Gavagnin, M.; Salierno, C.; Cimino, G. J. Nat. Prod. 1998, 61, 333-337. [Cited on page 61]

121. Guerriero, A.; Debitus, C.; Laurent, D.; D’Ambrosio, M.; Pietra, F. Tetrahedron Lett. 1998, 39, 6395-6398. [Cited on page 61]

122. Nishimura, S.; Matsunaga, S.; Shibazaki, M.; Suzuki, K.; Harada, N.; Naoki, H.; Fusetani, N. J. Nat. Prod. 2002, 65, 1353-1356. [Cited on page 61]

123. Seo, Y.; Cho, K. W.; Lee, H.; Rho, J.; Shin, J. J. Nat. Prod. 1999, 62, 122-126. [Cited on page 61]

124. Ayanoglu, E.; Walkup, R. D.; Sica, D.; Djerassi, C. Lipids 1982, 17, 617-625. [Cited on pages 62 and 63]

125. Wijekoon, W. M. D.; Ayanoglu, E.; Djerassi, C. Tetrahedron Lett. 1984, 25, 32853288. [Cited on page 62]

126. Carballeira, N. M.; Shalabi, F. J. Nat. Prod. 1993, 56, 739-746. [Cited on page 62]

127. Kluge, A. F.; Lillya, C. P. J. Org. Chem. 1971, 36, 1977-1988. [Cited on page 65]

128. Mucci, A.; Parenti, F.; Schenetti, L. Eur. J. Org. Chem. 2002, 938-940. [Cited on page 67]

129. Carballeira, N. M.; Rodriguez, J. Lipids 1991, 26, 324-326. [Cited on page 70]

130. Bergquist, P. R. The Marine Fauna of New Zealand: Porifera: Demospongiae: Part 5. Dendroceratida and Halisarcida; National Institute of Water and Atmospheric Research (NIWA): Wellington, 1996. [Cited on pages 72 and 73]

131. Karuso, P.; Bergquist, P. R.; Cambie, R. C.; Buckleton, J. S.; Clark, G. R.; Rickard, C. E. F. Aust. J. Chem. 1986, 39, 1643-1653. [Cited on pages 73 and 81]

132. Walker, R. P.; Faulkner, D. J. J. Org. Chem. 1981, 46, 1098-1102. [Cited on page 73]

133. Schmitz, F. J.; Chang, J. S.; Hossain, M. B.; van der Helm, D. J. Org. Chem. 1985, 50, 2862-2865. [Cited on pages 73 and 75]

134. Karuso, P.; Taylor, W. C. Aust. J. Chem. 1986, 39, 1629-1641. [Cited on pages 73, 75 and 83 ] 
135. Molinski, T. F.; Faulkner, D. J. J. Org. Chem. 1986, 51, 1144-1146. [Cited on pages 73 and 75]

136. Taylor, W. C.; Toth, S. Aust. J. Chem. 1997, 50, 895-902. [Cited on pages 73 and 75]

137. Abad, A.; Arnó, M.; Marín, L.; Zaragozá, R. J. Synlett 1991, 789-791. [Cited on page 74]

138. Abad, A.; Arnó, M.; Cuñat, A. C.; Marín, L.; Zaragozá, R. J. J. Org. Chem. 1992, 57, 6861-6869. [Cited on pages 74 and 81]

139. Abad, A.; Arnó, M.; Marín, L.; Zaragozá, R. J. J. Chem. Soc., Perkin Trans. 1 1993, 16, 1861-1867. [Cited on page 74]

140. Hambley, T. W.; Taylor, W. C.; Toth, S. Aust. J. Chem. 1997, 50, 391-394. [Cited on page 74$]$

141. Arnó, M.; González, M. A.; Zaragozá, R. J. J. Org. Chem. 2003, 68, 1242-1251. [Cited on pages 74, 75 and 80]

142. Keyzers, R. A.; Northcote, P. T.; Davies-Coleman, M. T. Nat. Prod. Rep. 2006, 23, 321-334. [Cited on page 75]

143. Miyamoto, T.; Sakamoto, K.; Arao, K.; Komori, T.; Higuchi, R.; Sasaki, T. Tetrahedron 1996, 52, 8187-8198. [Cited on page 75]

144. Betancur-Galvis, L.; Zuluaga, C.; Arnó, M.; González, M. A.; Zaragozá, R. J. J. Nat. Prod. 2002, 65, 189-192. [Cited on page 77]

145. Madaio, A.; Piccialli, V.; Sica, D.; Corriero, G. J. Nat. Prod. 1989, 52, 952-961. [Cited on pages 77 and 172]

146. Kraus, C. M.; Neszmélyi, A.; Holly, S.; Wiedemann, B.; Nenninger, A.; Torssell, K. B. G.; Bohlin, L.; Wagner, H. J. Nat. Prod. 1998, 61, 422-427. [Cited on pages 85 and 87]

147. Barrow, R. A.; Capon, R. J. Aust. J. Chem. 1994, 47, 1901-1918. [Cited on pages 87 and 90]

148. Quinn, R. J.; Tucker, D. J. J. Nat. Prod. 1991, 54, 290-294. [Cited on page 87]

149. Silverstein, R. M.; Webster, F. X. Spectrometric Identification of Organic Compounds; John Wiley \& Sons, Inc.: New York, 1998. [Cited on page 89]

150. Winstein, S.; Lucas, H. J. J. Am. Chem. Soc. 1938, 60, 836-847. [Cited on page 89]

151. MarinLit database, v13.5, May 30, 2006, Department of Chemistry, University of Canterbury: http://www.chem.canterbury.ac.nz/marinlit/marinlit.shtml. [Cited on page 93]

152. Heatley, H. G.; Stephenson, J. S. Nature 1957, 179, 1078. [Cited on page 93]

153. Anchel, M. J. Am. Chem. Soc. 1952, 74, 1588-1590. [Cited on page 93]

154. Anchel, M. Science 1955, 121, 607-608. [Cited on page 93]

155. Hearn, M. T. W.; Jones, E. R. H.; Thaller, V.; Turner, J. L. J. Chem. Soc., Perkin Trans. 1 1974, 2335-2336. [Cited on page 93] 
156. Cambie, R. C.; Craw, P. A.; Bergquist, P. R. J. Nat. Prod. 1987, 50, 948-949. [Cited on page 97$]$

157. Cambie, R. C.; Bergquist, P. R.; Karuso, P. J. Nat. Prod. 1988, 51, 1014-1016. [Cited on page 97]

158. Kernan, M. R.; Cambie, R. C.; Bergquist, P. R. J. Nat. Prod. 1990, 53, 724-727. [Cited on page 97]

159. Sato, A.; Morishita, T.; Shiraki, T.; Yoshioka, S.; Horikoshi, H.; Kuwano, H.; Hanzawa, H.; Hata, T. J. Org. Chem. 1993, 58, 7632-7634. [Cited on pages 97 and 154]

160. Tran, N. H.; Hooper, J. N. A.; Capon, R. J. Aust. J. Chem. 1995, 48, 1757-1760. [Cited on page 97]

161. Warabi, K.; Matsunaga, S.; van Soest, R. W. M.; Fusetani, N. J. Org. Chem. 2003, 68, 2765-2770. [Cited on pages 97, 99, 124, 145, 158 and 159]

162. Tsuda, M.; Takahashi, Y.; Fromont, J.; Mikami, Y.; Kobayashi, J. J. Nat. Prod. 2005, 68, 1277-1278. [Cited on page 97]

163. Rudi, A.; Erez, Y.; Benayahu, Y.; Kashman, Y. Tetrahedron Lett. 2005, 46, 86138616. [Cited on page 97]

164. Urban, S.; Butler, M. S.; Capon, R. J. Aust. J. Chem. 1994, 47, 1919-1924. [Cited on pages $99,105,108,112,117,120$ and 140]

165. Neeman, M.; Caserio, M. C.; Roberts, J. D.; Johnson, W. S. Tetrahedron 1959, 6, 36-47. [Cited on page 112]

166. Yoshida, W. Y.; Lee, K. K.; Carroll, A. R.; Scheuer, P. J. Helv. Chim. Acta 1992, 75 , 1721-1725. [Cited on pages 114, 117, 143, 152 and 154]

167. Andersen, R. J.; Faulkner, D. J.; Cun-heng, H.; van Duyne, G. D.; Clardy, J. J. Am. Chem. Soc. 1985, 107, 5492-5495. [Cited on page 140]

168. Lindquist, N.; Fenical, W. J. Org. Chem. 1988, 53, 4570-4574. [Cited on page 140]

169. Carroll, A. R.; Bowden, B. F.; Coll, J. C. Aust. J. Chem. 1993, 46, 489-501. [Cited on pages 140 and 143]

170. Urban, S.; Hobbs, L.; Hooper, J. N. A.; Capon, R. J. Aust. J. Chem. 1995, 48, 14911494. [Cited on pages 140 and 144]

171. Urban, S.; Capon, R. J. Aust. J. Chem. 1996, 49, 711-713. [Cited on page 140]

172. Reddy, M. V. R.; Faulkner, D. J.; Venkateswarlu, Y.; Rao, M. R. Tetrahedron 1997, 53, 3457-3466. [Cited on pages 140 and 143]

173. Davis, R. A.; Carroll, A. R.; Pierens, G. K.; Quinn, R. J. J. Nat. Prod. 1999, 62, 419-424. [Cited on page 140]

174. Reddy, M. V. R.; Rao, M. R.; Rhodes, D.; Hansen, M. S.; Rubins, K.; Bushman, F. D.; Venkateswarlu, Y.; Faulkner, D. J. J. Med. Chem. 1999, 42, 19011907. [Cited on pages 140 and 144] 
175. Ham, J.; Kang, H. Bull. Korean Chem. Soc. 2002, 23, 163-166. [Cited on pages 140 and 143]

176. Krishnaiah, P.; Reddy, V.; Venkatarama, G.; Ravinder, K.; Srinivasulu, M.; Raju, T.; Ravikumar, K.; Chandrasekar, D.; Ramakrishna, S.; Venkateswarlu, Y. J. Nat. Prod. 2004, 67, 1168-1171. [Cited on page 141]

177. Reddy, S. M.; Srinivasulu, M.; Satyanarayana, N.; Kondapi, A. K.; Venkateswarlu, Y. Tetrahedron 2005, 61, 9242-9247. [Cited on pages 141 and 144]

178. Bailly, C. Curr. Med. Chem. Anti Canc. Agents 2004, 4, 363-378. [Cited on pages 143 and 154]

179. Urban, S.; Hickford, S. J. H.; Blunt, J. W.; Munro, M. H. G. Curr. Org. Chem. 2000, 4, 765-807. [Cited on pages 143 and 155]

180. Kobayashi, J.; Cheng, J.; Kikuchi, Y.; Ishibashi, M.; Yamamura, S.; Ohizuma, Y.; Ohta, T.; Nozoe, S. Tetrahedron Lett. 1990, 31, 4617-4620. [Cited on pages 152 and 154]

181. Tsuda, M.; Nozawa, K.; Kobayashi, J. J. Nat. Prod. 2003, 66, 292-294. [Cited on pages 152 and 154]

182. Davis, R. A.; Christensen, L. V.; Richardson, A. D.; da Rocha, R. M.; Ireland, C. M. Mar. Drugs 2003, 1, 27-33. [Cited on pages 152 and 154]

183. Kang, H.; Fenical, W. J. Org. Chem. 1997, 62, 3254-3262. [Cited on page 152]

184. Chan, G. W.; Francis, T.; Thureen, D. R.; Offen, P. H.; Pierce, N. J.; Westley, J. W.; Johnson, R. K. J. Org. Chem. 1993, 58, 2544-2546. [Cited on pages 152 and 154]

185. Rudi, A.; Goldberg, I.; Stein, Z.; Frolow, F.; Benayahu, Y.; Schleyer, M.; Kashman, Y. J. Org. Chem. 1994, 59, 999-1003. [Cited on page 152]

186. Rudi, A.; Evan, T.; Aknin, M.; Kashman, Y. J. Nat. Prod. 2000, 63, 832-833. [Cited on pages 152 and 154]

187. Palermo, J. A.; Brasco, M. F. R.; Seldes, A. M. Tetrahedron 1996, 52, 2727-2734. [Cited on pages 152 and 154]

188. Schmid, J.; Amrhein, N. Phytochemistry 1995, 39, 737-749. [Cited on page 155]

189. Terpin, A.; Polborn, K.; Steglich, W. Tetrahedron 1995, 51, 9941-9946. [Cited on pages 156 and 157]

190. Gottlieb, H. E.; Kotlyar, V.; Nudelman, A. J. Org. Chem. 1997, 62, 7512-7515. [Cited on page 162] 